\title{
Adaptormoleküle zur Rekrutierung von \\ Transkriptionsfaktoren oder miRNAs an nicht native Bindestellen
}

\author{
Dissertation \\ zur Erlangung des Doktorgrades \\ der Naturwissenschaften
}

vorgelegt beim Fachbereich 14 Biochemie, Chemie und Pharmazie

der Goethe-Universität

in Frankfurt am Main

von

Mathias Bolz

aus Flörsheim am Main

Frankfurt am Main, 2021

(D30) 
Vom Fachbereich Biochemie, Chemie und Pharmazie der Goethe-Universität als Dissertation angenommen.

Dekan: Prof. Dr. Clemens Glaubitz

Erster Gutachter: Prof. Dr. Michael W. Göbel

Zweiter Gutachter: Prof. Dr. Alexander Heckel

Datum der Disputation: 26.05.2021 
„Every so often, you have to unlearn what you thought you already knew, and replace it by something more subtle"

Terry Pratchett 


\section{Kurzfassung}

Die Kontrolle der Genexpression ist eines der großen Ziele der chemischen Biologie. Gemäß dem klassischen Dogma der Molekularbiologe verläuft der Fluss der genetischen Information über die Transkription von DNA zur messenger RNA (mRNA) und durch die Translation von mRNA zu Proteinen. Auch wenn der ursprünglichen Formulierung dieses Dogmas verschiedene Aspekte hinzugefügt wurden, bleibt die Kernaussage unverändert. Eine Störung der Genexpression ist in vielen Fällen die Ursache für schwerwiegende Erkrankungen. Klassische Therapeutika, die im Allgemeinen aus kleinen Molekülen bestehen, können pathogene Proteine spezifisch binden und inhibieren. Allerdings greifen diese Wirkstoffe am Ende der Produktionskette ein und nicht alle Proteine können adressiert werden. Im Gegensatz dazu könnte ein Eingriff auf der Ebene der Transkription oder Translation die Expression der pathogenen Proteine auf ein normales Maß senken oder ganz verhindern. Als entscheidende Regulatoren der Genexpression stellen Transkriptionsfaktoren (TFs) einen interessanten Angriffspunkt zur Kontrolle der Transkription dar. TFs können über den Kontakt zu weiteren Proteinen die RNA-Polymerase II rekrutieren und so die Transkription starten. Für die Translation ist die Halbwertszeit der mRNA ein entscheidender Faktor. Die Lebensdauer wird durch eine Vielzahl an Proteinen und micro RNAs (miRNAs) reguliert. MiRNAs sind kurze Oligonukleotide, die in Argonautproteine eingebaut werden können. Die daraus resultierenden RNA-induced silencing complexes (RISCs) sind in der Lage, den Abbau der mRNA einzuleiten. Sowohl TFs als auch RISCs besitzen dabei Nukleinsäure-bindende Untereinheiten, die mit spezifische Sequenzen assoziieren. In gewisser Weise ist die molekulare Erkennung der Nukleinsäuren vergleichbar mit einer Postsendung, die aufgrund der Adresse korrekt zugestellt wird. Um in diesem Bild des täglichen Lebens zu bleiben: Bei einem Wechsel des Wohnorts ist es üblich, einen Nachsendeauftrag zu stellen. Dabei wird die alte Anschrift auf den Postsendungen mit einem neuen Adressetikett überklebt und die Zustellung erfolgt an den neuen Wohnort. Das zentrale Thema dieser Dissertation ist, dieses „Umetikettieren“ auch auf TFs und RISCs zu übertragen. Hierbei ist es notwendig, die Nukleinsäure-bindenden Untereinheiten der Komplexe, also die „alte Adresse“, vollständig zu blockieren und gleichzeitig eine hohe Affinität zu einer neuen Sequenz zu erzeugen. Hierzu könnten bifunktionale Adaptormoleküle verwendet werden.

Die Adaptoren für die Rekrutierung von TFs müssen in der Lage sein, sowohl die doppelsträngige DNA (dsDNA) als auch einen TF zu binden (Abbildung I). Dabei sollte eine Selbstbindung des Adaptors vermieden werden. In dieser Arbeit wurde der TF Sp1 als Ziel gewählt, da er an GC-reiche dsDNAs bindet. Dies ermöglicht die Wahl einer AT- oder GA-reichen DNA-Sequenz als Ziel der Umleitung, wodurch eine Selbstbindung des Adaptors minimiert werden sollte. Zur Erkennung der DNA war geplant, Pyrrol-Imidazol- 
Polyamide (PIPs), triplexbildende Oligonukleotide (TFOs) oder pseudokomplementäre PNAs einzusetzen. Für Letztere war es möglich, eine neue Syntheseroute zu einem Fmoc-geschützten Thiouracil-Monomer zu entwerfen. Dabei konnte eine selektive Alkylierung an der N1-Position des Thiouracils durchgeführt werden. Auf Basis der PIPs und der TFOs wurden jeweils verschiedene Adaptoren entworfen, deren Bindung zu ihren Zielen mit Band-Shift-Experimenten und im Fall der PIPs zusätzlich mit fluoreszenzbasierten Pulldown-Experimenten gezeigt wurde. Im Rahmen dieser Versuche zeigte sich, dass die PIP-basierten Systeme deutlich besser an die Zielsequenzen banden als die TFO-basierten Adaptoren. Das Konjugat K5a besaß hierbei die besten Eigenschaften. Weiterhin konnte mit diesem Adaptor in Pulldown-Experimenten gezeigt werden, dass Sp1 auf eine nicht kanonische AT-reiche Bindestelle umgeleitet wurde. Im Anschluss konnte das Sp1 in Western-Blots detektiert werden. Des Weiteren ließ sich zeigen, dass $\mathbf{K 5 a}$ in einem HeLa-Lysat über mehrere Stunden stabil war und somit eine Anwendung in Zellkulturexperimenten möglich sein sollte.

Für die Rekrutierung der RISCs war lediglich eine Erkennung zweier einzelsträngiger RNAAbschnitte notwendig. Hierzu wurden zwei LNAs oder LNA/DNA-Mixmere verwendet, die über einen Linker verknüpft waren (Abbildung I). Als Folge dieses Aufbaus mussten die beiden Adaptorhälften orthogonal sein, da eine Selbstbindung des Adaptors leichter als bei den TF-Adaptoren auftreten konnte. Diese Adaptoren wurden mit Band-Shift- und fluoreszenzbasierten Pulldown-Experimenten auf ihre Fähigkeit, eine Cy5-gelabelte miRNA auf eine Ziel-RNA umzuleiten, überprüft. Es konnte beobachtet werden, dass all-LNA Adaptoren sehr viele off-target-Effekt aufwiesen, welche die Umleitung von miRNAs verhinderte. Im Gegensatz dazu konnten mit DNA/LNA-Mixmeren eine vollständige Umleitung von miRNA-Modellen beobachtet werden. Es war ebenfalls möglich, spezifische RISCs aus HeLa-Lysaten mit unterschiedlichen Adaptoren in Pulldown-Experimenten zu isolieren und in nachfolgenden Western-Blots zu detektieren. Nachdem gezeigt war, dass eine Umleitung in vitro gelang, sollte die Funktion der Adaptoren in Zellkulturexperimenten geprüft werden. Allerdings konnten in diesen Versuchen keine eindeutigen Ergebnisse erhalten werden, sodass die biologische Relevanz der RISC-Umleitung bislang noch nicht bestätigt werden konnte.
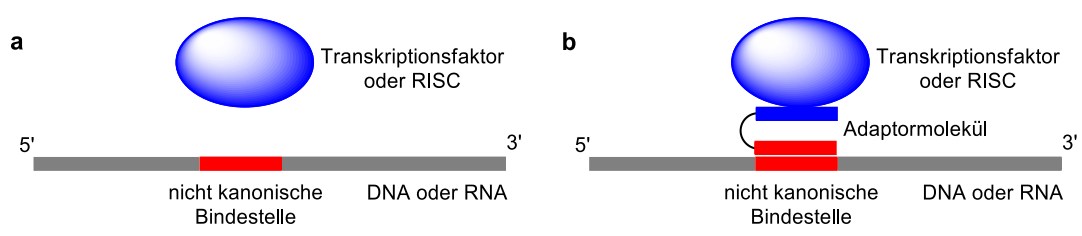

Abbildung I: Schematische Darstellung der Umleitung von TFs oder RISCs. a: Ein TF oder RISC (blau) ist nicht in der Lage mit einer Nukleinsäure zu interagieren, da diese keine Bindestelle aufweist (rot). b: Durch die Zugabe eines Adaptormoleküls erfolgt eine Umleitung der Proteine und die Genexpression kann beeinflusst werden. 


\section{Abstract}

The control of gene expression is one of the most important goals of chemical biology. According to the classical dogma of molecular biology the flow of genetic information proceeds via transcription from DNA to messenger RNA (mRNA) and through translation from mRNA to proteins. Even though the original dogma was extended in several aspects, there is no change in the central statement. A malfunction of gene expression often causes severe diseases. Classical therapeutics, which are typically small molecules, can bind and inhibit these pathogenic proteins specifically. Nevertheless, these agents interfere at the end of the production chain and there are undruggable proteins. In contrast, an intervention at the level of transcription or translation could reduce the pathogenic proteins to a normal level or prevent their expression completely. As important regulators of gene expression transcription factors (TFs) are interesting targets for transcriptional control. TFs can make contact to further proteins and recruit the RNA-polymerase II and start the transcription of a gene. An important aspect for translation is the half-life of the mRNA. The lifetime is controlled by several proteins and micro RNAs (miRNAs). MiRNAs are short oligonucleotides, which can be incorporated in argonaut proteins. The resulting RNA induced silencing complexes (RISCs) can initiate the degradation of the mRNA. Both TFs and RISCs contain a nucleic acid binding subunit for a sequence specific recognition. In a way, the molecular recognition of nucleic acid is comparable to a post, that is delivered correctly because of its address. To use the same metaphor: In case of a change of residence, a redirection service is usually ordered. Thereby the old address of the post is paste over with a new address label. The central goal of this dissertation is the transfer of this "relabeling" to TFs and RISCs. In this case it is necessary to cover the nucleic acid binding unit, the "old address", completely and to create a high affinity to a new sequence at the same time. This can be achieved by using bifunctional adaptor molecules.

The adaptor molecules for the redirection of TFs must have the ability to bind double stranded DNA (dsDNA) and TFs (Figure I). Thereby, a self-binding must be avoided. In this work the TF Sp1 was chosen as target since it binds to GC-rich dsDNA. This allows the choice of a AT- or GA-rich DNA sequence as target for redirection and minimize the possibility of self-binding. pyrrole-imidazole-polyamides (PIPs), triplex-forming oligonucleotides (TFOs) and pseudo complementary PNAs should be used for the recognition of DNA. For the latter it was possible to create a new synthetic route for a Fmoc-protected thiouracil monomer. Thereby, a selective alkylation of the N1-position of thiouracil could be achieved. Based on PIPs and TFOs, several adaptor molecules were created. The binding of the adaptor molecules to their target sequences was shown in band shift assays and in case of the PIP-adaptors by fluorescent based pulldown experiments as well. It turned out that the PIP-adaptors were more effective than the TFO-based systems. 
Especially the conjugate K5a was very effective. Subsequently, the adaptor was used in pulldown experiments to recruit Sp1 to a non-canonic AT-rich binding-site. This was proofed by a western blot that followed the pulldown. Additionally, it was shown, that K5a was stabile in a HeLa-lysate for several hours, and therefore it is suitable for cell culture experiments.

For the recruitment of RISCs, it was necessary to recognize two single stranded RNAs. As a result, the adaptor molecule was compromised of two LNAs or DNA/LNA-mixmers, that were connected by a linker (Figure I). In consequence of the design, the two parts of the adaptor must be orthogonal, since a self-binding was more likely than in the case of the TFadaptors. Those adaptors were tested in band shift and fluorescent based pulldown experiments on their ability to recruit a Cy5-labed miRNA to a target-RNA. It turned out that the all-LNA-adaptors showed to many off target effects, that limited their abilities to redirect miRNAs. In contrast the DNA/LNA-mixmers showed the expected behavior and a complete redirection of miRNA models. It was also possible to isolate specific RISCs from HeLa-lysates in pulldown experiments with multiple adaptors and to detect them in western blots. After the in vitro experiments indicate, that the redirection of RISCs was possible, the concept should be confirmed in cell culture trials. Unfortunately, the results of the cell culture experiments remained unclear and hard to reproduce. Therefore, the biological relevance of the concept could not be confirmed yet.
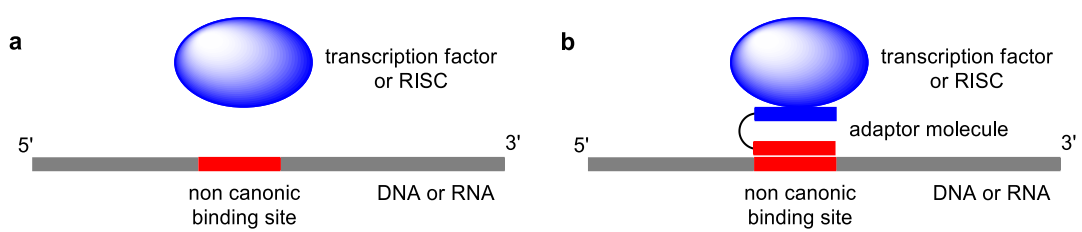

Figure I: Schematic representation of the redirection of TFs or RISCs. a: TF or RISC is unable to interact with a nucleic acid, since it has no binding site (red). $\mathbf{b}$ : The addition of an adaptor molecule induces a complexation and affects gene expression. 


\section{Inhaltsverzeichnis}

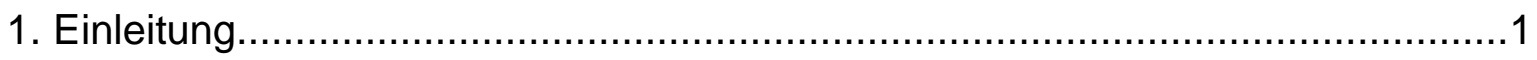

2. Nukleinsäuren und ihre Modifikationen .........................................................

2.1 Aufbau und Struktur von DNA und RNA ……................................................. 3

2.1.1 Strukturen der Nukleinsäuren.......................................................................... 4

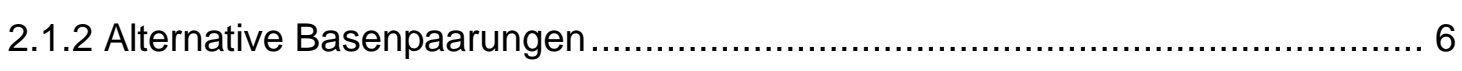

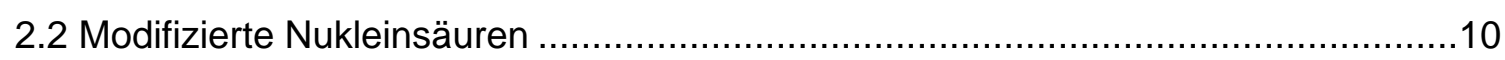

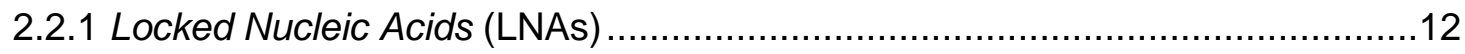

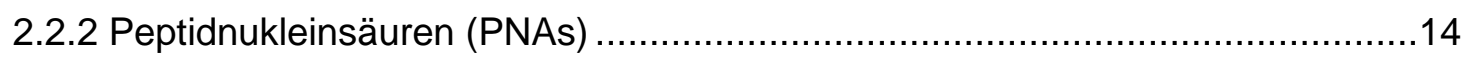

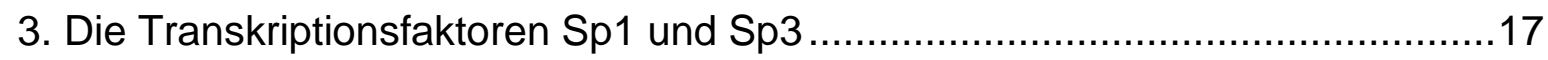

4. DNA-Erkennung und artifizielle Transkriptionsfaktoren (ATFs) ......................20

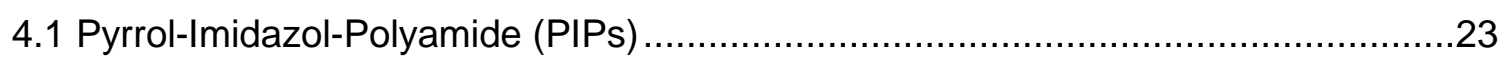

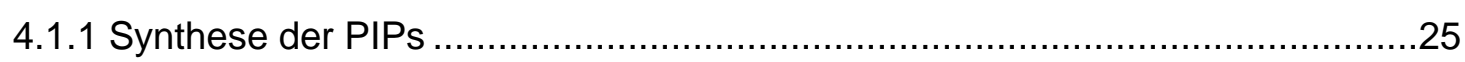

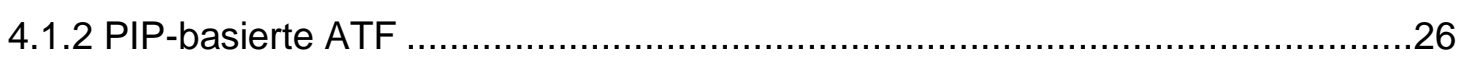

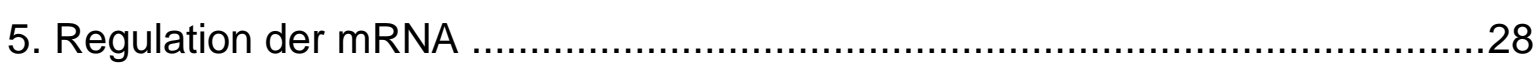

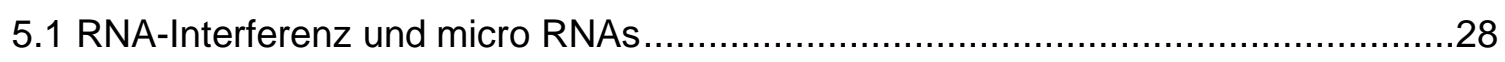

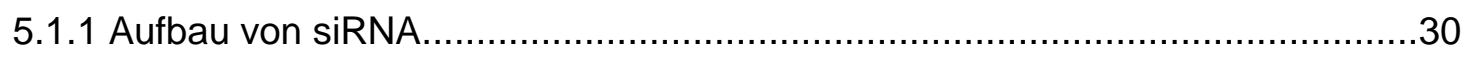

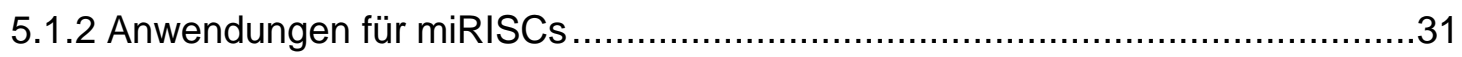

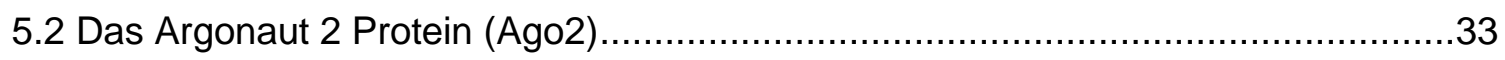

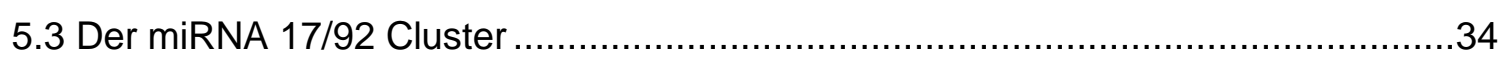

6 Oligonukleotid-basierte Therapien und Bioverfügbarkeit .................................36

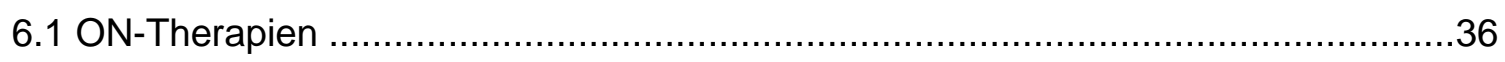

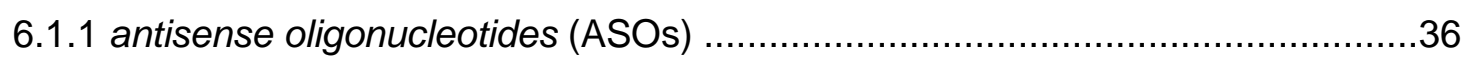

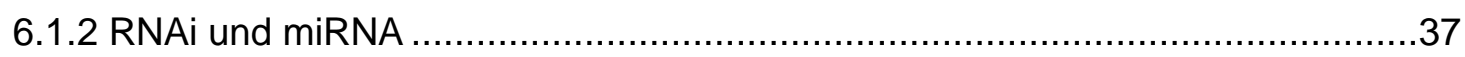

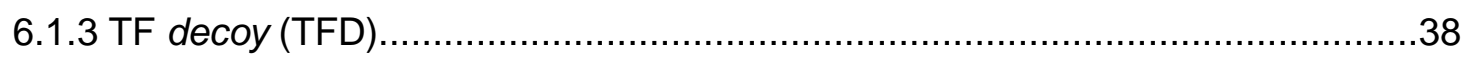

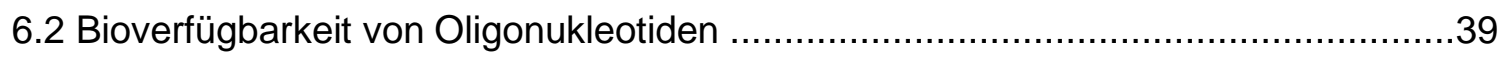

7 Adaptoren zur Umleitung von Sp1 auf nicht natürliche Bindestellen ..................41

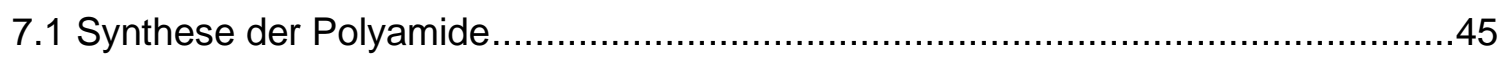

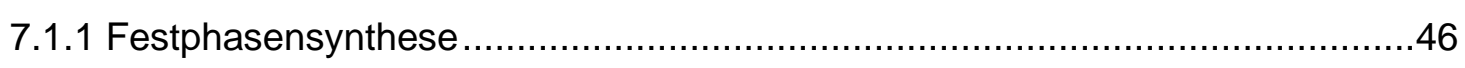

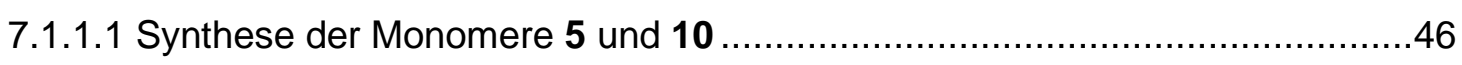

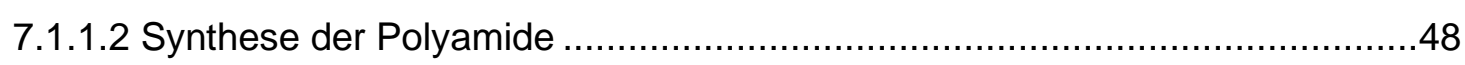

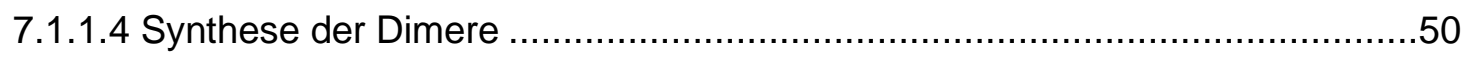

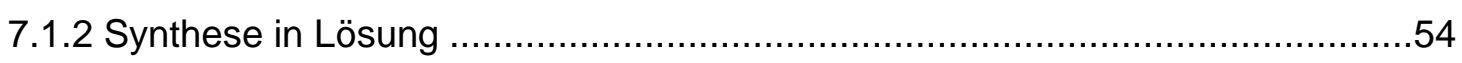

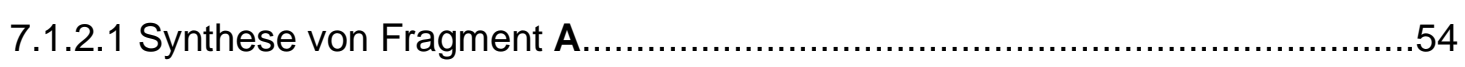

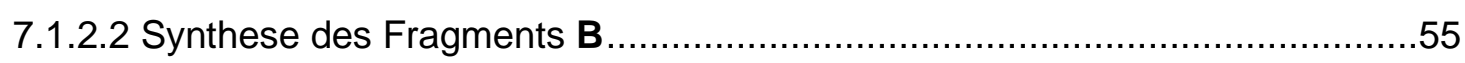

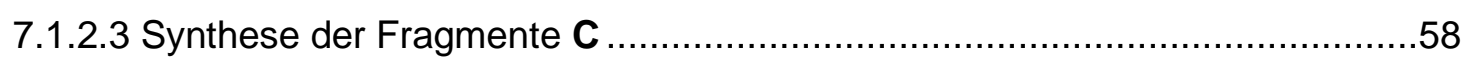

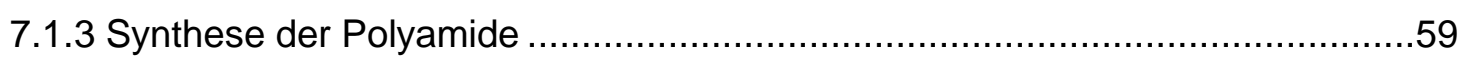




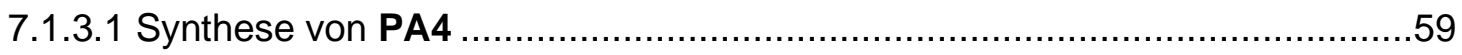

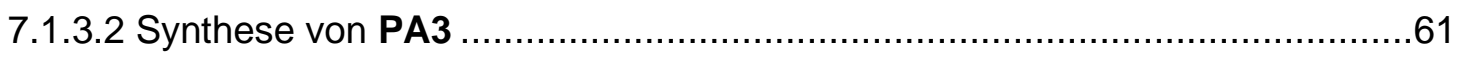

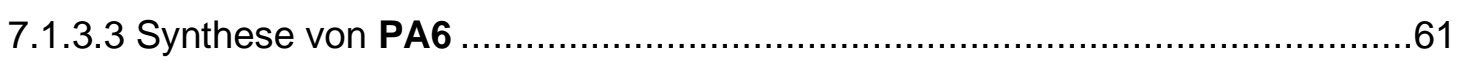

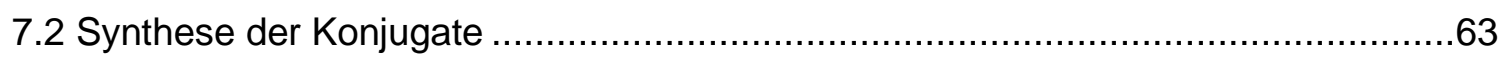

7.3 Experimente zur Umleitung von Sp1 auf eine AT-reiche Sequenz.........................67

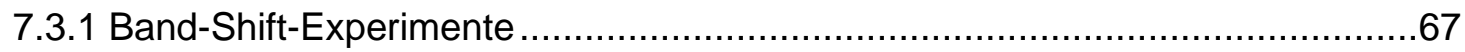

7.3.1.1 Experimente mit den Konjugaten K1 - K3 …....................................67

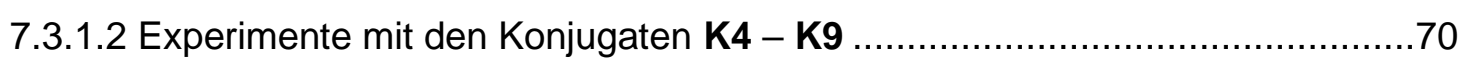

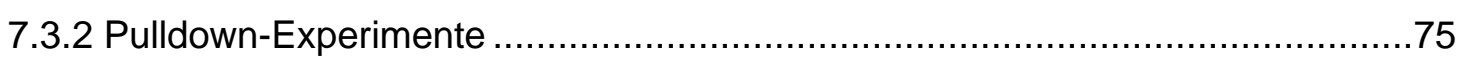

7.3.3 Stabilität der Konjugate in Zelllysaten ................................................. 81

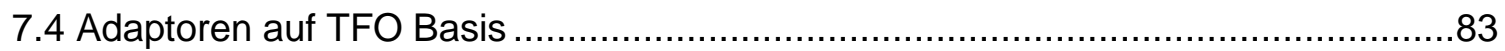

7.4.2 Band-Shift-Experimente mit den TFO-Adaptoren ........................................ 84

7.4.3 Vergleich der TFO-Adaptoren mit den PIP-Konjugaten .................................87

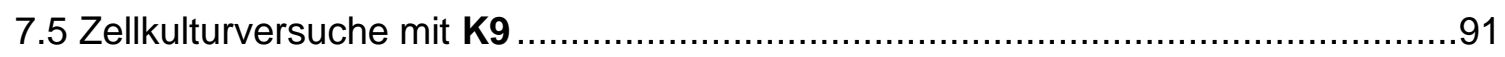

7.6 Bausteine für pseudokomplementäre PNA ….............................................92

8 Umleitung von hAgo2 mittels Adaptormolekülen .......................................97

8.2 Band-Shift und Pulldown-Experimente mit den LNA-Adaptoren .........................100

8.2.1 Selektivität der RISC-Bindung .................................................................. 107

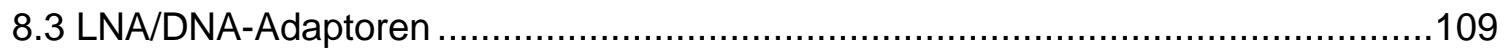

8.3.1 Band-Shift-Experimente mit den DNA/LNA-Mixmeren ..............................110

8.3.2 Pulldown-Experimente .................................................................... 114

8.3.3 Schmelzpunktmessungen ................................................................. 116

8.3.4 Isolierung von RISCs aus HeLa-Lysaten.............................................117

8.3.5 Zellkulturexperimente zur Umleitung von miR-20a auf die PIM1-mRNA.........119

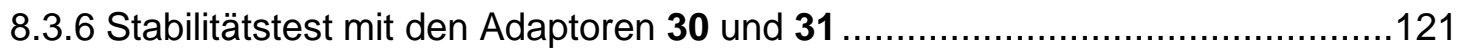

8.4 Gegen miR-let-7 gerichteter Adaptor 37 ...........................................................123

8.4.1 Zellkulturexperimente mit Adaptor 37 .................................................126

8.5 Vorgehen beim Entwurf der Adaptoren........................................................ 130

9 Zusammenfassung und Ausblick ........................................................ 132

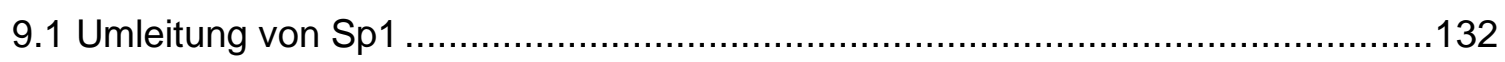

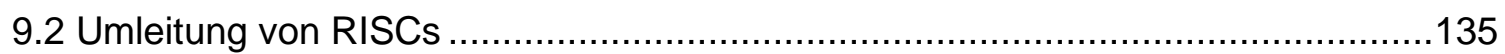

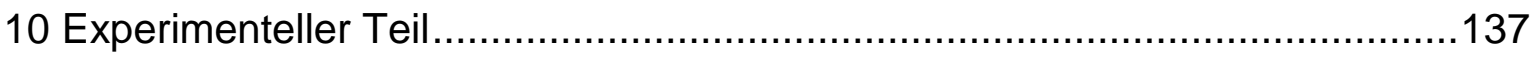

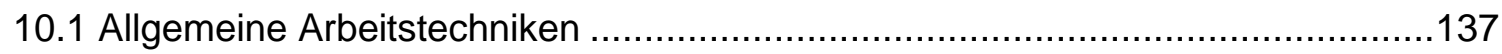

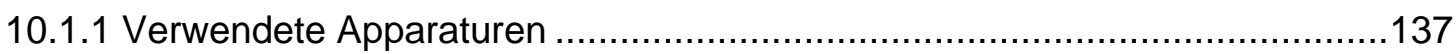

10.1.2 Hydrierungen unter erhöhtem Druck ..................................................137

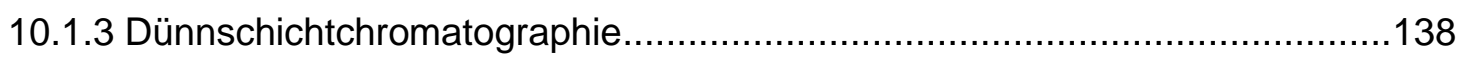

10.1.4 Präparative Säulenchromatographie .................................................138

10.1.5 Analytische und semipräparative rp-HPLC der Polyamide ..........................138 
10.2 Analytische und spektroskopische Methoden ..............................................140

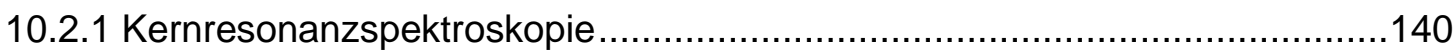

10.2.2 Massenspektrometrie .................................................................... 140

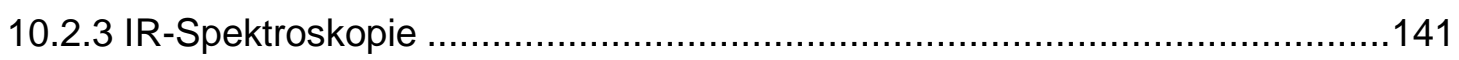

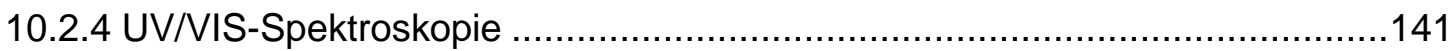

10.2.5 Schmelzpunktmessungen der Verbindungen ........................................141

10.2.6 Schmelzpunktmessungen der Oligonukleotide.......................................141

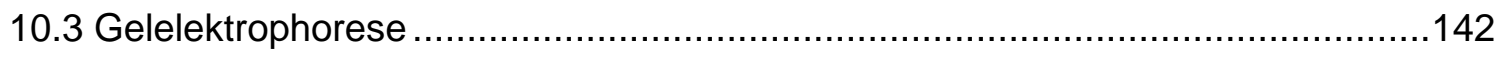

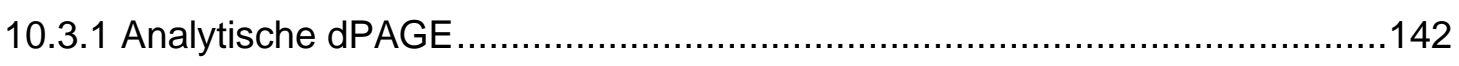

10.3.2 Präparative dPAGE..................................................................... 142

10.3.3 Band-Shift Experimente .................................................................... 142

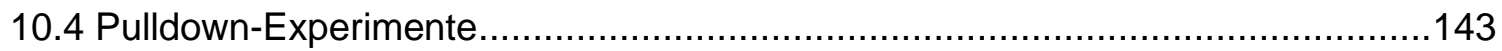

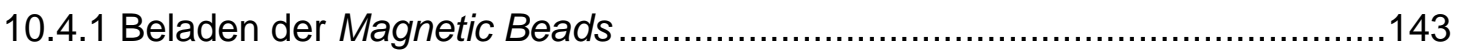

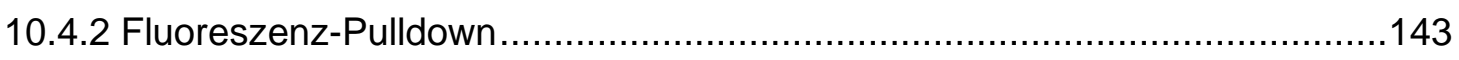

10.4.3 Pulldown-Experimente zur Proteinisolierung und Detektion mittels

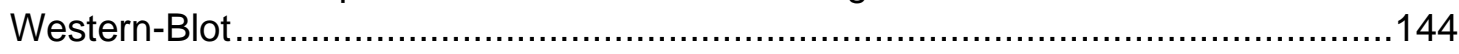

10.5 Synthese der Monomere für die Festphasensynthese ................................... 146

10.5.1 Synthese von 1-Methyl-2-trichloracetylpyrrol $\left(\mathrm{Py}-\mathrm{CCl}_{3}\right)$ 1 ..........................146

10.5.2 Synthese von 1-Methyl-4-nitro-2-trichloracetylpyrrol $\left(\mathrm{O}_{2} \mathrm{~N}-\mathrm{Py}-\mathrm{CCl}_{3}\right) 2$.........147

10.5.3 Synthese von Methyl-1-methyl-4-nitropyrrol-2-carboxylat $\left(\mathrm{O}_{2} \mathrm{~N}-\mathrm{Py}-\mathrm{OMe}\right)$ 3..148

10.5.4 Synthese von Methyl-4-[(tert-butoxycarbonyl)amino]-1-methylpyrrol-2-

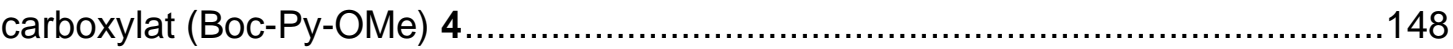

10.5.5 Synthese von 4-[(tert-Butoxycarbonyl)amino]-1-methylpyrrol-2-carbonsäure

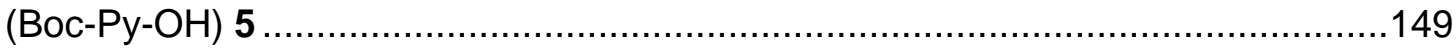

10.5.6 Synthese von 1-Methyl-2-trichloracetylimidazol $\left(\mathrm{Im}-\mathrm{CCl}_{3}\right) 6 \ldots \ldots \ldots \ldots \ldots \ldots . . . .150$

10.5.7 Synthese von 1-Methyl-4-nitro-2-trichloracetylimidazol $\left(\mathrm{O}_{2} \mathrm{~N}-\mathrm{Im}-\mathrm{CCl}_{3}\right) 7 \ldots . .151$

10.5.8 Synthese von Methyl-1-methyl-4-nitroimidazol-2-carboxylat $\left(\mathrm{O}_{2} \mathrm{~N}-\mathrm{Im}-\mathrm{OMe}\right) \mathbf{8}$

10.5.9 Synthese von Methyl-4-[(tert-butoxycarbonyl)amino]-1-methylimidazol-2carbonsäure (Boc-Im-OMe) 9

10.5.10 Synthese von 4-[(tert-butoxycarbonyl)amino]-1-methylimidazol-2-carboxylat

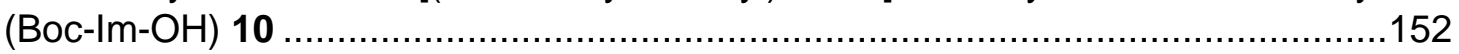

10.5.11 Synthese von 1-Methylpyrrol-2-carbonsäure (Py-OH) 13 …....................153

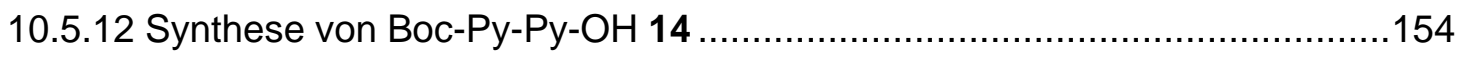

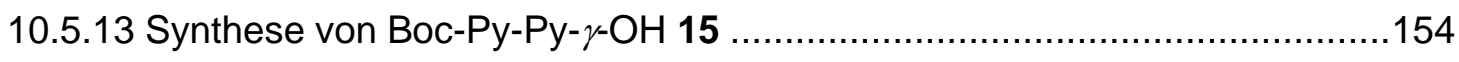

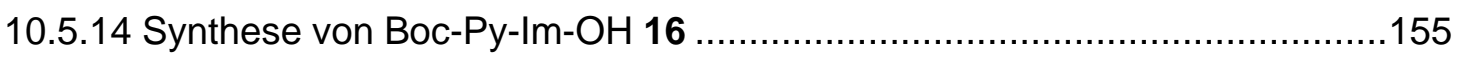

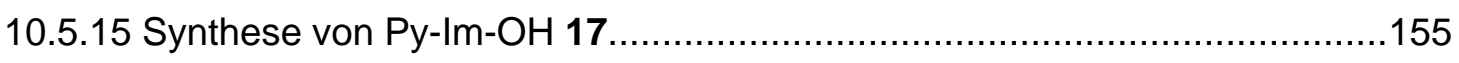

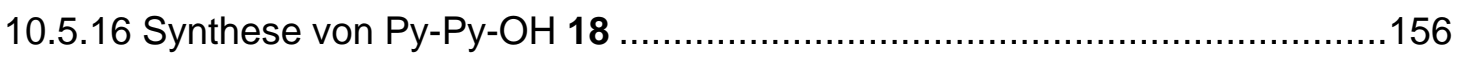

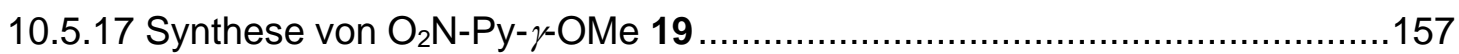

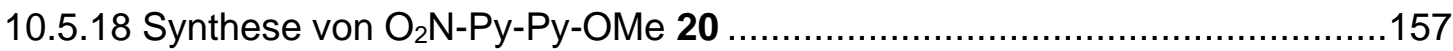




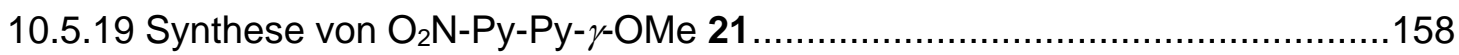

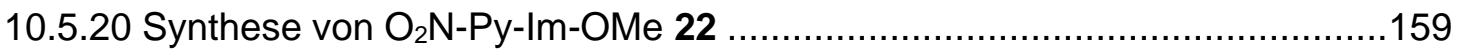

10.5.21 Synthese von Boc-Py-Py-OMe 23 .......................................................160

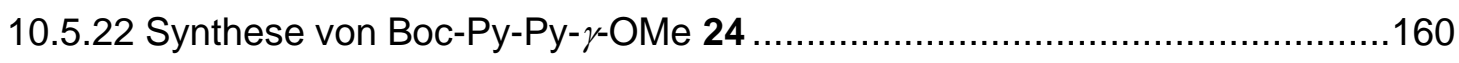

10.5.23 Synthese von Boc-Py-Im-OMe 25 ....................................................... 161

10.5.24 Synthese von 1-Methyl-4-nitropyrrol-2-carbonsäure $\left(\mathrm{O}_{2} \mathrm{~N}-\mathrm{Py}-\mathrm{OH}\right) 26$........162

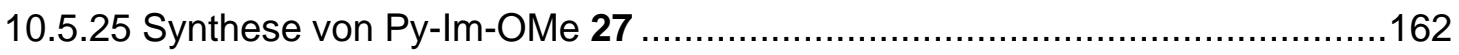

10.5.26 Synthese von Py-Py-OMe 28 ..............................................................163

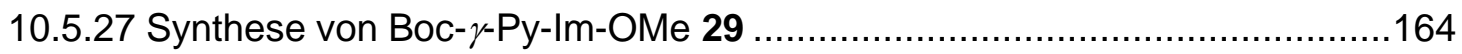

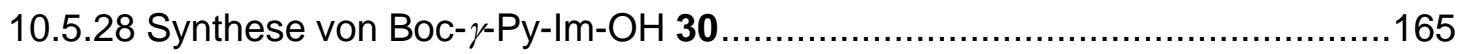

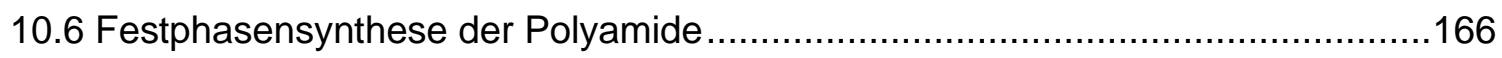

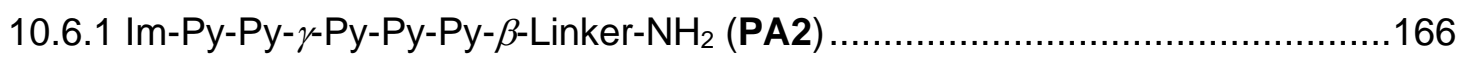

10.6.2 Im-Py-Py-Py- $\gamma$-Py-Py-Py-Py- $\beta$-Linker-NH $\mathrm{NH}_{2}$ (PA3) ..................................167

10.6.3 Py-Py-Py-Py- $\gamma$-Py-Im-Py-Py- $\beta$-Linker-NH $\mathrm{NH}_{2}$ (PA5) ...................................168

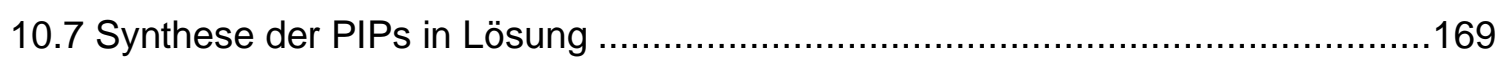

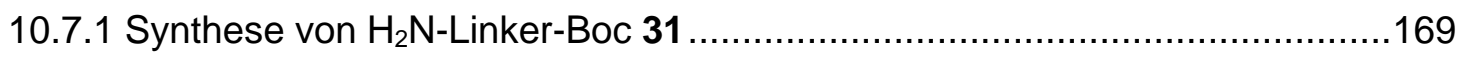

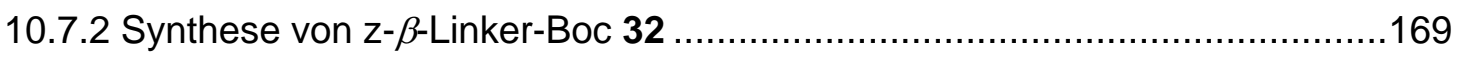

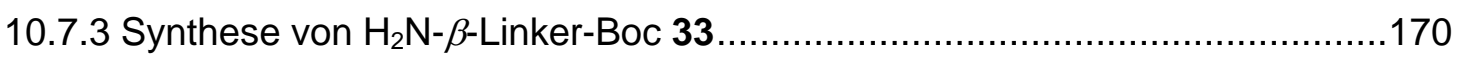

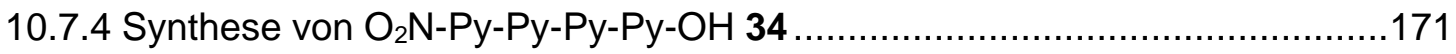

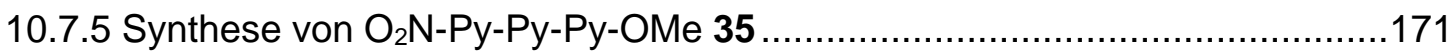

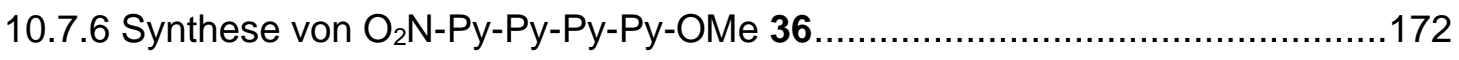

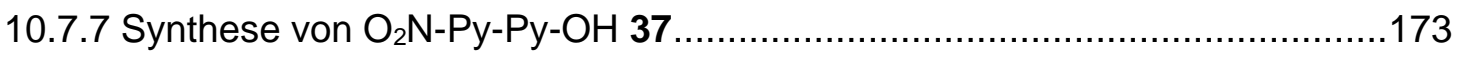

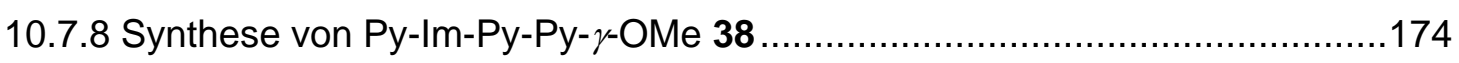

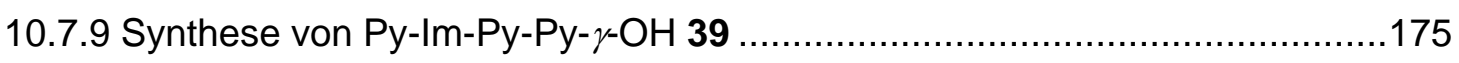

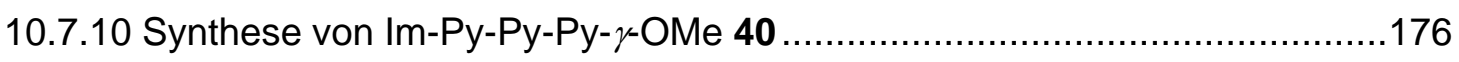

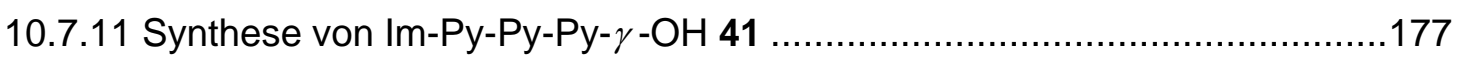

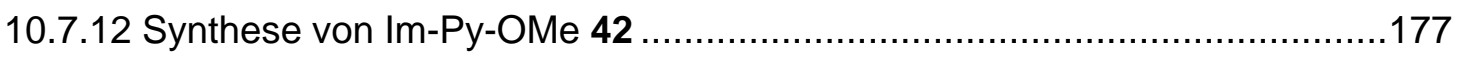

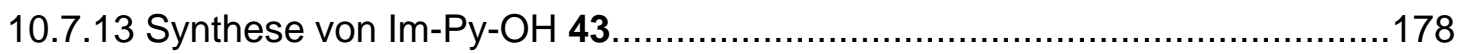

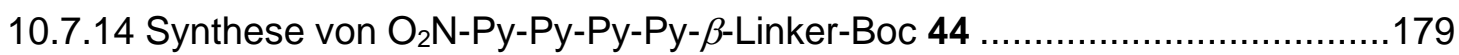

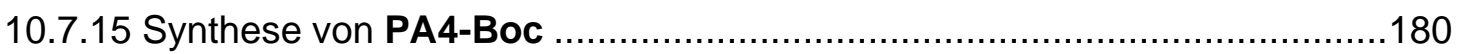

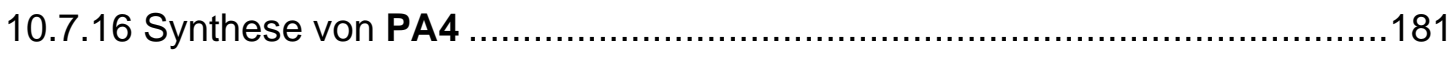

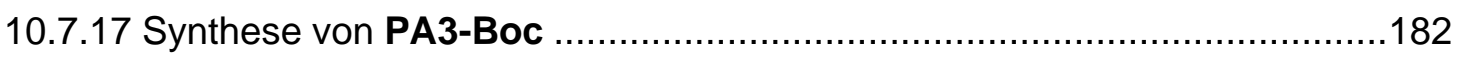

10.7.18 Synthese von $\mathrm{O}_{2} \mathrm{~N}-\mathrm{Py}$-Py-Py-Py-Linker-Boc 45..................................183

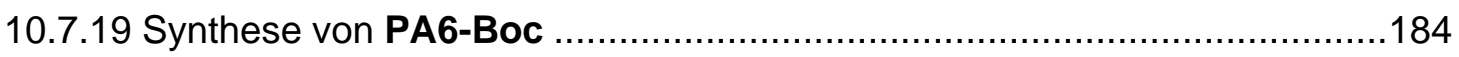

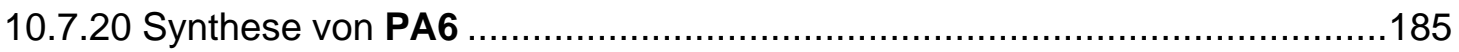

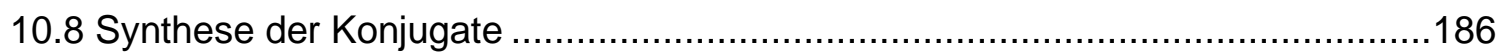

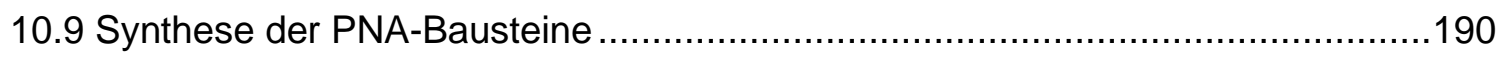


10.9.1 Synthese von Ethyl-2-(2-(2-methyl-4-methoxybenzyl)thiouracil-1-yl)acetat 48 190

10.9.2 Synthese von 4-Methoxy-2-methylbenzylalkohol $\mathbf{5 0 .}$ 191

10.9.3 Synthese von 2-(2-Methyl-4-methoxybenzyl)thiouracil 53 .191

10.9.4 Synthese von Ethoxycarbonyl-methyltrifluoromethansulfonat 55 . 193

10.9.5 Synthese von 2-(2-(2-Methyl-4-methoxybenzyl)thiouracil-1-yl)acetat 56 ......193

10.9.6 Synthese von 2-(4-Methoxybenzyl)thiouracil 61 ......................................194

10.9.7 Synthese von Ethyl-2-(2-(4-methoxybenzyl)thiouracil-1-yl)acetat 62 ...........195

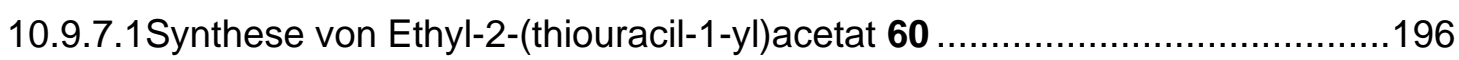

10.9.8 Synthese von 2-(2-(4-Methoxybenzyl)thiouracil-1-yl)acetat 63 ...................196

10.9.9 Synthese von 2-(4-Methoxybenzyl)thiouracil-Fmoc/Bn-PNA-Monomer $64 \ldots 197$

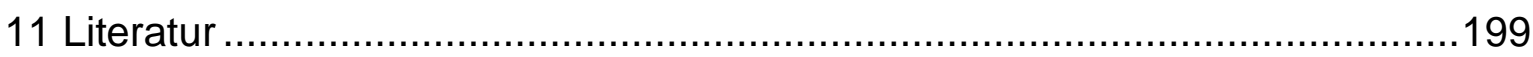

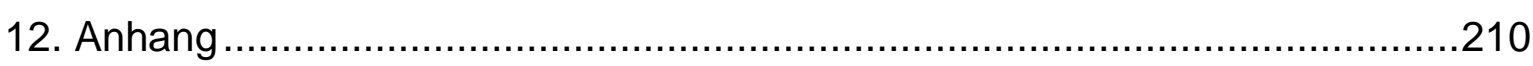

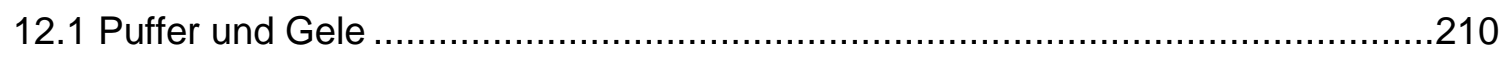

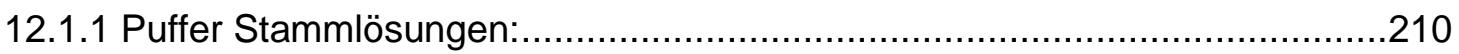

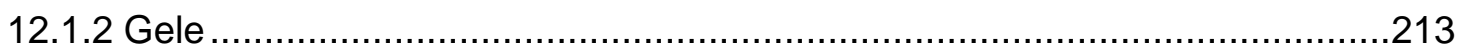

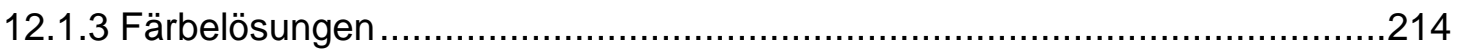

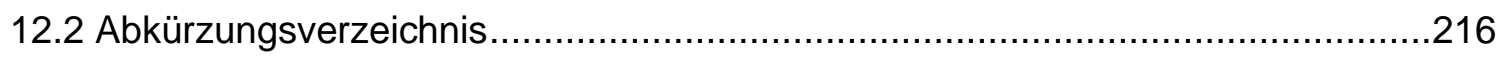

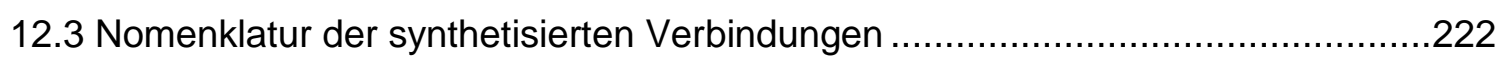

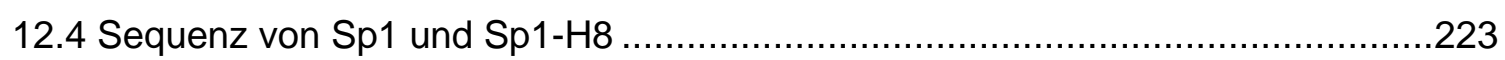

12.5 Erklärungen zu Kooperationen und Copy Right ..............................................224

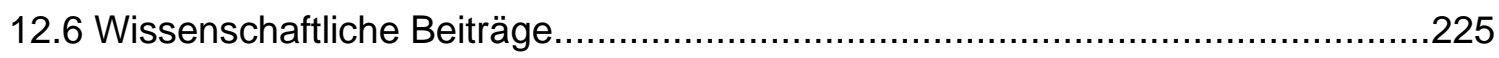

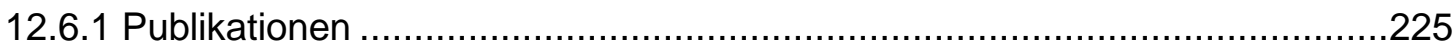

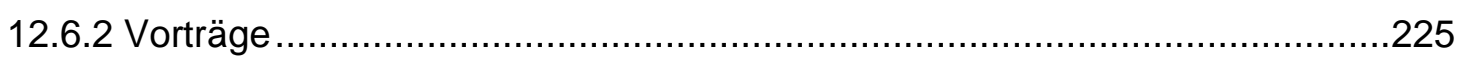

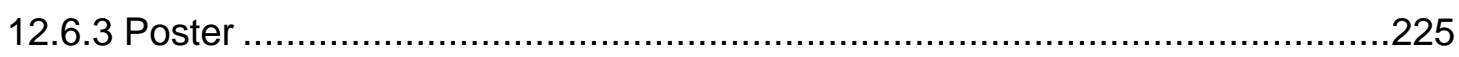

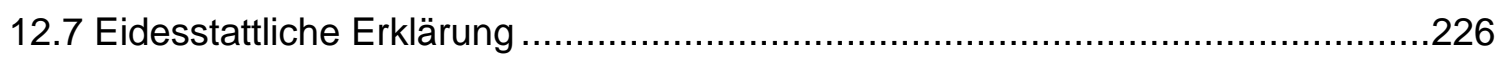




\section{Einleitung}

Eine wichtige Aufgabe der chemischen Biologie ist die Entwicklung molekularer Werkzeuge zur gezielten Beeinflussung der Genexpression. Eine gestörte Expression ist vor allem in Krebs- oder viralen Erkrankungen zu beobachten, deren Korrektur als Ansatzpunkt für Therapien dienen könnte. In diesem Zusammenhang sind Transkriptionsfaktoren (TFs) oder miRNAs interessante Ziele, da sie essenziell für die Regulation der Transkription und Translation sind. Einen Ansatz zur Kontrolle dieser Systeme stellen Oligonukleotid (ON)basierte Wirkstoffe dar, welche zelleigene Nukleinsäuren oder Proteine adressieren und so theoretisch alle Prozesse der Zelle regulieren können. Auch wenn die Stabilität und Bioverfügbarkeit der ON noch kritische Faktoren sind, konnten in den letzten Jahren deutliche Fortschritte im Bereich der ON-basierten Wirkstoffe erzielt werden. ${ }^{[1-3]}$ Beispielsweise stellen mRNA-basierte Impfstoffe, welche von den Firmen BioNTech, Moderna, oder CureVac entwickelt wurden, die ersten in Europa zugelassenen Vakzine zur Bekämpfung der COVID-19-Pandemie dar. Darüber hinaus ist die Regulation der mRNA mittels splice-switching oligonucleotides (SSOs) oder siRNAs eine der Hauptanwendung von ON-basierten Therapeutika. ${ }^{[2]}$ Auch wenn in diesen Bereichen große Fortschritte erzielt wurden, konnten noch keine Methoden zur Adressierung von TFs und miRNAs bis zur klinischen Anwendung entwickelt werden.

TFs sind essenzielle Aktivatoren der Genexpression. Sie sind in der Lage an spezifische Promotoren auf der DNA zu binden und die Transkription von Genen auszulösen. Seitdem mittels des Hefe-Zwei-Hybrid-Systems gezeigt werden konnte, dass die Aktivierung der Transkription auf Protein-Protein Wechselwirkungen beruht ${ }^{[4,5]}$ und somit auch mit artifiziellen TFs (ATFs) möglich ist, stellt der Aufbau von ATFs ein besonderes Ziel der chemischen Biologie dar. Dabei ist eine Herausforderung, dass die ATFs in den Zellkern gelangen und dort die doppelsträngige DNA (dsDNA) erkennen müssen. Die sequenzspezifische Bindung an DNA kann dabei durch proteinbasierte Systeme, insbesondere CRISPR/Cas $9,{ }^{[6]}$ triplexbildende ON (TFOs) ${ }^{[7]}$ und minor groove bindenden Molekülen, wie Pyrrol-Imidazol-Polyamide (PIPs), ${ }^{[8]}$ erfolgen. Allerdings stellt eine geringe Spezifität, Effektivität oder Bioverfügbarkeit der ATFs noch eine große Hürde für ihre Anwendungen dar. Während TFs für die Regulation der Genexpression bei der Transkription verantwortlich sind, können micro RNAs (miRNAs), in Form von RNA-induced silencing complexes (RISCs), als Regulatoren der mRNA nach der Transkription eingreifen. Dabei ist eine miRNA in der Lage, gleichzeitig eine Vielzahl an mRNAs zu kontrollieren und Abweichungen ihrer Expressionslevel können ein Auslöser von Krankheiten wie Krebs sein. ${ }^{\left[{ }^{9]}\right.}$ Aus diesen Gründen stellen miRNAs ebenfalls interessante Ziele dar und können therapeutisch eingesetzt werden (miR-Mimic) oder als Zielstruktur dienen (anti-miR). 
Aufgrund der vielfältigen Aufgaben der miRNAs, ist ihre Wirkung jedoch sehr komplex und dies stellt eine der Herausforderungen für die Entwicklung miRNA-basierter Therapeutika $\operatorname{dar}^{[9,10]}$

Während viele Ansätze, wie ATFs oder miR-Mimics darauf beruhen, die Funktion natürlicher Systeme nachzuahmen, wird im Arbeitskreis Göbel ein alternativer Ansatz verfolgt. ${ }^{[1-13]}$ Dabei sollen Adaptormoleküle verwendet werden, um TFs oder RISCs zu rekrutieren und somit an nicht nativen Bindestellen wirken zu lassen (Abbildung 1). In diesem Zusammenhang soll die über Protein-Protein-Kontakte erfolgende Wirkung von TFs und RISCs genutzt werden, welche keine direkte Bindung dieser Systeme an ihre Ziele erfordert. Im ersten Teil dieser Arbeit wurden Adaptoren für die Aktivierung der Genexpression weiterentwickelt und dabei verschiedene DNA-bindende Moleküle, wie PIPs ${ }^{[14,15]}$ TFOs $^{[16,17]}$ und PNAs ${ }^{[18,19]}$, verwendet. Im zweiten Teil dieser Arbeit wurden Adaptoren entworfen, welche eine Rekrutierung von RISCs an nichtkomplementäre Bindestellen und somit eine Regulation der Translation ermöglichen. ${ }^{[13]}$
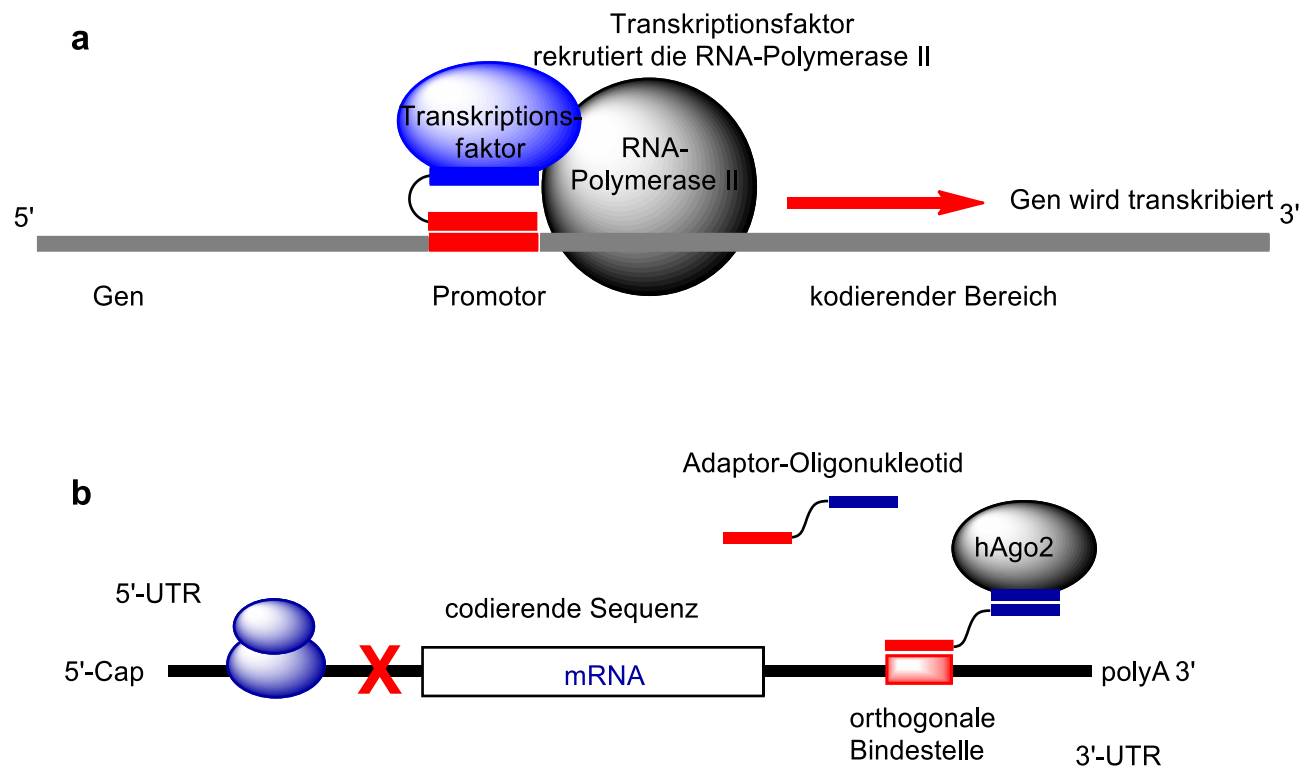

Abbildung 1: Schematische Darstellung der Funktion von Adaptormolekülen zur Umleitung von a: Transkriptionsfaktoren und b: RISCs. Dabei kann mit ersteren die Genexpression aktiviert werden, während letztere die Translation inhibieren. Die blauen und roten Rechtecke sollen die jeweils zueinander komplementären Bindestellen symbolisieren. 


\section{Nukleinsäuren und ihre Modifikationen}

Nukleinsäuren sind in Form der Desoxyribonukleinsäure (DNA) und der Ribonukleinsäure (RNA) die Grundlage des bekannten Lebens. Dabei dient die stabilere DNA im Allgemeinen als Speicher der genetischen Information, welche durch die Abfolge der Nukleobasen codiert wird. Im Gegensatz dazu besitzt die RNA vielfältigere Funktionen. Einerseits ist sie in Form der Messenger-RNA (mRNA), der Transfer-RNA (tRNA), sowie Ribosomaler RNA (rRNA) essenziell für die Proteinbiosynthese. Andererseits besitzt sie in Form der microRNA (miRNA), ${ }^{[20,21]}$ small interfering RNA (siRNA), ${ }^{[22]}$ long non-coding RNA $(\text { IncRNA })^{[23]}$ und weiterer nicht-kodierender RNAs ${ }^{[24]}$ regulierende Funktionen.

\subsection{Aufbau und Struktur von DNA und RNA}

DNA und RNA sind Biopolymere, die sich aus 3'-5'-verknüpften Nukleotiden zusammensetzen (Abbildung 2). Diese bestehen wiederum aus einem Phosphatrest (grün), einer (Desoxy)Ribose (rot) sowie einer Nukleobase (blau). Die Bausteine der DNA und RNA unterscheiden sich an der 2'-Position des Zuckers durch die An- oder Abwesenheit einer Hydroxygruppe. Diese besitzt einen großen Einfluss auf die Stabilität, Flexibilität, und Struktur der Nukleinsäuren und ist unter anderem für ihre unterschiedlichen Funktionen verantwortlich. So besitzt die DNA, durch die Abwesenheit der Hydroxygruppe, im Vergleich zur RNA das deutlich flexiblere Rückgrat, ${ }^{[25]}$ welches auch die stabileren Phosphordiesterbindungen aufweist. Während die Halbwertszeit der DNA auf ca. 30 Millionen Jahre geschätzt wird, ${ }^{[26]}$ sinkt diese für RNA in den Bereich von Jahren. ${ }^{[27]}$ Der Grund dafür ist, dass die 2'-OH Gruppe als internes Nukleophil agieren und so die Spaltung des Phosphordieesters beschleunigen kann. Gleichzeitig führt die Abwesenheit der Hydroxygruppe in der DNA dazu, dass sie unter sauren Bedingungen leichter depuriniert wird. Ein weiterer Unterschied ist in den Nukleobasen zu finden. Während DNA die Basen Adenin (A), Thymin (T), Cytosin (C) oder Guanin (G) enthält, kommt in der RNA Uracil (U) anstelle von $T$ vor. Abgesehen von diesen kanonischen Basen können in Nukleinsäuren
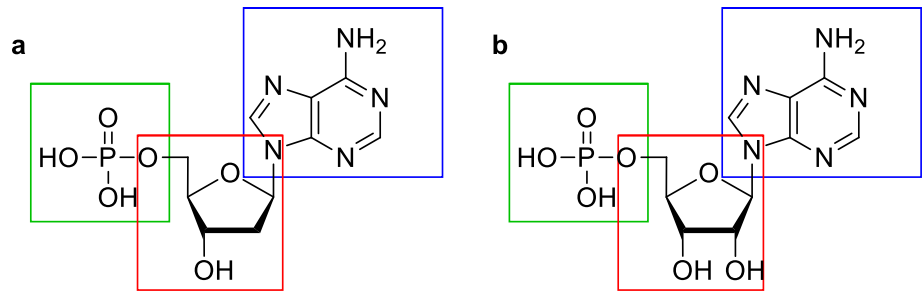

Abbildung 2: Beispiel eines Nukleotids am Beispiel des Desoxyadenosinmonophosphats (dAMP, a) und des Adenosinmonophosphats (AMP, b). Diese setzen sich aus Desoxyribose im Fall der DNA (a, rot) oder Ribose im Fall der RNA (b, rot), der Base Adenin (blau) und einem Phosphatrest (grün) an der 5'-OH-Gruppe zusammen. 
auch nichtkanonische Nukleoside wie Inosin, Pseudouidin oder 5-Methylcytidin $\left(\mathrm{m}^{5} \mathrm{C}\right)$ vorkommen. Während die erstgenannten Bausteine insbesondere in tRNAs zu finden, wo sie eine Großen Einfluss auf die Struktur besitzen, ${ }^{[28]}$ kann 5-Methylcytosin auch in der DNA gefunden werden. Bei einer Methylierung von $\mathrm{C}$ in Promotorregionen wird die Bindung von Transkriptionsfaktoren verhindert und so die Genexpression epigenetisch reguliert. ${ }^{[29]}$ Außerdem dient die Methylierung der DNA zur Unterscheidung von zelleigener und bakterieller oder viraler DNA. ${ }^{[30]}$

Ein weiterer Unterschied zwischen RNA und DNA ist in ihrer Sekundärstruktur zu finden. Während genomische DNA in Zellen als Doppelhelix vorliegt, ${ }^{[31]}$ besitzt die RNA keinen Gegenstrang. Dadurch ist ein RNA-Strang in der Lage, mit sich selbst zu binden und zu falten. Dies ermöglicht eine größere Anzahl an Sekundärstrukturen, wie stem-loop oder hairpin-, sowie pseudoknot-Strukturen. Aus diesen Strukturen und der unterschiedlichen Länge der verschiedenen RNA-Spezies ergeben sich die Vielzahl an Funktionen, die RNAs in Organismen ausüben können.

\subsubsection{Strukturen der Nukleinsäuren}

Wie zuvor erwähnt, liegt genomische DNA unter nativen Bedingungen als Doppelhelix bestehend aus zwei Einzelsträngen vor. Diese sind dabei antiparallel ausgerichtet, was bedeutet, dass jeweils ein $3^{\prime}$-Ende einem $5^{\prime}$-Ende gegenüber liegt (Abbildung 3, links). Die Bindung der beiden Stränge erfolgt durch Wasserstoffbrückenbindungen zwischen den Nukleobasen, wobei sich spezifisch Paare aus $G$ und $C$ sowie $A$ und T bilden (Abbildung 3, Mitte und rechts), welche als Watson-Crick-Paare bezeichnet werden. Darüber hinaus wird die Helix durch Van-der-Waals-Wechselwirkungen zwischen den übereinanderliegenden Basen stabilisiert, während die elektrostatische Repulsion des Phosphat-Rückgrats eine
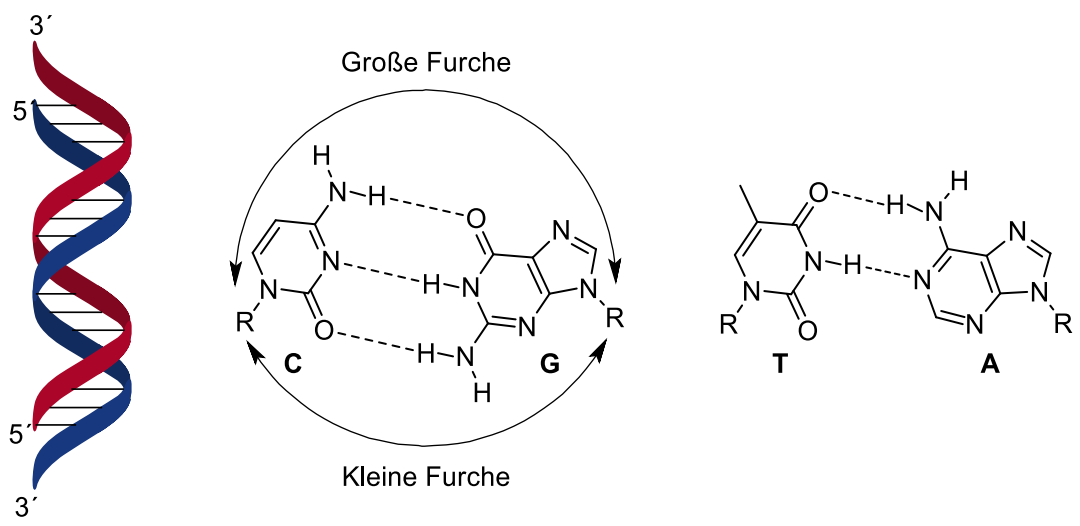

Abbildung 3: Struktur der DNA-Doppelhelix nach Watson und Crick (links). ${ }^{[31]}$ Dabei sind zwei DNA-Stränge über die Basenpaarung zwischen $\mathrm{G} \cdot \mathrm{C}$ (Mitte) und A•T (rechts) antiparallel verknüpft. Durch die Position des Rückgrats entsteht dabei eine große und eine kleine Furche (Mitte). 
Tabelle 1: Zusammenfassung der Parameter der drei Formen der DNA. ${ }^{[25]}$

\begin{tabular}{l|l|l|l} 
& A-Form & B-Form & Z-Form \\
\hline Drehsinn der Helix & rechtsgängig & rechtsgängig & linksgängig \\
\hline Durchmesser & $\approx 26 \AA$ & $\approx 20 \AA$ & $\approx 18 \AA$ \\
\hline Basenpaare pro Windung & 11 & 10.4 & 12 \\
\hline Höhe pro Basenpaar & $2.3 \AA$ & $3.4 \AA$ & $3.8 \AA$ \\
\hline $\begin{array}{l}\text { Neigung der Basenpaare zur } \\
\text { Achse der Helix }\end{array}$ & $19^{\circ}$ & $1^{\circ}$ & $9^{\circ}$ \\
\hline Zuckerkonformation & C3'-endo & C2'-endo & $\begin{array}{l}\text { Purine: C3'-endo } \\
\text { Pyrimidine: C2'-endo }\end{array}$ \\
\hline $\begin{array}{l}\text { Konformation der } \\
\text { glykosidischen Bindung }\end{array}$ & anti & anti & $\begin{array}{l}\text { Purine: syn } \\
\text { Pyrimidine: anti }\end{array}$ \\
\hline große Furche & & & Flach \\
\hline kleine Furche & eng und tief & breit und tief & sehr eng und tief \\
\hline
\end{tabular}

destabilisierende Wirkung besitzt. Aufgrund der Geometrie der Basenpaare und der daraus folgenden Stellung der Reste zueinander, entsteht in den Helices eine große und eine kleine Furche (Abbildung 3, Mitte). Da die DNA über ein sehr flexibles Rückgrat verfügt, ist sie in der Lage verschiedene Helixformen einzunehmen (Tabelle 1 und Abbildung 4). Die natürliche Form der DNA stellt dabei die von Watson und Crick 1953 aufgeklärte B-Form dar (Abbildung 4, Mitte). ${ }^{[31]}$ In dieser Form nimmt die Desoxyribose die sogenannte 2 '-endo-Konformation ein, wodurch ein maximaler Abstand der Phosphatreste gegeben ist (Abbildung 5, b, rechts). Die Basen stehen dabei anti zur Desoxyribose, was bedeutet, dass die Base vom Zuckermolekül weg zeigt (Abbildung 5, a) und aus sterischen Gründen günstiger ist. ${ }^{[25]}$ In der B-Form besitzt die Helix eine breite und tiefe große, sowie eine enge
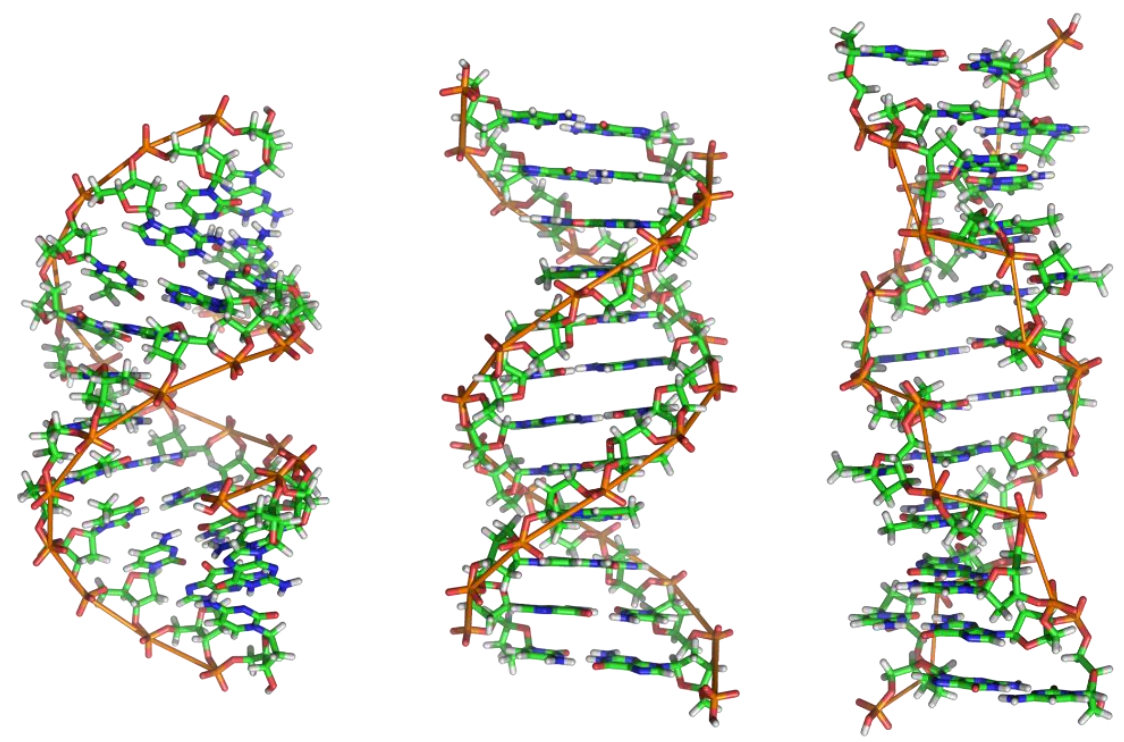

Abbildung 4: Strukturen der A-, B- und Z-DNA (von links nach rechts). ${ }^{[32]}$ 
a

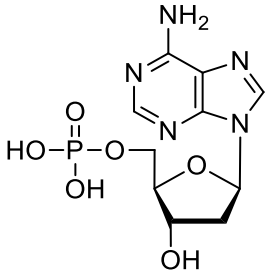

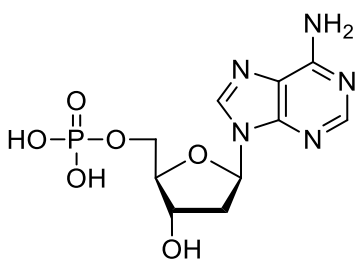

HO

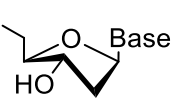

$\mathrm{HO}$

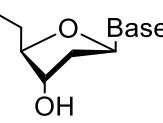

Abbildung 5: Konformationen der DNA-Nukleotide. a: Durch die Stellung der Nukleobase kann zwischen der syn- (links) und anti-Konformation (rechts) unterschieden werden. b: Die 3'-endo- (links) und 2'-endo-Konformation (rechts) der Desoxyribose. Dabei ist in der 2'-endo-Konformation der Abstand zwischen den Phosphatgruppen größer.

und tiefe kleine Furche. Aufgrund der unterschiedlichen funktionellen Gruppen, welche in die beiden Furchen ragen, ist eine selektive Erkennung der Doppelhelix sowohl in der großen als auch in der kleinen Furche möglich. Neben der B-Form existieren noch die Aund Z-Form der DNA. Die A-Form ist eine kompaktere Struktur der DNA (Abbildung 4, links), welche bereits von Watson und Crick postuliert ${ }^{[33]}$ und zunächst in dehydratisierten Kristallen entdeckt wurde. ${ }^{[34]}$ In der A-Form ändert sich die Konformation der Desoxyribose von 2'-endo zu 3'-endo (Abbildung 5, b, links). Diese konformationellen Änderungen führen zu einer engen großen und einer relativ breiten und flachen kleinen Furche. Auch wenn die A-Form für die DNA nur bedingt von Relevanz ist, stellt sie die Grundform aller RNA-Helices dar. Hierbei wird die Ribose in die 3'-endo-Konformation gezwungen, da es ansonsten zu massiven sterischen Wechselwirkungen kommen würde. ${ }^{[25,31]}$ Die unterschiedliche Form der Helices und die damit verbundene Struktur der Furchen ermöglicht es beispielsweise, dsDNA selektiv in der kleinen Furche zu erkennen, während dsRNA nicht adressiert wird. ${ }^{[35]}$ Die Z-Form der DNA bildet, im Gegensatz zu den anderen Formen, eine linksgängige Helix aus und kann bei Sequenzen mit alternierenden G.C-Paaren beobachtet werden (Abbildung 4, rechts). ${ }^{[36,37]}$ In diesem Fall weisen die Purin- und Pyrimidinbasen unterschiedliche Konformationen auf (Tabelle 1), wodurch die Z-DNA lediglich eine sehr enge Furche besitzt.

\subsubsection{Alternative Basenpaarungen}

Abgesehen von den Watson-Crick-Basenpaaren können Nukleinsäuren weitere Basenpaarungen ausbilden. Dazu gehören die Hoogsteen-Paare (Abbildung 6) oder, insbesondere im Fall der RNA, Wobble-Paare zwischen G und U. Letztere sind dabei unter anderem bei der Stabilisierung von Sekundärstrukturen der RNA entscheidend beteiligt. Dies kann insbesondere im Fall der tRNAs beobachtet werden. ${ }^{[25]}$ Auch Hoogsteen-Paare spielen bei der Stabilisierung von tRNAs ein Rolle, ${ }^{[38]}$ indem diese die Bildung von Tripelhelices ermöglichen, welche für die Tertiärstruktur von großer Bedeutung sind. Die Bildung von Tripelhelices ist jedoch nicht nur mit RNA sondern auch mit DNA möglich. ${ }^{[16,39]}$ Dabei lagert sich ein dritter Nukleinsäurestrang über Hoogsteen-Paarungen in der große 


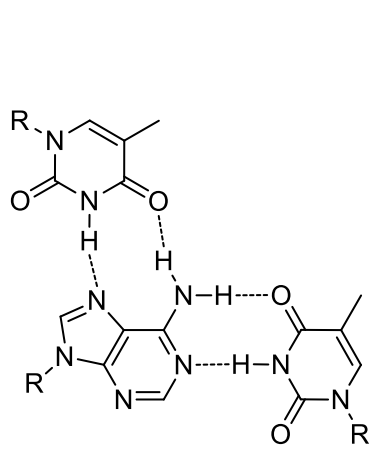

T*AT Triplett

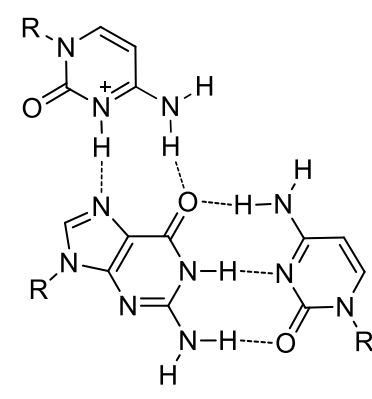

$\mathrm{C}^{+*} \mathrm{GC}$ Triplett

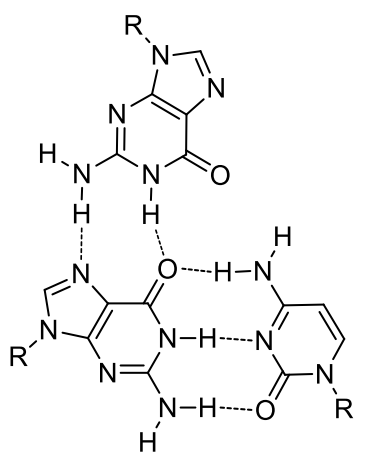

$\mathbf{G}^{*} \mathbf{G C}$ Triplett

Reverse-Hoogsteen-Paare<smiles>[R]n1cc(C)c(=O)n([R])c1=O</smiles>

T*AT Triplett

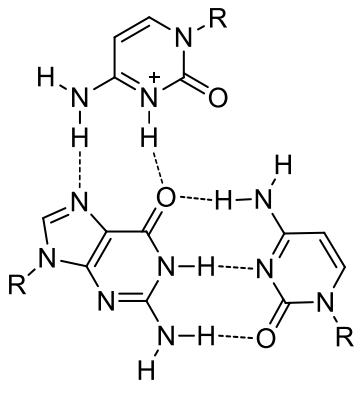

$\mathbf{C}^{+*} \mathbf{G C}$ Triplett

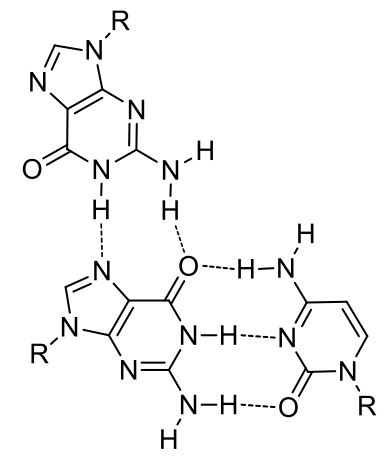

G*GC Triplett

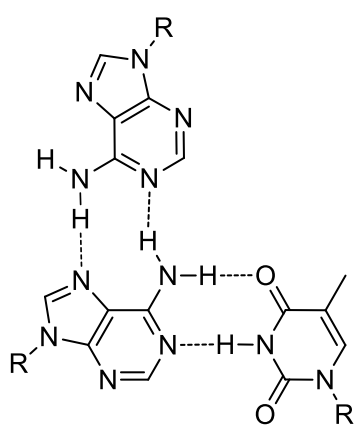

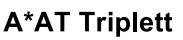

Abbildung 6: Hoogsteen-Basenpaarungen der vier Basen A, T, G und C. Dabei kann zwischen Hoogsteen (oben) und reversen Hoogsteen Paaren (unten) unterschieden werden. Diese unterscheiden sich durch die Stellung ihres Rückgrats (R) im Vergleich zum Purin-reichen Strang. Eine Hoogsteen-Paarung zwischen $C$ und einem $G \cdot C$ Paar ist nur mit protoniertem $C$ möglich.

Furche einer Doppelhelix an. Zur Ausbildung dieses Strukturtyps muss die dsDNA einen Homopurinstrang enthalten, da Hoogsteen-Paare nur an Purinen möglich sind (Abbildung 6). Darüber hinaus muss das triplexbildende ON (TFO) strukturelle Anforderungen erfüllen, die durch die Geometrie und Art der Hoogsteen-Paare festgelegt werden. Die Ursache hierfür ist einerseits, dass Hoogsteen-Paare mit Ausnahme von $A^{*} A \cdot T-T r i p l e t s$ in zwei Orientierungen möglich sind. Diese werden je nach der Orientierung des TFO-Strangs zum Purinstrang in Hoogsteen- und reverse Hoogsteen-Paare unterschieden (Abbildung 6). Eine Folge daraus ist, dass ein TFO entweder über Hoogsteen- oder reverse Hoogsteen-Paare binden muss. Hierbei ist zudem entscheidend, dass die Positionen der $\mathrm{C}^{\prime}$ '-Atome weitgehend isomorph sind, um Deformationen des ON-Rückgrats zu verhindern. Aufgrund der Geometrie der Hoogsteen-Paare sind jedoch nur die Tripletts mit $C$ und $T$ isomorph (Abbildung 7 ) und Homopyrimidin-TFOs binden bevorzugt über Hoogsteen-Paare und somit parallel zum Homopurinstrang. ${ }^{[40]}$ Allerdings können diese Paare nur mit protoniertem C gebildet werden, wodurch sie unter physiologischen Bedingungen nicht stabil sind. Abgesehen von CT-haltigen Strängen können jedoch auch GA-reiche ONs unter physiologischen Bedingungen Tripelhelices 
Hoogsteen-Paare

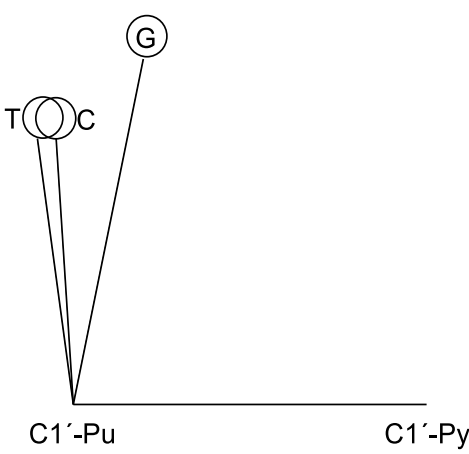

Reverse-Hoogsteen-Paare

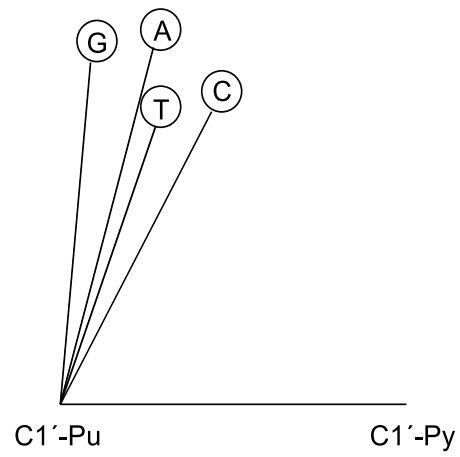

Abbildung 7: Schematische Darstellung der Lage der C1'-Atome bei Hoogsteen-Basenpaaren. ${ }^{[40]}$

bilden. Diese binden über eine Reverse-Hoogsteen-Basenpaarung und ordnen sich antiparallel zum purinreichen Strang des Duplex an. Außerdem können purinhaltige TFOs auch einzelne Ts tolerieren. ${ }^{[41]}$ Abgesehen von den bisher vorgestellten TFOs ist eine Triplexbildung auch mit GT-haltigen ON möglich. Hierbei können die ON aus poly-T und poly-G Blöcken bestehen oder eine alternierende Abfolge der Basen besitzen ${ }^{[42,43]}$ Die Zusammensetzung der TFOs bestimmt dabei ihr Bindeverhalten. Während die aus Blöcken aufgebauten TFOs über Hoogsteen-Paare binden und einen parallelen Triplex bilden, ist im alternierenden Fall eine reverse Hoogsteen-Paarung günstiger, woraus sich ein antiparalleler Triplex ergibt.

Außer den Tripelhelices können über Hoogsteen-Basenpaare auch G-Quadruplexe gebildet werden. Diese bestehen aus einer Überlagerung von mindestens drei G-Tetraden, welche wiederum einen Zusammenschluss von vier Guanosinen darstellen (Abbildung 8, a). Auch diese sind über Hoogsteen-Paare verknüpft und werden durch die Koordination eines zentralen Metallions stabilisiert. Hierfür werden Alkalimetalle in der Reihenfolge $\mathrm{K}^{+}>\mathrm{Na}^{+}>\mathrm{Li}^{+}$bevorzugt. Die Quadruplexe werden zusätzlich durch $\pi-\pi$-Wechselwirkungen zwischen den einzelnen Tetraden stabilisiert. Die Ausbildung von G-Quadruplexen kann zwischen mehreren Strängen erfolgen, wobei alle Nukleinsäuren der Sequenz $\mathrm{G}_{23} \mathrm{~N}_{\times} \mathrm{G}_{23} \mathrm{~N}_{\mathrm{x}} \mathrm{G}_{23} \mathrm{~N}_{\mathrm{x}} \mathrm{G}_{23}$ in der Lage solche Strukturen ohne Partnerstrang auszubilden. ${ }^{[44,45]}$ Dabei kann der ON-Stang sowohl parallel, antiparallel oder in einer Hybridform verlaufen (Abbildung 8, $\mathbf{b}-\mathbf{d}$ ). Während diese Strukturen zunächst als reine in vitro Effekte betrachtet wurden, konnten sie im Laufe der Zeit verstärkt in vivo nachgewiesen werden. Dabei ist jedoch nicht abschließend geklärt, ob dies ein Effekt der eingesetzten Methoden ist oder ob es sich um physiologisch relevante Strukturen handelt. ${ }^{[44-46]}$ 
a

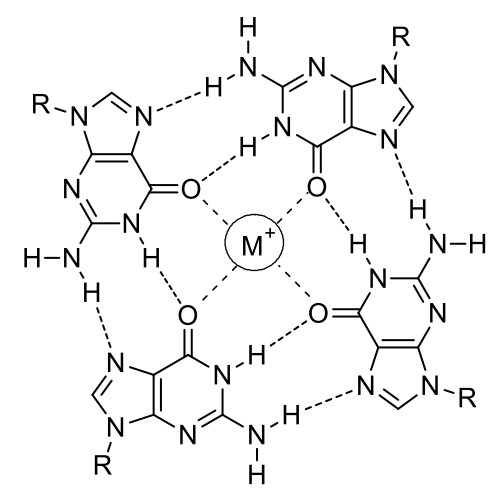

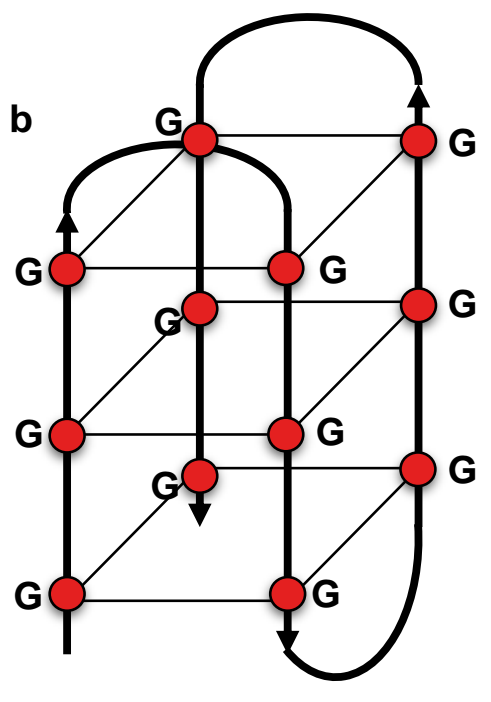

Antiparalel

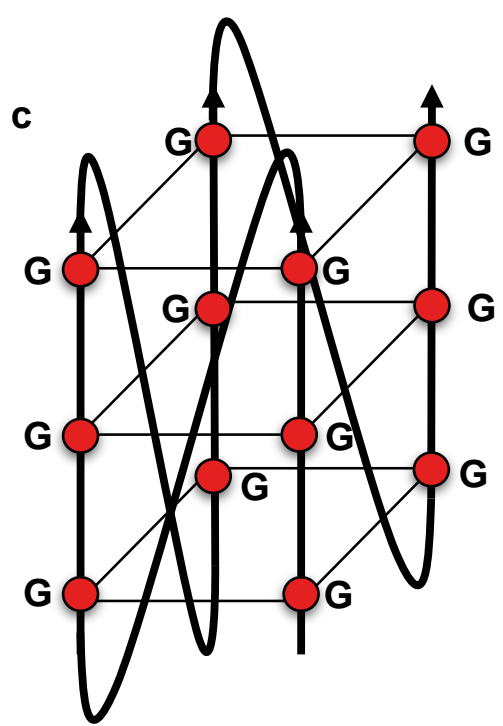

Parallel

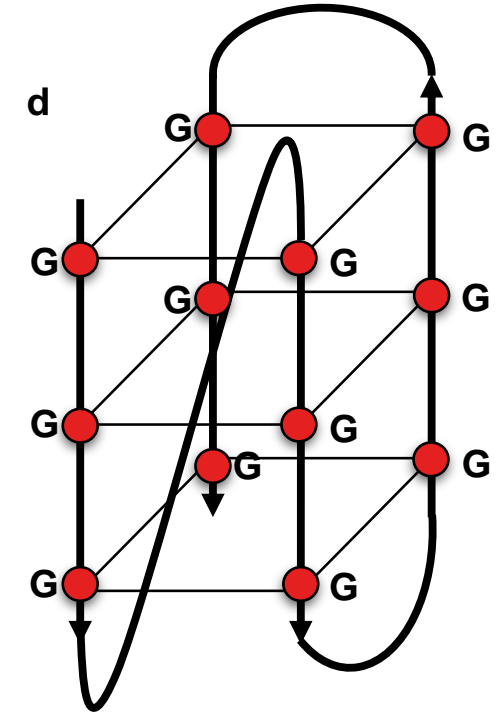

Hybrid

Abbildung 8: a: Schematische Darstellung einer G-Tetrade; $\mathbf{b}$ - d: Schematische Darstellung verschiedener intramolekularer G-Quadruplexe. Dabei werden die G-Tedraden durch Rauten und die Lage der Gs durch rote Kreise dargestellt. 


\subsection{Modifizierte Nukleinsäuren}

Aufgrund ihrer Flexibilität und der großen Anzahl an Funktionen sind RNAs ein interessantes medizinisches Ziel. ${ }^{[47]}$ Dabei ist die Adressierung der mRNA mittels antisense oligonucleotides (ASOs) oder RNA-induced silencing complexes (RISCs) die häufigste Anwendung. ${ }^{[9,47]}$ Darüber hinaus sind CRISPR-Cas9 (clustered regularly interspaced short palindromic repeats/CRISPR associated protein 9) basierte Systeme und die dafür notwendigen guide RNAs (gRNA) von großem Interesse. ${ }^{[47]}$ Ein Problem für diese Anwendungen stellt dabei die hohe Instabilität der RNA gegenüber Nukleasen dar. Im Fall der ASOs, welche die älteste Anwendung von ONs darstellten, ${ }^{[1,47]}$ wurden zunächst DNAs eingesetzt. ${ }^{[48]}$ Allerdings war auch bei diesen ein schneller Abbau durch Exo- und Endonukleasen zu beobachten. Zudem zeigte sich, dass die Stabilität eines RNA/DNA-Duplex geringer war als die eines entsprechenden RNA/RNA-Duplex. ${ }^{[49]}$ Um die Stabilität und die Affinität der ASOs zu erhöhen, wurden Modifikationen an der 2'-OH Gruppe sowie am Rückgrat vorgenommen (Abbildung 9). Dazu verwendete man zunächst 2'-OMe-RNA, welche ebenfalls in natürlicher RNA vorhanden ist. Die entsprechenden ASO wiesen neben einer erhöhten Stabilität gegenüber Nukleasen auch eine im Vergleich zu DNA erhöhte Affinität zu RNA auf. ${ }^{[47,50]}$ In diesem Fall konnte eine Erhöhung des Schmelzpunktes um $0.2-0.8^{\circ} \mathrm{C}$ pro Nukleotid beobachtet werden. Ausgehend davon wurde versucht, diesen Effekt durch längere Alkylketten zu verstärken. Dabei war die 2'-O-Methoxyethyl-RNA (2'-MOE) besonders effektiv und es konnte ein $\Delta T_{m}$ von $0.9-1.7^{\circ} \mathrm{C}$ pro Nukleotid beobachtet werden. ${ }^{[47]}$ Aufgrund ihrer größeren Ähnlichkeit zur RNA und ihrer höheren Kompatibilität mit RNA-bindenden Proteinen, wie dem Ago2, werden 2'-OMe-RNAs verstärkt im Bereich der siRNA eingesetzt. Da 2'-MOE-RNAs für diese Anwendungen weniger geeignet sind, werden sie im Bereich der ASOs verwendet. ${ }^{[4]}$

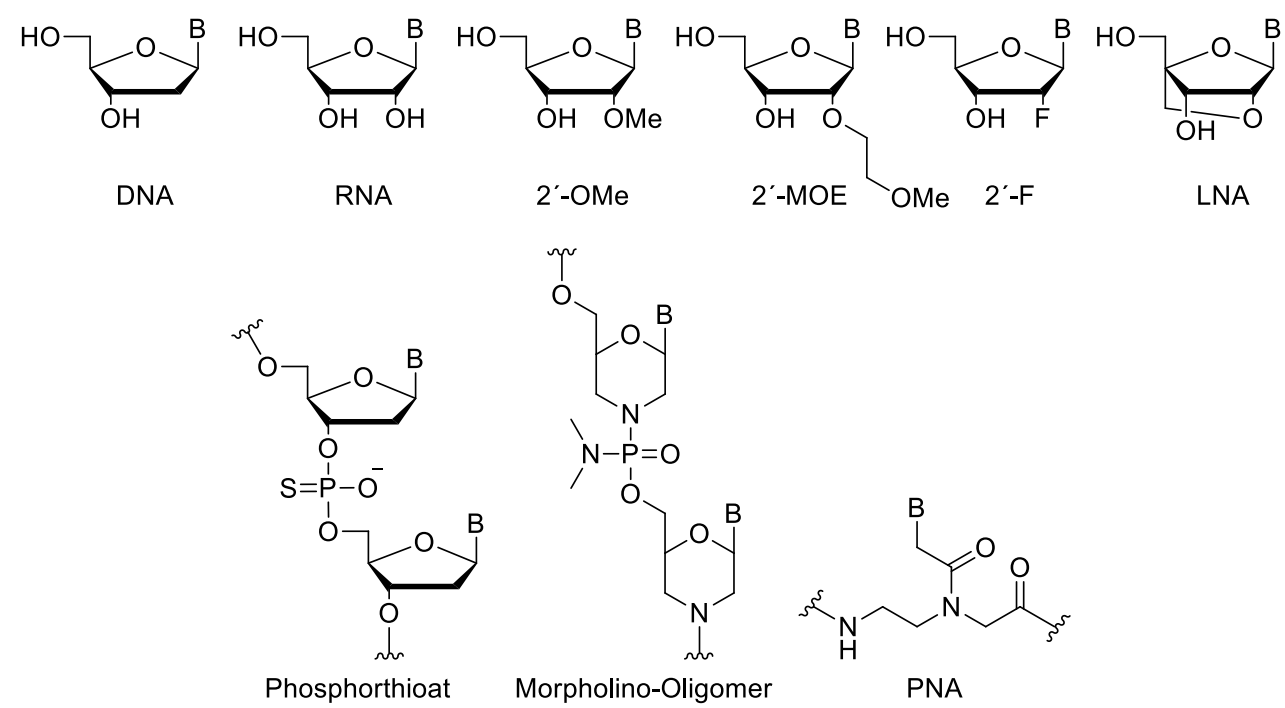

Abbildung 9: Mögliche Modifikationen an der 2'-OH Gruppe der Ribose (oben) und Modifikationen des Rückgrats (unten). 
Eine weitere Modifikation der RNA stellt die 2'-F-RNA dar, bei welcher die 2'-OH Gruppe durch ein Fluoratom substituiert ist. Dadurch konnte neben einer Erhöhung der Nukleasestabilität auch ein höhere Affinität erzielt werden $\left(\Delta \mathrm{T}_{\mathrm{m}}=2.5^{\circ} \mathrm{C}\right.$ pro Nukleotid). ${ }^{[47]}$ Aufgrund der Größe und Ladung des Fluors ist die 2'-F-RNA dabei ein sehr gutes Imitat der nativen RNA und kann ebenfalls für die Stabilisierung von siRNAs verwendet werden. In Kombination mit 2'-OMe-RNA können auf diese Weise vollständig modifizierte siRNAs aufgebaut werden, da sich die Einflüsse der Modifikationen auf die Struktur der ON ausgleichen und eine RNA nahe Struktur erhalten wird. ${ }^{[47]}$ Eine weitere Modifikation der Nukleoide stellen die 2' - 4' verbrückten locked nucleic acids (LNAs) dar (siehe Abschnitt 2.3.1).

Neben der 2'-Position der Ribose können auch Modifikationen am Rückgrat vorgenommen werden. In diesem Zusammenhang sind Phosphorthioate die älteste und am häufigsten verwendete Modifikation. ${ }^{[47,51]}$ Bei diesen wird ein ungebundener Sauerstoff des Phosphats durch Schwefel substituiert, wodurch die Nukleasestabilität der Phosphordiesterbindung drastisch erhöht wird. ${ }^{[47]}$ Allerdings führt dies zu einer verringerten Affinität der ONs $\left(\Delta \mathrm{T}_{\mathrm{m}}=0.5-0.7^{\circ} \mathrm{C}\right) . .^{[47,52]}$ Darüber hinaus wird durch die Substitution des Sauerstoffatoms durch Schwefel ein Stereozentrum erschaffen, dessen Kontrolle nur bedingt möglich ist. Dies hat die Bildung von stereoisomeren Verbindungen zur Folge, welche die Wirkung der ONs beeinflussen können. ${ }^{[4]}$ Andererseits wirkt sich die Verwendung von Phosphorthioaten positiv auf die Zellgängigkeit der ONs aus und verhindert eine rasche Ausscheidung der ONs durch Bindung an Albumin, ${ }^{[51]}$ wodurch die Vorteile dieser Modifikation deutlich überwiegen. Eine weitere Modifikation des Rückgrats sind Phosphoramidat-Morpholino-ONs (PMOs). Bei diesen wurde die Ribose durch ein funktionalisiertes Morpholin ersetzt und die Verknüpfung der Bausteine erfolgt durch ein Phosphoramidat. Somit besitzen PMOs bei physiologischem $\mathrm{pH}-$ Werten ein neutrales Rückgrat, ${ }^{[53]}$ was zu einer erhöhten Stabilität gegenüber Nukleasen und einer im Vergleich zu DNA gesteigerte Affinität zu RNAs führt. ${ }^{[47]}$ Das neutrale Rückgrat stellt jedoch eine Herausforderung bei der Anwendung von TFOs dar, da es eine Wechselwirkung mit SerumProteinen verhindert und dies zu einer erhöhten renalen Ausscheidung führt. ${ }^{[33]}$ Gleichzeitig erlaubt das neutrale Rückgrat der PMOs die Konjugation mit positiv geladenen cellpenetrating peptides (CPPs), welche die Zellaufnahme verbessern können. PMOs werden hauptsächlich als splice-switching ONs (SSOs) zur Regulation des Spleißen der mRNA eingesetzt, ${ }^{[2]}$ da sie nicht in der Lage sind, mit Proteinen wie der RNase H oder Ago2 zu interagieren. Eine noch drastischer Modifikation des ON-Rückgrats ist bei den Peptidnukleinsäuren (PNAs) zu finden (Abschnitt 2.3.2). Diese besitzen ein Rückgrat aus einem synthetischen Polypeptid, an das die Basen ebenfalls über Peptidbindungen 
angebracht sind. Dies hat zur Folge, dass PNAs gegen Nukleasen resistent sind und über ein neutrales Rückgrat verfügen.

\subsubsection{Locked Nucleic Acids (LNAs)}

Ein Grund für die im Vergleich zur DNA höhere Affinität von 2'-modifizierten ON zur RNA ist in der Struktur der Stränge zu finden. Obwohl die DNA ein flexibles Rückgrat besitzt und die Konformation der Desoxyribose relativ einfach von 2'-endo zu 3'-endo wechseln kann, ${ }^{[54]}$ wird die 2' -endo Konformation bevorzugt. Im Gegensatz dazu muss die Ribose die 3 '-endo Konformation einnehmen, da es ansonsten zu sterischen Wechselwirkungen zwischen 2'-OH, Nukleobase und Phosphatrest an der 3'-OH-Gruppe kommen würde. Als Resultat nehmen RNA/DNA-Hybride eine Mischform aus der A- und der B-Form ein. Hierbei liegt die RNA in der 3'-endo Konformation vor, während die Desoxyribose sowohl die 2'als auch die 3 '-endo Konformation einnimmt. Im Fall der 2'-modifizierten ONs liegt die Ribose ebenfalls in der $3^{\prime}$-endo Konformation vor und sie bilden eine A-Form artige Struktur aus. Somit ist ihre Struktur der RNA-Konformation deutlich ähnlicher und die Duplices deutlich thermostabiler. ${ }^{[55]}$ Um diesen Effekt zu verstärken, wurden die bizyklischen LNAs entwickelt. Bei diesen ist die 2'-OH Gruppe der Ribose über eine Methylengruppe mit dem 4'-Kohlenstoffatom verknüpft (Abbildung 9), wodurch der Zucker kovalent in die 3'-endo Konformation gezwungen wird. Als Resultat kann die thermische Stabilität eines RNA/DNA-Duplex durch den Einbau von LNA-Nukleotiden in den DNA-Strang massiv

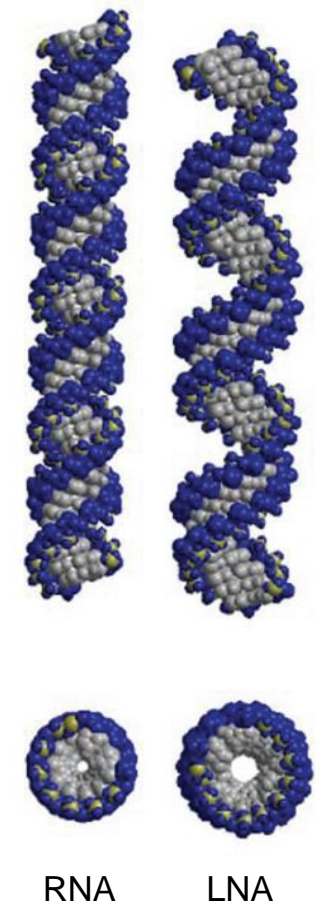


erhöht werden $\left(\Delta \mathrm{T}_{\mathrm{m}}=4-8{ }^{\circ} \mathrm{C}\right.$ pro Nukleotid). ${ }^{[47,54,57,58]}$ Ein Grund dafür ist, dass die starre Struktur der LNA auch benachbarte Desoxyribosen in die 3'-endo-Konformation zwingt. ${ }^{[54]}$ Die Auswirkungen der starren Struktur der LNA-Nukleotide zeigt sich auch in der Form von LNA/LNA Duplices. Dort ist die Helix deutlich gestreckter und breiter als bei der natürlichen RNA (Abbildung 10). ${ }^{[56,59]}$ In Hybrid-Duplices kann dahingegen eine Mischung beider Strukturen beobachtet werden. ${ }^{[56]}$ Aufgrund dieser strukturellen Unterschiede werden LNAs in Proteinkomplexen schlecht toleriert. Beispielsweise führt der Einbau von LNA-Nukleotiden in siRNA zu einer geringeren Aktivität der RNA-Interferenz (RNAi). Bei einem Einbau in DNA-Stränge kann die Anwesenheit von LNA-Nukleotiden die Rekrutierung der RNase $\mathrm{H}^{[60]}$ oder von $\mathrm{TFs}^{[61]}$ verhindern. Allerdings wird die Nukleasestabilität von ONs durch den Einbau von LNA-Nukleotiden deutlich erhöht.

Aufgrund ihrer hohen Affinität und Nukleasestabilität sind LNAs attraktive Modifikationen in ONs zur Regulierung von RNA. Obwohl LNAs nicht für den Einsatz in siRNA geeignet sind, können sie in Form von DNA/LNA-Mixmeren in ASOs oder anti-miRs eingesetzt werden. ${ }^{[47,57]}$ Im Fall der anti-miRs ist neben alternierenden DNA/LNA-Mixmeren auch der Einsatz von kurzen LNA-ONs (tiny-LNAs) möglich. ${ }^{[47,57,62]}$ ASOs werden je nach Anwendung in zwei Gruppen unterteilt, die eine unterschiedliche Positionierung der LNA-Nukleotide benötigen. Einerseits können ASOs als Gapmere eingesetzt werden. Diese ONs sind in der Lage, die RNase $\mathrm{H}$ zu rekrutieren, welche DNA/RNA-Hybride erkennt und die RNA spezifisch degradieren kann. Um die Funktion dieser Konstrukte zu gewährleisten, müssen Gapmere einen Block von mindestens 6 - 8 DNA-Basen enthalten. ${ }^{[57,60]}$ Die LNA-Nukleotide werden in diesem Fall als Blöcke an den Enden des Stranges eingebaut, um die Nukleasestabilität und die Affinität der ONs zu erhöhen. Die Wirkung der zweiten Gruppe der ASOs beruht auf der Bindung an die mRNA. Dort können sie als sterischer Block dienen und so die Translation inhibieren oder das Spleißen einer mRNA regulieren. In diesen Fällen werden Mixmere aus alternierenden Abfolgen an DNA und LNA verwendet, um die Rekrutierung der RNase $\mathrm{H}$ zu verhindern. Im Rahmen dieser Anwendungen konnte beobachtet werden, dass LNAs potenziell hepatotoxisch sind, ${ }^{[57]}$ wobei diese Wirkung von der Länge und Zusammensetzung des jeweiligen ONs abhängig ist. ${ }^{[63]}$

LNAs können zudem eingesetzt werden, um dsDNA zu adressieren. Beispielsweise führt der Einbau in TFOs zu einer Stabilisierung der Tripelhelix (Abbildung 11, links). ${ }^{[54]}$ Aufgrund ihrer hohen Affinität sind LNA-ONs oder LNA/DNA-Mixmere auch zur Stranginvasion fähig. ${ }^{[64-66]}$ Dazu können bifunktionale ONs (bisLNA) verwendet werden, welche an einen Strang einer dsDNA sowohl über Hoogsteen- als auch über Watson-Crick Basenpaarung binden können (Abbildung 11, Mitte). ${ }^{[66]}$ Eine andere Möglichkeit sind Zorro-LNAs (Abbildung 11, rechts). ${ }^{[64,65]}$ Diese besteht aus zwei, über einen starren Linker verbundene, ONs, welche in der Lage sind, versetzt an beide Stränge einer dsDNA zu binden. Die 
versetzten Target-Sequenzen verhindern dabei eine Selbstkomplementarität der Stränge, welche das ON inhibieren würden. Ein großes Problem für die Doppelstranginvasion (DSI) stellt jedoch die negative Ladung des Phosphat-Rückgrats und die hohe Stabilität des DNA-Doppelstrangs unter physiologischen Bedingungen dar. Hierdurch verlaufen die Stranginvasionen oft nur in geringer Effizienz und nur bei geringem GC-gehalt.

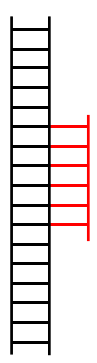

TFO

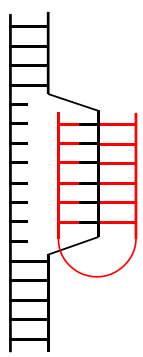

bisLNA

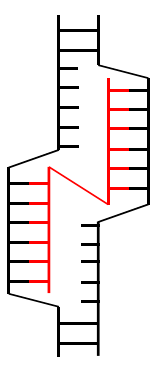

Zorro-LNA

Abbildung 11: Verschiedene LNA-Motive zur Bindung an dsDNA (schwarz). Dabei kann die LNA (rot) eine Tripelhelix bilden (links), oder in den Doppelstrang binden (rechts). BisLNAs (Mitte) stellen eine Mischform dar.

\subsubsection{Peptidnukleinsäuren (PNAs)}

PNAs sind Analoga der DNA, bei denen das Phosphordiesterrückgrat durch 2-Aminoethylglycin-Einheiten ersetzt wurde, welche durch Peptidbindungen verknüpft sind. Aufgrund ihrer Analogie zu Peptiden werden PNAs von ihrem N-Terminus zu ihrem C-Terminus notiert, wobei der N-Terminus dem 5'-Ende einer DNA entspricht. PNAs verfügen über ein neutrales Rückgrat, welches sowohl gegenüber Nukleasen und Proteasen stabil ist und gleichzeitig über eine hohe Flexibilität verfügt. ${ }^{[67]}$ Dennoch weicht die Struktur einer PNA/PNA-Helix deutlich von der Form anderer Nukleinsäuren ab und bildet die deutlich gestreckter P-Form aus. ${ }^{[68,69]}$ Aufgrund ihres neutralen Rückgrats und der nicht vorhandenen elektrostatischen Repulsion besitzt die PNA eine sehr hohe Affinität zu DNA und RNA, wobei die gebildeten Komplexe eine Mischform der jeweiligen Helix-Strukturen annehmen. ${ }^{[69]}$ Diese Komplexe können dabei bereits bei niedrigen Salzkonzentrationen Komplexe mit einer hohen thermischen Stabilität gebildet werden. ${ }^{[70,71]}$ Da das Rückgrat der PNA keine Chiralitätszentren aufweist, ist sie in der Lage sowohl parallel als auch antiparallel an eine DNA zu binden, wobei die antiparallele Anordnung bevorzugt wird. Das neutrale Rückgrat der PNA hat jedoch zur Folge, dass ihre Löslichkeit in wässrigen Medien gegenüber andern ONs geringer ist und ihr Einsatz dadurch limitiert wird. Dies kann jedoch durch den Einbau von Lysinen kompensiert werden, ${ }^{[0,71]}$ welche unter physiologischen Bedingungen positiv geladen sind. Die daraus resultierende elektrostatische Anziehung erhöht zudem die Affinität zur DNA und RNA. 


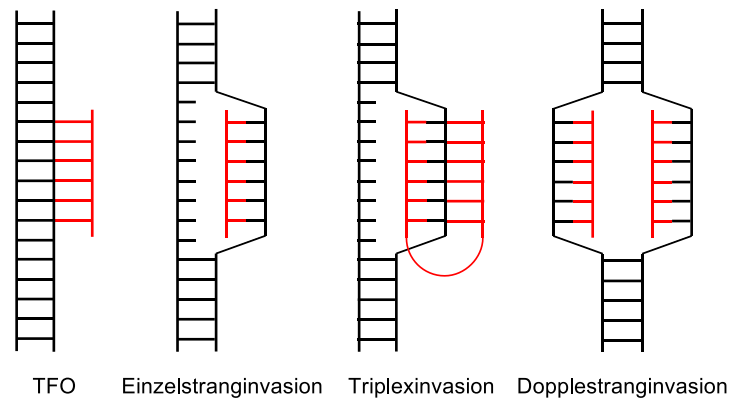

Abbildung 12: Bindungsmotive von PNA (rot) an dsDNA (schwarz). ${ }^{[71,72]}$

PNAs wurden ursprünglich auf Basis von Computermodellen entwickelt und sollten als TFOs eingesetzt werden. ${ }^{[70]}$ Aufgrund ihres neutralen, aber dennoch flexiblen Rückgrats und der fehlenden elektrostatischen Repulsion wurde eine bessere Affinität im Vergleich zu entsprechenden DNAs erwartet. Allerdings konnte bei der Anwendung der PNAs keine Triplexbildung beobachtet werden, sondern es trat eine Stranginvasion der PNA in den DNA-Doppelstrang auf (Abbildung 12, 2. von links). In nachfolgenden Experimenten zeigte sich, dass es sich hierbei nicht um eine Einzelstranginvasion sondern um einer Triplexinvasion (Abbildung 12, 2. von rechts) handelte. ${ }^{[70,71]}$ Somit stellen PNAs neben LNAs eine weitere ON-Klasse dar, die zu einer DSI fähig sind. Die Gründe hierfür sind die hohe Stabilität von PNA/DNA-Doppelsträngen, sowie das ungeladene Rückgrat der PNA. Die Triplexinvasion kann durch die Verknüpfung zweier PNAs zu einer bisPNA effektiver gestaltet werden. Wie bei der analogen bisLNA ist jedoch die Stabilität der dsDNA physiologischen Bedingungen der limitierende Faktor für die Ausbildung dieser Strukturen. Im Fall der PNA ist es möglich die Effizienz der DSI durch den Einbau positiv geladener Gruppen zu steigern. ${ }^{[71]}$

Ein grundsätzliches Problem der DSI ist der Umstand, dass die beiden benötigten ONs auch zueinander komplementär sind (Abbildung 12, rechts). ${ }^{[73]}$ Die Selbsthybridisierung steht dann in direkter Konkurrenz zur beabsichtigten Stranginvasion. Um dieses Problem zu vermeiden wurden die sogenannten pseudokomplementären PNAs vorgeschlagen. Dabei ersetzen die Basen Diaminopurin (D) und Thiouracil $\left(U_{S}\right)$ Adenin und Thymin. Die Bezeichnung pseudokomplementär wurde gewählt, da eine Basenpaarung zwischen D und
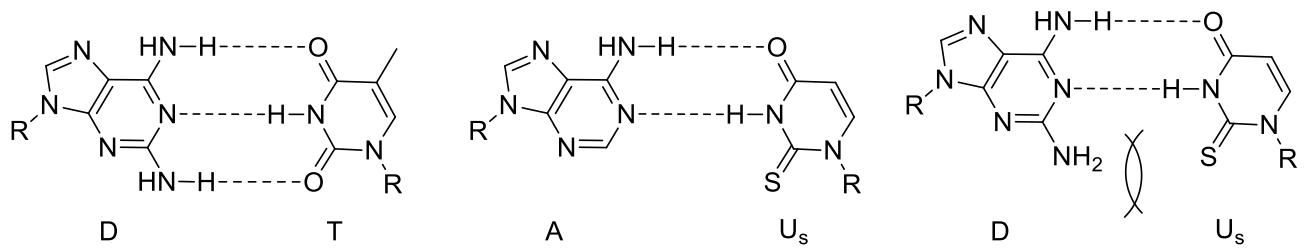

Abbildung 13: Basenpaare zwischen Diaminopurin (D), Thiouracil $\left(U_{s}\right), A$ und $T$. Dabei bildet ein $D \cdot T$ Paar drei Wasserstoffbrückenbindungen aus, was zu einer erhöhten Stabilität gegenüber einem $A \cdot T$ Paar führt (links). Zwischen $A \cdot U_{s}$ kann eine analoge Struktur zu A•T Paaren beobachtet werden (mitte), während sich ein $D \cdot U_{s}$ Paar, aufgrund sterischer Abstoßung zwischen der Amino- und der Thiogruppe, nicht bilden kann. 
$\mathrm{U}_{\mathrm{s}}$ aufgrund sterischer Hinderung nicht möglich ist, wodurch eine Hybridisierung der PNA-Stränge verhindert wird (Abbildung 13, rechts). Gleichzeitig kann D mit T drei Wasserstoffbrücken ausbilden (Abbildung 13, links). Damit ist dieses Basenpaar deutlich stabiler als ein analoges $A \cdot T-P a a r\left(\Delta T_{m}=3-6{ }^{\circ} \mathrm{C}\right.$ pro D). ${ }^{[73,74]}$ Die Bildung eines $A \cdot U_{s}$-Paars ist ebenso möglich (Abbildung 13, Mitte), auch wenn dabei eine leichte Destabilisierung des Duplex zu beobachten ist $\left(\Delta \mathrm{T}_{\mathrm{m}}=2-3^{\circ} \mathrm{C}\right.$ pro $\left.\mathrm{U}_{s}\right) \cdot{ }^{[73]}$ Für eine erfolgreiche Invasion muss die Zielsequenz jedoch zu mindestens $40 \%$ aus A•T-Basenpaaren bestehen. ${ }^{[75]}$ Zusätzlich limitiert die hohe Stabilität der dsDNA den Einsatz unter physiologischen Bedingungen. Allerdings kann die Effizienz der DSI mittels positiver Ladungen, beispielsweise durch die Konjugation mit einem nuclear localization signal (NLS), ${ }^{[6]}$ oder das Anbringen DNA-bindender Einheiten, wie Pyrrol-Imidazol-Polyamiden (PIP), ${ }^{[19]}$ deutlich gesteigert werden.

Neben der Bindung zu DNA können PNAs auch mit RNA stabile Komplexe bilden. Dabei können PNAs als ASOs eingesetzt werden und die Translation einer mRNA blockieren oder als SSO fungieren. ${ }^{[68,77]}$ Des Weiteren können PNAs als anti-miRs eingesetzt werden ${ }^{[78-80]}$ und aufgrund ihrer Fähigkeit zur Triplexinvasion können sie miRNAs bereits auf der Stufe der doppelsträngigen pri- und pre-miRNA adressieren. Somit ist es möglich, miRNAs bereits vor dem Einbau in RISCs zu regulieren. ${ }^{[78]}$ 


\section{Die Transkriptionsfaktoren Sp1 und Sp3}

Die Regulation der Genexpression erfolgt in eukaryotischen Zellen über Transkriptionsfaktoren (TFs). Diese binden an bestimmte, als Promotorelemente bezeichnete, Regionen einer DNA und rekrutieren über die Interaktion mit weiteren Proteinen eine RNA-Polymerase. In Eukaryonten gibt es drei RNA-Polymerasen, von denen die RNA-Polymerase II für die Synthese der mRNA verantwortlich ist. ${ }^{[81]}$ Eines der häufigsten Promotorelemente ist dabei die nach ihrer Sequenz benannte TATA-Box, welche 30 bis 100 bp vor dem Transkriptionsstart liegt und durch das TATA-Box-bindende Protein (TBP) erkannt wird. Neben diesem Element kann die Transkription auch durch die CAAT- und die GC-Box aktiviert werden, welche dabei bis zu $150 \mathrm{bp}$ vom Transkriptionsstart entfernt liegen können. Besonders die GC-Box spielt eine besondere Rolle bei der Expression von Haushaltsgenen, welche in vielen Fällen keine TATA-Box enthalten. ${ }^{[81]}$

Eine Familie der Transkriptionsfaktoren, welche an diese GC-Boxen binden, sind die Specificity Protein/Krüppel-like Factors (SP/KLF). Diese Familie beinhaltet mindestens 25 verschiedenen TFs, deren häufigster Vertreter das specificity protein 1 (Sp1) ist. ${ }^{\left[{ }^{[2,83]} \mathrm{Sp} 1\right.}$ war zudem der erste TF, der erfolgreich isoliert, geklont und zur Aktivierung der Transkription eingesetzt werden konnte. ${ }^{[84,85]} \mathrm{Sp} 1$ bindet die DNA über drei $\mathrm{C}_{2} \mathrm{H}_{2}$-Zinkfingerdomänen (Abbildung 14) an seine Konsensussequenz

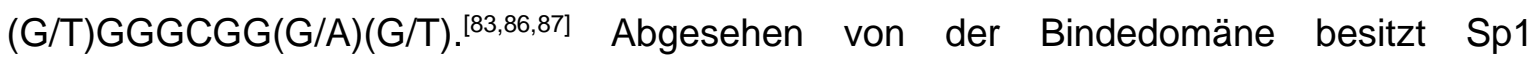
glutaminreiche Sequenzen, die als Aktivierungsdomänen (AD) fungieren und über den Kontakt mit weiteren Proteinen für die Rekrutierung der RNA-Polymerase II verantwortlich sind. In der Nachbarschaft der AD befinden sich Serin- und Threonin-reiche Domänen, ${ }^{[88]}$ welche beispielsweise durch Phosphorylierung oder Methylierung modifiziert werden können, wodurch die Stabilität und Aktivität des Sp1 beeinflusst werden. ${ }^{[89,90]}$

Sp1 ist einer der am besten untersuchten TFs und ist als ubiquitärer TF an der Regulation einer Vielzahl von Genen beteiligt. ${ }^{[83]}$ Unter diese Genen ist auch Sp1 selbst zu finden, sodass es einer Autoregulation unterliegt. ${ }^{[83,89]}$ Des Weiteren ist Sp1 entscheidend an der

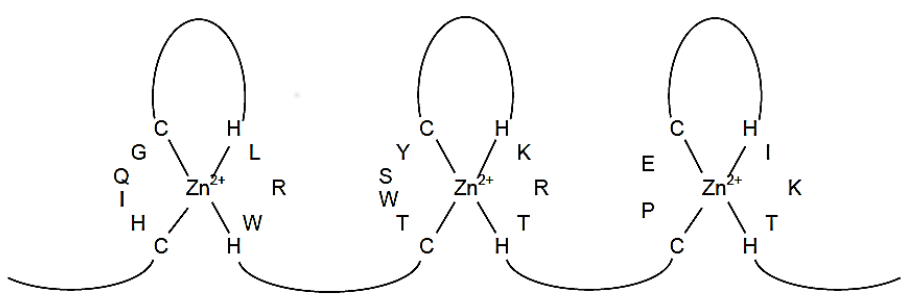

Abbildung 14: Zinkfingerdomäne des Sp1-Proteins. ${ }^{[87]}$ Dabei sind nur die Aminosäuren in der Nähe des Zinkions dargestellt. Die Erkennung der DNA erfolgt über Aminosäuren in den Finger 


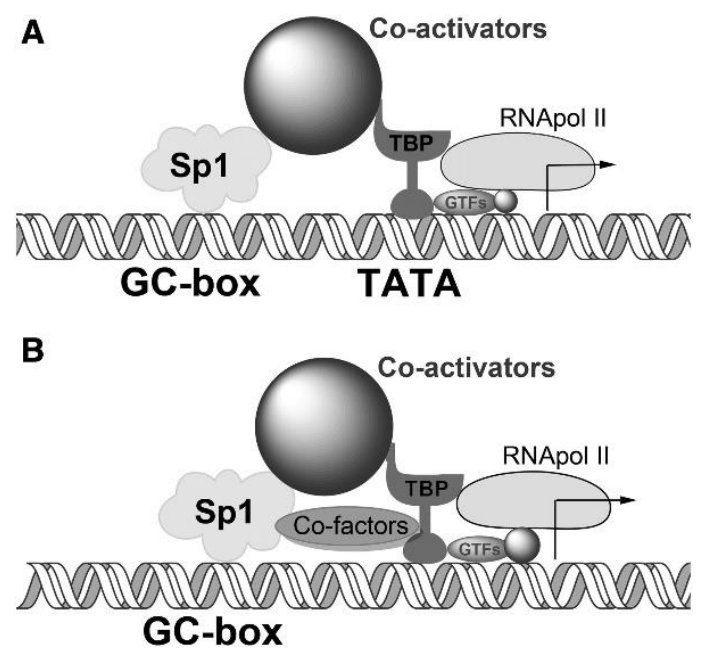

\begin{abstract}
Abbildung 15: Schematische Darstellung der Aktivierung der Genexpression durch Sp1. A: Transaktivierung durch Sp1 bei vorhandener TATA-Box. B: Transaktivierung für Gene ohne TATA-Box. In diesem Fall sind weitere Cofaktoren für die Rekrutierung des TBP notwendig. Mit Erlaubnis entnommen aus Vizcaíno et al.. ${ }^{[83]}$ Copyright (C 2015, Elsevier Inc..
\end{abstract}

Regulation von Haushaltsgenen ohne TATA-Box beteiligt (Abbildung 15, B). ${ }^{\left[{ }^{[3,86]}\right.}$ In diesen Fällen ist Sp1 in der Lage, das TBP zu rekrutieren, welches für die Initiation der Transkription essenziell ist. ${ }^{[83]}$ Aufgrund seiner Wechselwirkungen mit dem TBP kann Sp1 auch in der Transkription von Genen mit einer TATA-Box eine aktivierende Rolle spielen und dort als Coaktivator oder Corepressor fungieren (Abbildung 15, A). ${ }^{[86,89]}$ Falls in einer Promotorregion mehrere Bindestellen für Sp1 vorhanden sind, kann die Genexpression durch Sp1 synergistisch erfolgen und so verstärkt werden. ${ }^{[91,92]}$ Hierfür ist jedoch keine kooperative Bindung von Sp1 an die DNA verantwortlich, sondern die Bildung von Sp1-Tetrameren. ${ }^{[91]}$ Abgesehen von der Regulation von Haushaltsgenen spielt SP1 auch eine wichtige Rolle in der Regulierung des Zellzyklus ${ }^{[89,91]}$ und kann die epigenetischen Modulationen der DNA beeinflussen. ${ }^{\left[{ }^{11]}\right.}$ Beispielsweise ist Sp1 in der Lage, die Methylierung von DNA ${ }^{[91]}$ oder die Acetylierung von Histonen zu verändern. ${ }^{[89,91]}$

Neben Sp1 existiert mit Sp3 ein weiterer Vertreter der SP/KLF-Familie, der an GC-reiche Sequenzen bindet und die Funktion von Sp1 beeinflussen kann. ${ }^{[86]}$ SP3 besitzt im Gegensatz zu Sp1 verschiedene Isoformen, die nicht alle über eine aktivierende Domäne verfügen. ${ }^{\left[{ }^{89]}\right.}$ Darüber hinaus ist Sp3 nicht in der Lage, Multimere auszubilden und verfügt somit über keine synergistischen Eigenschaften. Dies führte dazu, dass Sp3 zunächst lediglich als Repressor der Transkription und Gegenspieler von Sp1 gesehen wurde. ${ }^{[86]}$ Allerdings zeigte sich, dass dieser Effekt hauptsächlich auftrat, wenn viele Bindestellen für Sp1 vorhanden sind und Sp1 als Tetramer agieren kann. In diesen Fällen kann Sp3 leichter an die DNA binden als SP1 und somit die Transkription abschwächen. ${ }^{[11]}$ Gleichzeitig konnte gezeigt werden, dass Sp3 auch zur Aktivierung der Transkription fähig ist. ${ }^{[6]}$ Beispielsweise konnte bei einer gleichzeitigen Überexpression von Sp1 und Sp3 eine verstärkte Aktivierung des Tumorsuppressors RASSF1A beobachtet werden. ${ }^{\left[{ }^{93]}\right.} \mathrm{Ob}$ es sich 
in diesem Fall um eine synergistische Aktivierung handelte ist jedoch umstritten, da es Hinweise auf eine unterschiedliche Verteilung der TFs im Zellkern gibt und sie somit nicht zeitgleich an denselben Promotor binden sollten. ${ }^{[94]}$ Des Weiteren regulieren Sp1 und SP3 unterschiedliche Gruppen von Genen, welche sich nur partiell überschneiden. ${ }^{[95,96]}$

Da bei der Transkription vieler Genen eine Beteiligung von Sp1 nachgewiesen werden konnte, entstand die Annahme, dass Sp1 für die Regulation von Haushaltsgenen essenziell wäre. ${ }^{[91]}$ Allerdings zeigte sich in knock-out-Experimenten an Mäusen, dass heterozygote Embryonen mit verminderten Sp1-Leveln kleiner als der Wildtyp, aber dennoch lebensfähig waren. ${ }^{[55,97]}$ Bei einem vollständigen knock-down von Sp1 waren die Embryonen nicht mehr

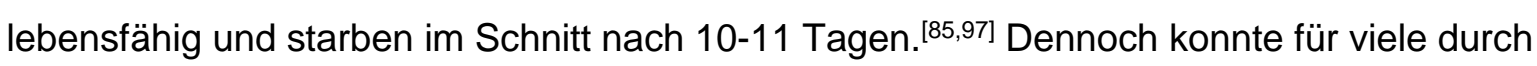
Sp1 regulierte Gene eine hohe Expression nachgewiesen werden. Als Erklärung dafür wurde in Betracht gezogen, dass Sp3 einen Teil der Aufgaben von Sp1 ausübte. ${ }^{[1]}$ Für diese Annahme sprach zudem, dass Embryonen mit verringerten Sp1- und Sp3-Leveln nicht mehr lebensfähig waren. ${ }^{[97]}$ Ebenso zeigte sich, dass ein Sp3-knock-out erst nach der Geburt letal war. ${ }^{[97]}$ Dies stellte einen Unterschied zu den Ergebnissen des Sp1 knock-out dar, welcher jedoch durch die unterschiedlichen von Sp1 und Sp3 regulierten Gene zu erklären war. Diese Ergebnisse zeigten, dass sowohl Sp1 als auch Sp3 essenziell für das embryonale Wachstum sind, aber die Expression der Haushaltsgene nicht vollständig von Sp1 abhängig ist. ${ }^{[85]}$ Dafür sprechen auch Hinweise auf die Abnahme der Sp1-Level mit zunehmendem Zellalter. ${ }^{[98]}$

Aufgrund seiner Rolle als Regulator des Zellzyklus und der Expression von Wachstumsfaktoren, ${ }^{[89,99]}$ sind die Sp1-Level einer Zelle entscheidend für ihr normales Wachstum. Während zu geringe Sp1-Level noch ausgeglichen werden können, ${ }^{[85,97]}$ ist eine Überexpression von Sp1 in vielen Krebsarten zu beobachten und ein Indikator für eine schlechte Prognose. ${ }^{[96,100]}$ Durch die Absenkung der Sp1-Level auf das Niveau gesunder Zellen kann das Tumorwachstum gebremst und die Bildung von Metastasen verhindert werden. ${ }^{[83]}$ Zwar sind die genauen Gründe, die zu einer Überexpression von Sp1 führen, nicht vollständig geklärt. Allerdings gibt es Hinweise darauf, dass die Autoaktivierung von Sp1 eine Rolle spielt. Eine weitere Ursache stellt die Inhibierung von Repressoren wie den ZBTB-Proteinen durch miRNAs dar. Die ZBTB-Proteine binden ebenfalls an GC-reiche Sequenzen und verhindern so die Expression der von $\mathrm{Sp} 1$ regulierten Gene und somit die Expression von Sp1 selbst. Zu den Repressoren der ZBTB-Proteine gehören onkogene miRNAs wie miR-17, miR-20a und miR-27a. Durch eine Inhibierung dieser miRNAs können die Sp1-Level normalisiert werden und somit das Tumorwachstum verlangsamt werden. ${ }^{[96]}$ 


\section{DNA-Erkennung und artifizielle Transkriptionsfaktoren (ATFs)}

Transkriptionsfaktoren sind für die Regulation der Genexpression essenziell und können diese über die spezifische Bindung an Promotoren inhibieren oder aktivieren. ${ }^{[101,102]}$ Hierzu verfügen TFs über drei wichtige Domänen, welche über Linkerdomänen (LD) verbunden sind. Diese Domänen sind ein Kernlokalisierungssignal (NLS), eine Aktivierungsdomäne $(A D)$ und eine DNA-bindende Domäne (DBD). ${ }^{\left[{ }^{8,103]}\right.}$ Dabei wird das NLS benötigt, damit die TFs in den Zellkern gelangen können. Die AD kann über den Kontakt zu weiteren Proteine die RNA-Polymerase II rekrutieren, während die DBD für die spezifische Erkennung der DNA verantwortlich ist. Um die Genexpression gezielt kontrollieren zu können, ist der Aufbau artifizieller Transkriptionsfaktoren (ATFs) eines der Ziele der chemischen Biologie. ${ }^{[8,103]}$ Eine der großen Herausforderungen ist dabei die spezifische Erkennung der dsDNA. Im Gegensatz zur RNA ist eine Erkennung der dsDNA über Watson-CrickBasenpaarung nur nach einer Trennung der DNA-Stränge möglich. Hierzu können LNAoder PNA-basierte ONs verwendet werden, welche zu DSI fähig sind. ${ }^{[64,66,71,73]}$ Allerdings ist die Effektivität dieser ONs unter physiologischen Bedingungen oft gering. Eine weitere Möglichkeit stellt eine proteinvermittelte Trennung der DNA-Stränge dar, wie sie im CRISPR/Cas9-System zu beobachten ist. Dadurch liegt die DNA partiell als Einzelstrang vor und kann durch die gRNA über Watson-Crick-Paarung erkannt werden. Abgesehen davon ist eine Erkennung der DNA auch mit positiv geladenen oder interkalierenden kleinen Molekülen möglich, jedoch geschieht dies in den meisten Fällen unspezifisch. Eine weitere Option zur sequenzspezifischen Adressierung der DNA stellt eine Wechselwirkung mit den funktionellen Gruppen der großen und kleinen Furche dar. Eine der ältesten Methoden ist dabei die Verwendung von TFOs, die über Hoogsteen-Basenpaarung in die große Furche der DNA binden. ${ }^{[16]}$ Auch wenn auf diese Weise nur Purin-reiche Sequenzen adressiert werden können, wurden TFO-basierte ATFs zur Regulierung der Genexpression eingesetzt. Diese kann durch Binden eines TFOs inhibiert werden. ${ }^{[104]}$ Für eine Aktivierung der Genexpression muss das TFO mit einer AD konjugiert werden. Hierzu wurden zwei Methoden verwendet. Einerseits wurden die TFOs mit einem DNA-hairpin konjugiert, das die Bindesequenz eines TFs enthielt, ${ }^{[7,17,105]}$ oder andererseits mit aktivierenden Peptiden, wie VP16, versehen. ${ }^{[106,107]}$ Auch wenn die Nukleasestabilität der TFOs ein großes Problem für ihre Anwendung darstellt, konnte sowohl in vitro ${ }^{[107]}$ als auch in Zellkulturexperimenten ${ }^{[7,107]}$ eine Aktivierung der Transkription nachgewiesen werden. Dennoch ist der Einsatz der TFOs, aufgrund ihrer Beschränkung auf Purin-reiche Sequenzen, stark limitiert.

Eine weitere Möglichkeit zur Erkennung der DNA ist die Verwendung natürlicher DBDs. ${ }^{[102,103,108]}$ Eine Klasse der DBDs stellen die sogenannten Zinkfingerproteine (ZFPs) 


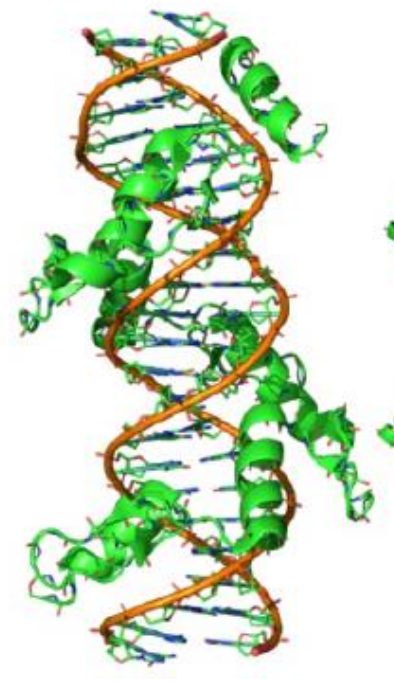

ZFP

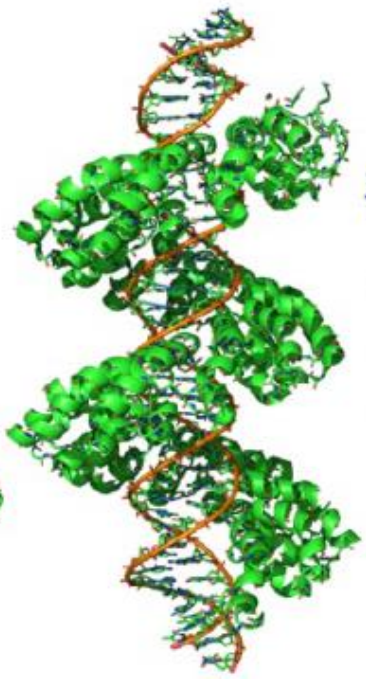

TALE

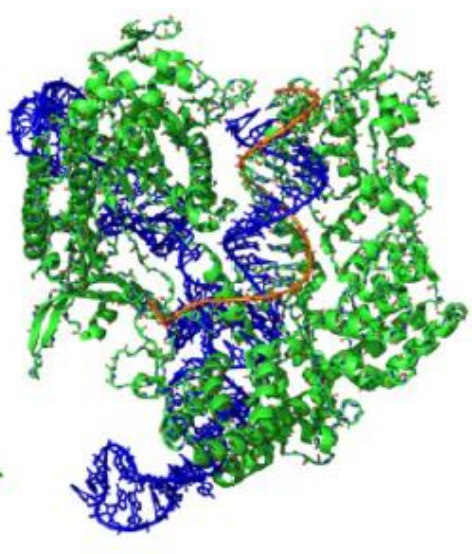

CRISPR/Cas9

Abbildung 16: Darstellung der Bindung von ZFP, TALE und CRISPR/Cas9 an DNA. Dabei sind die Proteine grün dargestellt. Die DNA ist in orange (links, Mitte) oder blau (rechts) gezeigt und die gRNA in orange (rechts). Entnommen aus Rathnam et al.. ${ }^{[109]}$

dar (Abbildung 16, links), zu denen auch Sp1 gehört (Abschnitt 3). Diese Proteine besitzen eine DBD, die zur Ausbildung ihrer Struktur $\mathrm{Zn}^{2+}$-Ionen koordiniert und die DNA über Aminosäuren in den daraus resultierenden Fingern erkennt. Durch eine Kombination verschiedener Zinkfinger, besteht die Möglichkeit spezifische DNA-Sequenzen gezielt zu adressieren. ${ }^{[109-112]}$ Allerdings ist das Design und die Herstellung entsprechender ZFPs sehr aufwändig ${ }^{[113]}$ und die Kombination von ZF-Domänen kann die Spezifität einzelner Domänen beeinflussen und so eine erhöhte off-target-Aktivität verursachen. ${ }^{[114]}$ Zum Aufbau eines ATFs können die ZFPs mit ADs wie VP16 oder VP64 kombiniert werden.

Eine andere Klasse an DBDs konnte in transcription activator-like effectors (TALEs) gefunden werden (Abbildung 16, Mitte). ${ }^{[109,115,116]}$ Diese Proteine wurden aus Bakterien der Gattung Xanthomonas isoliert ${ }^{[115]}$ und besitzen eine einzigartige Bindedomäne. Diese besteht aus Wiederholungen von 34 oder 35 Aminosäuren, ${ }^{[16]}$ wobei die Aminosäuren 12 und 13 für die sequenzspezifische Erkennung verantwortlich sind. Durch eine Variation an diesen Positionen ist es möglich, die Zielsequenz des Proteins zu programmieren, ${ }^{109,116]}$ was jedoch einen erhöhten synthetischen Aufwand erfordert. ${ }^{[6,114]}$ Analog zu den ZFPs ist die Fusion mit einer AD wie p65 oder VP64 zum Aufbau eines ATFs notwendig. ${ }^{[109,110]}$ Im Vergleich zu ZPFs besitzen TALEs besitzen eine höhere Sequenzspezifität und weisen nur geringe off-target-Effekte auf. Diese Eigenschaften sind im Allgemeinen ein großer Vorteil in der Anwendung. Da TFs jedoch in der Lage sind, auch leicht von der Konsensussequenz abweichende DNA-Abschnitte zu erkennen, kann die hohe Spezifität bei ATFs je nach Anwendung auch einen Nachteil darstellen. ${ }^{[14]}$ Des Weiteren erfolgt die DNA-Erkennung 
bei TALEs über die große Furche der DNA und die Adressierung methylierter DNA kann nicht in allen Fällen erfolgen. ${ }^{[6]}$

Mit dem guide RNA (gRNA) basierten CRISPR/Cas9-System steht eine neue und einfach anwendbare Methode zur Erkennung DNA zur Verfügung (Abbildung 16, rechts). ${ }^{[117,118]}$ Dieses System besteht aus einer Cas-Endonuklease, in vielen Fällen Cas9, und einer synthetischen gRNA. ${ }^{[6,117-119]}$ Die initiale Erkennung der DNA erfolgt über das Cas-Protein das protospacer-adjacent motif(PAM) bindet. Im Anschluss entwindet das Protein die DNA, welche dann über die gRNA erkannt wird. Ist die gRNA dabei vollständig komplementär zur DNA kann diese von Cas geschnitten werden. Das PAM des Cas9 $\left({ }^{5} \mathrm{NGG}\right)$ kommt dabei sehr häufig in der humanen DNA vor und da die Sequenz der gRNA ist frei wählbar ist, ermöglicht dies die Erkennung fast jeder Stelle des Genoms. ${ }^{[6,118]}$ Durch die Verwendung eines deaktivierten Cas-Proteins (dCas) kann CRISPR/Cas auch als DBD für ATFs eingesetzt werden. ${ }^{[120]}$ Auch in diesem Fall muss das System um eine AD erweitert werden, wobei zunächst VP16-Einheiten verwendet wurden. Der Effekt dieser Konstrukte war jedoch gering, konnte aber durch die Verwendung mehrerer gRNAs deutlich gesteigert werden. ${ }^{[6,119]}$ Eine andere Variante zur Aktivierung der Transkription stellen die sogenannten SunTags dar. ${ }^{[121]}$ Bei diesen wird das Cas9 mit einer Peptidkette versehen, welche von Antikörpern erkannt werden kann, die mit einer AD fusioniert sind. Dies ermöglicht es an einen ATF gleich mehrere ADs anzubringen, wodurch eine stärkere Aktivierung der Genexpression erzielt werden kann. Auf einem ähnlichen Konzept beruhen SAMs (synergistic activation mediators). ${ }^{[6,119,122]}$ Diese enthalten eine gRNA, die um zusätzliche stem-loops erweitert wurde. Diese können dann ebenfalls von Fusionsproteinen erkannt werden und so die Genexpression auslösen.

Gegenüber ZFP- oder TALE-basierten ATFs besitzt CRISPR/Cas9 zudem den Vorteil, dass aktivierbare Proteine möglich sind und so eine Aktivierung der Transkription durch externe Stimulation erfolgen kann. ${ }^{[119]}$ Außerdem ist die gRNA für die Erkennung der DNA verantwortlich, wodurch die Erkennungssequenz einfach angepasst werden kann. Des Weiteren ist es durch die Verwendung mehrerer gRNAs möglich, mit einem Protein verschiedene Sequenzen auf der DNA zu adressieren und so eine verstärkte Wirkung der ATFs zu erhalten. Ein Nachteil der CRISPR/Cas9-basierten Systeme ist jedoch, dass sie aus mindestens zwei bis drei Komponenten bestehen, welche alle in eine Zelle transfiziert werden müssen. Um dies zu erreichen, sind in manchen Fällen mehrere Vektoren notwendig ${ }^{[6,119]}$ und eine systemische Anwendung ist komplexer als bei den TALE- oder ZFP-basierten ATFs. Jedoch besteht auch bei diesen Systemen die Schwierigkeit, dass der ATF in die Zelle gelangen muss, weswegen die Entwicklung zellgängiger ATFs immer noch eine Herausforderung darstellt. ${ }^{[103]}$ 


\subsection{Pyrrol-Imidazol-Polyamide (PIPs)}

Eine weitere Klasse DNA-erkennender Moleküle stellen die minor groove binder dar. Diese sind kleine Verbindungen, welche die kleinen Furche der DNA spezifisch erkennen können. $\mathrm{Zu}$ diesen Verbindungen zählen unter anderem Farbstoffe der Hoechst-Klasse, die Naturstoffe Netropsin und Distamycin A oder Pyrrol-Imidazol-Polyamide (PIPs).

PIPs setzen sich aus N-Methylpyrrol (Py) und N-Methylimidazol (Im) zusammen und sind in der Lage, die kleine Furche der DNA selektiv zu erkennen. ${ }^{[123,124]}$ Diese Substanzen wurden ausgehend von den Naturstoffen Netropsin und Distamycin A entwickelt (Abbildung 17), welche eine hohe Affinität zu AT-reichen Regionen der DNA besitzen. Aufgrund ihrer Fähigkeit die Transkription zu inhibieren, wurden diese Stoffe als Chemotherapeutika in Betracht gezogen, allerdings erwiesen sie sich als zu toxisch und somit zur Anwendung ungeeignet. ${ }^{[125]}$ Eine genauere Analyse ihres Bindeverhaltens mittels NMR-Spektroskopie und Kristallstrukturanalyse ergab, dass Distamycin A mit einer Ziel-DNA sowohl in einem Verhältnis von 1:1 als auch von 1:2 komplexieren konnte. ${ }^{[126]}$ Bei den 1:2 Komplexen konnte jeweils eine Orientierung der Distamycin-Stränge vom $\mathrm{N}$-Terminus zum C-Terminus in 5'-3' Richtung der DNA beobachtet werden. Ausgehend von den Erkenntnissen über die Bindung von Netropsin und Distamycin entstand die Hypothese, dass sie eine Substitution von Py durch Im die Adressierung von G•C Paaren möglich sein sollte, was in der Gruppe von Peter Dervan bestätigt werden konnte. ${ }^{[123-125]}$ Dabei konnte zudem beobachtet werden, dass die eingesetzten Verbindungen entgegen der Erwartung nicht in einem Verhältnis von 1:1 mit der DNA komplexierten, sondern als antiparallele Dimere. ${ }^{[123]}$ In nachfolgenden Untersuchungen konnte gezeigt werden, dass zwei Polyamide unterschiedlicher Sequenz als Heterodimere an die DNA banden. ${ }^{[127]}$ Hierbei wurde das System durch die unterschiedliche Affinität der Peptide jedoch sehr komplex. Um diese Problem zu umgehen, wurden die beiden Peptide kovalent verknüpft und durch den Einbau einer GABA-Einheit konnte die Affinität zur DNA stark erhöht werden. ${ }^{[128]}$ Die daraus resultierenden PIPs banden als antiparalleler hairpin, wobei eine Orientierung der PIPs vom N- zu C-Terminus in 5'-3'-Richtung der DNA bevorzugt war (Abbildung 18). Des Weiteren konnten Paarungsregeln aufgestellt werden, durch die die Zielsequenz der PIPs vorhergesagt werden konnte. Ein Py/Py-Paar erkennt selektiv A•T-
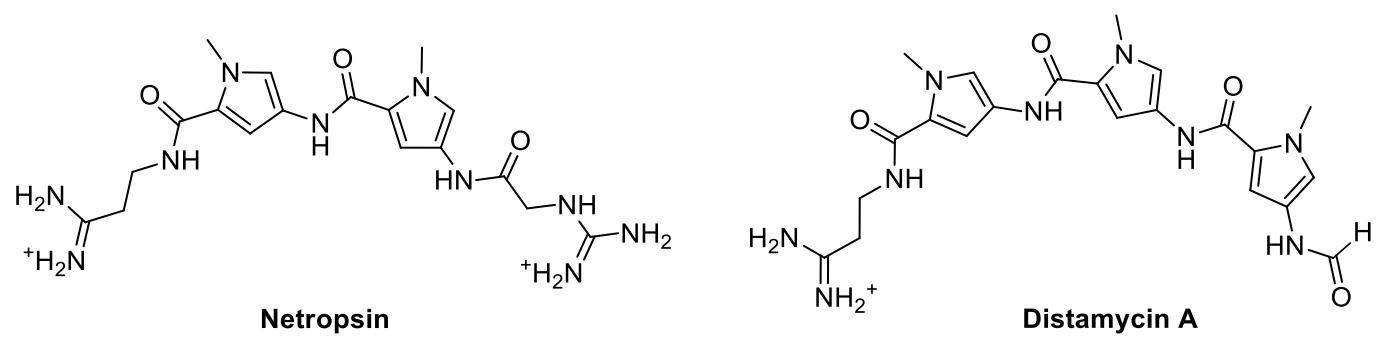

Abbildung 17: Struktur der Naturstoffe Netropsin und Distamycin A. 

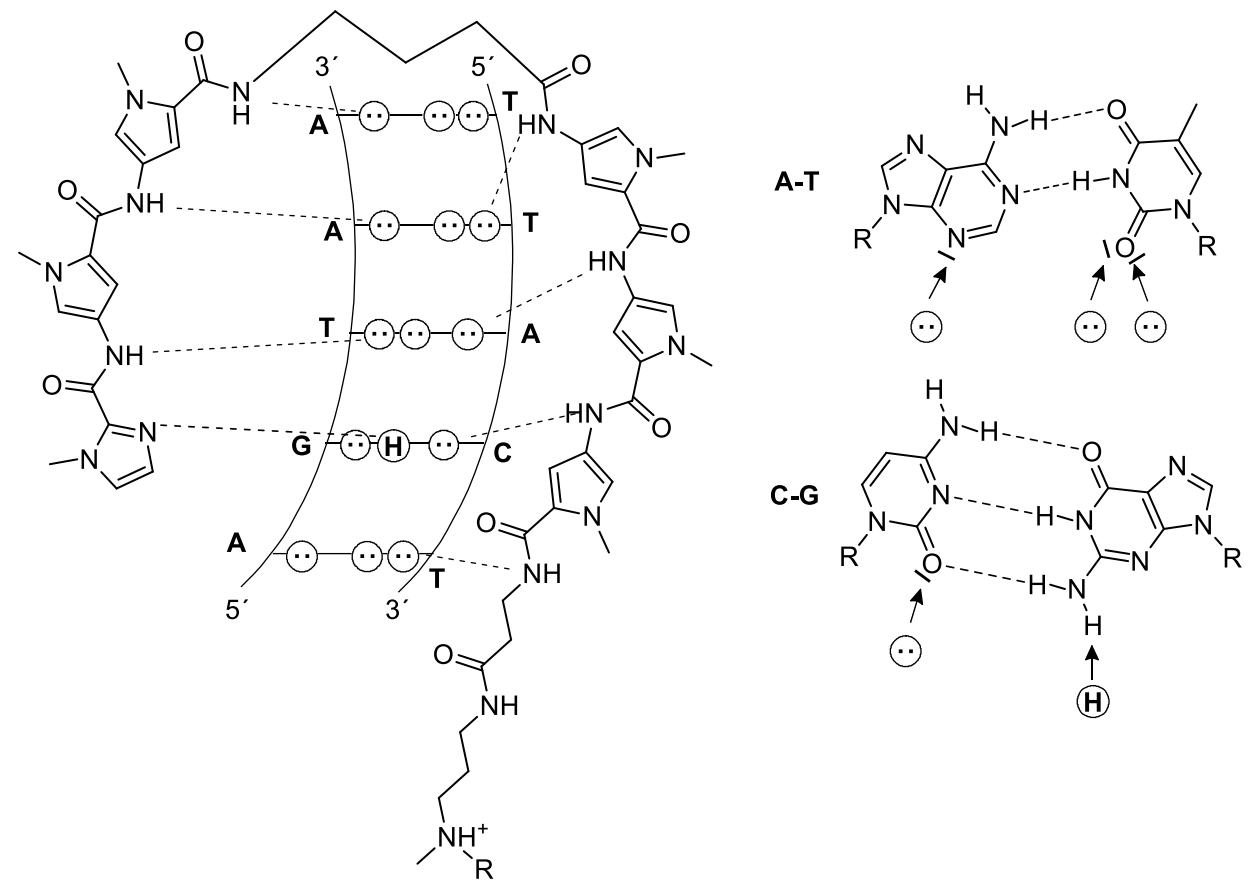

Abbildung 18: Darstellung der Bindung eines PIPs an die kleine Furche der DNA (links). ${ }^{[128]}$ Die gepunkteten Kreise stellen dabei die freien Elektronenpaare der Basen, Kreise mit $\mathrm{H}$ den N2-Wasserstoff des Guanins dar. Auf der rechten Seite sind die an Wechselwirkungen beteiligten Elektronenpaare und der Wasserstoff markiert.

oder T•A-Paare, wobei eine genauer Unterscheidung nicht möglich ist. Ein Paar aus $\mathrm{Im} / \mathrm{Py}$ bindet selektiv an G•C-Paare, während die Kombination Py/lm selektiv C•G-Paare adressiert (Abbildung 18). ${ }^{[129]}$ Mit der Kombination Im/Im können keine Basenpaare erkannt werden. Weiterhin konnte gezeigt werden, dass die Affinität der PIPs durch den Einbau eines $\beta$-Alanins $(\beta)$ am C-Terminus weiter gesteigert werden konnte, ${ }^{[130]}$ wobei $\beta$ bevorzugt A oder T erkennt. Dies hat zur Folge, dass der Einbau von $\beta$ zu Einschränkungen bei der Wahl möglicher Zielsequenzen führt. ${ }^{[131]}$ Eine andere Möglichkeit die Affinität und Selektivität der PIPs zu erhöhen, stellt die Substitution des GABA-turns durch eine $\alpha$-Aminosäure dar. ${ }^{[132]}$ Diese erhöht die Affinität der PIPs durch eine zusätzliche positive Ladung, während die Stellung der chiralen Aminogruppe eine reverse Bindung des PIPs verhindert. Zudem kann die Aminogruppe zur weiteren Funktionalisierung der PIPs genutzt werden. Mit einer Acetylierung konnte gezeigt werden, dass die Affinität der PIPs im Bereich eines unmodifizierten GABA-turns liegt, aber die Selektivität der Bindung deutlich erhöht ist. ${ }^{[132]}$

Da PIPs aus sechs Py- und Im-Einheiten nur einen kurzen DNA-Abschnitt von 5 bp adressieren können, wurde die Polyamid-Kette verlängert. Dabei können hairpin-PIPs auf eine Länge von zehn Einheiten verlängert werden, wobei die zu erkennende Sequenz auf 6 bzw. 7 bp erhöht wird. Darüber hinaus steigt die Affinität eines Achtmer-PIPs gegenüber einem Sechsmer-PIP um zwei bis drei Zehnerpotenzen und diese Verbindungen binden im niedrigen nanomolaren Bereich. ${ }^{[14]}$ Somit weisen diese PIPs Bindungskonstanten auf, die 
mit TFs vergleichbar sind. Da sie zudem die Zellmembran passieren können, sind sie in der Lage die Genexpression zu inhibieren. ${ }^{[15]}$ Die Verwendung eines Zehnmer-PIPs führt zu keiner weiteren Zunahme der Affinität und diese PIPs stellen die maximale Kettenlänge für hairpin-Polyamide dar. ${ }^{[132]}$ Bei längeren Ketten unterscheidet sich die Struktur der PIPs zu stark von der DNA-Helix, sodass eine Komplexierung ungünstig wird. In diesem Zusammenhang ist insbesondere die Erkennung von GC-reichen Sequenzen problematisch, da Im-Einheiten zu einer flachen und engen Struktur der PIPs führen. ${ }^{[133-135]}$ Um diesen Effekt auszugleichen ist es möglich, Py-Einheiten durch $\beta$-Einheiten zu substituieren. ${ }^{[136]}$ Auch diese verhalten sich analog zu Py, sind jedoch deutlich flexibler und ermöglichen so die Erkennung längerer DNA-Sequenzen. ${ }^{[137,138]}$ Allerdings liegt die Länge der Sequenzen mit ca. 9 bp unter den 16 bp, welche für eine einzigartige Zielsequenz benötigt werden. ${ }^{[139]} \mathrm{Um}$ diese zu erreichen, können sogenannte Tandempolyamide eingesetzt werden, ${ }^{[140,141]}$ bei denen bis zu drei PIPs über eine Aminofunktion im turn verknüpft werden. Auf diese Weise ist es möglich, bis zu 18 bp zu erkennen. ${ }^{[141]}$

Um die Spezifität der PIPs weiter zu erhöhen, wurde versucht zwischen $A \cdot T$ und T•A-Paaren zu unterscheiden. Dazu wurde $N$-Methyl-3-hydroxypyrrol verwendet, welches mit der 3'-Hydroxygruppe eine zusätzliche Wasserstoffbrücke mit $\mathrm{T}$ ausbilden kann. Allerdings sind diese Verbindungen sehr oxidationsempfindlich, was ihren Einsatz verhindert. ${ }^{[142]}$ Zur Steigerung der Affinität wurden auch zyklische PIPs verwendet, die zwar eine höhere Affinität als die hairpin-Polyamide besaßen, ${ }^{[143]}$ jedoch in Zellkulturexperimenten eine höhere Toxizität aufwiesen. ${ }^{[144]}$ Somit stellen die hairpin-PIPs die am Häufigsten eingesetzten PIPs dar.

\subsubsection{Synthese der PIPs}

Die Synthese der PIPs erfolgt typischerweise mittels Festphasensynthese. Dabei kann sowohl eine Boc-[145] als auch eine Fmoc-basierte ${ }^{[146]}$ Variante verwendet werden, die jeweils eine schnelle Synthese unterschiedlicher PIPs ermöglichen. Dabei stellt jedoch der Einbau von Im-Einheiten eine große Herausforderung dar. Diese Bausteine besitzen eine niedrige Nukleophilie und eine Kupplung auf ein an fester Phase gebundenes Im ist nur in schlechten Ausbeuten möglich. ${ }^{[147]}$ Um dieses Problem zu umgehen, können im Vorfeld Dioder Trimere synthetisiert und zur Kupplung verwendet werden. Dies bedeutet jedoch einen erhöhten Anteil an Synthese in Lösung. ${ }^{[145,148]}$ Mit der Verwendung von HATU als Aktivierungsmittel ist es möglich, die Festphasensynthese schneller und effektiver durchzuführen, jedoch bleibt die Kupplung auf Im in diesen Fällen problematisch. ${ }^{[149]}$ Für eine effiziente Kupplung auf Im-Einheiten wurden zwei Methoden entwickelt, die entweder den Einsatz eines Mikrowellenreaktors ${ }^{[150]}$ oder eine Aktivierung der Monomere mit 
Triphosgen (BTC) erfordern. ${ }^{[147,151]}$ In der BTC-Methode wird die Carbonsäure in situ zu einem Säurechlorid umgewandelt und im Anschluss zur Kupplung eingesetzt.

Abgesehen von der Festphasensynthese können PIPs auch in Lösung aufgebaut werden. Dies ist zwar zeitaufwendiger, eignet sich jedoch für die Herstellung größerer Mengen eines PIPs. ${ }^{[150]}$ Auch in dieser Methode können dimere oder trimere Bausteine eingesetzt werden, um die Synthese zu vereinfachen. Zum Aufbau dieser Einheiten kann neben einer Peptidkupplung auch eine Haloform-artige-Reaktion eingesetzt werden. ${ }^{[152-154]}$ Auch in diesem Fall kann der fragmentbasierte Ansatz die Zahl der Reaktionsschritte verringern und die Gesamtausbeute der Synthese erhöhen. Außerdem erhöht der modulare Aufbau die Flexibilität der Synthese unterschiedlicher PIPs. ${ }^{[152]}$

\subsubsection{PIP-basierte ATF}

Aufgrund ihrer Fähigkeit DNA spezifisch zu erkennen und die Transkription in Zellkulturexperimenten zu inhibieren, ${ }^{[15,155]}$ kommen PIPs auch als DBD in ATFs in Frage. Durch die Konjugation von PIPs mit aktivierenden Peptiden war es möglich, die Genexpression in vitro zu aktivieren. ${ }^{[156-158]}$ Allerdings waren diese Konstrukte nicht für Zellkulturexperimente geeignet, da die Konjugate ein relativ hohes Molekulargewicht besaßen und nicht von Zellen aufgenommen wurden. Aus diesem Grund wurde versucht, die aktivierende Domäne zu verkleinern. ${ }^{[159-161]}$ Die große Herausforderung bestand darin, Konjugate zu erhalten, die nicht nur die Genexpression in vitro beeinflussen konnten, ${ }^{[159]}$ sondern auch in Zellkulturexperimenten funktional waren. ${ }^{[160]}$ Zwar konnten zellgängige Konjugate erhalten werden, allerdings wurde die Genexpression nur mäßig aktiviert. ${ }^{[8,109]}$ Ausgehend von diesen Ergebnissen wurden Versuche unternommen, die Genexpression durch eine Regulation von epigenetischen Faktoren, wie der Histonacetylierung, zu aktivieren. ${ }^{[162]}$ Für diese Anwendung wurden PIPs mit einem Inhibitor der HistonDeacetylase (HDAC), SAHA (suberanilohydroxamic acid), kombiniert (Abbildung 19), wodurch eine selektive Inhibierung der HDAC ermöglicht wurde. Zwar war es mit diesen

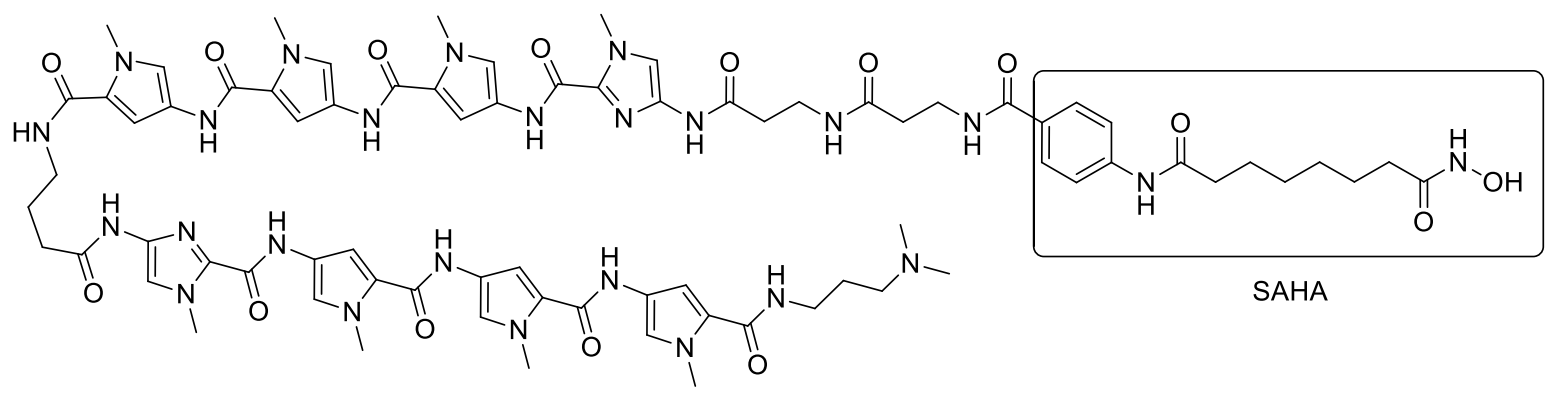

Abbildung 19: Struktur eines SAHA-PIPs. ${ }^{[163]}$ Die SAHA Einheit ist am N-Terminus angebracht und gesondert markiert. 


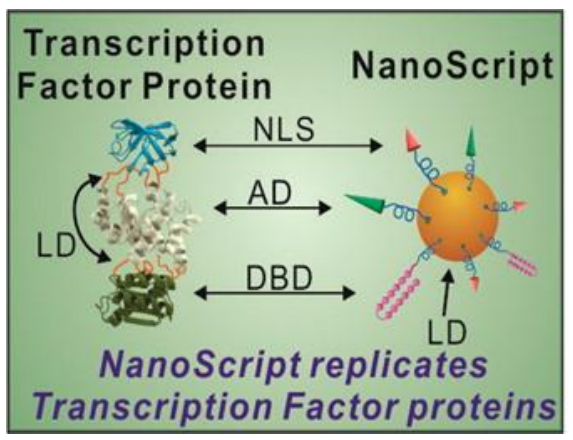

Abbildung 20: Schematische Darstellung eines NanoScripts im Vergleich zu einem TF, entnommen aus Patel et al.. ${ }^{[8]}$ Dabei steht LD für Linkerdomäne, NLS für Kernlokalisierungssignal, AD für Aktivierungsdomäne und DBD für DNA-bindende Domäne.

Konjugaten möglich die Genexpression zu regulieren, ${ }^{[163,164]}$ allerdings waren auch diese Verbindungen nur mäßig effizient. ${ }^{[8]}$ Ein weiteres Konzept zur Regulation der Genexpression stellen die sogenannten NanoScripts dar (Abbildung 20). ${ }^{[8,137]}$ Diese bestehen aus einem Goldnanopartikel, auf den funktionelle Domänen über Thiole aufgebracht sind. Dabei dienen PIPs als DBD, während weitere Peptide als NLS und AD fungieren und so einen ATF bilden. Diese Konstrukte bieten den Vorteil, dass alle Domänen mehrfach auf den Nanopartikeln vorhanden und dadurch in ihrer Wirkung effektiver sind. ${ }^{[138]}$ Außerdem erlaubt die Konstruktion dieser ATFs eine leichte Anpassung der NanoScripts, wodurch sie die Genexpression aktivieren ${ }^{[8,137]}$ oder inhibieren ${ }^{[138]}$ sowie epigenetische Modulationen ${ }^{[165]}$ vornehmen können. NanoScripts stellen die effektivsten PIP-basierten ATFs dar und sind in der Lage, die Genexpression in Zellkulturexperimenten zu modulieren. Auf diese Weise war es unter anderem möglich, die Umwandlung von mesenchymalen Stammzellen in Muskelzellen auszulösen. ${ }^{[137]}$

Trotz ihrer grundsätzlichen Eignung als DBD stellt die kurze Zielsequenz der PIPs ein Hindernis für ATFs dar. Zwar konnten mit den NanoScripts Sequenzen von 10 bp adressiert werden, allerdings liegt dieser Wert unter den $16 \mathrm{bp}$, welche für eine einzigartige Erkennung der DNA benötigt werden. ${ }^{[139,166]}$ Aufgrund der mangelnden Unterscheidung zwischen A•Tund T•A-Paaren wird eine eindeutige Erkennung der DNA zusätzlich erschwert, wodurch die Gefahr von off-target-Effekten deutlich ansteigt. Gleichzeitig können die PIPs, analog zu natürlichen TFs, auch Varianten ihrer Konsensussequenz erkennen. 


\section{Regulation der mRNA}

Neben der Regulation der Transkription kann die Genexpression auch auf der Ebene der Translation beeinflusst werden. Hierfür kann die mRNA als Angriffspunkt gewählt werden. Eine Interaktion kann dabei durch eine direkte Bindung an die mRNA erfolgen. Der älteste Ansatz stellt dabei die Verwendung von antisense ONs (ASOs) dar. ${ }^{[47,48,57,60,77]}$ Eine weitere Methode ist der gezielte Abbau von mRNAs mittels RNA-Interferenz (RNAi), die über eine small interfering RNA (siRNA) induziert werden kann. ${ }^{[167]}$ Des Weiteren sind micro RNAs als natürliche Regulatoren der mRNA ein geeignetes Mittel um die Lebensdauer der mRNA zu beeinflussen.

\subsection{RNA-Interferenz und micro RNAs}

RNA-Interferenz (RNAi) ist ein komplexer Prozess, der hautsächlich zur Abwehr von Virusinfektionen in einer Zelle dient. ${ }^{[167-169]}$ Dabei werden lange doppelsträngige RNAs, die normalerweise in einer Zelle nicht vorkommen würden, durch die Ribonuklease Dicer in Fragmente mit einer Länge von ca. 22 Nukleotiden geschnitten. Durch Einbau eines der beiden Stränge in das Argonaut 2 Protein (Ago2) wird dieses als sequenzspezifische Ribonuklease programmiert. Bindet dieser RNA-Protein-Komplex an eine vollständig komplementäre RNA, zum Beispiel die virale RNA, aus der er einmal hervorgegangen ist, so bewirkt die RNase $\mathrm{H}$ Aktivität von Ago2 einen katalytischen Abbau der viralen RNA (Abbildung 21, links). ${ }^{[167]}$ Man spricht vom RNA-induced silencing complex (RISC). Diese RNAi kann auch durch gezielte Zugabe kurzer synthetischer RNAs ausgelöst und gegen beliebige mRNAs einer Zelle gerichtet werden. Man spricht dann von siRNAs und von siRISCs. Der Einsatz von siRNAs zählt heute zu den wichtigsten Methoden, um den temporären knock-out eines Gens zu erreichen. ${ }^{[167]}$

Mechanistisch ähnlich, aber mit anderer Zielsetzung erfolgt die Bildung von micro RNAs (miRNAs). ${ }^{[167]}$ Diese werden im Zellkern als pri-miRNAs exprimiert, welche noch eine $5^{\prime}$-cap besitzen und 3 '-polyadenyliert sind. In dieser Form bilden sie eine hairpin-Struktur aus, wobei keine vollständige Basenpaarung vorliegt (Abbildung 21, oben). ${ }^{[167]}$ Die pri-miRNA kann durch den microprocessor complex bestehend aus dem Protein Pasha und der RNase Drosha in die 70-100 Nukleotide lange pre-miRNA prozessiert und daraufhin durch Exportin 5 aus dem Zellkern in das Cytosol transportiert werden. Dort wird die pre-miRNA durch Dicer weiter zu einer doppelsträngigen miRNA, bestehend dem guide-Strang und einem passenger-Strang, prozessiert. Von diesem Duplex wird daraufhin der guide-Strang in Ago2 eingebaut und so der RISC gebildet nun miRISC genannt, während der passanger- 


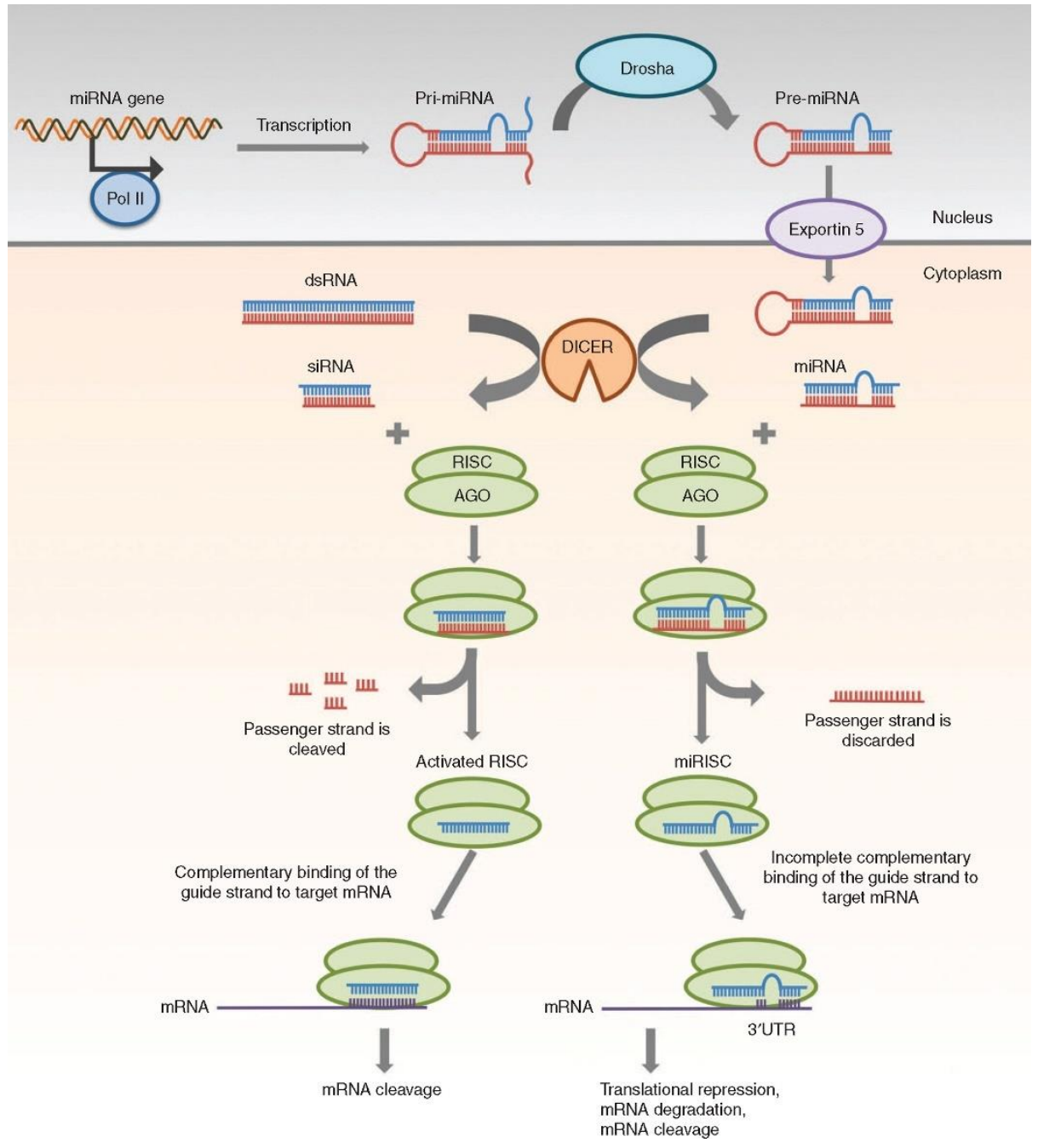

Abbildung 21: Gen-Silencing Mechanismus von siRNA und miRNA. Entnommen aus Lam et al. ${ }^{[167]}$

Strang verworfen wird (Abbildung 21, rechts). ${ }^{[167,170]}$

Strukturell sind siRISCs und miRISCs nicht unterscheidbar, wohl aber in ihrer Funktion. MiRISCs sind nämlich nicht vollständig komplementär zu den mRNAs der Zelle und schneiden sie daher nicht. Außerdem binden miRISCs in den meisten Fällen lediglich mit den Nukleotiden zwei bis sieben oder acht, der sogenannten seed-Region, an die 3'-UTR einer mRNA. ${ }^{[167]}$ Zwar ist auch eine zusätzliche Bindung durch die Nukleotide 13 bis 16 möglich, der sogenannten supplementary-Region. Dies kann jedoch nur bei ca. $5 \%$ aller Fälle beobachtet werden. ${ }^{[171,172]}$ Dementsprechend besitzen miRISCs oft nur eine kurze Zielsequenz auf der mRNA und sind somit deutlich unspezifischer als siRISCs. Eine miRNA kann beispielsweise über 100 mRNAs adressieren. Die unvollständige Bindung der miRNA führt dazu, dass miRISCs keine Nukleaseaktivität aufweisen. Stattdessen rekrutieren sie Glycin-Tryptophan-reiche GW182-Proteine, wie das tri-nucleotide repeat-containing protein 6 (TNRC 6). ${ }^{[173,174]}$ Diese interagieren mit weiteren Proteinen, welche den Stopp der Translation, oder eine Deadenylierung auslösen können. Ebenso kann die 5'-cap entfernt und durch diesen Prozessen der Abbau der mRNA ausgelöst werden. ${ }^{[174]}$ In seltenen Fällen, 
bei denen mRNA und miRNA eine hohe Komplementarität aufweisen, können die miRISC jedoch ebenfalls als Nuklease wirken. ${ }^{[167]}$ In analoger Weise übernehmen siRISCs die Funktionen der miRISCs, wenn die seed-Region einer siRNA der einer miRNA entspricht.

Aufgrund ihrer Fähigkeit, die Genexpression zu inhibieren und dabei nahezu jedes Ziel adressieren zu können, stellen siRNAs und miRNAs eine gute therapeutische Plattform dar, wobei die siRNA die weiter entwickelte Technologie ist. ${ }^{[1]}$ Dies liegt am weniger komplexen Mechanismus der siRISCs, wodurch ihre Wirkung besser vorherzusehen ist. Als therapeutische Ansätze im Bereich der RISCs können dabei siRNAs, miR-Mimics oder anti-miRs eingesetzt werden. ${ }^{[167]}$ Während siRNAs und miR-Mimics in Ago2 eingebaut werden, dienen anti-miRs als Inhibitoren von miRISCs, indem sie an die seed-Region einer miRNA binden.

\subsubsection{Aufbau von siRNA}

Seit ihrer Entdeckung 1998 ${ }^{[22]}$ sind siRNA-basierte RISCs ein häufig verwendetes System zum knock-out einzelner Gene, ${ }^{[167]}$ da siRISCs eine mRNA mit hoher Effizienz und Spezifität degradieren können. Aufgrund ihres häufigen Einsatzes war es zudem möglich, die Eigenschaften der benötigten ONs zu optimieren. Als klassische siRNAs werden zwischen 19 und 21 Nukleotide lange dsRNAs eingesetzt, bei denen an den jeweiligen 3 '-Enden der Einzelstränge zwei Nukleotide überlappen. Abgesehen davon können auch längere, aus 27 Nukleotiden bestehende dsRNAs verwendet werden. Diese RNAs müssen zunächst durch Dicer prozessiert werden und besitzen eine bis zu 100-fach höhere RNAi-Effizienz als die klassischen siRNAs. ${ }^{[167,175]}$ Allerdings besteht bei längeren dsRNAs die Gefahr, mit zelleigenen Abwehrmechanismen zu interagieren. Beispielsweise aktivieren RNA-Duplice von mehr als $30 \mathrm{bp}$ das angeborene Immunsystem und besitzen somit ungewollte Nebenwirkungen. ${ }^{[167,176]}$ Insbesondere sind GU-reiche Sequenzen zu vermeiden, da diese die Toll-like-Rezeptoren (TLR) 7 und 8 aktivieren. ${ }^{[1,167]}$ Beim Entwurf von siRNAs ist außerdem zu beachten, dass sich die Sequenz der Nukleotide $2-7$ von seed-Regionen bekannter miRNAs unterscheiden sollte, um eine miRISC-artige Wirkung zu verhindern. Des Weiteren ist es grundsätzlich möglich, beide Stränge der dsRNA in RISCs einzubauen. Um einen der Stränge zu bevorzugen, sollte die dsRNA asymmetrisch aufgebaut werden. Hierzu kann die Präferenz des Ago2 für die Basen U oder A am 5'-Ende des guide-Strang genutzt werden, wobei der Einbau von U präferiert wird. Da zudem derjenige RNA-Strang bevorzugt eingebaut wird, der am 5 '-Ende die instabileren Basenpaarungen aufweist, sollte der guide-Strang am 5'-Ende AU-reich und am 3'-Ende GC-reich sein. Um diesen Effekt zu verstärken, können modifizierte ONs eingesetzt werden, um stabilere Basenpaare zu erhalten. ${ }^{[167]}$ Die Verwendung von modifizierten ONs bietet zudem den Vorteil, dass die 
Nukleasestabilität der siRNA erhöht wird, welche beispielsweise im Blut nur wenige Minuten beträgt. ${ }^{[58]}$ Außerdem können die Modifikationen eine Aktivierung der Toll-like-Rezeptoren verhindern und die Anwendung der ONs somit sicherer machen. Allerdings ist bei den Modifikationen darauf zu achten, dass sie durch das Ago2 toleriert werden müssen und dass sie die thermische Stabilität der dsRNA nicht zu stark erhöhen. Beides würde die RISC-Bildung und die Effizienz der RNAi verringern. ${ }^{[167]}$ Im Allgemeinen gilt dabei, dass Modifikationen des passenger-Strangs besser toleriert werden und dort zu einer besseren Unterscheidung der beiden Stränge beitragen. ${ }^{[167]}$ Sollten Modifikationen in den guide-Strang eingeführt werden, ist jedoch darauf zu achten, dass zur Einlagerung einer RNA in Ago2 eine Phosphatgruppe am 5'-Ende benötigt wird. Diese kann auch in der Zelle durch Phosphorylierung einer freien 5'-Hydroxygruppe eingefügt werden, jedoch darf das 5 '-Ende keine Modifikationen aufweisen. ${ }^{[58,167]}$ Beim Einsatz modifizierter ONs im guide-Strang muss zudem beachtet werden, dass die Modifikationen die Struktur der RNA nicht zu stark verändern, da dies einen Einbau in Ago2 verhindern würde. Beispielsweise können einzelne LNA-Nukleotide im guide-Strang enthalten sein, ${ }^{[177]}$ allerdings nur in geringem Ausmaß und ihre Verwendung im passenger-Strang stellt die bessere Anwendung dar. ${ }^{[58,167]}$ Aufgrund ihrer strukturellen Ähnlichkeit zur RNA sind 2'-OMe- oder $2^{\prime}$-F-RNA die am besten geeigneten Modifikationen für den guide-Strang. ${ }^{[47,58]}$ Allerdings bedingt ein zu hoher Anteil einer dieser Modifikationen jeweils eine Abweichung von der natürlichen Form der RNA und somit zu einer geringeren RNAi-Aktivität. ${ }^{[58]}$ Da der Einbau von 2'-OMe-Nukleotiden die RNA-Helix überwindet, während die 2'-F-RNA eine Unterwindung hervorruft, können diese Effekte durch einen alternierenden Einbau beider Modifikationen ausgeglichen werden. Dies ermöglicht vollständig modifizierte ONs, die effizient zur RNAi fähig sind. ${ }^{[58,178]}$ Somit kann die Art und Anzahl der Modifikationen an den Verwendungszweck angepasst werden. Soll eine siRNA beispielsweise mittels eines Lipidnanopartikels (LNP) verabreicht werden, sind nur wenige Modifikationen notwendig, während beispielsweise eine Applikation von ON-GalNac-Konjugaten ein vollständig modifiziertes ON erfordert. ${ }^{[58]}$ Zusätzlich können siRNAs mit einem Phosphorthioat-Rückgrat versehen werden, wobei dies nur an den Enden der ONs toleriert wird. Bei einer vollständigen Modifikation sinkt die Effektivität der RNAi hingegen deutlich. ${ }^{[58,177]}$

\subsubsection{Anwendungen für miRISCs}

Im Vergleich zu siRISCs können miRISCs als therapeutisches Ziel oder als Therapeutikum dienen. ${ }^{[167]}$ Beispielsweise werden in Krebszellen oft die tumorunterdrückenden miRNAs 
miR-let-7a oder miR-34a unterexprimiert. In diesen Fällen können miR-Mimics genutzt werden, um den Anteil dieser tumorunterdrückenden miRNAs in der Zelle zu erhöhen. ${ }^{[179]}$ Hierzu können sowohl einzel- als auch doppelsträngige RNAs eingesetzt werden, wobei die doppelsträngige Variante deutlich effektiver ist. ${ }^{[167,179]}$ Für den Aufbau der miR-Mimics gelten dabei ähnliche Voraussetzungen wie für die siRNAs. Da jedoch die Sequenzen natürlicher miRNAs eingesetzt werden, ist der Entwurf in diesem Fall einfacher. Im Vergleich zu siRNAs besitzen miR-Mimics jedoch den Nachteil, dass ihre Wirkung deutlich komplexer und die Zahl der möglichen Ziele deutlich höher ist, was die Wahrscheinlichkeit von Nebenwirkungen erhöht. Da miRNAs zudem mit TLRs interagieren können, besteht beim Einsatz von miR-Mimics die Gefahr eine Immunantwort der Zelle auszulösen, wodurch weitere, unkontrollierbare Nebenwirkungen auftreten würden. ${ }^{[180,181]}$

Abgesehen von der Substitution von miRNA, können überexprimierte onkogene miRNAs durch anti-miRs inhibiert werden und so eine normale Zellfunktion wiederhergestellt werden. Die Wirkung der anti-miRs beruht dabei auf einer Bindung an die seed-Region der RISCs, wodurch diese blockiert wird und somit nicht mehr an ihre Zielsequenzen binden kann. Insofern sind anti-miRs in ihrer Wirkung mit ASOs zu vergleichen. Da anti-miRs einzelsträngig sein müssen, werden dort modifizierte ONs verwendet, um ihre Affinität und Nukleasestabilität zu erhöhen. Die ersten anti-miRs, welche auch als Antagomirs bezeichnet werden, bestanden dabei vollständig aus 2'-OMe-RNA. ${ }^{[182]}$ Durch den Einsatz von LNA/DNA- oder LNA/2'-OMe-RNA-Mixmeren konnte die Effizienz der anti-miRs weiter gesteigert werden. ${ }^{[9,183]}$ Aufgrund der hohen Affinität der LNA zu RNA ermöglicht sie zudem den Einsatz von 8-mer LNAs mit Phosphorthioat-Rückgrat, sogenannten tiny-LNAs, die ganze miR-Familien inhibieren können. ${ }^{[62]}$ Neben der blockierenden Wirkung der anti-miRs, gibt es Hinweise, dass vollständig komplementäre anti-miRs fähig sind, miRNAs aus den RISCs zu lösen. ${ }^{[184,185]}$ Abgesehen von LNA kann auch PNA für den Aufbau von anti-miRs verwendet werden. Diese ONs sind in der Lage, sowohl an RISCs als auch an Vorformen der miRNA zu binden. ${ }^{[78,79]}$ Des Weiteren können PNAs mit positiv geladenen Peptiden konjugiert werden, wodurch ihre Zellaufnahme verbessert wird. Dabei besteht die Möglichkeit, positiv geladene PNA-Konjugate zu verwenden, um die Transfektion von miR-Mimics zu verbessern. In Form solcher Konjugate konnten gleichzeitig anti-miRs und miR-Mimics in eine Zelle eingebracht werden. ${ }^{[79]}$ 


\subsection{Das Argonaut 2 Protein (Ago2)}

Das Ago2 spielt als aktives Protein eine entscheidende Rolle in der RNAi. Wie alle Vertreter der Ago-Familie ist es auf die Bindung kurzer RNAs spezialisiert und kann durch diese RNAs mit der mRNA interagieren. Das Ago2 setzt sich aus einer Domäne am Amino-Terminus ( $N$, sowie der PAZ- (PIWI-ARGONAUTE-ZWILLE), der Mid- (Mittel), der PIWI- und zweier Linker-Domänen zusammen (Abbildung 22). ${ }^{[186,187]}$ Die Mid-Domäne besitzt eine Bindetasche für das 5' -Ende des guide-Strangs, in die das 5'-Phosphat und das erste Nukleotid eingebaut werden. ${ }^{[187]}$ Die PAZ-Domäne ist in der Lage, das 3'-Ende des guide-Strangs zu binden, wodurch die RNA fest in das Ago2 eingebaut und vor Nukleasen geschützt wird. ${ }^{[186,187]}$ Dabei wird die RNA so eingebaut, dass lediglich die seedund die supplementary-Region zugänglich sind. Die PIWI-Domäne ähnelt in ihrer Struktur der RNase $\mathrm{H}$ und ist für die Spaltung der mRNA bei siRISCs verantwortlich. Außerdem kann diese Domäne mit GW182-Proteinen wechselwirken und ist somit auch die aktive Einheit bei miRISC-basierten Prozessen. ${ }^{[186]}$ Die $N$-Domäne des Proteins spielt ebenfalls für die RNase-Aktivität des Ago2 eine wichtige Rolle, indem sie die A-Form des RNA-Duplex stört und für die Entsorgung des geschnittenen Substrats verantwortlich ist. ${ }^{[186]}$ Die beiden Linker-Domänen sorgen für die Flexibilität des Proteins, welche für die Bindung der mRNA benötigt wird. ${ }^{[186]}$ Ein Beispiel dafür ist die Helix 7 des Linkers L2, welche sich im Bereich der seed-Region befindet. Nach der Bindung der mRNA ändert diese ihre Konformation deutlich und kann im Anschluss mit der kleinen Furche der RNA-Helix wechselwirken. Da sich die Struktur der kleinen Furche bei der Bildung von G•U-Wobble-Paare verändert, könnte dies ein Mechanismus sein, der die Erkennung dieser Paare verhindert und so die Spezifität der RISCs erhöht. ${ }^{[188]}$

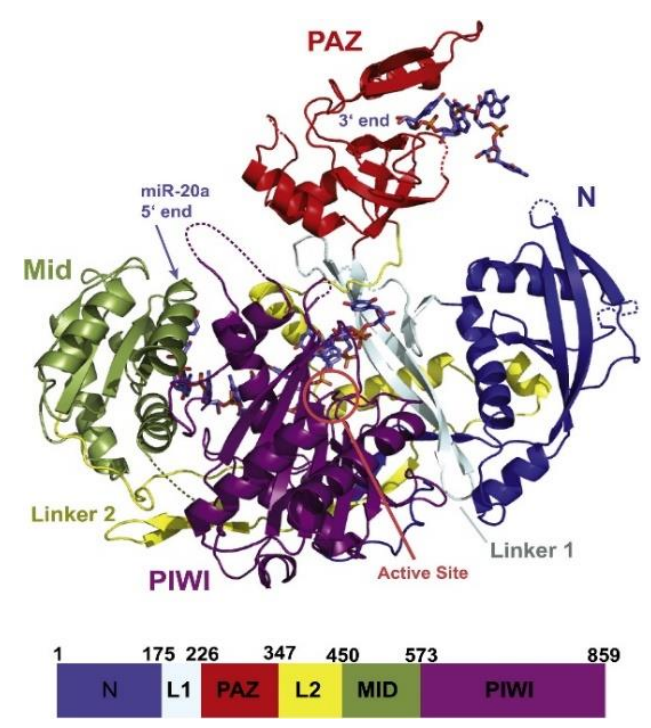

Abbildung 22: Schematische Darstellung eines RISCs bestehend aus Ago2 und miR-20a (oben). Eine schematische Darstellung der Primärstruktur ist unten gezeigt. Mit Erlaubnis entnommen aus Elkayam et al.. ${ }^{[187]}$ Copyright @ 2012, Elsevier Inc.. 


\subsection{Der miRNA 17/92 Cluster}

Eine der am besten untersuchten miRNA-Familien stellt der miR-17/92 Cluster dar. ${ }^{[189]}$ Dieser Cluster besteht aus den miRNAs miR-17, miR-18a, miR-19a, miR-20a, miR-19b-1 sowie miR-92a-1 und wurde 2004 identifiziert. ${ }^{[190]}$ Die miRNAs dieser Familie sind in vielen Krebsarten überexprimiert und so wurde dieser Cluster als erstes als oncomiR bezeichnet. ${ }^{[191]}$ Abgesehen von dem miR-17/92 Cluster gehören auch die paralogen Cluster miR-106b/25 und miR-106a/363 Cluster zu dieser miR-Familie. Diese beinhalten die miR-106b, miR-93 und miR-25, sowie miR-106a, miR-18b, miR-20b, miR-19b-2, miR-92a-2 und miR-363. ${ }^{[189]}$ Aufgrund ihrer seed-Sequenzen ist es möglich diese Familie in vier Unterfamilien aufzuteilen (Tabelle 2).

In gesunden Zellen spielt die miR-17/92 Familie eine entscheidende Rolle bei der embryonalen Entwicklung. In Tierversuchen konnte gezeigt werden, dass ein knock-down des miR-17/92 Custers zu Fehlbildungen an Skelett und Lunge zur Folge hat und kurz nach der Geburt zum Tod führt. ${ }^{[189,192]}$ Auch beim Menschen führt eine verringerte Expression des miR-17/92 Clusters zu Fehlbildungen am Skelett, wie es beispielsweise beim Feingold-Syndrom zu beobachten ist. ${ }^{[189,193]}$ Als Ursache konnte eine Mutation des MYCN-Gens ausgemacht werden, das den TF N-Myc codiert. Dieser ist ein wichtiger Aktivator des miR-17/92 Clusters. In einer weiteren Variante dieser Krankheit erfolgt eine heterozygote Deletion im Bereich des miR-17/92 Clusters, wodurch seine Expression verhindert wird. Darüber hinaus spielt der miR-17/92 Cluster eine entscheidende Rolle bei der Entwicklung von B-Zellen, kann jedoch bei einer Überexpression auch lymphoproliferative Erkrankungen auslösen. ${ }^{[189]}$

Tabelle 2: Sequenzen der Vertreter der miR-17/92, miR-106b/25 und miR-106a/363 Cluster unterteilt nach ihren seedSequenzen. Diese sind in hellblau dargestellt. Dabei wurden miR-19-1 und miR-19-2 sowie miR-92a-1 und miR-92a-2 zusammengefasst.

\begin{tabular}{l|l|l}
\hline \hline miR-17-Familie & hsa-miR-17-5p & CAAAGUGCUUACAGUGCAGGUAG \\
\cline { 2 - 3 } & hsa-miR-20a-5p & UAAGUGCUUAUAGUGCAGGUAG \\
\cline { 2 - 3 } & hsa-miR-20b-5p & CAAAGUGCUCAUAGUGCAGGUAG \\
\cline { 2 - 3 } & hsa-miR-106a-5p & AAAAGUGCUUACAGUGCAGGUAG \\
\cline { 2 - 3 } & hsa-miR-106b-5p & UAAAGUGCUGACAGUGCAGAU \\
\cline { 2 - 3 } & hsa-miR-93-5p & CAAAGUGCUGUUCGUGCAGGUAG \\
\hline \hline \multirow{2}{*}{ miR-18-Familie } & hsa-miR-18a-5p & UAAGGUGCAUCUAGUGCAGAUAG \\
\cline { 2 - 3 } & hsa-miR-18b-5p & UAAGGUGCAUCUAGUGCAGUUAG \\
\hline \hline \multirow{2}{*}{ miR-19-Familie } & hsa-miR-19a-3p & UGUGCAAAUCUAUGCAAAACUGA \\
\cline { 2 - 3 } & hsa-miR-19b-3p & UGUGCAAAUCCAUGCAAAACUGA \\
\hline \hline \multirow{2}{*}{ miR-92-Familie } & hsa-miR-92a-3p & UAUUGCACUUGUCCCGGCCUGU \\
\cline { 2 - 3 } & hsa-miR-25-3p & CAUUGCACUUGUCUCGGUCUGA \\
\cline { 2 - 3 } & hsa-miR-363-3p & AAUUGCACGGUAUCCAUCUGUA \\
\hline \hline
\end{tabular}


Während der miR-17/92 Cluster in der embryonalen Entwicklung eine wichtige Rolle spielt, ist er in vielen Krebsarten überexprimiert und fördert das Tumorwachstum. Ein Grund dafür ist die Inhibierung der Expression des Cyclin-abhängigen Kinase (CDK) Inhibitors 1 auch, p21 genannt, durch miR-17 und miR-20a. ${ }^{[183,194]}$ p21 ist für die Regulation des Zellzyklus entscheidend, wirkt dabei tumorinhibierend und kann Apoptose auslösen. Außerdem können miR-17 und miR-20a die Expression von ZBTB-Proteinen unterdrücken, wodurch der TF Sp1 verstärkt exprimiert wird, welcher ebenfalls das Tumorwachstum fördern kann. Abgesehen davon ist der miR-17/92 Cluster auch an der Regulation der E2F-Familie beteiligt. ${ }^{[189,195]}$ Dies ist eine Familie von TFs, die unter anderem an der Auslösung von Apoptose beteiligt sind. Dabei erfolgt die Regulation in beiden Richtungen, da E2Fs die Expression des miR-17/92 Clusters aktivieren und gleichzeitig durch die miRNAs reguliert werden. Da hohe E2F-Level für das Auslösen der Apoptose notwendig sind, kann diese durch hohe miRNA-Level verhindert und so das Tumorwachstum gefördert werden. ${ }^{[195]}$ Aufgrund dieser Eigenschaften stellt der miR-17/92 Cluster entscheidende Marker und Angriffspunkte bei vielen Krebserkrankungen dar. 


\section{Oligonukleotid-basierte Therapien und Bioverfügbarkeit}

Beim Design von Wirkstoffen spielen Selektivität und Sicherheit eine besondere Rolle. Konventionelle Wirkstoffe bestehen häufig aus kleinen Molekülen, welche spezifisch an bestimmte Proteinenregionen binden können. Dabei besteht das Problem, dass eine Erkennung nicht immer möglich ist und somit nicht alle zellulären Prozesse adressierbar sind. ${ }^{[1]}$ Eine Abhilfe könnte ein früherer Eingriff durch die Beeinflussung der Genexpression darstellen. Hierfür ist jedoch eine Bindung an RNA oder DNA notwendig, was mit kleinen Molekülen nur bedingt spezifisch möglich ist. ${ }^{[1]}$ In diesem Zusammenhang bieten ON-basierte Therapeutika den Vorteil, dass sie nahezu jede Sequenz spezifisch über Basenpaarung adressieren können, solange diese sterisch zugänglich ist. Bei der Anwendung stellen jedoch die Größe und die negative Ladung der ONs ein Problem bei der Aufnahme in die Zelle dar. Des Weiteren sind die Stabilität der ONs, sowie die Aktivierung zelleigener Abwehrmechanismen, beispielsweise der TLRs, eine Hindernis. Trotz dieser Schwierigkeiten steigt die Zahl der durch die Food and Drug Administration (FDA) oder die European Medicines Agency (EMA) zugelassenen ON-basierten Wirkstoffe in den letzten Jahren stark an, wobei in den meisten Fällen seltene Krankheiten adressiert werden. ${ }^{[2,3]}$ Im Folgenden werden einige Therapieansätze sowie Methoden für die Verteilung der ON vorgestellt, wobei mRNA-basierte Wirkstoffe nicht behandelt werden.

\subsection{ON-Therapien}

\subsection{1 antisense oligonucleotides (ASOs)}

Im Bereich der ON-basierten Therapeutika sind ASOs die ältesten und häufigsten Vertreter. Von den elf im Juni 2020 durch die FDA oder EMA zugelassenen ON-Therapeutika, sind sieben ASO-basiert. ${ }^{[2,3,196]}$ Dazu zählt auch das erste, allerdings mittlerweile zurückgezogene, ON-Therapeutikum Fomivirsen. ${ }^{[1,2]}$ Dieses konnte die Transkription der mRNA in Cytomegalieviren durch einen sterischen Block inhibieren und so bei AIDS-Erkrankten gefährliche Infektionen des Auges verhindern. Allerdings wurde diese Anwendung durch bessere HIV-Therapeutika überflüssig. Nach der Zulassung von Fomivirsen dauerte es 15 Jahre, bis das nächste ASO-Therapeutikum, das Gapmer Mipomersen, von der FDA zugelassen wurde. Die Zulassung durch die EMA wurde jedoch aufgrund von Sicherheitsbedenken verweigert, da es schwere Leberschäden auslösen kann. ${ }^{[2]} 2016$ wurde mit dem splice-switching ON (SSO) Eteplirsen das erste systemisch applizierbare ON-Therapeutika durch die FDA zugelassen, jedoch verweigerte die EMA erneut die Zulassung. ${ }^{[2,47]}$ Mit Nusinersen wurde im selben Jahr ein weiteres SSO sowohl 
durch die FDA als auch durch die EMA zugelassen. ${ }^{[2,3]}$ Insgesamt kommen im Bereich der ASOs sowohl Gapmere als auch SSOs zum Einsatz. ${ }^{[2,3,196]}$ Für die Gapmere werden 2'-MOE-RNA/DNA-Mixmere mit einem Phosphorthioatrückgrat verwendet, deren Anwendungsgebiete Leberkrankheiten sind. Die SSOs bestehen in vielen Fällen aus 2'-MOE-RNAs oder Morpholino-ONs (PMOs) und werden zur Behandlung seltener Muskelkrankheiten, wie der Duchenne-Muskeldystrophie eingesetzt. ${ }^{[2,196]}$ Hierbei konnte insbesondere bei den PMO-basierten ASOs schwere Nebenwirkungen, wie Hepatotoxizität, festgestellt werden, wodurch ihre Zulassung beschränkt und somit ihr Einsatz limitiert wird. ${ }^{[2]}$

\subsubsection{RNAi und miRNA}

Eine andere Gruppe der ON-Therapeutika stellen siRNAs dar, auf Basis derer im Juni 2020 zwei Medikamente zugelassen waren und sich weitere in der Zulassung befinden ${ }^{[3]}$ Der erste Vertreter der RNAi-Therapeutika, Patisiran, wurde 2018 und damit 20 Jahre nach dem ersten ASO zugelassen und dient zur Behandlung der hereditären ATTR-Amyloidose. ${ }^{[197]}$ Patisiran besteht aus einer mit wenigen 2'-OMe-Nukleotiden modifizierten dsRNA und wird in Lipidnanopartikeln (LNPs) appliziert. Allerdings ist seine Wirksamkeit begrenzt und es muss in Kombination mit Steroiden angewendet werden. ${ }^{[2]}$ Der zweite Vertreter dieser Klasse, Givosiran, wurde Ende 2019 zugelassen und wird gegen die akute intermittierende Porphyrie eingesetzt. Givosiran ist ein vollständig modifiziertes dsON bestehend aus alternierenden 2'-F- und 2'-OMe-Nukleotiden deren Enden durch Phosphorthioate (PS) weiter stabilisiert werden. Der passenger-Strang ist am 3'-Ende mit $\mathrm{N}$-Acetylgalactosamin (GalNAc) konjugiert, um die Aufnahme der Verbindung in die Leber zu erleichtern.

Im Gegensatz zu siRNAs haben miRNA-basierte Ansätze bisher noch keine Phase III Studien erreicht. ${ }^{[2,10]}$ Dies liegt einerseits an der komplexeren Wirkung der miRNAs und andererseits an den Anwendungen, bei denen es sich in vielen Fällen um virale und Krebserkrankungen handelt. Dies erfordert eine Verteilung der ONs über die Leber hinaus, was eine große Herausforderung darstellt. In der Wirkstoffentwicklung sind die anti-miRs weiter fortgeschritten und mit Miravirsen konnte ein erstes anti-miR erfolgreich in Phase II getestet werden. ${ }^{[1,10]}$ Dieses wurde gegen das Hepatitis-C-Virus eingesetzt und in den Studien konnte gezeigt werden, dass die Anwendung sicher war. Außerdem konnte die Virenlast deutlich gesenkt, jedoch keine vollständige Heilung erzielt werden. ${ }^{[1]} \mathrm{Da}$ gleichzeitig effektivere Medikamente auf den Markt kamen, wurden die Studien zu Miravirsen eingestellt. ${ }^{[1]}$ Weitere anti-miR-basierte Wirkstoffe befinden sich derzeitig in Phase II-Studien ${ }^{[2]}$ Im Gegensatz zu anti-miRs sind die Anwendungen von miR-Mimics noch seltener in fortgeschrittenen klinischen Studien zu finden und es gibt nur wenige 
Ansätze, die in Phase II getestet werden. ${ }^{[2,10]} 2013$ begannen mit dem ersten Vertreter dieser Klasse, MRX34, Phase I Studien, welche 2016 aufgrund gravierender Nebenwirkungen gestoppt wurden. ${ }^{[1,10]}$ MRX34 war ein Mimic der miR-34a, die in Krebszellen herunterreguliert ist, und wurde in Lipidnanopartikeln verabreicht.

\subsubsection{TF decoy (TFD)}

Die bisher vorgestellten Ansätze beruhen alle darauf, die Genexpression durch Wechselwirkung mit mRNA beeinflussen. Dies hat den Vorteil, dass die ONs lediglich in die Zelle, jedoch nicht in den Nukleus gelangen müssen. Außerdem ist die Erkennung von dsDNA mit ONs nicht ohne weiteres möglich und auf Stranginvasion oder Triplexbildung begrenzt. Allerdings sind beide Technologien zu wenig entwickelt, um in klinischen Studien getestet zu werden. ${ }^{[1]}$ Die am weitesten entwickelte Methode zur Beeinflussung der Transkription stellen TF decoys (TFD) dar. Dieser Ansatz beruht auf kurzen, partiell modifizierten dsDNAs, welche die Bindesequenz eines TFs enthalten. Somit können sie kompetitiv TFs binden und auf diese Weise die Expression von Genen inhibieren. ${ }^{[198,199]}$ Im Gegensatz zu anderen ON-Therapeutika besitzen sie den Vorteil, dass kurze dsDNAs von Zellen aufgenommen werden können, ${ }^{[198,199]}$ wobei dies über die Bindung an Rezeptoren oder carrier-basiert erfolgen kann. Ein Problem dieses Ansatzes stellt jedoch die geringe Nukleasestabilität der dsDNA im zellulären Milieu dar. Um die Stabilität zu erhöhen, ist es möglich, die ONs zu modifizieren. Beispielsweise können PS eingesetzt werden, die sowohl die Nukleasestabilität als auch die Zellaufnahme der ONs verbessern. ${ }^{[199,200]}$ Des Weiteren können modifizierte Nukleotide, wie LNAs oder PNAs genutzt werden, um die Nukleasestabilität zu erhöhen. ${ }^{[61,201]}$ Allerdings müssen diese Nukleotide außerhalb der Bindestellen der TFs eingesetzt werden, da ansonsten die Bindung der TFs verhindert würde. Eine weitere Variante um die Nukleasestabilität zu erhöhen, stellt die Verwendung von hairpin- oder zyklischen DNAs dar. ${ }^{[199]}$ Auf dieser Basis konnten in vorklinischen Studien gute Ergebnisse erzielt werden und TFD-ONs wurden bis in Phase III getestet. Zwar zeigten sich bei diesem Ansatz keine Nebenwirkungen, allerdings konnten gegenüber Placebos keine signifikanten Effekte beobachtet werden. ${ }^{[1,199]}$ 


\subsection{Bioverfügbarkeit von Oligonukleotiden}

Eines der größten Probleme bei der Anwendung von therapeutischen ONs stellt ihre geringe Bioverfügbarkeit dar. Die Ursachen hierfür sind die Größe und die negative Ladung der ONs, welche eine Zellaufnahme verhindern. ${ }^{[1]}$ Des Weiteren muss der Abbau der ONs durch Nukleasen verhindert werden, wodurch eine systemische Applikation der ONs weitgehend verhindert wird. Dies hat zur Folge, dass therapeutische ONs entweder lokal appliziert werden oder bei Leberkrankheiten zum Einsatz kommen, da die Leber vergleichsweise leicht zu adressieren ist. ${ }^{[2]}$ Ein weiteres Problem bei der Applikation von ONs ist, dass exogene ONs meist einen bakteriellen oder viralen Ursprung besitzen. Dies hat zur Folge, dass Rezeptoren wie TLRs zellfremde ONs erkennen und eine Immunantwort auslösen können. ${ }^{[1,202,203]} \mathrm{Zu}$ diesen Rezeptoren gehören TLR9, welcher unmethylierte CpG-Motive in ssDNA erkennt, ${ }^{[203]}$ sowie TLR3, TLR7 und TLR8, welche durch exogene RNAs aktiviert werden. ${ }^{[1]}$ Diese Rezeptoren erkennen insbesondere GU-reiche und poly-U-haltige Sequenzen. Um eine Reaktion des Immunsystems zu verhindern, sollten diese Sequenzen entweder vermieden oder durch modifizierte Nukleotide wie 2'-F- oder $2^{\prime}$-OMe-RNA ersetzt werden. ${ }^{[1]}$ Beim Einsatz von modifizierten ONs besteht jedoch die Gefahr, dass diese toxisch wirken können. Beispielsweise kann der Einsatz von 2'-MOEPS-Gapmeren zu Thrombozytopenie führen, ${ }^{[53]}$ während LNAs hepatotoxisch wirken können. ${ }^{[57]}$

Die Bioverfügbarkeit von ONs kann durch Modifikationen erhöht werden. Bei der Verwendung eines PS-Rückgrats kann neben einer erhöhten Nukleasestabilität der ONs auch eine verbesserte Zellaufnahme beobachtet werden. ${ }^{[1,47]}$ Außerdem können PS-ONs an Albumin oder andere Serum-Proteine binden, wodurch ihre Verweildauer nach der Applikation erhöht wird. Da die negative Ladung des Phosphordiesterrückgrats und die daraus resultierende elektrostatische Repulsion mit der Zellmembran einen der Gründe für die schlechte Zellinternalisierung darstellt, könnte man annehmen, dass die Zellaufnahme durch ein neutrales Rückgrat verbessert wird. Allerdings zeigte sich, dass die neutralen PMOs nur schlecht und die ebenfalls neutralen PNAs gar nicht in Zellen aufgenommen werden. ${ }^{[1]}$ Das neutrale Rückgrat ermöglicht jedoch eine Konjugation mit positiv geladenen cell penetrating peptides (CPPs) wodurch die Zellaufnahme verbessert werden kann. ${ }^{[2,79]}$ Aufgrund der fehlenden Ladung binden PMOs und PNAs außerdem eher schlecht an Serumproteine, wodurch diese ONs nur eine geringe Verweildauer im Blut besitzen und schnell renal ausgeschieden werden. ${ }^{[2]} \mathrm{Da}$ insbesondere ASOs entweder ein PS-Rückgrat besitzen oder auf PMOs basieren und ihre Anwendung auf die Leber oder eine lokale Applikation beschränkt ist, können diese ONs ohne weitere Hilfsmittel verabreicht werden. Außerdem erlaubt die erhöhte Nukleasestabilität dieser Verbindungen den Einsatz von 
Konjugaten. Dabei werden abgesehen von CPPs insbesondere GalNAc-Konjugate eingesetzt. ${ }^{[2]}$ Bei diesen wird die Bindung von GalNAc an den Asialoglycoproteinrezeptor 1 (ASGPR) genutzt, welche zur Aufnahmen der ONs mittels Endozytose führt. Da ASGPR besonders stark in Leberzellen exprimiert wird, eignet sich GalNAc besonders für die Adressierung der Leber. ${ }^{[1,2]}$ Eine andere Methode zur Funktionalisierung von ONs, ist die Konjugation mit Polyethylenglycol (PEG). Dies sorgt durch Vergrößerung des Molekulargewichts zu einer erhöhten Verweildauer im Blut in Folge einer verminderten renalen Ausscheidung. ${ }^{[1,9]}$ Allerdings können PEGylierte ONs allergische Reaktionen auslösen, was ihren Einsatz limitiert.

Die zuvor genannten Methoden eignen sich nur für stark modifizierte ONs, die eine hohe Nukleasestabilität aufweisen. Schwach modifizierte ONs müssen hingegen vor Nukleasen geschützt werden, um intakt in die Zelle zu gelangen. Eine Möglichkeit hierzu bieten virale Vektoren wie Lentiviren, Adenoviren, and Adeno-assoziierte Viren. ${ }^{[204]}$ Bei der Verwendung viraler Vektoren besteht jedoch immer das Risiko, dass sie eine Immunantwort hervorrufen und somit Nebeneffekte auslösen. Zudem ist die Herstellung viraler Vektoren in großen Maßstäben deutlich komplizierter als die nicht viraler Systeme. ${ }^{[9,180,204]}$ Ein Beispiel für nicht virale Vektoren sind LNPs. Diese bestehen aus kationischen oder ionisierbaren Lipiden, welche die Aufnahme der Partikel erleichtern, sowie aus Cholesterol und PEGylierten Lipiden. ${ }^{[2,204]}$ Diese Vektoren werden beispielsweise bei Patisiran erfolgreich angewendet. ${ }^{[1,2,197]}$ Die Verwendung dieser Vektoren hat jedoch den Nachteil, dass sie bevorzugt von der Leber aufgenommen werden und für die Aufnahme in andere Zelltypen funktionalisiert werden müssen. ${ }^{[2]}$ Durch eine stärkere Funktionalisierung erhöht sich jedoch die Gefahr toxischer Nebeneffekte, was ihren Einsatz limitiert. ${ }^{[2,204]}$

Bei der Entwicklung ON-basierter Wirkstoffe konnten in den vergangenen Jahren deutliche Fortschritte erzielt werden, was die steigende Zahl zugelassener Produkte zeigt. Dennoch stellt die Bioverfügbarkeit der ONs eine große Hürde für den Einsatz dar. Insbesondere für einen systemischen Einsatz der ONs fehlen geeignete Methoden. Dennoch stell die lokale Applikation eine Alternative dar, die zudem toxische Nebenwirkungen verhindern kann. 


\section{Adaptoren zur Umleitung von Sp1 auf nicht natürliche Bindestellen}

Transkriptionsfaktoren (TFs) sind entscheidende Regulatoren der Genexpression. Sie bilden über ihre Aktivierungsdomäne $(A D)$ Komplexe mit weiteren Proteinen und können so die RNA-Polymerase II rekrutieren. Dabei kommt es mehr auf die Nähe als auf die exakte räumliche Anordnung an. Im Hefe-zwei-Hybrid-System zum Beispiel werden die DNA-bindende-Domäne (DBD) und die AD eines TFs komplett voneinander getrennt und mit anderen Proteinen fusioniert. ${ }^{[4,5]}$ Erst ein Ligand, der gleichzeitig beide dieser anfusionierten Proteine bindet, stellt die räumliche Nähe von DBD und AD wieder her. Obwohl sich dieses nichtkovalente Proteinensemble massiv vom ursprünglichen TF unterscheidet, führt es doch zur effizienten Aktivierung von Reportergenen. Darauf gründet sich unsere Erwartung, dass ein TF auch dann zur Aktivierung eines nachgeschalteten Gens führen sollte, wenn dieser nicht direkt an den Promotor bindet, sondern nur indirekt, vermittelt durch ein Adaptormolekül (Abbildung 23). In der Vergangenheit wurden verschiedene Versuche unternommen, artifizielle TFs (ATFs) zu entwerfen. ${ }^{[7,8,17,105,156,159]}$ $\mathrm{Da}$ dies eine selektive Erkennung der DNA erfordert, wurden unter anderem Pyrrol-Imidazol-Polyamide (PIPs) als DNA-bindende Einheit verwendet. ${ }^{[8,156,159]}$ Nach Verknüpfung mit speziellen Peptiden als minimalistische AD konnten sie die Genexpression in vitro ${ }^{[156,159]}$ und in Zellkulturexperimenten ${ }^{[8]}$ erhöhen. Ein alternativer Ansatz stellt die Verwendung bifunktioneller ONs dar. Diese bestanden aus einem triplexbildenden ON (TFO) und einer hairpin-DNA, die eine Bindestelle für einen natürlichen TF enthielt. ${ }^{[7,17,105]}$ Auch mit diesen Adaptoren konnte die Genexpression in vitro[105] und in Zellkulturexperimenten ${ }^{[7]}$ aktiviert werden.

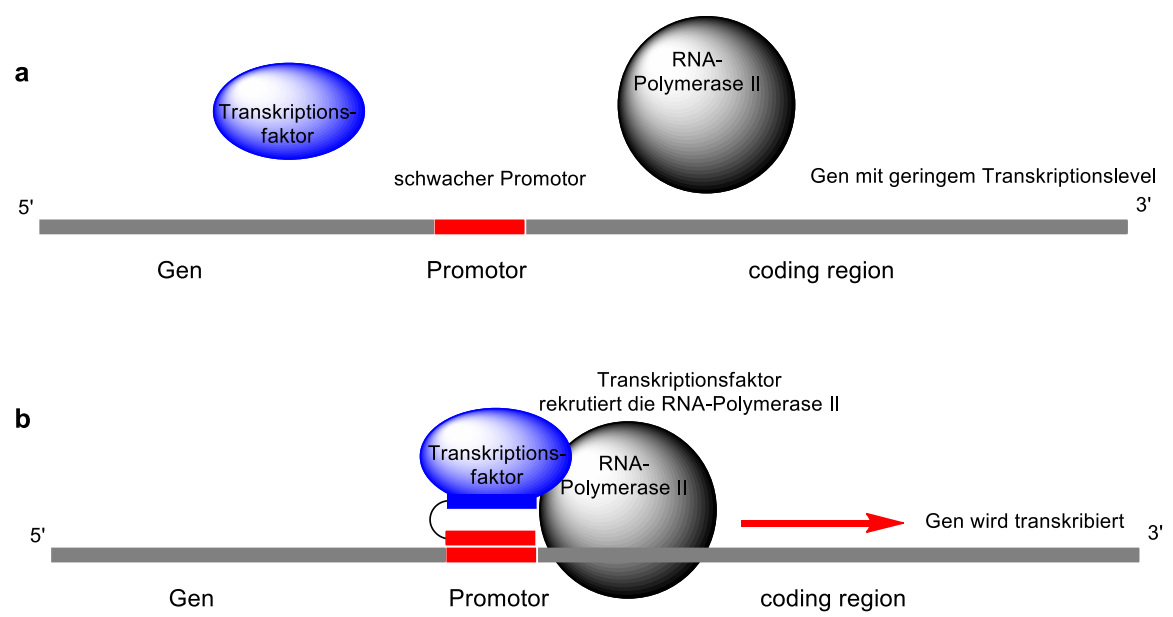

Abbildung 23: Allgemeines Konzept zur Umleitung von Transkriptionsfaktoren am Beispiel eines Gens mit geringer Transkriptionsrate, aufgrund eines schwachen Promotors (a). Durch die Zugabe eines Adaptors wird ein Transkriptionsfaktor indirekt an diesen Promotor gebunden, welcher die RNA-Polymerase II rekrutiert und die Transkriptionsrate erhöht (b). 
Auf Basis dieser Arbeiten entstand in unserer Gruppe die Idee, diese Konzepte zu kombinieren und einen Adaptor aus einem PIP und einer hairpin-DNA aufzubauen, um TFs zu rekrutieren und auf nicht natürliche Bindestellen umzuleiten (Abbildung 23). Dabei besitzen diese Konstrukte ein geringeres Molekulargewicht als entsprechende hairpin-TFOs und sind potenziell weniger anfällig gegenüber Nukleasen. Darüber hinaus kann auf den Einsatz aktivierender Peptide verzichtet werden, von welchen bekannt ist, dass sie die den Einsatz der PIP-ATFs limitieren. ${ }^{[159]}$ Für den Aufbau der PIP-Adaptoren ist jedoch darauf zu achten, dass PIP und DNA orthogonal zueinander sind, um eine Inhibierung des Adaptors durch eine Bindung des PIPs an die eigene DNA zu verhindern. Aus diesem Grund wurden der TF Sp1 als Ziel gewählt, welcher eine GC-reiche Sequenz erkennt und das PIP so designt, dass es an AT-reiche Sequenzen bindet.

In vorausgegangenen Arbeiten konnte in unserer Gruppe bereits ein entsprechendes Konjugat K1 aus der gegen Sp1 gerichteten DNA 2 und dem PIP PA1 synthetisiert werden (Abbildung 24). ${ }^{[11,12]}$ Zur Synthese wurde die DNA 2 auf fester Phase mit einem Diisocyanat umgesetzt und im Anschluss mit PA1 gekuppelt (Informationen zur Nomenklatur der Verbindungen sind in Anhang $12.3 \mathrm{zu}$ finden). Es zeigte sich jedoch, dass eine Reinigung des Konjugats mittels rp-HPLC nur bedingt möglich war und die unkonjugierte DNA nicht abgetrennt werden konnte. Allerdings war es mit dem verunreinigten Material bereits

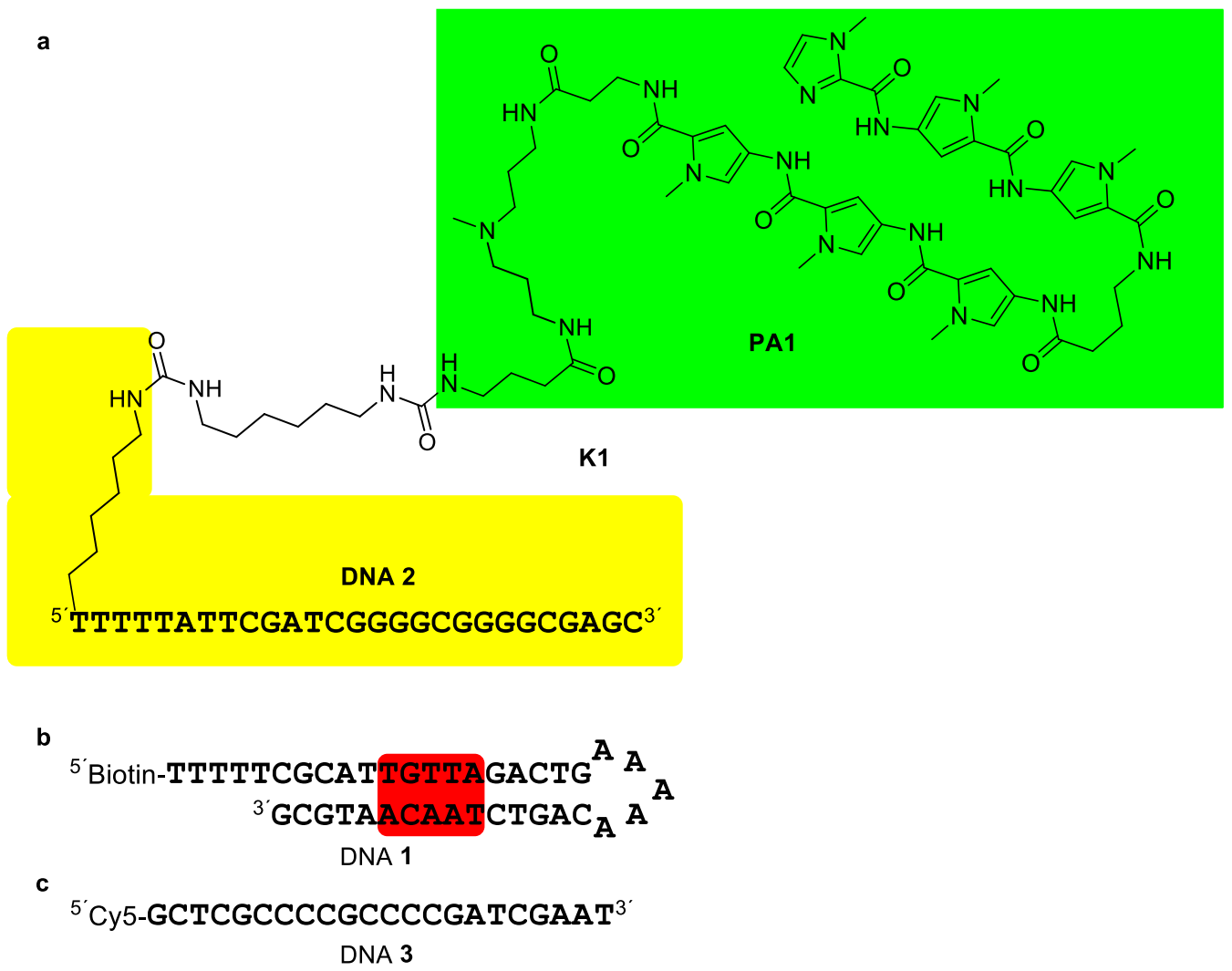

Abbildung 24: a: Struktur des Konjugats K1 bestehend aus dem PIP PA1 (grün) und der DNA 2 (gelb); b: Sequenz der ZielDNA 1, die Bindestelle für K1 ist rot markiert; c: DNA 3: Gegenstrang zu DNA 2. 


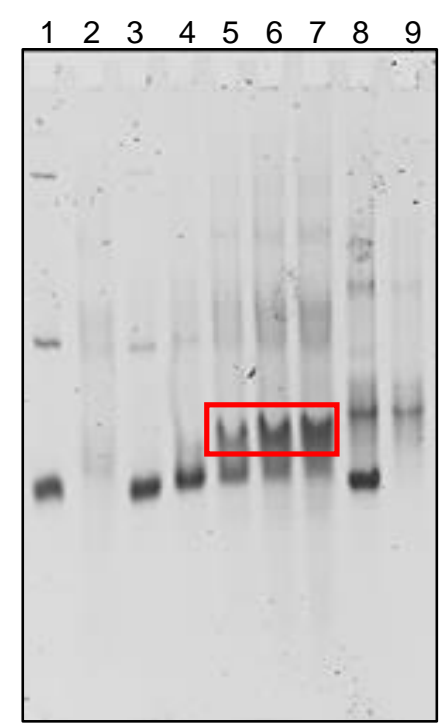

Abbildung 25: Band-Shift-Experimente mit dem Konjugat K1, entnommen und adaptiert aus Bolz (2015). ${ }^{[12]}$ Dabei konnte eine Bindung von K1 an die DNA 1 beobachtet werden (roter Kasten). Im Gegensatz dazu konnte K1a nicht an die DNA 1 binden und wies eine breite Bande auf (Lane $8+9)$. Lane 1: DNA $1(1 \mu \mathrm{M})$; Lane 2: K1 $(4 \mu \mathrm{M})$; Lane 3: DNA $1(1 \mu \mathrm{M})+\mathrm{K} 1$ $(1 \mu \mathrm{M})$; Lane 4: DNA $1(1 \mu \mathrm{M})+\mathrm{K} 1(2 \mu \mathrm{M})$; Lane 5: DNA $1(1 \mu \mathrm{M})+\mathrm{K} 1(4 \mu \mathrm{M})$; Lane 6: DNA $1(1 \mu \mathrm{M})+\mathrm{K} 1(6 \mu \mathrm{M})$; Lane 7: DNA $1(1 \mu \mathrm{M})+\mathrm{K} 1(8 \mu \mathrm{M})$; Lane 8: DNA $1(1 \mu \mathrm{M})+\mathrm{K} 1 \mathrm{a}(1 \mu \mathrm{M})$; Lane 9: K1a $(1 \mu \mathrm{M})$. Die Proben wurden $1 \mathrm{~h}$ bei $4{ }^{\circ} \mathrm{C}$ in einem TEMg-Puffer inkubiert.

möglich, in Band-Shift-Experimenten eine Bindung von K1 an die Zielsequenz auf DNA 1 nachzuweisen. Der PIP-Teil von K1 (Abbildung 24, grün) sollte an die TGTTA-Sequenz der DNA 1 binden (Abbildung 24, rot). Dadurch sollte die Bande von DNA 1 im nativen Gel retardiert werden. Dieser Bandshift war bei großen Überschüssen von K1 tatsächlich zu beobachten (Abbildung 25, rot markiert). Wurde jedoch der DNA-Teil von K1 mit DNA 3 zum Doppelsträngigen Adaptor K1a hybridisiert, war keine Bindung an DNA 1 mehr zu beobachten. Lane 8 in Abbildung 25 zeigt lediglich ein Experiment mit geringen Konzentrationen von K1a, doch konnte in weiteren Versuchen auch bei hoher Konzentration dieses Adaptors kein Bandshift mehr beobachtet werden. Zusätzlich fiel die relativ bereite Bande des Adaptors auf (Abbildung 25, Lane 9). Eine mögliche Erklärung für die geringe Affinität des Konjugats $\mathrm{K1a}$ ist die intramolekulare Wechselwirkung des PIP-Teils von K1a mit dem eigenen DNA-Teil, sobald dieser als Duplex vorliegt. Diese Beobachtung ist sehr problematisch, da der GC-reiche Duplex zum Einfangen von Sp1 benötigt wird. Schließlich entsprach auch die Affinität von K1 zur Ziel-DNA 1 nicht den Erwartungen, was später als Motivation zur Synthese von Achtmer-PIPs diente, die sich erfahrungsgemäß durch eine stark erhöhte Affinität auszeichnen. ${ }^{[14]}$

Ausgehend von diesen Ergebnissen galt es im nächsten Schritt die Umleitung des TFs Sp1 mittels Adaptormolekülen nachzuweisen. Hierzu sollten Pulldown-Experimente durchgeführt werden, in denen Sp1 auf die DNA 1 umgeleitet und im Anschluss in Western-Blots detektiert wurde. Hierzu waren geeignete Konjugate notwendig, wozu die Synthese, Reinigung und Struktur der PIPs sowie der Konjugate optimiert werden musste. 
Dabei war geplant, die Synthese der PIPs auf eine Festphasensynthese umzustellen und die Sequenz der PIPs auf insgesamt acht Py- und Im-Einheiten auszuweiten, um die Affinität der Konjugate zu erhöhen. Zur genaueren Untersuchung der Bindung der Adaptoren an die DNA 1 sollten dann Band-Shift- und Pulldown-Experimente mit anschließender Fluoreszenzdetektion durchgeführt und so geeignete Kandidaten für die Umleitung von Sp1 gewählt werden. Da bereits TFO-basierte Adaptoren beschrieben waren, ${ }^{[7]}$ mussten diese mit den PIP-Adaptoren verglichen werden, um das effektivere System zu bestimmen. Hierzu wurden an die Literatur angelehnte TFO-Adaptoren aufgebaut und in Band-Shift-Experimenten auf ihre Affinität zu spezifischen Ziel-DNAs untersucht. Im Anschluss war geplant sie mit den PIP-Adaptoren zu verglichen, wozu die PIP-Adaptoren an die gleichen Ziel-DNAs binden mussten. Um eine möglichst breite Basis an DNA-bindenden Molekülen zu testen, wurde als dritte Variante der Einsatz pseudokomplementärer PNAs in Betracht gezogen. ${ }^{[75,205]}$ Hierzu sollte eine Methode etabliert werden, die den Aufbau eines Thiouracil-Monomers erlaubte. 


\subsection{Synthese der Polyamide}

Ausgehend von der Struktur des Polyamids PA1, welches aus meiner Masterarbeit vorhanden war, ${ }^{[12]}$ wurden die im Folgenden vorgestellten PIPs synthetisiert (Abbildung 26). Da das aus PA1 resultierende Konjugat nur eine geringe Affinität zu seiner Ziel-DNA besaß, war es notwendig, die Länge der PIPs auf acht Py und Im-Einheiten zu erhöhen (PA3 - PA5), um die Affinität zu steigern. ${ }^{[14]}$ Darüber hinaus sollte das Bindungsverhalten der PIPs genauer untersucht werden. Hierzu wurden einerseits die Linker der Polyamide verkürzt (PA2 und PA6), um den Einfluss weniger flexibler Komplexe auf die Umleitung zu untersuchen. Mit PA6 sollte zusätzlich geprüft werden, welchen Effekt eine Eliminierung der $\beta$-Gruppe hatte. Da diese analog zu Py eine Bindung an A oder T bevorzugt, kann sich dies in manchen Fällen negativ auf die Bindung der PIPs auswirken. ${ }^{[131]}$ Des Weiteren wurde untersucht, ob die Orientierung der PIPs auf der Ziel-DNA 1 einen Einfluss auf die Affinität besaßen. Hierzu wurde die Polyamide PA4 und PA5 eingesetzt (Abbildung 27). PA3 besaß auf der DNA 1 eine Mismatch-Bindestelle und diente als Negativkontrolle.

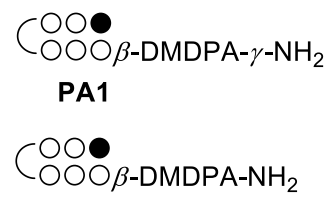

PA2

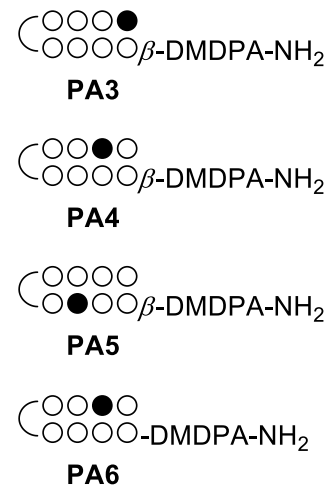

PA6

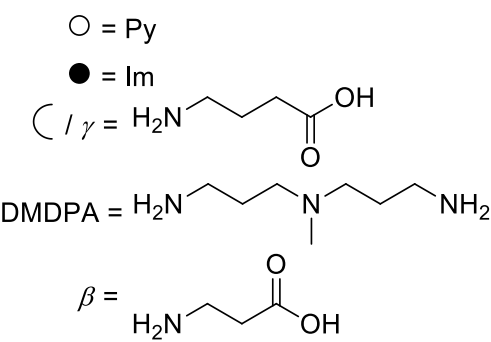

Abbildung 26: Sequenzen der in dieser Arbeit synthetisierten PIPs. Die vollständige Konstitution von PA1 ist in Abbildung 24 gezeigt.

Ein weiterer Grund für das Entfernen der endständigen $\gamma$-Einheit des PA1 in den PIPs PA2 - PA6 war die zum Aufbau der PIPs gewählte Festphasensynthese. Diese ist literaturbekannt und bietet gegenüber einer Synthese in Lösung den Vorteil, dass PIPs unterschiedlicher Sequenz schneller herzustellen und leichter zu variieren sind. ${ }^{[145-147,150,151]}$ Für die PIPs PA2 - PA6 war diese Methode geeignet, da die Abspaltung der PIPs vom Träger mit 3,3'-Diamino- $N$-methyl-diaminopropylamin (DMDPA) durchgeführt wurde und so

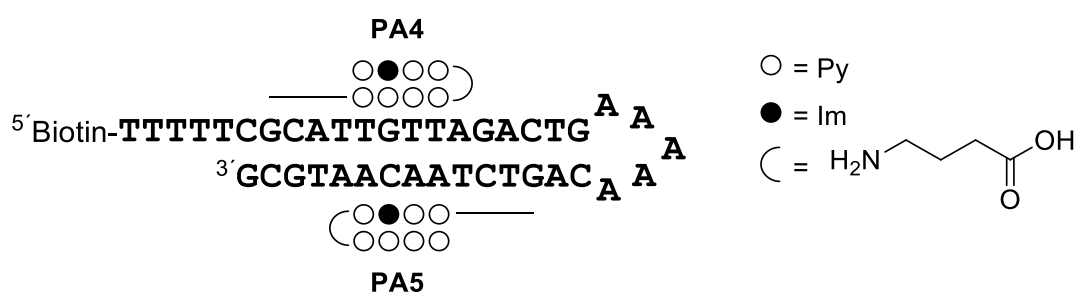

Abbildung 27: Bindung der PIPs PA4 und PA5 an die DNA 1. 
das vollständige PIP erhalten wird. Im Gegensatz dazu müsste eine Abspaltung mit einem Peptid aus DMDPA und Boc-GABA erfolgen, um den in PA1 verwendeten Linker zu erhalten. Bei dieser Verbindung handelte es sich jedoch um eine hochviskose Flüssigkeit, die nicht zur Abspaltung geeignet ist. In diesem Fall müsste das PIP mit DMDPA abgespalten und die GABA-Einheit postsynthetisch eingefügt werden.

\subsubsection{Festphasensynthese}

Für die Festphasensynthese der PIPs mussten zunächst geeignete Schutzgruppen (Boc oder Fmoc) sowie die Kupplungsmethode gewählt werden. Für die Standardaktivierung der Monomere mit Hydroxybenzotriazolen war bekannt, dass bei Kupplungen auf Im schlechte Ausbeuten erhalten wurden und im Allgemeinen lange Reaktionszeiten notwendig waren. ${ }^{[145,147,150,206]}$ Aus diesem Grund sollte in dieser Arbeit eine von Su et al. entwickelte Methode verwendet werden, mit welcher die Kupplung auf Im problemlos möglich sein sollte. ${ }^{[147]}$ Hierbei wurden die Monomere zunächst mittels Triphosgen (BTC) in situ in Säurechloride umgewandelt und zur Kupplung verwendet. Die in der beschriebenen Methode verwendete Boc-basierte Schutzgruppenstrategie wurde in dieser Arbeit übernommen. Dementsprechend wurden die Bausteine 5 und 10, ausgehend von N-Methylpyrrol und N-Methylimidazol synthetisiert (Schema 1).

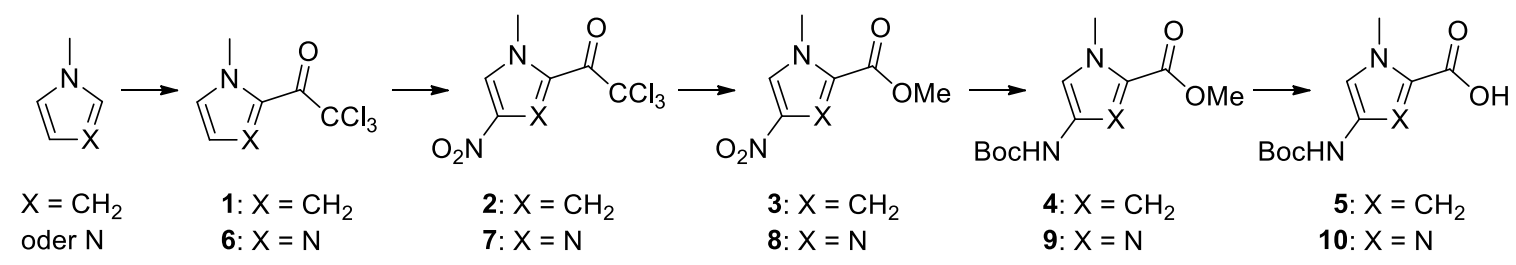

Schema 1: Syntheseplan für die Monomere 5 und 10 ausgehend von $\mathrm{N}$-Methylpyrrol und $\mathrm{N}$-Methylimidazol.

\subsubsection{Synthese der Monomere 5 und 10}

Die Synthese des Monomers $\mathbf{5}$ verlief in den ersten Teilen analog zu in vorherigen Arbeiten durchgeführten Synthesen. ${ }^{[12,145,153,207]}$ Dabei wurde von N-Methylpyrrol ausgegangen und dieses zunächst mit Trichloracetylchlorid (TCACl) zu Verbindung 1 umgesetzt. Im Anschluss erfolgte eine Nitrierung mit $100 \%$ iger $\mathrm{HNO}_{3}$ in Essigsäureanhydrid zu Verbindung 2. Verbindung 3 wurde daraufhin durch den zweiten Schritt einer HaloformReaktion mit NaOMe erhalten. (Schema 2, oben). Zwar stellte diese Route eine effiziente Synthese der Verbindung 3 dar, jedoch waren sehr reaktive und aggressive Verbindungen notwendig. Aus diesem Grund sollte die Synthese unter milderen Bedingungen durchgeführt werden (Schema 2, unten). Dies galt insbesondere für die Synthese der 


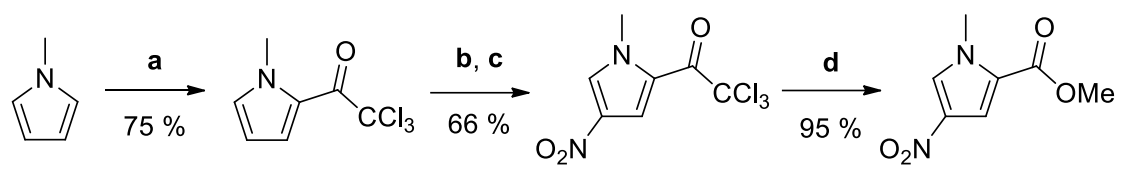

1

2

3

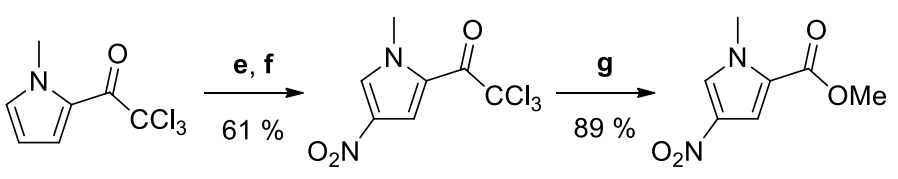

1

Schema 2: Synthese von Verbindung 3. Im oberen Teil ist die ursprüngliche Syntheseroute zu sehen. Im unteren Teil befindet sich die modifizierte Variante. a: TCACl, DCM, RT; b: $\mathrm{HNO}_{3}(100 \% \mathrm{ig}), \mathrm{Ac}_{2} \mathrm{O},-50^{\circ} \mathrm{C}$ auf RT; c: Isopropanol, $-50^{\circ} \mathrm{C} ; \mathbf{d}$ : $\mathrm{NaH}$, $\mathrm{MeOH}, \mathrm{RT}$; e: $\mathrm{HNO}_{3}\left(65 \%\right.$ ig), $\mathrm{Ac}_{2} \mathrm{O},-50{ }^{\circ} \mathrm{C}$ auf RT; f: $\mathrm{H}_{2} \mathrm{O}, \mathrm{RT}$; g: DMAP, $\mathrm{MeOH}, \mathrm{RT}$.

Verbindung 2. Dort wurde $100 \%$ ige $\mathrm{HNO}_{3}$ verwendet, um in situ Acetylnitrat zu erzeugen. Nach der Reaktion war es notwendig, die Reaktionslösung einzuengen, damit die abschließende Fällung der Verbindung 2 mit Isopropanol effektiv verlief. Da Acetylnitrat nur in bestimmten Konzentrationsbereichen sicher zu handhaben ist, stellte dies ein Problem dar. Zudem musste die Fällung mit Isopropanol bei $-40^{\circ} \mathrm{C}$ durchgeführt werden und die entstandene Essigsäure konnte nicht vollständig entfernt werden. Allerdings zeigte sich, dass die Nitrierung auch mit $65 \%$ iger $\mathrm{HNO}_{3}$ möglich war. ${ }^{[208]}$ Im Anschluss an die Reaktion erfolgte die Aufarbeitung durch das Überführen der Reaktionslösung auf Eis. Dabei entstand ein Präzipitat, welches im Anschluss säulenchromatographisch gereinigt wurde. Somit konnte, bei vergleichbaren Ausbeuten, ein Produkt erhalten werden, dass vollständig frei von Essigsäuren und regioisomeren Nitrierungsprodukten war.

Die ursprüngliche Synthese der Verbindung 3 verlief zwar in hohen Ausbeuten (Schema 2, oben), allerdings erforderte die Synthese den Einsatz von stöchiometrischen Mengen $\mathrm{NaH}$ und es sollte nach weniger reaktiven und atomökonomischeren Reagenzien gesucht werden. In diesem Fall zeigte sich, dass statt der Haloform-Reaktion mit NaOMe auch eine DMAP katalysierte Reaktion mit vergleichbaren Ausbeuten möglich war. ${ }^{[209]}$ Um die Verbindung $\mathbf{3}$ in das entsprechende Monomer 5 umzusetzen, musste im nächsten Schritt die Nitrogruppe reduziert und die Schutzgruppe eingeführt werden. Aufgrund der großen Instabilität des entstehenden Amins, erfolgte dies in einem Schritt. ${ }^{[210]}$ Dazu wurde die Reduktion in Anwesenheit von $\mathrm{Boc}_{2} \mathrm{O}$ durchgeführt. Auf diese Weise konnte $\mathbf{4}$ in sehr guten Ausbeuten erhalten und im Anschluss zum Monomer 5 verseift werden (Schema 3).

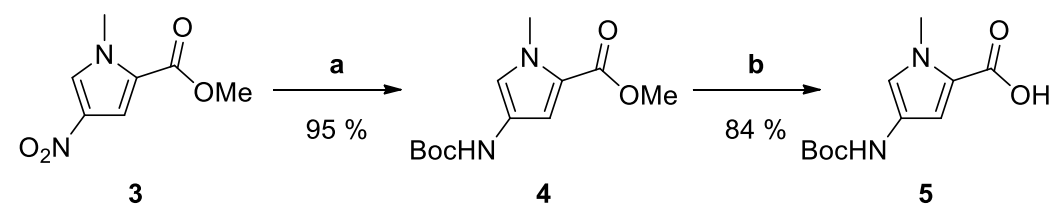

Schema 3: Synthese von Verbindung 5. a: $\mathrm{H}_{2}$ (1 bar), $\mathrm{Pd} / \mathrm{C}, \mathrm{Boc}_{2} \mathrm{O}, \mathrm{MeOH}, \mathrm{RT}$; b: $2 \mathrm{M} \mathrm{NaOH}, \mathrm{MeOH}, 60^{\circ} \mathrm{C}$. 


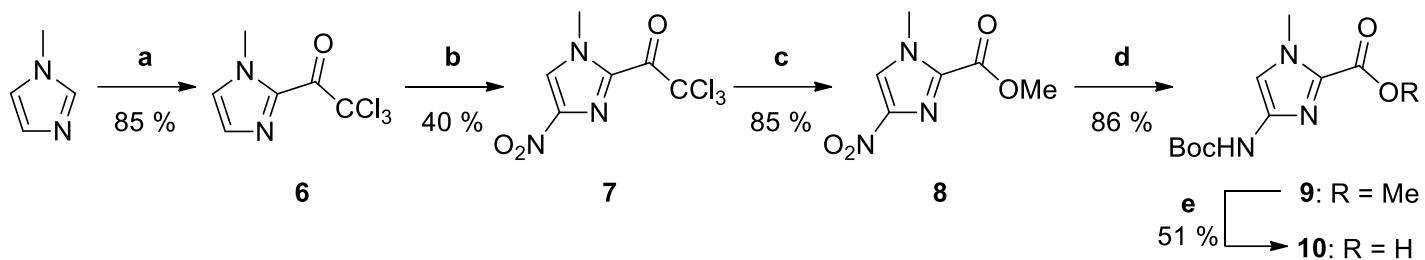

Schema 4: Synthese des Monomers 10. a: TCACI, DCM, RT; b: $\mathrm{HNO}_{3}\left(100 \%\right.$ ig), konz. $\mathrm{H}_{2} \mathrm{SO}_{4}, \mathrm{Ac}_{2} \mathrm{O},-50{ }^{\circ} \mathrm{C}$ auf RT; c: DMAP, $\mathrm{MeOH}, \mathrm{RT} ; \mathbf{d}: \mathrm{H}_{2}$ (1 bar), $\mathrm{Pd} / \mathrm{C}, \mathrm{Boc}_{2} \mathrm{O}, \mathrm{MeOH} ; \mathbf{e}: \mathrm{KOH}_{\mathrm{aq}}$, THF.

Das Monomer 10 wurde auf ähnliche Weise synthetisiert (Schema 4). Diese Syntheseroute konnte in einer parallelen Arbeit etabliert werden ${ }^{[211]}$ und zeigte sich effektiver als die in der Literatur beschriebenen Varianten. ${ }^{[145,210]}$ Zunächst wurde $N$-Methylimidazol mit TCACl zu Verbindung 6 umgesetzt. Im Anschluss erfolgte die Nitrierung zu 7. Im Vergleich zur entsprechenden Verbindung 2 verlief diese Reaktion jedoch deutlich schlechter. Ein Grund hierfür ist die geringere Reaktivität des Imidazols, weswegen der Reaktion zusätzlich katalytische Mengen $\mathrm{H}_{2} \mathrm{SO}_{4}$ zugesetzt werden musste. Durch den zusätzlichen Stickstoff konnte bei der Aufarbeitung ein signifikanter Einfluss des pH-Werts beobachtet werden. Lag dieser zu sehr im Sauren war die Verbindung in Wasser partiell löslich, bei zu basischen Bedingungen bestand die Gefahr der Hydroxylierung. Der Umsatz zu Verbindung 8 erfolgte analog zu Verbindung 3 mittels DMAP und Methanol. In Analogie zu Verbindung 4 konnte Verbindung 9 ebenfalls durch eine Reduktion in Gegenwart von $\mathrm{Boc}_{2} \mathrm{O}$ durchgeführt werden. Die anschließende Verseifung zu Verbindung 10 gelang hingegen nur in mäßigen Ausbeuten. Dabei bereitete die Instabilität der Verbindung Probleme, da sie, im Gegensatz zu Verbindung 5, verstärkt zur Decarboxylierung neigte.

\subsubsection{Synthese der Polyamide}

Nach der Synthese der Monomere, sollte die Kupplung der PIPs über in situ generierte Carbonsäurechloride erfolgen. Dazu inkubierte man die Monomere mit BTC und 2,4,6-Collidin in THF, bevor sie mit DIPEA versetzt und zur Kupplung verwendet wurden. Als Träger verwendete man ein $\beta$-Ala-Pam-Harz. Zunächst sollte diese Methode in der Synthese des PIPs PA2 erprobt werden. Dazu benötigte man neben dem Monomer 5 noch die Bausteine 6 und 11 (Abbildung 28). Nach Abschluss der Synthese sollte das Polyamid gemäß der Literatur mit DMDPA 12 abgespalten werden, woraufhin das vollständige Polyamid erhalten wurde. ${ }^{[147,212]} \mathrm{Im}$ Verlauf der Festphasensynthese stellte jedoch die Überprüfung der Kupplungseffizienz ein Problem dar. Aus vorangegangen Arbeiten war bekannt, dass Standardmethoden wie der Kaiser-Test nicht anwendbar waren. ${ }^{[206]}$ Aus diesem Grund musste die Effizienz der Kupplungsschritte mittels rp-HPLC erfolgen. Allerdings ist diese Art der Überprüfung sehr zeitaufwändig und hierbei war die hohe Oxidationsempfindlichkeit der freien 4-Aminopyrrole problematisch. Nach Abschluss der 


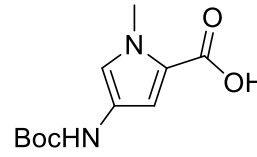

5<smiles>Cn1ccnc1C(=O)C(Cl)(Cl)Cl</smiles>

6<smiles>O=C(O)CCCNC(=O)c1ccccc1</smiles>

11<smiles>CN(CCCN)CCCN</smiles>

12

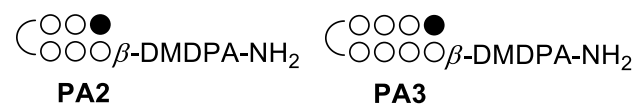

Abbildung 28: Bausteine für die Synthese der PIPs PA2 und PA3 (oben) und deren Sequenz (unten).

Synthese zeigte sich die Reinigung des Polyamids als kritisch, da das im Überschuss eingesetzte Amin 12 vor der Reinigung mittels rp-HPLC entfernt werden sollte, um $\mathrm{pH}$-Effekte zu vermeiden. Da dies aufgrund des hohen Siedepunktes des Amins nicht im Vakuum möglich war, wurde PA2 zunächst durch Zugabe von $\mathrm{Et}_{2} \mathrm{O}$ gefällt.. ${ }^{[212]}$ Jedoch konnte auch auf diese Weise nicht der gesamte Überschuss des Amins entfernt werden und so wurde das Rohprodukt vor der Reinigung mit TFA angesäuert. Trotz dieser Probleme konnte PA2 erhalten werden, auch wenn die Ausbeuten mit ca. $9 \%$ eher gering waren. Zudem konnten deutliche Abbrüche nach den ersten drei Pyrrolen beobachtet werden.

Nachdem die Synthese eines Sechsmer-Polyamids möglich war, sollte als nächstes PA3 synthetisiert werden. Auch in diesem Fall waren keine Kupplungen auf Im-Gruppen notwendig, wodurch die Synthese potenziell vereinfacht wurde. Zwar konnte PA3 erhalten werden, allerdings war die Ausbeute deutlich geringer als bei PA2 und lag nur bei ca. $3 \%$. Wie schon in der Synthese von PA2 konnten auch in diesem Fall neben dem vollständigen Polyamid deutliche Abbrüche nach der Hälfte der Einbauten beobachtet werden. Diese Beobachtungen waren konsistent mit Arbeiten von Fallows et al., in denen ebenfalls eine geringe Kupplungseffizienz nach Einbau der GABA-Gruppe beschrieben wurde. ${ }^{[213]}$ Als eine mögliche Ursache wurden in dieser Arbeit erhöhte $\pi$ - $\pi$-Wechselwirkungen innerhalb eines Polyamids oder zwischen mehreren Polyamiden genannt, welche die Kupplung weiterer Monomere erschwerten.

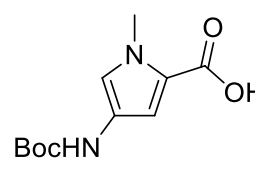

5

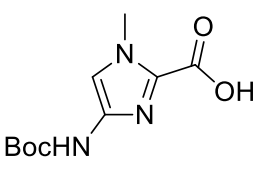

10<smiles>O=C(O)CCCNC(=O)O</smiles>

11

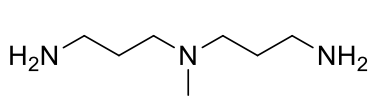

12

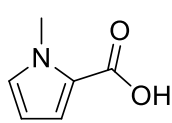

13

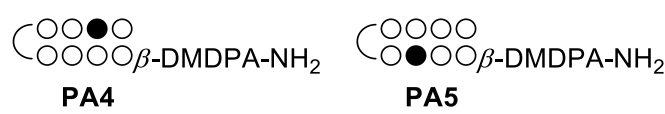

Abbildung 29: Bausteine für die Synthese der PIPs PA4 und PA5 (oben) und deren Sequenz (unten).

Im Anschluss wurde versucht, die Polyamide PA4 und PA5 unter Verwendung der Monomere 5 und 10 sowie der Verbindungen 11 - 13 zu synthetisieren (Abbildung 29). Verbindung 13 konnte dabei durch die Verseifung von Verbindung 1 erhalten werden 


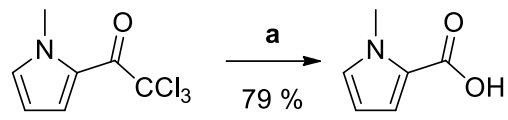

13

Schema 5: Synthese von Verbindung 13. a: $\mathrm{NaOH}_{\mathrm{aq}}, \mathrm{MeOH}$.

(Schema 5). ${ }^{[208]}$ Jedoch wurde wie bei PA3 ein frühzeitiger Abbruch der Synthesen beobachtet und die vollängen PIPs konnten nicht erhalten werden. Aufgrund dieser Ergebnisse wurde entschieden, die Festphasensynthese mit Dimeren durchzuführen, welche bereits von der Dervan-Gruppe genutzt wurden, um die Kupplung auf Im-Bausteine zu umgehen. ${ }^{[145]}$ Dadurch sollte die Zahl der Kupplungsschritte von neun auf vier bis fünf verringert und zudem die Kupplung auf Im-Bausteine, sowie die Verwendung der Verbindung 11 verhindert werden. Aufgrund dieser Überlegungen wurden die Monomere 14 - 18 synthetisiert (Abbildung 30).

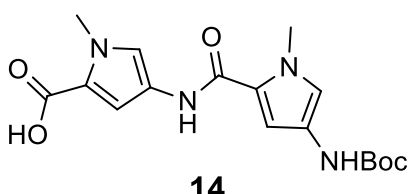

14

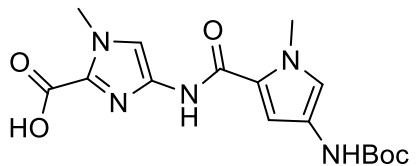

16
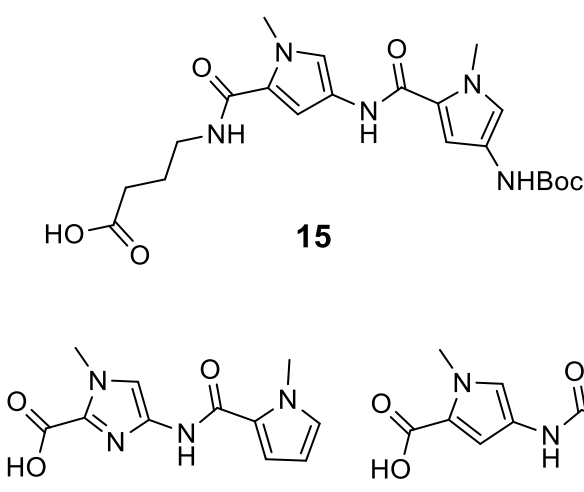

17

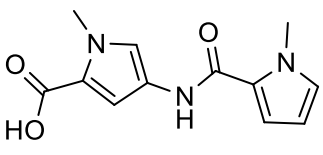

18

Abbildung 30: Dimere für die Festphasensynthese der Polyamide PA4 und PA5.

\subsubsection{Synthese der Dimere}

Aufgrund der strukturellen Ähnlichkeit der Verbindungen 14 - 16, wurden die Synthesen nach einem vergleichbaren Schema durchgeführt (Schema 6). Dazu wurde zunächst ein entsprechendes Dimer mittels einer Haloform-artigen-Reaktion aufgebaut, im Anschluss die Schutzgruppe eingeführt und daraufhin verseift.

Als erstes Dimer wurde Verbindung 14 aufgebaut. Die Synthese verlief dabei im ersten Schritt nach einer bekannten Vorschrift. ${ }^{[12,153,207]}$ Dabei wurde 3 zunächst reduziert und im Anschluss mit 2 zu 20 umgesetzt. Analog zu der Synthese der Monomere, sollte die Einführung der Boc-Gruppe während der Reduktion erfolgen. Da die dimeren Nitroverbindungen jedoch schlecht löslich waren, musste die Reduktion mit erhöhtem Druck und Temperatur durchgeführt werden. Die so erhaltene Verbindung 23 wurde im Anschluss in sehr guten Ausbeuten (98\%) zu Verbindung 13 verseift. 


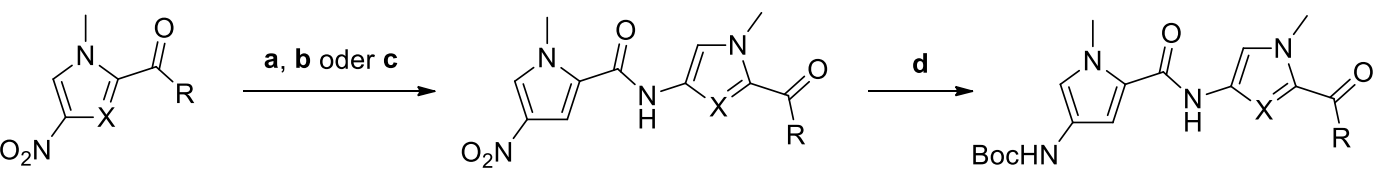

$\begin{aligned} \text { 3: } \mathrm{R} & =\mathrm{OMe} ; \mathrm{X}=\mathrm{CH} \\ \text { 19: } \mathrm{R} & =\mathrm{GABA}-\mathrm{OMe} ; \mathrm{X}=\mathrm{CH} \\ \text { 8: } \mathrm{R} & =\mathrm{OMe} ; \mathrm{X}=\mathrm{N}\end{aligned}$
20: $\mathrm{R}=\mathrm{OMe} ; \mathrm{X}=\mathrm{CH} ; 86 \%$

21: $\mathrm{R}=\mathrm{GABA}-\mathrm{OMe} ; \mathrm{X}=\mathrm{CH} ; 81 \%$

22: $R=O M e ; X=N ; 77 \%$
23: $\mathrm{R}=\mathrm{OMe} ; \mathrm{X}=\mathrm{CH} ; 82 \%$
24: $\mathrm{R}=\mathrm{GABA}-\mathrm{OMe} ; \mathrm{X}=\mathrm{CH} ; 79 \%$
25: $\mathrm{R}=\mathrm{OMe} ; \mathrm{X}=\mathrm{N} ; 87 \%$

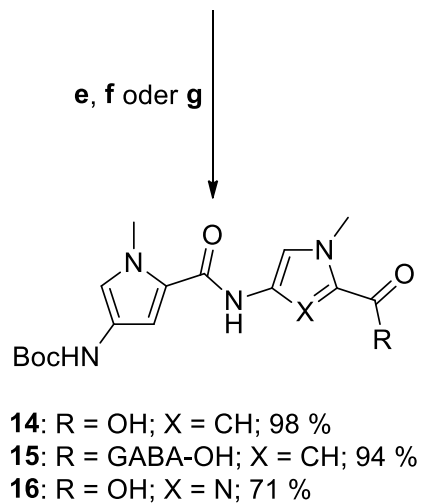

Schema 6: Synthese der Verbindungen 14, 15 und 16. a: $\mathrm{H}_{2}$ (1 bar), Pd/C, EE; b: 2, DIPEA, DCM, RT; c: 26, HOBt, DIC, DIPEA, DMF, $60{ }^{\circ} \mathrm{C}$; d: $\mathrm{H}_{2}$ (40 bar), $\mathrm{Pd} / \mathrm{C}, \mathrm{Boc}_{2} \mathrm{O}, \mathrm{MeOH}, 50^{\circ} \mathrm{C}$; e: $\mathrm{NaOH}, \mathrm{MeOH} / \mathrm{H}_{2} \mathrm{O}$ (1:3.3), RT; f: $\mathrm{LiOH} \cdot \mathrm{H}_{2} \mathrm{O}, \mathrm{MeOH} / \mathrm{H}_{2} \mathrm{O}$ (3:1), RT; g: $\mathrm{KOH}, \mathrm{THF} / \mathrm{H}_{2} \mathrm{O}(1: 2), \mathrm{RT}$.

Für die Synthese von Verbindung 15 musste zunächst der Startbaustein 19 synthetisiert werden (Schema 7). Dieser konnte durch eine Haloform-Reaktion von 2 mit $\gamma$-Aminobuttersäuremethylester-Hydrochlorid erhalten werden. Im Anschluss sollte die Synthese analog zu Verbindung 14 erfolgen (Schema 6). Dabei stellte sich zunächst die Frage, ob die Synthese der Verbindung 21 analog zu der der Verbindung $\mathbf{2 0}$ möglich war. In der Vergangenheit war es in unserer Gruppe nicht möglich, die Haloform-Reaktion in konstant guten Ausbeuten durchzuführen, wenn kein $\mathrm{NaH}$ eingesetzt wurde. ${ }^{[153,207]}$ Diese Beobachtungen konnten jedoch nicht bestätigt werden und nach der Reduktion von Verbindung 19 bei RT und Normaldruck in EE verlief die anschließende Reaktion mit 2 auch ohne die Zugabe von $\mathrm{NaH}$ in konstant guten Ausbeuten (81\%).

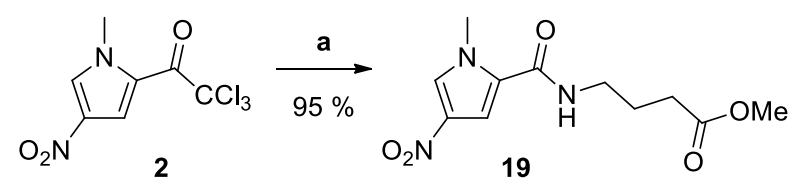

Schema 7: Synthese von Verbindung 19. a: $\gamma$-Aminobuttersäuremethylester Hydrochlorid, DIPEA, DCM.

Für die Synthese der Verbindung 16 musste das Konzept leicht verändert werden. Hier war eine Haloform-Reaktion mit 2 nicht möglich, da die Aminogruppe an Position 4 des Imidazols nicht nukleophil genug war. Aus diesem Grund erfolgte der Aufbau des Dimers über eine Peptidkupplung. Dazu musste Verbindung 2 zunächst in die entsprechende Carbonsäure 26 umgewandelt werden, was in guten Ausbeuten (79\%) gelang (Schema 8). ${ }^{[208]}$ Auch die anschließende Kupplung zu Verbindung 22 konnte in guten Ausbeuten (77\%) durchgeführt werden. Nach der Einführung der Boc-Gruppe erfolgte die 


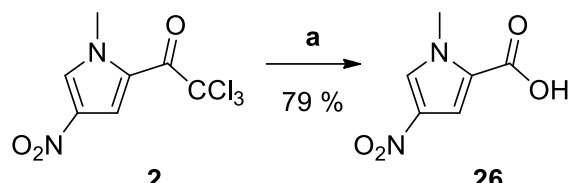

Schema 8: Synthese von Verbindung 26. a: $\mathrm{NaOH}, \mathrm{H}_{2} \mathrm{O}$.

Verseifung zu Verbindung 25. Analog zu Verbindung 10 bestand auch hier die Möglichkeit einer Decarboxylierung, diese war jedoch nicht zu beobachten und 16 konnte in guten Ausbeuten erhalten werden (71\%).

Auch die Synthese der endständigen Dimere 17 und 18 sollte nach der zuvor angewendeten Syntheseroute ablaufen (Schema 9), wobei die Einführung der Boc-Gruppe nicht notwendig war. Wie bereits in der Synthese von Verbindung 22 war eine Haloform-Reaktion zum Aufbau der Verbindung 27 nicht möglich, da Verbindung 1 deutlich weniger elektrophil als 2 war. Auch der Aufbau der Verbindung 28 sollte über eine Peptidkupplung verlaufen. Aus diesem Grund wurde die Carbonsäure 13 verwendet. Im Anschluss erfolgte die Synthese der Dimere $\mathbf{2 7}$ und $\mathbf{2 8}$ in guten Ausbeuten, welche im Fall der Verbindung 28 höher waren. Dies war jedoch aufgrund der höheren Reaktivität des Amins zu erwarten. Abschließend konnten die Bausteine 17 und 18 durch Verseifung erhalten werden. Diese konnten in beiden Fällen mit sehr guten Ausbeuten durchgeführt werden. Bei Verbindung 17 stellte auch die Decarboxylierung kein Problem dar.

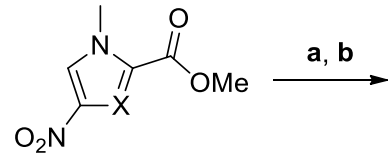

3: $\mathrm{X}=\mathrm{CH}$

8: $X=N$<smiles>[X]c1cn(C)c(C(=O)OC)n1</smiles>

27: $\mathrm{X}=\mathrm{N} ; 71 \%$ 28: $\mathrm{X}=\mathrm{CH} ; 89 \%$

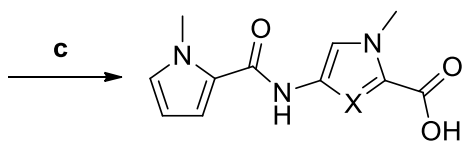

17: $X=N ; 86 \%$ 18: $\mathrm{X}=\mathrm{CH} ; 92 \%$

Schema 9: Synthese von Verbindung 17 und 18. a: $\mathrm{H}_{2}$ (1 bar), $\mathrm{Pd} / \mathrm{C}$, EE; b: 13, $\mathrm{HOBt}$, DIC, DIPEA, $60{ }^{\circ} \mathrm{C}$; c: $\mathrm{NaOH}_{\mathrm{aq}}, \mathrm{MeOH}$

Im Anschluss wurden diese Bausteine in der Festphasensynthese der Polyamide PA4 und PA5 eingesetzt. Dabei war es leider erneut nicht möglich, die Polyamide effizient aufzubauen und es entstanden allenfalls analytische Mengen des Volllängenprodukts. In diesen Fällen war die Kupplung der GABA-Dimere nicht effizient genug und führte zum Abbruch der Synthese.

Aufgrund dieser Ergebnisse wurde für die Synthese von PA5 ein neues Dimer eingesetzt (30). Dieses enthielt die GABA-Gruppe am N-Terminus, wodurch die Kupplungseffizienz gesteigert werden sollte. Hierzu wurde zunächst Verbindung 22 reduziert und im Anschluss mit 11 in moderaten Ausbeuten (53\%) zu Verbindung 29 gekuppelt (Schema 10). Diese konnte danach zu Verbindung $\mathbf{3 0}$ verseift werden. Baustein $\mathbf{3 0}$ wurde daraufhin mit den Verbindungen 14 und 18 zur Synthese von PA5 eingesetzt. Dabei trat bei der Aktivierung von 30 mit BTC eine Gelbildung auf, welche den Einsatz der Verbindung erschwerte. 


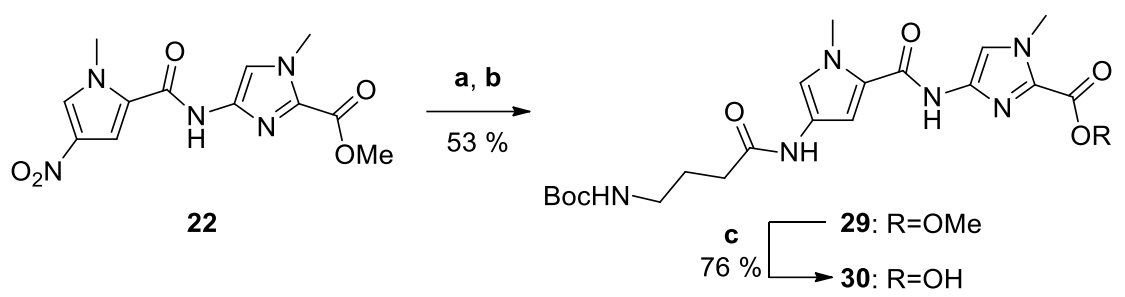

Schema 10: Synthese des Bausteins 30. a: $\mathrm{H}_{2}(40 \mathrm{bar}), \mathrm{Pd} / \mathrm{C}, \mathrm{EE}, 40^{\circ} \mathrm{C} ; \mathbf{b}: 11, \mathrm{HOBt}$, DIC, DIPEA, DMF, RT; c: $\mathrm{KOH}$ aq, $\mathrm{MeOH}, \mathrm{RT}$.

Dennoch konnte die Synthese durchgeführt werden und das erhaltene Rohprodukt mittels HPLC analysiert werden. Dabei zeigte sich ein Hauptpeak (Abbildung 31), welcher im Anschluss isoliert und massenspektrometrisch als PA5 identifiziert wurde. Allerdings wurde PA5 ebenfalls nur in einer Ausbeute von ca. $10 \%$ erhalten.

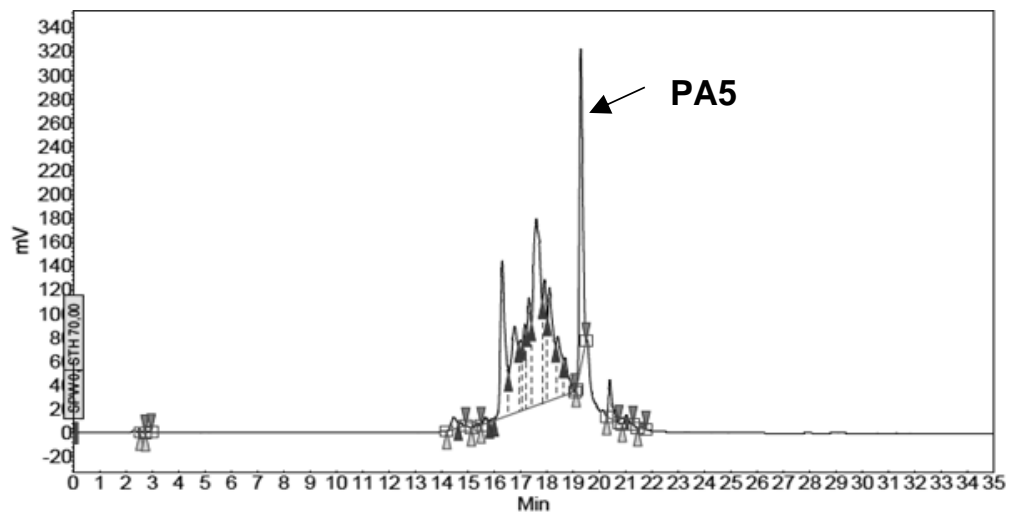

Abbildung 31: Rohprodukt der Festphasensynthese von PA5. Dabei ist ein deutlicher Produktpeak bei 19 min zu sehen. Laufbedingungen: Linearer Gradient von $10 \%$ B zu 70 \% B in 30 min. A: $0.1 \%$ TFA in $\mathrm{H}_{2} \mathrm{O}$; $\mathrm{B}$ : ACN.

Nachdem mittels Festphasensynthese nur die Polyamide PA2 und PA5 in ausreichenden Mengen erhalten wurden und die Synthese auch mit den Dimeren nicht effektiv durchzuführen war, mussten alternative Synthesewege für die Polyamide PA3, PA4 und PA6 in Betracht gezogen werden. Dazu kam der Aufbau der PIPs in Lösung in Frage, welche bereits in der Vergangenheit erfolgreich für den Aufbau von PIPs mit sechs Py- oder Im-Einheiten angewendet wurde und mit der größere Mengen der PIPs zugänglich waren. ${ }^{[12,153,207]}$ Einen zusätzlichen Vorteil für diese Methode stellten die bereits synthetisierten Dimere dar, welche auch in der Synthese in Lösung verwendet werden konnten. 


\subsubsection{Synthese in Lösung}

Die Synthese der Polyamide in Lösung erforderte eine Änderung der Strategie, da ein linearer Aufbau nicht praktikabel war. Wegen der Ähnlichkeit der Sequenzen der PIPs PA3, PA4 und PA6 wurden sie in drei Fragmente unterteilt (Abbildung 32). Fragment A (rot) stellte dabei die Linkereinheit dar, welcher für PA3 und PA4 identisch war. Fragment B (gelb) bildete die erste Einheit aus vier Pyrrolen und war für alle PIPs identisch. Das abschließende Fragment C (grün) bestand aus den verbleibenden drei Py- und Im- sowie der GABA-Einheit. Eine vergleichbare Strategie konnte in vorangegangenen Arbeiten für die Synthese von PA1 erfolgreich umgesetzt werden. ${ }^{[12,153,207]}$ Hierzu wurden die einzelnen Fragmente mittels Haloform-Reaktionen aufgebaut und im Anschluss zunächst die Fragmente $\mathbf{A}$ und $\mathbf{B}$ verknüpft. Das so erhaltene Fragment wurde daraufhin mit $\mathbf{C}$ verknüpft und somit das vollständige PIP erhalten. Dieses allgemeine Vorgehen sollte auch für die Synthese der Achtmer-PIPs PA3, PA4 und PA6 angewendet werden.

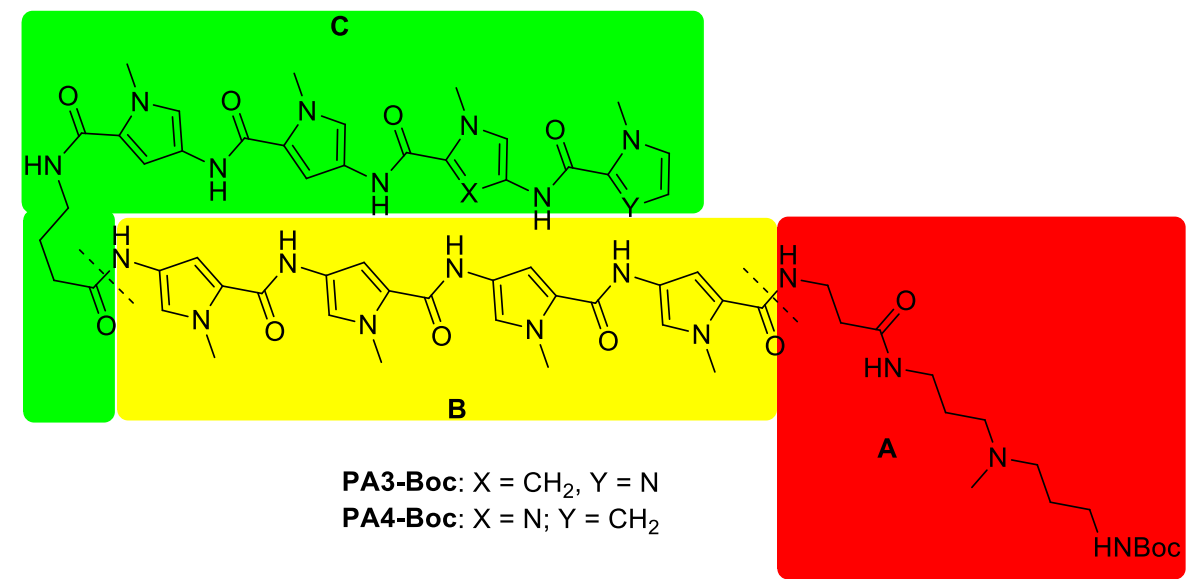

Abbildung 32: Aufteilung der Polyamide PA3-Boc und PA4-Boc in drei Fragmente. Diese Unterteilen sich in den Linker A (rot), ein mittleres Fragment B (gelb) und das Endfragment C (grün).

\subsubsection{Synthese von Fragment $\boldsymbol{A}$}

Das Fragment A (33) war für die PIPs PA3 und PA4 identisch, während das für PA6 benötigte Fragment eine Zwischenstufe (31) der Synthese von 33 darstellte. Die Synthese verlief nach bekannten Vorschriften (Schema 11). ${ }^{[12,153]}$ Dabei wurde zunächst eine Aminogruppe des DMDPAs mit $\mathrm{Boc}_{2} \mathrm{O}$ geschützt und Verbindung 31 in moderaten

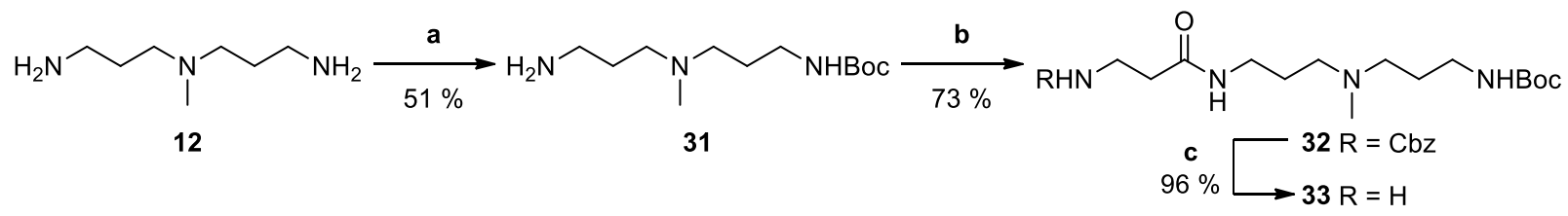

Schema 11: Synthese von Verbindung 33. a: $\mathrm{Boc}_{2} \mathrm{O}$, Dioxan, RT; b: Cbz- $\beta$-Ala-OH, HOBt, DIC, DIPEA, DMF, $60^{\circ} \mathrm{C}$; $\mathbf{c}: \mathrm{H}_{2}$ (1 bar), $\mathrm{Pd} / \mathrm{C}, \mathrm{MeOH}, \mathrm{RT}$. 
Ausbeuten erhalten. Im Anschluss wurde 31 mit einem Cbz-geschützten $\beta$-Alanin gekuppelt und die Schutzgruppe konnte im Anschluss unter Erhaltung der Boc-Gruppe reduktiv entfernt werden. Die resultierende Verbindung $\mathbf{3 3}$ stellte das vollständige Fragment $\mathbf{A}$ dar.

\subsubsection{Synthese des Fragments $\boldsymbol{B}$}

Für das Fragment B (34) standen, ausgehend von Verbindung 20, zwei Synthesewege zur Auswahl. Dabei war die Überlegung, ob das Fragment linear, über Haloform-Reaktionen, oder über die Verknüpfung zweier Dimere, mittels Peptidkupplung, aufgebaut werden sollte. Aus vorausgegangenen Arbeiten unserer Gruppe war bekannt, dass die Haloform-Reaktion mit guten Ausbeuten verlief und zu Produkten von großer Reinheit führte. ${ }^{[12,207]}$ Gleichzeitig wiesen die Verbindungen $\mathbf{2 0}$ und $\mathbf{3 5}$ in den meisten Lösemitteln nur eine geringe Löslichkeit auf, was die Vermutung nahelegte, dass dies auch für Verbindung 36 gelten sollte. Dies wäre bei der Haloform-Reaktion von Vorteil, da sie in DCM durchgeführt wird und das Produkt durch Präzipitation isoliert und gereinigt werden kann. Bei einer Peptidkupplung bestünde dagegen der Nachteil, dass diese in DMF durchgeführt werden müsste, worin die Peptide löslich sind. Da bei einer Peptidkupplung zudem schwerlösliche Nebenprodukte, wie Alkylharnstoffe entstehen können, wären weitere Reinigungen erschwert und dieser Weg nur bedingt praktikabel. Aus diesem Grund wurde der lineare Aufbau bevorzugt (Schema 12).
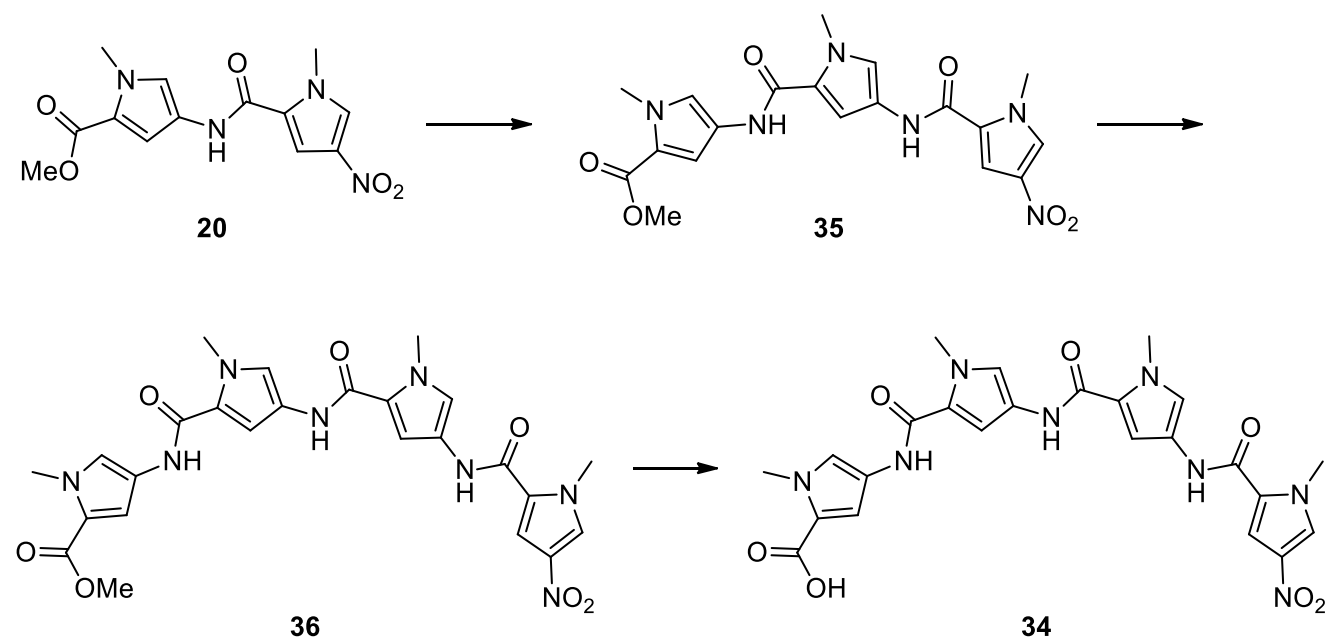

Schema 12: Syntheseroute zur Synthese des Fragments B für das Polyamid PA4.

Hierzu wurde zunächst die Verbindung 35 aufgebaut. Dazu wurde die Nitrogruppe von 20 unter erhöhtem $\mathrm{H}_{2}$-Druck und erhöhter Temperatur in EE reduziert und im Anschluss in einer Haloform-Reaktion mit 2 zu Verbindung 35 umgesetzt (Schema 13). Die Synthese der Verbindung 36 sollte analog erfolgen. Allerdings konnte die Verbindung 35 nicht vollständig reduziert werden und auch das Erhöhen der Temperatur sowie die Verlängerung der 


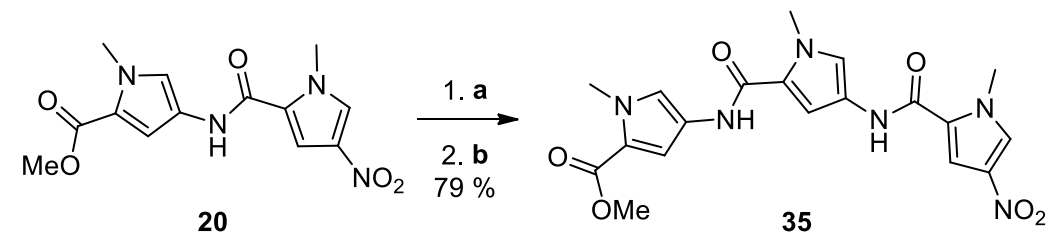

Schema 13: Synthese von Verbindung 35. a: $\mathrm{H}_{2}(40 \mathrm{bar}), \mathrm{Pd} / \mathrm{C}, \mathrm{EE}, 45^{\circ} \mathrm{C}$; b: 2, DIPEA, DCM, RT.

Reaktionszeit brachten in diesem Fall keinen Erfolg. Erst nach der Zugabe von $\mathrm{MeOH}$, konnte eine erfolgreiche Reduktion beobachtet werden, allerdings verlief die anschließende Haloform-Reaktion zu Verbindung 36 nur in schlechten Ausbeuten (37\%). Aufgrund der langen Reaktionszeit konnte die Oxydation des endständigen Amins nicht ausgeschlossen werden und die Reduktion wurde in Methanol wiederholt. Zwar gelang diese vollständig, allerdings zersetzte sich das Amin während der Aufarbeitung, was durch eine Braunfärbung der Lösung sichtbar wurde. Dadurch konnten in der nachfolgenden Haloform-Reaktion nur schlechte Ausbeuten (38\%) erhalten werden (Schema 14, links oben) und es zeigte sich, dass überschüssiges Methanol die Reaktion störte, da es mit Verbindung 2 zu dem Methoxyester 3 reagierte (Schema 15).

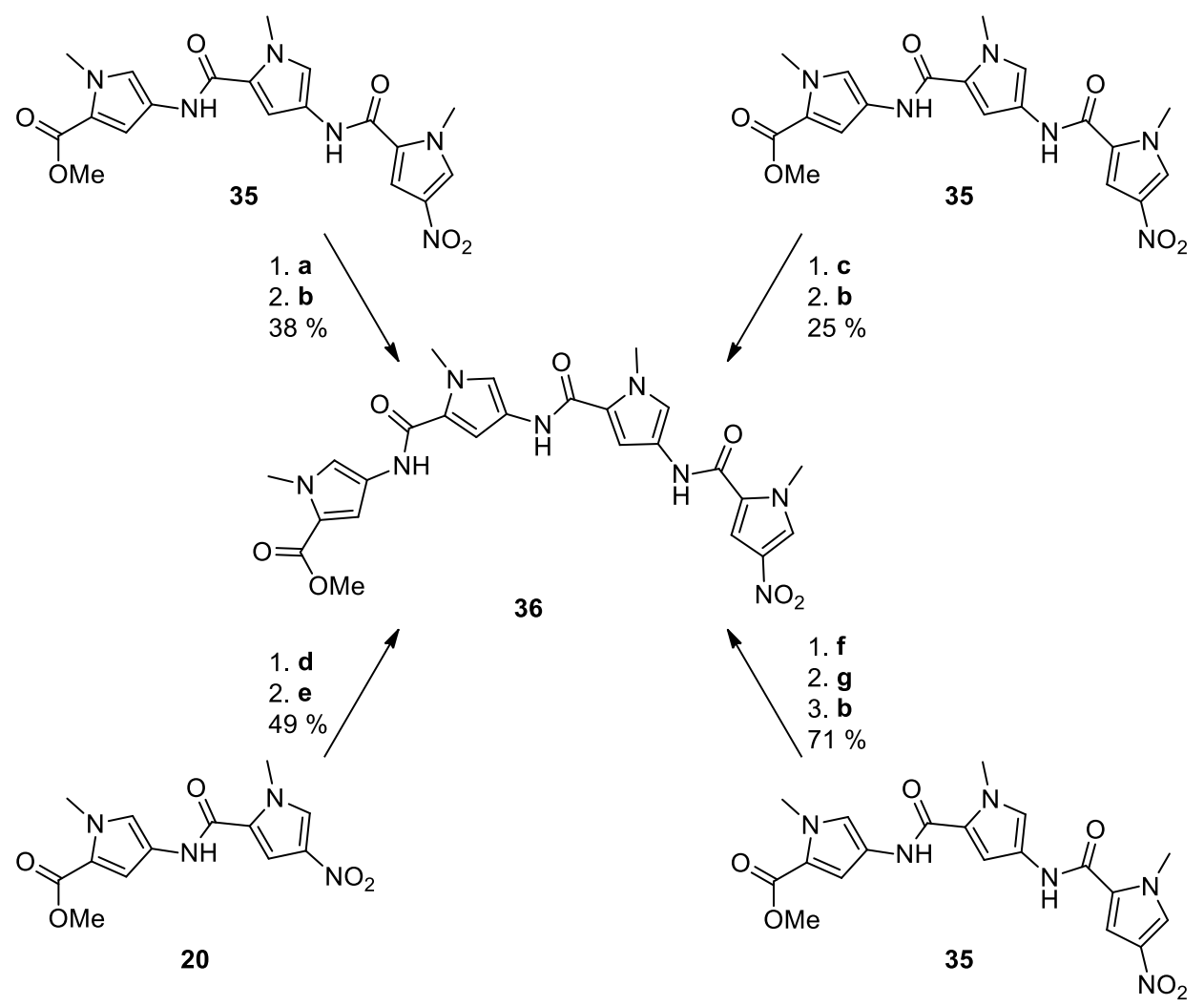

Schema 14: Verschiedene Synthesewege zur Verbindung 36. a: $\mathrm{H}_{2}(40 \mathrm{bar}), \mathrm{Pd} / \mathrm{C}, \mathrm{MeOH}, 45^{\circ} \mathrm{C}$; b: 2, DIPEA, DCM, RT; c: $\mathrm{NaBH}_{4}, \mathrm{Pd} / \mathrm{C}, \mathrm{MeOH}, \mathrm{RT}$; d: $\mathrm{H}_{2}(40 \mathrm{bar}), \mathrm{Pd} / \mathrm{C}, \mathrm{EE}, 40^{\circ} \mathrm{C}$; e: $37, \mathrm{HOBt}$, DIC, DIPEA, DMF, $60{ }^{\circ} \mathrm{C} ; \mathbf{f}: \mathrm{H}_{2}(40 \mathrm{bar}), \mathrm{Pd} / \mathrm{C}$, $\mathrm{Boc}_{2} \mathrm{O}, \mathrm{MeOH}, 45^{\circ} \mathrm{C} ; \mathbf{g}:$ TFA/DCM.

Um die Probleme während der Reduktion zu umgehen, wurde nach alternativen Wasserstoff-Donoren gesucht, welche eine Reaktion bei Raumtemperatur und Normaldruck ermöglichten. Als erste Alternative wurde eine Transfer-Hydrierung in 


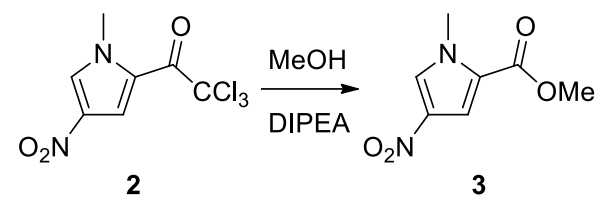

Schema 15: Nebenreaktion von Verbindung 2 mit $\mathrm{MeOH}$.

Erwägung gezogen, bei der Triethylsilan (TES) als Wasserstoffquelle diente. ${ }^{[214]}$ Allerdings war auch in diesem Fall keine vollständige Reduktion der Verbindung 35 zu beobachten. Eine weitere Alternative stellte die Verwendung von $\mathrm{NaBH}_{4}$ in Methanol dar. ${ }^{[215,216]}$ In diesem Fall konnte die Reduktion bei Normaldruck und RT in $1 \mathrm{~h}$ durchgeführt werden. Aufgrund der Instabilität der entstandenen Amine war eine Aufarbeitung der Reaktion jedoch nicht möglich und die Reaktionslösung wurde lediglich über Celite filtriert. Dies hatte zu Folge, dass neben dem Amin noch Borsalze vorhanden waren und beim Trocknen nicht das gesamte $\mathrm{MeOH}$ entfernt werden konnte. In der nachfolgenden Haloform-Reaktion mit 2 zeigte sich ebenfalls, dass Verbindung 3 als Nebenprodukt entstand. Da auch die Zersetzung des Amins ein zusätzliches Problem darstellte, konnte $\mathbf{3 6}$ nur in schlechten Ausbeuten (25\%) erhalten werden (Schema 14, rechts oben).

Ausgehend von diesen Ergebnissen blieben für die Synthese von 36 nur zwei Varianten. Entweder musste bei der Reduktion auf Methanol als Lösemittel verzichtet werden, oder das entstehende Amin musste in situ in ein stabiles Zwischenprodukt umgewandelt werden. Dadurch könnte das $\mathrm{MeOH}$ vor der Haloform-Reaktion entfernt werden, ohne dass die Gefahr einer Zersetzung bestünde. Der Verzicht auf Methanol als Lösemittel war für den linearen Ansatz nur bedingt möglich, da eine Hydrierung in EE nichtvollständig verlief und auf DMF ebenfalls verzichtet werden sollte, weil dieses die Aufarbeitung der Reaktion deutlich erschweren würde. Aus diesem Grund wurde geprüft, ob es möglich war, Verbindung $\mathbf{3 6}$ ausgehend von Verbindung 20 aus zwei Dimeren aufzubauen (Schema 14, links unten). Hierzu musste 20 zu Verbindung $\mathbf{3 7}$ verseift werden (Schema 16). Daraufhin wurde 20 reduziert und im Anschluss mittels einer Peptidkupplung mit der Carbonsäure 37 verknüpft. Verbindung 36 konnte auf diese Weise in mäßigen Ausbeuten (49\%) erhalten werden. Allerdings war eine Reinigung der Verbindung 36 durch Präzipitation in diesem Fall nicht möglich, da in der Peptidkupplung schwerlösliche Nebenprodukte wie Diisopropylharnstoff entstanden, welche nicht abgetrennt werden konnten. Somit musste Verbindung 36 säulenchromatographisch gereinigt werden, was jedoch aufgrund der geringen Löslichkeit der Verbindung keine geeignete Methode darstellte und diese Syntheseroute somit nur als Notlösung dienen konnte. Da keine der getesteten Syntheserouten zufriedenstellend verlief, wurde daraufhin versucht, das aus $\mathbf{3 5}$ entstehende Amin in eine stabilere Form zu überführen. Analog zu den zuvor synthetisierten Dimeren wurde entstandene das Amin in situ mit $\mathrm{Boc}_{2} \mathrm{O}$ geschützt. Das 


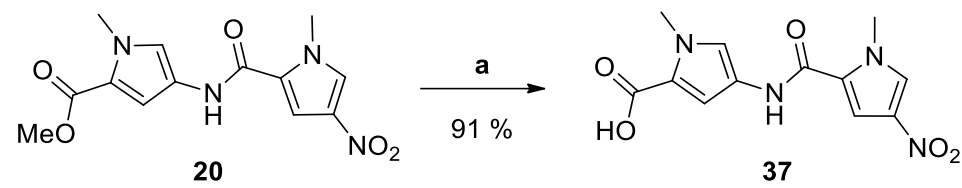

Schema 16: Synthese der Verbindung 37. a: $\mathrm{NaOH}_{\mathrm{aq}}$, EtOH, 1 h, Reflux.

resultierende Zwischenprodukt war ausreichend stabil, wodurch das $\mathrm{MeOH}$ entfernt werden konnte. Zur weiteren Umsetzung entfernte man die Boc-Gruppe mit TFA in DCM und in einer nachfolgenden Haloform-Reaktion wurde $\mathbf{3 6}$ in guten Ausbeuten erhalten $(71 \%$, Schema 14, rechts unten). Im Anschluss erfolgte die Verseifung zum Baustein 34 (Schema 17).

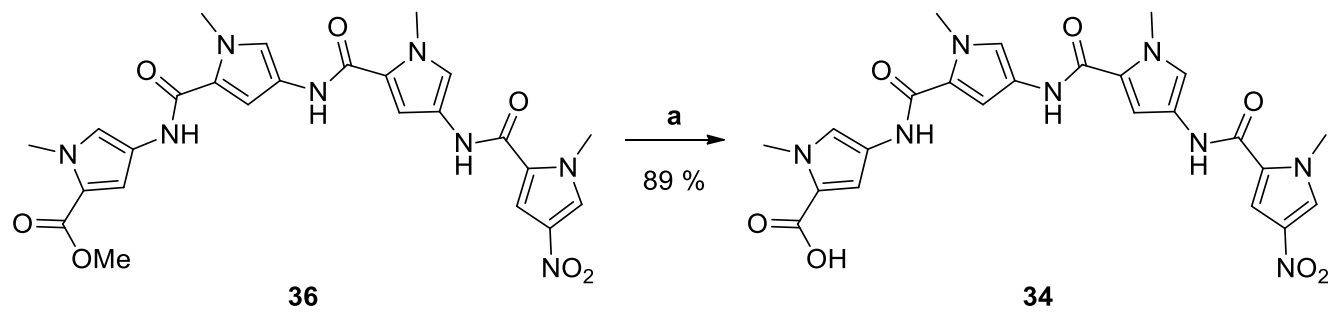

Schema 17: Synthese des Fragmetes B. a: $\mathrm{NaOH}_{\mathrm{aq}}, \mathrm{EtOH}, 1 \mathrm{~h}$, Reflux.

\subsubsection{Synthese der Fragmente $\boldsymbol{C}$}

Analog zur Synthese des Fragments B konnten auch die Fragmente C (39 und 41) linear oder aus zwei Blöcken aufgebaut werden. Da aus der Synthese des Polyamids PA1 bekannt war, dass das Fragment C (Im-Py-Py- $\gamma$-OMe) besser löslich war als das Fragment B. ${ }^{[12,153]}$ Zusätzlich war davon auszugehen, dass die Kupplung auf Im-Bausteine nicht sehr effektiv verlief, sodass der lineare Ansatz verworfen wurde. Als Ausgangsmaterial diente in beiden Fällen Verbindung 24, welche entschützt werden musste und dann mit den Verbindungen 17 oder $\mathbf{4 3}$ gekuppelt wurde (Schema 18). Im Gegensatz zur Synthese der Verbindung 36 musste die Entschützung der Verbindung 24 mit methanolischer $\mathrm{HCl}$

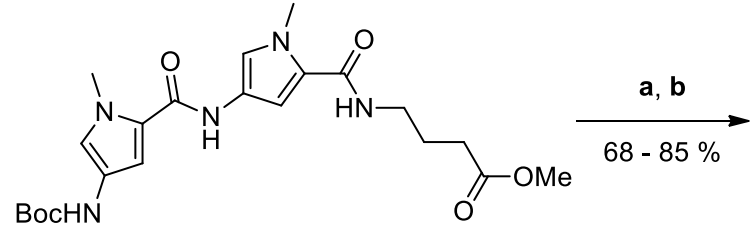

24

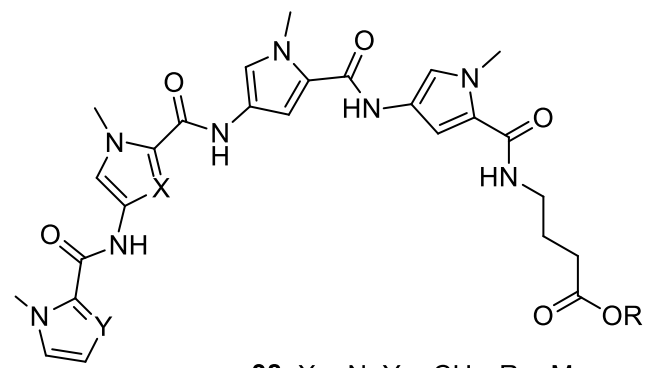

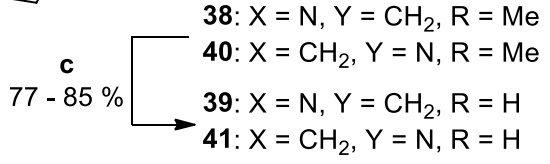

Schema 18: Synthese der Fragmente C. a: $\mathrm{AcCl}, \mathrm{MeOH}, 0^{\circ} \mathrm{C}$ auf $\mathrm{RT}, 1 \mathrm{~h}$; b: 17 oder 43, HBTU, DIPEA, DMF, RT; c: $\mathrm{LiOH} \bullet \mathrm{H}_{2} \mathrm{O}, \mathrm{MeOH} / \mathrm{H}_{2} \mathrm{O}, \mathrm{RT}$. 


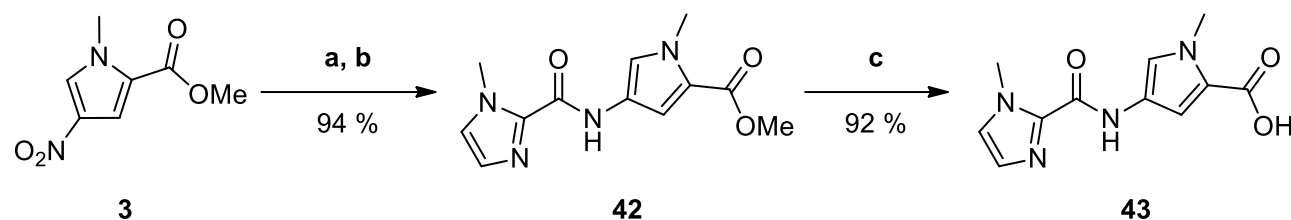

Schema 19: Synthese von Verbindung 43. a: $\mathrm{H}_{2}$ (1 bar), Pd/C, EE, RT; b: 6, DIPEA, RT; c: $\mathrm{NaOH}_{a q}$, EtOH, Reflux.

erfolgen, da ansonsten die Gefahr bestand, dass Reste der TFA in der Peptidkupplung reagierten, wodurch ein TFA-geschütztes Amin entstünde. Durch die Kupplung des Amins mit 17, sowie der anschließenden Verseifung mit LiOH, konnte 39 in guten Ausbeuten (je $85 \%$ ) erhalten werden. Für die Synthese von Verbindung 41 musste zunächst Verbindung $\mathbf{4 3}$ hergestellt werden. Dies geschah ausgehend von Verbindung 3, welche reduziert und im Anschluss in einer Haloform-Reaktion mit 8 zu Verbindung 42 umgesetzt wurde, welche man im Anschluss zur Carbonsäure $\mathbf{4 3}$ verseifte. Beide Reaktionen verliefen dabei in sehr guten Ausbeuten (>90\%, Schema 19). Die finale Kupplung zu Verbindung 40 verlief in moderaten Ausbeuten (68\%), während in der abschließenden Verseifung zu 41 gute Ausbeuten (77\%) erhalten wurden.

\subsubsection{Synthese der Polyamide}

Nachdem die benötigten Fragmente aufgebaut waren, mussten diese zu den vollständigen PIPs verknüpft werden. Dabei galt es, zunächst die Fragment $\mathbf{A}$ und $\mathbf{B}$ zu verknüpfen und im Anschluss mit $\mathbf{C}$ zu konjugieren. Hierbei musste man zunächst das PIP PA4 synthetisieren, dessen Aufbau mittels Festphasensynthese bisher nicht möglich war. In analoger Weise sollten dann PA3 und PA6 aufgebaut werden.

\subsubsection{Synthese von PA4}

Für die Synthese von PA4 wurden zunächst die Verbindungen $\mathbf{3 3}$ und $\mathbf{3 4}$ mittels einer Peptidkupplung zu Verbindung $\mathbf{4 4}$ verknüpft, wobei die Reaktion in guten Ausbeuten verlief (80 \%, Schema 20). Zum Aufbau des vollständigen PIPs wurde 44 in $\mathrm{MeOH}$ reduziert. Bei der Aufarbeitung der Reduktion konnte jedoch eine Braunfärbung der Lösung beobachtet werden, die auf eine Zersetzung des Amins hindeutete. Die Anschließende Kupplung mit Verbindung 39 verlief in schlechten Ausbeuten (27\%). Im Gegensatz zu der Synthese der Verbindung $\mathbf{3 6}$ war in diesem Fall keine in situ Schützung mit Boc möglich. Dies würde zu einer zweifach Boc-geschützten Verbindung führen, wodurch eine selektive Entschützung unmöglich und somit ein Aufbau des PIPs verhindert wäre. Somit musste eine alternative Methode gefunden werden, um die Zersetzung des Amins zu unterbinden. Da die Peptidkupplung zwischen dem Amin und 39 in DMF erfolgte, wurde sie in situ durchgeführt. 


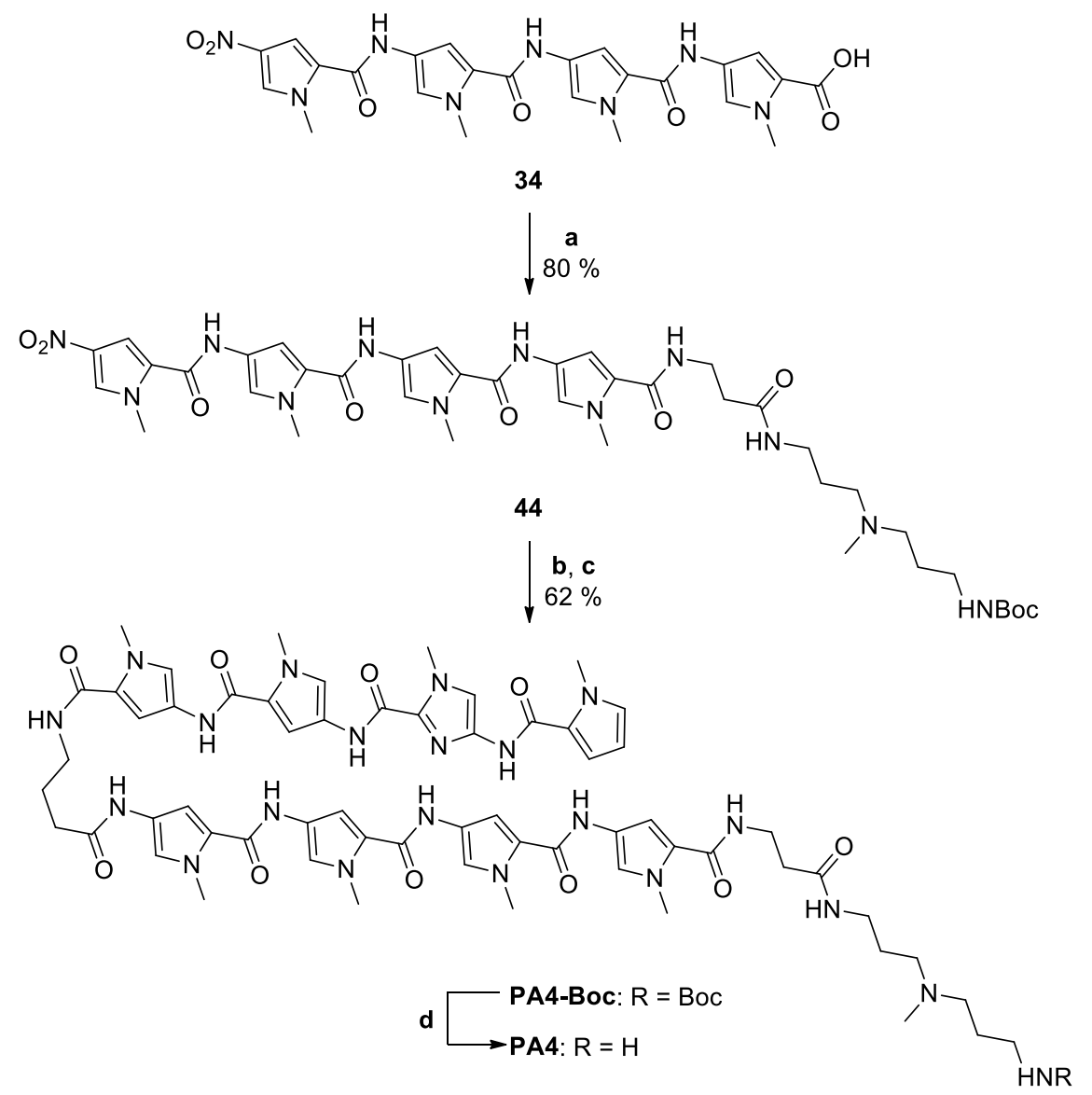

Schema 20: Synthese des Polyamids PA4. a: 33, HOBt, DIC, DIPEA, DMF, $60{ }^{\circ} \mathrm{C}$; b: $\mathrm{H}_{2}, \mathrm{Pd} / \mathrm{C}(1$ bar), DMF; c: $\mathbf{3 9}$, HBTU; DIPEA, DMF, RT, d: TFA/DCM, RT, quant.

Hierzu aktivierte man die Verbindung 39 in DMF und gab diese Lösung, nach Entfernen des Wasserstoffs, zu der Reduktionslösung. Auf diese Weise konnte PA4-Boc in ordentlichen Ausbeuten (62\%) erhalten werden und eine Zersetzung des Amins war nicht zu beobachten. PA4 konnte daraufhin durch Entfernen der Boc-Gruppe mit TFA in DCM erhalten werden. Eine Analyse per rp-HPLC zeigte, dass das Rohprodukt nur geringe Verunreinigungen aufwies (Abbildung 33) und PA4 ohne weitere Reinigung zur Synthese der Konjugate eingesetzt werden kann.

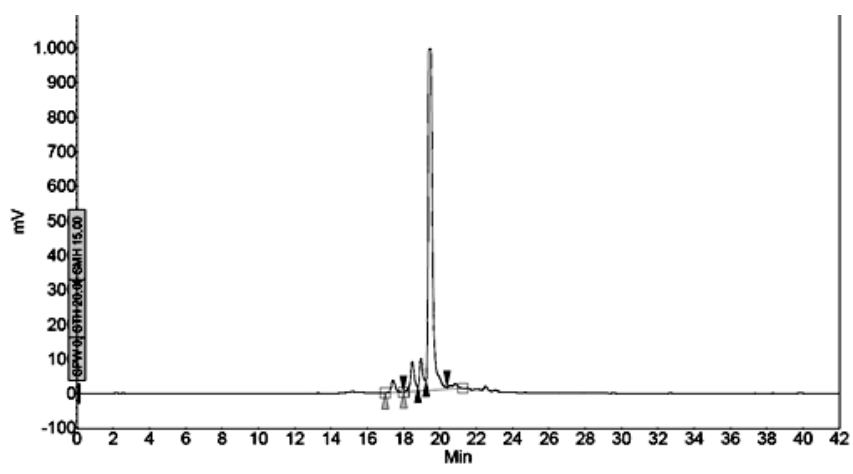

Abbildung 33: HPLC-Chromatogramm des Rohproduktes von PA4. Laufbedingungen: Linearer Gradient von $10 \%$ B zu $70 \%$ $B$ in 30 min. A: $0.1 \%$ TFA in $\mathrm{H}_{2} \mathrm{O}$; $\mathrm{B}$ : ACN. 


\subsubsection{Synthese von PA3}

Die Synthese des PIPs PA3 sollte analog zu der von PA4 durchgeführt werden, jedoch waren $60^{\circ} \mathrm{C}$ als Temperatur der abschließenden Peptidkupplung vorgesehen. Hierdurch sollten mögliche $\pi$ - $\pi$-Wechselwirkungen der Fragmente verhindert werden und dies zu einer höheren Ausbeute führen. Allerdings konnte PA3-Boc nach der Reaktion von $\mathbf{3 5}$ mit $\mathbf{4 1}$ nur in schlechten Ausbeuten erhalten werden (27\%, Schema 21). Die genaue Ursache hierfür fand sich leider nicht. Allerdings musste das Rohprodukt mehrfach säulenchromatographisch gereinigt werden, was zumindest einen Teil der Verluste erklärt. PA3 erhielt man durch die Entschützung mit TFA in DCM. Auch in diesem Fall konnte das PIP direkt zur Synthese der Konjugate verwendet werden.
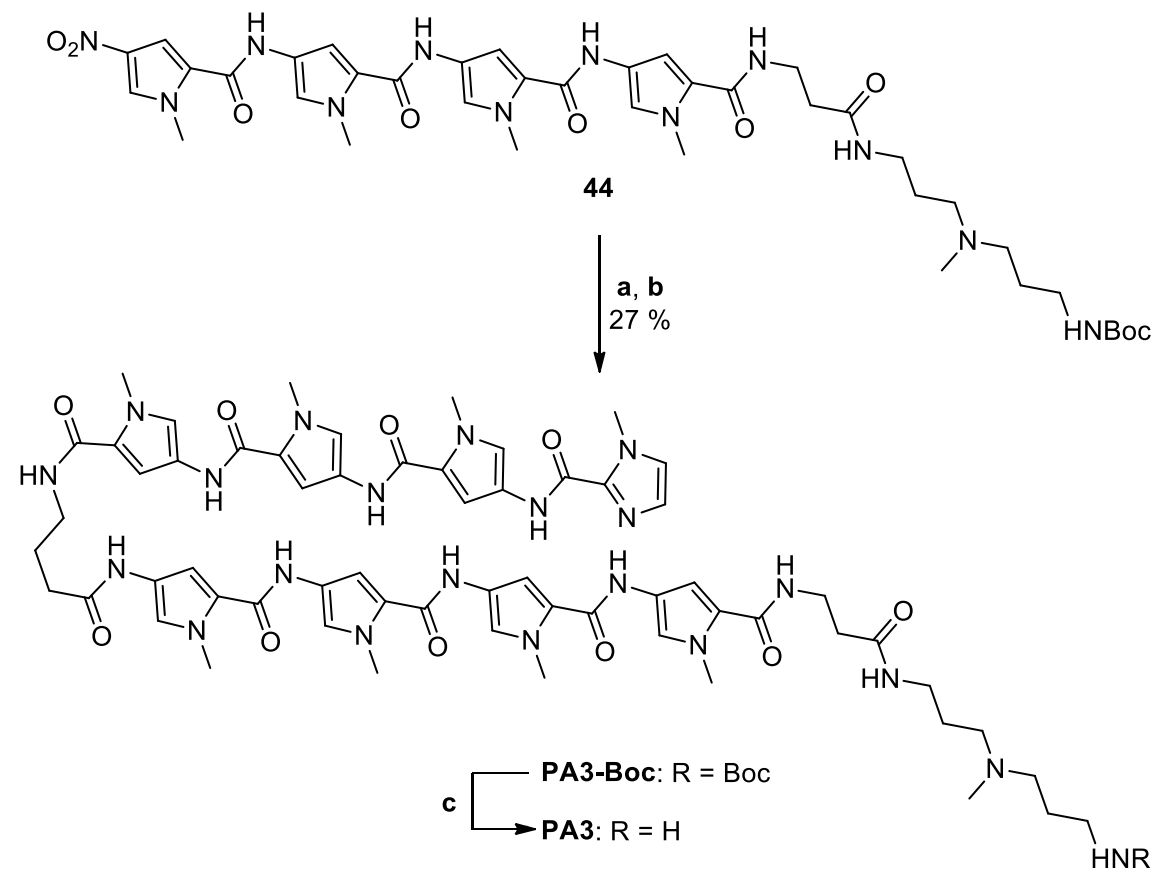

Schema 21: Synthese von PA3. a: $\mathrm{H}_{2}$ (1 bar), Pd/C, DMF, RT; b: 41, HBTU, DIPEA, DMF, $60{ }^{\circ} \mathrm{C}$; c: TFA/DCM, RT, quant.

\subsubsection{Synthese von PA6}

Das PIP PA6 wurde in Analogie zu PA4 und PA3 aufgebaut. Hierzu wurde zunächst Verbindung 34 mit 31 zu 45 umgesetzt (Schema 22). Im Anschluss erfolgte eine Reduktion in DMF und das entstandene Amin wurde in situ mit Verbindung 39 umgesetzt. Auch in diesem Fall wurde die Kupplung bei $60^{\circ} \mathrm{C}$ durchgeführt und PA6-Boc konnte in guten Ausbeuten (73\%) erhalten werden. Durch Entfernen der Boc-Gruppe mit TFA in DCM erhielt man im Anschluss PA6, welches ebenfalls direkt zum Aufbau der Konjugate verwendet werden konnte. 


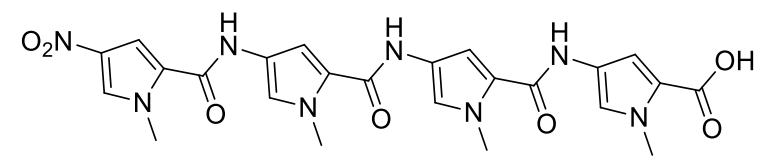

34
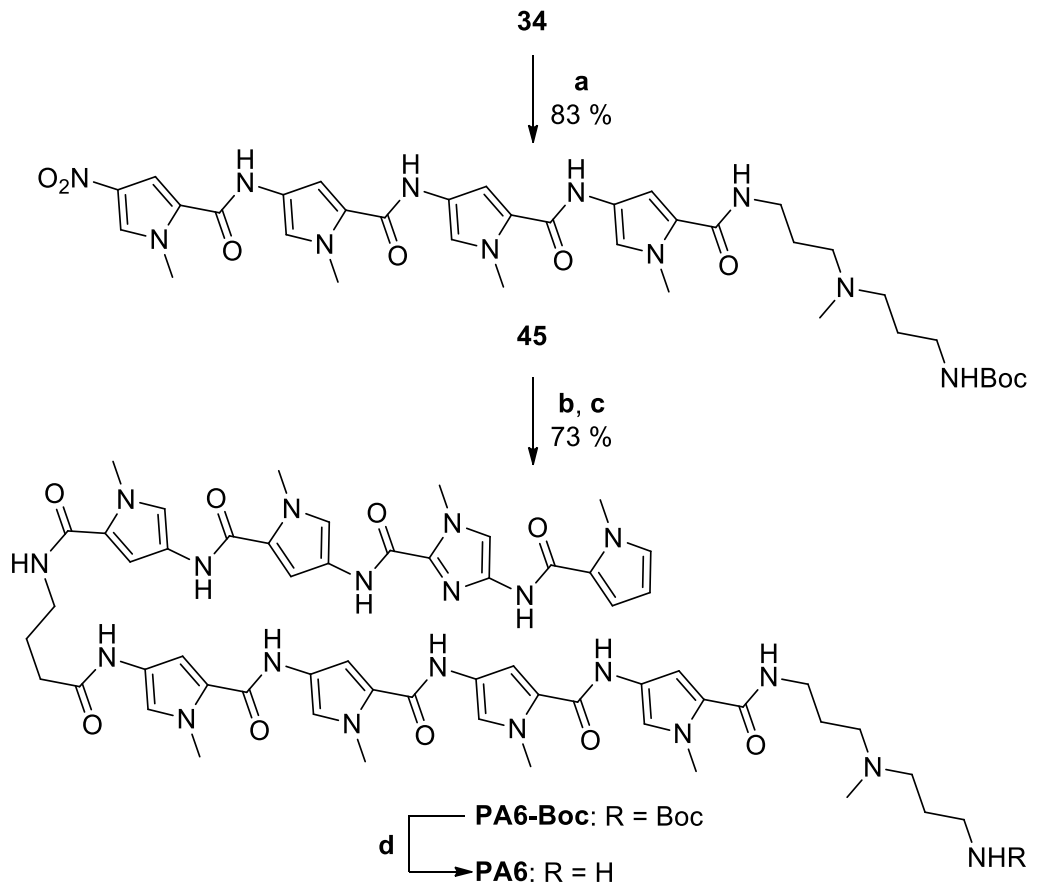

Schema 22: Synthese von PA6. a: 31, HOBt, DIC, DIPEA, DMF, $60{ }^{\circ} \mathrm{C}$; b: $\mathrm{H}_{2}$, Pd/C, DMF, RT; c: 39, HOBt, DIC; DIPEA, $60{ }^{\circ} \mathrm{C}$, d: TFA/DCM, RT, quant. 


\subsection{Synthese der Konjugate}

Die Konjugation der zuvor synthetisierten Polyamide erfolgte nach einer Methode von Kubo et al. (Schema 23). ${ }^{[217]}$ Dabei wurde eine auf fester Phase gebundene DNA mit Aminolinker zunächst mit Hexamethylendiisocyanat umgesetzt. Daran schloss sich die Reaktion mit dem Polyamid an. Nach der Abspaltung der DNA vom Träger konnte das Konjugat erhalten werden. In meiner Masterarbeit konnte ich zeigen, dass die Synthese des Konjugats K1 möglich war (Abbildung 35). Allerdings gab es Probleme bei der Reinigung mittels rp-HPLC und das Konjugat konnte nicht hinreichend von den Edukten sowie einem nicht charakterisierten Nebenprodukt getrennt werden ${ }^{[12]}$ Als eine alternative Methode wurde die denaturierende Polyacrylamid-Gelelektrophorese (dPAGE) in Betracht gezogen und in ersten Versuchen erschien eine Trennung möglich. Wie erhofft konnten mittels einer präparativen dPAGE drei Banden isoliert werden (Abbildung 34). Dabei war bereits bekannt, dass die unterste Bande aus DNA 2, sowie dem Produkt aus der Kupplung mit dem Diisocyanat bestand (Lane 2). Im Gegensatz dazu zeigte K1 ein langsameres Laufverhalten (Lane 3) und die oberste der Banden konnte durch Massenspektrometrie als Dimer der DNA 2 identifiziert werden. Dieses entsteht durch Verknüpfung des Diisocyanats mit den Aminoenden zweier benachbarter DNA-Stränge.

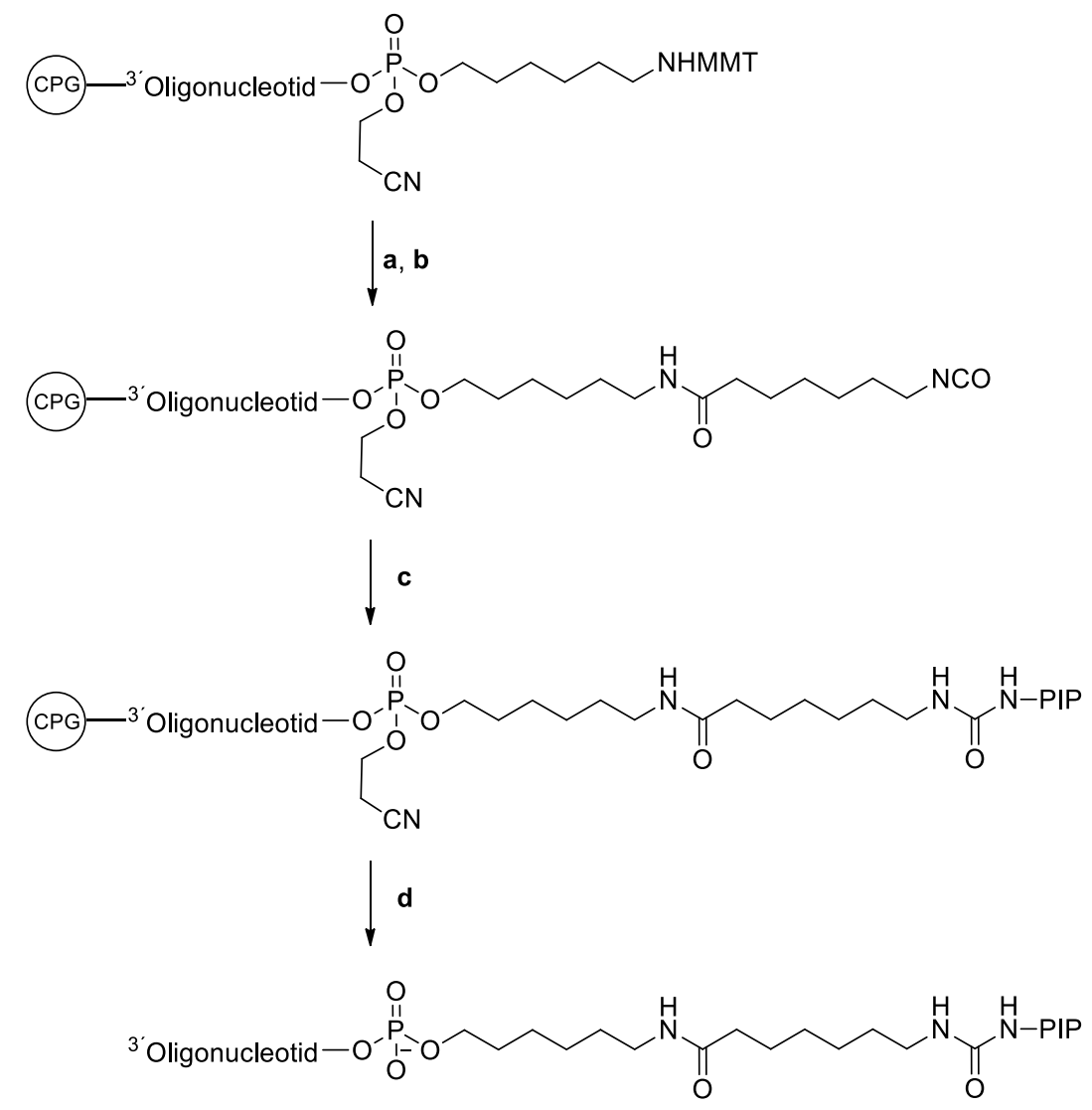

Schema 23: Allgemeines Vorgehen für die Synthese der Konjugate. a: $3 \%$ TFA oder TCA in DCM; b: OCN- $\left(\mathrm{CH}_{2}\right)_{6}-\mathrm{NCO}$, DIPEA, ACN, RT; c: PIP-NH 2 , DIPEA, ACN/MeOH oder DMF, d: $\mathrm{NH}_{3}\left(32 \%\right.$ ig), $55^{\circ} \mathrm{C}$. 


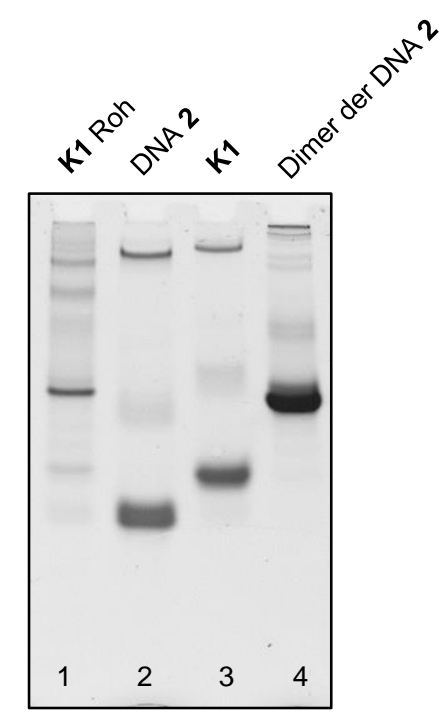

Abbildung 34: Denaturierende PAGE nach der Trennung von K1 mittels präparativer PAGE. Dieses Gel ist repräsentativ für die Trennung der PIPs PA2 - PA8. Lane 1: Rohprodukt; Lane 2: unkonjugierte DNA 2; Lane 3: K1; Lane 4: Dimer der DNA 2. $16 \%$ dPAGE. Die Detektion der Banden erfolgte durch Färbung mit SYBR Gold, die Charakterisierung durch Massenspektrometrie.

Nachdem eine Methode zur Synthese und Reinigung der Konjugate etabliert war, wurden als nächstes die Konjugate K2 und K3 aus der DNA 2 und den Polyamiden PA2 und PA3 synthetisiert (Abbildung 35). Jedoch zeigte sich in späteren Experimenten, dass ein Duplex aus der DNA 2 und DNA 3 nicht für die Konjugate geeignet war, da dieser Mismatch-Bindestellen für die PIPs aufwies und so ihre Affinität verringerte (Abschnitt 7.3.1). Aus diesem Grund wurden Konjugate auf Basis der DNA 4 verwendet, die keine Bindestelle für die PIPs enthielt (Abbildung 36). Mit dieser Sequenz konnte in einer Arbeit von Raiber et al. die Bindung von Sp1 nachgewiesen werden. ${ }^{[218]}$ Zunächst wurde K4 aus der DNA 4 und PA2 synthetisiert, um zu prüfen, ob auch die Verwendung DNA 4 zu Selbstbindungen führte. Nachdem dies nicht der Fall war, wurde die DNA 4 im Anschluss mit PA4 zu K5, mit PA5 zu K6, mit PA6 zu K7 und mit PA3 zu K8 umgesetzt (Abbildung 36). Darüber hinaus wurde K9 aus PA4 und DNA 6 aufgebaut, welches in Zellkulturexperimenten eingesetzt werden sollte. Die DNA 6 stellte dabei einen hairpin aus den DNAs $\mathbf{4}$ und $\mathbf{5}$ dar, der einen stabileren Duplex ausbilden und eine höhere Stabilität gegenüber Nukleasen besitzen sollte. Aufgrund der längeren Sequenz der DNA 6 war
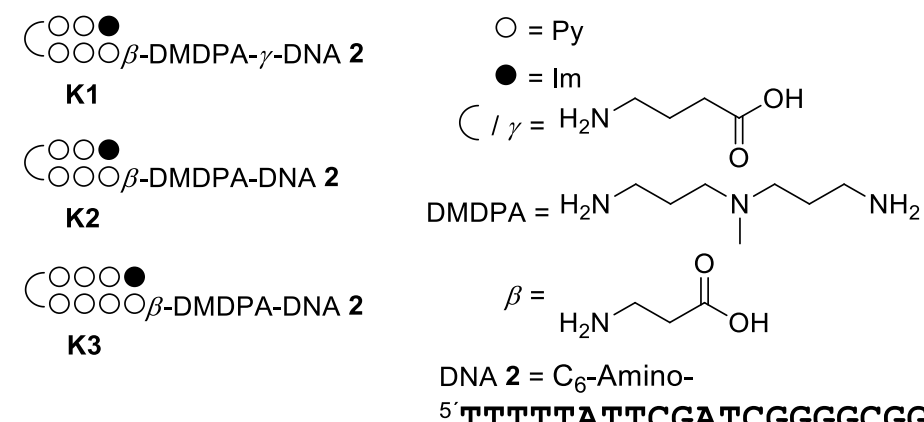

5'TTTTTATTCGATCGGGGCGGGGCGAGC

Abbildung 35: Struktur der Konjugate K1 - K3. 


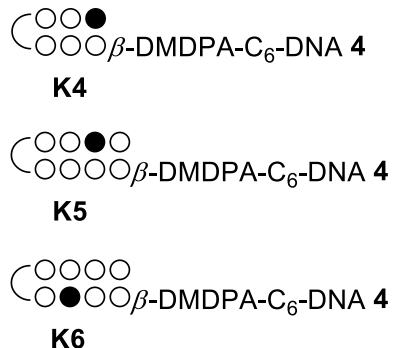

K6

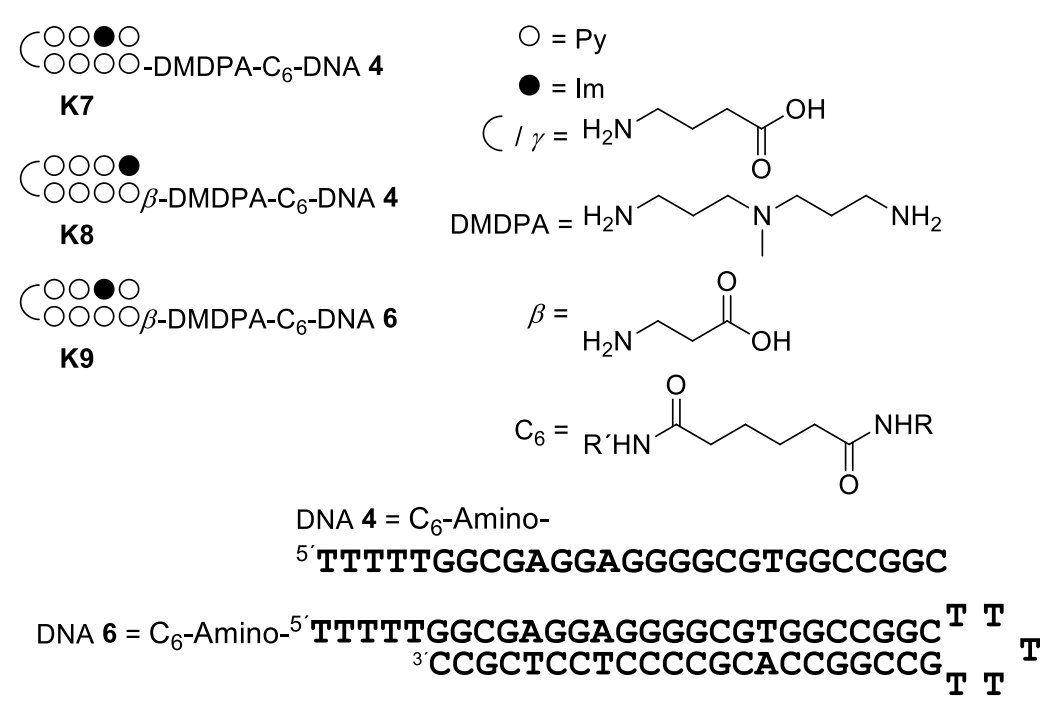

Abbildung 36: Sequenzen der Konjugate K4 - K9.

jedoch die dPAGE-Reinigung des Adaptors K9 problematisch, da der Laufunterschied zwischen Konjugat und unkonjugierter DNA zu gering für eine saubere Trennung war. Dementsprechend konnte nach der dPAGE noch ein deutlicher Anteil der DNA 6 beobachtet werden (Abbildung 37, a). Dies erforderte eine weitere Reinigung, welche mittels rp-HPLC erfolgte (Abbildung 37, b). Eine anschließende Analyse mittels analytischer dPAGE zeigte, dass $\mathbf{K 9}$ nun in hoher Reinheit vorlag (Abbildung 37, c). Auch die Charakterisierung des Konjugats gestaltete sich schwierig, da aufgrund der höheren molekularen Masse der Verbindung ein massenspektrometrischer Nachweis des Konjugats nicht möglich war. Jedoch konnte sowohl in der dPAGE als auch in der rp-HPLC ein retardiertes Laufveralten gegenüber der unkonjugierten DNA beobachtet werden, was ein

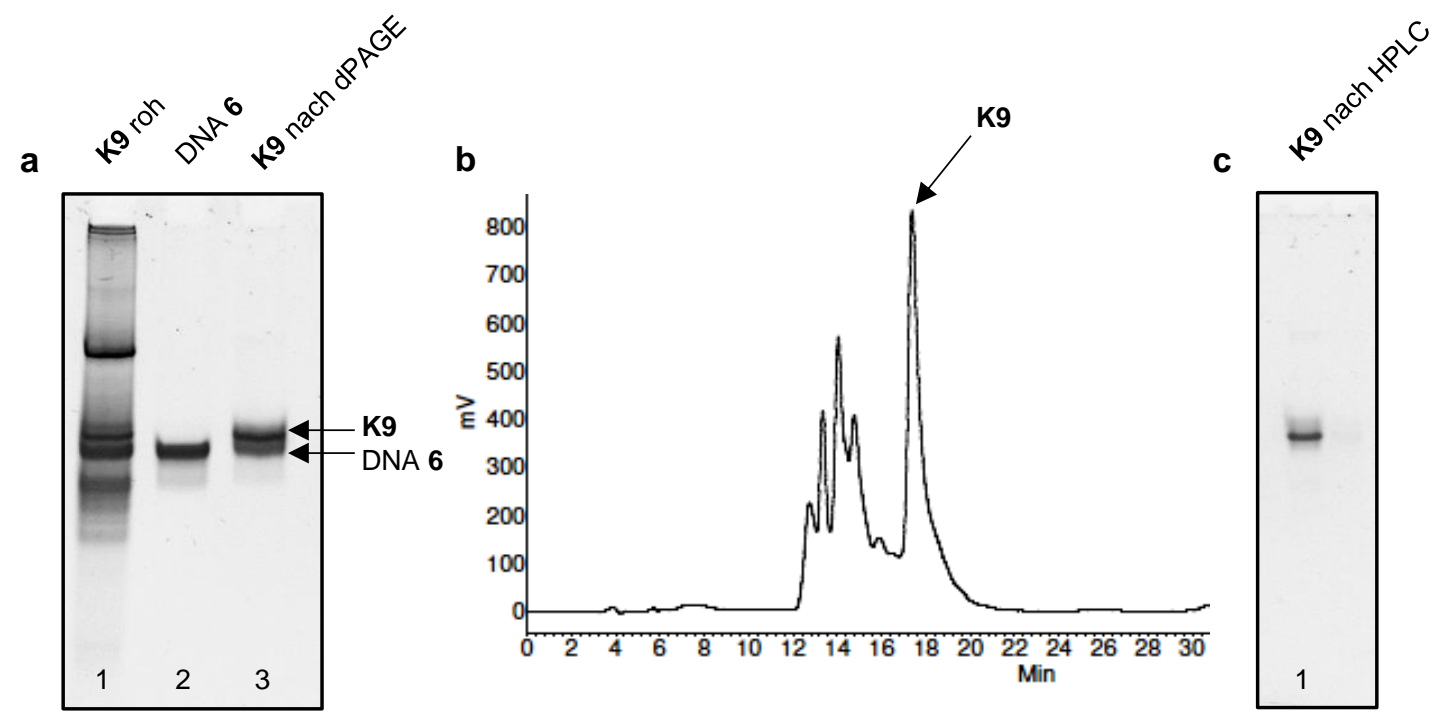

Abbildung 37: Reinigung des Konjugats K9 mittels dPAGE und HPLC. a: Analytik des Konjugats nach der Reinigung mittels dPAGE. Lane 1: Rohprodukt der Reaktion; Lane 2: Isolierte DNA 6; Lane 3: Isoliertes Konjugat K9. b: Chromatogramm der rp-HPLC-Trennung von K9. Dabei entspricht das Signal nach $17 \mathrm{~min}$ dem Konjugat. c: Analytik des Konjugats nach der Reinigung mittel HPLC. 16\% dPAGE. Die Detektion der Banden erfolgte durch Färbung mit SYBR Gold. Laufbedingungen $r p$-HPLC: Linearer Gradient von $10 \%$ B zu $40 \%$ B in 25 min. A: $0.1 \mathrm{M}$ TEAA in $\mathrm{H}_{2} \mathrm{O}$; B: $0.1 \mathrm{M}$ TEAA in ACN. 
deutlicher Hinweis auf ein Konjugat war. Ein weiterer Hinweis konnte aus der UV/VIS-Spektroskopie gewonnen werden. Dort war eine, dem Absorptionsmaximum eines PIPs entsprechende, Absorption bei $320 \mathrm{~nm}$ zu beobachten. ${ }^{[154]}$ Des Weiteren konnte gezeigt werden, dass das Konjugat an die Ziel-DNA 1 band (Abschnitt 7.3.1, Abbildung 47) und sein Verhalten dem des analogen Konjugats K5a entsprach, das aus K5 und der DNA 5 gebildete wurde (Abbildung 38). Zusammengenommen weist dies auf die Identität des Konjugats K9 hin.

Für die Umleitung von Sp1 war es zudem notwendig, die einzelsträngigen Konjugate K1 - K8 mit ihren Gegensträngen zu hybridisieren. Dies erfolgte für die Konjugate K1 - K3 mit DNA 3 und für die Konjugate K4 - K8 mit DNA 5 (Abbildung 38).

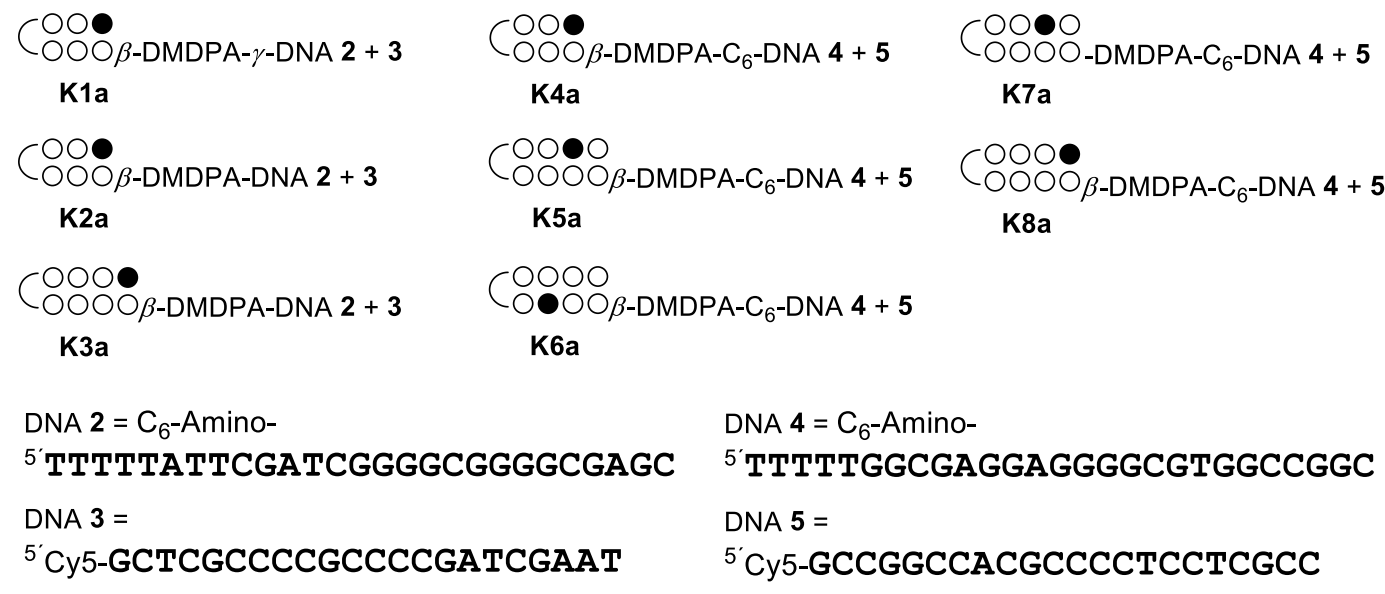

Abbildung 38: Sequenzen der doppelsträngigen Konjugate K1a - K8a. 


\subsection{Experimente zur Umleitung von Sp1 auf eine AT-reiche Sequenz}

Bevor mit den Umleitungsexperimenten begonnen werden konnte, musste die Bindung der Konjugate an die DNA 1 anhand von Band-Shift-Experimenten bestätigt werden. Im Anschluss sollte der an GC-reiche Sequenzen bindende TF Sp1 in einem in vitro-Assay auf die AT-reiche DNA 1 umgeleitet werden. Dazu sollten Pulldown-Experimente durchgeführt werden. Für diese wurde die biotinylierte DNA 1 an Streptavidin beladene Magnetic Beads gebunden. Nach der Inkubation mit einem Adaptor oder Sp1 konnten die Beads mit einem Magnetstand gesammelt, ungebundenes Material durch Waschen der Beads entfernt werden. Zunächst waren Pulldown-Experimente mit Cy5-gelabelten Adaptoren geplant, um eine geeignete Inkubationszeit zu ermitteln und die Zahl der Waschschritte zu optimieren. Hierzu wurden nach Beendigung des Experiments die DNA-Stränge des Konjugats durch Erhöhen des pH-Werts getrennt und die Fluoreszenz der Cy5-gelabelten Stränge detektiert. Zur besseren Vergleichbarkeit mussten die erhaltenen Werte normiert werden und hierfür galt es ein geeignetes Bezugsystem zu finden. Für die Umleitung von Sp1 folgte nach dem Waschen der Beads eine SDS-PAGE mit anschließendem Western-Blot und Sp1 wurde durch spezifische Antikörper nachgewiesen.

\subsubsection{Band-Shift-Experimente}

Nachdem in meiner Masterarbeit bereits mit dem verunreinigten Konjugat K1 eine Bindung an die DNA 1 nachgewiesen wurde, ${ }^{[12]}$ konnte das gereinigte Konjugat eingesetzt werden, um das Bindeverhalten genauer zu untersuchen. Hierbei galt es insbesondere, Verhältnisse zwischen DNA 1 und Konjugat zu ermitteln, bei denen eine Bindung nachzuweisen war. Des Weiteren verlangte der Befund, dass K1a eine geringere Affinität als K1 aufwies, eine genauere Untersuchung. Durch den Vergleich von K1 und K1a mit den Konjugaten K2 und K2a sollte der Einfluss eines verkürzten Linkers auf die Bindung an DNA 1 betrachtet werden.

\subsubsection{Experimente mit den Konjugaten $\mathbf{K} \mathbf{1}-\mathbf{K} \mathbf{3}$}

Da sich in meiner Masterarbeit zeigte, dass die Anwesenheit von $\mathrm{Mg}^{2+}$-lonen im Puffer keinen Einfluss auf die Stabilität der Bindung des Konjugats an DNA 1 hatte, ${ }^{[12]}$ wurden die Experimente zur besseren Vergleichbarkeit in 0.5x SSPE-Puffer durchgeführt. Erste Versuche mit $\mathbf{K} \mathbf{1}$ zeigten, dass ein fünffacher Überschuss des Konjugats $\mathbf{K} \mathbf{1}$ zu einer deutlichen Abnahme der Bande der DNA 1 und zu einem retardierten Laufverhalten der ON führte. Auf Grundlage dieser Ergebnisse wurden die Konjugate K1 und K2 verglichen 


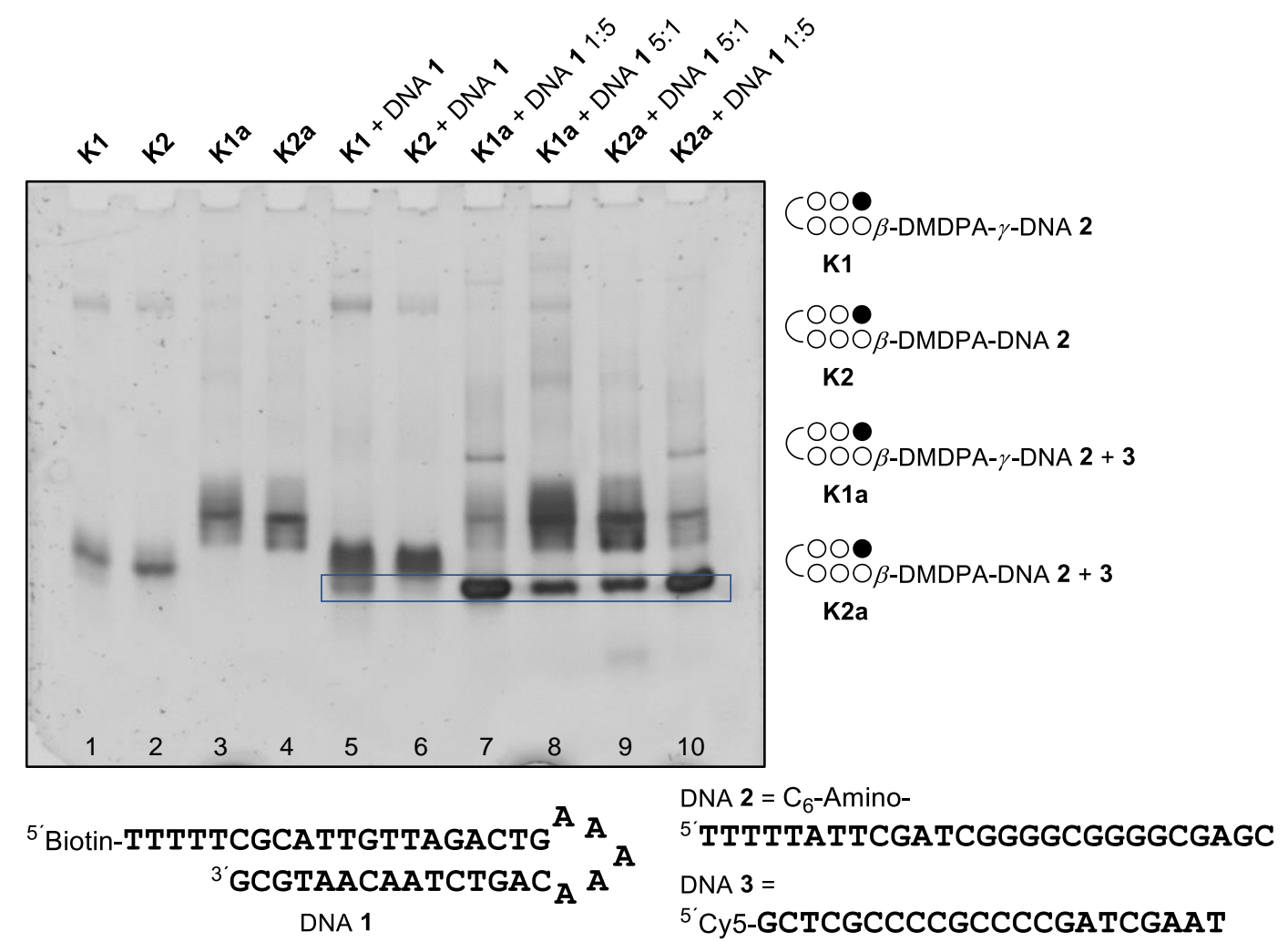

Abbildung 39: Band-Shift-Experimente mit K1 und K2, sowie K1a und K2a. Lane 1: K1 (2 $\mu$ M); Lane 2: K2 (2 $\mu$ M); Lane 3: K1a $(1 \mu \mathrm{M})$; Lane 4: K2a $(1 \mu \mathrm{M})$; Lane 5: DNA $1(0.5 \mu \mathrm{M})+\mathrm{K} 1(2.5 \mu \mathrm{M})$; Lane 6: DNA $1(0.5 \mu \mathrm{M})+\mathrm{K2}(2.5 \mu \mathrm{M})$; Lane 7 : DNA $1(2.5 \mu \mathrm{M})+\mathrm{K1a}(0.5 \mu \mathrm{M})$; Lane 8: DNA $1(0.5 \mu \mathrm{M})+\mathrm{K1a}(2.5 \mu \mathrm{M})$; Lane 9: DNA $1(0.5 \mu \mathrm{M})+\mathrm{K} 2 \mathrm{a}(2.5 \mu \mathrm{M})$; Lane 10: DNA $1(2.5 \mu \mathrm{M})+\mathrm{K} 2 \mathrm{a}(0.5 \mu \mathrm{M})$. Die Proben wurden $3 \mathrm{~h} 0.5 \mathrm{x}$ SSPE bei RT inkubiert. $16 \%$ nativ PAGE. Die Detektion der Banden erfolgte durch Färbung mit SYBR Gold. Die Bande der DNA 1 ist blau eingerahmt.

(Abbildung 39). Es zeigte sich, dass ein fünffacher Überschuss an K2 einen vollständigen Shift der DNA 1 bewirkte (Lane 6, blauer Kasten), während unter Verwendung von K1 noch eine schwache Bande der DNA 1 zu beobachten war (Lane 5, blauer Kasten). In nachfolgenden Experimenten zeigte sich, dass K2 bereits mit vier Äquivalenten eine vollständige Bindung an die DNA 1 aufwies und somit auf eine höhere Affinität als K1 geschlossen werden konnte.

Im Anschluss daran wurden die durch Hybridisierung mit DNA 3 erhaltenen Konjugate K1a und K2a untersucht. Diese wurden entweder in einem fünffachen Überschuss (Lane $8+9$ ) oder fünffachem Unterschuss (Lane $7+10$ ) zur DNA 1 verwendet. Es konnte jedoch in keinem der Fälle eine Bindung an die Zielsequenz beobachtet werden. Zusätzlich zeigte sich, dass die Banden der Konjugate sehr breit waren (Lane $3+4)$, was den zuvor in unserer Gruppe erhaltenen Ergebnissen entsprach. ${ }^{[12]}$ Im Fall von K2a konnten dabei mehrere Banden beobachtet werden (Lane 4), welche nicht eindeutig zuzuordnen waren. Eine Vermutung war jedoch, dass diese Banden durch Sekundärstrukturen der Konjugate hervorgerufen wurden. Um diese Vermutung zu bestätigen, wurde der Duplex aus DNA 2 und 3 auf Bindestellen für die PIPs untersucht. Dabei konnten Mismatch-Bindestellen gefunden werden (Abbildung 40, oben). In diesen Fällen war für die $\beta$-Einheit der PIPs nur 


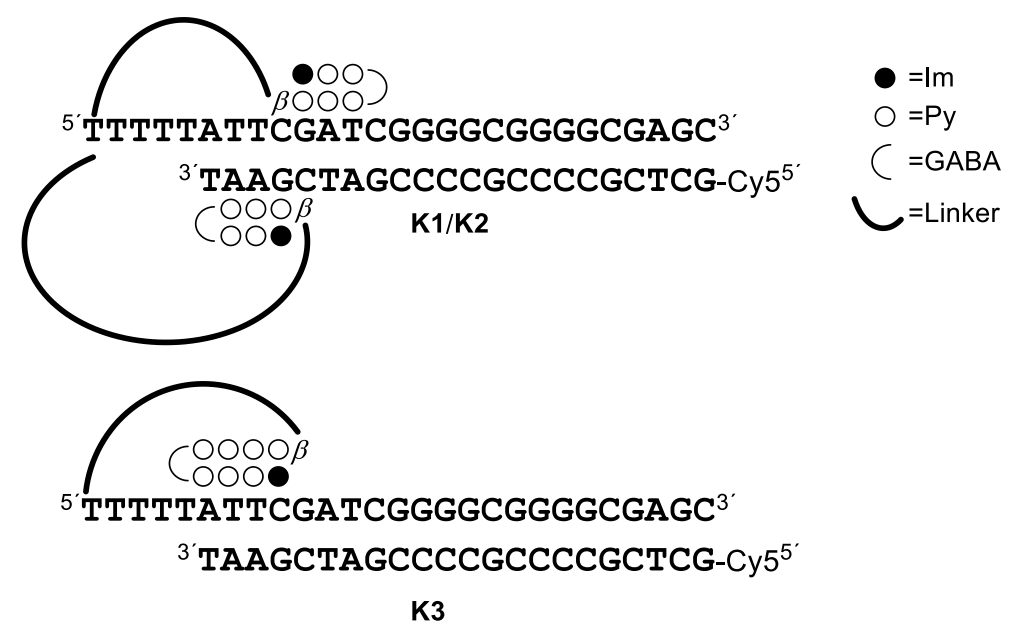

Abbildung 40: Beispiele für die intramolekulare Wechselwirkung der Konjugate K1, K2 und K3.

eine Wechselwirkung mit G oder C möglich, wodurch die Affinität der PIPs für diese Stellen deutlich herabgesetzt wird. ${ }^{[131]} \mathrm{Da}$ es sich jedoch um intramolekulare Wechselwirkungen handelte, war eine Selbstbindung dennoch möglich und führte zu einer Inhibierung des Adaptors. Aufgrund dieser Ergebnisse wurden die Experimente mit den Konjugaten K1 und K2 eingestellt, da die Sequenz des Duplex aus DNA 2 und $\mathbf{3}$ nicht für Konjugate mit Sechsmer-PIPs geeignet war.

Analog zu K1 und K2 waren auch für die Konjugate mit längeren PIPs intramolekulare Wechselwirkungen zu erwarten (Abbildung 40, unten). Um diese Vermutung zu bestätigen, wurden Experimente mit den Konjugaten K3 und K3a durchgeführt. Diese besaßen zwar auf der DNA 1 nur eine Mismatch-Bindestelle, da die Affinität der Achtmer-PIPs deutlich über der der Sechsmer-PIPs liegt, ${ }^{[14]}$ war eine Bindung von K3 an die DNA 1 aber nicht auszuschließen. In den Band-Shift-Experimenten konnte dies bestätigt werden (Abbildung 41, Lane 4-8) und ab einem vierfachen Überschuss war die Bande der DNA 1 nicht mehr zu beobachten (Lane 7, blauer Kasten). Somit lag die Affinität des Konjugats K3 im Bereich der Konjugate K1 und K2. Analog zu K2a wies das entsprechende Konjugat K3a mehrere Banden auf (Lane 3), welche auf intramolekulare Wechselwirkungen hindeuteten, und zeigte keine Bindung an die DNA 1. Eine Möglichkeit die Selbstinhibierung der Konjugate zu verhindern, wäre es, die DNA 3 an ihrem 3'-Ende um mehrere Nukleotide zu verkürzen. Auf diese Weise würde die Bindestelle der PIPs aus den Adaptoren entfernt, wodurch diese eine höhere Affinität zu DNA 1 aufweisen sollten. Dieser Ansatz hätte jedoch längere einzelsträngige Bereiche in den Adaptoren zur Folge, wodurch eine geringere Nukleasestabilität zu erwarten war. Aus diesem Grund wurde dieser Ansatz verworfen und es wurden keine weiteren Konjugate auf Basis der DNA 2 aufgebaut. 


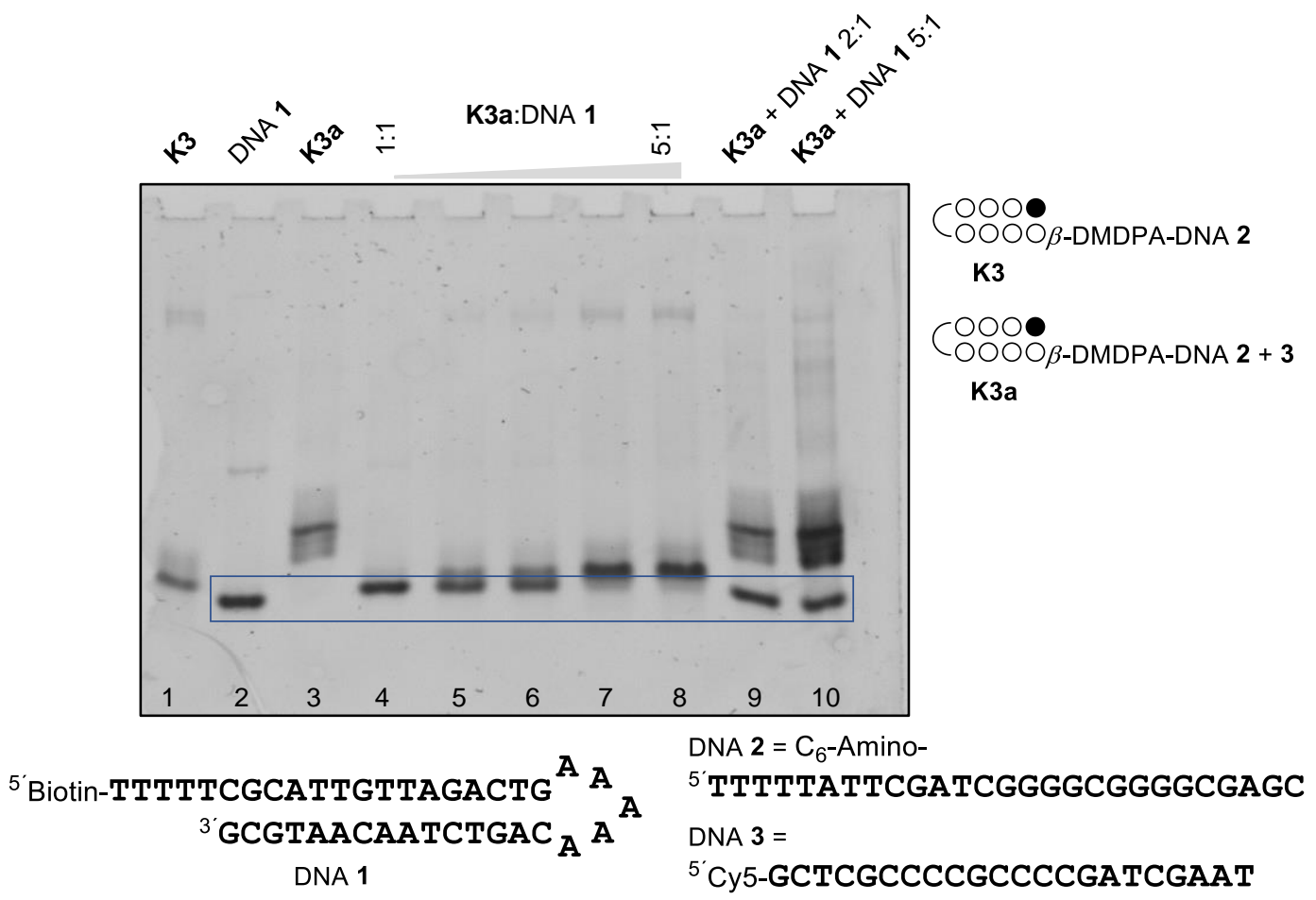

Abbildung 41: Band-Shift-Experiment mit K3 und K3a. Lane 1: K3 $(2 \mu \mathrm{M})$; Lane 2: DNA $1(0.5 \mu \mathrm{M})$; Lane 3: K3a (1 $\mu \mathrm{M})$; Lane 4: DNA $1(0.5 \mu \mathrm{M})+$ K3 $(0.5 \mu \mathrm{M})$; Lane 5: DNA $1(0.5 \mu \mathrm{M})+$ K3 $(1 \mu \mathrm{M})$; Lane 6: DNA $1(0.5 \mu \mathrm{M})+$ K3 $(1.5 \mu \mathrm{M})$; Lane 7: DNA $1(0.5 \mu \mathrm{M})+\mathrm{K} 3(2 \mu \mathrm{M})$; Lane 8: DNA $1(0.5 \mu \mathrm{M})+\mathrm{K3}(2.5 \mu \mathrm{M})$; Lane 9: DNA $1(0.5 \mu \mathrm{M})+\mathrm{K3a}(1 \mu \mathrm{M})$; Lane 10: DNA 1 $(0.5 \mu \mathrm{M})+\mathrm{K} 3 \mathrm{a}(2.5 \mu \mathrm{M})$. Die Proben wurden in 0.5x SSPE $2 \mathrm{~h}$ bei RT inkubiert. $16 \%$ nativ PAGE. Die Detektion der Banden erfolgte durch Färbung mit SYBR Gold. Die Bande der DNA 1 befindet sich im blauen Kasten.

\subsubsection{Experimente mit den Konjugaten $\mathbf{K} \mathbf{4}-\mathbf{K} \mathbf{9}$}

Nachdem die DNA 2 nicht zum Aufbau der Konjugate geeignet war, da sich die resultierenden Adaptormoleküle selbst inhibierten, musste eine neue DNA für die Umleitung von Sp1 gewählt werden. Dazu war am 5'-Ende eine deutlich von DNA 2 verschiedene Sequenz erforderlich, da die internen Wechselwirkungen durch diesen Bereich zustande kamen (Abbildung 42, rot unterlegt). Aus diesem Grund wählte man die DNA 4, welche bereits in einer Arbeit der Balasubramanian-Gruppe zur Isolierung von Sp1 eingesetzt wurde $^{[218]}$ und zudem keine Bindestellen für die PIPs aufwies. Aus DNA 4 wurde zunächst das zu K2 analoge Konjugat K4 aufgebaut und in Band-Shift-Experimenten auf seine Funktion getestet. Dabei wies K4 ab einem dreifachen Überschuss eine gute Bindung an die DNA 1 auf und war mit dem Konjugat K2 vergleichbar. Dennoch war in manchen Fällen auch bei einem vierfachen Überschuss kein vollständiges Verschwinden der DNA 1 zu

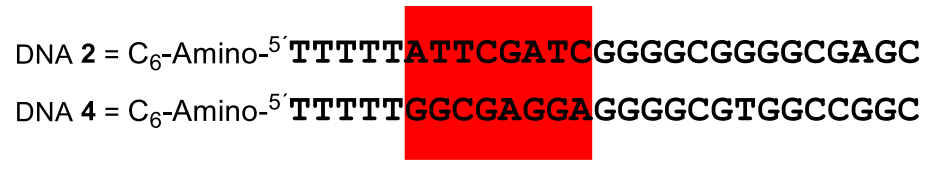

Abbildung 42: Vergleich der DNAs 2 und 4. Im Fall der DNA 4 unterschied sich die Sequenz deutlich von dem Teil der DNA 2 , der für die intramolekularen Wechselwirkungen verantwortlich war. 


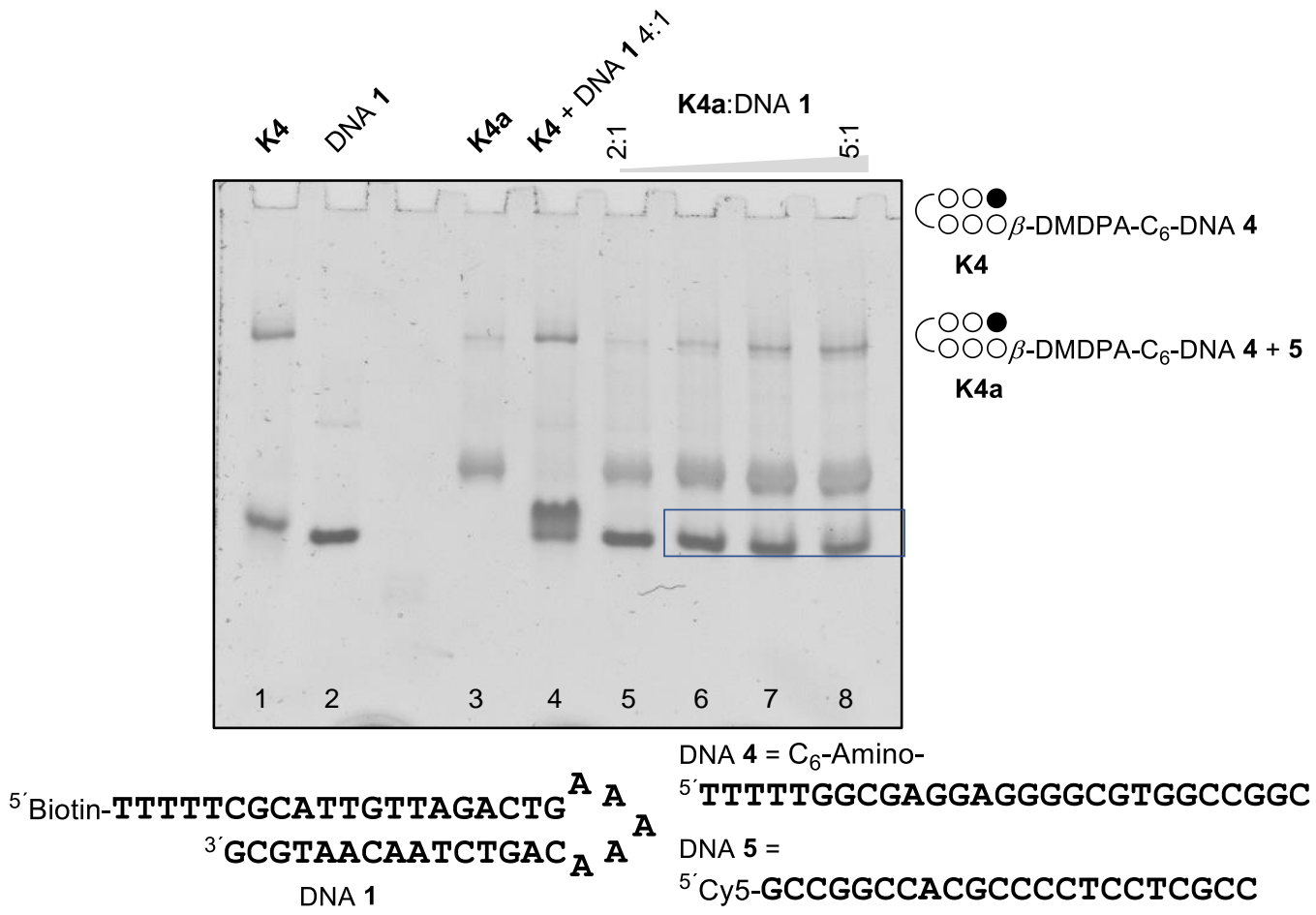

Abbildung 43: Band-Shift Experimente mit K4 und K4a. Lane 1: K4 $(2 \mu \mathrm{M})$; Lane 2: DNA 1 (0.5 $\mu \mathrm{M})$; Lane 3: K4a (1 $\mu \mathrm{M})$; Lane 4: DNA $1(0.5 \mu \mathrm{M})+\mathrm{K} 4(2 \mu \mathrm{M})$; Lane 5: DNA $1(0.5 \mu \mathrm{M})+\mathrm{K} 4 \mathrm{a}(1 \mu \mathrm{M})$; Lane 6: DNA $1(0.5 \mu \mathrm{M})+\mathrm{K} \mathbf{4 a}(1.5 \mu \mathrm{M})$; Lane 7 : DNA $1(0.5 \mu \mathrm{M})+\mathrm{K} 4 \mathrm{a}(2 \mu \mathrm{M})$; Lane 8: DNA $1(0.5 \mu \mathrm{M})+\mathrm{K} 4 \mathbf{a}(2.5 \mu \mathrm{M})$. Die Proben wurden über Nacht in 0.5x SSPE bei RT inkubiert. $16 \%$ nativ PAGE. Die Detektion der Banden erfolgte durch Färbung mit SYBR Gold. Die Veränderung der Banden der DNA 1 sind blau markiert.

beobachten (Abbildung 43, Lane 4). Nach der Hybridisierung mit der DNA 5 wies das resultierende Konjugat K4a eine deutlich schmalere Bande auf (Lane 3) als die Konjugate K1a - K3a. Das deutete darauf hin, dass in diesem Fall keine Selbstbindung vorlag. Dennoch konnte für K4a keine direkte Bindung an die DNA 1 beobachtet werden. Ab einem Verhältnis von 4:1 wurde die Bande der DNA 1 jedoch weniger fokussiert (Lane 8 und 9) und da dieser Effekt reproduziert wurde, war davon auszugehen, dass die Bindung des Konjugats die Ursache darstellte. Dies bedeutete gleichzeitig, dass die Affinität von K4a an die Ziel-DNA 1 gering war, wodurch sich der Komplex durch das unterschiedliche Laufverhalten der ON während der Elektrophorese auflöste. Aus diesen Beobachtungen konnten zwei Erkenntnisse gewonnen werden. Erstens schienen bei K4a keine oder kaum internen Wechselwirkungen zwischen PIP-Teil und DNA-Duplex aufzutreten. Die zweite Beobachtung war, dass die Affinität der Sechsmer-PIPs zu gering war, um eine stabile Bindung der Konjugate an die DNA 1 zu ermöglichen und sie somit nicht zur Umleitung von Sp1 geeignet waren. Aus den Experimenten mit K3 konnte jedoch geschlossen werden, dass die Achtmer-PIPs eine deutlich höhere Affinität als die Sechsmer-PIPs besaßen, da bereits bei einem Mismatch-Fall eine mit den Sechsmer-PIPs vergleichbare Affinität zu beobachten war. Aufgrund der in der Dervan-Gruppe erhaltenen Ergebnisse, war davon auszugehen, dass die Affinität im Match-Fall 10-100fach höher sein sollte. ${ }^{[14]}$ Dementsprechend wurden als nächstes die auf Achtmer-PIPs basierten Konjugate K5 und 


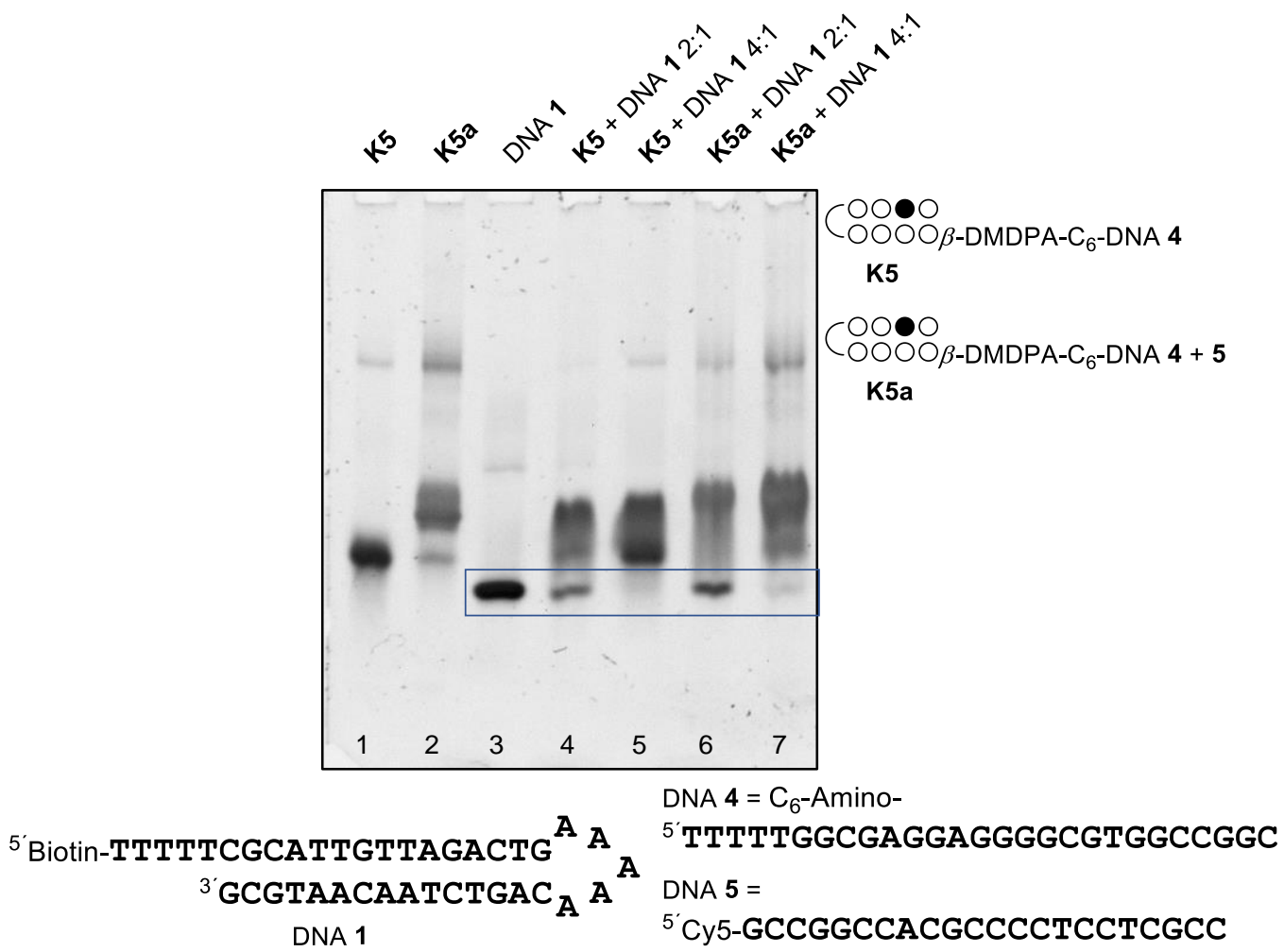

Abbildung 44: Band-Shift-Experiment mit K5. Lane 1: K5 (2 $\mu \mathrm{M})$; Lane 2: K5a (2 $\mu \mathrm{M})$; Lane 3: DNA 1 (0.5 $\mu \mathrm{M})$; Lane 4: DNA 1 + K5 $(1 \mu \mathrm{M})$; Lane 5: DNA $1(0.5 \mu \mathrm{M})+$ K5 $(2 \mu \mathrm{M})$; Lane 6: DNA $1(0.5 \mu \mathrm{M})+$ K5a $(1 \mu \mathrm{M})$; Lane 7: DNA $1(0.5 \mu \mathrm{M})+$ K5a $(2 \mu \mathrm{M})$. Die Proben wurden über Nacht in 0.5x SSPE bei RT inkubiert. $16 \%$ nativ PAGE. Die Detektion der Banden erfolgte durch Färbung mit SYBR Gold. Die Bande der DNA 1 ist blau markiert.

K5a getestet (Abbildung 44). Diese zeigten eine gute Bindung an die DNA 1. Mit K5 konnte bereits bei einem doppelten Überschuss eine deutliche Abnahme der DNA 1 beobachtet werden (Lane 4) und ein vierfacher Überschuss führte zu einem vollständigen Verschwinden der Ziel-Bande (Lane 5, blauer Kasten). Im Gegensatz dazu waren mit den zuvor verwendeten Konjugaten K1-K4 erst ab einem dreifachen Überschuss geringe Effekte zu beobachten. Mit K5a konnten analoge Ergebnisse erzielt werden. Mit zwei Äquivalenten des Konjugats war eine deutliche Abnahme der DNA 1 und ein Shift von K5a zu beobachten (Lane 6) und bei einem vierfachen Überschuss war die DNA 1 nur noch in Spuren zu detektieren (Lane 7). Diese Ergebnisse zeigten, dass die Achtmer-PIPs eine ausreichende Affinität für die Konjugate besaßen und sich zur Isolierung von Sp1 eignen sollten.

Als nächstes stellte sich die Frage, ob die Bindungsorientierung des Konjugats auf der DNA 1 optimal war. Im Fall der Konjugate $\mathbf{K} \mathbf{1}$ bis $\mathbf{K} \mathbf{5}$ zeigte die DNA des Konjugats in Richtung des 5'-Endes der DNA 1 (Abbildung 45). Da dieses in den geplanten Pulldown-Experimenten an die Magnetic Beads gebunden war, konnte eine sterische Wechselwirkung zwischen den Beads und der Konjugat-DNA nicht ausgeschlossen werden. Im Fall des Konjugats K6 war die DNA 4 hingegen in Richtung des turns der DNA 1 gerichtet (Abbildung 45) und die Bindung der DNA 1 an die Beads hätte somit keinen Einfluss. In Band-Shift-Experimenten wiesen die Konjugate $\mathbf{K} 6$ und $\mathbf{K} 6 \mathbf{a}$ jedoch nur eine 


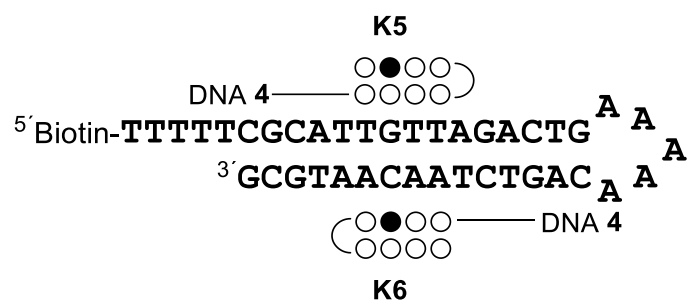

Abbildung 45: Orientierung der Konjugate K5 und K6 nach der Bindung an die DNA 1.

geringe Bindung an die DNA 1 auf und ihre Affinitäten schienen im Bereich der Konjugate K4 und K4a zu liegen. Somit stellten diese Konjugate keine geeigneten Alternativen zu K5 dar.

Nachdem die Frage der Bindungsorientierung geklärt war, wurde getestet, ob das Entfernen der $\beta$-Einheit einen Einfluss auf die Bindung der Konjugate hatte. Dazu wurden die Konjugate K5 und K7 verglichen (Abbildung 46) und in den Experimenten konnte kein Unterschied in der Bindung an die DNA 1 festgestellt werden. Sowohl K7 (Lane $7+8$ ) als auch K7a (Lane $5+6$ ) zeigten bei einem doppelten Überschuss eine gute Bindung an DNA 1, welche vergleichbar mit der den Konjugaten K5 (Lane 10) und K5a (Lane 9) waren. Nachdem das Verkürzen des Linkers keinen Einfluss auf die Affinität der Konjugate hatte, wurde das Konjugat K5a für die Umleitung von Sp1 eingesetzt und auch das für

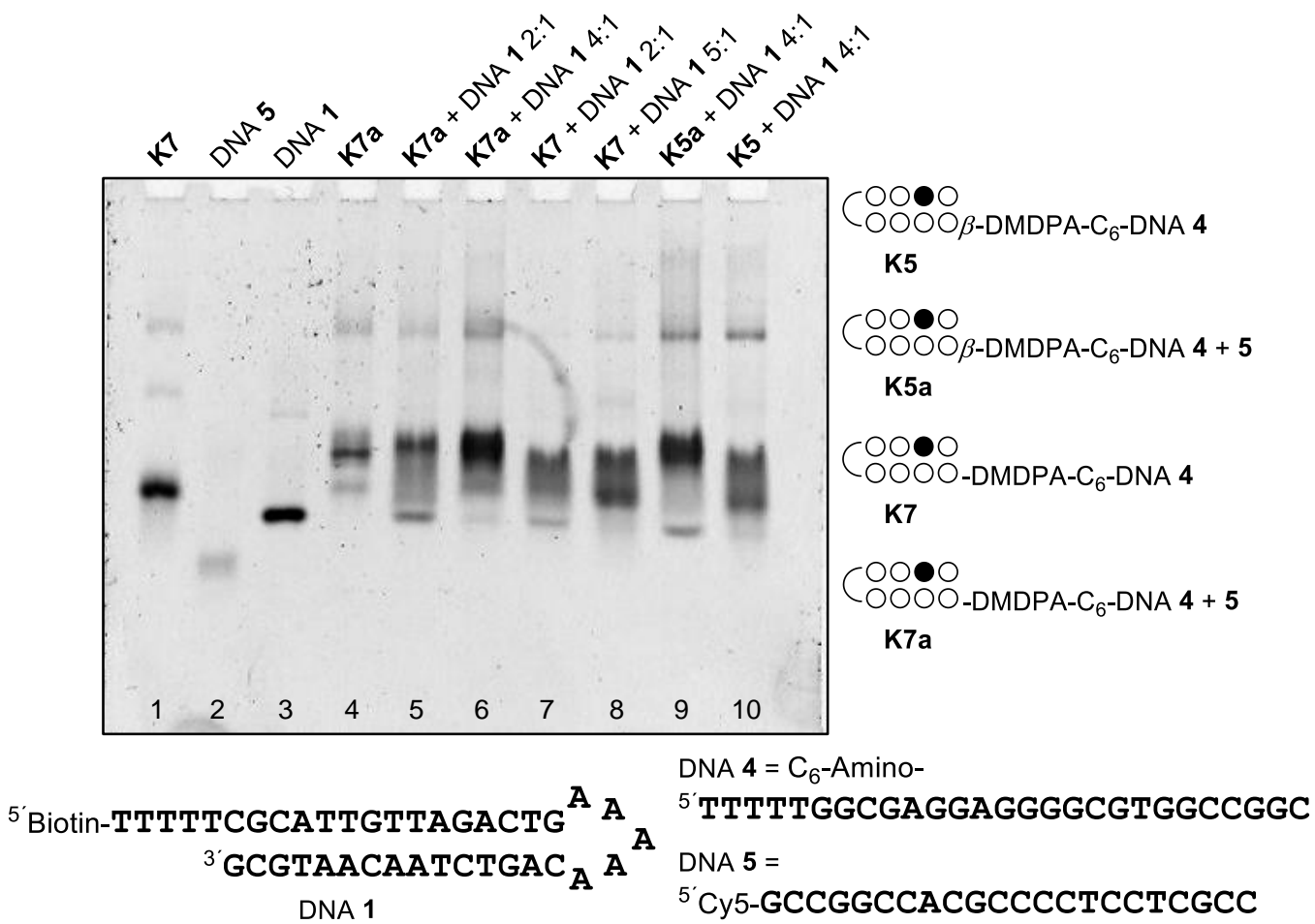

Abbildung 46: Band-Shift-Experimente mit K5, K7, K5a und K7a. Lane 1: K7 (2 $\mu \mathrm{M})$; Lane 2: DNA 5 (2 $\mu$ M); Lane 3: DNA 1 $(0.5 \mu \mathrm{M})$; Lane 4: K7a $(1 \mu \mathrm{M})$; Lane 5: DNA $1(0.5 \mu \mathrm{M})+\mathrm{K} 7 \mathrm{a}(1 \mu \mathrm{M})$; Lane 6: DNA $1(0.5 \mu \mathrm{M})+\mathrm{K} 7 \mathrm{a}(2 \mu \mathrm{M})$; Lane 7: DNA 1 $(0.5 \mu \mathrm{M})+$ K7 $(1 \mu \mathrm{M})$; Lane 8: DNA $1(0.5 \mu \mathrm{M})+$ K7 $(2 \mu \mathrm{M})$; Lane 9: DNA $1(0.5 \mu \mathrm{M})+$ K5a $(2 \mu \mathrm{M})$; Lane 10: DNA $1(0.5 \mu \mathrm{M})$ + K5 $(2 \mu \mathrm{M})$. Die Proben wurden $3 \mathrm{~h}$ bei RT in 0.5x SSPE inkubiert. $16 \%$ nativ PAGE. Die Detektion der Banden erfolgte durch Färbung mit SYBR Gold. 
Zellkulturexperimente vorgesehene Konjugat K9 wurde auf Basis des Polyamids PA4 aufgebaut. Im Gegensatz zu den zuvor verwendeten Konjugaten, enthielt das Konjugat K9 eine hairpin-DNA, deren Sequenz sich aus den DNAs $\mathbf{4}$ und $\mathbf{5}$ zusammensetzte. Nach der Synthese des Konjugats K9 trat das Problem auf, dass es nicht mittels Massenspektrometrie charakterisiert werden konnte und nur bekannt war, dass es sich um ein Konjugat handeln musste (vgl. Abschnitt 7.2). Um zu zeigen, dass dieses funktional war, sollte es mit dem analogen Adaptor K5a verglichen werden. Wenn das erhaltene Konjugat tatsächlich K9 war, sollte die Laufstrecke in einer nativ PAGE und die Affinität zu DNA 1 mit K5a identisch sein. Die Band-Shift-Experimente wurden dabei in Puffer 1 (25 mM HEPES- $\mathrm{NaOH} \mathrm{pH} 7.5,100 \mathrm{mM} \mathrm{KCl}, 2.5 \mathrm{mM} \mathrm{MgCl} 2,0.01 \mathrm{mM} \mathrm{ZnCl}_{2}, 5 \%$ Glycerol) durchgeführt, welcher physiologische Bedingungen besser nachstellte als der 0.5x SSPE-Puffer. Dabei wurde untersucht, ob in Anwesenheit von $\mathrm{K}^{+}$-und $\mathrm{Mg}^{2+}$-Ionen eine Bindung an DNA 1 möglich war. In den Experimenten konnte auch in Puffer 1 eine gute Bindung des Konjugats K5a an die DNA 1 beobachtet werden (Abbildung 47, Lane 4). Darüber hinaus zeigte sich, dass die Konjugate K5a und K9 eine nahezu identisch Laufstrecke aufwiesen und sich die Form ihrer Banden ähnelte (Lane 2 und 3). Außerdem war in beiden Fällen eine gute Bindung an die DNA $1 \mathrm{zu}$ beobachten (Lane 4 und 5). Aufgrund dieser Ergebnisse war davon auszugehen, dass es sich bei dem Konjugat um K9 handelte.

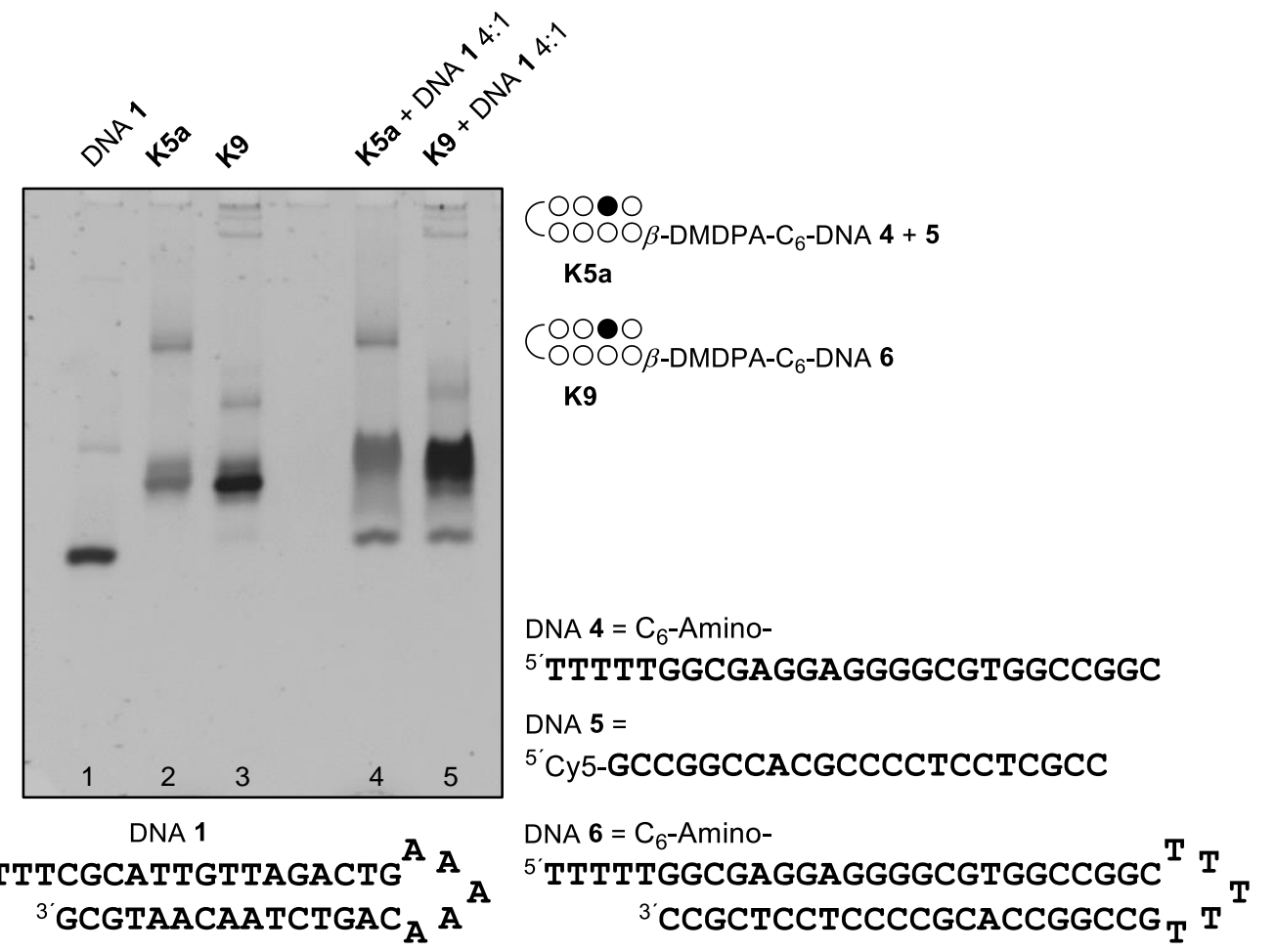

Abbildung 47: Band-Shift-Experiment mit den Konjugaten mit K5a und K9. Lane 1: DNA 1 (0.5 $\mu \mathrm{M})$; Lane 2: K5a $(2 \mu \mathrm{M})$; Lane 3: K9 $(2 \mu \mathrm{M})$; Lane 4: DNA $1(0.5 \mu \mathrm{M})+\mathbf{K 5 a}(2 \mu \mathrm{M})$; Lane 5: DNA $1(0.5 \mu \mathrm{M})+\mathbf{K 9}(2 \mu \mathrm{M})$. Die Proben wurden über Nacht bei $37^{\circ} \mathrm{C}$ in Puffer 1 inkubiert. Die Detektion der Banden erfolgte durch Färbung mit SYBR Gold. 
Mit den Konjugaten K5a und K9 waren zwei Adapormoleküle vorhanden, mit denen eine Umleitung von Sp1 möglich schien und die in Pulldown-Experimenten eingesetzt werdensollten. Gleichzeitig fehlte ein Konjugat, das als Negativkontrolle dienen konnte. Hierzu wurden die Verbindungen K8 und K8a aufgebaut und (Abbildung 48) in Puffer 1 getestet. Hierbei konnte analog zu K3a erwartungsgemäß keine Bindung an die DNA 1 nachgewiesen werden. Dies zeigte, dass K8a eine geeignete Negativkontrolle für die geplanten Pulldown-Experimente darstellte.

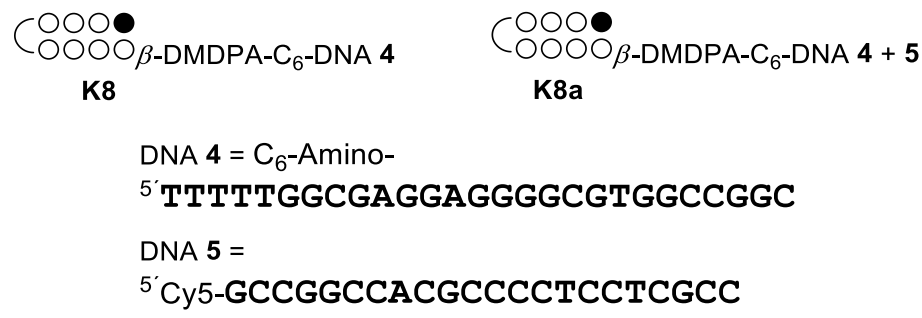

Abbildung 48: Sequenz der Konjugate K8 und K8a.

\subsubsection{Pulldown-Experimente}

Ein Fernziel dieses Projektes ist die Synthese von Adaptormolekülen, die nicht nur in Zellen, sondern auch in deren Kerne eindringen können. Dort sollen sie nach Rekrutierung des ubiquitären TFs Sp1 diesen an AT-reiche Promotorsequenzen umleiten und somit eine Hochregulierung nachgeschalteter Gene bewirken können (vgl. Abbildung 23, Seite 41). Im Rahmen dieser Dissertation ist ein biologischer proof of principle noch nicht ernsthaft versucht worden. Um sich diesem Ziel aber anzunähern, wurden Pulldown-Experimente durchgeführt, in denen zumindest alle relevanten Bindungsvorgänge eindeutig nachgewiesen werden konnten: Dabei steht die biotinylierte DNA 1 als Modell für die AT-reiche Promotorregion. Mit ihr assoziiert das Adaptormolekül sowie der daran gebundene TF Sp1, der selbst keine Affinität zum AT-reichen Duplex von DNA 1 hat. Wird nun DNA 1 mit Hilfe Streptavidin-haltiger Magnetic Beads über ihr Biotin eingefangen, so lässt sich das über den Adaptor indirekt gebundene Sp1 schließlich durch einen Western-Blot nachweisen. Um zu diesem Punkt zu gelangen, mussten aber noch wichtige Parameter des Pulldown-Experiments optimiert werden. Dazu wurde in einem nochmals vereinfachten Versuchsaufbau statt des Proteins Sp1 lediglich eine fluoreszenzmarkierte DNA eingefangen, die zum einzelsträngigen Teil des jeweiligen Adaptors, nicht aber zur biotinylierten DNA 1, komplementär ist. Am Ende des Versuchs wurde diese bei $\mathrm{pH} 10$ von den Beads abgetrennt und ihre Floreszenz vermessen. Bei einem Pulldown von DNA 1 sollte in Abwesenheit von Adaptoren daher keine fluoreszierende DNA detektiert werden können. In Gegenwart des Adaptors hingegen würde diese die indirekte Bindung an DNA 1 vermitteln (Abbildung 49). 
In den vorrausgegangenen Band-Shift-Experimenten konnten die Konjugate K5a, K7a und K9 als geeignete Adaptoren für eine Umleitung von Sp1 identifiziert werden. In Bezug auf die Inkubation mussten einerseits ein Puffer und eine geeignete Inkubationszeit gewählt werden. Im Gegensatz zu den Band-Shift-Studien wurden die Pulldown-Experimente anstelle des 0.5x SSPE-Puffers in Puffer $Z$ (25 mM HEPES- $\mathrm{NaOH}$ pH 7.5, $100 \mathrm{mM} \mathrm{KCl}$, $12.5 \mathrm{mM} \mathrm{MgCl}_{2}, 0.01 \mathrm{mM} \mathrm{ZnCl}_{2}, 20 \%$ Glycerol) durchgeführt, der bereits in ähnlichen Versuchen der Balasubramanian-Gruppe zum Einsatz kam ${ }^{[218]}$ und außerdem zur Isolierung des Sp1 aus HeLa-Zellen verwendet wurde. Auf der Suche nach geeigneten Bedingungen wurde zunächst die Zahl der Waschschritte optimiert und nach einer Normierungsmethode für die Fluoreszenz gesucht. Bei den Waschschritten war darauf zu achten, möglichst viel ungebundenes Material zu entfernen, ohne das gebundene Konjugat abzulösen. Dazu wurde die DNA 1 entweder mit K5a oder einem Duplex der DNAs 4 und 5, als Negativkontrolle, inkubiert und im Anschluss zwischen einem und fünf Mal gewaschen. Dabei konnte mit K5a eine hohe, aber konstant abnehmende Fluoreszenz beobachtet werden. Dies war ein Indiz dafür, dass in den Waschschritten auch gebundenes Konjugat entfernt wurde. Im Fall des Duplex aus den DNAs $\mathbf{4}$ und $\mathbf{5}$ war ab drei Waschschritten keine weite Abnahme der Restfluoreszenz zu beobachten. Da die detektierte Fluoreszenz bei den Experimenten mit K5a nach drei Waschschritten noch vergleichsweise hoch war, wurde in den nachfolgenden Pulldown-Experimenten dreimal gewaschen. Nach einer Reihe von Pulldowns zeigte sich, dass die Fluoreszenzwerte der Negativkontrollen stark variierte und nicht zur Normierung der Experimente geeignet war. Stattdessen wurden die erhaltenen Werte entweder auf eine analoge Menge des eingesetzten Konjugats oder auf einen, an Beads gebundenen, Duplex der DNAs 2a und $\mathbf{3}$ oder 4a und $\mathbf{5}$ normiert (DNA 2a und 4a wurden durch Biotinylierung von DNA 2 und $\mathbf{4}$ erhalten). Bei der Bestimmung der optimalen Inkubationszeit war darauf zu achten, dass einerseits die Komplexierung des Adaptors mit der DNA 1 nahezu vollständig war. Andererseits ist bei Experimenten mit Sp1 oder gar bei zellbiologischen Anwendungen darauf zu achten, dass es nicht durch überlange Inkubationszeiten zu einer Degradation von Sp1 oder der Adaptormoleküle kommt. In Pulldown-Experimenten konnte gezeigt werden, dass eine maximale Komplexierung zwischen K5a und DNA 1 nach 5 bis $7 \mathrm{~h}$ erhalten wurde (Abbildung 49). Da jedoch bereits nach $3 \mathrm{~h}$ bereits $84 \%$ dieses Werts detektiert wurden und bei einer kürzeren Inkubation von einer geringeren Degradation des Sp1 auszugehen war, wurde die Inkubation für die nachfolgenden Experimente auf $3 \mathrm{~h}$ begrenzt.

Mit den optimierten Bedingungen sollte die Bindung der Konjugate $\mathrm{K} 1 \mathrm{a}-\mathrm{K} 7 \mathrm{a}$ an die DNA 1 in Pulldown-Experimenten genauer untersucht werden. Da die Pulldown-Experimente eine empfindlichere Methode als die Band-Shift-Experimente darstellten, sollte hiermit eine 

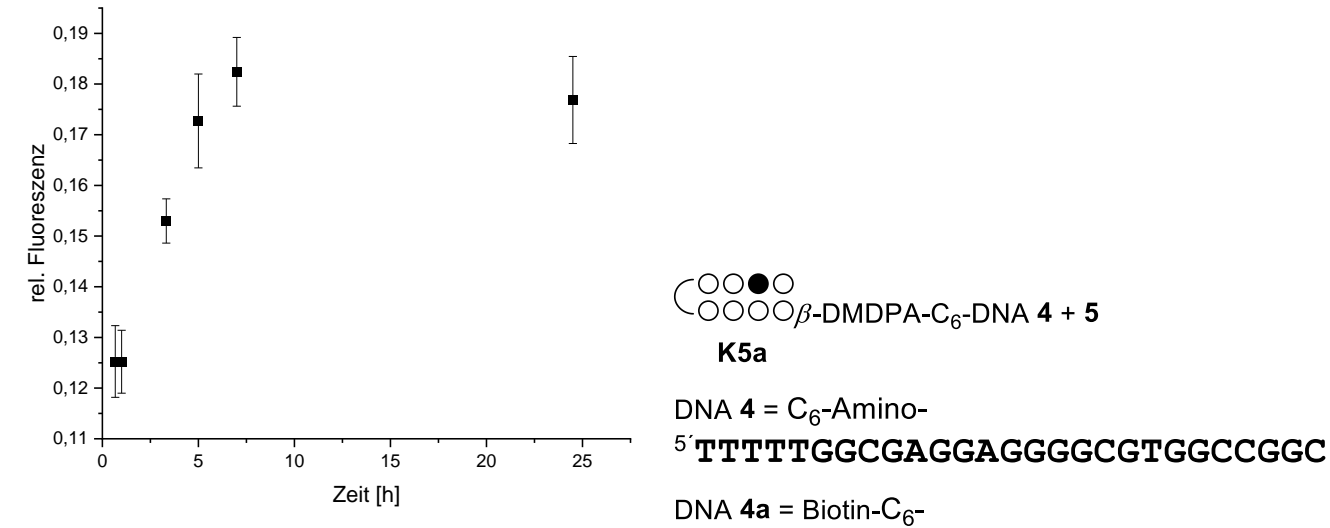

Abbildung 49: Zeitlicher Verlauf der Komplexbildung aus K5a und DNA 1 in Puffer Z. Die Proben wurden dreimal gewaschen und die gemessene Fluoreszenz auf den Wert eines Duplex aus DNA 4a und $\mathbf{5}$ normiert.

genauere Aussage über die Affinität getroffen werden können, insbesondere bei Konjugaten, die in den Band-Shift-Experimenten eine vergleichbare Komplexierung zeigten. Des Weiteren wurde der Einfluss der PIP-Länge auf die Bindung der Konjugate sowie die Auswirkungen der intramolekularen Wechselwirkungen auf die Affinität der Konjugate K1a - K3a untersucht. Dabei war zu beachten, dass die Cy5-Markierte DNA 3 der Konjugate K1a - K3a einen Labelinggrad von 60 \% besaß, während dieser bei den Konjugaten K4a - K7a 100 \% betrug. Um die Ergebnisse vergleichen zu können, wurde die gemessene Fluoreszenz auf eine 100 nM Lösung der jeweiligen Konjugate normiert. In den Experimenten wiesen die Konjugate K5a und K7a die mit Abstand beste Bindung an die DNA 1 auf und die erhaltenen Fluoreszenzwerte waren untereinander vergleichbar (Abbildung 50). Für das Konjugat K6a war der Fluoreszenzwert hingegen nur halb so hoch und analog zu den Band-Shift-Experimenten deutete dies auf eine deutlich schlechtere Bindung an die DNA 1 hin. Dies zeigte, dass die Bindung der DNA 1 an Magnetic Beads keinen negativen Einfluss auf die Bindung des Konjugats K5a hatte und es offensichtlich zu keiner sterischen Abstoßung zwischen der Konjugat-DNA und den Beads kam. Außerdem zeigte sich auch hier, dass die auf Achtmer-PIPs basierenden Konjugate eine deutlich höhere Affinität besaßen als die Sechsmer-PIP-basierten. Von den Sechsmeren wies das Konjugat K4a die höchsten Fluoreszenzwerte auf, auch wenn die Werte mit denen des Konjugats K2a vergleichbar waren. Auch dies war konsistent mit den vorherigen Ergebnissen und der Vergleich der Konjugate K2a und K4a wies darauf hin, dass die intramolekularen Wechselwirkungen im Fall von K2a nur einen geringen Einfluss auf die Bindung der DNA 1 hatten. Im Fall des Konjugats K1a war die erhaltene Fluoreszenz deutlich niedriger. Die Ursache hierfür könnte der längere Linker darstellen, der die Ausbildung von intramolekularen Wechselwirkungen erleichtern und somit das Konjugat 

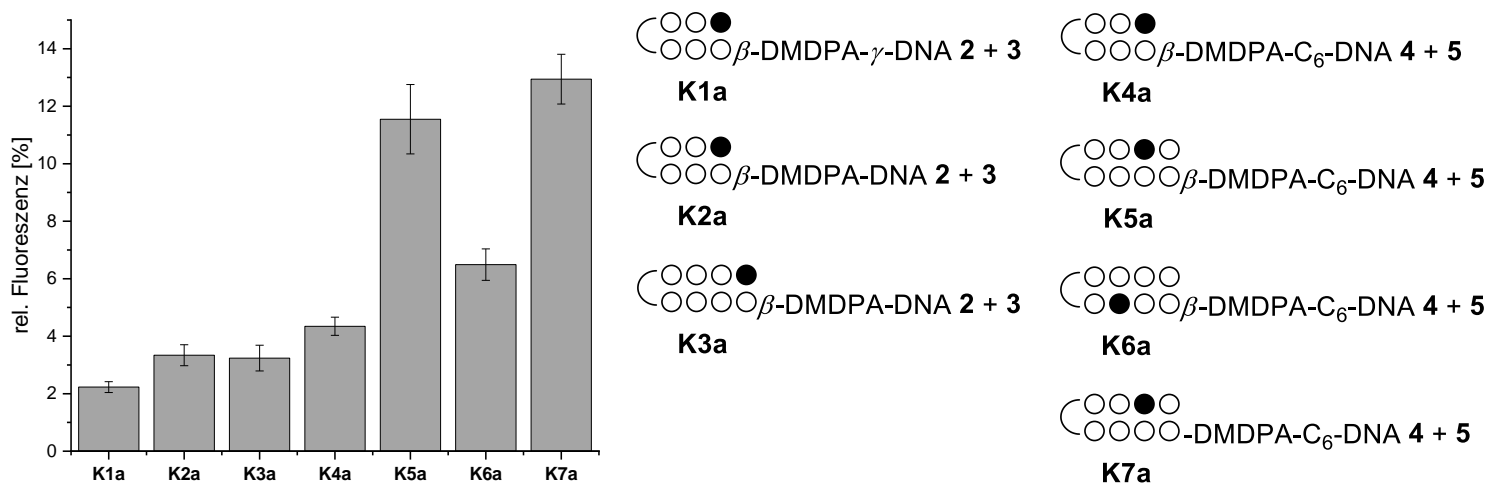

Abbildung 50: Pulldown-Experimente mit DNA 1 (300 nM) und den Konjugaten K1a - K7a (100 nM). Die Proben wurden $3 \mathrm{~h}$ bei RT in Puffer Z inkubiert. Die erhaltene Fluoreszenz wurde auf eine $100 \mathrm{nM}$ Lösung der jeweiligen Konjugate normiert. Die Ergebnisse stellen den Mittelwert aus drei unabhängigen Messungen dar.

stärker inhibieren könnte. Mit der Negativkontrolle K3a, die auf der DNA 1 nur eine Mismatch-Bindestelle besaß, konnten Fluoreszenzwerte beobachtet werden, die denen der Sechsmer-PIPs entsprachen. Gleichzeitig waren die Werte deutlich geringer als die der Konjugate K5a und K7a. Daraus konnte abgeleitet werden, dass die Affinität der Konjugate wie erwartet in einem Mismatch-Fall deutlich abnahm und eine erfolgreiche Umleitung nur in einem Match-Fall gelingen sollte. Somit konnten die Ergebnisse der Band-ShiftExperimente in den Pulldown-Experimenten bestätigt werden. Da sich auch in diesen Versuchen zeigte, dass die Konjugate K5a und K7a ähnliche Eigenschaften besaßen, wurde zur Umleitung von Sp1, wie zuvor geplant, das Konjugat K5a verwendet.

Die ersten Umleitungsversuche wurden mit rekombinantem Sp1 (Promega) durchgeführt (Abbildung 51). Auch wenn in den vorangegangenen Experimenten gezeigt werden konnte, dass die Bindung der DNA 1 an die Magnetic Beads keinen Einfluss auf die Affinität von K5a besaß, war es dennoch denkbar, dass eine Bindung von Sp1 durch sterische Hinderung inhibiert werden könnte. Aus diesem Grund wurden die Konjugate K5a und K6a in Pulldown-Experimenten eingesetzt. Mit K5a wurde dabei eine gute Bindung von Sp1 erwartet, während der Effekt bei K6a deutlich geringer ausfallen sollte. Als Positivkontrolle wurde ein Duplex aus den DNAs 2a (biotinyliert) und $\mathbf{3}$ verwendet, der eine direkte Bindestelle für Sp1 enthält. In diesen Experimenten sollte eine möglichst vollständige Komplexbildung erzielt werden, weshalb die Proben $20 \mathrm{~h}$ inkubiert wurden. Dabei zeigte sich mit K5a eine deutlich sichtbare Sp1-Bande (Lane 1), aus der sich schließen ließ, dass Sp1 umgeleitet werden konnte. Außerdem war die Umleitung mit K5a deutlich effizienter als mit K6a (Lane 2) und somit war davon auszugehen, dass auch hier keine sterischen Wechselwirkungen vorlagen. Gleichzeitig war die Bande mit K6a schwächer als bei einer Inkubation der DNA 1 mit Sp1 (Lane 3). Eine Erklärung hierfür wäre, dass das Sp1 an K6a gebunden war, sich jedoch kein stabiler Komplex mit der DNA 1 bildete. Daraufhin wurde 


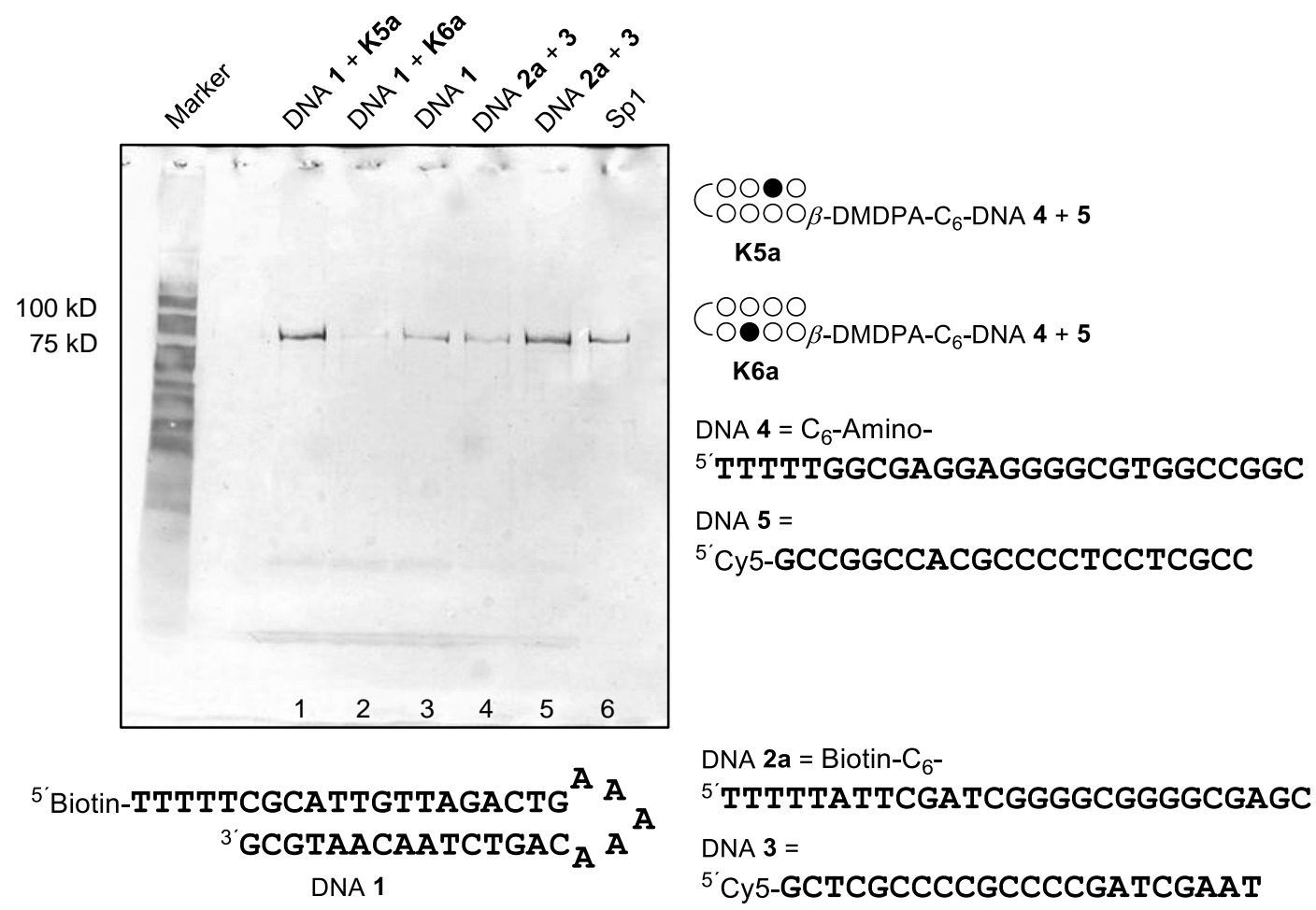

Abbildung 51: Umleitung von rekombinantem Sp1 mittels Pulldown-Experiment und nachfolgendem Western-Blot. Die Detektion der Banden erfolgte mit einem Sp1-spezifischen Antikörper. Lane 1: K5a (100 nM)+ DNA 1 (300 nM); Lane 2: K6a (100 M) + DNA 1 (300 nM); Lane 3: DNA 1 (300 nM); Lane 4: DNA 2a + 3 (je 100 nM); Lane 5: DNA 2 + 3 (ohne Cy5) (je $100 \mathrm{nM}$ ); Lane 6: Sp1 $(1 \mu \mathrm{L})$. Die Proben wurden $20 \mathrm{~h}$ bei RT inkubiert. In allen Fällen wurde $1 \mu \mathrm{L}$ einer Sp1-Lösung $(215 \mathrm{ng} / \mu \mathrm{L})$ eingesetzt.

das Sp1 mit dem Konjugat in den Waschschritten entfernt. In nachfolgenden Experimenten mit K5a zeigte sich, dass ein vermitteltes Einfangen von Sp1 schon bei kürzeren Inkubationszeiten ( $3 \mathrm{~h}$ ) möglich war. Somit konnte das Konzept der Umleitung auf eine nicht kanonische AT-reiche Bindestelle bestätigt werden. Allerdings war bei diesen Ergebnissen zu beachten, dass im Kontrollexperiment, bei welchem lediglich die DNA 1 mit Sp1 inkubiert wurde (Lane 3), uneinheitliche Ergebnisse erhalten wurden. Analog zu den fluoreszenzbasierten Pulldown-Experimenten variierte die Intensität der detektierten Sp1-Bande. Aufgrund dieser Befunde waren weitere Experimente notwendig, in denen auch untersucht werden sollte, ob die Umleitung mit dem Konjugat K9 möglich war. An diesem Punkt trat jedoch das Problem auf, dass das rekombinante Sp1 nicht mehr durch Promega vertrieben wurde. Daraufhin wurde ein rekombinantes $\mathrm{Sp} 1$ eines anderen Hersteller bezogen, welches in Western-Blots aber nicht durch den in dieser Arbeit verwendeten Antikörper detektiert werden konnte. Schließlich isolierte man ein rekombinantes Sp1-H8 aus E.coli als HisTag-Fusionsprotein (vgl. Anhang 11.4), um eine besser Reinigung zu ermöglichen.

Mit dem so gewonnenen Sp1 konnten weitere Untersuchungen durchgeführt werden. In ersten Experimenten fiel wiederum auf, dass das isolierte $\mathrm{Sp} 1$ eine überraschend hohe Affinität zur DNA 1 aufwies und im Western-Blot eine sehr starke Bande beobachtet werden 
konnte. Im Gegensatz zu den zuvor durchgeführten Experimenten konnten hierbei jedoch keine Variationen in der Intensität der Banden beobachtet werden. Um auszuschließen, dass dieser oder die zuvor beobachteten Effekte durch den Puffer $Z$ verursacht wurden, wiederholte man die Experimente in Puffer 1. Dieser wies einen geringeren Zuckeranteil auf $(5 \%$ statt $20 \%$ ), wodurch die Lösung eine verminderte Viskosität besaß, was die Waschschritte vereinfachte. Darüber hinaus war die Konzentration der $\mathrm{Mg}^{2+}$-lonen mit $2.5 \mathrm{mM}$ deutlich geringer als im Puffer $Z(12.5 \mathrm{mM})$ und stellte physiologische Bedingungen besser nach. ${ }^{[219]}$ Hierdurch sollten mögliche durch $\mathrm{Mg}^{2+}$-lonen vermittelte Bindungen verhindert werden. Diese Anpassungen führten zu einer minimalen Verbesserung, auch wenn die Affinität zur DNA 1 weiterhin sehr hoch war (Abbildung 52, Lane 1). Eine andere Erklärung für das Auftreten dieser Bande war eine mäßige Reinheit des isolierten Sp1. Die Aufreinigung erfolgte in diesem Fall lediglich über den His-Tag und so konnte nicht ausgeschlossen werden, dass die gereinigten Fraktionen andere Proteine enthielten, durch die die Banden verursacht wurden. Um zu sehen wie spezifisch die Bindung der Proteine war, wurde die DNA 1 mit einem vierfachen Überschuss der DNA 6 inkubiert, die eine Bindestelle für Sp1 aufwies. Auf diese Weise konnte eine Bindung von Sp1 an die DNA 1 verhindert und nur eine sehr schwache Bande detektiert werden (Abbildung 52, Lane 2).

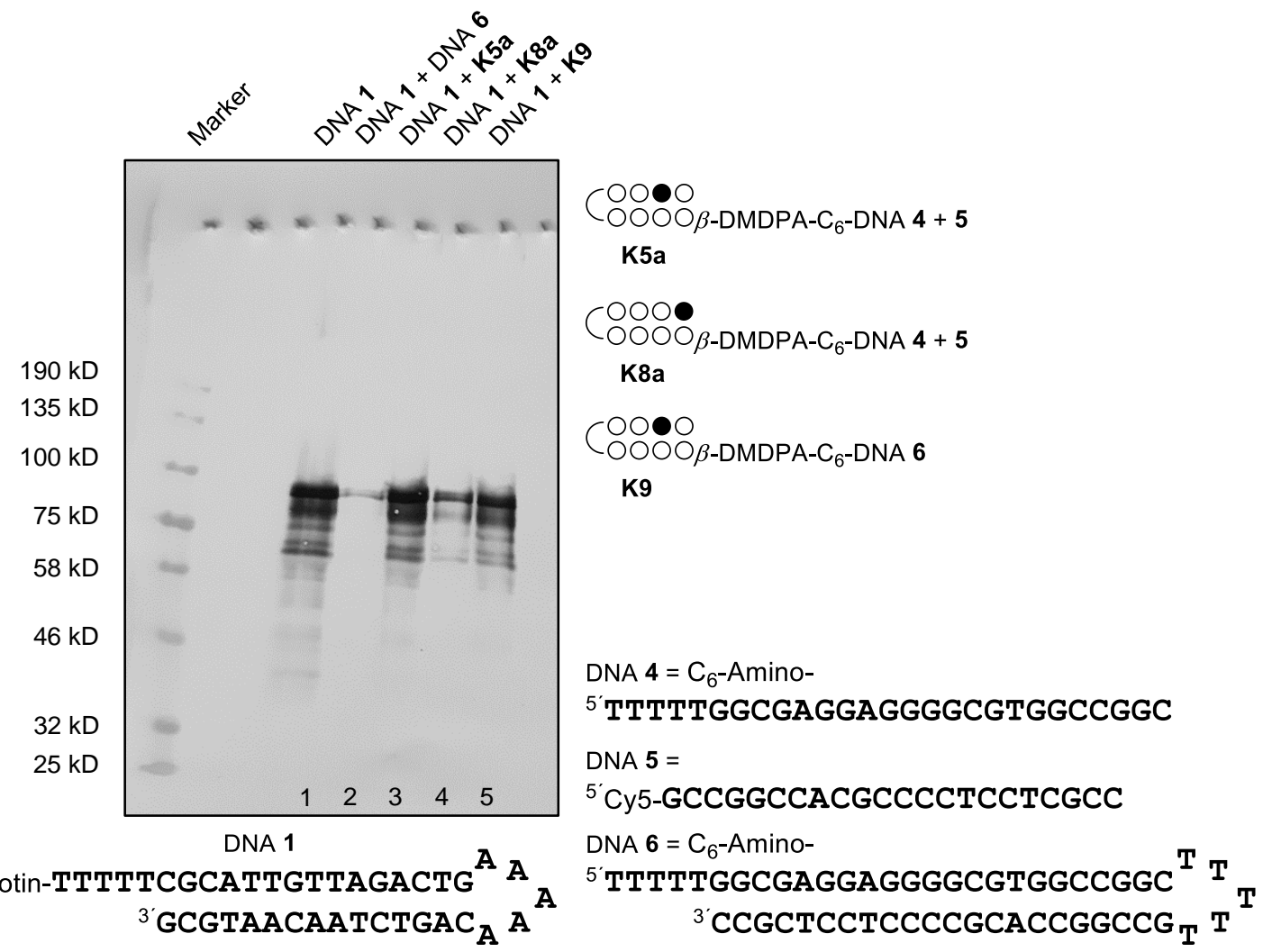

Abbildung 52: Umleitung von Sp1-H8 mittels Pulldown-Experiment und nachfolgendem Western-Blot. Die Detektion der Banden erfolgte mit einem Sp1-spezifischen Antikörper. Lane 1: DNA 1 (100 nM); Lane 2: DNA 1 (100 nM) + DNA 6 (400 nM); Lane 3: DNA $1(100 \mathrm{nM})+$ K5a (400 nM); Lane 4: DNA 1 (100 nM) + K8a (400 nM); Lane 5: DNA 1 (100 nM) + K9 (400 nM). Die Proben wurden $3 \mathrm{~h}$ bei RT in Puffer 1 inkubiert. 
Auf der Grundlage dieser Ergebnisse konnten Pulldown-Experimente mit Sp1-H8 und den Konjugaten K5a, K8a und K9 durchgeführt werden. Dabei wurden die Konjugate ebenfalls im vierfachen Überschuss eingesetzt, um alles Sp1 zu binden. Dadurch sollte nach dem Waschen nur über das Konjugat gebundenes Sp1 zu detektieren sein. Die Konjugate K5a und K9 (Abbildung 52, Lane 3 und 5) wiesen dabei eine starke Bande auf, was für eine Umleitung von Sp1 sprach. Mit der Negativkontrolle K8a war hingegen nur eine schwache Bande zu beobachten (Lane 4). Dies zeigte, dass bei einem Einsatz eines schlecht bindenden Konjugats das SP1 in den Waschschritten entfernt werden konnten.

Aus diesen Versuchen ergibt sich weitere Evidenz für die Umleitung von Sp1. Die Adaptoren K5a und K9 sollten daraufhin in Zellkulturexperimenten auf ihre Fähigkeit zur Transkriptionsaktivierung untersucht werden. Als Vorarbeiten hierzu war geplant, die Stabilität der Konjugate in HeLa-Cytosolen genauer zu untersuchen. Außerdem sollten die Affinität der PIP-Konjugate mit der von Adaptoren auf TFO-basis vergleichen werden. Diese Systeme waren literaturbekannt und konnten in Zellkulturexperimenten die Genexpression aktivieren. ${ }^{[7]}$

\subsubsection{Stabilität der Konjugate in Zelllysaten}

In den in vitro Experimenten konnte gezeigt werden, dass die Umleitung von Sp1 grundsätzlich möglich war. Da für weitere Untersuchungen zur Funktion der Adaptoren Zellkulturexperimente geplant waren, wurde als Vorbereitung die Stabilität der Konjugate in einer zellulären Umgebung überprüft. Hierzu wurde das Konjugat K5a in HeLa-Cytosolen ${ }^{[13]}$ unterschiedlicher Konzentration (1.5, 5.2 und $6.6 \mu \mathrm{g} / \mu \mathrm{L})$ sowohl bei RT als auch bei $37^{\circ} \mathrm{C}$ inkubiert. In einem ersten Versuch wurde $\mathbf{K 5 a}$ in einem ein HeLa-Lysat mit einer geringen Proteinkonzentration $(1.5 \mu \mathrm{g} / \mu \mathrm{L})$ bei RT inkubiert und es konnte eine sehr hohe Stabilität des Konjugats beobachtet werden. Dabei konnte das Konjugat auch nach sechs Tagen nachgewiesen werden. In diesem Experiment zeigte sich zudem, dass die Bande von K5a in einem Bereich lag, in der keine zelleigenen ONs vorkamen. Somit war eine Detektion der Konjugat-Bande trotz starker Hintergrundbanden möglich. Ausgehend von diesen Ergebnissen wurde das Experiment mit höheren Proteinkonzentration $(5.2-6.6 \mu \mathrm{g} / \mu \mathrm{L})$ wiederholt, wobei von einer geringeren Stabilität der Konjugate auszugehen war. Tatsächlich war die Bande des Konjugats bereits nach einem Tag bei RT vollständig verschwunden und bei einer Inkubation bei $37^{\circ} \mathrm{C}$ (Abbildung 53) war das Konjugat nur für $5 \mathrm{~h}$ nachzuweisen. Da der Adaptor im Cytosol für mehrere Stunden stabil war und analoge TFO-basierte Systeme trotz einer geringen Nukleasestabilität eine Aktivierung der Transkription auslösen konnten, ${ }^{[7]}$ war davon auszugehen, dass eine Aktivierung der Transkription auch mit den PIP-Konjugaten möglich sein sollte. 


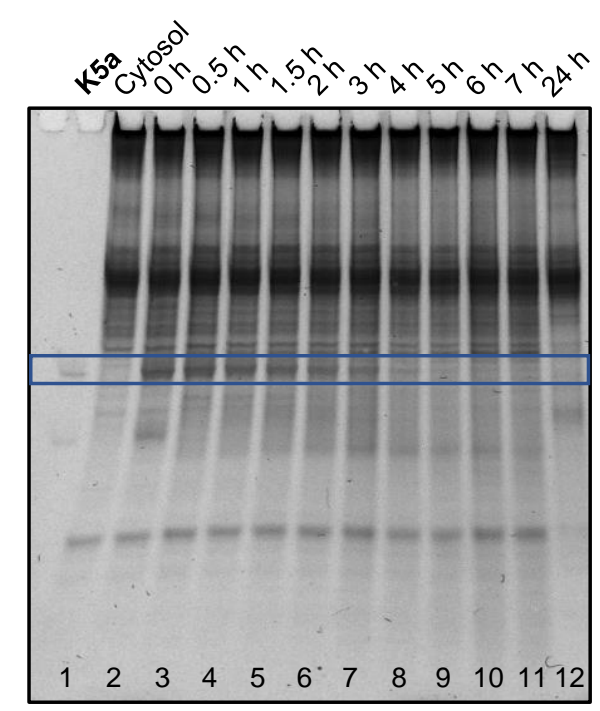

Abbildung 53: Stabilitätstest mit K5a $(2 \mu \mathrm{M})$ in HeLa-Lysat $\left(5.2 \mu \mathrm{g} / \mu \mathrm{L}\right.$ gesamt Protein). Die Proben wurden bei $37^{\circ} \mathrm{C}$ inkubiert. Die Bande des Adaptors wird durch den blauen Kasten markiert. Die starken Hintergrundbanden stammen von zelleigenen ONs. 


\subsection{Adaptoren auf TFO Basis}

Da in den vorangegangenen Experimenten gezeigt werden konnte, dass die PIP-basierten Adaptoren K5a und K9 Sp1 auf eine AT-reiche DNA umleiten konnten und in Zelllysaten eine ausreichende Stabilität besaßen, sollte ihre Affinität mit der von TFO-basierten Adaptoren verglichen werden. Diese wurden bereits zur Rekrutierung von TFs auf nicht kanonische Bindestellen und zur Aktivierung der Genexpression in Zellen eingesetzt. ${ }^{[7,17,105]}$ Dazu wurden Purin*Purin•Pyrimidin TFOs (Abbildung 6) mit einer hairpin-DNA kombiniert, welche eine Bindestelle für einen TF besaß. ${ }^{[7]}$ Es war daher naheliegend, das Konzept für die Umleitung von Sp1 zu adaptieren (Abbildung 54) und mit den PIP-Konjugaten zu vergleichen. Dazu musste die Ziel-DNA eine Bindestelle für die Konjugate K5a und K9 enthalten. Ausgehend von einer durch Ghosh et al. verwendeten TFO-Sequenz (DNA 7) ${ }^{[105]}$ wurde ein Sp1-bindendes hairpin-TFO (DNA 8) entworfen. Die DNA 13 diente dabei als Ziel-DNA (Abbildung 55). Diese enthielt dabei eine Bindestelle für die PIP-Konjugate (rot), die im Bindebereich des TFOs lag. Da Polypurinsequenzen eine enge kleine Furche besitzen ${ }^{[220]}$ und dies die Bindung der PIPs erschweren kann, wurde eine zusätzliche Bindestelle in der Nähe des turns als Alternative eingefügt (blau), um eine Bindung der PIPs sicherzustellen. Abgesehen von der DNA 7 war geplant, weitere TFOs zu untersuchen, um einen möglichst affinen Adaptor zu erhalten. Da der Entwurf von TFOs nicht trivial und die Ausbildung von Triplexen nur teilweise vorhersehbar ist, wurde eine Arbeit von Vekhoff et al. als Vorlage verwendet. ${ }^{[221]}$ In dieser Arbeit wurden empirische Regeln aufgestellt, die auf der Verteilung und dem Anteil der verwendeten Basen (z.B. G und A)

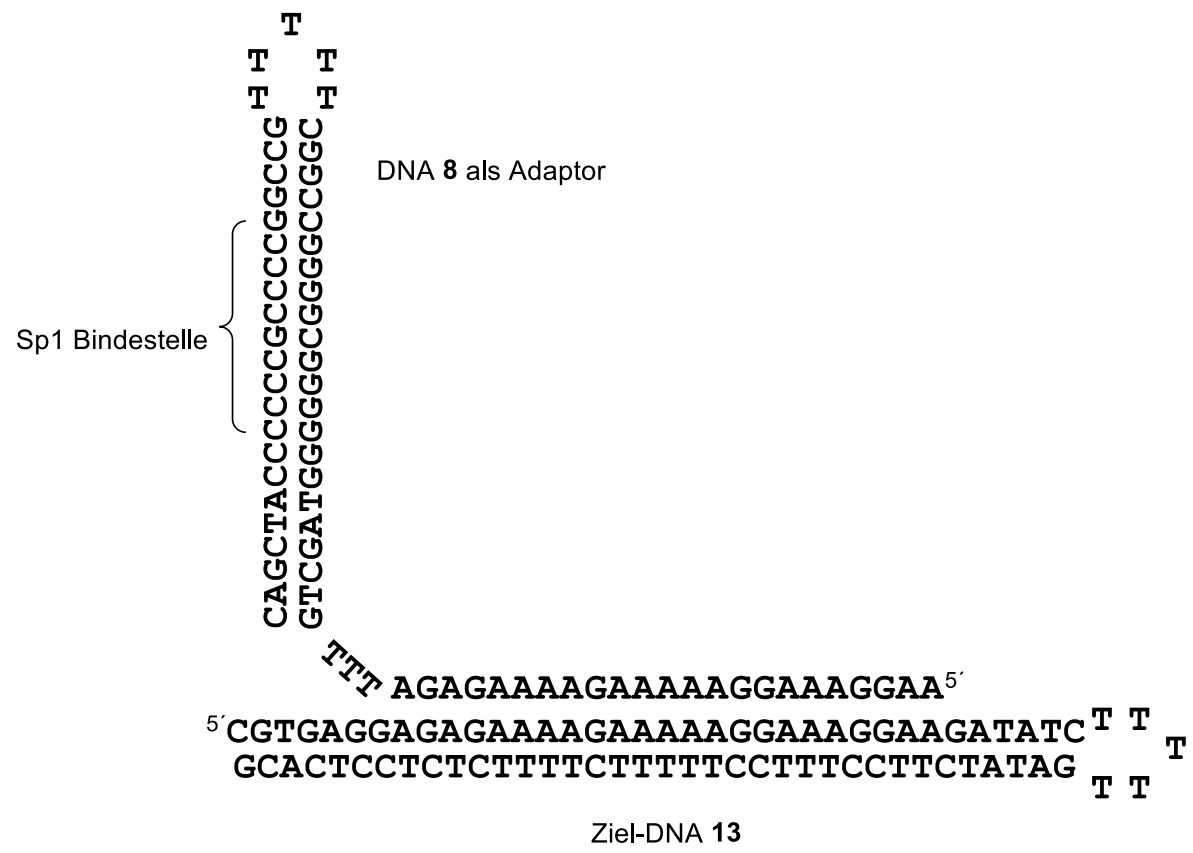

Abbildung 54: Allgemeine Darstellung der Bindung der TFO basierten Adaptoren an die entsprechende Ziel-DNA am Beispiel der DNAs 8 und 13. 


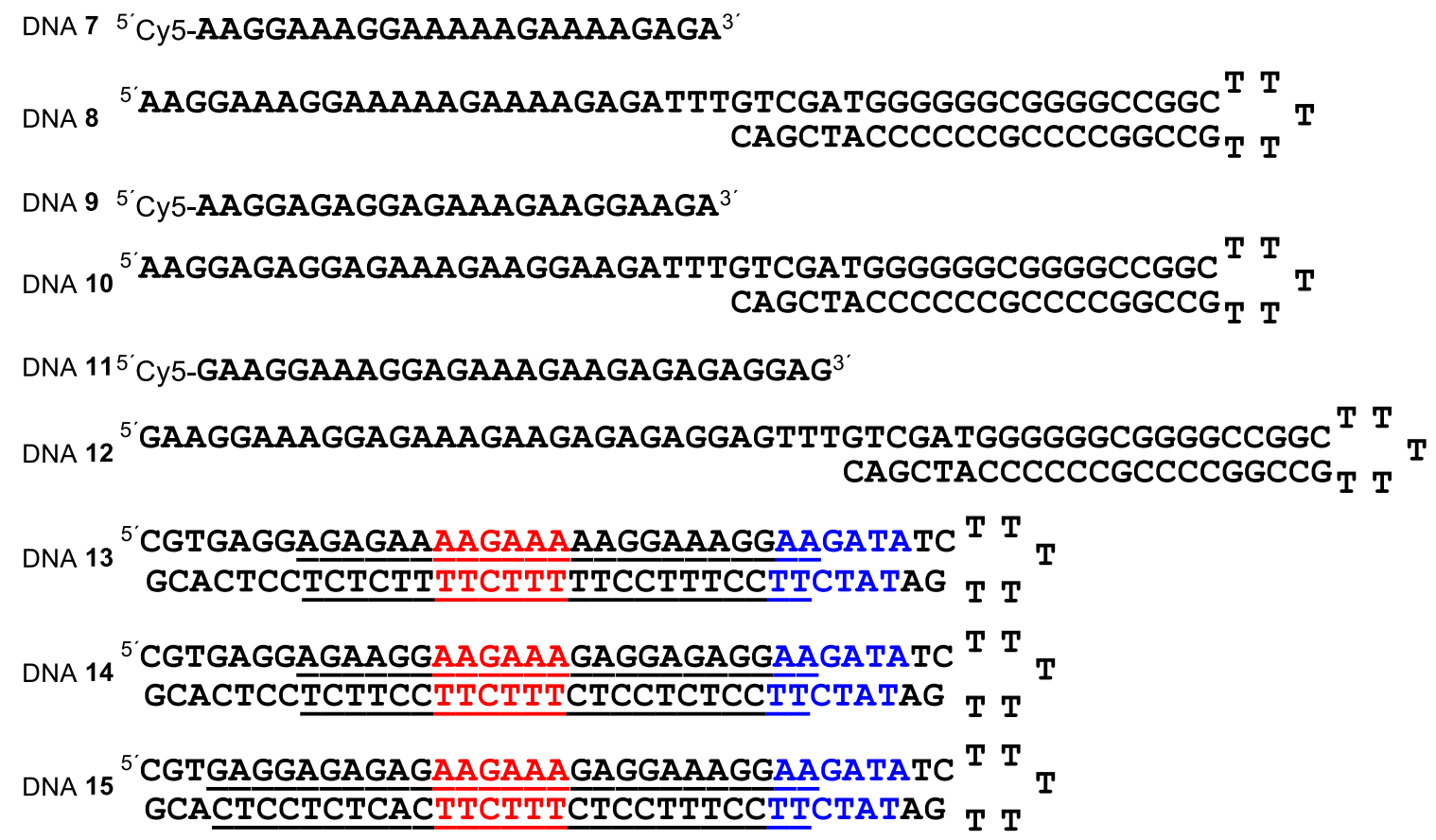

Abbildung 55: Sequenzen der Verwendeten TFOs 7 - 12 sowie ihrer Ziel-DNAs 13 - 15. In den Ziel-DNAs 13 - 15 sind die jeweiligen Bindestellen für die TFOs unterstrichen. Die Bindestellen für die PIP-Konjugate sind rot und blau geschrieben.

beruhen. Auf dieser Basis konnte abgeschätzt werden, ob eine Triplexbildung wahrscheinlich ist. Bei Anwendung dieser Regeln zeigte sich, dass die Ausbildung einer Triplehelix mit der DNA 7 eher unwahrscheinlich war. Der Grund hierfür lag in einem zu hohen Anteil an As. Um die Wahrscheinlichkeit einer Triplexbildung zu erhöhen, wurde die Sequenz der DNA 7 unter Erhalt der PIP-Bindestelle variiert und der G-Anteil erhöht. Daraus resultierte mit DNA 9 ein neues TFO und mit DNA 10 eine entsprechende Variante der DNA 8. Die DNA 14 stellt die Ziel-DNA dar. Zusätzlich wurde ein 28mer entworfen (DNA 11), welches eine höhere Sequenzspezifität aufweisen und somit weniger Nebeneffekte generieren sollte. Auch dieses wurde unter Anwendung der Regeln aus der DNA 7 abgeleitet. Daraus resultierten die DNAs 11 und 12 sowie die Ziel-DNA 15 (Abbildung 55).

\subsubsection{Band-Shift-Experimente mit den TFO-Adaptoren}

Die entworfenen TFO-Adaptoren (DNA 8, 10, und 12) sollten in Band-Shift-Experimenten auf ihre Affinität zu ihren Ziel-DNAs 13 - 15 und auf ihre Selektivität hin untersucht werden. Gleichzeitig wollte man ihre Affinität mit der der PIP-Konjugate vergleichen. Darüber hinaus war geplant die Selektivität der TFOs anhand von Kreuzexperimenten nachzuweisen. Hierzu galt es zunächst geeignete Bedingungen zu finden, mit denen eine Triplexbildung zu beobachten war. In diesen Versuchen wurden im ersten Schritt die Cy5-markierten TFOs 7, 9, und 11 eingesetzt und die Banden der TFOs nach der Elektrophorese über die 


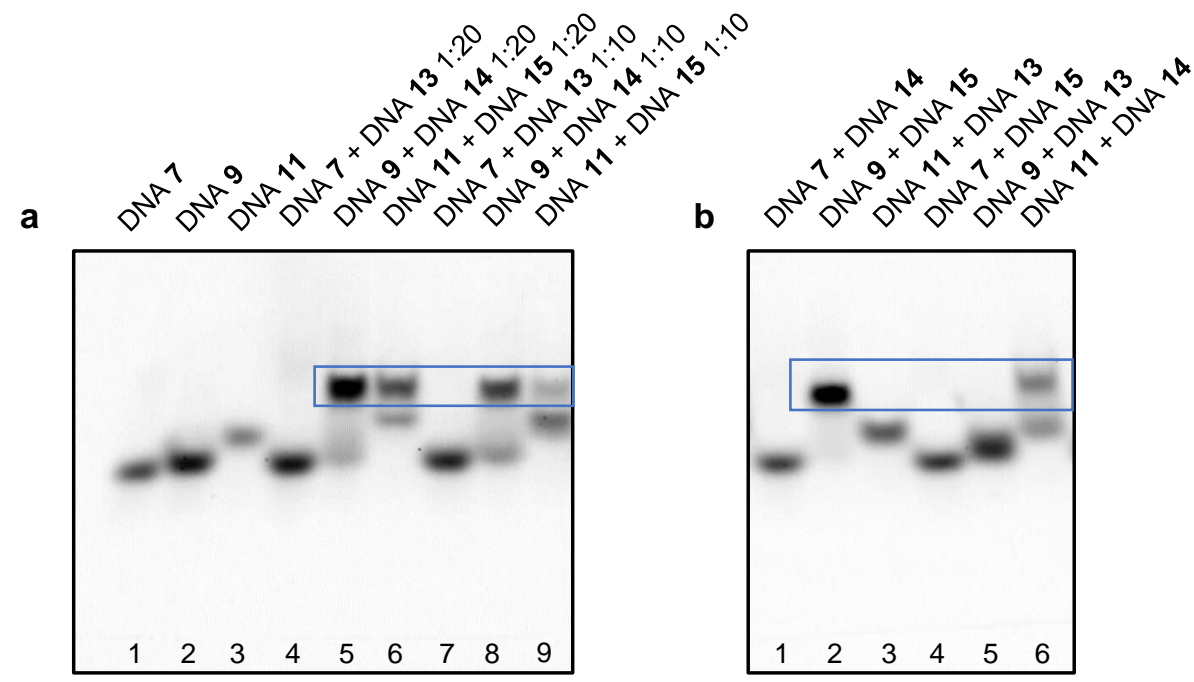

Abbildung 56: Band-Shift-Experiment mit Cy5 gelabelten TFOs. a: TFOs 7, 9 und 11 (je $500 \mathrm{nM}$ ) sowie die Ziel-DNAs 13 , 14 und 15. Lane 1: DNA 7; Lane 2: DNA 9; Lane 3: DNA 11; Lane 4: DNA 7 + DNA 13 (5 $\mu \mathrm{M})$; Lane 5: DNA 9 + DNA 14 $(5 \mu \mathrm{M})$; Lane 6: DNA 11 + DNA $15(5 \mu \mathrm{M})$; Lane 7: DNA 7 + DNA $13(10 \mu \mathrm{M})$; Lane 8: DNA 9 + DNA $14(10 \mu \mathrm{M})$; Lane 9 : DNA 11 + DNA $15(10 \mu \mathrm{M})$. : Kreuzexperimente mit den TFOs 7, 9 und 11 (je $500 \mathrm{nM}$ ) und den Ziel-DNAs 13, 14 und 15 (je $10 \mu \mathrm{M})$. Lane 1: DNA 7 +DNA 14; Lane 2: DNA 9 + DNA 15; Lane 3: DNA 11 + DNA 13; Lane 4: DNA 7 + DNA 15; Lane 5: DNA 9 + DNA 13; Lane 6: DNA 11 + DNA 14. Die Proben wurden 20 h bei $37^{\circ} \mathrm{C}$ inkubiert. $8 \%$ nativ PAGE. Die Detektion der Banden erfolgte über die Cy5-markierten DNAs. Die Banden der entstandenen Komplexe sind blau eingerahmt.

Fluoreszenz detektiert.

Auf der Suche nach optimalen Verhältnissen, wurden die entsprechenden TFOs zunächst mit einem zehnfachen der Ziel-DNAs für $20 \mathrm{~h}$ bei $37^{\circ} \mathrm{C}$ in Triplexpuffer $(50 \mathrm{mM}$ HEPES-NaOH pH 7.0, $50 \mathrm{mM} \mathrm{NaCl}, 2 \mathrm{mM} \mathrm{MgCl}_{2}$ ) inkubiert (Abbildung 56, a, Lane 7 - 9). Dabei konnte für die DNA 9 eine intensive neue Bande beobachtet werden (a, Lane 8), welche auf eine Triplexbildung schließen ließ. Diese war jedoch nicht vollständig. Für die DNA 11 war eine schwache Bindung zu beobachten (a, Lane 9), während mit der DNA 7 keine Triplexbildung stattfand (a, Lane 7). Bei Experimenten mit einem zehnfachen Überschuss der TFOs konnte in keinem Fall eine vollständige Triplexbildung beobachtet werden. Auf Grundlage dieser Ergebnisse wurden die TFOs mit einem 20fachen Überschuss der Ziel-DNAs inkubiert. In diesem Fall wies die DNA 9 eine fast vollständige Komplexbildung auf (Abbildung 56, a, Lane 5). Auch mit der DNA 11 konnte ein hoher Anteil des Triplex beobachtet werden (a, Lane 6), während mit der DNA 7 keine Effekte auftraten. Somit war dieses TFO unter den gewählten Bedingungen nicht zu einer Triplexbildung in der Lage und für die gewünschte Anwendung ungeeignet.

Ausgehend von diesen Ergebnissen wurde die Spezifität der Triplexbildung in Kreuzexperimenten untersucht. Hierbei wurden keine Effekte erwartet, da sich die Sequenzen der DNAs 7, 9 und 11 weitgehend unterschieden. Entgegen dieser Annahme konnte eine Triplexbildung sowohl zwischen den DNAs 9 und 15 als auch zwischen 11 und 14 beobachtet werden (Abbildung 56, b, blauer Kasten). Dabei war die Komplexbildung der 
DNA 9

\section{AGAAGGAAGAAAGAGGAGAGGAA ${ }^{5}$ \\ 5'CGTGAGGAGAGAGAAGAAAGAGGAAAGGAAGATATC \\ DNA 15 \\ DNA 11 \\ GAGGAGAGAGAAGAAAGAGGAAAGGAAG ${ }^{5}$ \\ 5.CGTGAGGAGAAGGAAGAAAGAGGAGAGGAAGATATC \\ DNA 14}

Abbildung 57: Mismatch-Stellen zwischen den DNAs 9 und 15 sowie 11 und 14. Die Bindestellen sind gelb unterlegt. Dabei sind nur die Purinsträng der DNAs 14 und 15 gezeigt.

DNA 9 mit der DNA 15 (b, Lane 2) sogar vergleichbar mit der der eigentlichen Ziel-DNA 14 (a, Lane 5). Aufgrund dieser Befunde wurden die Sequenzen der TFOs 9 und 11 verglichen und eine Übereinstimmung von 12 Nukleotiden gefunden (Abbildung 57, gelb). Da für beide TFOs eine gute Bindung beobachtet werden konnte, lag die Annahme nahe, dass die Komplexbildung über diese 12 Nukleotide erfolgte. Eine mögliche Erklärung für die unterschiedliche Ausprägung der Effekte wäre, dass längere ungebundene Bereiche die Affinität durch eine erhöhte elektrostatische Repulsion herabsetzten. Dadurch würde die DNA 11 schwächer binden als die DNA 9. Diese Ergebnisse wiesen darauf hin, dass die Triplexbildung deutlich weniger selektiv war als angenommen und die Komplexbildung auch mit Teilsequenzen der TFOs möglich war. Dabei betrug die Teilsequenz wahrscheinlich 12 Nukleotide und lag somit unter den 16, die für eine spezifische Anwendung in Organismen benötigt würden.

Da mit den TFOs 9 und 11 Bedingungen gefunden wurden, die eine Triplexbildung ermöglichten, wurde als nächstes die Fragestellung untersucht, ob der hairpin in den Adaptoren 8, 10 und 12 einen Einfluss auf die Affinität besaß. Auch hierzu wurden Band-Shift-Experimente durchgeführt (Abbildung 58). Dabei konnten die vorherigen Ergebnisse bestätigt werden und mit der DNA 10 eine deutliche Komplexbildung beobachtet werden (Lane 5, blauer Kasten). Allerdings war in diesem Fall ein größerer Anteil des freien Adaptors zu beobachten als im Fall der DNA 9. Dies deutete darauf hin, dass die Affinität des Adaptors aufgrund des hairpins geringer war als bei dem entsprechenden TFO. Auch für die DNA 12 konnte eine Komplexbildung beobachtet werden (Lane 8, roter Kasten). Diese war jedoch deutlich geringer als bei dem entsprechenden TFO 11, was ebenfalls auf eine Abnahme der Affinität schließen ließ. Mit der DNA 8 zeigten sich, wie in den Experimenten mit DNA 7, keine Effekte (Lane 2). Im Anschluss wurden die Experimente in Puffer $\mathrm{Z}$ wiederholt, um zu überprüfen, ob $\mathrm{K}^{+}$-Ionen und höhere $\mathrm{Mg}^{2+}-$ Konzentrationen die Triplexbildung beeinflussten. In den Versuchen konnte jedoch kein Unterschied beobachtet werden. In weiteren Experimenten konnte zudem gezeigt werden, dass die DNA 10, analog zu DNA 9, einen Komplex mit der DNA 15 
bildete. Dies zeigte, dass die Spezifität der hairpin-TFOs ebenfalls geringer als erwartet war. Dennoch konnte anhand der Band-Shift-Experimente gezeigt werden, dass der Adaptor 10 zur Umleitung von Sp1 geeignet war. Allerdings war die Affinität der Adaptoren deutlich geringer als die der PIP-Adaptoren an DNA 1.

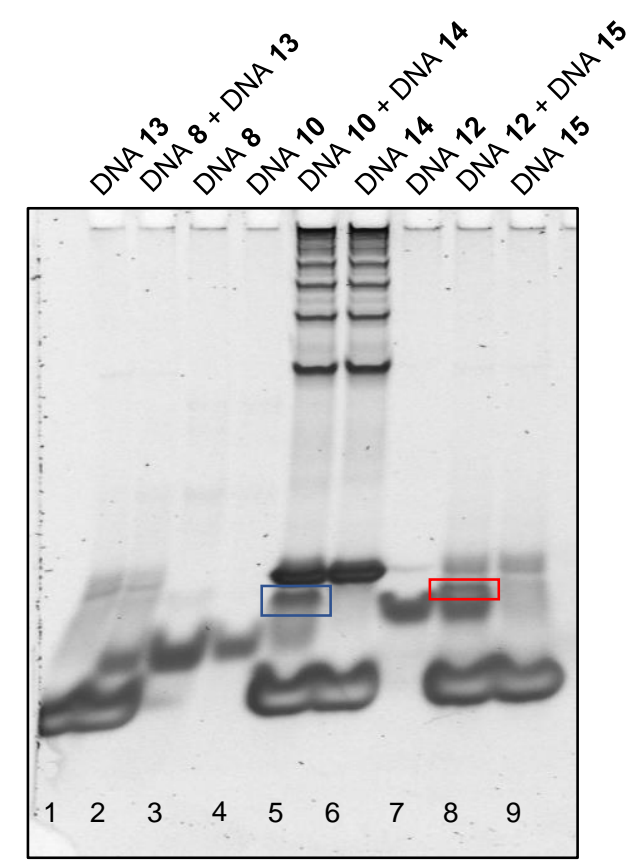

Abbildung 58: Band-Shift mit den DNAs 8, 10 und 12 (je $200 \mathrm{nM}$ ) und den Ziel-DNAs 13, 14 oder 15 (je $4 \mu \mathrm{M}$ ). Lane 1: DNA 13, Lane 2: DNA 8 + DNA 13; Lane 3: DNA 8; Lane 4: DNA 10; Lane 5: DNA 10 + DNA 14; Lane 6: DNA 14; Lane 7: DNA 11; Lane 8: DNA 11 + DNA 15; Lane 9: DNA 15. Die Proben wurden $23 \mathrm{~h}$ bei $37^{\circ} \mathrm{C}$ in Triplexpuffer inkubiert. $8 \%$ nativ PAGE. Die Detektion der Banden erfolgte durch Färbung mit SYBR Gold. Die Banden der Triplexe sind farbig markiert. Die DNA 14 wurde im Vorfeld dieses Experiments nicht annealed. Dadurch lagen neben dem hairpin selbstkomplementäre Oligomere vor.

\subsubsection{Vergleich der TFO-Adaptoren mit den PIP-Konjugaten}

Um die TFO-Adaptoren mit den PIP-basierten Systemen genauer vergleichen zu können, war es notwendig, sie unter analogen Bedingungen zu untersuchen. Dazu wurde das Konjugat K5a mit den DNAs 13 - 15 (Abbildung 59) in Triplexpuffer bei $37^{\circ} \mathrm{C}$ inkubiert. Um auszuschließen, dass sich die Affinität von K5a im Triplexpuffer änderte, wurde die DNA 1 als Kontrolle eingesetzt. Zusätzlich sollte die Bindung von K5a an die DNA 1 mit der an die DNAs 13 - 15 verglichen werden. Hierbei war zu beachten, dass die DNAs zwei Bindestellen für K5a aufwiesen (Abbildung 59, rot und blau) und somit auch eine mehrfache Bindung des Konjugats möglich war. Dies könnte zu verschiedenen Komplexen führen, welche ein unterschiedliches Laufverhalten zeigen sollten. Auch dies wurde in den Band-Shift-Experimenten untersucht. Aufgrund der zuvor mit den PIP-Konjugaten erhaltenen Ergebnisse wurde $\mathbf{K 5 a}$ in einem vierfachen Überschuss eingesetzt. Die 


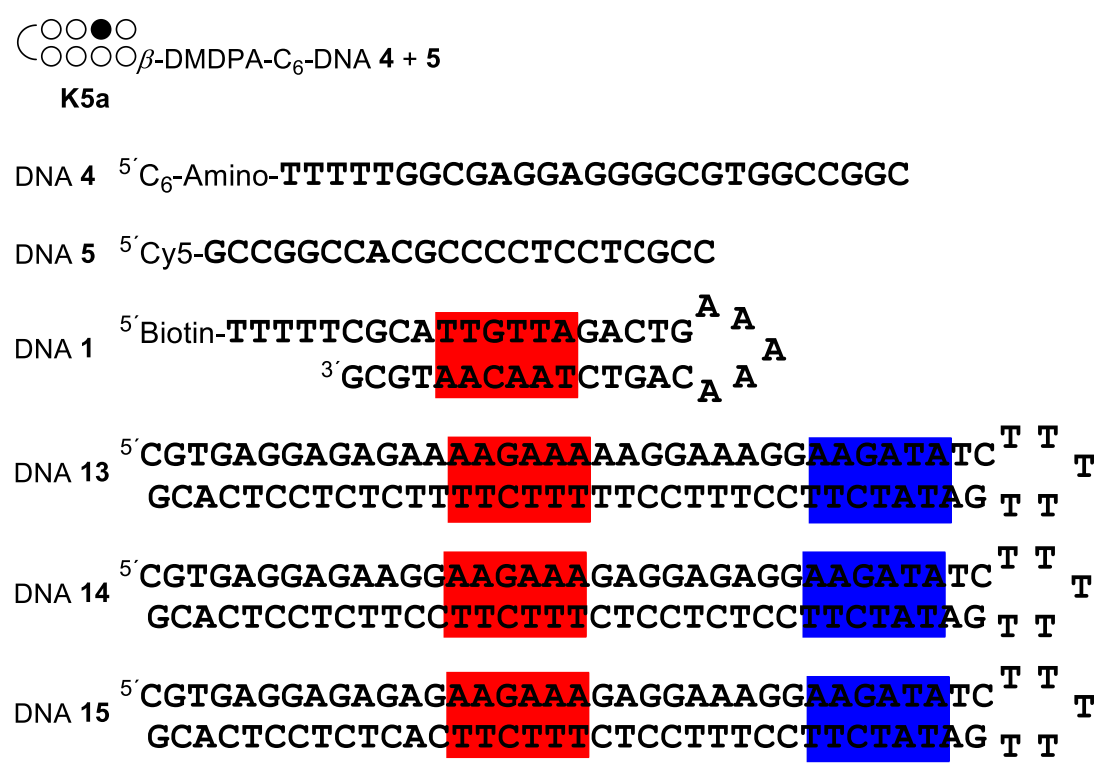

Abbildung 59: Für die Band-Shift-Experimente eingesetzte ONs. Die Bindestellen für K5a sind rot unterlegt. Die alternativen Bindestellen für die Konjugate sind blau unterlegt.

Detektion der Banden erfolgte dabei sowohl über eine Färbung des Gels als auch über das Cy5-gelabelte Konjugat (Abbildung 60, a und b). Analog zu den vorhergehenden Experimenten war die Bande der DNA 1 nach der Bindung des Konjugats K5a kaum noch nachzuweisen, wodurch eine Störung der Komplexbildung durch den Puffer auszuschließen war (Abbildung 60, a, Lane 3). Auch die Bande der DNA 13 war nach der Inkubation mit K5a sehr geschwächt und der entstehende Komplex migrierte deutlich langsamer (Abbildung 60, a, Lane 4). In beiden Fällen konnte auch in der Cy5-Detektion beobachtet werdenden, dass das Konjugat eine kürzerer Laufstrecke aufwies (b, Lane 3 und 4) als im ungebundenen Fall (b, Lane 1). Zudem zeigte sich mit der DNA 13, dass die Bande des Komplexes nur etwa ein Drittel der Intensität des freien Konjugats aufwies. Von den vier Äquivalenten des Adaptors wäre demnach nur einer gebunden. Daraus kann auf eine 1:1 Stöchiometrie geschlossen werden. Im analogen Experiment mit den DNAs $\mathbf{1 4}$ und 15 konnte jedoch kein klarer Band-Shift beobachtet werden (a, b, Lane 5 und 6). Allerdings wurde das Konjugat im Überschuss eingesetzt und es war nicht auszuschließen, dass die Bande des Komplexes durch die des freien Konjugats überlagert wurde. Um eine bessere Auflösung zu erhalten, wurde das Experiment mit einem Unterschuss von K5a wiederholt (Abbildung 60, c). Wie im vorhergehenden Experiment führte die Komplexbildung von K5a mit den DNAs 1 und 13 zu einer langsameren Migration (c, Lane 2 und 3). Dabei zeigte sich, die beobachtete Laufstrecke des Komplexes aus DNA 13 und K5a unabhängig von der Konzentration des Konjugats war (vgl. b, Lane 4 und c Lane 3) und auch dies sprach für eine einfache Bindung von K5a an DNA 13. Im Fall der DNAs 14 und 15 konnte nun ebenfalls eine langsamere Migration des Adaptors beobachtet werden und die Banden waren deutlich fokussierter als die des freien Konjugats (Abbildung 60, c, Lane 4 und 5). 


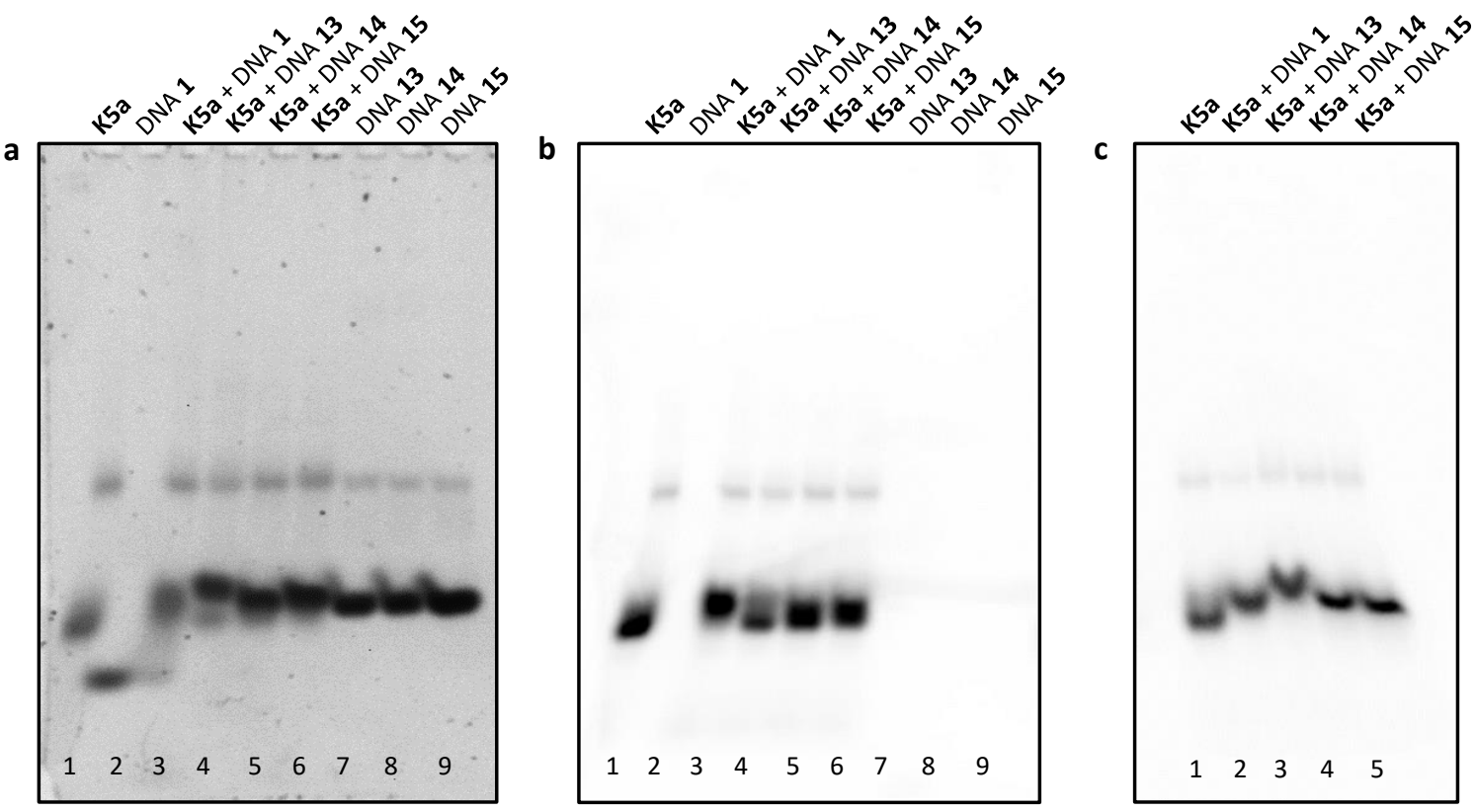

Abbildung 60: Band-Shift mit den Ziel-DNAs 1 sowie $\mathbf{1 3}-\mathbf{1 5}$ und K5a. a + b: K5a (2 $\mu \mathrm{M})$, Ziel-DNAs (0.5 $\mu \mathrm{M})$. Lane 1: K5a; Lane 2: DNA 1; Lane 3: K5a + DNA 1; Lane 4: K5a + DNA 13; Lane 5: K5a + DNA 14; Lane 6: K5a + DNA 15; Lane 7: DNA 13; Lane 8: DNA 14; Lane 9: DNA 15. c: K5a (0.5 $\mu \mathrm{M})$, Ziel-DNAs $(2 \mu \mathrm{M})$. Lane 1: K5a; Lane 2: K5a + DNA 1; Lane 3: K5a + DNA 13; Lane 4: K5a + DNA 14; Lane 5: K5a + DNA 15. Die Proben wurden $20 \mathrm{~h}$ bei $37^{\circ} \mathrm{C}$ in Triplexpuffer inkubiert. $8 \%$ nativ PAGE. Die Detektion der Banden erfolgte durch Färbung mit SYBR Gold (a) oder über die Cy5-markierten DNA 5 $(\mathbf{b}+\mathbf{c})$.

Daraus ließ sich schließen, dass K5a auch mit den DNAs 14 und 15 vollständig komplexierte. Allerdings war der Effekt auf die Laufstrecke geringer war als im Fall der DNA 13. Aus dieser Beobachtung konnten zwei Schlüsse gezogen werden. Dies deutete einerseits darauf hin, dass auf den DNAs 14 und 15 nur eine der Bindestellen besetzt wurde und bedeutete andererseits, dass sich die Bindestelle auf DNA 13 von denen der anderen DNAs unterscheiden musste. Da die Bindestelle in der Nähe des turns auf allen DNAs identisch ist, konnte davon ausgegangen werden, dass K5a mit der rot markierten Stelle assoziiert (Abbildung 59). Außerdem war aufgrund des größeren Shifts von DNA 13 anzunehmen, dass die Affinität von K5a zu dieser Bindestelle höher war als zu den rot markierten Sequenzen in DNA 14 und 15. Für diese DNAs konnte keine direkte Aussage über die Bindestellen getroffen werden. Da es im Fall der DNA 13 jedoch keine Hinweise auf eine Komplexierung der blauen Sequenz gab, war anzunehmen, dass diese auch in den DNAs $\mathbf{1 4}$ und $\mathbf{1 5}$ nicht mit $\mathbf{K 5 a}$ interagiert. Somit kann geschlossen werden, dass für die Wechselwirkung von K5a mit seinen Ziel-DNAs die jeweils roten Positionen verantwortlich sind. Eine mögliche Erklärung für die unterschiedliche Affinität zu den Bindestellen besteht darin, dass der Bereich auf der DNA 13 von A-T-Paaren umgeben ist, welche im Allgemeinen zu einer höheren Affinität der PIPs führen, ${ }^{[131]}$ während die Bindestellen auf den DNAs 14 und 15 von G.C-Paaren abgeschlossen wurden. Die entscheidende Erkenntnis war jedoch, dass eine Mehrfachbindung an die DNAs 13 - 15 
unwahrscheinlich und somit ein Vergleich der PIP-Konjugate mit den TFO-Adaptoren ohne Berücksichtigung der zweiten Bindestelle möglich ist.

In den Band-Shift-Experimenten mit K5a konnte bei einem vierfachen Überschuss der Ziel-DNAs 13 - 15 in keinem der Fälle eine Bande des freien Konjugats beobachtet werden. Somit war davon auszugehen, dass die Affinitäten von K5a zu den DNAs 13 - 15 in einem ähnlichen Bereich lagen, wie die zu DNA 1 und damit deutlich höhere Affinitäten als die TFO-Adaptoren besaßen, bei denen auch bei einer fünffach höheren Konzentration der Ziel-DNAs kein vollständiges Verschwinden der Adaptor-Bande zu beobachten war. Darüber hinaus war auch die Spezifität der TFOs geringer als erwartet und lag unter den erforderlichen 16 bp, womit auch dieser potenzielle Vorteil der TFOs weniger ausgeprägt war. Ein weiterer Vorteil der PIP-Konjugate ist, dass sie auch bei einem Überschuss zur Ziel-DNA binden, was bei den TFOs nicht beobachtet wurde. Des Weiteren war die Zielsequenz der PIP-Adaptoren deutlich flexibler zu wählen als die der TFOs. Aufgrund dieser Ergebnisse wurden mit den TFO-Adaptoren keine Pulldown-Experimente durchgeführt, da die Adaptoren nicht effektiv genug waren. Da für eine Bindung der TFO-Adaptoren ein 20facher Überschuss des Targets benötigt wurde und in den vorangegangenen Experimenten eine hohe unspezifische Bindung des rekombinanten Sp1 zu beobachten war, konnte zudem angenommen werden, dass die TFO-Adaptoren nicht mit den Pulldown-Experimenten kompatibel waren. Aus diesem Grund sollten vorrangig die PIP-Adaptoren eingesetzt werde und auf ihre Fähigkeit, die Expression eines Modellprotein zu aktivieren, getestet werden. In Rahmen dieser Experimente war geplant, auch die DNA 10 einzusetzen und mit den PIP-Konjugaten zu vergleichen. Ein Grund hierfür war, dass mit den PIP-Konjugaten stärkere off-target-Effekte zu erwarten waren und dies zu einer verminderten Transkriptionsaktivierung führen könnte. Mit den TFO-Adaptoren sollten diese Effekte geringer sein und somit war eine stärkere Genexpression nicht auszuschließen. 


\subsection{Zellkulturversuche mit K9}

In den vorangegangenen Experimenten konnte gezeigt werden, dass die PIP-basierten Adaptoren Sp1 auf eine nicht natürliche Bindestelle umleiten konnten. Dies lieferte jedoch keinen Hinweis, ob auch die Transkription aktiviert werden könnte. Um dies zu überprüfen, waren Zellkulturexperimente geplant, in denen die Aktivierung der Transkription durch einen Luciferase-Assay detektiert werden sollte. In Zusammenarbeit mit der Arbeitsgruppe Marschalek wurde die Zielsequenz der DNA 9 ( ${ }^{5}$ AGAAGGAAGAAAGAGGAGAGGAA) fünfmal in die Promotorregion der Luciferase eingebaut und diese konnte sowohl von dem PIP-Adaptor K9 als auch von dem TFO-Adaptor $\mathbf{1 0}$ aktiviert werden. Zur Normierung diente eine konstante Expression von GFP. Um gleichbleibende Ergebnisse zu erhalten, wurden dazu stabil transfizierte HeLa-Zellen über ein Sleeping-Beauty-Transposon ${ }^{[222]}$ hergestellt. In den Zellkulturexperimenten wurde zunächst das Konjugat $\mathbf{K 9}$ eingesetzt, mit dem die besten Ergebnisse zu erwarten waren. Dieses wurde ohne Transfektionsreagenzien eingesetzt, da aus Arbeiten zu TF decoys bekannt war, dass kurze dsDNAs in Zellen aufgenommen werden können ${ }^{[199]}$ und auch die PIPs zellgängige Moleküle sind. ${ }^{[15]}$ Dabei konnten im hohen nanomolaren Bereich minimale Effekte beobachtet werden, die auf eine erhöhte Transkription hindeuten. Da es sich um einen ersten Test handelte, wurde $\mathbf{K} \mathbf{9}$ lediglich mit unbehandelten Zellen verglichen und auf weitere Kontrollen verzichtet. Aus diesen Gründen zeigen die Ergebnisse zwar, dass die Zugabe des Adaptors wohlmöglich zu einer erhöhten Transkription führt. Es konnte jedoch nicht geklärt werden, ob die Umleitung von Sp1 oder ein anderer Mechanismus dafür verantwortlich war. Weitere Experimente wurden wegen eines Defekts des Messgeräts ausgesetzt und konnten wegen der Covid-19-Pandemie nicht fortgeführt werden. 


\subsection{Bausteine für pseudokomplementäre PNA}

Als weitere Klasse DNA-bindender Moleküle fiel die Wahl auf pseudokomplementäre PNAs. Diese enthalten anstelle der Basen A und T Diaminopurin (D) und Thiouracil ( $\left.U_{s}\right)$ wodurch eine Selbsthybridisierung der PNAs durch sterische Wechselwirkungen verhindert wird. Gleichzeitig bilden sie stabile Duplices mit der DNA und sind zur Doppelstranginvasion in der Lage. ${ }^{[223]}$ Die Synthese der PNAs war mittels Fmoc-basierter Festphasensynthese geplant, wofür die Monomere 46 und 47 benötigt wurden (Abbildung 61, a), welche nicht kommerziell verfügbar waren ${ }^{[75]}$ und synthetisiert werden mussten. In der Bachelorarbeit von Kerim Yilmaz ${ }^{[224]}$ konnte der Baustein 46 erfolgreich aufgebaut werden, während die Synthese des Monomers 47 nicht gelang. Hierbei war insbesondere die Synthese der Verbindung 48 (Abbildung 61, b) problematisch, da das gewünschte Isomer nur zu $35 \%$ erhalten wurde und zusätzlich eine Alkylierung am N3 (48a) und am Sauerstoff (48b) beobachtet wurde. Auch in der nachfolgenden Verseifung konnten nur mäßige Ausbeuten erhalten werden, da die stark säurelabile 2-Methyl-4-methoxybenzyl-Gruppe (MMPM) eine saure Aufarbeitung der Reaktion verhinderte. In der vorliegenden Arbeit sollte die Synthese des Monomers 47 optimiert werden.

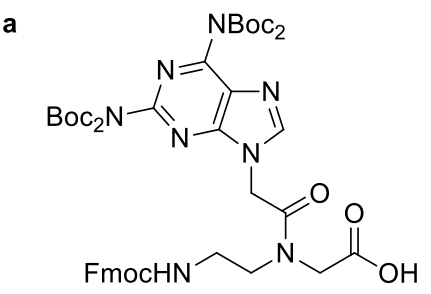

46

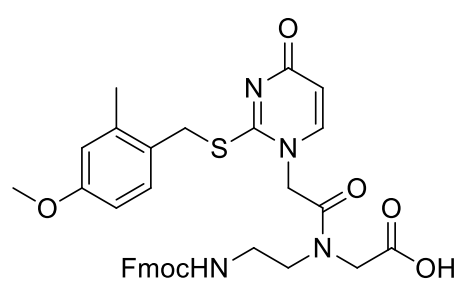

47

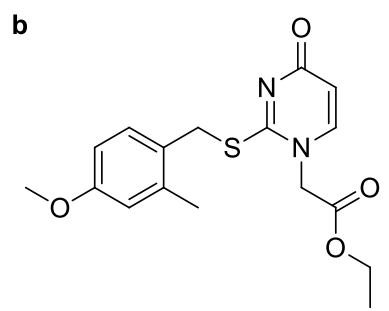

48

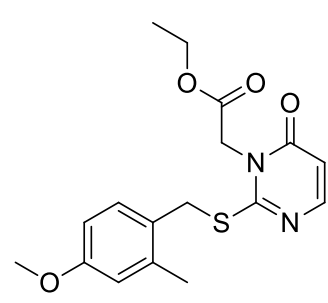

$48 a$

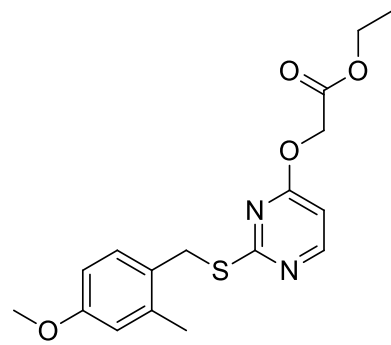

48b

Abbildung 61: a: Monomere für die Festphasensynthese pseudokomplementärer PNAs. b: Produkte bei der Alkylierung des MMPM-geschützten Thiouracils.

Für die Synthese der Verbindung 48 musste zunächst $U_{s}$ mit der MMPM-Gruppe geschützt werden (Schema 24). Dazu wurde, ausgehend von Aldehyd 49, das Bromid 51 synthetisiert, welches dann weiter mit $U_{s}$ umgesetzt wurde. Zwar gelang die Synthese von Verbindung 51 in guten Ausbeuten, allerdings zeigte sich, dass die Verbindung sehr reaktiv war und schon bei Raumtemperatur zur Polymerisation neigte. Aufgrund der schlechten Löslichkeit des $U_{s}$, musste die Reaktion in einem Gemisch aus EtOH und KOH durchgeführt 


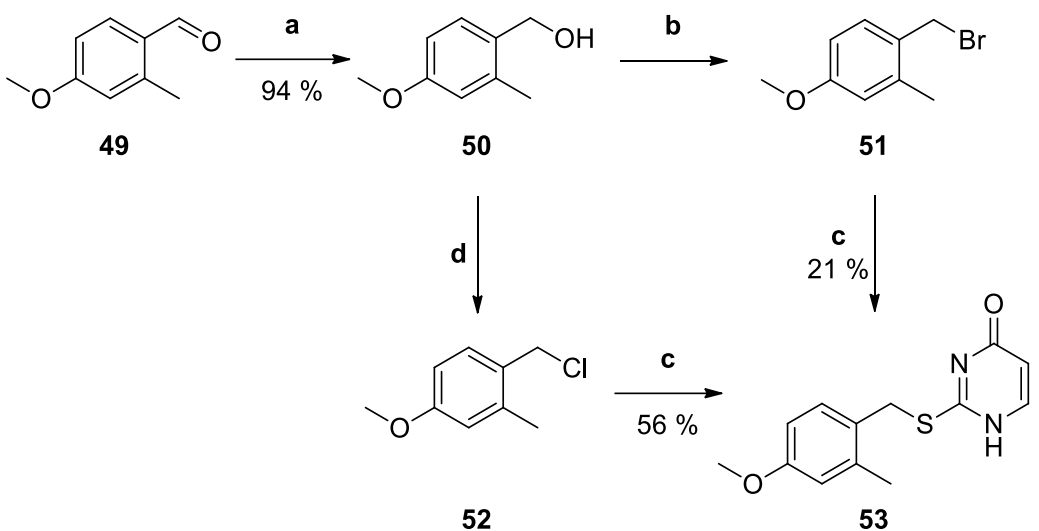

Schema 24: Synthese von Verbindung 53. a: $\mathrm{NaBH}_{4}, \mathrm{MeOH}, \mathrm{RT} ; \mathbf{b}: \mathrm{PBr}_{3}, \mathrm{DCM}$; c: Thiouracil, $\mathrm{KOH}, \mathrm{EtOH} / \mathrm{H}_{2} \mathrm{O} ; \mathrm{RT} ; \mathbf{d}$ : TMSCl, RT.

werden, wobei $\mathbf{5 1}$ mit EtOH zum einem Ethoxyether reagierte und $\mathbf{5 3}$ nur in schlechten Ausbeuten (21\%) erhalten wurde. Um dies zu umgehen, wurde der Alkohol 50 zunächst in situ in das weniger reaktive Chlorid 52 überführt ${ }^{[225]}$ und zu der Lösung des $U_{s}$ gegeben. Auf diese Weise konnte 53 in mäßigen Ausbeuten (56\%) erhalten werden. Da eine Alkylierung der Verbindung $\mathbf{5 3}$ mit NaOEt in EtOH sowie dem Bromid $\mathbf{5 4}$ (Abbildung 62) nur mit einer geringen Selektivität an N1 verlief, musste ein Weg gefunden werden, die Reaktion von N3 sowie des Sauerstoffs zu verhindern. Hierzu wurde der Sauerstoff des $U_{s}$ zunächst in situ mit TMS geschützt. ${ }^{[226,227]}$ Aufgrund des sterischen Anspruchs der TMSGruppe konnte dadurch auch das N3 des $U_{s}$ abgeschirmt werden. Allerdings war eine Alkylierung mit dem Bromid $\mathbf{5 4}$ nicht mehr möglich und es musste das Triflat $\mathbf{5 5}$ (Abbildung 62) eingesetzt werden. ${ }^{[227]}$ Die Verbindung 48 konnte in guten Ausbeuten erhalten werden (60 - $80 \%$ ). Da die Reaktion unter leicht sauren Bedingungen verlief, durfte die Silylierung jedoch nicht länger als $1 \mathrm{~h}$ dauern, da ansonsten die MMPM-Gruppe

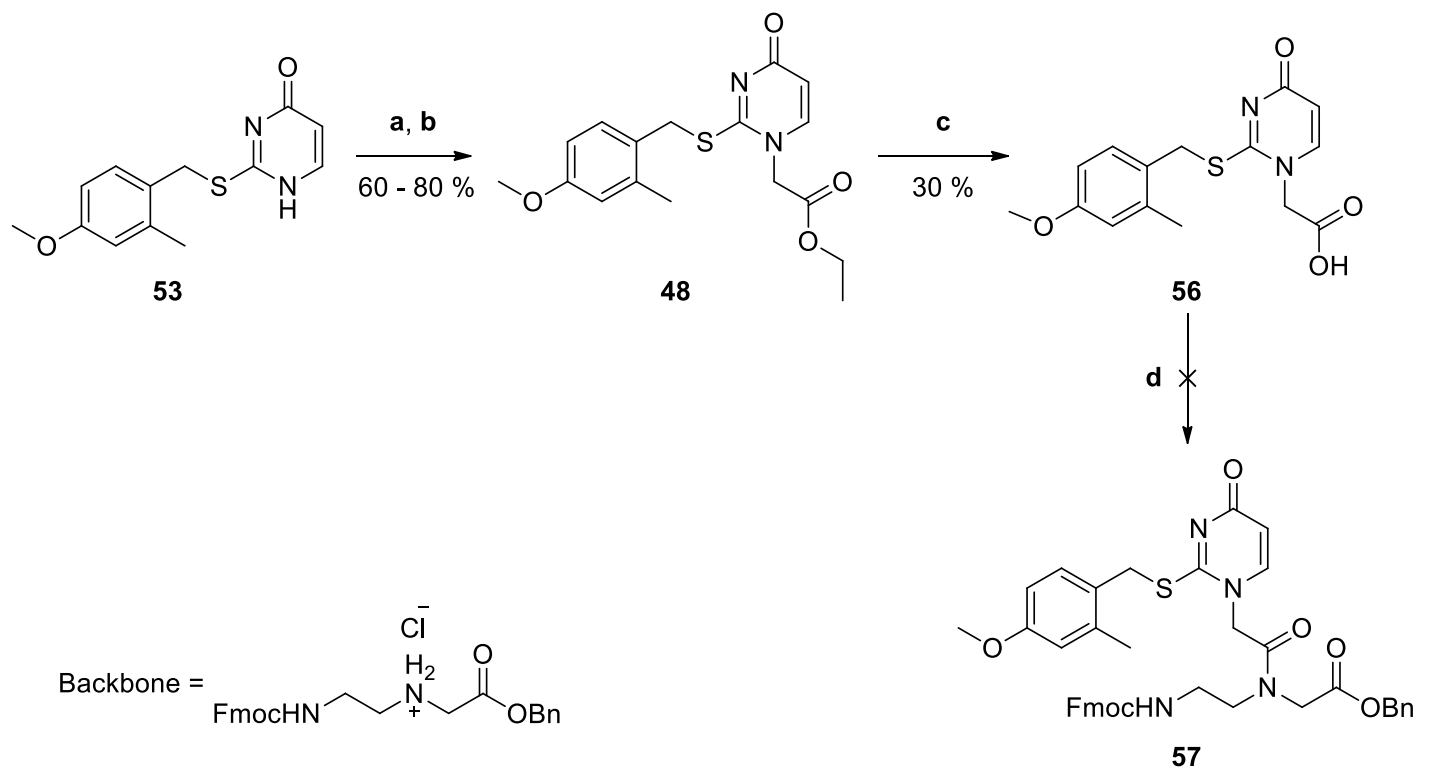

Schema 25: Synthese von Verbindung 57. a: 1. HMDS, Saccharin, b: 55, DCM, Reflux; c: LiOH, MeOH/THF/H $\mathrm{O}$ (3:7:1), RT; d: 1. HBTU, DIPEA, 2. Backbone, DMF, RT. Die Verbindung 57 konnte nicht isoliert werden. 


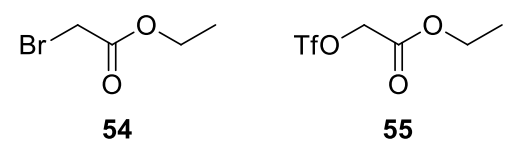

Abbildung 62: Alkylierungsmittel für N1 des MMPM-geschützten Thiouracils.

abgespalten wurde und dies zur Alkylierung des Schwefels führte (analog zu Schema 26). Im Anschluss wurde $48 \mathrm{zu}$ Verbindung 56 verseift. Dabei war in einer Reaktionskontrolle mittels Dünnschichtchromatographie eine schnelle und vollständige Umsetzung zu beobachten. Jedoch erwies sich die Aufarbeitung als kompliziert, da die Lösung aufgrund der Labilität der Schutzgruppe nicht angesäuert werden konnte. Dies erschwerte die Präzipitation der Verbindung 56, welche nur in schlechten Ausbeuten (30\%) und geringen Mengen (max. 14 mg) erhalten werden konnte. Die erhaltene Carbonsäure wurde daraufhin mit dem Backbone verknüpft und mittels Massenspektrometrie konnte die Verbindung 57 nachgewiesen werden. Allerdings gelang eine Isolierung der Verbindung nicht. Hierbei war die geringe Zugänglichkeit der Carbonsäure ein entscheidender Faktor und so wurde eine alternative Syntheseroute der Verbindung $\mathbf{5 6}$ getestet, in der zunächst die Säurefunktion und dann die Schutzgruppe eingeführt werden sollte. Dazu musste die Verbindung 60 aufgebaut werden (Schema 26), indem das $U_{s}$ zunächst in situ silyliert und im Anschluss mit Verbindung $\mathbf{5 5}$ alkyliert wurde. Allerdings war die Synthese von $\mathbf{6 0}$ auf diese Weise nicht möglich und es konnten lediglich die Verbindungen $\mathbf{5 8}$ und $\mathbf{5 9}$ isoliert werden.

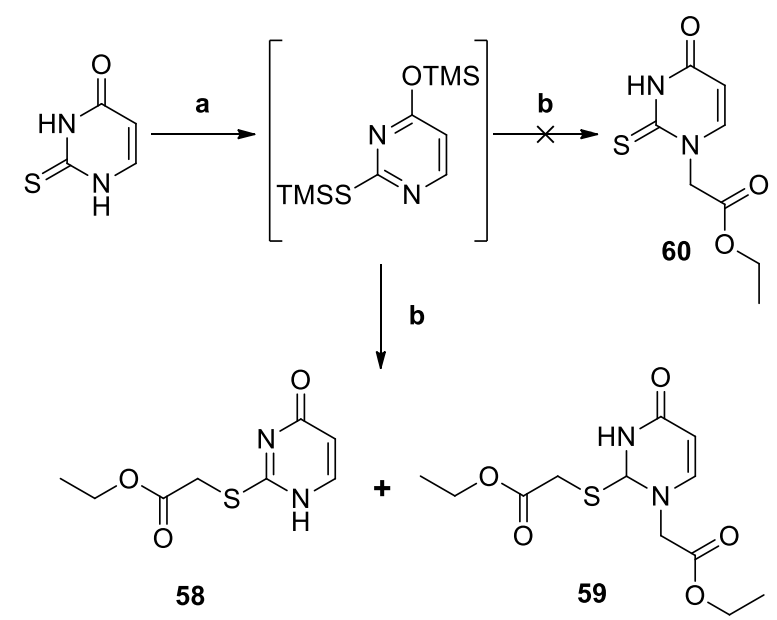

Schema 26: Versuch der direkten Alkylierung von 2-Thiouracil. Allerdings konnten nur die Verbindungen $\mathbf{5 8}$ und $\mathbf{5 9}$ isoliert werden. a: HMDS, Saccharin, $\mathrm{DCM}, 60^{\circ} \mathrm{C}$; b: $\mathbf{5 5}$, DCM, $60^{\circ} \mathrm{C}$.

Nachdem die Synthese der Verbindung 56 nicht in ausreichenden Mengen erhalten werden konnte und die hohe Säurelabilität der MMPM-Gruppe ein großes Problem darstellte, war es notwendig, eine stabilere Schutzgruppe zu verwenden. Hierbei fiel die Wahl auf die in der Boc-basierte Festhasensynthese genutzte PMB-Gruppe, ${ }^{[228]}$ welche elektronenärmer als die MMPM-Gruppe war. Da die Entfernung der Schutzgruppen in der Boc-basierten Festphasensynthese mit einer Mischung aus Trifluormethansulfonsäure und TFA erfolgte, während im Fmoc-basierten Fall TFA/TIPS/ $\mathrm{H}_{2} \mathrm{O}$ (95:2.5:2.5) eingesetzt wurde, stellte sich 
die Frage, ob die PMB-Gruppe in der Fmoc-Synthese eingesetzt werden konnte. In einer Arbeit von Góngora-Benítez et al. an PMB-geschützten Cystein konnte gezeigt werden, dass eine Entfernung der PMB-Gruppe mit 95\%iger TFA in $2 \mathrm{~h}$ bei $40^{\circ} \mathrm{C}$ möglich war. ${ }^{[229]}$ $\mathrm{Da}$ das Thiouracil eine bessere Abgangsgruppe darstellen sollte, wurde davon ausgegangen, dass die Schutzgruppe auch in $1 \mathrm{~h}$ bei RT entfernt werden könnte. Zur Überprüfung wurde die Verbindung 62 synthetisiert (Schema 27) und im Anschluss in einer Mischung aus TFA/TIPS/ $\mathrm{H}_{2} \mathrm{O}$ (95:2.5:2.5) zu Verbindung 60 entschützt. Dazu wurde zunächst $U_{S}$ mit PMBCl zu Verbindung 61 umgesetzt, wobei höhere Ausbeuten (61\%) als in der vergleichbaren Reaktion zu Verbindung 53 (max. $56 \%$ ) erhalten wurden. Im Anschluss erfolgte die Alkylierung an N1 analog zur Synthese von 48. Aufgrund der größeren Stabilität der PMB-Gruppe, war die Reaktionszeit in diesem Fall weniger kritisch und es konnten vergleichbare Ausbeuten (58\%) zur Synthese von 48 erhalten werden. Um die Abspaltung der PMB-Gruppe zu testen, wurde Verbindung 62 in TFA/TIPS/ $\mathrm{H}_{2} \mathrm{O}$ (95:2.5:2.5) aufgenommen und $1 \mathrm{~h}$ bei RT inkubiert. Dabei konnte mittels DC-Kontrolle bereits nach 30 min ein deutlicher und nach 1 h ein vollständiger Umsatz der Verbindung 62 beobachtet werden. Nach Entfernen des Lösemittels wurde das Rohprodukt mittels Massen- und NMR-Spektrometrie untersucht (Abbildung 63). Dabei konnte eine vollständige Entfernung der PMB-Gruppe beobachtet und das erhaltene Produkt als Verbindung 60 identifiziert werden. Nachdem gezeigt werden konnte, dass die PMB-Gruppe als Schutzgruppe geeignet war, sollte daraus das entsprechende Monomer 65 synthetisiert werden. Dazu wurde Verbindung 62 mit LiOH verseift und die

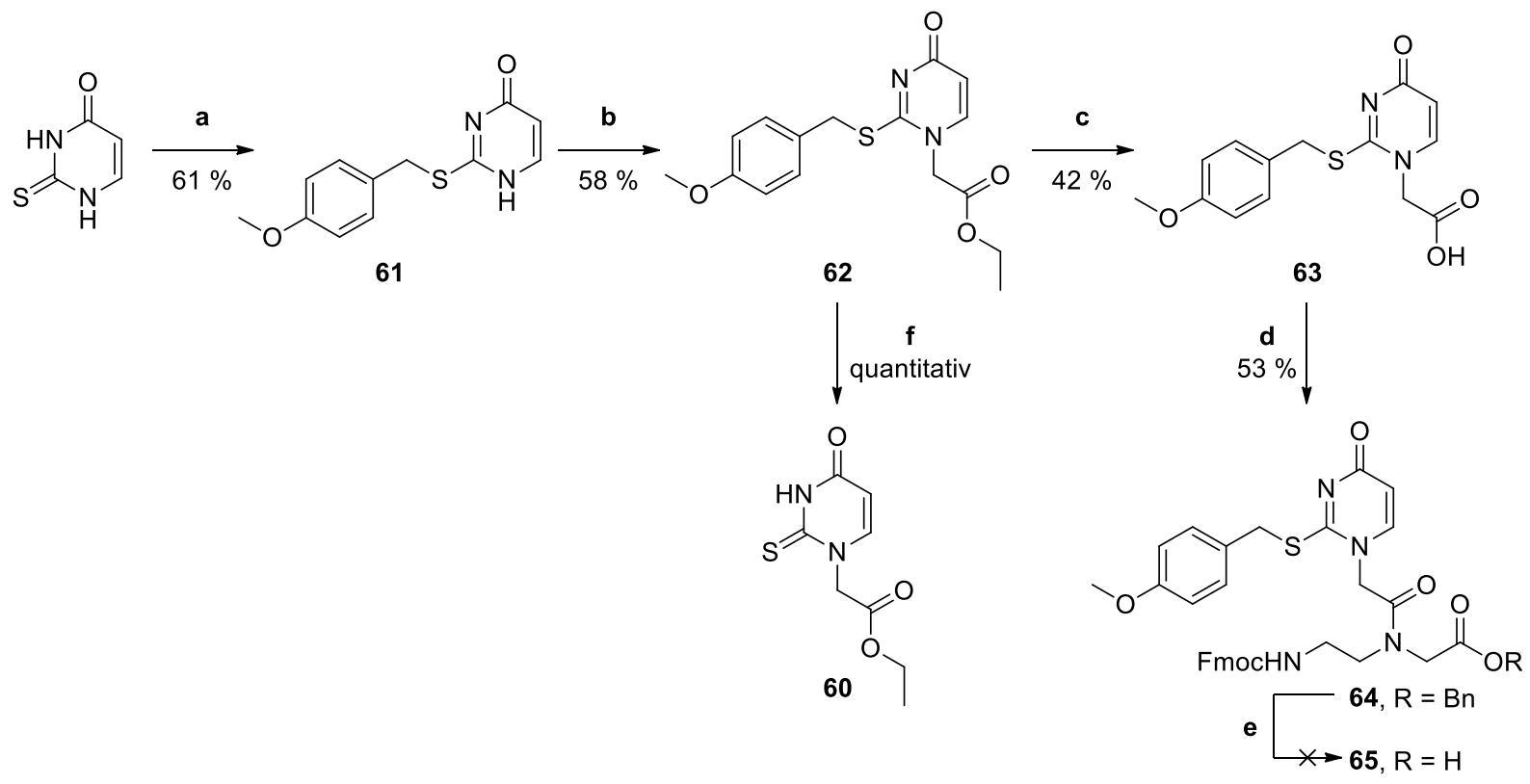

Schema 27: Synthese von Verbindung 64. a: 1. $\mathrm{KOH}, 2$ : $\mathrm{PMBCl}$, EtOH/ $\mathrm{H}_{2} \mathrm{O}, 61 \%$, RT; b: 1. HMDS, Saccharin, 2. 55, DCM Reflux; c: $\mathrm{LiOH}, \mathrm{MeOH} / \mathrm{THF} / \mathrm{H}_{2} \mathrm{O}$ (3:7:1), RT; d: 1. HBTU, DIPEA, 2. Backbone, DMF, RT; e $\mathrm{NaOH}, \mathrm{THF} / \mathrm{H}_{2} \mathrm{O}, \mathrm{RT}$; f: TFA/TIPS/ $\mathrm{H}_{2} \mathrm{O}(95: 2.5: 2.5), 1 \mathrm{~h}, \mathrm{RT}$. 


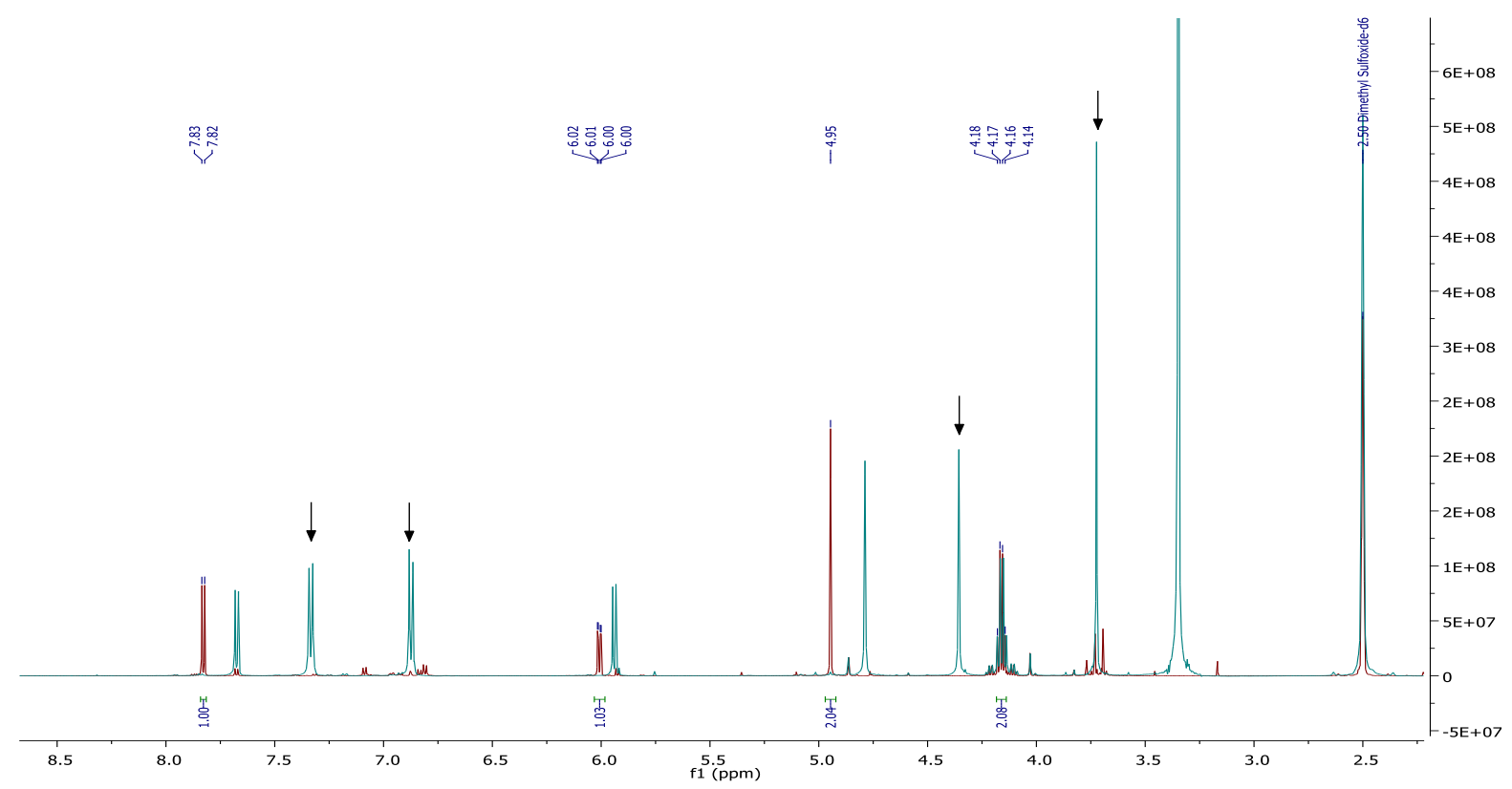

Abbildung 63: Überlagerung der ${ }^{1} \mathrm{H}-\mathrm{NMR}-S p e k t r e n$ der Verbindungen 62 vor (blau) und 60 nach (rot) der Inkubation in TFA/TIPS/ $\mathrm{H}_{2} \mathrm{O}$ (95:2.5:2.5). Die Signale der PMB-Gruppe sind mit Pfeilen markiert. Nach der Reaktion waren diese Signale nicht mehr zu beobachten und die erhaltene Verbindung entsprach 60.

Reaktion verlief in deutlich höheren Ausbeuten (53\%) als bei der MMPM geschützten Verbindung (42\%). Im Anschluss wurde Verbindung 63 an das PNA-Backbone gekuppelt, wobei man 64 in moderaten Ausbeuten (53\%) erhielt. Die Verseifung der Verbindung 64 zum Monomer 65 misslang jedoch, da neben der Benzyl- auch die Fmoc-Gruppe entfernt wurde.

Nachdem in dieser Arbeit eine effiziente und selektive Methode zur Alkylierung von $U_{s}$ entworfen und eine mit $\mathrm{PMB}$ eine geeignete Schutzgruppe für die Fmoc-basierte Festphasensynthese gefunden wurde, führte Frau Catharina Kost dieses Thema in ihrer Masterarbeit fort. ${ }^{[230]}$ Dort konnte das Monomer 65 erfolgreich synthetisiert und in eine PNA eingebaut werden. Zeitgleich wurde durch Hudson et al. ebenfalls die Synthese eines PMB-geschützten Thiouracils-Monomers publiziert. ${ }^{[205]}$ 


\section{Umleitung von hAgo2 mittels Adaptormolekülen}

MiRNAs sind kurze nicht kodierende RNAs mit einer Länge von ca. 22 Nukleotiden. ${ }^{[1,231]}$ Diese können von Ago2 gebunden werden und bilden so RISCs (RNA-induced silencing complexes) aus. Diese interagieren über die seed-Region mit der 3 '-UTR von mRNAs und inhibieren deren Transkription (Abbildung 64, a). Dies erfolgt über die Rekrutierung von GW-Proteinen wie TNRC6, welche den Abbau der mRNA auslösen. ${ }^{[174]}$ Eine Dysregulation der miRNAs kann im Zusammenhang mit vielen schweren Krankheiten, wie Krebs, beobachtet werden. ${ }^{[232]}$ Dabei ist in vielen Fällen eine Überexpression bestimmter miRNAs, beispielsweise des miR-17/92 Clusters, ${ }^{[191]} \mathrm{zu}$ beobachten. Eine Möglichkeit überexprimierte miRNAs zu inhibieren, stellen sogenannte anti-miRs dar, welche an die seed-Region eines RISC binden (Abbildung 64, b). ${ }^{[182,183]}$ Neben ihrer Überexpression kann auch das Fehlen von miRNAs ein Auslöser von Krankheiten sein. In diesen Fällen kann die Funktion der miRNAs durch doppelsträngige miR-Mimics widerhergestellt werden. ${ }^{[180]}$ Durch eine kombinierte Transfektion von anti-miRs und miR-Mimics ist es möglich, onkogene miRNAs zu inhibieren und gleichzeitig tumorunterdrückendende Funktionen der Zellen zu reaktivieren. ${ }^{[79]}$

Da die Wirkung der RISCs über Protein-Protein-Kontakte erfolgt, entstand in unserer Gruppe die Idee, Adaptormoleküle zu verwenden, um RISCs auf nicht kanonische mRNAs umzuleiten (Abbildung 64, c). Auf diese Weise wäre es mit einem Molekül möglich, sowohl
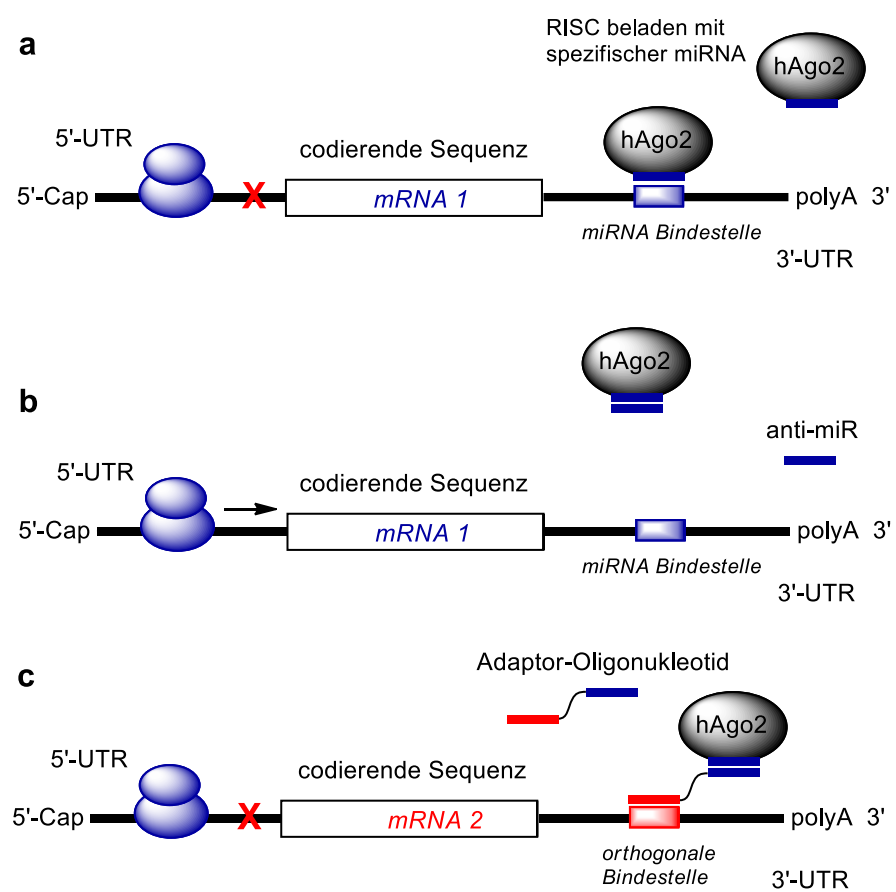

Abbildung 64: Allgemeines Konzept zur Umleitung von RISC. a: Ein RISC bindet an die 3'-UTR einer mRNA. Die miRNA und ihre Bindestelle sind in Blau gezeigt. b: Ein anti-miR ON bindet an den RISC und verhindert die Bindung an die 3'-UTR. Dadurch wird die mRNA translatiert. c: Der Adaptor bindet mit dem blauen Teil den RISC und leitet inn mit dem roten Part auf die 3'-UTR einer zweiten mRNA. Dadurch wird die Translation unterdrückt. Ribosome sind durch blaue Ovale dargestellt. ${ }^{[13]}$ 
onkogene miRNAs als auch tumorfördernde Proteine zu inhibieren. Um sowohl die miRNA als auch die mRNA adressieren zu können, musste der Adaptor aus zwei ONs bestehen. Hierbei stellt eine Hälfte des Adaptors ein anti-miR dar, welches RISCs bindet, während die andere Hälfte als ASO fungiert, welches gegen eine entsprechende mRNA gerichtet ist. Zur Verknüpfung der beiden Hälften wurde mit einem Hexaethylenglycol-Linker (HEG) ein möglichst langer und hydrophiler Linker verwendet. Mit diesem sollte einerseits eine sterische Abstoßung zwischen RISC und der mRNA verhindert und andererseits eine hydrophobe Kontraktion vermieden werden. In dieser Arbeit war geplant, das Konzept der Umleitung mittels Pulldown-Experimenten zu überprüfen. Dazu sollte zunächst ein Cy5-gelabeltes miRNA-Mimic auf eine orthogonale Ziel-RNA umgeleitet werden. Im Anschluss waren Pulldown-Experimente geplant, in denen RISCs aus HeLa-Lysaten isoliert und dann mittels Western-Blot detektiert wurden. Als Ziel-miRNA wurde die miR-20a gewählt (RNA 17 und 17a, Abbildung 65), welche zum miR-17/92 Cluster gehört und in vielen Tumorzellinien überexprimiert ist. Die Ziel-RNA musste hinsichtlich ihrer Sequenz orthogonal zur miR-20a sein und durfte zudem keine Bindestellen für RISCs enthalten. Dies traf für die RNA 19 zu. Um einen möglichst nukleaseresistenten Adaptor zu erhalten, wurde der Adaptor 18 vollständig aus LNA-Basen aufgebaut. Um die Effektivität des Adaptors mit einem anti-miR vergleichen zu können, wurde die gegen miR-20a gerichtete LNA 16 als Kontrolle verwendet.

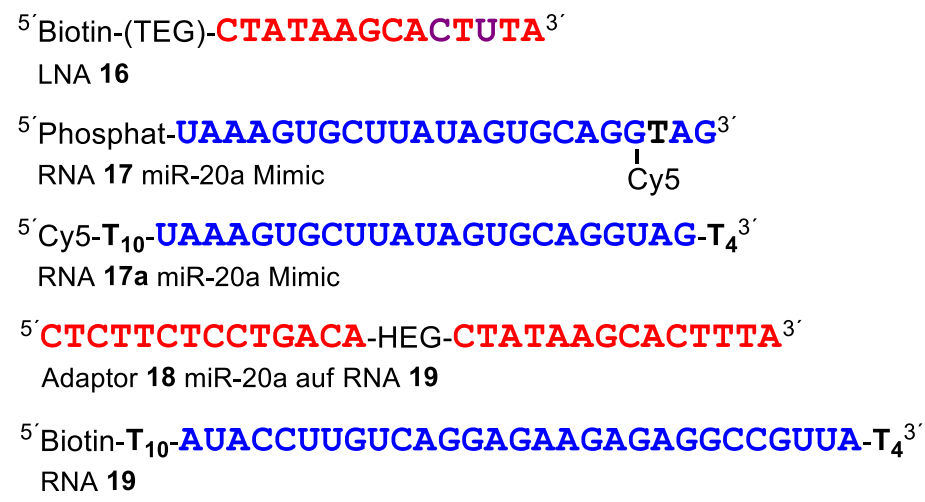

Abbildung 65: Für die Pulldown-Experimente benötigte ONs. Dabei steht Rot für LNA, Violett für 2'-Methoxy RNA, Blau für RNA und Schwarz für DNA. LNA 16 bindet unmittelbar an die RNAs 17 und 17a. Die Bindung dieser miRNA-Modelle an die nicht komplementäre RNA 19 hingegen, bedarf der Vermittlung durch das Adaptormolekül 18.

Parallel zu den in vitro Experimenten sollten die Adaptoren in Kooperation mit der Gruppe von Prof. Hartmann von der Philipps Universität Marburg zu Umleitungsexperimenten in Zellkulturen eingesetzt werden. Für diese Experimente wurden chronisch-myeloische Leukämiezellen (K562) verwendet, von denen bekannt war, dass sie miR-20a überexprimierten. Zu den Zielen der miR-20a gehört das tumorunterdrückende Protein p21, welches Apoptose auslösen kann. ${ }^{[183]}$ In der Hartmann-Gruppe konnte zuvor gezeigt werden, dass die Zugabe einer gegen miR-20a gerichteten LNA zu einer erhöhten 
p21-Expression führte. ${ }^{[183]}$ Als weiteres Ziel des Adaptors wurde die tumorfördernde Proteinkinase Pim-1 gewählt. Diese wird in K562-Zellen überexprimiert und fördert das Zellwachstum. ${ }^{[233,234]}$ Aus vorhergehenden Arbeiten der Hartmann-Gruppe war ebenfalls bekannt, dass die PIM1-mRNA durch eine siRNA an Position 1491, als auch durch ein Mimic der miR-33a desaktiviert werden konnte. ${ }^{[233]}$. Davon ausgehend wurden zwei Adaptormoleküle entworfen, welche die miRNA-20a an diese Stellen umleiten konnten (Adaptor 20 und 21, Abbildung 66). Zusätzlich wurde der Adaptor 22 als Transfektionskontrolle eingesetzt. Dieser war gegen die RNA 19 gerichtet und konnte keine miRNA binden. Mit diesen Adaptoren sollten die Pim-1-Level in K562-Zellen gesenkt und gleichzeitig die p21-Level erhöht werden. Darüber hinaus konnte Adaptor 22 als Negativkontrolle in den Pulldown-Experimenten verwendet werden.

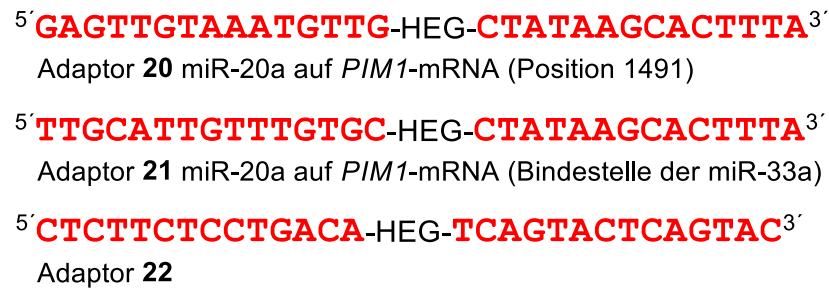

Abbildung 66: LNA-Adaptoren für die Zellkulturexperimente. 


\subsection{Band-Shift und Pulldown-Experimente mit den LNA-Adaptoren}

Zur Bestätigung des Konzepts der Umleitung wurden fluoreszenzbasierte PulldownExperimente durchgeführt. Die biotinylierte RNA 19 stellte in diesem Versuch ein Modell der 3'-UTR dar, auf die ein RISC mittels Adaptormolekül umgeleitet werden sollte. Im ersten Schritt dieser Versuche wurde das fluoreszenzmarkierte miR-Mimic 17a anstelle des natürlichen miRNA-hAgo2-Komplexes verwendet. Eine direkte Komplementarität zwischen Ziel-RNA 19 und miR-Mimic 17a besteht nicht. Diese muss erst durch den Adaptor vermittelt werden. Im fluoreszenzbasierten Experiment wurde die RNA 19 an Magnetic Beads gebunden und im Anschluss mit RNA 17a in Puffer 2 (50 mM Tris- $\mathrm{HCl}$ $\mathrm{pH} 8,100 \mathrm{mM} \mathrm{KCl}, 2 \mathrm{mM} \mathrm{MgCl}_{2}$ ) inkubiert. Nach dem Entfernen der ungebundenen RNA konnte in Anwesenheit des Adaptors 18 eine ca. 100fach höhere Fluoreszenz detektiert werden als in dessen Abwesenheit (das fluoreszenzmarkierte miRNA-Modell wurde zur Messung bei pH 10 von den Magnetic Beads abgelöst). Da in einem analogen Versuch mit der direkt an Adaptor 17a bindenden anti-miR-LNA 16 ein vergleichbarer Wert erhalten wurde, konnte davon ausgegangen werden, dass die Umleitung effektiv war. Allerdings fiel in diesen Experimenten auf, dass die RNA 19 abgebaut wurde. Das hatte zur Folge, dass mit RNA 19 beladene Beads nicht gelagert werden konnten. Die hohe Instabilität gegen Nukleasen verhinderte außerdem ihren Einsatz in der Isolierung von RISCs aus HeLa-Lysaten. Aus diesem Grund wurden die Experimente mit der analogen 2'-OMe-RNA 23 wiederholt und der Adaptor 22 als Negativkontrolle eingesetzt Abbildung 67). Auch in diesen Fall konnte in Anwesenheit des Adaptors eine deutlich erhöhte Fluoreszenz gegenüber dem ON 23 beobachtet werden (92fach), und auch mit dem Adaptor 22 konnte keine Bindung der RNA 17a beobachtet werden, wodurch das Konzept der Umleitung auf Basis von ONs bestätigt wurde.

Zur weiteren Bestätigung des Konzepts wurde in einem Pulldown-Experiment versucht, miR-20a beladene RISCs aus HeLa-Lysaten zu isolieren. Die Detektion der Komplexe

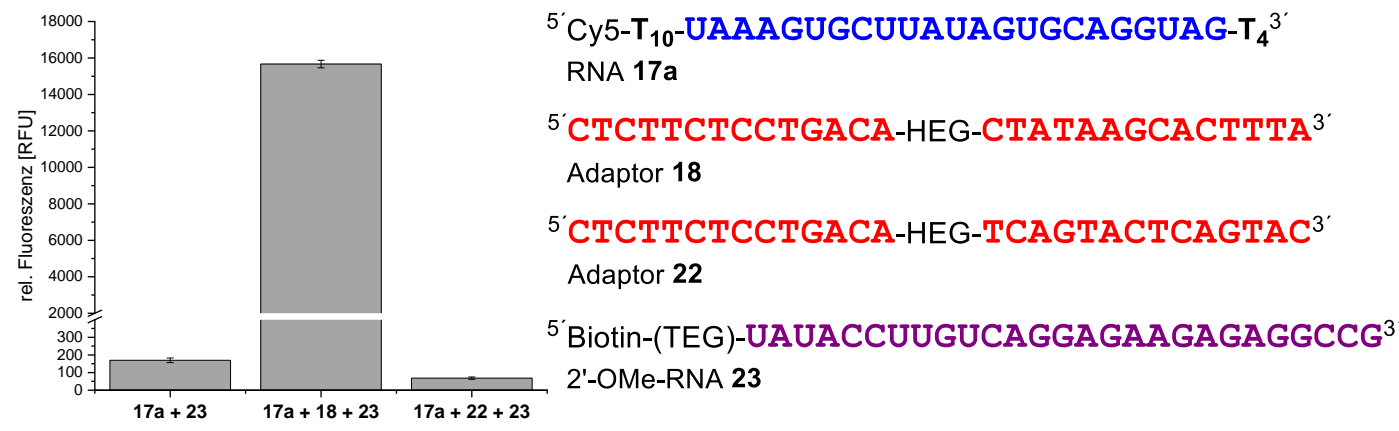

Abbildung 67: Ergebnisse der Pulldown-Experimente mit den ONs 17a, 18, 22 und 23 (je $100 \mathrm{nM}$ ). Dabei konnte mit dem Adaptor 18 eine Erhöhung der Fluoreszenz um den Faktor 92 beobachtet werden. Inkubation: 3 h, RT in Puffer 2. 

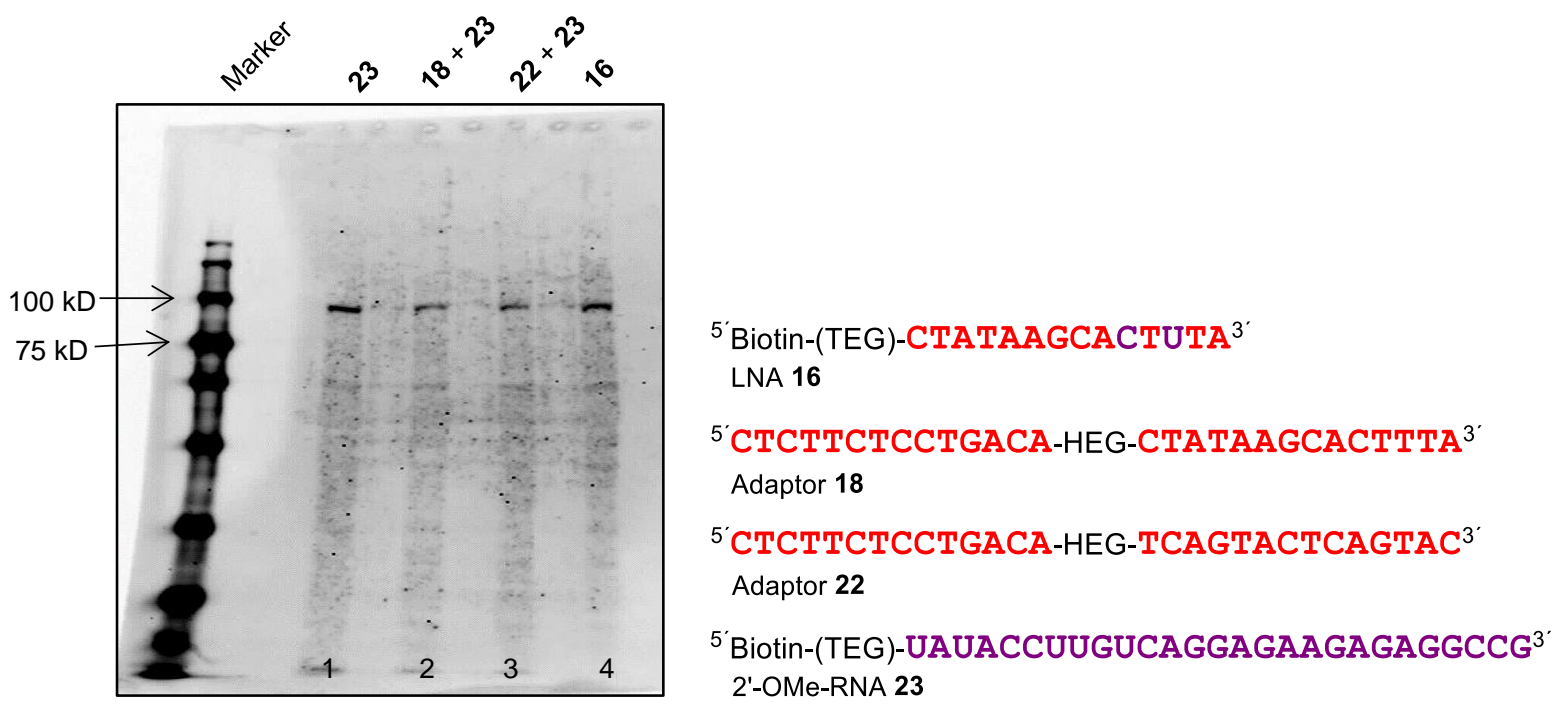

Abbildung 68: Isolation von RISC-Komplexen mit 2'-OMe-RNA 23 mit den Adaptoren 18 oder 22. Lane 1: ON 23 (100 nM); Lane 2: ON 23 (100 nM) + Adaptor 18 (100 nM); Lane 3: ON 23 (100 nM) + Adaptor 23 (100 nM); Lane 4: LNA 16 (100 nM). Die Proben wurden $3 \mathrm{~h}$ in HeLa-Lysat inkubiert.

erfolgte mittels eines nachfolgenden Western-Blots (Abbildung 68). In der Positivkontrolle mit LNA 16 (Lane 4), die nicht nur die fluoreszenzbasierten miRNA-Modelle 17 und 17a, sondern auch die natürlichen RISCs binden sollte, wurde wie erhofft eine stake Bande beobachtet, die im erwarteten Größenbereich von $100 \mathrm{kD}$ lag. Im eigentlichen Umleitungsexperiment mit dem biotinylierten ON 23 und Adaptor 18 konnte jedoch nur eine schwache Bande beobachtet werden (Lane 2). Als Negativkontrolle wurde auch ein Versuch mit ON 23 und Adaptor 22 durchgeführt (Lane 4). LNA 22 ist komplementär zu ON 23 nicht aber zu miR-20a. Die Bandenintensität im Western-Blot war jedoch vergleichbar stark mit Lane 2. Völlig unerwartet war die starke hAgo2-Bande mit ON 23 allein (Lane 1), deren Intensität dem Ergebnis des Versuchs mit LNA 16 entsprach. Bei der Auswahl der Sequenz von ON 23 war nicht überprüft worden, ob diese Sequenz nicht andere hoch exprimierte miRNA unmittelbar binden könnte. Dies ist offensichtlich der Fall. Bei einer nachträglichen Überprüfung fand sich in ON 23 eine Mismatch-Bindestelle für die miR-let-7-Familie (Abbildung 69), bei der die Basen drei bis sieben der seed-Region komplementär waren und das Nukleotid an Position zwei ein G•U-Wobble-Paar bilden konnte. Auch wenn die Bindung von RISCs an Mismatch-Stellen nicht häufig vorkommt, ${ }^{[171]}$ gab es in diesem Fall zwei Gründe, die für eine Bindung sprachen. Einerseits beinhaltet die miR-let-7-Familie einige der am höchsten exprimierten miRNAs und andererseits besitzen

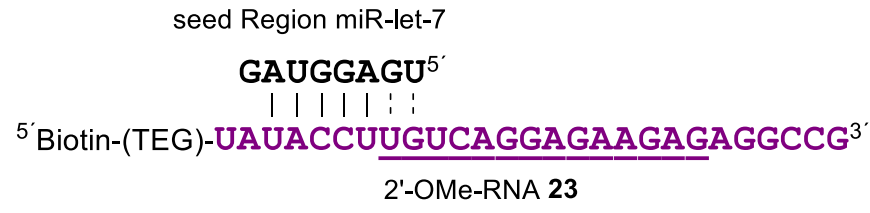

Abbildung 69: Bindestelle für miR-let-7 auf dem ON 23. Dabei sind die Basen 3 - 7 komplementär und das Nukleotid 2 kann ein G•U-Wobble-Paar bilden. Die Bindestelle der Adaptoren ist unterstrichen. 
2'-OMe-RNAs eine höhere Affinität zu RISCs als entsprechende RNAs. Eine Kombination dieser Faktoren könnte die beobachtete starke hAgo2-Bande in Lane 1 erklären. Da die Bindestelle für miR-let-7 in unmittelbarer Nachbarschaft zur Ziel-Sequenz der Adaptoren 18 und 22 lag, würde die Zugabe dieser Adaptoren zu ON 23 das Andocken von miR-let-7 abschwächen, was die schwachen Banden in Lane 2 und 3 erklärt. In der Kombination von ON 23 und Adaptor 18 sollte bei erfolgreicher Umleitung aber ähnlich viel hAgo2 isoliert werden können, wie mit LNA 16. Dies ist aber nicht der Fall.

Da die Ergebnisse des Western-Blots im Gegensatz zu den Pulldown-Experimenten mit RNA 17a standen, sollte die Komplexbildung des Adaptors in Band-Shift-Experimenten betrachtet werden (Abbildung 70, Lane 1 - 6). Hierzu wurde Adaptor 18 bei RT mit den Ziel-ONs 17 und 23 inkubiert und es sollte überprüft werden, ob die Bildung des ternären Komplexes vollständig war oder andere Sekundärstrukturen auftraten. Im Zuge dieser Experimente zeigte sich, dass der Adaptor 18 partiell als Dimer vorlag (Lane 2 - 6, roter Kasten). Dennoch konnten der Adaptor mit den ONs 17 und 23 hybridisieren (Lane 4 - 6). Während der Duplex aus Adaptor 18 und RNA 17 (Lane 5, schwarz) deutlich unter dem ternären Komplex (Lane 6, orange) lief, traf dies für den Duplex aus ON 23 und Adaptor 18 nicht zu (Lane 4, grün) und die ausgebildete Struktur zeigte ein stärker retardiertes

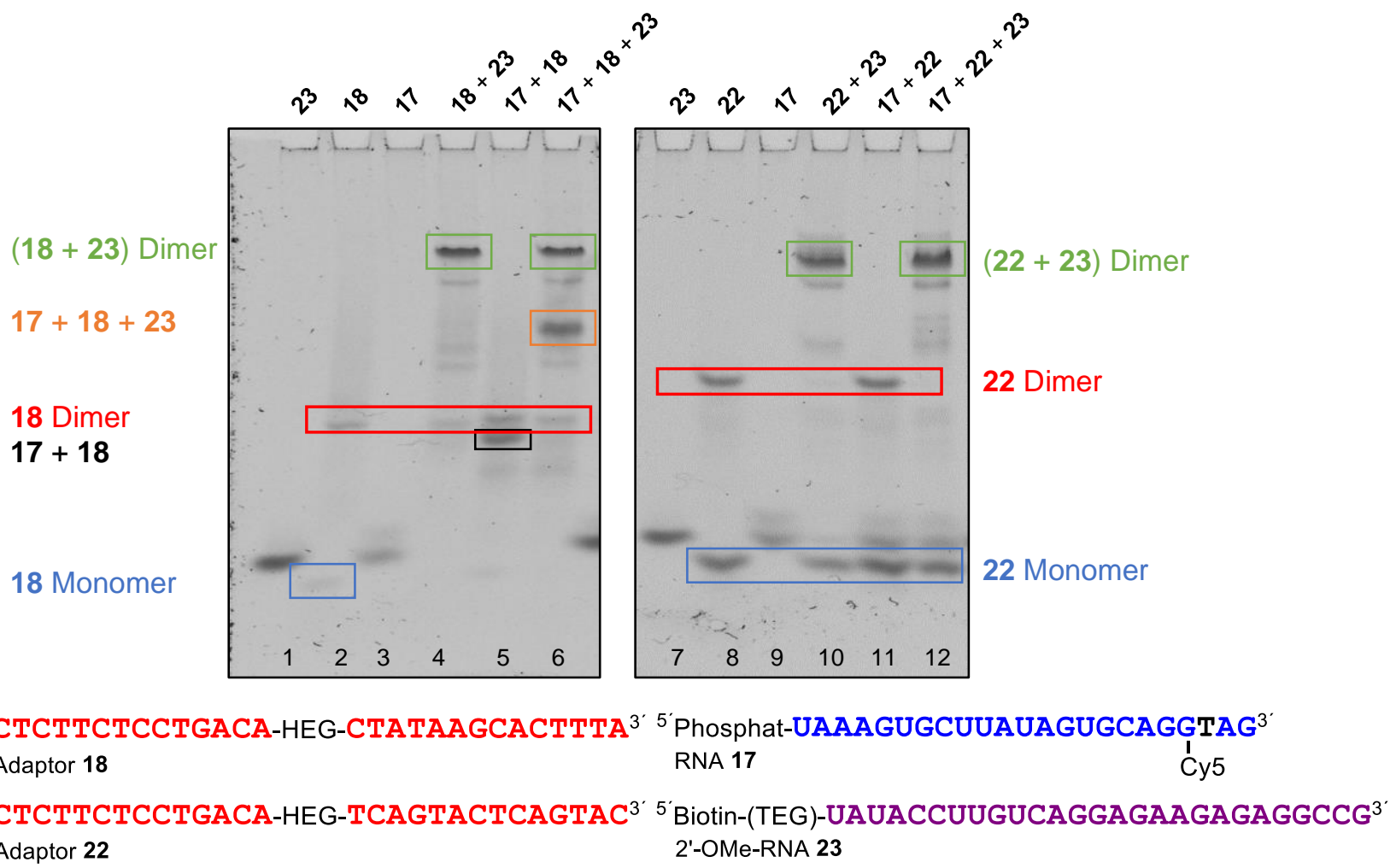

Abbildung 70: Band-Shift Experimente mit Adaptor 18 (Lane 1 - 6) und Adaptor 22 (Lane 7 - 10). Lane 1 und 7: ON 23; Lane 2: Adaptor 18; Lane 8: Adaptor 22; Lane 3 und 9: RNA 17; Lane 4 und 10: ON 23 + Adaptor 18 oder 22; Lane 5 und 11: RNA 17 + Adaptor 18 oder 22; Lane 6 und 12: RNA 17 + ON 23 + Adaptor 18 oder 22. Die Proben wurden $3 \mathrm{~h}$ bei RT in Puffer 2 inkubiert. Die Konzentration der ON betrug in allen Fälle ungefähr $1 \mu$ M. 16 \% nativ PAGE. Die Detektion der Banden erfolgte durch Färbung mit SYBR Gold. 
Laufverhalten als der ternäre Komplex. Das ließ auf eine größere Struktur schließen und in Kombination mit dem beobachteten Dimer des Adaptors deutete dies auf einen quartären Komplex hin. Hierbei müssten zwei Adaptoren über die gegen miR-20a gerichtenten Stränge hybridisieren (Abbildung 72). In Gegenwart aller ONs war jedoch der ternäre Komplex die bevorzugte Struktur dar (Lane 6). Trotz dieser Beobachtung konnte nicht ausgeschlossen werden, dass die Dimerisierung des Adaptors die Bindung der RISCs verhinderte.

Aufgrund dieser Ergebnisse sollten auch die anderen Adaptoren in Band-ShiftExperimenten auf mögliche Sekundärstrukturen untersucht werden. Dabei zeigte sich, dass der Adaptor 22 ebenfalls partiell als Dimer vorlag (Abbildung 70, Lane $8+11$, rot). Analog zu Adaptor 18 konnte jedoch eine gute Bindung an das ON 23 beobachtet werden (Lane 10, blau), wobei das Dimer deutlich besser als das Monomer band und wodurch auch hier ein quartärer Komplex entstand.

Das Experiment mit dem gegen die Nukleotide ab Position 1491 der PIM1-mRNA gerichteten Adaptor 20 zeigte, dass dieser als Monomer vorlag und nur eine geringe Dimerisierung aufwies (Abbildung 71, Lane 3). Zur besseren Detektion der gebildeten Spezies wurden zusätzlich zu der Färbung des Gels auch die Cy5-gelabelten ONs detektiert und die Bilder überlagert. Mit der RNA 25 konnte eine vollständige Hybridisierung beobachtet werden. Der entstandene Komplex wies jedoch ein stark retardiertes Laufverhalten auf (Lane 4, grün), was darauf hindeutete, dass auch in diesem Fall die gegen miR-20a gerichteten Adaptorhälften hybridisierten und sich ein quartärer Komplex ausbildete. Zur RNA 17a besaß der Adaptor nur eine geringe Affinität (Lane 5, schwarz) und in diesem Fall waren großen Mengen monomeren Adaptors und der RNA zu detektieren. Der ternäre Komplex aus Adaptor 20 und den ONs 17a und 25 konnte zwar nachgewiesen werden (Lane 6, orange), dennoch waren in diesem Fall noch größere Menge der Di- und Monomere zu beobachten (Lane 6, grün, schwarz und blau). Somit war davon auszugehen, dass der Adaptor 20 nur eine geringe Affinität zu seinen Zielen aufwies und eine Umleitung von RISCs war nicht zu erwarten.

Analog zu Adaptor 20 lag auch der Adaptor 21 zu großen Teilen als Monomer vor (Abbildung 71, Lane 9). Allerdings waren hier zusätzlich verschiedene Dimere (rot) und Trimere (blau) zu beobachten, was auf eine geringe Orthogonalität der Adaptorhälften schließen ließ. Darüber hinaus konnte weder mit der RNA 17a noch mit RNA 26 eine vollständige Hybridisierung beobachtet werden (Lane 10 und 11) und diese führte zur Bildung komplexerer Strukturen. Obwohl auch hier die Bildung eines ternären Komplexes beobachtet werden konnte (Lane 12, orange) und dieser die bevorzugte Spezies darstellte, waren immer noch größere Anteile ungebundener ONs vorhanden. Dementsprechend war 


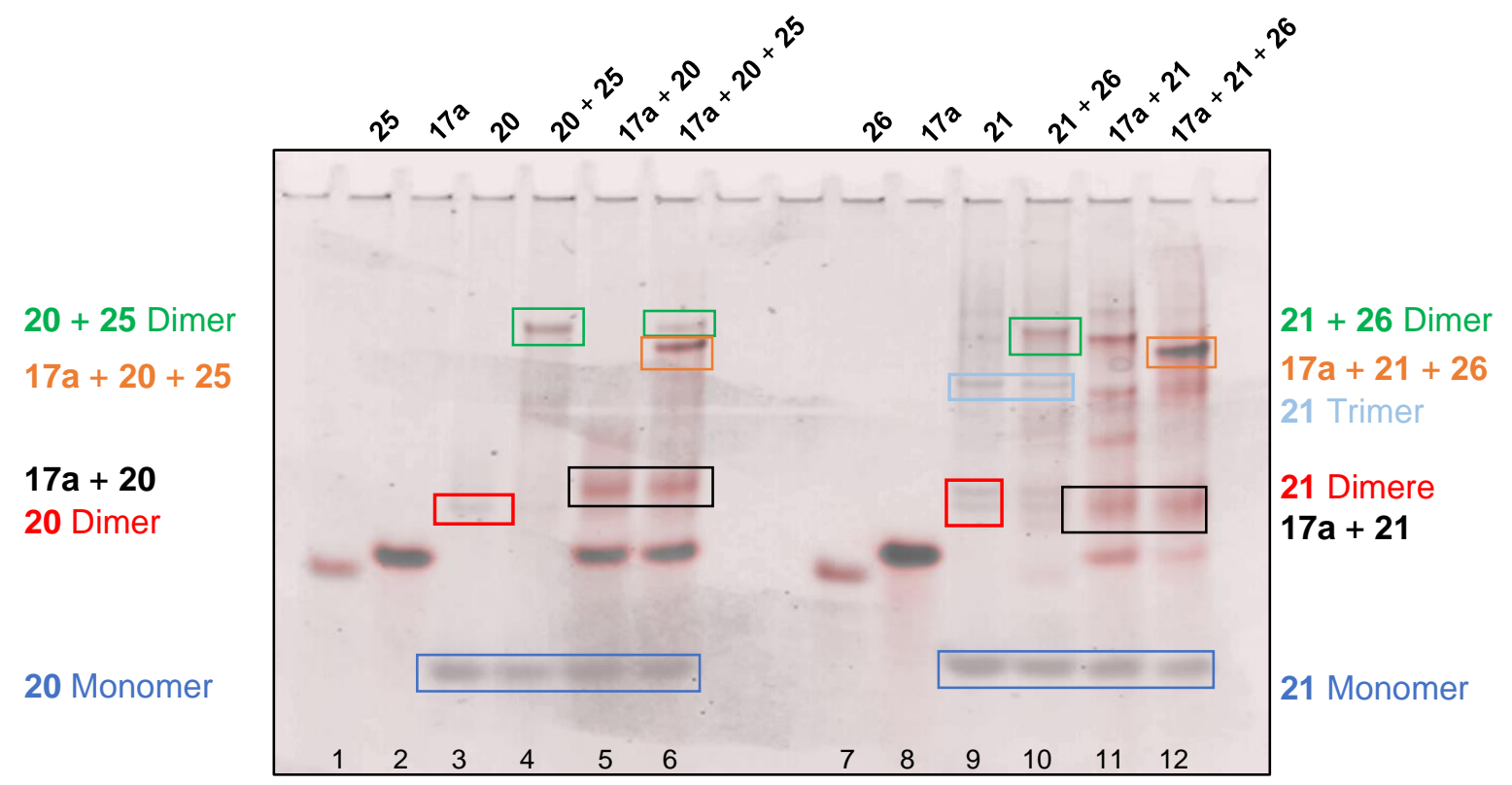

\footnotetext{
5'GAGTTGTAAATGTTG-HEG-CTATAAGCACTTTA ${ }^{3}$ 5' Cy5-T 10 $^{\prime}$-UAAAGUGCUUAUAGUGCAGGUAG-T ${ }^{3}$ Adaptor 20 miR-20a auf PIM1-mRNA (Position 1491) RNA 17a miR-20a

5'TTGCATTGTTTGTGC-HEG-CTATAAGCACTTTA ${ }^{3}$ 5'

Adaptor 21 miR-20a auf PIM1-mRNA (Bindestelle der miR-33a) RNA 25 PIM1-mRNA (Position 1491)

${ }^{5}$ 'Cy5-T 10-GCACAAACAAUGCAAUCAACAG-T ${ }^{3}{ }^{3}$ RNA 26 PIM1-mRNA (Bindestelle der miR-33a)
}

\begin{abstract}
Abbildung 71: Band-Shift Experiment mit den Adaptoren 20 (Lane 1 - 6) und 21 (Lane 9 - 14). Die Abbildung stellt eine Überlagerung der SYBR-Gold-Färbung (schwarz) und der Cy5-Detekton (rote Banden) dar. Lane 1: RNA 25; Lane $2+8$ : RNA 17a; Lane 3: Adaptor 20; Lane 4: Adaptor 20 + RNA 25; Lane 5: Adaptor 20 + RNA 17a; Lane 6: Adaptor 20 + RNA 17a + RNA 25; Lane 7: RNA 26; Lane 9: Adaptor 21; Lane 10: Adaptor 21 + RNA 26; Lane 11: Adaptor 21 + RNA 17a; Lane 12: Adaptor 21 + RNA 17a + RNA 26. Die Proben wurden 3 h bei RT in Puffer 2 inkubiert. Die Konzentration der ON betrug in allen Fällen ungefähr $1 \mu \mathrm{M} .16 \%$ nativ PAGE.
\end{abstract}

auch in diesem Fall die Umleitung von RISCs fraglich.

Aufgrund der Tatsache, dass die Adaptoren 20 und 21 offensichtlich als Monomere vorlagen, jedoch nur eine geringe Affinität zu ihnen Ziel-RNAs aufwiesen, musste angenommen werden, dass sie intramolekulare hairpin-Strukturen ausbildeten. Diese würden den Adaptor abschirmen und die Bindung der Ziel-RNAs verhindern. Darüber hinaus wiesen die quartären Komplexe darauf hin, dass die Adaptorhälften teilweise komplementär sein mussten und in der Folge die Umleitung inhibierten. Um einen besseren Überblick über die möglichen Sekundärstrukturen zu erhalten, wurden Strukturanalysen durchgeführt. Hierzu wurde sowohl der Exiqon LNA Oligo Optimizer als auch die Nupack Web Application eingesetzt. ${ }^{[235,236]}$ Um einen Überblick über mögliche Interaktionen zwischen den einzelnen LNA-Strängen zu erhalten, wurde der Oligo Optimizer verwendet. Bei einer Komplementarität beider Stränge eines Adaptors war die Ausbildung eines internen hairpins wahrscheinlich. Eine Analyse der vollständigen Adaptoren war mit dem Oligo Optimizer nicht möglich, da es in diesem System keine Möglichkeit gab Linker einzufügen. Aufgrund der hohen Stabilität von LNA-Basenpaaren gelang es außerdem 
nicht den Linker durch das Einfügen nicht bindender Basen zu ersetzten. Um die mögliche Struktur der Volllängen-Adaptoren zu betrachten, wurde die Nupack Web Application eingesetzt. Bei dieser wurden die Adaptoren als RNA-Stränge betrachtet und der Linker konnte durch das Einfügen von Nukleotiden nachgestellt werden. Wurden dort Sekundärstrukturen gefunden, deren Basenpaarung den Ergebnissen des Oligo Optimizers entsprach, wurde die Struktur als wahrscheinlich angesehen. Zusätzlich sollte es mit den potenziellen inter- und intramolekularen Strukturen möglich sein, die Ergebnisse der Band-Shift-Experimente zu erklären. Unter diesen Voraussetzungen konnten für alle Adaptoren Sekundärstrukturen gefunden werden (Abbildung 72), von deren Existenz im Folgenden ausgegangen wird.

Für den Adaptor 18 war eine Hybridisierung der gegen miR-20a gerichteten Stränge möglich, was mit dem beobachteten Dimer und quartären Komplex übereinstimmte. Hierbei erfolgte die Basenpaarung zu großen Teilen über die gegen die seed-Region gerichtete Sequenz. Zwar konnte das Dimer durch eine freie miR-20a aufgelöst werden, allerdings war anzunehmen, dass das Dimer die Bindung eines RISCs verhinderte. Dies wäre eine Erklärung, warum die Umleitung in fluoreszenzbasierten Pulldown-Experimenten

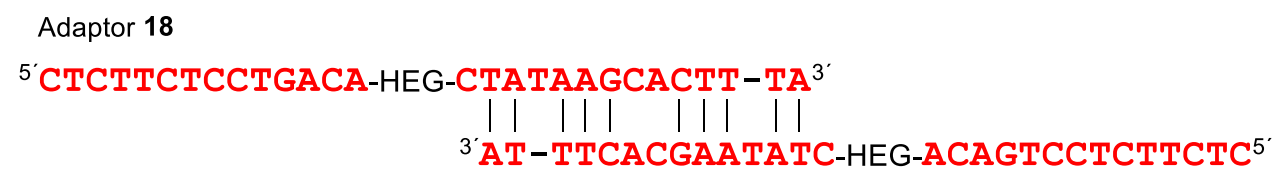

Abbildung 72: Mögliche Wechselwirkungen der Adaptoren 18, 20, 21 und 22. 
erfolgreich verlief, während die Umleitung von RISCs nicht gelang. Der Adaptor 22 konnte sowohl ein Dimer als auch eine hairpin-Struktur ausbilden, welche auch zu beobachten waren. Die Ausbildung einer hairpin-Struktur erklärte auch die bevorzugte Bindung des Dimers an das ON 23. Im Fall des Dimers war der gegen ON 23 gerichtete Teil des Adaptors frei zugänglich, während er im hairpin abgeschirmt war.

Für den Adaptor 20 war analog zu 18 die Ausbildung eines Duplex der gegen miR-20a gerichteten Stränge denkbar, allerdings war in den Band-Shift-Experimenten nur monomerer Adaptor zu beobachten und die Dimerisierung trat erst nach Bindung an RNA 25 auf (Abbildung 71, Lane 3 und 4). In den Strukturanalysen zeigte sich, dass der Adaptor 20 einen sehr stabilen hairpin bilden konnte, in welchem die gegen die PIM1-mRNA gerichtete Sequenz noch zugänglich war. Dies erklärte, wieso eine Hybridisierung mit RNA 25 gelang. Im Gegensatz dazu war der gegen miR-20a gerichtete Teil stark abgeschirmt und eine Bindung der RNA 17a wurde verhindert. Die Bildung des ternären Komplexes erfolgte in diesem Fall wahrscheinlich über eine Öffnung des hairpins durch die RNA 25, wodurch der gegen miR-20a gerichtete Teil des Adaptors zugänglich wurde. Gleichzeitig konnte in einer Wiederholung des Band-Shift-Experiments gezeigt werden, dass eine Inkubation bei $37^{\circ} \mathrm{C}$ zu einer besseren Hybridisierung des Adaptors 20 mit der RNA 17a führte, was auf eine thermische Öffnung des hairpins hindeutete.

Der Adaptor $\mathbf{2 1}$ war ebenfalls in der Lage einen stabilen hairpin auszubilden, wodurch beide Hälften des Adaptors abgeschirmt wurden. Darüber hinaus waren beide Hälften selbstkomplementär. Somit konnten für diesen Adaptor verschiedene polymere Strukturen angenommen werden, welche auch im Band-Shift-Experiment zu beobachten waren. Außerdem erklärte sich dadurch die Ausbildung der quartären Komplexe, die nach der Hybridisierung einer der Adaptorhälften auftraten. Die geringe Affinität des monomeren Adaptors gegenüber der Ziel-RNA 26 konnte durch die Bildung des hairpins schlüssig erklärt werden.

Auf Basis dieser Ergebnisse wurden die Experimente mit den reinen LNA-Adaptoren eingestellt, da davon auszugehen war, dass eine Umleitung von RISCs durch die Sekundärstrukturen der Adaptoren verhindert würde. Um die intra- und intermolekularen Wechselwirkungen zu schwächen oder zu verhindern, sollten DNA/LNA-Mixmere eingesetzt werden, für die im Allgemeinen geringere Affinitäten zu erwarten waren. Gleichzeitig stellte sich aufgrund der beobachteten Bindung von RISCs an ON 23 die Frage, inwieweit eine selektive Umleitung von RISCs möglich war. Da dies eine Grundvoraussetzung des Konzepts war, musste ein Nachweis für die Bindung spezifischer RISCs erbracht werden, bevor weitere Adaptoren eingesetzt werden konnten. 


\subsubsection{Selektivität der RISC-Bindung}

Zunächst wurde überprüft, ob eine Bindung von RISCs mit allen LNAs möglich war. Hierzu wurde eine Siebenmer-LNA gegen die seed-Region der miR-20a-Familie eingesetzt (LNA 27, Abbildung 73) und mit der LNA 28 verglichen. Diese stellte eine verkürzte Version des nichtbindenden Teils des Adaptors 22 dar, welcher keine Komplementarität zu seed-Regionen von miRNAs aufwies. In Pulldown-Experimenten mit nachfolgendem Western-Blot konnte gezeigt werden, dass mit LNA 27 hAgo2 isoliert werden Abbildung 73, Lane 1) konnte, während dies mit LNA 28 nicht möglich war (Lane 2). Dies bedeutete zwar, dass LNAs eine gewisse Komplementarität zu miRNAs aufweisen müssen, um RISCs zu binden, allerdings war keine eindeutige Aussage über die Spezifität der LNA 27 möglich.

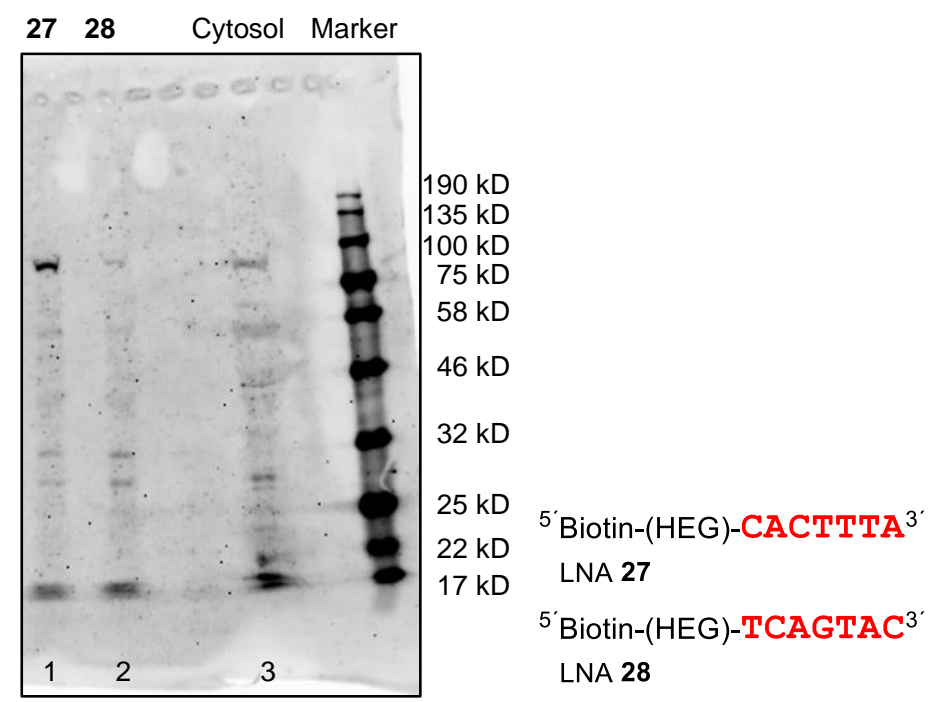

Abbildung 73: Isolation von RISC durch Pulldown mit den LNAs 27 und 28; die Banden wurden durch Western-Blot nach Elektrophorese durch spezifische Antikörper gegen human Ago2 (hAgo2) sichtbar gemacht. Lane 1: HeLa-Cytosol und LNA 27 (100 nM); Lane 2: HeLa-Cytosol und LNA 28 (100 nM); Lane 3: HeLa Cytosol (3 $\mu \mathrm{L})$. Die Proben wurden $3 \mathrm{~h}$ bei RT inkubiert.

Aus diesem Grund wurde versucht, die mit LNA 27 gebundenen miRNAs mittels Next Generation Sequencing zu identifizieren. Dazu wurde LNA 27 in HeLa-Lysat inkubiert und im Anschluss versucht die miRNAs mittels Tri-Reagent ${ }^{\circledR}$ zu isolieren. Zwar war bekannt, dass die Isolierung von miRNAs mit Tri-Reagent $\AA^{\circledR}$ in Anwesenheit vollständig komplementärer LNA-basierter anti-miRs nur mäßig effektiv verlief, ${ }^{[237]}$ da die LN 27 jedoch deutlich kürzer war, wurde eine bessere Isolierung der miRNAs erhofft. Die anschließende Sequenzierung wurde durch die Firma GenXPro durchgeführt. Allerdings konnten dabei keine miRNAs gefunden werden. Es lag daher nahe, dass die Isolierung der miRNAs mit dem Tri-Reagent ${ }^{\circledR}$ nicht gelang oder sie nicht aus dem RISC gelöst wurden und dadurch nicht zu isolieren waren. Falls jedoch mit dem Tri-Reagent ${ }^{\circledR}$ LNA 27-miRNA-Komplexe isoliert worden sind, könnte die stark gebundene LNA 27 die RT-PCR inhibieren. Aus 
diesem Grund wurden diese Versuche beendet und nach einem alternativen Nachweis für die Selektivität gesucht.

Da die Experimente mit LNA 27 zeigten, dass RISCs durch komplementäre LNAs gebunden wurden, während dies mit nichtkomplementären LNAs nicht möglich war, entstand die Idee, unterschiedliche miRISCs nacheinander in Pulldown-Experimenten zu isolieren. Hierbei sollte zunächst eine miRNA-Familie aus einem HeLa-Lysat nachweislich entfernt werden und im Anschluss eine weitere miRNA-Familie adressiert werden. Diese wäre nur dann zu detektieren, wenn der vorhergehende Pulldown selektiv verliefe. Neben der miR-20a-Familie wurde als zweites Ziel die miR-let-7-Familie gewählt, welche von der LNA 29 adressiert wurde. Da die miR-let-7-Familie eine höhere Expression aufweisen sollte als der miR-17/92-Cluster, wurde das Lysat zunächst mit einem Überschuss der LNA 27 inkubiert (Abbildung 74, Lane 1). Um nachzuweisen, dass alle RISCs der miR-20a-Familie entfernt waren, wurde das Lysat erneut mit LNA 27 inkubiert, wobei eine deutlich geringere hAgo2-Bande zu beobachten war (Lane 2). Der Überstand wurde daraufhin mit der LNA 29 inkubiert und es konnte erneut eine starke hAgo2-Bande detektiert werden (Lane 3). Die Intensität dieser Bande nahm bei einer zweiten Inkubation mit LNA 29 ab (Lane 4), auch wenn sie aufgrund der Häufigkeit von miR-let-7 immer noch stärker als nach der zweiten Inkubation mit LNA 27 war. Somit gelang es, mit unterschiedlichen miR-Familien beladene RISCs unabhängig voneinander zu isolieren. Dies bedeutete auch, dass die Bindung der RISCs mittels spezifischer Basenpaarung erfolgte und die Selektivität auch für eine Umleitung mit den Adaptoren gegeben sein sollte.

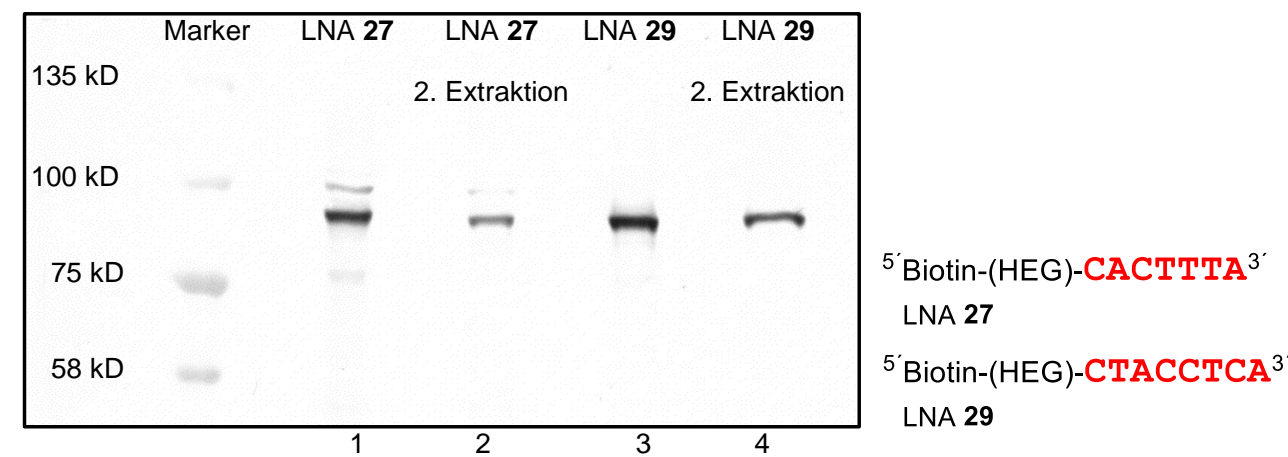

Abbildung 74: Selektive Isolation von RISC durch Pulldown mit den LNAs 27 und 29. Die Banden wurden in einem Western-Blot nach der Elektrophorese durch spezifische Antikörper gegen hAgo2 sichtbar gemacht. Lane 1: HeLa-Lysat und LNA 27; Lane 2: HeLa-Lysat und LNA 27 2. Extraktion; Lane 3: HeLa-Lysat und LNA 29; Lane 4: HeLa-Lysat und LNA 29 2. Extraktion. Die Proben wurden je $1 \mathrm{~h}$ bei RT inkubiert. Die Konzentration der LNAs betrug jeweils $1 \mu \mathrm{M} .{ }^{[13]}$ 


\subsection{LNA/DNA-Adaptoren}

Nachdem gezeigt werden konnte, dass sich RISCs durch Basenpaarung selektiv einfangen lassen, galt es in einem nächsten Schritt DNA/LNA-Mixmer-Adaptoren zu designen. Diese sollten durch in vitro Experimente auf ihre Fähigkeit RISCs zu rekrutieren untersucht werden. Parallel dazu wurde die Umleitung von RISCs in Zellkulturversuchen betrachtet. ${ }^{[238]}$ Für die in vitro Experimente wurde ausgehend von Adaptor 18 der Adaptor $\mathbf{3 0}$ entworfen (Abbildung 75). Dabei wurde ungefähr die Hälfte der Nukleotide durch DNA ersetzt und die Lage der LNA-Basen so gewählt, dass die Bildung von Dimeren verhindert wurde. Um eine hohe Stabilität gegenüber Nukleasen zu erhalten, wurden die Enden der Stränge mit LNA-Basen versehen. Bei der Verteilung der LNAs galt es, größere Abfolgen an DNA-Nukleotiden zu vermeiden, um die Rekrutierung der RNase $\mathrm{H}$ zu verhindern. Nachdem sich in den vorhergehenden Experimenten zeigte, dass das Ziel-ON 23 ebenfalls RISCs binden konnte, wurde es auf die Bindestelle des Adaptors 30 verkürzt (ON 24, Abbildung 75), wodurch die zu miR-let-7a komplementäre Sequenz entfiel.

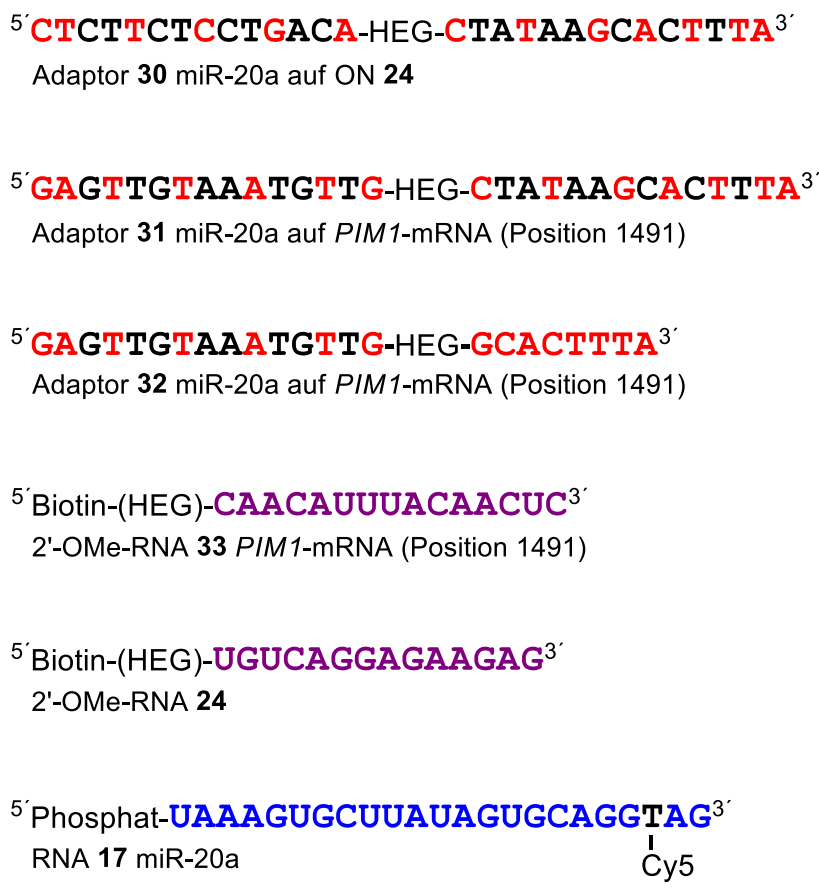
intramolekulare Sekundärstrukturen der Adaptoren sind auf der rechten Seite gezeigt. Dabei steht Rot für LNA, Schwarz für DNA, Blau für RNA und Violett für 2'-Methoxy RNA.

Für die Zellkulturexperimente wurden ausgehend von Adaptor 20 die Adaptoren $\mathbf{3 1}$ und $\mathbf{3 2}$ abgeleitet (Abbildung 75). Dabei entsprach der der Adaptor 31 in seiner Sequenz dem Adaptor 20, während der Adaptor 32 gegen die seed-Region der miR-20a-Familie gerichtet war. Da dieser Adaptor eine größere Anzahl an RISCs adressieren konnte, wurden mit inm größere Effekte erwartet. Analog zu Adaptor 20 war davon auszugehen, dass auch die Adaptoren 31 und 32 einen hairpin ausbilden konnten (Abbildung 75, rechts). Diese sollten 
jedoch eine geringere Stabilität aufweisen als im Fall des Adaptors $\mathbf{2 0}$ und somit bereits bei RT zu einer Hybridisierung mit den Ziel-ONs fähig sein. Für die Bindestelle der miR-33a wurde kein Adaptor entworfen, da keine Möglichkeit bestand eine Selbstinhibierung des Adaptors zu verhindern. Der Grund dafür war, dass der entsprechende Adaptor 21 eine Vielzahl an Sekundärstrukturen aufwies und einen sehr stabilen hairpin formte.

\subsubsection{Band-Shift-Experimente mit den DNA/LNA-Mixmeren}

Zunächst wurde in Band-Shift Experimenten geprüft, ob der Einsatz der DNA/LNA-Mixmere die Ausbildung der intermolekularen Sekundärstrukturen verhinderte und wie sich die neuen Adaptoren gegenüber den LNA-Analoga verhielten (Abbildung 76). Außerdem sollte die Auswirkungen eines Überschusses der Adaptoren gegenüber ihren Ziel-ONs untersucht werden. Dabei war aus statistischen Gründen zu erwarten, dass eine Erhöhung der Adaptorkonzentration zu einem erhöhten Anteil der binären Komplexe gegenüber dem ternären Komplex führen sollte.

Zunächst wurde der Adaptor $\mathbf{3 0}$ betrachtet, mit dem keine Dimerisierung beobachtet werden konnte (Abbildung 76, a, Lane 2). Dies zeigte, dass die intermolekularen Sekundärstrukturen bei den DNA/LNA-Mixmeren nicht ausgebildet wurden. Außerdem konnte die vollständige Hybridisierung zwischen 30 und den ONs 17 oder 24 zu binären Komplexen (Abbildung 76, a, Lane $4+5$ ) sowie dem ternären Komplex (Lane 6) beobachtet werden. Im Gegensatz zu den Experimenten mit Adaptor 18 waren nach der Hybridisierung mit ON 24 keine quartären Komplexe sichtbar (Lane 4). Des Weiteren konnte die erwartete Abhängigkeit der Komplexbildung von der Adaptorkonzentration beobachtet werden und ein zweifacher Überschuss des Adaptors führte zu einer verstärkten Bildung der binären Komplexe (Lane 7).

Mit dem Adaptor 31 konnte ebenfalls eine weitgehend vollständige Bildung der binären Komplexe, sowie des ternären Komplexes beobachtet werden (Abbildung 76, b, Lane 4 -6). Analog zu Adaptor 30 konnte auch hier keine Wechselwirkungen der gegen miR-20a gerichteten Hälften des Adaptors festgestellt werden. Beim Vergleich der Laufstrecke der Adaptoren $\mathbf{3 0}$ und $\mathbf{3 1}(\mathbf{a}+\mathbf{b}$, Lane 2) mit der RNA 17 fiel auf, dass $\mathbf{3 0}$ (28 Basen) langsamer durch das Gel wanderte als RNA 17, während Adaptor 31 (29 Basen) schneller migrierte. Da $\mathbf{3 1}$ ein Nukleoid mehr enthielt als Adaptor $\mathbf{3 0}$ und somit eher langsamer als $\mathbf{3 0}$ laufen sollte, lag es nahe, dass die Bildung des erwarteten hairpins die Ursache war. Aufgrund der guten Hybridisierung des Adaptors mit RNA 17 konnte jedoch davon ausgegangen werden, dass der hairpin den Adaptor nicht inhibierte. Bei einem Überschuss des Adaptors $\mathbf{3 1}$ konnte im Gegensatz zu Adaptor $\mathbf{3 0}$ kein Einfluss auf die 

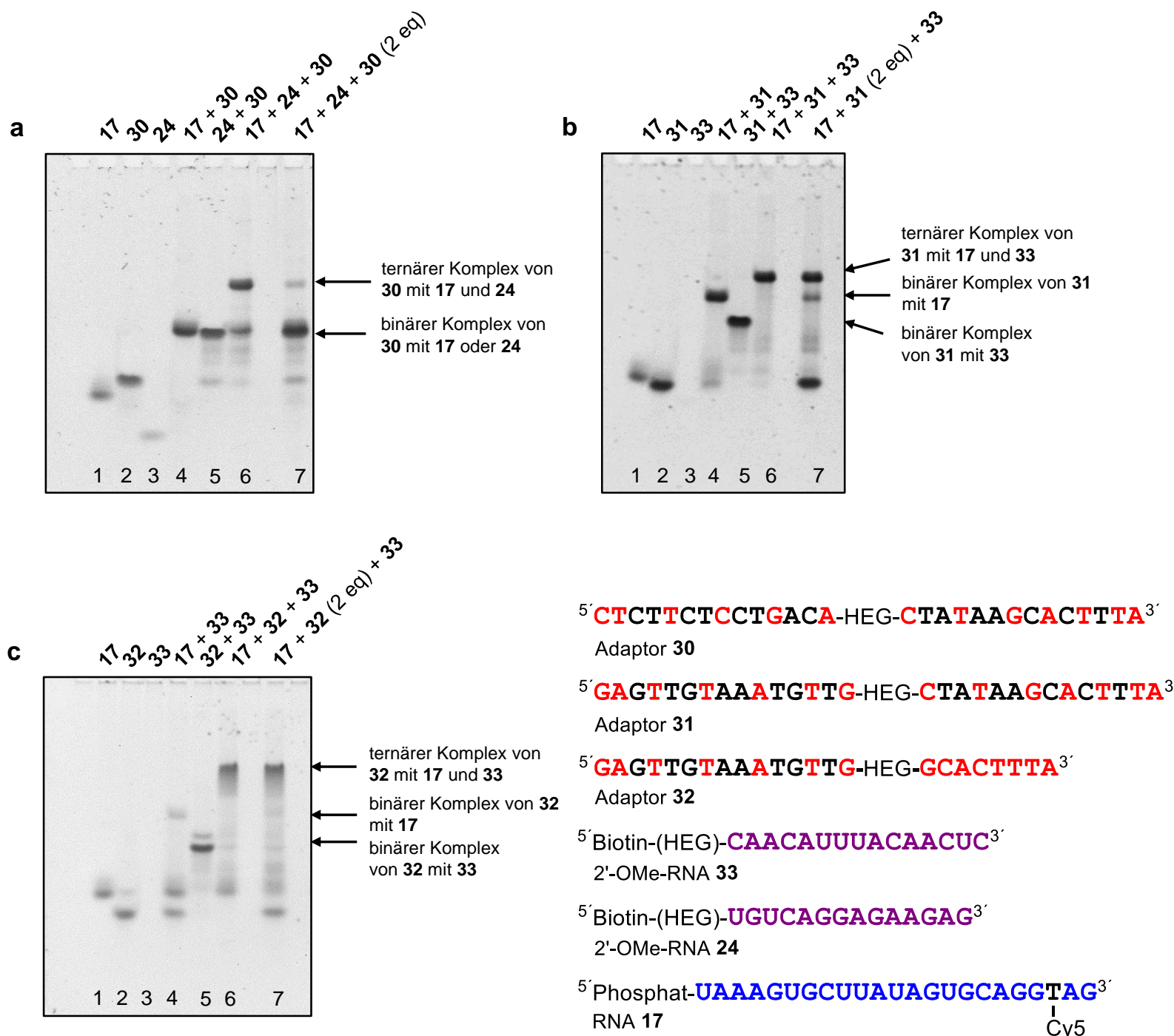

Abbildung 76: Band-Shift Experimente der Adaptoren 30 (a), 31 (b) und 32 (c). Die Proben wurden bei RT $16 \mathrm{~h}$ inkubiert. Lane 1: RNA 17; Lane 2: Adaptor 30 (a), 31 (b) oder 32 (c); Lane 3: ON 24 (a) oder 33 (b + c); Lane 4: Adaptor 30 (a), 31 (b) oder 32 (c) + RNA 17; Lane 5: Adaptor 30 (a), 31 (b) oder 32 (c) + ON 24 (a) oder 33 (b + c); Lane 6: RNA 17 + Adaptor 30 (a), 31 (b) oder 32 (c) + ON 24 (a) oder 33 (b + c); Lane 7: RNA 17 + 2 eq Adaptor 30 (a), 31 (b) oder 32 (c) + ON 24 (a) oder $33(\mathbf{b}+\mathbf{c})$. Die Proben wurden $16 \mathrm{~h}$ bei RT in Puffer 2 inkubiert. $16 \%$ nativ PAGE. Die Detektion der Banden erfolgte durch Färbung mit SYBR Gold. Die Standardkonzentration der ON betrug $1 \mu \mathrm{M}$.

Bildung des ternären Komplexes beobachtet werden und der überschüssige Adaptor lag als Monomer vor (b, Lane 7). Eine mögliche Erklärung wäre, dass der hairpin des Adaptors durch die Bindung des ON 33 geöffnet und die Hybridisierung mit RNA 17 durch diese Konformationsänderung bevorzugt wurde. Dieses Verhalten ähnelte dem einer kooperativen Bindung, bei der das Andocken eines Liganden eine Konformationsänderung hervorruft und dadurch die Bindung weiterer Liganden erleichtert. Charakteristisch für diese Systeme ist ein makroskopisches alles-oder-nichts Verhalten, welches auch für den Adaptor 31 zu beobachten war. ${ }^{[239]}$ Aufgrund dieser Analogie wird das für die Bildung des ternären Komplexes aus Adaptor $\mathbf{3 1}$ und den ONs $\mathbf{1 7}$ und $\mathbf{3 3}$ beobachtete Verhalten ebenfalls als kooperativ bezeichnet. 
Mit dem Adaptor 32 konnten ähnliche Ergebnisse wie mit Adaptor 31 erhalten werden (Abbildung 76, c). Auch in diesem Fall war die Bildung eines hairpins aus dem Laufverhalten des Adaptors abzuleiten (Lane 2). Da der hairpin des Adaptors 32 mehr LNA-Basen enthielt als der des Adaptors $\mathbf{3 1}$ war davon auszugehen, dass der hairpin stabiler war und somit die Bindung der RNA 17 weitgehend abschwächte, wie in Lane $4 \mathrm{zu}$ sehen ist. Die Hybridisierung mit ON 33 erfolgte jedoch vollständig (Lane 5), genauso wie die Bildung des ternären Komplexes aus Adaptor 32 und den ONs 17 und 33 (Lane 6). Analog zu Adaptor 31 führte ein Überschuss des Adaptors zu keiner Abnahme des ternären Komplexes (Lane 7) und somit konnte auch in diesem Fall von einem kooperativen Bindeverhalten ausgegangen werden.

Nachdem gezeigt wurde, dass die DNA/LNA-Mixmere $\mathbf{3 1}$ und $\mathbf{3 2}$ mit den kurzen ONs 17 und 33 vollständig hybridisieren konnten, sollte gezeigt werden, dass ein ternärer Komplex auch mit einem längeren Ausschnitt der PIM1-mRNA (RNA 34) ${ }^{[240]}$ möglich war. Aufgrund der Länge der RNA 34 von über 400 bp war davon auszugehen, dass sich ihr Laufverhalten durch die Bindung des Adaptors nur wenig verändern würde, wodurch die Band der RNA 34 durch eine SYBR-Gold-Färbung nicht von der des Komplexes zu unterscheiden wäre. Aus

a

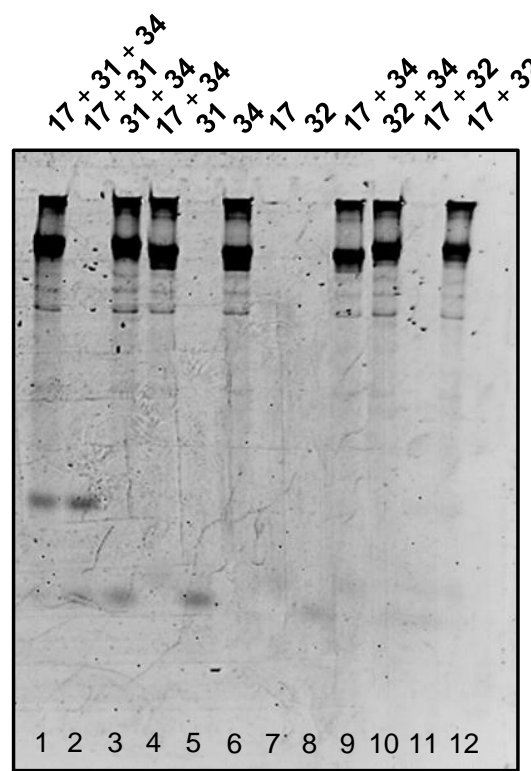

b

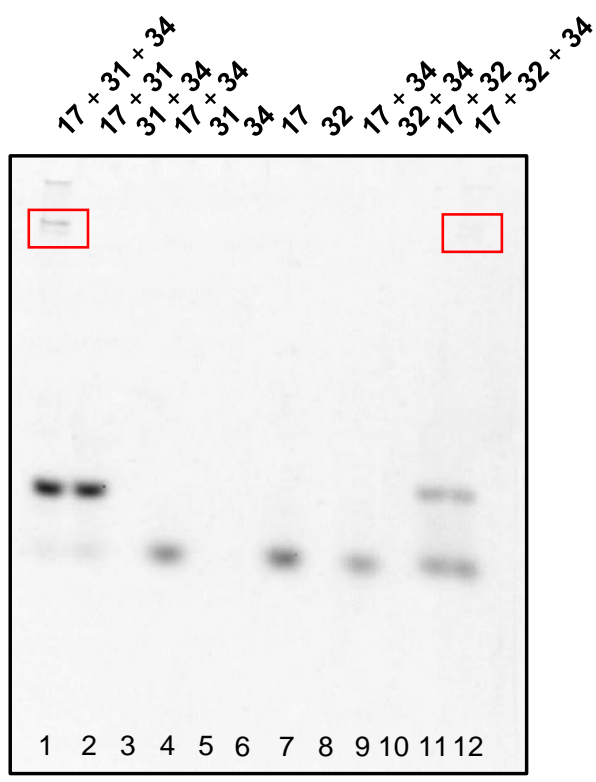

5'GAGTTGTAAATGTTG-HEG-CTATAAGCACTTTA ${ }^{3}$

Adaptor 31

5'GAGTTGTAAATGTTG-HEG-GCACTTTA ${ }^{3}$ 5'Phosphat-UAAAGUGCUUAUAGUGCAGGTAG ${ }^{3}$ Adaptor 32 RNA 17

Abbildung 77: Band-Shift-Experiment mit den Adaptoren 31 und 32 sowie der RNA 34. a: Färbung mit SYBR Gold, b: Detektion der Cy5-gelabelten RNA 17. Lane 1: RNA 17 + RNA 34 + Adaptor 31; Lane 2: RNA 17 + Adaptor 31; Lane 3: RNA 34 + Adaptor 31; Lane 4: RNA 17 + RNA 34; Lane 5: Adaptor 31; Lane 6: RNA 34; Lane 7: RNA 17; Lane 8: Adaptor 32; Lane 9: RNA17 + RNA 34; Lane 10: Adaptor 32 + RNA 34; Lane 11: RNA 17 + Adaptor 32; Lane 12: RNA 17 + Adaptor 32 + RNA 34. Die Proben wurden $2 \mathrm{~h}$ in Puffer 2 inkubiert. $8 \%$ nativ PAGE. Die Konzentration der ON betrug in allen Fällen ungefähr $1 \mu \mathrm{M}$. 


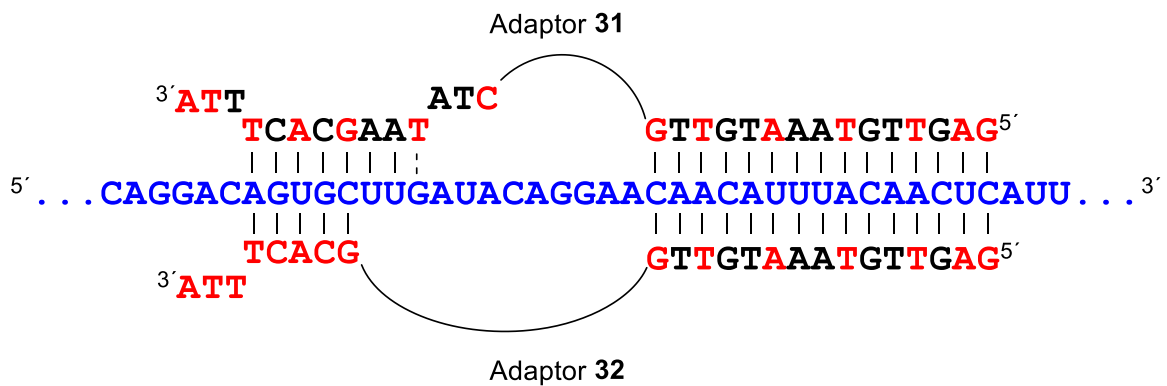

Abbildung 78: Schematische Darstellung der möglichen doppelten Bindung der Adaptoren $\mathbf{3 1}$ (oben) und $\mathbf{3 2}$ (unten) an die RNA 34.

diesem Grund erfolgte zusätzlich eine Detektion der Cy5-gelabelten RNA 17 (Abbildung 77, b). Entgegen der Erwartung zeigte sich, dass die Bindung der Adaptoren an die RNA $34 \mathrm{zu}$ einer langsameren Migration führte (Abbildung 77, a, Lane 3 und 10). Obwohl die Bande der RNA 34 vollständig shiftete, war dennoch eine deutliche Bande des Adaptors zu erkennen, was darauf schließen ließ, dass die RNA 34 im Unterschuss vorlag. Nach der Inkubation von RNA 34 mit den Adaptoren und RNA 17 änderte sich das Migrationsverhaltens nicht mehr (Lane 1 und 12). Die Detektion der ternären Komplexe konnte somit nur über die Cy5-gelabelte RNA 17 erfolgen. Es zeigte sich jedoch, dass mit beiden Adaptoren nur sehr geringe Anteile des ternären Komplexes gebildet wurden. Dabei war der Anteil im Fall des Adaptors 31 (Lane 1, roter Kasten) höher als im Fall des Adaptors 32 (Lane 12, roter Kasten). Diese Beobachtung stand im Widerspruch zu den vorherigen Experimenten mit ON 33, bei denen die Adaptoren eine erhöhte Affinität zur RNA 17 aufwiesen, wenn sie zuvor die PIM1-Sequenz gebunden hatten. Aus diesem Grund wurde eine Bindung beider Adaptorhälften an die RNA 34 in Betracht gezogen und deren Sequenz genauer untersucht. In der Nähe der Bindestelle der Adaptoren lag eine zu der gegen miR-20a gerichteten Hälfte der Adaptor komplementäre Sequenz (Abbildung 78). Dies ließ den Schluss zu, dass die Adaptoren an zwei Stellen an die RNA 34 banden, wodurch die Hybridisierung mit der RNA 17 verhindert wurde. Dabei fiel auf, dass der Adaptor 31 zwar eine höhere Anzahl an Basenpaare mit RNA 34 ausbilden konnte als 32 , aber dennoch besser an RNA 17 band. Als mögliche Ursache für diese Beobachtung kam die höhere Anzahl der LNA-Basen in Adaptor 32 in Frage.

Die mögliche zweifache Bindung des Adaptors an die PIM1-mRNA war auch im Hinblick auf die Zellkulturexperimente kritisch, da sie auch die Umleitung von RISCs verhindern würde. Da die Proben jedoch bei RT inkubiert wurden, war eine Wiederholung des Experiments bei $37^{\circ} \mathrm{C}$ notwendig, um die Bedingungen der Zellkulturexperimente besser nachzubilden (Abbildung 79). Dabei konnte bei $37^{\circ} \mathrm{C}$ (Lane 1) ein deutlich höherer Anteil des ternären Komplexes beobachtet werden als bei RT (Lane 2). Somit konnte gezeigt werden, dass die Umleitung einer miRNA auch an einen längeren Ausschnitt der 
PIM1-mRNA durchaus möglich war und es wurde angenommen, dass dies auch für die Umleitung von RISCs in den Zellkulturexperimenten gelingen könnte.
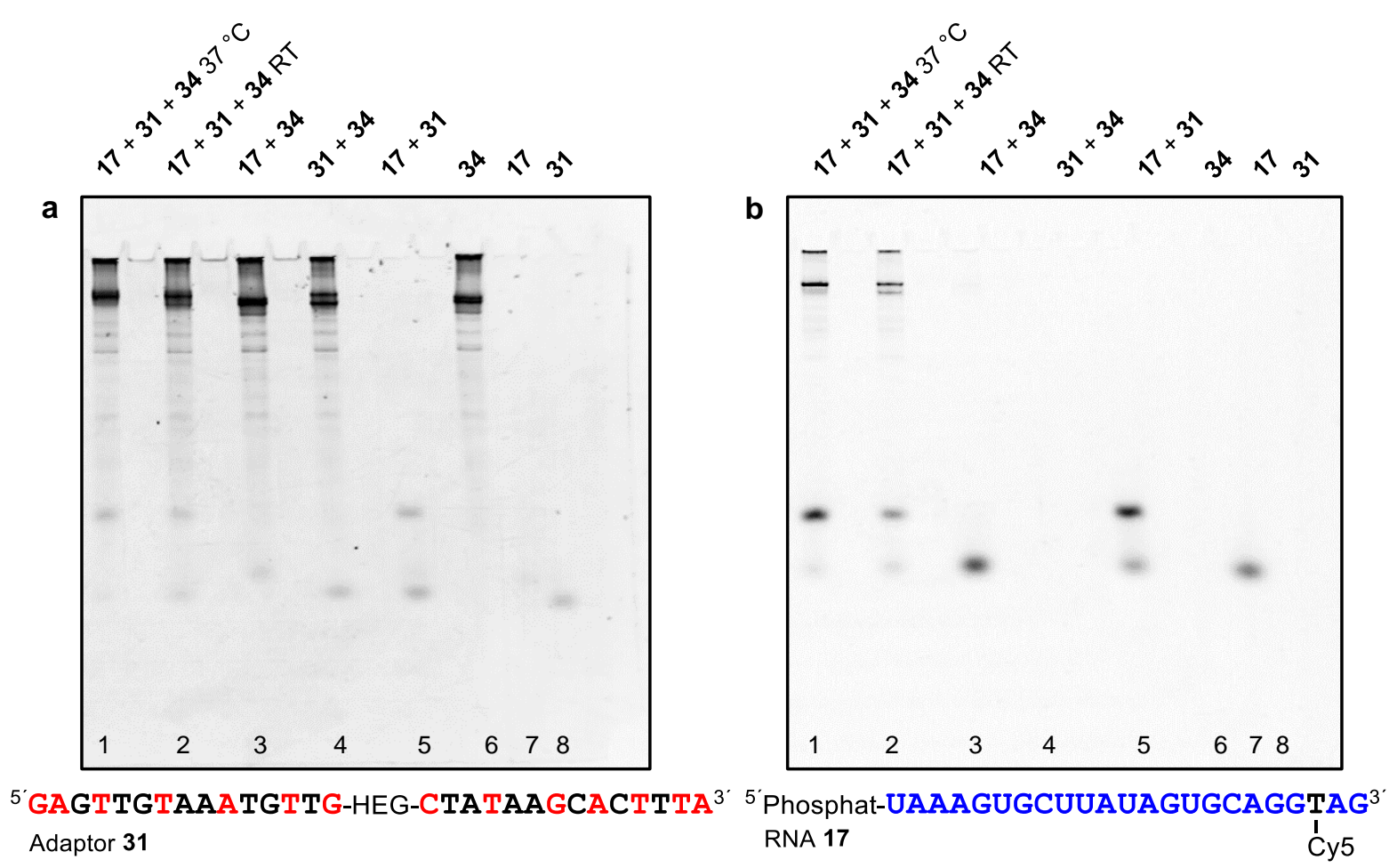

Abbildung 79: Band-Shift-Experimente mit Adaptor 31 und den RNAs 17 und 34. a Färbung mit SYBR Gold, b Detektion über Cy5 Lane 1: RNA 17 + RNA 34 + Adaptor 31, $37^{\circ} \mathrm{C}$; Lane 2: RNA 17 + RNA 34 + Adaptor 31, RT; Lane 3: RNA 17 + RNA 34; Lane 4: RNA 34 + Adaptor 31; Lane 5: RNA 17 + Adaptor 31; Lane 6: RNA 34; Lane 7: RNA 17: Lane 8: Adaptor 31. $8 \%$ nativ PAGE. Die Proben wurden für $2 \mathrm{~h}$ in Puffer 2 inkubiert. Die Konzentrationen der ON betrugen $1 \mu \mathrm{M}$.

\subsubsection{Pulldown-Experimente}

Im Anschluss an die Band-Shift-Experimente sollte die Bildung der ternären Komplexe in fluoreszenzbasierten Pulldown-Experimenten bestätigt werden. Diese Methode erlaubte zudem die Untersuchung der Abhängigkeit des ternären Komplexes von der Konzentration der Adaptoren 30 - 32. Hierzu wurde die 2'-OMe-RNA 24 an Magnetic Beads gebunden und im Verhältnis 1:1 mit dem nicht komplementären miRNA-Modell 17 versetzt. Nun wurde der Adaptor $\mathbf{3 0}$ in steigender Konzentration zugegeben. Nach der Inkubationszeit führte man den Pulldown durch, wusch und trennte dann die fluoreszenzmarkierte RNA 17, falls vorhanden, durch einen pH-Sprung von den Beads ab (Abbildung 80, schwarz). Dabei konnte ein nahezu linearer Anstieg der Fluoreszenz bis zu einem Verhältnis von 1:1.25:1 (24/30/17) beobachtet werden, bei dem die maximale Fluoreszenz erreicht wurde. Bei höheren Konzentrationen des Adaptors fielen die Werte stark ab und bei einem sechsfachen Überschuss konnten noch ca. $10 \%$ des Maximums detektiert werden. Dies bestätigte die Ergebnisse der Band-Shift-Experimente und deutete auf eine unabhängige Hybridisierung der beiden Adaptorhälften hin. Analog dazu wurden die Adaptoren 31 (rot) 


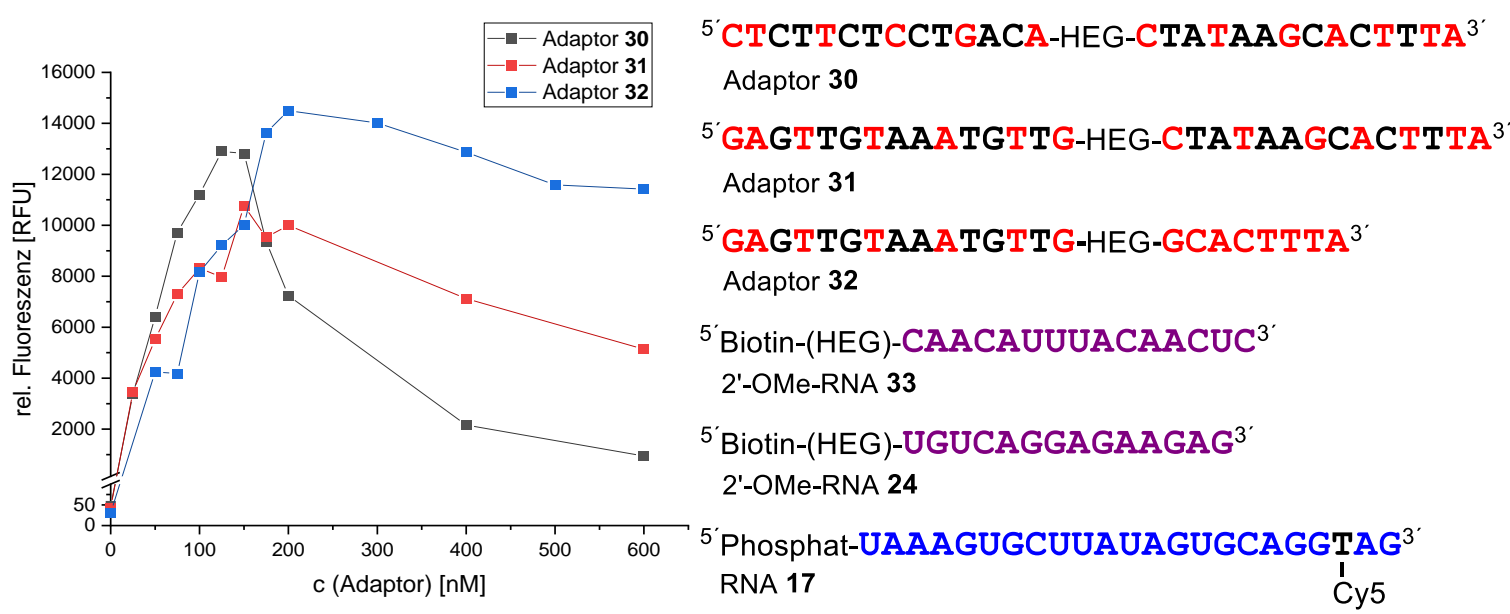

Abbildung 80: Titrationsexperiment mit den Adaptoren 30 (Schwarz), 31 (rot) und 32 (blau). Dabei wurden die ONs 17 und 24 oder $\mathbf{3 3}$ in einem Verhältnis von 1:1 vorgelegt und mit unterschiedlichen Konzentrationen des Adaptors $1 \mathrm{~h}$ bei RT in Puffer 2 inkubiert.

und 32 (blau) betrachtet, wozu sie in steigender Konzentration zu den ONs 17 und 33 gegeben wurden. Auch hier war zunächst ein steiler linearer Anstieg der Fluoreszenz zu Adaptors 31 verschob sich das Maximum nur leicht und lag bei 1:1.5:1 (33/31/17), während der Effekt bei Adaptor 32 mit einem Verhältnis von 1:2:1 (33/32/17) deutlich ausgeprägter war. Bei höheren Konzentrationen der Adaptoren traten jedoch größere Unterschiede auf. Im Fall des Adaptors 31 zeigte sich eine langsame, fast lineare Abnahme der Fluoreszenz, welche bei einem sechsfachen Überschuss des Adaptors 31 noch ca. $50 \%$ des maximalen Werts betrug. Dies entsprach in etwa dem fünffachen Wert des Adaptors 30. Für den Adaptor 32 war die Abnahme der Fluoreszenz noch geringer und es konnten bei einem sechsfachen Überschuss noch ca. 80 \% des maximalen Werts detektiert werden, was dem zehnfachen Wert des Adaptors 30 entsprach. Da in den Pulldown-Experimenten die ONs 17 und $\mathbf{3 3}$ vorgelegt und dann mit den Adaptoren $\mathbf{3 1}$ und $\mathbf{3 2}$ versetzt wurden, konnte man zudem annehmen, dass die Bindung der Adaptoren an ON 33 deutlich schneller verlief als die an RNA 17. Dieses Verhalten wies darauf hin, dass die Bindung des Adaptors an ON 33 die Hybridisierung mit RNA 17 erleichterte und war ein weiterer Hinweis auf die Kooperativität der Adaptoren. Zwar erschien dieses kooperative Verhalten auf den ersten Blick ungünstig, da es einen negativen Einfluss auf die Affinität der Adaptoren zu den miRNAs besaß. Gleichzeitig war die Bildung des ternären Komplexes dadurch jedoch unabhängig von der Adaptorkonzentration, was in späteren Anwendungen vorteilhaft sein könnte, da so eine Übertitration durch den Adaptor verhindert wurde. Im Falle des ON 30 bestände bei einer zu hohen Adaptorkonzentration die Möglichkeit, dass lediglich der anti-miR-Effekt vorhanden wäre und jedoch keine Inhibierung der Translation aufträte. Im Gegensatz dazu würde der Adaptor 31 bevorzugt nach der Bindung an die Ziel-RNA mit den RISCs interagieren und sollte somit seine Funktion behalten. 


\subsubsection{Schmelzpunktmessungen}

Ausgehend von den Ergebnissen der Band-Shift- und den Pulldown-Experimente mit den Adaptoren gab es starke Hinweise, dass die Adaptoren 31 und 32 hairpin-Elemente ausbildeten (Abbildung 75). Somit sollten die Adaptoren doppelsträngige Bereiche besitzen und beim Erwärmen eine Hyperchromizität aufweisen, auch wenn nur ein geringer Unterschied in der Absorption erwartet wurde. Für einen orthogonalen Adaptor sollte hingegen keine Hyperchromizität auftreten und mit Schmelzpunktmessungen könnte so ein weiterer Hinweis auf mögliche hairpin-Strukturen gefunden werden. Um dies zu überprüfen, wurden die Adaptoren $\mathbf{3 0}$ und $\mathbf{3 1}$ betrachtet. Diese wiesen eine vergleichbare Länge (28 gegen 29 Basen) auf, wodurch mögliche Änderungen der Absorption besser vergleichbar sein sollten als mit dem kürzeren Adaptor 32 (23 Basen). Außerdem war davon auszugehen, dass nur mit Adaptor 31 eine Hyperchromizität auftrat, jedoch nicht mit $\mathbf{3 0}$. In den Schmelzpunktmessungen konnten diese Annahmen bestätigt werden und während der Adaptor $\mathbf{3 0}$ kein Schmelzverhalten aufwies, ${ }^{[13]}$ konnte für den Adaptor $\mathbf{3 1}$ ein Schmelzpunkt von ungefähr $62^{\circ} \mathrm{C}$ bestimmt (Abbildung 81). Dies zeigte, dass der Adaptor 31 doppelsträngige Abschnitte enthielt und in Kombination mit den Ergebnissen der Band-Shift- und Pulldown-Experimente war die Ausbildung der angenommenen hairpin-Struktur sehr wahrscheinlich. Bei einer genaueren Betrachtung des Kurvenverlaufs der Heizzyklen wurden zudem Anzeichen für einen weiteren Schmelzpunkt von ca. $32{ }^{\circ} \mathrm{C}$ gefunden, was auf eine partielle Öffnung des hairpins hindeuten könnte. Diese würde die gute Komplexierung des Adaptors 31 an die RNA 17 erklären, da größere Bereiche der Bindestelle leichter zugänglich wären. Ebenso würde dies erklären, warum die Affinität des Adaptors 20 stieg, wenn dieser bei $37^{\circ} \mathrm{C}$ inkubiert wurde. Für den Adaptor $\mathbf{3 2}$ waren diese Effekte nicht möglich, da die gegen miR-20a gerichtete Sequenz deutlich kürzer war und auch bei einer partiellen Öffnung des Adaptors nicht zugänglich sein sollte, was ebenfalls in den Band-Shift- Experimenten zu beobachten war.

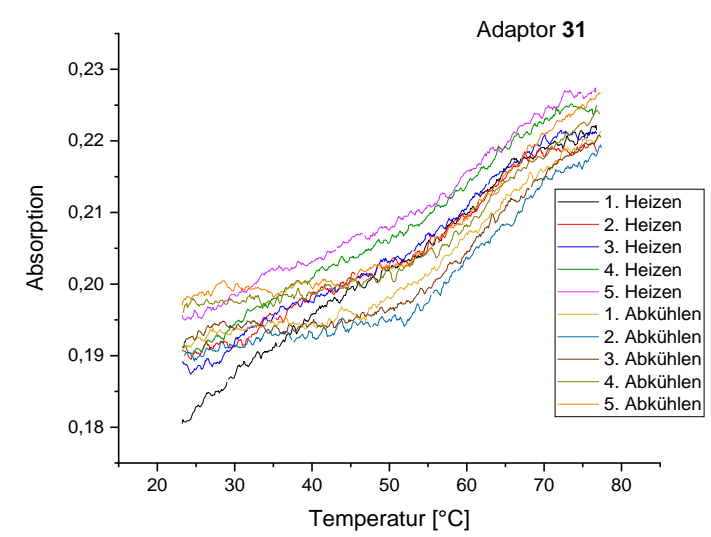

Abbildung 81: Schmelzkurven des Adaptors 31. Der Adaptor $(1 \mu \mathrm{M})$ wurde in $1 \mathrm{~mL}$ Puffer 2 in fünf Zyklen zwischen $23^{\circ} \mathrm{C}$ and $77^{\circ} \mathrm{C}$ gemessen. Dabei konnte für den Adaptor 31 ein $\mathrm{T}_{\mathrm{m}}$ von ungefähr $62{ }^{\circ} \mathrm{C}$ erhalten werden. ${ }^{[13]}$ 
Um der Fragestellung nachzugehen, ob die hairpin-Struktur einen Einfluss auf die Bindung des Adaptors zu seinen Ziel-ONs hatte, wurden die Schmelzpunkte der Adaptorhälften mit den ONs 17 oder 33 bestimmt (Abbildung 82). ${ }^{[13]}$ Als Kontrollen wurden die Mixmere 35 und 36 betrachtet, welche die beiden Hälften von Adaptor 31 repräsentierten. Dabei zeigte sich, dass die Hybridisierung mit ON 33 nicht beeinflusst wurde und sowohl mit Adaptor 31 als auch mit ON 35 konnte ein Schmelzpunkt von $76^{\circ} \mathrm{C}$ bestimmt werden. Der Schmelzpunkt des Duplex zwischen den ONs 31 und $17\left(72^{\circ} \mathrm{C}\right)$ war gegenüber dem Duplex aus den ONs 36 und $17\left(74^{\circ} \mathrm{C}\right)$ um ca. $2^{\circ} \mathrm{C}$ erniedrigt. Gleichzeitig wies der Duplex von RNA 17 mit Adaptor $30\left(73^{\circ} \mathrm{C}\right)$ ebenfalls eine Erniedrigung von $1^{\circ} \mathrm{C}$ gegenüber dem Duplex aus den ONs 17 und 36 auf. Somit konnte davon ausgegangen werden, dass die Ursache der leichten Schmelzpunkterniedrigung eher in einer elektrostatischen Repulsion der ungebundenen RNA mit der ungebundenen Adaptorhälfte zu suchen war als in der hairpin-Struktur des Adaptors 31. Da der Schmelzpunkt immer noch bei über $70^{\circ} \mathrm{C}$ lag, sollte eine Hybridisierung unter physiologischen Bedingungen nicht beeinflusst werden.
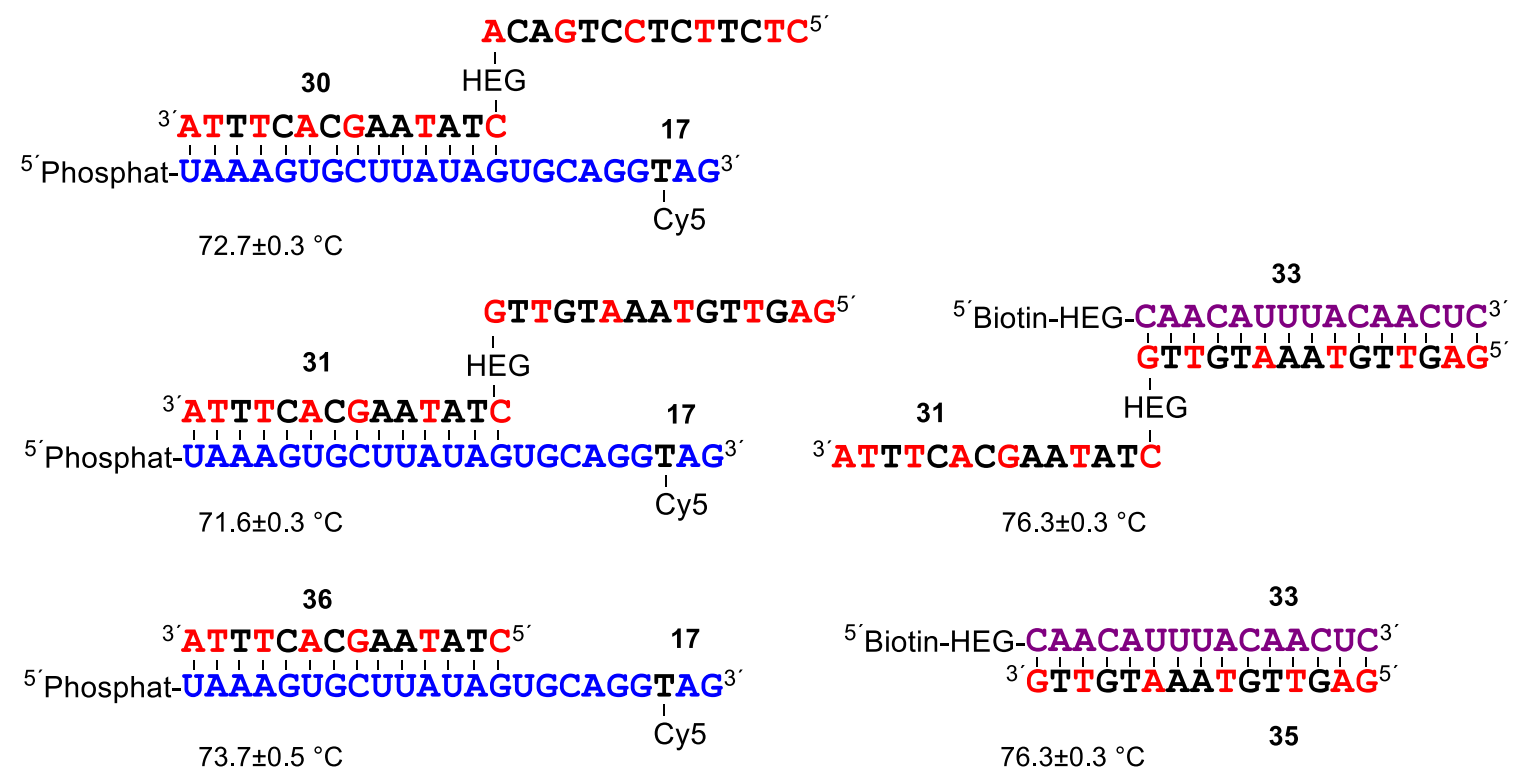

Abbildung 82: Schmelzpunkte der Adaptoren 30 and $\mathbf{3 1}$ mit den ONs 17 und 33. Diese wurden mit den ONs 35 and 36 vergleichen, welche die beiden Fragmente des Adaptors 31 darstellen. Die ONs $(1 \mu \mathrm{M})$ wurden in $1 \mathrm{~mL}$ des Puffers 2 für $20 \mathrm{~h}$ bei $37^{\circ} \mathrm{C}$ inkubiert. Die Absorption bei $260 \mathrm{~nm}$ wurde in einem Bereich von $20^{\circ} \mathrm{C}$ bis $90^{\circ} \mathrm{C}$ gemessen. Die Schmelzpunkte stellen die Mittelwerte $( \pm \mathrm{SD})$ aus mindestens drei unabhängigen Messungen dar. ${ }^{[13]}$

\subsubsection{Isolierung von RISCs aus HeLa-Lysaten}

In den vorangegangenen Experimenten konnte mit den Adaptoren 30-32 eine erfolgreiche Umleitung der Modell-RNA 17 auf verschiedene Ziel-ONs beobachtet werden. Daraufhin sollte versucht werden, RISCs aus HeLa-Lysat zu isolieren, um das Konzept der Umleitung auf Basis von in vitro Experimenten zu bestätigen. Dazu wurden zunächst mit ON 24 beladene Magnetic Beads entweder mit oder ohne Adaptor 30 in einem HeLa-Lysat 


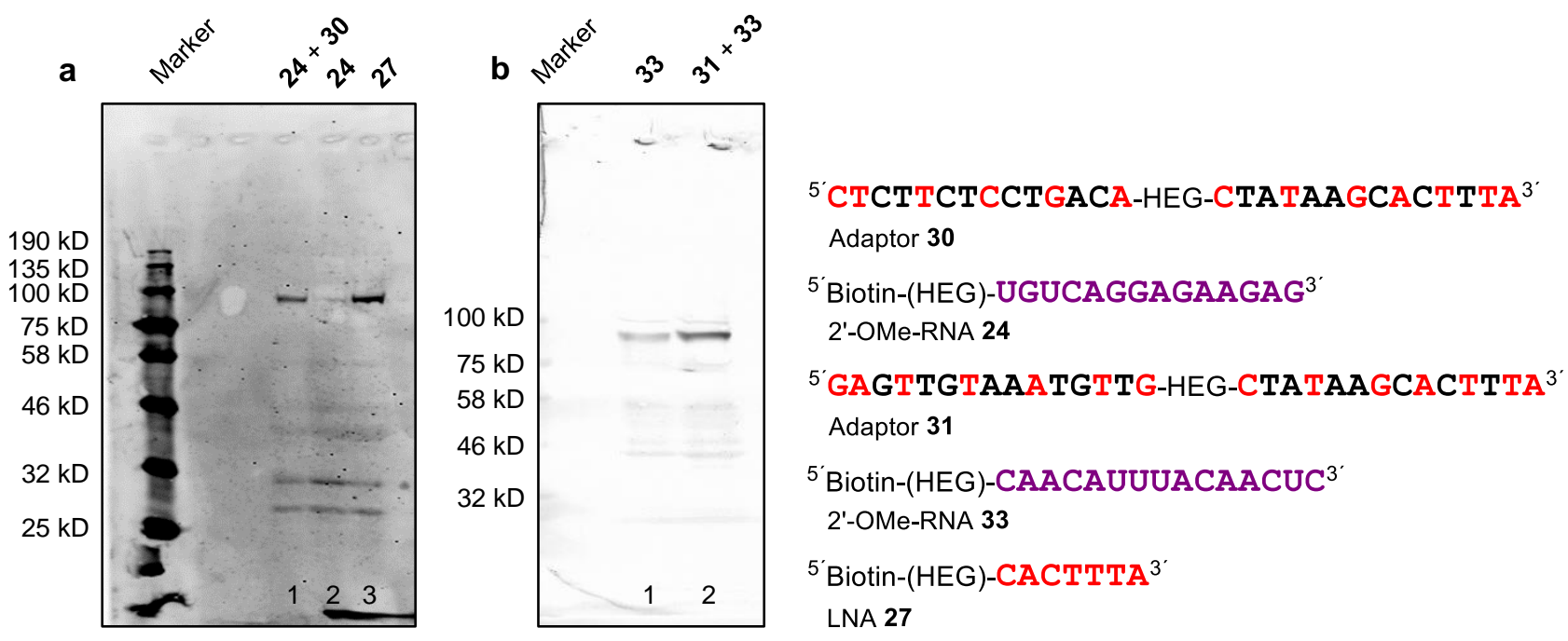

Abbildung 83: Isolation von RISC-Komplexen durch Pulldown-Experimente mit a: ON 24 mit Adaptor 30; b: ON 33 und Adaptor 31. Lane 1: ON 24 + Adaptor 30; Lane 2: ON 24; Lane 3: LNA 27. b: Lane 1: ON 33; Lane 2: ON 33 + Adaptor 31. Die Banden wurden durch Western-Blot nach Elektrophorese durch spezifische Antikörper gegen hAgo2 sichtbar gemacht. a: Die Konzentration der ONs betrug jeweils $100 \mathrm{nM}$ und die Detektion erfolgte mittels Fluoreszenz-Antikörper; b: Die Konzentration der ONs betrug jeweils $300 \mathrm{nM}$ und die Detektion erfolgte mittels Färbung (BCIP/NBT).

inkubiert (Abbildung 83, a). Als Positivkontrolle diente dabei die LNA 27 (Lane 3). Hierbei konnte in Anwesenheit des Adaptors 30 eine deutliche hAgo2-Bande detektiert werden (Lane 1), während in Abwesenheit des Adaptors nur eine minimale Bande zu beobachten war (Lane 2). Zwar war die mit Adaptor $\mathbf{3 0}$ erhaltene Bande weniger intensiv als mit der LNA 27 (Lane 3), diese war jedoch gegen die gesamte miR-20a-Familie gerichtet und konnte somit potenziell mehr RISCs adressieren. Auf Grundlage dieses Experiments konnte gezeigt werden, dass die Umleitung von mit miR-20a beladenen RISCs durch Adaptormoleküle möglich war, was das Konzept auf der Basis von in vitro Experimenten bestätigte. Daraufhin wurde das Experiment mit Adaptor 31 wiederholt, um zu zeigen, dass eine Umleitung auf verschiedene Zielstrukturen möglich war (Abbildung 83, b). Auch in diesem Fall konnte mit dem Adaptor 31 eine deutliche hAgo2-Bande beobachtet werden (Lane 2). Allerdings fiel auf, dass der Hintergrund mit dem Ziel-ON 33 (Abbildung 83, b, Lane 1) höher war als im vorhergehenden Experiment (Abbildung 83, a, Lane 2). Als Ursache hierfür konnte eine Mismatch-Bindung von RISCs an das ON 33 nicht ausgeschlossen werden. Da die Bande in Anwesenheit des Adaptors deutlich intensiver war, zeigte sich, dass auch Adaptor $\mathbf{3 1}$ in der Lage war RISCs umzuleiten. Nachdem es mit den Adaptoren $\mathbf{3 0}$ und $\mathbf{3 1}$ möglich war, miR-20a beladene RISCs auf orthogonale Ziele umzuleiten, wurde die Selektivität der Umleitung geprüft. Dazu wurden die Adaptoren 30 und 31 jeweils mit den ONs 24 und 33 inkubiert (Abbildung 84). Dabei zeigte sich, dass mit Adaptor $\mathbf{3 0}$ nur in Kombination mit ON 24 eine hAgo2-Bande zu beobachten war (Lane 2), während dies für Adaptor 31 nur mit ON 33 auftrat (Lane 5). In allen anderen Fällen konnte nur eine schwache Hintergrundbande beobachtet werden. Somit war eine Umleitung von 


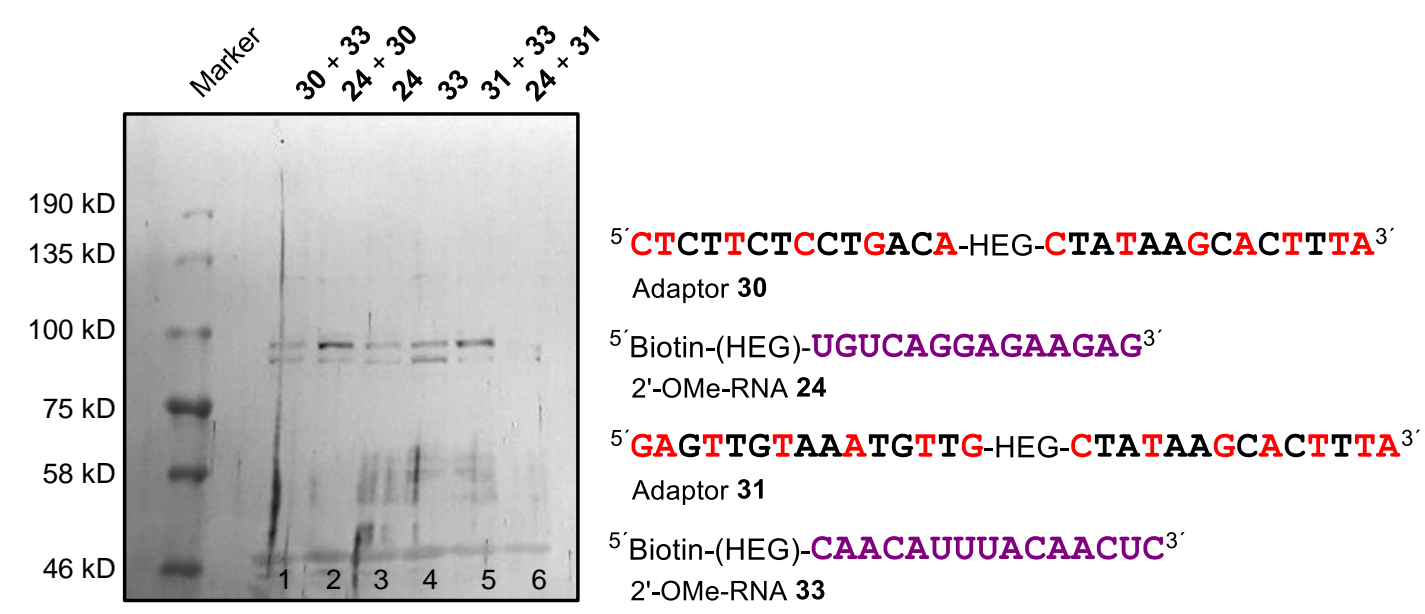

Abbildung 84: Selektive Isolierung von RISCs mittels der Adaptoren 30 und 31. Lane 1: ON 33 + Adaptor 30; Lane 2: ON 24+ Adaptor 30; Lane 3: ON 24; Lane 4: ON 33; Lane 5: ON 33 + Adaptor 31; Lane 6: ON 24 + Adaptor 31. Die Banden wurden durch Western-Blot nach Elektrophorese durch spezifische Antikörper gegen hAgo2 sichtbar gemacht. Detektion mittels Färbung (BCIP/NBT). Konzentration der ONs betrug jeweils $300 \mathrm{nM}$ in $100 \mu \mathrm{L}$.

RISC nicht nur auf unterschiedliche Zielsequenzen möglich, sondern konnte auch selektiv erfolgen.

Mit Hilfe von in vitro-Experimenten konnte gezeigt werden, dass die Umleitung von miR-20a beladener RISCs auf unterschiedliche Zielsequenzen möglich war. Darüber hinaus konnte in Kreuzexperimenten nachgewiesen werden, dass die Umleitung sequenzspezifisch erfolgte. Außerdem zeigte sich, dass die hairpin-Struktur des Adaptors 31 die Umleitung von RISCs nicht verhinderte. Allerdings war unklar, ob eine Bindung beider Adaptorhälften an die PIM1-mRNA die Effizienz der Umleitung abschwächen könnte.

\subsubsection{Zellkulturexperimente zur Umleitung von miR-20a auf die PIM1-mRNA}

Parallel zu den Band-Shift- und Pulldown-Experimenten wurden in der Gruppe von Prof. Hartmann Zellkulturexperimente mit den Adaptoren durchgeführt. ${ }^{[238]}$ Dabei wurden K562-Zellen mit den Adaptoren 20 - 22 transfiziert und untersucht, ob eine Erhöhung der p21-Level oder eine niedrigere Pim-1-Expression erzielt werden konnte. Mit Adaptor 20 konnte dabei in manchen Experimenten eine minimale Reduktion der Pim-1-Level beobachtet werden, allerdings war dieser Effekt nur bedingt reproduzierbar. Entgegen der Erwartung waren die p21-Level bereits zu Beginn sehr so hoch, sodass die erhoffte Hochregulierung dieses Proteins nur schwer detektiert werden konnte. Mit Adaptor 21 ließen sich überhaupt keine Effekte beobachten. Nachdem in den Band-Shift-Experimenten gezeigt wurde, dass die LNA-Adaptoren eine starke Selbstinhibierung aufwiesen, wurden die Experimente mit ihnen eingestellt und durch die Mixmer-Adaptoren $\mathbf{3 1}$ und $\mathbf{3 2}$ ersetzt (Abbildung 85). In diesen Experimenten konnten in den untransfizierten Zellen und mit der 
Transfektionskontrolle 22 nur geringe p21-Level beobachtet werden (Abbildung 85, Lane 1 - 3). Mit dem Adaptor 31 konnte eine Reduktion der Pim-1-Level gezeigt werden, auch wenn diese nur gering ausgeprägt war (Lane $6+7)$. Die p21-Expression bleib hingegen unbeeinflusst. Im Fall des Adaptors 32 trat der umgekehrte Effekt auf. Dabei waren die p21-Level erhöht, während auf die Pim-1-Expression kein Einfluss sichtbar war (Lane $8+9$ ). Für den Adaptor 20 konnten hingegen kein Einfluss auf die Proteinexpression festgestellt werden (Lane 4 und 5). Allerdings bestand das Problem, dass auch diese Ergebnisse schlecht reproduzierbar waren.

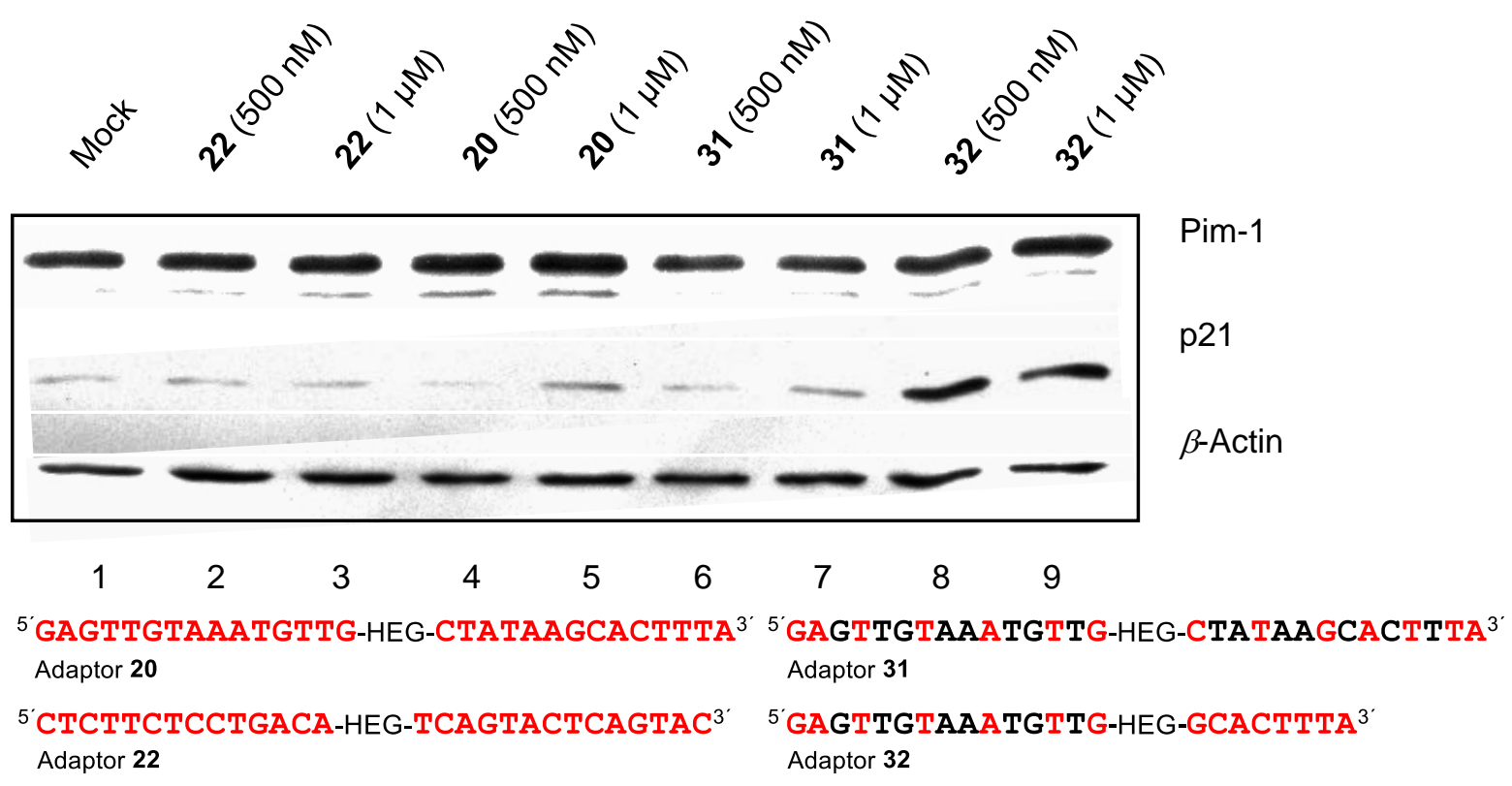

Abbildung 85: Zellkultur-Experimente mit den Adaptoren 20, 22, 31 und 32 . ON 22 diente als Negativkontrolle. Mock: unbehandelte Zellen. $\beta$-Actin wurde als Expressionskontrolle verwendet. Die Experimente wurden von Laura Thomas aus der Gruppe von Prof. Hartmann (Universität Marburg) durchgeführt.

Da aus Experimenten des Hartmann-Labors ${ }^{[233]}$ und unserer Gruppe ${ }^{[240]}$ bekannt war, dass die 3'-UTR der PIM1-mRNA um Nukleotid 1491 herum zugänglich war, ergab sich die Frage, ob die Bindestelle für den gegen miR-20a gerichteten Teil der Adaptoren für die schwankenden Effekte verantwortlich war. Durch eine zweifache Bindung des Adaptors an die PIM1-mRNA würde die Komplexierung mit RISCs verhindert und der Adaptor inhibiert. Außerdem waren die genauen Verhältnisse zwischen der PIM1-mRNA und der miR-20a in den K562-Zellen nicht bekannt. Bei einer zu hohen Konzentration der PIM1-mRNA gegenüber der miR-20a bestand jedoch das Problem, dass ein Effekt auf Pim-1 kaum nachzuweisen wäre. Zusätzlich war die Transfektion der K562-Zellen nicht mit einer konstanten Effizienz möglich. ${ }^{[238]}$ Eine weitere Überlegung war, dass die DNA/LNA-Mixmere eine deutlich geringere Nukleasestabilität aufwiesen als ursprünglich angenommen wurde. 


\subsubsection{Stabilitätstest mit den Adaptoren 30 und 31}

Um die Stabilität der DNA/LNA-Mixmere gegenüber Nukleasen zu untersuchen, wurden die Adaptoren 30 und 31 in HeLa-Lysaten bei RT und bei $37^{\circ} \mathrm{C}$ inkubiert. In den Experimenten zeigte sich, dass die Adaptoren bei RT über mehrere Tage relativ stabil waren (Abbildung 86, $\mathbf{a}$ und $\mathbf{b}$, Lane $2-8$, rot). Zwar war die Bande des Adaptors $\mathbf{3 0}$ bereits nach einem Tag deutlich abgeschwächt, konnte jedoch auch nach $4 \mathrm{~d}$ noch nachgewiesen werden. Der Adaptor 31 war hingegen auch nach $7 \mathrm{~d}$ noch nachzuweisen und zeigte innerhalb der ersten $4 \mathrm{~d}$ nur einen geringen Abbau. Wie zu erwarten, trat der Abbau der Adaptoren bei einer Inkubationen bei $37^{\circ} \mathrm{C}$ deutlich früher ein (Abbildung 86, a und $\mathbf{b}$, Lane 10 - 16). Im Fall des Adaptors 30 zeigte sich bereits nach $3 \mathrm{~h}$ ein deutlicher Abbau (a, Lane 12) und nach $24 \mathrm{~h}$ war der Adaptor nicht mehr zu detektieren (Lane 13). Im Gegensatz dazu wies der Adaptor 31 nach $3 \mathrm{~h}$ nur eine geringe Degradierung auf (b, Lane 12), konnte jedoch nach $24 \mathrm{~h}$ ebenfalls nicht mehr detektiert werden (b, Lane 13). Allerdings war das Lysat nach einer Inkubation von $24 \mathrm{~h}$ bei $37^{\circ} \mathrm{C}$, im Unterschied zu der Inkubation bei RT, deutlich getrübt, was auf eine verstärkte Präzipitation bei $37^{\circ} \mathrm{C}$ hindeutete. Da nach $24 \mathrm{~h}$ nicht einmal Abbauprodukte der Adaptoren zu beobachten waren, konnte nicht ausgeschlossen werden, dass die Adaptoren ebenfalls präzipitierten uns somit

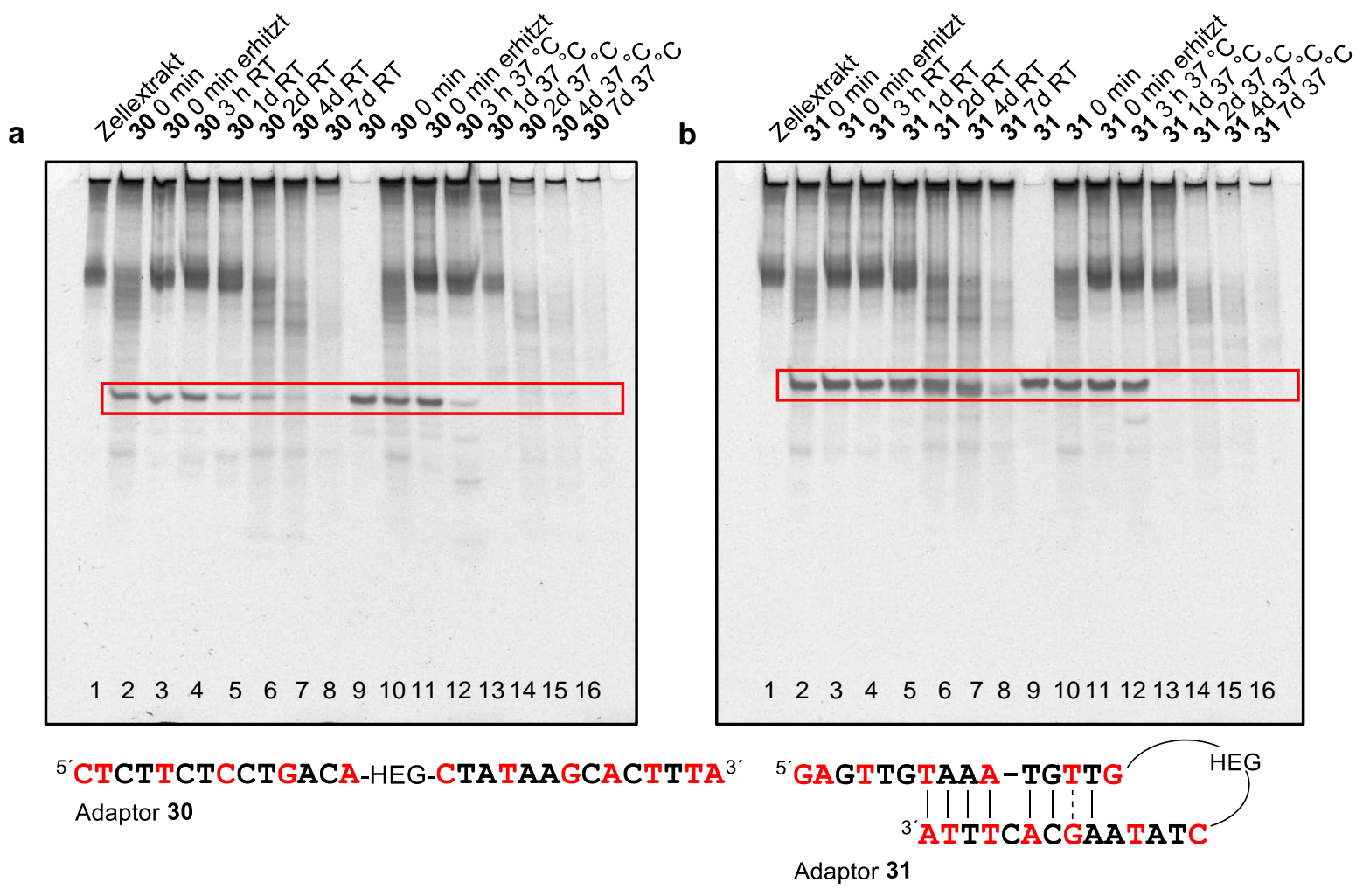

Abbildung 86: Stabilitätstest mit den Adaptoren 30 (a) und 31 (b) (je $2 \mu \mathrm{M}$ ). Die Adaptoren wurden dabei sowohl bei RT als auch bei $37^{\circ} \mathrm{C}$ inkubiert. Die Proben des ersten Tages wurden vor der Elektrophorese für 5 min auf $90{ }^{\circ} \mathrm{C}$ erwärmt, bei den späteren Proben wurde darauf verzichtet, um einen möglichen beschleunigten Abbau oder die Präzipitation des Adaptors zu vermeiden. Die Detektion der Banden erfolgte durch Färbung mit SYBR Gold. Die Adaptorbanden sind rot markiert, der starke Hintergrund wird durch zelleigene ONs verursacht. $16 \%$ dPAGE. 
nicht mehr zu beobachten waren. Aus diesem Grund konnte keine endgültige Aussage über die Stabilität der Adaptoren getroffen werden, jedoch zeigten diese Experimente, dass der Adaptor $\mathbf{3 1}$ einen geringeren Abbau als Adaptor $\mathbf{3 0}$ aufwies. Dies ließ den Schluss zu, dass die hairpin-Struktur einen stabilisierenden Effekt besaß.

Aufgrund der geringen Reproduzierbarkeit der Zellkulturexperimente und da eine Degradierung der Adaptoren als Ursache nicht belegt werden konnte, wurden die Experimente mit den gegen miR-20a gerichteten Adaptoren eingestellt. 


\subsection{Gegen miR-let-7 gerichteter Adaptor 37}

Für einen biologischen proof of principle ist es wichtig, eine Derepression solcher Proteine zu zeigen, die durch die fragliche miRNA im verwendeten Zelltyp herunterreguliert sind. Noch wichtiger ist es allerdings, durch das Umleiten der miRISCs eine Absenkung des neuen Zielproteins zu erreichen. Dies konnte in den Experimenten mit miR-20a und Pim-1 nicht eindeutig beobachtet werden. Eine Grundvoraussetzung für den Erfolg ist eine bestimmte Stöchiometrie der involvierten Nukleinsäuren: Die 3'-UTR der Ziel-RNA sollte zu einem hohen Anteil mit einem RISC-beladenen Adaptor belegt sein. Dies setzt eine hinreichende Menge an umzuleitender miRNA voraus. Andernfalls würden unbeladene und damit inaktive Adaptoren mit den RISC-beladenen um die Bindestelle konkurrieren. Um diese kontraproduktive Situation zu vermeiden, dürfte die Umleitung solcher miRNAs am aussichtsreichsten sein, die in möglichst hoher Zahl in einer Zelle vorkommen. Noch bedeutend häufiger als miR-20a sind in fast allen Zellen die miRNAs der let-7-Familie anzutreffen. Im Gegensatz zu miR-20a handelt es sich bei ihnen keineswegs um oncomiRs. Sie haben im Gegenteil sogar tumorhemmende Eigenschaften, die man eigentlich nicht blockieren sollte. Um jedoch die Inhibierung eines Zielproteins durch RISC-Umleitung zu demonstrieren, erschienen miR-let-7a und seine Verwandten als aussichtsreichste Kandidaten. Die nachfolgend geschilderten Experimente hatten daher zum Ziel, miR-let-7a auf die bekannte Bindestelle 1491 in der 3'-UTR der PIM1-mRNA umzuleiten. Hierzu wurde der zu Adaptor 32 analoge Adaptor 37 (Abbildung 87) entworfen und in Band-Shift- sowie Pulldown-Experimenten auf sein Bindeverhalten untersucht. Parallel dazu wurden in der Hartmann-Gruppe statt der K562-Zellen die stabiler zu transfizierenden HeLa-Zellen für die Zellkulturexperimente eingesetzt. ${ }^{[238]}$

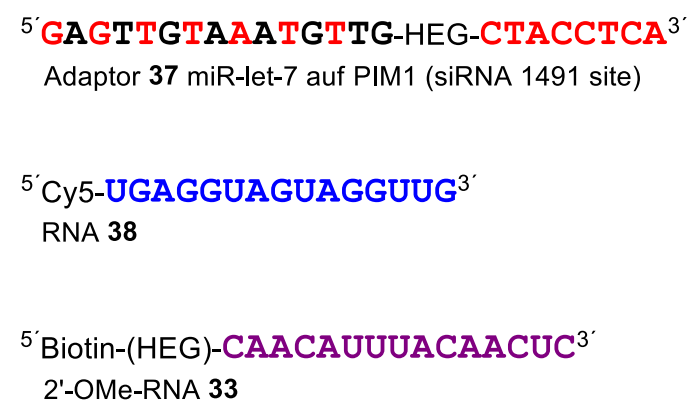

Abbildung 87: Sequenz der ONs 37 und 38. Eine mögliche hairpin-Struktur des Adaptors ist auf der rechten Seite gezeigt. Dabei steht Rot für LNA, Schwarz für DNA, Blau für RNA und Violett für 2'-OMe-RNA.

Wie schon bei den zuvor verwendeten Adaptoren wurde Adaptor 37 auf eine mögliche Bildung von Sekundärstrukturen überprüft. Es zeigte sich, dass auch Adaptor $\mathbf{3 7}$ eine hairpin-Struktur ausbilden konnte (Abbildung 87, rechts). Zusätzlich wurde die PIM1-mRNA auf mögliche Bindestellen des gegen die miR-let-7-Familie gerichteten Teil des Adaptors untersucht. Hierbei konnten zwar komplementäre Bereiche gefunden werden, allerdings 
lagen diese weit von dem Nukleotid 1491 entfernt, sodass eine doppelte Bindung des Adaptors eher unwahrscheinlich war. Die Funktion des Adaptors wurde zunächst in Band-Shift- und Pulldown-Experimenten mit dem Cy5-markierten miRNA-Modell 38 geprüft. Von besonderem Interesse waren dabei Hinweise auf eine mögliche Selbststruktur (Abbildung 87). Im Anschluss sollte die Umleitung von RISCs in HeLa-Lysat getestet werden.

In den Band-Shift-Experimenten konnte ein zu Adaptor 32 analoges Verhalten beobachtet werden. Allerdings war die Bindung an miR-let-7a besser als die von Adaptor 32 an miR-20a. Auch in diesem Fall war die Bildung des ternären Komplexes aus Adaptor $\mathbf{3 7}$ und den ONs $\mathbf{3 3}$ und $\mathbf{3 8}$ unabhängig von der Konzentration des Adaptors und es konnte wieder von einer Art kooperativer Bindung ausgegangen werden. Die fluoreszenzbasierten Pulldown-Experimente wurden analog zu den Versuchen mit Adaptor 32 durchgeführt und es zeigte sich ein vergleichbares Verhalten der Adaptoren (Abbildung 88). Hierbei konnte ein linearer Anstieg der Fluoreszenz bis zu einem Verhältnis von 1:1:1 beobachtet werden, auf die eine deutlich geringere Zunahme bis zu einem Maximum bei 1:1.75:1 (33/37/38) folgte. Analog zu Adaptor 32 fiel die detektierte Fluoreszenz bei höheren Adaptorkonzentrationen nur schwach ab und selbst bei einem sechsfachen Überschuss konnten noch rund $70 \%$ der maximalen Fluoreszenz detektiert werden. Daraus konnte abgeleitet werden, dass auch der Adaptor 37 ein kooperatives Bindeverhalten aufwies, aber dennoch zur Umleitung von RISCs geeignet sein sollte. Daraufhin wurden Band-ShiftExperimente mit der 412mer RNA 34 durchgeführt (Abbildung 89). In diesem Ausschnitt der PIM1-mRNA war die mögliche Bindestelle für den gegen miR-let-7a gerichteten Teil des Adaptors nicht vorhanden und dementsprechend war eine vollständige Bildung des ternären Komplexes zu erwarten. Analog zu den Adaptoren $\mathbf{3 1}$ und $\mathbf{3 2}$ führte die Bindung des Adaptors 37 zu einer langsameren Migration der RNA 34 (Lane 4), während die

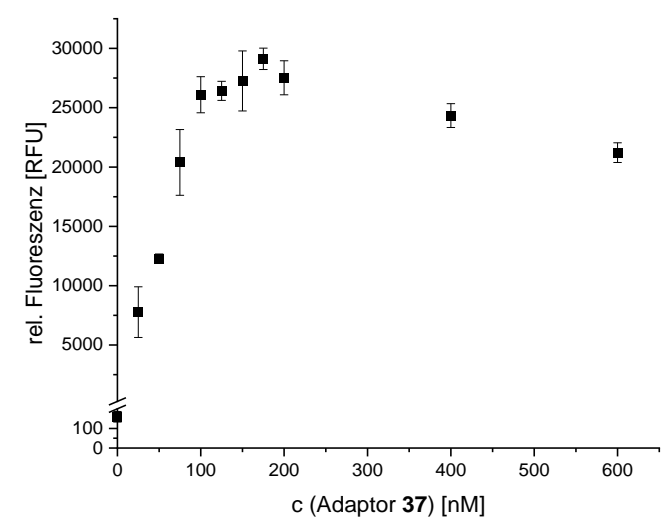

Abbildung 88: Fluoreszenz-Pulldown mit Adaptor 37 und den ONs 33 und 38 (je 100 nM) Die Proben wurden 1 h in Puffer 2 inkubiert. Dabei konnte ein Maximum bei einem Verhältnis von 1:1.75:1 (33/37/38) beobachtet werden. 


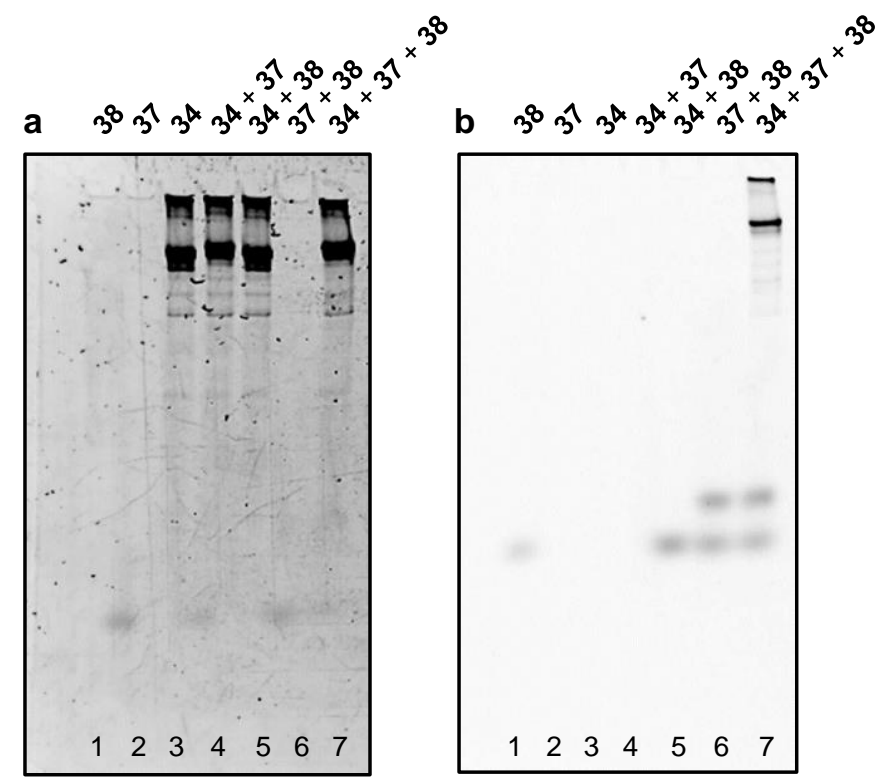

Abbildung 89: Band-Shift-Experiment mit den RNAs 34 und 38 und dem Adaptor 37. Detektion mittels a: SYBR Gold Färbung, b: Cy5-Fluoreszenz. Lane 1: RNA 38; Lane 2: Adaptor 37; Lane 3: RNA 34; Lane 4: RNA 34 + Adaptor 37; Lane 5: RNA 34 + RNA 38; Lane 6: RNA 38 +Adaptor 37; Lane 7: RNA 34 + RNA 38 + Adaptor 37. Die Proben wurden 2 h in Puffer 2 bei RT inkubiert. Die Konzentration der ONs betrug in allen Fällen ungefähr $1 \mu \mathrm{M}$. $8 \%$ nativ PAGE.

Bindung der RNA 38 keinen weiteren Effekt hatte. Allerdings konnte bei Detektion der Cy5gelabelten RNA 38 eine intensive Bande beobachtet werden (Abbildung 89, b, Lane 7), die auf die Ausbildung des ternären Komplexes schließen ließ. Die Cy5-Detektion zeigte zusätzlich noch einen deutlichen Anteil des binären Komplexes zwischen RNA 38 und Adaptor 37 sowie der ungebundenen RNA 38. Dies war jedoch, analog zu den Experimenten mit den Adaptoren 31 und 32, durch einen Unterschuss der RNA 34 zu erklären. Dies zeigte, dass die Bildung des ternären Komplexes aus den ONs 37, 34 und 38 möglich war. Mit dem verwendeten Konstrukt konnte jedoch eine Bindung beider Adaptorhälften an die PIM1-mRNA nicht vollständig ausgeschlossen werden.

Nachdem gezeigt wurde, dass die Umleitung einer Modell-RNA mit Adaptor 37 erfolgreich war, wurde er eingesetzt, um miR-let-7 beladene RISCs aus HeLa-Lysaten zu isolieren (Abbildung 90). Darüber hinaus wurde die Selektivität des Adaptors untersucht. Dazu wurde der Adaptor 37 mit einem Ausschnitt der PIM1-mRNA (ON 33) sowie der orthogonalen Zielsequenz des Adaptors 30 (ON 24) inkubiert. Dabei zeigte sich, dass der Adaptor 37 nur in Gegenwart des ON 33 hAgo2 umleiten konnte (Lane 2). Ohne den Adaptor oder in Kombination mit ON 24 war dagegen nur eine schwache Bande zu beobachten (Lane $3+1)$.

Somit ergab sich aus den in vitro Experimenten, dass sich nach den ONs $\mathbf{3 0}$ und $\mathbf{3 1}$ auch der dritte Adaptor 37 zur Umleitung von RISCs eignete. Zusätzlich zeigten die Erfahrungen mit Adaptor 37, dass neben miR-20a auch die miR-let-7-Familie adressiert werden konnte, wodurch das Konzept nicht auf eine miR-Familie beschränkt war. 


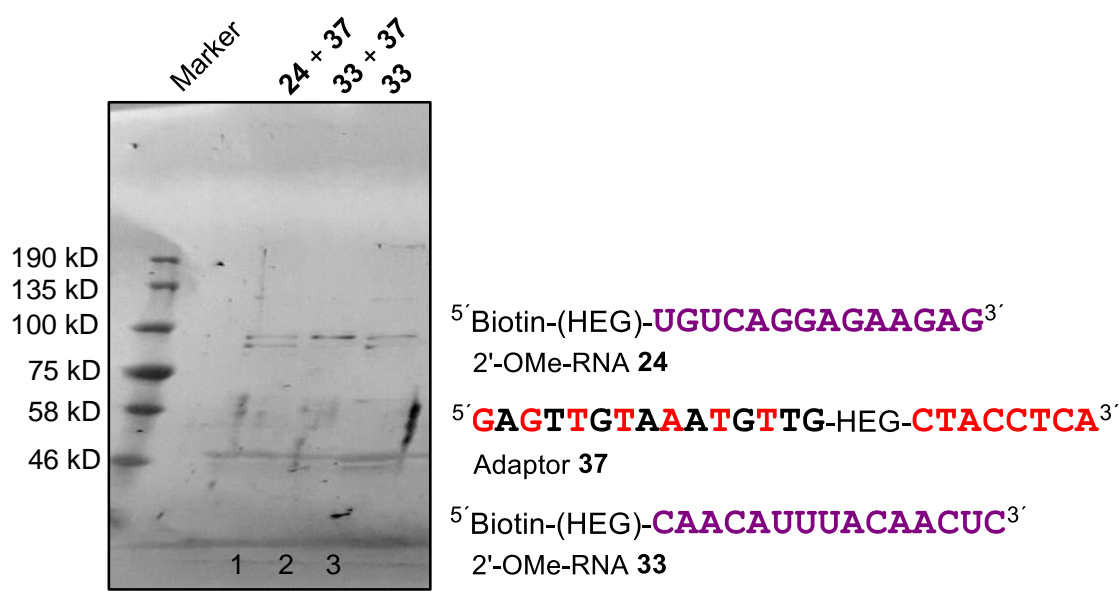

Abbildung 90: Selektive Isolierung von RISCs mittels des Adaptors 37. Lane 1: ON 24 + Adaptor 37; Lane 2: Adaptor 37 + ON 33; Lane 3: ON 33; Die Banden wurde durch Western-Blot nach Elektrophorese durch spezifische Antikörper gegen hAgo2 sichtbar gemacht. Detektion mittels Färbung (BCIP/NBT). Die Proben wurden für $3 \mathrm{~h}$ bei RT in Puffer 2 inkubiert. Die Konzentration der ONs betrug jeweils $300 \mathrm{nM}$ in $100 \mu \mathrm{L}$.

\subsubsection{Zellkulturexperimente mit Adaptor 37}

In den Zellkulturexperimenten wurden zusätzlich zu Adaptor 37 verschiedene Kontrolladaptoren verwendet (Abbildung 91). Die ONs 39 und 40 konnten an die PIM1-mRNA binden, waren jedoch nicht in der Lage RISCs zu rekrutieren. Mit innen sollte ausgeschlossen werden, dass die Bindung des Adaptors 37 auch ohne die Rekrutierung von RISCs einen Einfluss auf die Pim-1-Expression hatte und mögliche Effekte lediglich auf Konformationsänderungen der mRNA oder einem sterischen Block beruhen könnten. Der Adaptor 41 war komplementär zur miR-let-7-Familie, sollte aber nicht mit der PIM1-mRNA interagieren. Mit ihm sollte überprüft werden, ob die Bindung des Adaptors an die miR-let-7Familie einen Effekt auf die Pim-1-Expression induzieren konnte. Der Adaptor 42 sollte keine Funktion besitzen und diente wie die DNA 43 als Transfektionskontrolle.

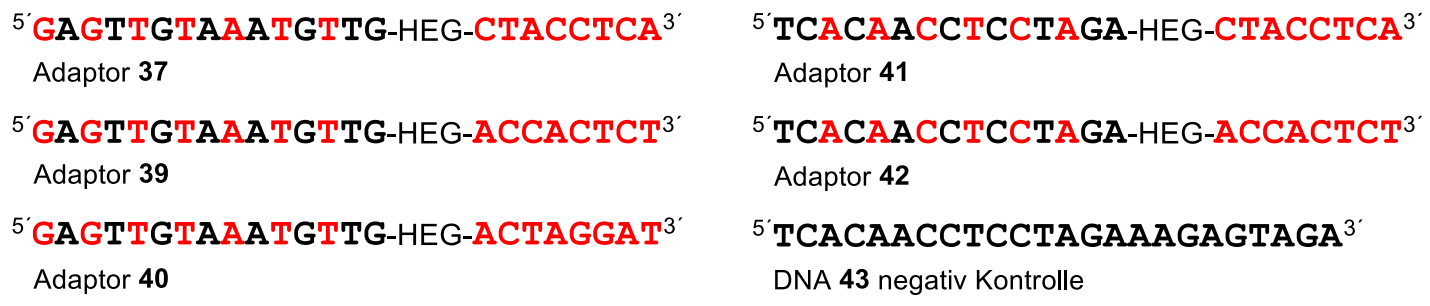

Abbildung 91: Für die Zellkulturexperimente eingesetzte ON. Dabei steht Rot für LNA und Schwarz für DNA.

In ersten Experimenten konnten mit Adaptorkonzentrationen von $50 \mathrm{nM}-200 \mathrm{nM}$ eine Reduktion von Pim-1 beobachtet werden, während dies mit den Negativkontrollen 39 oder 40 nicht auftrat. Die Ergebnisse wurden so interpretiert, dass eine Adaptorbindung ohne RISC-Rekrutierung (39 und 40) keinen Einfluss hatte, wohingegen der miR-let-7-beladene 
a

43

41

$37 \quad$ siRNA

b

Mock 43

42

$37 \quad$ siRNA

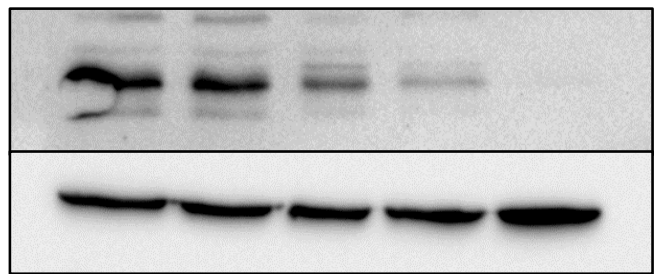

23

4

5

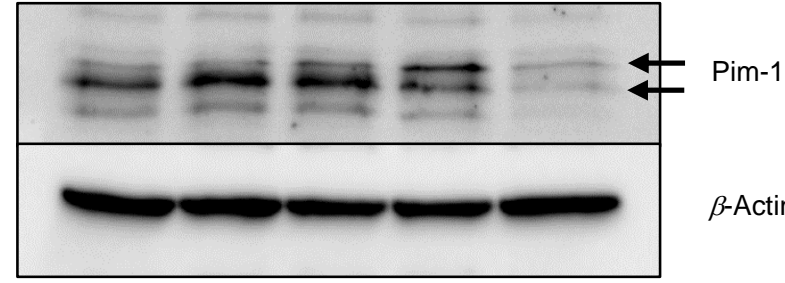

Abbildung 92: Zellkulturexperimente mit dem Adaptor 37 (200 nM). a: Mit frischen Zellen, b: mit gealterten Zellen. Für Pim-1 konnte eine Doppelbande detektiert werden (b, Pfeile). $\beta$-Actin wurde als Expressionskontrolle verwendet. Die Experimente wurden von Laura Thomas aus der Gruppe von Prof. Hartmann (Universität Marburg) durchgeführt.

Adaptor 37 den gewünschten Effekt bewirkte. Um auszuschießen, dass ein anti-miR-Effekt auf die miR-let-7-Familie die Ursache für die reduzierte Pim-1-Expression war, wurden Experimente mit den Adaptoren 37 und 41 durchgeführt (Abbildung 92, a). Auch hier konnte eine deutliche Reduktion der Pim-1-Expression durch den Adaptor 37 beobachtet werden (Lane 4). Allerdings wurde die Expression auch durch den Adaptor 41 inhibiert (Lane 3). Um auszuschließen, dass ein anti-miR-Effekt die Ursache der Reduktion war, wurde eine gegen miR-let-7 gerichtete Achtmer-LNA transfiziert, die jedoch keinen Effekt auf die Pim-1-Expression besaß. Somit konnte ein reiner anti-miR-Effekt ausgeschlossen werden. Allerdings befand sich im kodierenden Bereich der PIM1-mRNA eine Mismatch-Bindestelle für den Adaptor 41. Damit war nicht auszuschließen, dass die Reduktion der Pim-1-Level durch eine miR-let-7-Umleitung auf diese Stelle verursacht wurde. Beim Vergleich von Daten aus mehreren unabhängigen Versuchen fiel auf, dass die Effekte des Adaptors von der Zahl der Passagen abhing und bei steigendem Zellalter geringer wurde (Abbildung 92, b, Lane 4). Dies führte dazu, dass über diese Versuche eine mittlere Reduktion der Pim-1-Expression von 20 bis $40 \%$ beobachtet werden konnte, womit die Effekte des Adaptors deutlich unter denen der siRNA lagen und auch schlechter als die vergleichbarer miR-Mimics waren. ${ }^{[233]}$ Des Weiteren wurde die Auswertung durch das Auftreten zusätzlicher Pim-1-Banden beeinträchtigt (Abbildung 92, b), die mit zunehmendem Zellalter vermehrt beobachtet werden konnten. Dabei zeigte sich, dass diese Banden selbst bei Zugabe einer siRNA nicht gleichmäßig reduziert werden konnten (b, Lane 5). Eine eindeutige Aussage über die Funktion der Adaptoren ließ sich somit nicht treffen.

Auf Basis dieser Ergebnisse wurden die Exprimente mit den Adaptoren vorerst zurückgestellt, da es mit dem gewählten System nicht möglich war, das Konzept der RISC-Umleitung in Zellkulturexperimenten zu bestätigen. Das gewählte Testsystem war dabei sehr komplex und konnte nicht konsistent ausgewertet werden. Dadurch blieb die 
Aussagekraft der Experimente eingeschränkt. Darüber hinaus stellte sich jedoch die Frage, ob weitere Ursachen für die mangelnde Funktion der Adaptoren vorlagen. Hierbei waren sowohl grundlegende konzeptionelle Hindernisse als auch adaptorspezifische Probleme denkbar.

In Bezug auf die konzeptionellen Ursachen ist zwar nicht grundsätzlich nicht auszuschließen, dass RISCs eine direkte Bindung an die RNA benötigen, um GW-Proteine zu rekrutieren. In diesem Fall wäre eine Unterdrückung der Translation durch die Umleitung von RISCs nicht möglich. Gegen diese These sprach jedoch, dass mit Adaptor 37 in einigen Fällen eine Repression der Pim-1-Expression erzielt wurde. Ein weiteres grundlegendes Problem stellte eine Eliminierung der miRNA aus den RISCs im Anschluss an eine Hybridisierung mit dem Adaptor dar. ${ }^{[185]}$ In diesem Fall ginge das für die Wirkung entscheidende hAgo2-Protein verloren. Allerdings sollte dieser Effekt nur bei vollständig komplementären anti-miRs auftreten. In diesem Fall wäre auch eine Isolierung von RISCs in Pulldown-Experimenten nicht möglich. Da dies jedoch mit unterschiedlichen Adaptoren gelang, ist auch diese Hypothese widerlegt.

Da es keine konkreten Hinweise auf konzeptionelle Ursachen gab, war davon auszugehen, dass adaptorspezifische Probleme vorlagen. In diesem Zusammenhang war insbesondere das kooperative Bindeverhalten der Adaptoren zu beachten. Im Fall der Adaptoren 31, 32 und 37 erfolgte die Rekrutierung von RISCs bevorzugt nach der Bindung des Adaptors an die PIM1-mRNA, während eine Hybridisierung des freien Adaptors aufgrund ihrer hairpin-Struktur erschwert wurde. Zwar bot dieses Verhalten auch Vorteile, wie eine erhöhte Nukleasestabilität, allerdings ergaben sich auch potenzielle Nachteile. Beispielsweise erhöhte dieses Verhalten die Wahrscheinlichkeit von off-target-Effekten, wie bei den Adaptoren 31 und 32 zu beobachten war. In diesem Fall band die anti-miR-Hälfte des Adaptors ebenfalls an die PIM1-mRNA und verhinderte so eine Rekrutierung von RISCs. Da die RNA 34 nicht die vollständige 3'-UTR der PIM1-mRNA abbildet, konnte dieser Effekt für Adaptor 37 nicht ausgeschlossen werden. Als Folge des kooperativen Bindeverhaltens der Adaptoren und der unbekannten Sekundärstruktur der PIM1-mRNA konnte zudem eine sterische Abschirmung der anti-miR-Hälfte des Adaptors nicht ausgeschlossen werden. Dabei stellte sich die Frage, wie der Adaptor nach der Bindung an die mRNA orientiert und ob er für RISCs zugänglich war. Die Experimente mit RNA 34 zeigten zwar, dass eine proteinfreie miRNA umgeleitet werden konnte, was gegen eine sterische Abschirmung des Adaptors sprach. Allerdings ist der sterische Anspruch eines RISCs deutlich höher, wodurch die Ergebnisse nicht ohne weiteres übertragen werden können.

Um diese Effekte auszuschließen, wäre ein vollständig orthogonaler Adaptor notwendig, der zunächst mit RISCs interagieren und im Anschluss an die mRNA binden könnte. Bei 
der Verwendung orthogonaler Adaptoren ist jedoch zu beachten, dass diese eine geringere Nukleasestabilität aufwiesen als die hairpin-Adaptoren, wie in den Stabilitätstests mit den Adaptoren $\mathbf{3 0}$ und $\mathbf{3 1}$ gezeigt werden konnte. Somit müsste die Stabilität der Adaptoren erhöht werden, wozu Phosphorthioate verwendet werden können. Da diese zusätzlich die Affinität der Adaptoren leicht reduzieren, ${ }^{[47]}$ könnten auch off-target-Effekte geschwächt oder vollständig verhindert werden. Somit sollten mögliche Folgeexperimenten mit Adaptoren dieses Typs durchgeführt werden. 


\subsection{Vorgehen beim Entwurf der Adaptoren}

Beim Aufbau von Adaptoren aus bifunktionalen ONs besteht eine der Herausforderungen darin, eine hinreichende Orthogonalität der Adaptorhälften zu erzielen, damit intra- oder intermolekulare Wechselwirkungen vermieden werden können. Hierauf ist insbesondere bei der Verwendung von LNA-Nukleotiden zu beachten, da diese die Affinität der ONs deutlich erhöhen. Daher erfordert der Aufbau der Adaptoren eine genaue Planung, damit sie ihre vorgesehene Funktion erfüllen können. Ausgehend von den in dieser Arbeit beobachteten Schwierigkeiten wird im Folgendem ein Leitfaden aufgestellt werden, welcher den zukünftigen Aufbau der Adaptoren erleichtern kann.

Zu den grundlegenden Problemen dieser Arbeit zählte die partielle Selbstkomplementarität der Adaptoren die zu intermolekularen Wechselwirkungen führte. Diese Effekte traten insbesondere bei den LNA-Adaptoren auf und konnten durch die Verwendung von DNA/LNA-Mixmeren verhindert werden. Gleichzeitig war es mit den Mixmeren nicht möglich, intramolekulare hairpin-Strukturen auszuschließen. Der Einfluss dieser Strukturen auf die Umleitung der RISCs konnte dabei nicht vollständig aufgeklärt werden und erfordert weitere Untersuchungen. Um potenzielle hairpin-Strukturen schon in der Planung der Adaptoren zu erkennen und gegebenfalls zu verhindern, sind Analysen mit dem LNA Oligo Optimizer von Quiagen, sowie der NUPACK Web Applikation vonnöten. ${ }^{[235,236]}$ Dabei können die Einflüsse der LNA-Nukleotide mit dem LNA Oligo Optimizer untersucht werden, um komplementäre Abschnitte der Adaptorhälften zu identifizieren. Auf diese Weise können intermolekulare Wechselwirkungen ausgeschlossen und mögliche hairpin-Strukturen lokalisiert werden. Um die Vollängen-Adaptoren zu überprüfen, ist der Einsatz der NUPACK Web Applikation zu empfehlen. Mit dieser Applikation können die Adaptoren als RNAs betrachtet und der Linker durch nichtkomplementäre Basen nachgestellt werden. Falls beide Programme identische Basenpaarungen voraussagen, muss man von der Bildung einer hairpin-Struktur ausgehen.

Im Anschluss an den Entwurf müssen die Adaptoren auf ihre Funktion getestet werden. Hierzu empfehlen sich Band-Shift-Experimente, in denen die Bildung des ternären Komplexes überprüft und der Adaptor auf eine mögliche Kooperativität hin untersucht werden kann. In Experimenten mit längeren Ausschnitten der 3'-UTR der Ziel-RNA kann eine mögliche Bindung beider Adaptorhälften an die mRNA ausgeschlossen werden. Die Ergebnisse der Band-Shifts sollten daraufhin in fluoreszenzbasierten PulldownExperimenten bestätigt werden. Dabei kann die Abhängigkeit des ternären Komplexes von der Adaptorkonzentration genauer untersucht werden. Nach diesen Versuchen sollte man die Isolierung von RISCs in Pulldown-Experimenten verifizieren, bevor der Adaptor in Zellkulturen eingesetzt werden kann. 
Daraus ergibt sich die folgende Vorgehensweise:

- 1. Auswahl geeigneter Ziel-RNAs und miR-Familien und Überprüfung des resultierenden Adaptors auf Orthogonalität.

- 2. Prüfung der Zielsequenz auf mögliche Bindestellen für beide Hälften des Adaptors, was möglichst zu vermeiden ist.

- $\quad$ 3. Verteilung der LNA-Basen mit dem Ziel, eine möglichst hohe Stabilität und Affinität bei geringen Nebeneffekten zu erhalten.

- 4. Prüfung der Adaptoren auf intramolekulare Sekundärstrukturen (hairpins)

- 5. Band-Shift-Experimente mit kurzen und langen Ziel-RNAs.

- 6. Pulldown-Experimente mit fluoreszenzmarkierten Oligonukleotiden.

- 7. Pulldown-Experimente mit Zelllysat.

- 8. Zellkulturexperimente mit geeigneten Reporterproteinen. 


\section{Zusammenfassung und Ausblick}

\subsection{Umleitung von Sp1}

Im Rahmen dieser Arbeit konnten die PIPs PA2, PA3 und PA5 mittels Festphasensynthese und die PIPs PA3, PA4 und PA6 in Lösung erfolgreich aufgebaut werden. Hierbei war es möglich, die Synthese der Grundbausteine 2 und $\mathbf{3}$ mit weniger reaktiven Substanzen durchzuführen. Die Synthese der PIPs in Lösung konnte durch eine in situ Einführung der Boc-Gruppen während der Reduktion und die somit verhinderte Zersetzung der Amine effektiv durchgeführt werden. Für den finalen Aufbau der PIPs erwies sich eine direkt auf die Reduktion der Nitrogruppe folgende Peptidkupplung als gute Methode. Im Anschluss konnten die PIPs erfolgreich mit einem ON gekuppelt und die Konjugate nachfolgend mittels dPAGE gereinigt werden. Unter Verwendung der DNAs 4, 5 und 6, sowie der Polyamide PA4 und PA6 erhielt man die Adaptoren K5a, K7a und K9. In Band-Shift-Experimenten konnte gezeigt werden, dass sie mit einer guten Affinität und Spezifität an definierte Zielsequenzen banden. Anhand von Pulldown-Versuchen war es möglich, die Rekrutierung des TFs Sp1 an eine nicht natürliche Bindestelle zu zeigen. Als alternatives Konzept wurden Adaptoren auf TFO-Basis entworfen. In Band-Shifts konnte dabei eine Bindung der DNA 10 an die Ziel-DNA 14 beobachtet werden. Allerdings besaß dieser Adaptor eine geringere Affinität als die PIP-Konjugate. Darüber hinaus zeigte sich, dass diese DNA 10 auch mit der partiell komplementären DNA 15 wechselwirkte und somit deutlich weniger spezifisch war als erhofft. Zusätzlich konnte in dieser Arbeit eine Syntheseroute zu einem Fmoc-geschützten Thiouracil-PNA-Monomer (70) entworfen werden. Dabei wurde die Eignung von PMB als Schutzgruppe nachgewiesen und eine Methode zur selektiven Alkylierung der N1-Position des Thiouracils entwickelt. Auf diese Weise war es möglich, eines der größten Hindernisse bei der Synthese von Thiouracil-Monomeren zu beheben.

In zukünftigen Arbeiten wäre es notwendig zu untersuchen, ob der Adaptor K9 oder die DNA 10 durch Rekrutierung von Sp1 die Transkription eines Reportergens, z.B. einer Luciferase, aktivieren können. Dazu sollten Zellkulturexperimente mit oder ohne Transfektionsmittel durchgeführt werden. Als Negativkontrollen käme neben der unkonjugierten DNA 6 auch ein PIP-Konjugat auf Basis von PA3 in Frage. Mit diesem könnte überprüft werden, ob die Aktivierung der Transkription tatsächlich durch das Umleiten von Sp1 ausgelöst wird, oder ob die dsDNA der Adaptoren andere Signalwege aktiviert, welche die Transkription erhöhen könnten. Darüber hinaus wäre es notwendig, die Nukleasestabilität der Adaptoren zu erhöhen, indem man z.B. die Nukleotide an den 5'und $3^{\prime}$-Enden durch LNAs und das Rückgrat an diesen Positionen, sowie im turn durch 
Phosphorthioate ersetzt. Sollten die Adaptoren die Genexpression des Modellsystems aktivieren können, wäre es notwendig, ihre Spezifität zu erhöhen. Im Fall der PIP-Konjugate war die kurze und AT-reiche Zielsequenz die Ursache für eine geringe Spezifität, weil Pyrrole nicht zwischen $A$ und $T$ unterscheiden können. Um dies zu beheben, wäre es denkbar, vermehrt Guanosinreste in die Ziel-DNA einzubauen, die durch Imidazole spezifisch erkannt werden können. Hierdurch wird jedoch die Synthese der PIPs anspruchsvoller und bei zu hohen Im-Anteilen sinkt oftmals die Affinität der PIPs. Dem könnte jedoch durch die Substitution von Pyrrol durch $\beta$-Alanin entgegengewirkt werden. Außerdem ermöglicht dieser Austausch den Aufbau längerer Polyamidketten, wodurch sich ebenfalls die Spezifität steigern lässt. ${ }^{[137]}$ Eine andere Möglichkeit, die Länge der Ziel-Sequenz zu erhöhen, wäre die Verwendung von Tandem-PIPs, ${ }^{[140,141,148]}$ mit welchen bis zu 18 bp erkannt werden können. ${ }^{[141]}$

Ein weiterer Punkt für zukünftige Arbeiten stellt die Wahl des Transkriptionsfaktors dar. Hierfür wäre NF-кB ein interessantes Ziel, da es in den meisten Zelllinien im Cytosol vorliegt und erst durch eine externe Stimulierung in den Zellkern eindringt. ${ }^{[241]}$ Somit bestünde die Möglichkeit, den Adaptor zu transfizieren und im Anschluss eine gezielte Aktivierung der Transkripten auszulösen. Hierdurch könnte ein besseres Signal zu Rausch Verhältnis erhalten werden, um die Aktivierung der Transkription störungsfreier zu detektiert.

Für die TFO- und PNA-basierten Adaptorsysteme wären ebenfalls weitere Untersuchungen notwendig. Bei den TFO-basierten Adaptoren könnten LNA-Nukleotide im TFO eingebaut werden, da diese die Stabilität der Triplexbildung erhöhen. ${ }^{[54]}$ Somit wäre es möglich, die Affinität der Adaptoren und gleichzeitig ihre Nukleasestabilität zu verbessern. Für die pseudokomplementären PNAs ist zunächst die Wahl einer Sequenz entscheidend, die eine Duplexinvasion unter physiologischen Bedingungen erlaubt. Diese sollte daraufhin mit einer gegen den ausgewählten TF gerichteten DNA verknüpft werden. Zum Aufbau dieser Konjugate sollte neben den in dieser Arbeit verwendeten Diisocyanaten auch Di-NHS-Ester oder Click-Cycloadditionen in Betracht gezogen werden. Sind funktionale Konjugate vorhanden, die aus zwei Einzelsträngen bestehen, müsste sichergestellt werden, dass die Transfektionseffizienz aller Komponenten gleichmäßig gewährleistet ist, da andernfalls eine Doppelstranginvasion durch pseudokomplementäre PNAs nicht funktioniert. Die kovalente Verknüpfung beider Stränge ist zwar ein strategisch einfaches Konzept, synthetisch jedoch mit großem Aufwand verbunden. Als Alternative wäre es denkbar, beide PNA-Stränge mit einer Hälfte des gewünschten DNA-Duplex zu konjugieren (Abbildung 93). Somit würden die pseudokomplementären PNA-Stränge auf nicht kovalente Weise miteinander verknüpft und gleichzeitig die dsDNA-Bindestelle für den TF erzeugt. ${ }^{[242,243]}$ 
Zusammenfassung und Ausblick

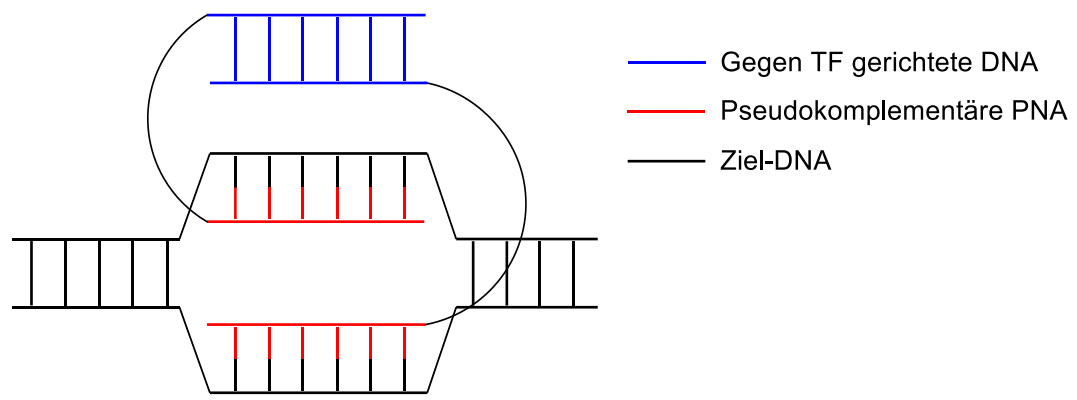

Abbildung 93: Schematische Darstellung der Bindung eines Adaptors auf Basis von pseudokomplementärer PNA. 


\subsection{Umleitung von RISCs}

Im zweiten Teil dieser Arbeit konnten RISCs in vitro erfolgreich auf nicht natürliche Bindestellen umgeleitet werden. Hierzu wurden Adaptoren aus DNA/LNA-Mixmeren verwendet, welche über einen HEG-Linker verknüpft waren. In Band-Shift- und Pulldown-Experimenten wurde gezeigt, dass die Umleitung eines fluoreszenzmarkierten miRNA-Modells auf mRNA-Modelle unterschiedlicher Länge möglich war. In diesen Versuchen konnte zudem beobachtet werden, dass die Adaptoren 31, 32 und 37 gegenüber ihren beiden Partnersträngen ein Verhalten aufwiesen, dass dem einer kooperativen Bindung ähnelte. Die Ursache hierfür waren intramolekulare hairpin-Strukturen, durch welche der anti-miR-Teil des Adaptors blockiert wurde. Dies hatte zur Folge, dass die Bildung des ternären Komplexes aus Adaptor, miRNA und mRNA nach der Bindung des Adaptors an die mRNA bevorzugt wurde. Während dieses Verhalten bei kurzen Zielsequenzen keinen Einfluss auf die Bildung des ternären Komplexes hatte, zeigten sich an längeren Ausschnitten der PIM1-mRNA, dass eine Bindung beider Adaptorhälften möglich war. Dies hatte zur Folge, dass der ternäre Komplex nicht gebildet werden konnte. In Pulldown-Experimenten war es mit den Adaptoren möglich, RISCs umzuleiten und in einem anschließenden Western-Blot nachzuweisen. Diese Umleitung verlief sequenzspezifisch. In parallel durchgeführten Zellkulturexperimenten konnte in der Gruppe von Prof. Hartmann (Universität Marburg) gezeigt werden, dass mit Adaptor 37 eine Reduktion der Pim-1-Expression in HeLa-Zellen möglich war. Allerdings waren die Effekte nur schlecht zu reproduzieren und es konnte eine Abhängigkeit vom Zellalter beobachtet werden. Aufgrund der derzeitigen Datenlage können die steigernden und inhibierenden Effekte der RISC-Umleitung auf die Expression von Zielproteinen weder bestätigt noch widerlegt werden.

Da sich in dieser Arbeit zeigte, dass es mit dem gewählten Testsystem nicht möglich war die biologischen Effekte der RISC-Umleitung zu demonstrieren, stellt die Suche nach einem geeigneterem Versuchsaufbau eine der Aufgaben für zukünftige Arbeiten dar. Nachdem sich zelleigene Proteine in dieser Arbeit als ungünstige Ziele erwiesen, wäre zu überlegen, ein Reporterplasmid zu verwenden und die Funktion des Adaptors in einem Luciferase-Assay zu überprüfen. Dabei sollte sich die 3'-UTR der Ziel-RNA von der zelleigener mRNAs möglichst unterscheiden, um off-target-Effekt zu verhindern. Auch darf die mRNA des Zielproteins nicht in zu hoher Konzentration vorliegen, da für ein optimales Funktionieren ein Überschuss der miRNA vonnöten ist. Um zu überprüfen, ob die Zielsequenz innerhalb einer stark gefalteten mRNA zugänglich ist, könnten Gapmere oder siRNAs verwendet werden. Eine weitere Alternative stellen künstliche Nukleasen dar, 
welche in unserer Gruppe eingesetzt werden und die in der Lage, sind auch lange RNAs sequenzspezifisch zu schneiden. ${ }^{[240]}$

Des Weiteren sollten die Adaptoren so aufgebaut werden, dass eine intramolekulare hairpin-Struktur vermieden wird, da diese die Affinität des Adaptors verringert. Hierzu müssen die Adaptorhälften vollständig orthogonal sein. Nachdem sich in dieser Arbeit zeigte, dass die ungefalteten Adaptoren anfälliger gegenüber Nukleasen sind, sollten sie mit einem Phosphorthioat-Rückgrat versehen werden, um ihre Stabilität zu erhöhen. Darüber hinaus sollte auch die Reihenfolge der Adaptorhälften genauer untersucht werden. Die bisher verwendeten Adaptoren begannen mit dem ASO am 5'-Ende (Abbildung 94, links), allerdings wurde diese Anordnung willkürlich gewählt. Aus diesem Grund ist es sinnvoll, auch die umgekehrte Orientierung zu testen, bei der die Adaptoren am 5'-Ende mit der anti-miR-Sequenz beginnen (Abbildung 94, rechts). Auf diese Weise würde die Positionierung des Linkers und somit auch die räumliche Orientierung der Adaptoren verändert. Außerdem wäre es hierdurch denkbar, off-target-Effekte zu verhindern und intramolekulare Wechselwirkungen der Adaptorhälften abzuschwächen.

Wenn mit diesen Experimenten die Steuerung von Proteinkonzentrationen durch RISC-Umleitung gelingt, sollten im Anschluss medizinisch relevante Ziele gesucht werden. Hierbei sind bevorzugt miRNAs zu wählen, die beispielsweise in Krebszellen überexprimiert sind und in normalen Zellen sehr geringe Expressionslevel aufweisen. Dadurch wäre die Wirkung der Adaptoren in gesunden Zellen nur gering, während ein starker Effekt in den Zielzellen zu erwarten ist.

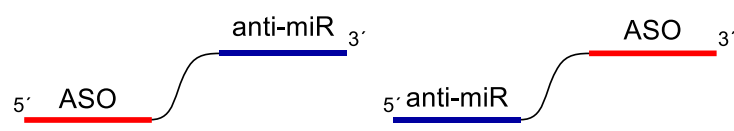

Abbildung 94: Möglicher Aufbau der Adaptoren. Links: Der Adaptor beginnt am 5'-Ende mit dem ASO-Teil; rechts: Der Adaptor beginnt am 5'-Ende mit dem anti-miR. 


\section{Experimenteller Teil}

\subsection{Allgemeine Arbeitstechniken}

Wasser- und/oder sauerstoffempfindlichen Substanzen wurden unter Argon gehandhabt. Hierzu wurden die Apparaturen vor Gebrauch im Ölpumpenvakuum getrocknet und anschließend mit Argon gespült.

Absolute Lösemittel wurden von den Firmen Acros oder Sigma Aldrich bezogen.

Chemikalien wurden von den Firmen Sigma Aldrich, TCI, Alfa Aesar, Fluka, Carbolution oder Fluorochem bezogen und ohne weitere Aufarbeitung eingesetzt.

Oligonukleotide wurden von den Firmen BioTeZ und Bio Spring, Iba und Eurogentec bezogen.

Sp1 wurde von Promega (E6391) bezogen oder von Frau Dr. Ute Scheffer isoliert und bereitgestellt.

Die HeLa-Lysate wurden von Frau Elisabeth Kalden bereitgestellt. ${ }^{[13]}$

Bei Arbeiten mit DNA wurde steriles MiliQ-Wasser und für Arbeiten mit RNA DEPC-Wasser verwendet.

Streptavidin beladene Magnetic Beads wurden von der Firma Promega bezogen.

\subsubsection{Verwendete Apparaturen}

Zum Einengen kleiner Volumina wurde eine Speed Vac Plus SC110A der Firma Savant oder eine RVC 2-18 der Firma Christ genutzt.

Für Zentrifugationen wurde eine Mikro 220r der Firma Hettich verwendet.

\subsubsection{Hydrierungen unter erhöhtem Druck}

Eine Autoklavenhülse wurde mehrere Minuten lang mit Argon gespült. Im Anschluss erfolgte die Zugabe des Lösemittels, des Katalysators und der zu reduzierenden Substanz. Dann wurde die Apparatur geschlossen, drei Mal mit Argon auf einen Druck von fünf Bar befüllt und das Gas wieder abgelassen. Dieser Vorgang wurde mit $\mathrm{H}_{2}$ wiederholt und erst dann der gewünschte Druck eingestellt. Nach beendeter Reaktion wurde die Apparatur auf RT abgekühlt und anschließend der Druck abgelassen. Danach befüllte man drei Mal mit Argon, bevor die Apparatur geöffnet werden konnte. 


\subsubsection{Dünnschichtchromatographie}

Zur Dünnschichtchromatographie wurden DC-Fertigfolien Alugramm ${ }^{\circledR}$ Xtra SIL G/UV 254 der Firma Macherey-Nagel mit einem Fluoreszenz-Indikator für 254 nm verwendet.

Zum Anfärben wurden die Folien mit einer Lösung von Ninhydrin in Ethanol und Eisessig benetzt und anschließend mit einer Heatgun erhitzt.

\subsubsection{Präparative Säulenchromatographie}

Für die präparative Säulenchromatographie wurde Kieselgel 60 der Firma Macherey-Nagel verwendet. Für die präparative Säulenchromatographie wurden Lösemittel technischer Qualität verwendet.

\subsubsection{Analytische und semipräparative rp-HPLC der Polyamide}

Für die analytische rp-HPLC wurden folgende Geräte verwendet: JASCO DG-980-50, JASCO LG-980-02, JASCO Pu-980, JASCO UV-970, JASCO MD 2010 Plus. Dazu eine 150/4 Nucleodur C18 HTec 5mm Säule der Firma Macherey-Nagel. Es wurden bei einem Fluss von $0.7 \mathrm{~mL} / \mathrm{min}$ entweder isokratische Bedingungen oder der folgende Gradient aus A: $0.1 \%$ TFA in $\mathrm{H}_{2} \mathrm{O}$ und $\mathrm{B}$ : $\mathrm{ACN}$ verwendet:

\begin{tabular}{|r|r|r|}
\hline \multicolumn{1}{|l|}{ leit } & \multicolumn{1}{|l|}{ A } \\
\hline $0 \min$ & $90 \%$ & $10 \%$ \\
\hline $2 \min$ & $90 \%$ & $10 \%$ \\
\hline $30 \mathrm{~min}$ & $30 \%$ & $70 \%$ \\
\hline $40 \mathrm{~min}$ & $30 \%$ & $70 \%$ \\
\hline
\end{tabular}

Für die semipräparative Trennung wurde eine Waters 2525 Binary Gradient Module Pump sowie ein Waters 2487 Detektor verwendet. Dazu eine VP 250/21 Nucleodur C18 HTec, $7 \mu m$ Säule der Firma Macherey-Nagel. Die Trennung erfolgte bei einem Fluss von $9 \mathrm{ml} / \mathrm{min}$ mit einem isokratischem Gemisch $0.1 \%$ TFA in Wasser und ACN oder einem der folgenden Gradienten aus $\mathrm{A}$ : $0.1 \%$ TFA in $\mathrm{H}_{2} \mathrm{O}$ und $\mathrm{B}$ : $\mathrm{ACN}$ : 
Für PA5:

\begin{tabular}{|r|r|r|}
\hline \multicolumn{1}{|l|}{ Zeit } & A & \\
\hline $0 \min$ & $90 \%$ & $10 \%$ \\
\hline $5 \min$ & $90 \%$ & $10 \%$ \\
\hline $35 \mathrm{~min}$ & $30 \%$ & $70 \%$ \\
\hline $38 \mathrm{~min}$ & $30 \%$ & $70 \%$ \\
\hline
\end{tabular}

Für PA4 und PA6:

\begin{tabular}{|r|r|r|}
\hline \multicolumn{1}{|l|}{ Zeit } & \multicolumn{2}{|l|}{ A } \\
\hline $0 \min$ & $90 \%$ & $10 \%$ \\
\hline $5 \min$ & $90 \%$ & $10 \%$ \\
\hline $35 \mathrm{~min}$ & $35 \%$ & $65 \%$ \\
\hline $38 \mathrm{~min}$ & $35 \%$ & $65 \%$ \\
\hline
\end{tabular}




\subsection{Analytische und spektroskopische Methoden}

\subsubsection{Kernresonanzspektroskopie}

Die NMR-Spektren wurden an folgenden Spektrometern aufgenommen:

$\begin{array}{ll}\text { Bruker DPX 250: } & { }^{1} \mathrm{H}(250.1 \mathrm{MHz}),{ }^{13} \mathrm{C}(62.9 \mathrm{MHz}) \\ \text { Bruker 300: } & { }^{1} \mathrm{H}(300.1 \mathrm{MHz}),{ }^{13} \mathrm{C}(75.5 \mathrm{MHz}) \\ \text { Bruker AVANCE 400: } & { }^{1} \mathrm{H}(400.1 \mathrm{MHz}),{ }^{13} \mathrm{C}(100.6 \mathrm{MHz}) \\ \text { Bruker AVANCE 500: } & { }^{1} \mathrm{H}(500.1 \mathrm{MHz}),{ }^{13} \mathrm{C}(125.8 \mathrm{MHz}) \\ \text { Bruker DRX 600: } & { }^{1} \mathrm{H}(600.1 \mathrm{MHz}),{ }^{13} \mathrm{C}(151.0 \mathrm{MHz})\end{array}$

Alle aufgeführten ${ }^{13} \mathrm{C}$-NMR-Spektren sind ${ }^{1} \mathrm{H}$-Breitband-entkoppelt. Die Angabe der chemischen Verschiebung bezieht sich auf die $\delta$-Skala in ppm. Die NMR-Spektren wurden standardmäßig bei $300 \mathrm{~K}$ aufgenommen. Zur Kalibrierung der ${ }^{1} \mathrm{H}-\mathrm{NMR}$ - und ${ }^{13} \mathrm{C}$-Spektren dienen die Restprotonen- und Lösemittelsignale der deuterierten Lösemittel:

$$
\begin{aligned}
& { }^{1} \mathrm{H}-\mathrm{NMR}\left(\mathrm{CDCl}_{3}: 7.26 \mathrm{ppm} \text {; DMSO- } d_{6}: 2.5 \mathrm{ppm}\right) \\
& { }^{13} \mathrm{C}-\mathrm{NMR}\left(\mathrm{CDCl}_{3}: 77.16 \mathrm{ppm} \text {; DMSO- } d_{6}: 39.52 \mathrm{ppm}\right)
\end{aligned}
$$

Für die Beschreibung der Multiplizität der NMR-Signale wurden folgende Abkürzungen verwendet:

$\mathrm{s}=$ Singulett; $\mathrm{d}$ = Dublett; $\mathrm{t}=$ Triplett; $\mathrm{m}=$ Multiplett; $\mathrm{dd}=$ Dublett von Dublett; $\mathrm{q}=$ Quartett; $\mathrm{p}=$ Pentett. Breite Signale sind mit br gekennzeichnet.

\subsubsection{Massenspektrometrie}

Die Massenspektrometrie wurde von der Serviceeinheit Massenspektrometrie der Universität Frankfurt durchgeführt.

LC-ESI-Massenspektrometrie wurde an einem Surveyor MSQ der Firma ThermoFisher durchgeführt.

MALDI-Massenspektrometrie wurde an Voyager-DE STR der Firma PerSeptive Biosystems durchgeführt.

MALDI-Präzisionsmassen wurden an LTQ Orbitrap XL der Firma ThermoFisher gemessen. Die Massenspektrometrie (ESI/TOF) der Oligonukleotide wurde von Martin Held und Alexandra Schuck aus dem AK Heckel an einem LCMS-Gerät mit einem micrOTOF-Q II 
Detektor der Firma Bruker durchgeführt. Es wurde eine Agilent 1200 Series HPLC mit einem $\mathrm{MeOH} / 5 \mathrm{mM}$ TEAA Puffer (Gradient 0 - $60 \%$ ) und einer 125x2.1 mm MultoKrom 5-C18 Säule bei einer Flussrate von $0.2 \mathrm{~mL} / \mathrm{min}$ verwendet.

\subsubsection{IR-Spektroskopie}

Die Spektren wurden mit einem Spectrum Two IR-Spektrometer der Firma PerkinElmer mittels einer UATR-Einheit aufgenommen. Die Proben wurden mit der UATR-Einheit als Feststoff auf einen Diamanten gepresst und gemessen. Die Lagen der Absorptionsbanden werden in $\mathrm{cm}^{-1}$ angegeben. Die Ausprägung der Absorptionsbanden wird durch die folgenden Abkürzungen beschrieben.

$\mathrm{w}=$ schwach; $\mathrm{m}$ = mittelstark; $\mathrm{s}=$ stark; breite Banden wurden mit br abgekürzt .

\subsubsection{UV/VIS-Spektroskopie}

Die Konzentrationen der Oligonukleotide wurden mittels UV/VIS-Spektroskopie bestimmt. Dazu wurde ein NanoDrop 2000c Spektrometer der Firma ThermoSientific genutzt. Dazu wurden die Extinktionskoeffizienten nach einem nearest neighbor Modell berechnet. ${ }^{[244]}$ Zur Vereinfachung wurden die Einflüsse der Modifikationen vernachlässigt.

\subsubsection{Schmelzpunktmessungen der Verbindungen}

Die Ermittlung der Schmelzpunkte erfolgte durch über die Kapillarmethode an einem Schmelzpunktbestimmungsgerät des Typs MPM-H2 der Firma Schorpp Gerätetechnik.

\subsubsection{Schmelzpunktmessungen der Oligonukleotide}

Vor der Messung inkubierte man die ONs ( $1 \mu \mathrm{M}$ pro Strang) in Puffer $2(1 \mathrm{~mL} ; 100 \mathrm{mM} \mathrm{KCl}$, $2 \mathrm{mM} \mathrm{MgCl}, 50 \mathrm{mM}$ Tris- $\mathrm{HCl} \mathrm{pH}$ 8) über Nacht bei $37^{\circ} \mathrm{C}$. Die Schmelzpunktmessungen wurden an einem UV-VIS-Spektrometer (Evolution 300, Thermo Scientific) unter Verwendung einer $1 \mathrm{~mL}$ Küvette (Hellma Analytics) mit einer Weglänge von $1 \mathrm{~cm}$ durchgeführt. Die Temperatur der Messzelle wurde in der Lösung gemessen. Die Änderung der UV-Absorption wurde bei $260 \mathrm{~nm}$ zwischen $20^{\circ} \mathrm{C}$ und $90^{\circ} \mathrm{C}$ bestimmt, wobei die Temperaturänderungen $1^{\circ} \mathrm{C} / \mathrm{min}$ betrug. Es wurden drei bis fünf Zyklen aufgenommen und die erhaltenen Kurven individuell mit einem sigmoidalen Fit in OriginLabs gefittet. Die Schmelzpunkte sind als Durchschnitt der erhalten Werte angegeben. 


\subsection{Gelelektrophorese}

\subsubsection{Analytische dPAGE}

Für die analytische dPAGE wurden 16\% Gele (7 M Harnstoff, 1x TBE-Puffer; Acrylamid:Bisacrylamid 19:1) verwendet. Die Proben wurden mit dem gleichen Volumen des denaturierenden 2x Ladepuffers ( $8 \mathrm{M}$ Harnstoff, $20 \mathrm{mM}$ EDTA, $0.2 \%$ Orange G) gemischt und $5-10 \mathrm{~min}$ auf $90^{\circ} \mathrm{C}$ erhitzt. Für die Elektrophorese wurde ein $0.5 \times$ Tris-Borat-EDTA-Laufpuffer (TBE) verwendet und eine Spannung von $200-220 \mathrm{~V}$ angelegt. Man ließ den Farbstoff bis in das untere Drittel des Gels migrieren. Im Anschluss erfolgte eine Färbung mittels SYBR Gold (1:10000 in 10 mM Tris-HCl pH 7.5, 1 mM EDTA, $15-20 \mathrm{~min}$ ) und eine Detektion mittels Fotographie unter Verwendung eines Grünfilters.

\subsubsection{Präparative dPAGE}

Für die präparative dPAGE wurden $16 \%$ Gele (7M Harnstoff, 1x TBE-Puffer, Acrylamid:Bisacrylamid 19:1) verwendet. Die Proben wurden in einer konzentrierten Harnstoff-Lösung aufgenommen, mit etwas denaturierendem 2x Ladepuffer versetzt und für 5-10 min auf $90^{\circ} \mathrm{C}$ erwärmt. Für der Elektrophorese wurde ein steriler $0.5 \times$ TBE-Laufpuffer verwendet und eine Spannung von $230-250 \mathrm{~V}$ angelegt. Man ließ den Farbstoff bis zur Hälfte des Gels migrieren. Dann wurden die Banden mittels UV-shadowing sichtbar gemacht und ausgeschnitten. Die Gelfragmente wurden über Nacht mit einem Gelelutionspuffer (500 mM NaOAc pH 7.0, 2 mM EDTA, $0.1 \%$ SDS) inkubiert. Nach der Elution wurden die Proben durch einen Zentrifugalfilter (VWR, 516-0235, $13000 \mathrm{x} \mathrm{g}$ ) filtriert. Die Filtrate wurden mit dem dreifachen Volumen EtOH versetzt und über Nacht bei $-20^{\circ} \mathrm{C}$ gelagert. Danach zentrifugierte man die Proben bei 30 min bei $18620 \mathrm{x} \mathrm{g}$ und der Überstand entfernt. Die erhaltenen Pellets wurden in $\mathrm{H}_{2} \mathrm{O}$ aufgenommen und die ONs mittels Gelfiltration entsalzt.

\subsubsection{Band-Shift Experimente}

Für die Band-Shift-Experimente wurden die Proben in den entsprechenden Puffern zwischen $3 \mathrm{~h}$ und $24 \mathrm{~h}$ bei RT oder $37^{\circ} \mathrm{C}$ inkubiert und im Anschluss mit dem Ladepuffer versetzt.

Für die Elektrophorese wurde ein $0.5 \times$ TBE-Laufpuffer und $8 \%$ oder $16 \%$ Nativgele (Acrylamid:Bisacrylamid: 37.5:1, 1x TBE-Puffer, $5 \%$ Glycerin) verwendet. Dabei verwendete man zwischen 10 und 20 Taschen, die mit $10 \mu \mathrm{L}$ oder $6 \mu \mathrm{L}$ der Proben befüllt 
wurden. Es wurde eine Spannung von 80 - $120 \mathrm{~V}$ angelegt und man ließ den Ladepuffer ungefähr bis zur Mitte des Gels migrieren. Die Färbung erfolgte mittels SYBR Gold (1:10000 in $10 \mathrm{mM}$ Tris- $\mathrm{HCl} \mathrm{pH}$ 7.5, $1 \mathrm{mM}$ EDTA, 15 - $20 \mathrm{~min}$ ) und die Detektion wurde mittels Fotographie unter Verwendung eines Grünfilters durchgeführt. Die Cy5-Detektionen erfolgten mittels einem FUSION Xpress ${ }^{\mathrm{TM}}$ Multi-Imaging System.

\subsection{Pulldown-Experimente}

\subsubsection{Beladen der Magnetic Beads}

Streptavidin beladene Magnetic Beads $(600 \mu \mathrm{L}$, Bindekapazität $0.75 \mu \mathrm{mol} / \mu \mathrm{L})$ wurden dreimal mit 0.5x SSPE-Puffer gewaschen. Im Anschluss wurde eine Lösung der biotinylierten Oligonukleotide $(2 \mu \mathrm{M})$ in $0.5 x$ SSPE $(450 \mu \mathrm{L})$ mit $10 \%$ RotiB-Block (Roth) zugegeben und über Nacht bei Raumtemperatur geschüttelt. Danach wurden die Beads mit Hilfe eines Magneten gesammelt, der Überstand entfernt und die Beads dreimal mit 0.5x SSPE gewaschen. Nach der Zugabe von 0.5x SSPE (450 $\mu \mathrm{L})$ wurden die Beads bei $4^{\circ} \mathrm{C}$ gelagert.

\subsubsection{Fluoreszenz-Pulldown}

\section{Allgemeines Vorgehen:}

Ein Aliquot beladener Beads (100 mM - $400 \mathrm{nM}$ ) wurde in den jeweiligen Puffern (je $50 \mu \mathrm{L}-100 \mu \mathrm{L}$ ), der $10 \%$ Roti闹-Block enthielt, suspendiert und mit den Oligonukleotiden versetzt. Die Proben wurden zwischen $1 \mathrm{~h}$ und $24 \mathrm{~h}$ inkubiert, mit Hilfe eines Magneten gesammelt und anschließend mit dem entsprechenden Puffer gewaschen. Danach versetzte man die Proben mit $0.5 x$ SSPE $(97 \mu \mathrm{L})$ sowie $0.1 \mathrm{M} \mathrm{NaOH}(3 \mu \mathrm{L})$ und inkubierte diese Lösung für 30 min. Die Suspension wurde in schwarze 96-well-microtiter Platten (Corning costar) überführt und die Fluoreszenz der Cy-5-gelabelten Stränge gemessen $\left(\lambda_{\mathrm{ex}}\right.$ $=649 \mathrm{~nm}, \lambda_{\mathrm{em}}=670 \mathrm{~nm}$, Tecan Safire II).

\section{Experimente mit den PIP-DNA Konjugaten:}

Für die Inkubation und das Waschen der Proben wurde 0.5x SSPE-Puffer, Puffer Z oder Puffer 1 verwendet. Die Proben wurden drei Mal gewaschen.

\section{Experimente mit den DNA/LNA Adaptoren:}

Für die Inkubation und das Waschen der Proben wurde Puffer 2 verwendet. Die Proben wurden fünf Mal gewaschen. 


\subsubsection{Pulldown-Experimente zur Proteinisolierung und Detektion mittels Western-Blot}

\section{Allgemeines Vorgehen}

Ein Aliquot der beladenen Beads wurde mit der gewünschten Proteinmischung in An- oder Abwesenheit der Konjugate oder der Adaptoren für 1 bis $3 \mathrm{~h}$ bei RT inkubiert. Im Anschluss wurden die Beads gewaschen, mit Laemmli-Puffer $(6 \mu \mathrm{L})$ versetzt und für $5-10$ min auf $90{ }^{\circ} \mathrm{C}$ erhitzt. Die Proben wurden mittels SDS-PAGE analysiert $(6 \%$ oder $8 \%$ stacking, $8 \%$ oder $10 \%$ resolving Gel). Dazu verwendete man den SDS-Laufpuffer und legte eine Spannung von $100-120 \mathrm{~V}$ an. Daraufhin transferierte man die Proteine bei einer Leistung von $8 \mathrm{~W}$ über 30 min auf eine PVDF-Membran, welche daraufhin mit $10 \%$ Roti̊-Block in Wasser oder $0.5 \%$ Casein (Hammarsten grade) geblockt wurde. Die anschließende Inkubation der Membran mit dem Erstantikörper erfolgte in Tris-buffered saline (TBS)-Puffer und dem jeweiligen Blockierungsreagenz. Dann wurde die Membran dreimal mit TBST (TBS mit $0.1 \%$ Tween 20) gewaschen, mit einem funktionalisierten Zweitantikörper in TBS inkubiert und erneut dreimal mit TBST gewaschen. Danach erfolgte die Detektion der Banden.

\section{Experimente zur Isolierung von SP1:}

Für die Isolierung von SP1 wurden die Beads (100 oder 300 - 400 nM) mit den jeweiligen Konjugaten und ONs (je 100 oder $400 \mathrm{nM}$ ) in Puffer $Z$ oder Puffer $1\left(\mathrm{~V}_{\text {ges }}=100 \mu \mathrm{L}\right)$ mit Sp1 $(1 \mu \mathrm{L}, 215 \mathrm{ng} / \mu \mathrm{L})$ inkubiert. Die Proben wurden drei Mal gewaschen. Der Erstantikörper (Sigma-Aldrich, SAB1404397) wurde in einer Verdünnung von 1:650 verwendet. Als Zweitantikörper wurde ein AP-linked-Antikörper (Cell Signaling, 7056S) in einer Verdünnung von 1:1500 verwendet. Die Detektion erfolgte über eine Färbung mit Nitroblautetrazoliumchlorid (NBT) und 5-Brom-4-chlor-3-indoxylphosphat (BCIP). In der Färbereaktion wird BCIP nach Abspaltung der Phosphat-Gruppe zu einem Indigo-Farbstoff oxidiert, während NBT zu einem Formazan-Farbstoff reduziert wird.

\section{Experimente zur Isolierung von hAgo2:}

Für die Isolierung von hAgo2 wurden die Beads ( $1 \mu \mathrm{M}$ für die Selektivitäts-Pulldowns und 100 - $300 \mathrm{nM}$ für Experimente mit den Adaptoren) in HeLa-Lysat inkubiert ( $\mathrm{V}_{\text {ges }}=$ $100-300 \mu \mathrm{L})$. Die Proben wurden fünf Mal mit Puffer 2 gewaschen. Der Erstantikörper (Sino Biological, 11079-T36) wurde in einer Verdünnung von 1:200 bis 1:400 eingesetzt. Als Zweitantikörper verwendete man entweder einen fluoreszenzmarkierten Antikörper (ThermoFisher Scientific, 35563) in einer Verdünnung von 1:4000 oder einen AP-linked- 
Antikörper (Cell Signaling, 7054S) in einer Verdünnung von 1:2000. Die Detektion erfolgte im Fall des fluoreszenzmarkierten Antikörpers mittels des FUSION Xpress ${ }^{\mathrm{TM}}$ Multi-Imaging Systems und im Fall der AP-linked-Antikörper über eine Färbung mit NBT und BCIP. 


\subsection{Synthese der Monomere für die Festphasensynthese}

\subsubsection{Synthese von 1-Methyl-2-trichloracetylpyrrol $\left(\mathrm{Py}-\mathrm{CCl}_{3}\right) 1$}

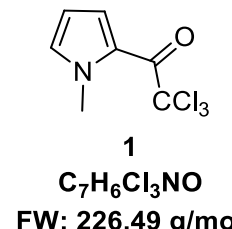

$\mathrm{Zu}$ einer Lösung aus Trichloracetylchlorid $(22.5 \mathrm{~mL}, 200 \mathrm{mmol}, 1.0 \mathrm{eq})$ in abs. DCM (100 mL) wurde 1- $N$-Methylpyrrol $(17.8 \mathrm{~mL}, 200 \mathrm{mmol}, 1.0 \mathrm{eq})$ in DCM (100 mL) über $2 \mathrm{~h}$ zugegeben und die resultierende braune Mischung $20 \mathrm{~h}$ bei RT gerührt. Anschließend gab man eine Lösung von $\mathrm{K}_{2} \mathrm{CO}_{3}(14 \mathrm{~g})$ in Wasser $(100 \mathrm{~mL}) \mathrm{zu}$ und trennte die Phasen. Die wässrige Phase wurde mit DCM extrahiert und die organische Phase über $\mathrm{MgSO}_{4}$ getrocknet. Nach Entfernen des Solvens unter vermindertem Druck und einer säulenchromatographischen ( $\mathrm{CH} / \mathrm{DCM}$ 7:3) Aufarbeitung, konnte 1 als leicht gelber Feststoff erhalten werden.

Ausbeute: $34.2 \mathrm{~g}, 151 \mathrm{mmol}, 75 \%$.

${ }^{1} \mathrm{H}-\mathrm{NMR}\left(300 \mathrm{MHz}, \mathrm{CDCl}_{3}\right) \delta=7.51\left(\mathrm{dd}, J=4.4,1.6 \mathrm{~Hz}, 1 \mathrm{H}, \mathrm{C}^{3}-\mathrm{H}\right), 6.99-6.93(\mathrm{~m}, 1 \mathrm{H}$, $\mathrm{C}^{5}-\mathrm{H}$ ), 6.22 (dd, $J=4.4,2.4 \mathrm{~Hz}, 1 \mathrm{H}, \mathrm{C}^{4}-\mathrm{H}$ ), 3.97 (s, 3H, N-CH ) ppm.

${ }^{13} \mathrm{C}-\mathrm{NMR}\left(75 \mathrm{MHz}, \mathrm{CDCl}_{3}\right) \delta=173.1(\mathrm{C}=\mathrm{O}), 133.8\left(\mathrm{C}^{5}\right), 124.2\left(\mathrm{C}^{3}\right), 122.0\left(\mathrm{C}^{2}\right), 109.0\left(\mathrm{C}^{4}\right)$, $96.5\left(\mathrm{CCl}_{3}\right), 38.7\left(\mathrm{~N}-\mathrm{CH}_{3}\right) \mathrm{ppm}$.

DC: $R_{f}: 0.44(\mathrm{CH} / \mathrm{DCM} 7: 3)$

Schmelzpunkt: $65-66^{\circ} \mathrm{C} \quad$ Literatur: $64^{\circ} \mathrm{C} .{ }^{[207]}$

IR (Wellenzahl cm ${ }^{-1}$ ): 3122 (w), 2955 (w), 1652 (s), 1521 (m), 1456 (m), 1399, (s), 1357 (s), 1331 (s), $1243(\mathrm{~m}), 1205(\mathrm{~m}), 1099(\mathrm{~m}), 1066(\mathrm{~m}), 979(\mathrm{~m}), 880(\mathrm{w}), 841$ (s), 805 (s), 740 (s), $684(\mathrm{~s}), 597(\mathrm{~s}), 564(\mathrm{w}), 525(\mathrm{~m})$.

MS (ESI): $\quad \quad m / z$ ber. für $\mathrm{C}_{7} \mathrm{H}_{6} \mathrm{Cl}_{3} \mathrm{NO}$ ([M]-): 225.0; gef.: 224.8. 
10.5.2 Synthese von 1-Methyl-4-nitro-2-trichloracetylpyrrol $\left(\mathrm{O}_{2} \mathrm{~N}-\mathrm{Py}-\mathrm{CCl}_{3}\right) 2$

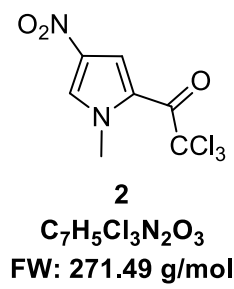

Variante A:

Verbindung $1(15.0 \mathrm{~g}, 66.2 \mathrm{mmol}, 1.0 \mathrm{eq})$ wurde in $\mathrm{Ac}_{2} \mathrm{O}(150 \mathrm{~mL})$ gelöst und auf $-50{ }^{\circ} \mathrm{C}$ abgekühlt. Daraufhin gab man 100\%ige $\mathrm{NHO}_{3}(5.5 \mathrm{~mL}, 132 \mathrm{mmol}, 2.0 \mathrm{eq}) \mathrm{zu}$, wobei eine Temperatur von $-40^{\circ} \mathrm{C}$ nicht überschritten werden durfte. Im Anschluss wurde $30 \mathrm{~min}$ bei $-50^{\circ} \mathrm{C}$ und $4 \mathrm{~h}$ bei RT gerührt. Dann engte man die Lösung um ca. die Hälfte ein, kühlte sie auf $-50^{\circ} \mathrm{C}$ ab und gab Isopropanol (120 mL) hinzu. Nach 30 min fiel ein Feststoff aus, der abfiltriert wurde. Das Filtrat wurde erneut eingeengt, mit Isopropanol (100 mL) versetzt und auf $-50^{\circ} \mathrm{C}$ abgekühlt. Hierbei fiel erneut ein hellgelber Feststoff aus, der ebenfalls abfiltriert wurde. Die Feststoffe wurden vereint und im Vakuum getrocknet.

Ausbeute: $11.9 \mathrm{~g}, 43.8 \mathrm{mmol}, 66 \%$.

\section{Variante B:}

Verbindung 1 (15.0 g, $66.2 \mathrm{mmol}, 1.0 \mathrm{eq})$ wurde in $\mathrm{Ac}_{2} \mathrm{O}(80 \mathrm{~mL})$ gelöst und auf $-50{ }^{\circ} \mathrm{C}$ abgekühlt. Während der anschließenden Zugabe von 65\%iger $\mathrm{HNO}_{3}(8.3 \mathrm{~mL}, 119 \mathrm{mmol}$, $1.8 \mathrm{eq})$ musste die Temperatur unter $-40^{\circ} \mathrm{C}$ gehalten werden. Im Anschluss wurde $3 \mathrm{~h}$ gerührt und dabei langsam auf RT erwärmt. Nach beendeter Reaktion wurde die Lösung in Eiswasser gegeben, wobei ein gelber Feststoff ausfiel. Dieser wurde abfiltriert und säulenchromatographisch (CH/EE 5:1 auf 4:1) gereinigt. Das Produkt wurde als farbloser Feststoff erhalten.

Ausbeute: $10.9 \mathrm{~g}, 40.2 \mathrm{mmol}, 61 \%$.

${ }^{1} \mathrm{H}-\mathrm{NMR}\left(500 \mathrm{MHz}, \mathrm{CDCl}_{3}\right) \delta=7.95(\mathrm{~d}, J=1.7 \mathrm{~Hz}, 1 \mathrm{H}), 7.75(\mathrm{~d}, J=1.4 \mathrm{~Hz}, 1 \mathrm{H}), 4.05$ $(\mathrm{s}, 3 \mathrm{H}) \mathrm{ppm}$.

${ }^{13} \mathrm{C}-\mathrm{NMR}\left(126 \mathrm{MHz}, \mathrm{CDCl}_{3}\right) \delta=173.9,135.5,130.4,121.6,117.7,95.0,39.9 \mathrm{ppm}$.

DC: $R_{f}: 0.60(\mathrm{CH} / \mathrm{EE} 5: 1)$

IR (Wellenzahl cm ): 3138 (w), 1691 (s), $1530(\mathrm{~m}), 1514(\mathrm{~m}), 1493(\mathrm{~s}), 1423(\mathrm{~m}), 1403(\mathrm{~m})$, 1338 (w), 1310 (s), 1224 (m), 1181 (m), 1110 (s), 1077 (w), 994 (m), 852 (s), 812 (s), 799 (s), 748 (s), 714 (s), 684 (s), 610 (m), 581 (s), 519 (w), 483 (w), 476 (w), 429 (w), 415 (w). 
10.5.3 Synthese von Methyl-1-methyl-4-nitropyrrol-2-carboxylat $\left(\mathrm{O}_{2} \mathrm{~N}-\mathrm{Py}-\mathrm{OMe}\right)$ 3

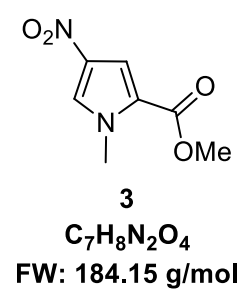

Verbindung 2 (2.00 g $7.38 \mathrm{mmol}, 1.0$ eq) wurde in $\mathrm{MeOH}(15 \mathrm{~mL})$ suspendiert, mit DMAP (90 mg, $0.74 \mathrm{mmol}, 0.1 \mathrm{eq}$ ) versetzt und $2 \mathrm{~h}$ bei RT gerührt. Im Anschluss wurde die Suspension filtriert und der Feststoff mit $\mathrm{MeOH}$ gewaschen. Das Filtrat wurde eingeengt, erneut mit $\mathrm{MeOH}$ suspendiert und filtriert, um weiteres Produkt zu erhalten. Verbindung 3 konnte als farbloser Feststoff erhalten werden.

Ausbeute: $1.21 \mathrm{~g}, 6.57 \mathrm{mmol}, 89 \%$.

${ }^{1} \mathrm{H}-N M R\left(300 \mathrm{MHz}, \mathrm{DMSO}-d_{6}\right) \delta=8.28\left(\mathrm{~d}, J=1.7 \mathrm{~Hz}, 1 \mathrm{H}, \mathrm{C}^{5}-\mathrm{H}\right), 7.32(\mathrm{~d}, J=2.1 \mathrm{~Hz}, 1 \mathrm{H}$, $\left.\mathrm{C}^{3}-\mathrm{H}\right), 3.93\left(\mathrm{~s}, 3 \mathrm{H}, \mathrm{N}-\mathrm{CH}_{3}\right), 3.80\left(\mathrm{~s}, 3 \mathrm{H}, \mathrm{COOCH}_{3}\right) \mathrm{ppm}$.

${ }^{13}$ C-NMR $\left(75 \mathrm{MHz}\right.$, DMSO- $\left.d_{6}\right) \delta=159.9,134.2,129.5,122.7,111.6,51.9,37.5 \mathrm{ppm}$.

Schmelzpunkt: $119-120^{\circ} \mathrm{C} \quad$ Literatur: $120-122^{\circ} \mathrm{C}^{[245]}$

10.5.4 Synthese von Methyl-4-[(tert-butoxycarbonyl)amino]-1-methylpyrrol-2carboxylat (Boc-Py-OMe) 4

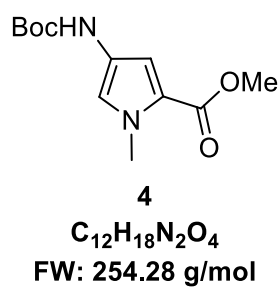

Verbindung 3 (4.94 g, $26.8 \mathrm{mmol}, 1.0 \mathrm{eq})$ wurde in abs. EE (100 mL) gelöst und mit $\mathrm{Pd} / \mathrm{C}$ (500 mg, $10 \%$ auf Aktivkohle) versetzt. Die Suspension wurde $3 \mathrm{~h}$ in einer $\mathrm{H}_{2}$-Atmosphäre gerührt und im Anschluss über Celite filtriert. Das Lösemittel wurde unter vermindertem Druck entfernt und der Rückstand kurz im Vakuum getrocknet. Dann wurde abs. $\mathrm{MeOH}$ (30 mL) sowie $\mathrm{Boc}_{2} \mathrm{O}(6.43 \mathrm{~g}, 29.5 \mathrm{mmol}, 1.1 \mathrm{eq})$ in abs. $\mathrm{MeOH}(20 \mathrm{~mL})$ zugegeben und die Lösung $15.5 \mathrm{~h}$ bei RT gerührt. Nach dem Entfernen des Lösemittels unter vermindertem Druck, wurde der Rückstand säulenchromatographisch (CH/EE 7:2) gereinigt. 4 wurde als farbloser Feststoff erhalten.

Ausbeute: $6.47 \mathrm{~g}, 25.4 \mathrm{mmol}, 95 \%$. 
${ }^{1} \mathrm{H}-\mathrm{NMR}\left(300 \mathrm{MHz}, \mathrm{DMSO}-d_{6}\right) \delta=9.08(\mathrm{~s}, 1 \mathrm{H}, \mathrm{NH}), 7.08\left(\mathrm{~s}, 1 \mathrm{H}, \mathrm{C}^{5}-\mathrm{H}\right), 6.62\left(\mathrm{~s}, 1 \mathrm{H}, \mathrm{C}^{3}-\mathrm{H}\right)$, $3.78\left(\mathrm{~s}, 3 \mathrm{H}, \mathrm{N}-\mathrm{CH}_{3}\right), 3.70\left(\mathrm{~s}, 3 \mathrm{H}, \mathrm{O}-\mathrm{CH}_{3}\right), 1.43$ (s, 9H, $\left.\mathrm{CH}_{3}-\mathrm{Boc}\right) \mathrm{ppm}$.

${ }^{13}$ C-NMR $\left(75 \mathrm{MHz}\right.$, DMSO- $\left.d_{6}\right) \delta=160.8,152.8,123.2,119.3,118.7,107.5,78.6,50.9,36.1$, $28.2 \mathrm{ppm}$.

DC: $R_{f}: 0.40(\mathrm{CH}: \mathrm{EE} 7: 2)$

Schmelzpunkt: $110-111^{\circ} \mathrm{C} \quad$ Literatur: $109^{\circ} \mathrm{C} .^{[246]}$

IR (Wellenzahl cm'-1): 3345 m, 3166 w, 2967 w, 1805 w, 1714 m, 1680 s, 1587 m, 1552 m, 1453 s, 1406 m, 1388 m, 1367 m, 1287 w, 1264 m, 1230 s, 1167 s, 1149 s, 1115 s, 1058 s, 994 m, 961 w, 889 m, 818 w, 778 s, 742 m, 658 m, 627 m, 602 m, 542 w, 477 w, 431 w. MS (ESI): $\quad \quad m / z$ ber. für $\mathrm{C}_{8} \mathrm{H}_{11} \mathrm{~N}_{2} \mathrm{O}_{4}\left([\mathrm{M}+\mathrm{H}-(t-\mathrm{Bu})]^{+}\right): 199.1$; gef.: 199.1.

HRMS (MALDI): $\quad m / z$ ber. für $\mathrm{C}_{12} \mathrm{H}_{18} \mathrm{~N}_{2} \mathrm{NaO}_{4}\left([\mathrm{M}+\mathrm{Na}]^{+}\right)$: 277.11588; gef.: 277.11601.

\subsubsection{Synthese von 4-[(tert-Butoxycarbonyl)amino]-1-methylpyrrol-2- carbonsäure (Boc-Py-OH) 5}

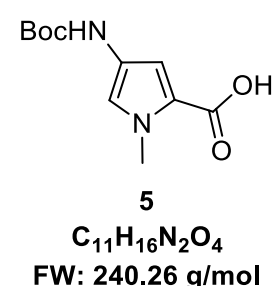

Verbindung 4 (4.64 g, $18.2 \mathrm{mmol}, 1.0 \mathrm{eq})$ wurde in $\mathrm{MeOH}(15 \mathrm{~mL}$ ) suspendiert, mit einer $2 \mathrm{M} \mathrm{NaOH}$-Lösung $(10 \mathrm{~mL}, 20 \mathrm{mmol}, 1.1 \mathrm{eq})$ versetzt und auf $60^{\circ} \mathrm{C}$ erwärmt. Nach $4.5 \mathrm{~h}$ wurde weitere $\mathrm{NaOH}$ (400 mg, $10 \mathrm{mmol}, 0.6 \mathrm{eq}$ ) zugegeben, die Lösung auf RT abgekühlt und weitere $16.5 \mathrm{~h}$ bei RT gerührt. Im Anschluss extrahierte man viermal mit $\mathrm{Et}_{2} \mathrm{O}(20 \mathrm{~mL})$, säuerte die wässrige Phase mit $10 \%$ iger $\mathrm{H}_{2} \mathrm{SO}_{4}$ an und extrahierte viermal mit $\mathrm{EE}(20 \mathrm{~mL})$. Die vereinigten organischen Phasen wurden über $\mathrm{MgSO}_{4}$ getrocknet und das Lösemittel unter vermindertem Druck entfernt. Der erhaltene hellbraune Schaum wurde in DCM $(5 \mathrm{~mL})$ gelöst und mit $\mathrm{CH}(20 \mathrm{~mL})$ versetzt. Die erhaltene Suspension wurde erneut eingeengt und Verbindung 5 als farbloser Feststoff erhalten.

Ausbeute: 3.70 g, 15.4 mmol, 84 \%. 
${ }^{1} \mathrm{H}-\mathrm{NMR}\left(300 \mathrm{MHz}, \mathrm{DMSO}-\mathrm{d}_{6}\right) \delta=9.02(\mathrm{~s}, 1 \mathrm{H}, \mathrm{NH}), 7.03\left(\mathrm{~s}, 1 \mathrm{H}, \mathrm{C}^{5}-\mathrm{H}\right), 6.57(\mathrm{~d}, J=1.7 \mathrm{~Hz}$, $\left.1 \mathrm{H}, \mathrm{C}^{3}-\mathrm{H}\right), 3.76\left(\mathrm{~s}, 3 \mathrm{H}, \mathrm{N}-\mathrm{CH}_{3}\right), 1.43\left(\mathrm{~s}, 9 \mathrm{H}, \mathrm{CH}_{3}-\mathrm{Boc}\right) \mathrm{ppm}^{\mathrm{a}}$

${ }^{13}$ C-NMR $\left(75 \mathrm{MHz}\right.$, DMSO- $\left.d_{6}\right) \delta=161.9,152.8,122.9,119.7,118.8,107.6,78.5,36.1$, $28.2 \mathrm{ppm}$.

Schmelzpunkt: $150-151^{\circ} \mathrm{C} \quad$ Literatur: $151-151.5^{\circ} \mathrm{C}^{[247]}$

IR (Wellenzahl cm ${ }^{-1}$ ): 3349 w, 2952 w br, 2628 w, 1695 s, 1667 s, 1585 m, 1555 w, 1527 s, 1451 s, 1386 s, 1281 s, 1244 s, 1199 m, 1159 s, 1112 m, 1061 m, 998 m, 889 m, 824 w, 808 w, 778 m, 723 m, 690 w, 661 w, 623 m, 610 w, 561 w, 495 w, 454 w, 429 w.

MS (ESI): $\quad \quad m / z$ ber. für $\mathrm{C}_{11} \mathrm{H}_{15} \mathrm{~N}_{2} \mathrm{O}_{4}\left([\mathrm{M}-\mathrm{H}]^{-}\right): 239.1$; gef.: 239.1 .

HRMS (MALDI): $\quad m / z$ ber. für $\mathrm{C}_{11} \mathrm{H}_{16} \mathrm{~N}_{2} \mathrm{NaO}_{4}\left([\mathrm{M}+\mathrm{Na}]^{+}\right)$: 263.10023; gef.: 263.09921 .

\subsubsection{Synthese von 1-Methyl-2-trichloracetylimidazol $\left(\mathrm{Im}-\mathrm{CCl}_{3}\right) 6$}

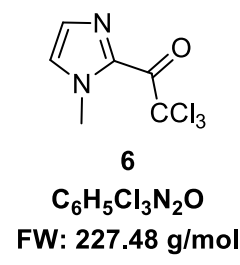

Zu einer Lösung aus Trichloracetylchlorid (11.2 mL, $100 \mathrm{mmol}, 1.0 \mathrm{eq})$ in abs. DCM (60 mL) gab man langsam eine Mischung aus $N$-Methylimidazol $(8.00 \mathrm{~mL}, 100 \mathrm{mmol}, 1.0 \mathrm{eq})$ in DCM (60 mL). Im Anschluss wurde die Lösung $16 \mathrm{~h}$ bei RT gerührt und die Lösung auf $0{ }^{\circ} \mathrm{C}$ gekühlt. Dann gab man tropfenweise NEt $(14.0 \mathrm{~mL}, 100 \mathrm{mmol}, 1.0 \mathrm{eq}) \mathrm{zu}$. Das Lösemittel wurde unter vermindertem Druck entfernt und das Rohprodukt säulenchromatographisch gereinigt ( $\mathrm{CH} / \mathrm{EE} 3: 1)$. Verbindung 6 konnte als farbloser Feststoff erhalten werden.

Ausbeute: $19.2 \mathrm{~g}, 84.4 \mathrm{mmol}, 84 \%$.

${ }^{1} \mathrm{H}-\mathrm{NMR}\left(500 \mathrm{MHz}, \mathrm{DMSO}-d_{6}\right) \delta=7.35(\mathrm{~s}, 1 \mathrm{H}), 7.16(\mathrm{~s}, 1 \mathrm{H}), 4.06\left(\mathrm{~s}, 3 \mathrm{H}, \mathrm{N}-\mathrm{CH}_{3}\right) \mathrm{ppm}$.

${ }^{13} \mathrm{C}-\mathrm{NMR}\left(126 \mathrm{MHz}\right.$, DMSO- $\left.d_{6}\right) \delta=172.4,136.3,130.7,128.7,94.9$, $37.3 \mathrm{ppm}$.

DC: $R_{\mathrm{f}}: 0.56(\mathrm{CH}: \mathrm{EE} \mathrm{3:1)}$

Schmelzpunkt: $77-78^{\circ} \mathrm{C} \quad$ Literatur: $79-80^{\circ} \mathrm{C} .^{[207]}$

\footnotetext{
a Das Signal des Säureprotons konnte aufgrund eines Austauschs mit dem im Lösemittel enthaltenen Wasser im nicht detektiert werden.
} 
10.5.7 Synthese von 1-Methyl-4-nitro-2-trichloracetylimidazol $\left(\mathrm{O}_{2} \mathrm{~N}-\mathrm{Im}-\mathrm{CCl}_{3}\right) 7$

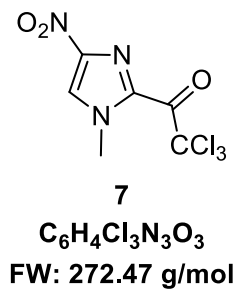

Verbindung 6 (10.1 g, $44.4 \mathrm{mmol}, 1.0 \mathrm{eq})$ wurde in $\mathrm{Ac}_{2} \mathrm{O}(75 \mathrm{~mL})$ gelöst und auf $-45^{\circ} \mathrm{C}$ abgekühlt. Im Anschluss wurden 100\%ige $\mathrm{HNO}_{3}(6 \mathrm{~mL}, 144 \mathrm{mmol}, 3.2 \mathrm{eq})$ und konz. $\mathrm{H}_{2} \mathrm{SO}_{4}$ $(280 \mu \mathrm{L})$ zugegeben, wobei die Temperatur unter $-40{ }^{\circ} \mathrm{C}$ gehalten wurde. Die Lösung wurde 30 min bei $-40^{\circ} \mathrm{C}$ gerührt, dann auf RT erwärmt und $21 \mathrm{~h}$ gerührt. Im Anschluss gab man die Lösung auf Eiswasser ( $580 \mathrm{~mL}$ ) und stellte mit $\mathrm{K}_{2} \mathrm{CO}_{3}$ einen $\mathrm{pH}$-Wert von ca. 4 ein. Der entstandene farblose Niederschlag wurde abfiltriert und im Vakuum getrocknet.

Ausbeute: $4.86 \mathrm{~g}, 17.8 \mathrm{mmol}, 40 \%$.

${ }^{1} \mathrm{H}-\mathrm{NMR}\left(500 \mathrm{MHz}, \mathrm{CDCl}_{3}\right) \delta=7.94(\mathrm{~s}, 1 \mathrm{H}), 4.16(\mathrm{~s}, 3 \mathrm{H}) \mathrm{ppm}$.

${ }^{13} \mathrm{C}-\mathrm{NMR}\left(126 \mathrm{MHz}, \mathrm{CDCl}_{3}\right) \delta=173.0,133.8,131.6,126.1,93.6,38.5 \mathrm{ppm}$.

DC: $R_{f}: 0.73(\mathrm{CH}: E E ~ 1: 2)$

10.5.8 Synthese von Methyl-1-methyl-4-nitroimidazol-2-carboxylat $\left(\mathrm{O}_{2} \mathrm{~N}-\mathrm{Im}\right.$ OMe) 8

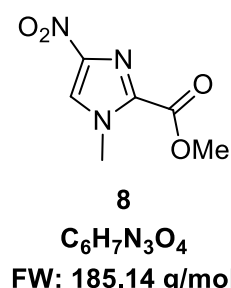

Verbindung 7 (4.00 g, $14.7 \mathrm{mmol}, 1.0 \mathrm{eq})$ und DMAP (90.0 mg, 734 umol, $0.05 \mathrm{eq}$ ) wurden in $\mathrm{MeOH}(28 \mathrm{~mL})$ suspendiert und $8 \mathrm{~h}$ bei $\mathrm{RT}$ gerührt. Im Anschluss filtrierte man den Feststoff ab und engte das Filtrat ein. Der Rückstand wurde mit $\mathrm{MeOH}$ suspendiert und erneut filtriert, um weiteres Produkt zu erhalten. Verbindung 8 wurde als farbloser Feststoff erhalten.

Ausbeute: $2.32 \mathrm{~g}, 12.5 \mathrm{mmol}, 85 \%$.

${ }^{1} \mathrm{H}-\mathrm{NMR}\left(500 \mathrm{MHz}, \mathrm{CDCl}_{3}\right) \delta=7.85(\mathrm{~s}, 1 \mathrm{H}), 4.12(\mathrm{~s}, 3 \mathrm{H}), 3.98(\mathrm{~s}, 3 \mathrm{H}) \mathrm{ppm}$.

${ }^{13} \mathrm{C}-\mathrm{NMR}\left(126 \mathrm{MHz}, \mathrm{CDCl}_{3}\right) \delta=158.8,134.8,132.0,124.5,53.2,37.3 \mathrm{ppm}$.

DC: $R_{f}: 0.38(C H: E E ~ 1: 2)$ 
MS (ESI): $\quad \quad m / z$ ber. für $\mathrm{C}_{6} \mathrm{H}_{8} \mathrm{~N}_{3} \mathrm{O}_{4}\left([\mathrm{M}+\mathrm{H}]^{+}\right): 186.1$; gef.: 186.2.

HRMS (MALDI): $\quad m / z$ ber. $\mathrm{C}_{6} \mathrm{H}_{8} \mathrm{~N}_{3} \mathrm{O}_{4}\left([\mathrm{M}+\mathrm{H}]^{+}\right): 186.05093 ;$ gef.: 186.05090 .

10.5.9 Synthese von Methyl-4-[(tert-butoxycarbonyl)amino]-1-methylimidazol2-carbonsäure (Boc-Im-OMe) 9

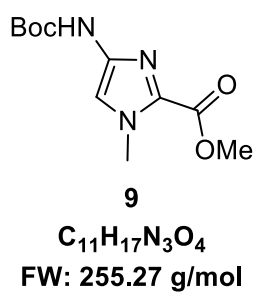

Verbindung 8 (1.00 g, 5.40 mmol, 1.0 eq) wurde mit Boc $2 \mathrm{O}$ (3.53 g, $16.2 \mathrm{mmol}, 3.0 \mathrm{eq})$ in abs. $\mathrm{MeOH}(80 \mathrm{~mL})$ gelöst, mit $\mathrm{Pd} / \mathrm{C}$ (100 mg, $10 \%$ auf Aktivkohle) versetzt und bei RT in einer $\mathrm{H}_{2}$-Atmosphäre $6 \mathrm{~h}$ gerührt. Im Anschluss rührte man in einer Argon-Atmosphäre weitere $17 \mathrm{~h}$ bei RT. Die Suspension wurde über Celite filtriert und das Lösemittel unter vermindertem Druck entfernt. Das Rohprodukt wurde säulenchromatographisch $(\mathrm{CH}: \mathrm{EE} 1: 2)$ gereinigt und Verbindung 9 als farbloser Feststoff erhalten.

Ausbeute: $1.18 \mathrm{~g}, 4.62 \mathrm{mmol}, 86 \%$.

${ }^{1} \mathrm{H}-\mathrm{NMR}\left(300 \mathrm{MHz}, \mathrm{DMSO}-d_{6}\right) \delta=9.71(\mathrm{~s} b r, 1 \mathrm{H}), 7.32(\mathrm{~s} b r, 1 \mathrm{H}), 3.88(\mathrm{~s}, 3 \mathrm{H}), 3.78(\mathrm{~s}, 3 \mathrm{H})$, $1.44(\mathrm{~s}, 9 \mathrm{H}) \mathrm{ppm}$.

${ }^{13}$ C-NMR $\left(75 \mathrm{MHz}\right.$, DMSO- $\left.d_{6}\right) \delta=158.9,152.7,138.1,130.7,113.9,79.0,51.7,35.4$, $28.1 \mathrm{ppm}$.

DC: $R_{f}: 0.46(\mathrm{CH}: \mathrm{EE} \mathrm{1:2)}$

10.5.10 Synthese von 4-[(tert-butoxycarbonyl)amino]-1-methylimidazol-2carboxylat (Boc-Im-OH) 10

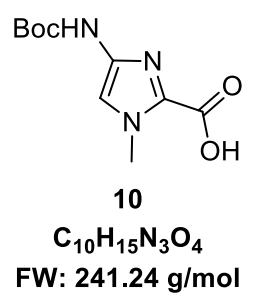

$\mathrm{Zu}$ einer Lösung aus $\mathrm{KOH}(1.49 \mathrm{~g}, 26.6 \mathrm{mmol}, 6.0 \mathrm{eq})$ in $\mathrm{H}_{2} \mathrm{O}$ (158 mL) gab man Verbindung 9 (1.13 g, $4.43 \mathrm{mmol}, 1.0 \mathrm{eq})$ in THF $(72 \mathrm{~mL})$. Die erhaltenen Suspension wurde $1 \mathrm{~h}$ bei RT gerührt und im Anschluss mit $\mathrm{H}_{2} \mathrm{O}(30 \mathrm{~mL})$ und $\mathrm{EE}(30 \mathrm{~mL})$ versetzt. Die 
Phasen wurden getrennt und die wässrige Phase zweimal mit EE ( $30 \mathrm{~mL}$ und $15 \mathrm{~mL}$ ) gewaschen. Die wässrige Phase wurde dann mit $1 \mathrm{M} \mathrm{HCl}(26 \mathrm{~mL})$ versetzt und dreimal mit $\mathrm{EE}\left(30 \mathrm{~mL}\right.$ ) extrahiert. Die vereinigten organischen Phasen wurden über $\mathrm{Na}_{2} \mathrm{SO}_{4}$ getrocknet und das Lösemittel unter vermindertem Druck entfernt. Verbindung 10 wurde als farbloser Feststoff erhalten.

Ausbeute: $540 \mathrm{mg}, 2.2 \mathrm{mmol}, 51 \%$.

${ }^{1} \mathrm{H}-\mathrm{NMR}\left(600 \mathrm{MHz}, \mathrm{DMSO}-d_{6}\right) \delta=9.60(\mathrm{~s} \mathrm{br}, 1 \mathrm{H}), 7.26(\mathrm{~s} \mathrm{br}, 1 \mathrm{H}), 3.87$ (s, 3H), 1.44 (s, 9H) ppm. ${ }^{\text {b }}$

${ }^{13}$ C-NMR $\left(151 \mathrm{MHz}\right.$, DMSO- $\left.d_{6}\right) \delta=159.9,152.7,137.6,131.8,113.5,78.9,51.7,35.4$, $28.1 \mathrm{ppm}$.

MS (ESI): $\quad \quad m / z$ ber. für $\mathrm{C}_{10} \mathrm{H}_{14} \mathrm{~N}_{3} \mathrm{O}_{4}\left([\mathrm{M}-\mathrm{H}]^{-}\right): 240.1$; gef.: 240.0 .

HRMS (MALDI): $\quad m / z$ ber. für $\mathrm{C}_{10} \mathrm{H}_{15} \mathrm{~N}_{3} \mathrm{NaO}_{4}\left([\mathrm{M}+\mathrm{Na}]^{+}\right)$: 264.09548; gef.: 264.09444 .

\subsubsection{Synthese von 1-Methylpyrrol-2-carbonsäure (Py-OH) 13}

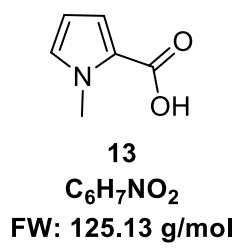

Verbindung 1 (3.20 g, $14.1 \mathrm{mmol}, 1.0 \mathrm{eq})$ wurde in $\mathrm{MeOH}(9.5 \mathrm{~mL})$ suspendiert, mit $2 \mathrm{M}$ $\mathrm{NaOH}(35 \mathrm{~mL}, 70 \mathrm{mmol}, 5.0 \mathrm{eq})$ versetzt und $23 \mathrm{~h}$ bei RT gerührt. Die Lösung wurde mit $1 \mathrm{M} \mathrm{HCl}$ angesäuert, und der Niederschlag abfiltriert. Der gelbe Feststoff wurde getrocknet. Das Filtrat wurde mit viermal mit EE $(40 \mathrm{~mL})$ extrahiert und über $\mathrm{Na}_{2} \mathrm{SO}_{4}$ getrocknet. Das Lösemittel wurde entfernt und weiteres Produkt als brauner Feststoff erhalten.

Ausbeute: $1.44 \mathrm{~g}, 11.5 \mathrm{mmol}, 79 \%$.

${ }^{1} \mathrm{H}-\mathrm{NMR}\left(500 \mathrm{MHz}, \mathrm{DMSO}-d_{6}\right) \delta=12.14(\mathrm{~s}, 1 \mathrm{H}, \mathrm{OH}), 7.03\left(\mathrm{t}, J=2.0 \mathrm{~Hz}, 1 \mathrm{H}, \mathrm{C}^{5}-\mathrm{H}\right), 6.78$ (dd, $J=3.9,1.8 \mathrm{~Hz}, 1 \mathrm{H}, \mathrm{C}^{3}-\mathrm{H}$ ), 6.05 (dd, $J=3.9,2.5 \mathrm{~Hz}, 1 \mathrm{H}, \mathrm{C}^{4}-\mathrm{H}$ ), $3.83\left(\mathrm{~s}, 3 \mathrm{H}, \mathrm{N}-\mathrm{CH}_{3}\right) \mathrm{ppm}$. ${ }^{13} \mathrm{C}-N M R\left(126 \mathrm{MHz}\right.$, DMSO- $\left.d_{6}\right) \delta=162.0(\mathrm{C}=\mathrm{O}), 129.8\left(\mathrm{C}^{5}\right), 122.5\left(\mathrm{C}^{2}\right), 117.3\left(\mathrm{C}^{3}\right), 107.3$ $\left(\mathrm{C}^{4}\right), 36.3\left(\mathrm{~N}-\mathrm{CH}_{3}\right) \mathrm{ppm}$.

\footnotetext{
${ }^{b}$ Das Säureproton konnte aufgrund eines zu schnellen Austauschs nicht detektiert werden.
} 


\subsubsection{Synthese von Boc-Py-Py-OH 14}

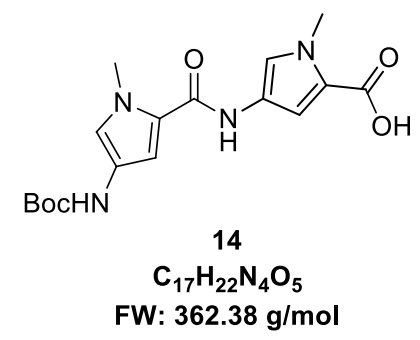

Verbindung 23 (500 mg, $1.33 \mathrm{mmol}, 1.0$ eq) wurde in $\mathrm{MeOH}(3 \mathrm{~mL})$ gelöst und mit $2 \mathrm{M}$ $\mathrm{NaOH}(10 \mathrm{~mL}, 20 \mathrm{mmol}, 15.0$ eq) versetzt. Nach $4 \mathrm{~h}$ bei RT wurde die Lösung mit $1 \mathrm{M} \mathrm{HCl}$ angesäuert und mit EE extrahiert. Die organische Phase wusch man mit Brine und trocknete über $\mathrm{MgSO}_{4}$. Das Lösemittel wurde unter vermindertem Druck entfernt und 14 als bräunlicher Feststoff erhalten.

Ausbeute: $389 \mathrm{mg}, 1.07 \mathrm{mmol}, 81 \%$.

${ }^{1} \mathrm{H}-\mathrm{NMR}\left(500 \mathrm{MHz}, \mathrm{DMSO}-\mathrm{d}_{6}\right) \delta=12.13$ (s br, 1H), 9.81 (s, 1H), 9.09 (s, 1H), 7.40 (d, $J=1.8 \mathrm{~Hz}, 1 \mathrm{H}), 6.88(\mathrm{~s}, 1 \mathrm{H}), 6.85-6.78(\mathrm{~m}, 2 \mathrm{H}), 3.81(\mathrm{~s}, 3 \mathrm{H}), 3.79(\mathrm{~s}, 3 \mathrm{H}), 1.45$ $(\mathrm{s}, 9 \mathrm{H}) \mathrm{ppm}$.

${ }^{13} \mathrm{C}-\mathrm{NMR}\left(126 \mathrm{MHz}\right.$, DMSO- $\left.d_{6}\right) \delta=162.0,158.4,152.9,122.7,122.7,122.4,120.3,119.5$, $117.1,108.4,103.8,78.3,36.1,36.1,28.2 \mathrm{ppm}$.

MS (ESI): $\quad \quad m / z$ ber. für $\mathrm{C}_{17} \mathrm{H}_{23} \mathrm{~N}_{4} \mathrm{O}_{5}\left([\mathrm{M}+\mathrm{H}]^{+}\right)$: 363.2; gef.: 363.2 .

HRMS (MALDI): $\quad m / z$ ber. für $\mathrm{C}_{17} \mathrm{H}_{22} \mathrm{~N}_{4} \mathrm{NaO}_{5}\left([\mathrm{M}+\mathrm{Na}]^{+}\right): 385.14824 ;$ gef.: 385.14664 .

\subsubsection{Synthese von Boc-Py-Py- $\gamma$-OH 15}

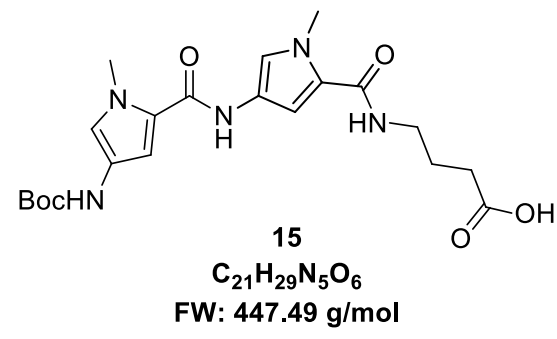

Zu einer Suspension von 24 (500 mg, $1.08 \mathrm{mmol}, 1.0 \mathrm{eq}$ ) in $\mathrm{MeOH} / \mathrm{H}_{2} \mathrm{O}(3: 1,20 \mathrm{~mL}$ ) wurde bei $0{ }^{\circ} \mathrm{C} \mathrm{LiOH} \bullet \mathrm{H}_{2} \mathrm{O}(230 \mathrm{mg}, 5.42 \mathrm{mmol}, 4.2 \mathrm{eq})$ gegeben und über Nacht gerührt, wobei die Mischung auf RT erwärmte. Die Lösung wurde mit $\mathrm{HCl}$ angesäuert und im Anschluss mit EE extrahiert. Die vereinigten organischen Phasen wurden mit Brine gewaschen und über $\mathrm{Na}_{2} \mathrm{SO}_{4}$ getrocknet. Das Lösemittel wurde unter vermindertem Druck entfernt und der Rückstand im Vakuum getrocknet. 
Ausbeute: $450 \mathrm{mg}, 1.01 \mathrm{mmol}, 94 \%$.

${ }^{1} \mathrm{H}-\mathrm{NMR}\left(500 \mathrm{MHz}, \mathrm{DMSO}-d_{6}\right) \delta=12.04(\mathrm{~s} b r, 1 \mathrm{H}), 9.80(\mathrm{~s}, 1 \mathrm{H}), 9.08$ (s, 1H), 8.01 (t, $J=5.7 \mathrm{~Hz}, 1 \mathrm{H}), 7.16(\mathrm{~d}, J=1.7 \mathrm{~Hz}, 1 \mathrm{H}), 6.89(\mathrm{~s}, 1 \mathrm{H}), 6.86(\mathrm{~d}, J=1.6 \mathrm{~Hz}, 1 \mathrm{H}), 6.82(\mathrm{~s}, 1 \mathrm{H})$, 3.80 (s, 3H), 3.79 (s, 3H), 3.18 (q, $J=6.7 \mathrm{~Hz}, 2 \mathrm{H}), 2.25$ (t, $J=7.4 \mathrm{~Hz}, 2 \mathrm{H}), 1.71$ (p, $J=7.2 \mathrm{~Hz}, 2 \mathrm{H}), 1.46(\mathrm{~s}, 9 \mathrm{H}) \mathrm{ppm}$.

${ }^{13}$ C-NMR $\left(126 \mathrm{MHz}\right.$, DMSO- $\left.d_{6}\right) \delta=174.3,161.4,158.4,152.9,122.9,122.9,122.3,122.1$, $117.8,117.0,104.2,103.8,78.3,37.9,36.1,35.9,31.2,28.2,24.8$ ppm.

MS (ESI): $\quad \quad m / z$ ber. für $\mathrm{C}_{21} \mathrm{H}_{28} \mathrm{~N}_{5} \mathrm{O}_{6}\left([\mathrm{M}-\mathrm{H}]^{-}\right)$: 446.2 ; gef.: 446.2 .

\subsubsection{Synthese von Boc-Py-Im-OH 16}

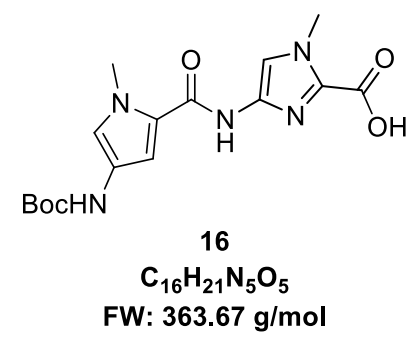

Verbindung 25 (310 mg, $820 \mu \mathrm{mol}, 1.0 \mathrm{eq})$ wurde in $5 \mathrm{~mL}$ THF gelöst und mit KOH (380 mg, $6.8 \mathrm{mmol}, 8.2 \mathrm{eq})$ in $\mathrm{H}_{2} \mathrm{O}(10 \mathrm{~mL})$ versetzt. Die Lösung rührte man $2 \mathrm{~h}$ bei RT und säuerte im Anschluss mit $\mathrm{HCl}$ an. Der entstandenen Niederschlag wurde abfiltriert und der farblose Feststoff im Vakuum getrocknet.

Ausbeute: $212 \mathrm{mg}, 583 \mathrm{mmol}, 71 \%$.

${ }^{1} \mathrm{H}-\mathrm{NMR}\left(250 \mathrm{MHz}, \mathrm{DMSO}-d_{6}\right) \delta=10.55$ (s, 1H), 9.05 (s br, 1H), 7.58 (s, 1H), 6.97 (s br, $1 \mathrm{H}), 6.91$ (d, $J=1.7 \mathrm{~Hz}, 1 \mathrm{H}), 3.91(\mathrm{~s}, 3 \mathrm{H}), 3.81$ (s, 3H), 1.45 (s, 9H) ppm. ${ }^{\mathrm{c}}$

\subsubsection{Synthese von Py-Im-OH 17}

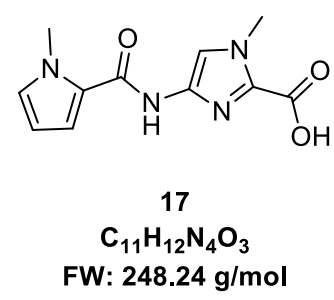

Verbindung 27 (246 mg, $936 \mu \mathrm{mol}, 1.0 \mathrm{eq})$ wurde in $\mathrm{MeOH}(10 \mathrm{~mL})$ suspendiert und mit $\mathrm{NaOH}$ (44 mg, $1.1 \mathrm{mmol} 1.2 \mathrm{eq})$ versetzt. Dazu gab man $\mathrm{H}_{2} \mathrm{O}(10 \mathrm{~mL})$ und erhitzte die

\footnotetext{
c Das Signal des Säureprotons konnte aufgrund zu schnellen eines Austauschs nicht detektiert werden.
} 
Mischung zum Sieden. Nach $3 \mathrm{~h}$ wurde die entstandene Lösung abgekühlt, zweimal mit DCM $(30 \mathrm{~mL})$ gewaschen und mit konz. $\mathrm{HCl}$ angesäuert, bis ein farbloser Niederschlag ausfiel. Dieser wurde abfiltriert und im Vakuum getrocknet.

Ausbeute: $199 \mathrm{mg}, 803 \mu \mathrm{mol}, 86 \%$.

${ }^{1} \mathrm{H}-\mathrm{NMR}\left(300 \mathrm{MHz}, \mathrm{DMSO}-d_{6}\right) \delta=10.55(\mathrm{~s}, 1 \mathrm{H}), 7.61(\mathrm{~s}, 1 \mathrm{H}), 7.16(\mathrm{dd}, J=4.0,1.6 \mathrm{~Hz}, 1 \mathrm{H})$, $6.99-6.95(\mathrm{~m}, 1 \mathrm{H}), 6.03(\mathrm{dd}, J=3.9,2.6 \mathrm{~Hz}, 1 \mathrm{H}), 3.92(\mathrm{~s}, 3 \mathrm{H}), 3.88(\mathrm{~s}, 3 \mathrm{H}) \mathrm{ppm} .^{\mathrm{d}}$

${ }^{13}$ C-NMR $\left(75 \mathrm{MHz}\right.$, DMSO- $\left.d_{6}\right) \delta=160.1,158.7,137.5,131.7,128.9,124.5,114.9,114.0$, $107.0,36.5,35.5 \mathrm{ppm}$.

MS (ESI): $\quad m / z$ ber. $\mathrm{C}_{11} \mathrm{H}_{13} \mathrm{~N}_{4} \mathrm{O}_{3}\left([\mathrm{M}+\mathrm{H}]^{+}\right): 249.1 ;$ gef.: 249.2

HRMS (MALDI): $\quad m / z$ ber. für $\mathrm{C}_{11} \mathrm{H}_{13} \mathrm{~N}_{4} \mathrm{O}_{3}\left([\mathrm{M}+\mathrm{H}]^{+}\right)$: 249.09822; gef.: 249.09863 .

\subsubsection{Synthese von Py-Py-OH 18}

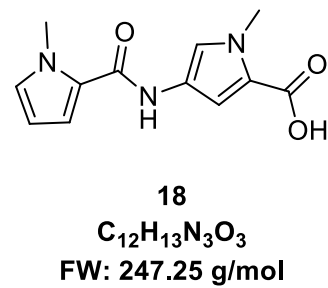

Verbindung 28 (630 mg, $2.4 \mathrm{mmol}, 1.0 \mathrm{eq}$ ) wurde in $\mathrm{MeOH}(8 \mathrm{~mL})$ suspendiert, mit einer $1 \mathrm{M} \mathrm{NaOH}$-Lösung ( $15 \mathrm{~mL}, 15 \mathrm{mmol}, 6.3 \mathrm{eq}$ ) versetzt und für $2 \mathrm{~h}$ zum Sieden erhitzt. Im Anschluss wurde für $18 \mathrm{~h}$ bei RT gerührt. Nach beendeter Reaktion wurde die Lösung mit EE extrahiert und anschließend mit $2 \mathrm{M} \mathrm{HCl}$ angesäuert. Die erhaltene Lösung wurde mit EE extrahiert, die organische Phase mit Brine gewaschen und über $\mathrm{MgSO}_{4}$ getrocknet. Das Lösemittel wurde unter vermindertem Druck entfernt und das Produkt als gelber Feststoff erhalten.

Ausbeute: $580 \mathrm{mg}, 2.34 \mathrm{mmol}, 91 \%$.

${ }^{1} \mathrm{H}-\mathrm{NMR}\left(500 \mathrm{MHz}, \mathrm{DMSO}-d_{6}\right) \delta=12.15(\mathrm{~s} b r, 1 \mathrm{H}), 9.78(\mathrm{~s}, 1 \mathrm{H}), 7.41(\mathrm{~d}, J=1.8 \mathrm{~Hz}, 1 \mathrm{H})$, $6.94(\mathrm{~d}, J=2.0 \mathrm{~Hz}, 1 \mathrm{H}), 6.89$ (dd, $J=3.9,1.6 \mathrm{~Hz}, 1 \mathrm{H}), 6.82(\mathrm{~d}, J=1.9 \mathrm{~Hz}, 1 \mathrm{H}), 6.05$ (dd, $J=3.7,2.6 \mathrm{~Hz}, 1 \mathrm{H}), 3.86(\mathrm{~s}, 3 \mathrm{H}), 3.82(\mathrm{~s}, 3 \mathrm{H}) \mathrm{ppm}$.

${ }^{13} \mathrm{C}-\mathrm{NMR}\left(126 \mathrm{MHz}\right.$, DMSO- $\left.d_{6}\right) \delta=162.0,158.6,128.2,125.3,122.6,120.3,119.5,112.6$, 108.3, 106.7, 36.2, $36.2 \mathrm{ppm}$.

MS (ESI): $\quad m / z$ ber. für $\mathrm{C}_{12} \mathrm{H}_{14} \mathrm{~N}_{3} \mathrm{O}_{3}\left([\mathrm{M}+\mathrm{H}]^{+}\right):$248.1; gef.: 248.2 .

\footnotetext{
${ }^{d}$ Das Signal des Säureprotons konnte aufgrund zu schnellen eines Austauschs nicht detektiert werden.
} 


\subsubsection{Synthese von $\mathrm{O}_{2} \mathrm{~N}-\mathrm{Py}-\gamma-\mathrm{OMe} 19$}

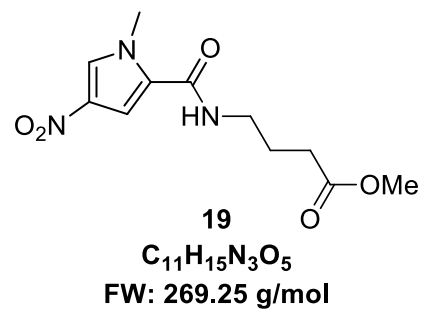

Verbindung 2 (1.50 g, $5.56 \mathrm{mmol}, 1.0 \mathrm{eq})$ und $\gamma$-Aminobuttersäuremethylester-Hydrochlorid (940 mg, $6.13 \mathrm{mmol}, 1.1 \mathrm{eq})$ wurden in abs. DCM (10 mL) suspendiert und mit DIPEA (1.9 mL, $8.3 \mathrm{mmol}, 1.5 \mathrm{eq}$ ) versetzt. Die Lösung wurde $27 \mathrm{~h}$ bei RT gerührt, im Anschluss auf Kieselgel absorbiert und säulenchromatographisch (CH/EE 1:1) gereinigt. Das Produkt wurde als farbloser Feststoff erhalten.

Ausbeute: $1.42 \mathrm{~g}, 5.39 \mathrm{mmol}, 95 \%$.

${ }^{1} \mathrm{H}-\mathrm{NMR}\left(500 \mathrm{MHz}, \mathrm{CDCl}_{3}\right) \delta=8.40(\mathrm{t}, J=5.5 \mathrm{~Hz}, 1 \mathrm{H}), 8.12(\mathrm{~d}, J=1.9 \mathrm{~Hz}, 1 \mathrm{H}), 7.42(\mathrm{~d}$, $J=2.0 \mathrm{~Hz}, 1 \mathrm{H}), 3.89(\mathrm{~s}, 3 \mathrm{H}), 3.58(\mathrm{~s}, 3 \mathrm{H}), 3.20$ (q, $J=6.8 \mathrm{~Hz}, 2 \mathrm{H}), 2.36$ (t, $J=7.4 \mathrm{~Hz}, 2 \mathrm{H}$ ), $1.74(\mathrm{p}, J=7.1 \mathrm{~Hz}, 2 \mathrm{H}) \mathrm{ppm}$.

${ }^{13}$ C-NMR $\left(126 \mathrm{MHz}, \mathrm{CDCl}_{3}\right) \delta=173.1,159.9,133.8,127.9,126.4,107.3,51.3,37.9,37.4$, 30.7, 24.4 ppm.

DC: $R_{f}: 0.30(\mathrm{CH} / \mathrm{EE} \mathrm{1:1)}$

HRMS (MALDI): $\quad m / z$ ber. für $\mathrm{C}_{11} \mathrm{H}_{16} \mathrm{~N}_{3} \mathrm{O}_{5}\left([\mathrm{M}+\mathrm{H}]^{+}\right): 270.10845 ;$ gef.: 270.10854 .

\subsubsection{Synthese von $\mathrm{O}_{2} \mathrm{~N}-\mathrm{Py}-\mathrm{Py}-\mathrm{OMe} 20$}

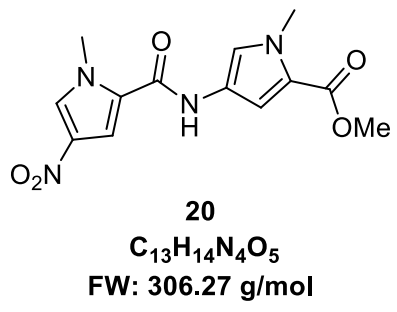

Verbindung 3 (4.38 g, $23.8 \mathrm{mmol}, 1.0 \mathrm{eq})$ wurde in abs. EE (100 mL) gelöst, mit $\mathrm{Pd} / \mathrm{C}$ (400 mg, $10 \%$ auf Aktivkohle) versetzt und $19.5 \mathrm{~h}$ bei $\mathrm{RT}$ in einer $\mathrm{H}_{2}$-Atmosphäre gerührt. Nach Filtration der Suspension über Celite entfernte man das Lösemittel unter vermindertem Druck. Der Rückstand wurde kurz getrocknet und anschließend in abs. DCM $(40 \mathrm{~mL})$ aufgenommen. Nach der Zugabe von Verbindung 2 (7.08 g, $26.1 \mathrm{mmol}, 1.1 \mathrm{eq})$ in abs. DCM (15 mL) und DIPEA $(6.0 \mathrm{~mL}, 35 \mathrm{mmol}, 1.5 \mathrm{eq})$ rührte man $4.5 \mathrm{~h}$ bei RT. 20 fiel als gelber Feststoff aus und wurde abfiltriert und getrocknet. 
Ausbeute: $6.26 \mathrm{~g}, 20.4 \mathrm{mmol}, 86 \%$.

${ }^{1} \mathrm{H}-N M R\left(500 \mathrm{MHz}, \mathrm{DMSO}-\mathrm{d}_{6}\right) \delta=10.26(\mathrm{~s}, 1 \mathrm{H}), 8.19(\mathrm{~d}, J=1.8 \mathrm{~Hz}, 1 \mathrm{H}), 7.55(\mathrm{~d}$, $J=2.0 \mathrm{~Hz}, 1 \mathrm{H}), 7.45(\mathrm{~d}, J=1.9 \mathrm{~Hz}, 1 \mathrm{H}), 6.89$ (d, $J=2.0 \mathrm{~Hz}, 1 \mathrm{H}), 3.95$ (s, 3H), $3.84(\mathrm{~s}, 3 \mathrm{H})$, $3.74(\mathrm{~s}, 3 \mathrm{H}) \mathrm{ppm}$.

${ }^{13}$ C-NMR $\left(126 \mathrm{MHz}\right.$, DMSO- $\left.d_{6}\right) \delta=160.8,156.9,133.8,128.3,126.1,122.2,120.9,118.9$, 108.3, 107.7, 51.1, 37.5, 36.3 ppm.

Schmelzpunkt: $250^{\circ} \mathrm{C}$ (Zersetzung) Literatur: $262^{\circ} \mathrm{C} \cdot .^{[245]}$

IR (Wellenzahl cm-1): 3373 (m), 3138 (w), 3029 (w), 2960 (w), 1693 (s), 1662 (s), 1568 (s), $1536(\mathrm{~m}), 1503(\mathrm{~m}), 1479$ (s), 1444 (s), 1420 (m), 1393 (s), 1365 (m), 1314 (s), 1247 (s), 1213 (s), $1187(\mathrm{~m}), 1151$ (w), 1119 (s), 1101 (s), 1060 (m), 1008 (w), 969 (w), .888 (w), 844 (m), $814(\mathrm{~m}), 780(\mathrm{~m}), 747(\mathrm{~m}), 713(\mathrm{w}), 653(\mathrm{w}), 630(\mathrm{~m}), 604(\mathrm{~m}), 587(\mathrm{~m}), 573(\mathrm{~m}), 457$ (w), $423(\mathrm{~m})$.

MS (ESI): $\quad m / z$ ber. für $\mathrm{C}_{13} \mathrm{H}_{15} \mathrm{~N}_{3} \mathrm{O}_{5}\left([\mathrm{M}+\mathrm{H}]^{+}\right): 307.1$; gef.: 307.1.

HRMS (MALDI): $\quad m / z$ ber. für $\mathrm{C}_{13} \mathrm{H}_{14} \mathrm{~N}_{3} \mathrm{O}_{5}\left(\left[\mathrm{M}^{-} \mathrm{e}^{-}\right]^{+}\right)$: 306.09587; gef.: 306.09606 .

\subsubsection{Synthese von $\mathrm{O}_{2} \mathrm{~N}-\mathrm{Py}-\mathrm{Py}-\gamma$-OMe 21}

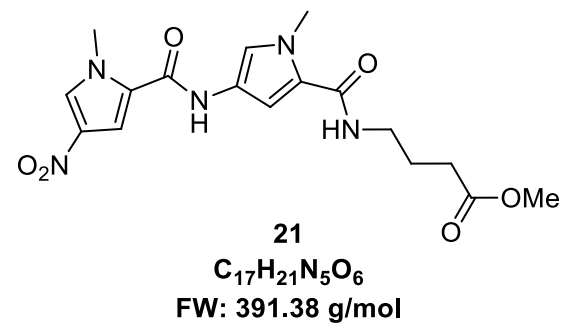

Verbindung 19 (400 mg, $1.49 \mathrm{mmol}, 1.0 \mathrm{eq}$ ) wurde mit Pd/C (50 mg, $10 \%$ auf Aktivkohle) in abs. EE $(10 \mathrm{~mL})$ suspendiert und in einer $\mathrm{H}_{2}$-Atmosphäre bei $\mathrm{RT} 18 \mathrm{~h}$ gerührt. Im Anschluss wurde über Celite filtriert und das Lösemittel entfernt. Der Rückstand wurde in abs. DCM (10 mL) aufgenommen, mit 2 (480 mg, $1.78 \mathrm{mmol}, 1.2 \mathrm{eq})$ sowie DIPEA (0.5 mL, $3 \mathrm{mmol}, 2.0 \mathrm{eq}$ ) versetzt und zwei Tage bei RT gerührt. Der entstandene gelbe Feststoff wurde abfiltriert und im Vakuum getrocknet.

Ausbeute: $470 \mathrm{mg}, 1.20 \mathrm{mmol}, 81 \%$.

${ }^{1} \mathrm{H}-\mathrm{NMR}\left(300 \mathrm{MHz}, \mathrm{DMSO}-d_{6}\right) \delta=10.23(\mathrm{~s}, 1 \mathrm{H}), 8.16(\mathrm{~d}, J=1.4 \mathrm{~Hz}, 1 \mathrm{H}), 8.08(\mathrm{t}, J=5.6 \mathrm{~Hz}$, 1H), $7.57(\mathrm{~d}, J=1.7 \mathrm{~Hz}, 1 \mathrm{H}), 7.20(\mathrm{~d}, J=1.3 \mathrm{~Hz}, 1 \mathrm{H}), 6.85(\mathrm{~d}, J=1.4 \mathrm{~Hz}, 1 \mathrm{H}), 3.95(\mathrm{~s}, 3 \mathrm{H})$, $3.80(\mathrm{~s}, 3 \mathrm{H}), 3.58(\mathrm{~s}, 3 \mathrm{H}), 3.18(\mathrm{q}, J=6.4 \mathrm{~Hz}, 2 \mathrm{H}$ ), 2.34 (t, $J=7.4 \mathrm{~Hz}, 2 \mathrm{H}$ ), $1.81-1.67$ (m, 2H) ppm. 
${ }^{13}$ C-NMR $\left(75 \mathrm{MHz}\right.$, DMSO- $\left.d_{6}\right) \delta=173.3,161.3,156.9,133.9,128.3,126.4,123.3,121.4$, $118.1,107.6,104.1,51.3,37.8,37.6,36.1,30.9,24.7$ ppm.

MS (ESI): $\quad \quad m / z$ ber. für $\left.\mathrm{C}_{17} \mathrm{H}_{20} \mathrm{~N}_{5} \mathrm{O}_{6}([\mathrm{M}-\mathrm{H}]]^{-}\right): 390.1$; gef.:390.1

HRMS (MALDI): $\quad m / z$ ber. für $\mathrm{C}_{17} \mathrm{H}_{22} \mathrm{~N}_{5} \mathrm{O}_{6}\left([\mathrm{M}+\mathrm{H}]^{+}\right)$: 392.15646; gef.: 392.15498 .

\subsubsection{Synthese von $\mathrm{O}_{2} \mathrm{~N}-\mathrm{Py}$-Im-OMe 22}

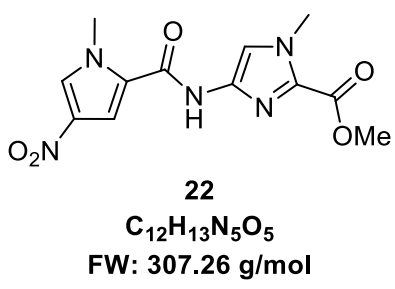

Verbindung 26 (590 mg, $3.47 \mathrm{~mol}, 1.1 \mathrm{eq})$ wurde in abs. DMF $(5 \mathrm{~mL})$ gelöst und mit HOBt (530 mg, $3.47 \mathrm{mmol}, 1.1 \mathrm{eq}, 12 \% \mathrm{H}_{2} \mathrm{O}$ ) und DIC (1.1 mL, $6.9 \mathrm{mmol}, 2.2 \mathrm{eq}$ ) versetzt und bei RT 29 h gerührt.

Verbindung 8 (580 mg, 3.20 mmol, 1 eq) wurde in abs. EE (10 mL) gelöst, mit Pd/C (70 mg, $10 \%$ auf Aktivkohle) versetzt und $23 \mathrm{~h}$ bei $\mathrm{RT}$ in einer $\mathrm{H}_{2}$-Atmosphäre gerührt. Im Anschluss wurde über Celite filtriert und das Lösemittel entfernt. Nach kurzem Trocknen wurde abs. DMF (4 mL), die oben beschriebene Lösung sowie DIPEA (1.1 mL, $6.3 \mathrm{mmol}$, 2 eq) zugegeben und $3 \mathrm{~h}$ auf $60^{\circ} \mathrm{C}$ erwärmt. Danach wurde $16 \mathrm{~h}$ bei RT und erneut $3 \mathrm{~h}$ bei $60^{\circ} \mathrm{C}$ gerührt. Im Anschluss wurde die Lösung auf Eiswasser $(50 \mathrm{~mL})$ gegeben und der Niederschlag abfiltriert. Das Rohprodukt wurde in einer Mischung aus $\mathrm{MeOH}, \mathrm{EE}$ und DCM gelöst, mit $1 \mathrm{M} \mathrm{HCl}$ versetzt und mit DCM extrahiert. Das Lösemittel wurde unter vermindertem Druck entfernt und das Rohprodukt säulenchromatographisch ( $\mathrm{CH} / \mathrm{EE} \mathrm{1:2)}$ gereinigt. Das Produkt konnte als farbloser Feststoff erhalten werden.

Ausbeute: $740 \mathrm{mg}, 2.41 \mathrm{mmol}, 77 \%$.

${ }^{1} \mathrm{H}-\mathrm{NMR}\left(250 \mathrm{MHz}, \mathrm{DMSO}-\mathrm{d}_{6}\right) \delta=11.13(\mathrm{~s}, 1 \mathrm{H}), 8.19(\mathrm{~d}, J=1.8 \mathrm{~Hz}, 1 \mathrm{H}), 7.80(\mathrm{~d}$, $J=2.0 \mathrm{~Hz}, 1 \mathrm{H}), 7.68(\mathrm{~s}, 1 \mathrm{H}), 3.96(\mathrm{~s}, 3 \mathrm{H}), 3.94(\mathrm{~s}, 3 \mathrm{H}), 3.82(\mathrm{~s}, 3 \mathrm{H}) \mathrm{ppm}$.

DC: $R_{f}: 0.45(C H / E E ~ 1: 3)$ 


\subsubsection{Synthese von Boc-Py-Py-OMe 23}

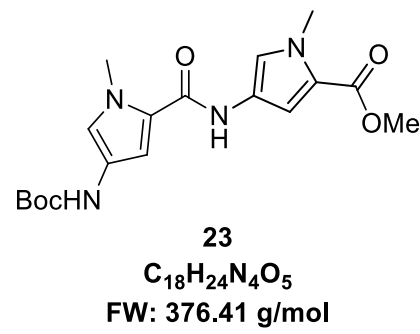

Verbindung 20 (1.74 g, $5.68 \mathrm{mmol}, 1.0 \mathrm{eq}), \mathrm{Boc}_{2} \mathrm{O}(2.48 \mathrm{~g}, 11.4 \mathrm{mmol}, 2.0 \mathrm{eq})$ und $\mathrm{Pd} / \mathrm{C}$ (180 mg, $10 \%$ auf Aktivkohle) wurden in abs. $\mathrm{MeOH}(10 \mathrm{~mL})$ suspendiert. Es wurde $18 \mathrm{~h}$ bei $45^{\circ} \mathrm{C}$ und 40 bar $\mathrm{H}_{2}$-Druck gerührt. Man filtrierte die Suspension über Celite und entfernte das Lösemittel unter vermindertem Druck. Der Rückstand wurde ohne weitere Aufarbeitung weiter umgesetzt.

Ausbeute: $1,75 \mathrm{~g}, 4.65 \mathrm{mmol}, 82 \%$.

${ }^{1} \mathrm{H}-N M R\left(500 \mathrm{MHz}, \mathrm{CDCl}_{3}\right) \delta=9.85(\mathrm{~s}, 1 \mathrm{H}), 9.10(\mathrm{~s}, 1 \mathrm{H}), 7.44(\mathrm{~d}, J=1.8 \mathrm{~Hz}, 1 \mathrm{H})$, $6.92-6.86(\mathrm{~m}, 2 \mathrm{H}), 6.83(\mathrm{~s}, 1 \mathrm{H}), 3.83(\mathrm{~s}, 3 \mathrm{H}), 3.80(\mathrm{~s}, 3 \mathrm{H}), 3.73(\mathrm{~s}, 3 \mathrm{H}), 1.45(\mathrm{~s}, 9 \mathrm{H}) \mathrm{ppm}$.

${ }^{13} \mathrm{C}-\mathrm{NMR}\left(126 \mathrm{MHz}, \mathrm{CDCl}_{3}\right) \delta=160.8,158.4,152.9,123.0,122.6,122.4,120.7,118.5$, $117.2,108.4,103.8,78.3,51.0,36.2,36.0,28.2$ ppm.

MS (ESI): $\quad \quad m / z$ ber. für $\mathrm{C}_{18} \mathrm{H}_{23} \mathrm{~N}_{4} \mathrm{O}_{5}\left([\mathrm{M}-\mathrm{H}]^{-}\right)$: 375.2; gef.: 375.2.

\subsubsection{Synthese von Boc-Py-Py- $\gamma$-OMe 24}

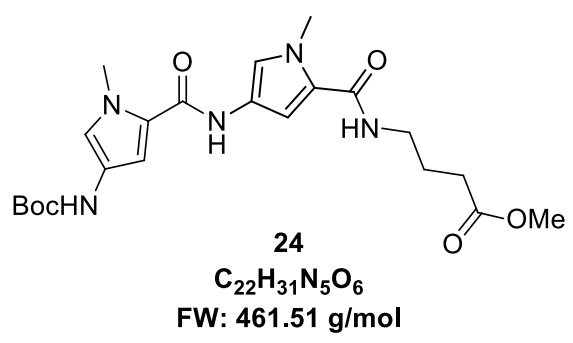

Verbindung 21 (2.00 g, $5.11 \mathrm{mmol}, 1.0 \mathrm{eq}), \mathrm{Boc}_{2} \mathrm{O}$ (2.23 g, $10.2 \mathrm{mmol}, 2.0 \mathrm{eq}$ ) and $\mathrm{Pd} / \mathrm{C}$ (200 mg, $10 \%$ auf Aktivkohle) wurden in abs. $\mathrm{MeOH}\left(40 \mathrm{~mL}\right.$ ) suspendiert und in bei $45^{\circ} \mathrm{C}$ und 45 bar $\mathrm{H}_{2}$-Druck $19 \mathrm{~h}$ gerührt. Die Suspension wurde über Celite filtriert und das Lösemittel unter vermindertem Druck entfernt. 24 konnte als farbloser Schaum erhalten werden.

Ausbeute: Quantitativ.

${ }^{1} \mathrm{H}-\mathrm{NMR}\left(500 \mathrm{MHz}, \mathrm{CDCl}_{3}\right) \delta=9.81(\mathrm{~s}, 1 \mathrm{H}), 9.09(\mathrm{~s}, 1 \mathrm{H}), 8.02(\mathrm{t}, J=5.7 \mathrm{~Hz}, 1 \mathrm{H}), 7.15(\mathrm{~d}$, $J=1.7 \mathrm{~Hz}, 1 \mathrm{H}$ ), 6.88 (s br, 1H), 6.85 (d, $J=1.7 \mathrm{~Hz}, 1 \mathrm{H}), 6.81$ (s $b r, 1 \mathrm{H}), 3.80(\mathrm{~s}, 3 \mathrm{H}), 3.78$ 
(s, 3H), $3.58(\mathrm{~s}, 3 \mathrm{H}), 3.18(\mathrm{q}, J=6.7 \mathrm{~Hz}, 2 \mathrm{H}), 2.34$ (t, $J=7.2 \mathrm{~Hz}, 2 \mathrm{H}), 1.77-1.70$ (p, $J=7.2 \mathrm{~Hz}, 2 \mathrm{H}), 1.45$ (s, 9H) ppm.

${ }^{13} \mathrm{C}-\mathrm{NMR}\left(126 \mathrm{MHz}, \mathrm{CDCl}_{3}\right) \delta=173.2,161.4,158.4,152.9,122.9,122.8,122.3,122.1$, $117.8,117.0,104.2,103.8,78.3,51.3,37.7,36.1,35.9,30.8,28.2,24.7$ ppm.

MS (ESI): $\quad \quad m / z$ ber. für $\mathrm{C}_{22} \mathrm{H}_{30} \mathrm{~N}_{5} \mathrm{O}_{6}\left([\mathrm{M}-\mathrm{H}]^{-}\right):$460.2; gef.: 460.3 .

HRMS (MALDI): $\quad m / z$ ber. für $\mathrm{C}_{22} \mathrm{H}_{32} \mathrm{~N}_{5} \mathrm{O}_{6}\left([\mathrm{M}+\mathrm{H}]^{+}\right): 462.23471$; gef.: 462.23335 .

\subsubsection{Synthese von Boc-Py-Im-OMe 25}

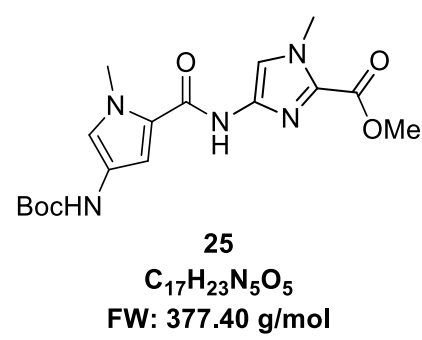

Verbindung 22 (520 mg, $1.69 \mathrm{mmol}, 1.0 \mathrm{eq}$ ) wurde mit Pd/C (50 mg, $10 \%$ auf Aktivkohle) und $\mathrm{Boc}_{2} \mathrm{O}$ (740 mg, $\left.3.40 \mathrm{mmol}, 2.0 \mathrm{eq}\right)$ in abs. $\mathrm{MeOH}(15 \mathrm{~mL})$ suspendiert und bei 40 bar $\mathrm{H}_{2}$-Druck über Nacht bei $50^{\circ} \mathrm{C}$ gerührt. Im Anschluss wurde über Celite filtriert und das Lösemittel unter vermindertem Druck entfernt. Das Produkt wurde als farbloser Schaum erhalten.

Ausbeute: Quantitativ.

${ }^{1} \mathrm{H}-\mathrm{NMR}\left(300 \mathrm{MHz}, \mathrm{DMSO}-d_{6}\right) \delta=10.62(\mathrm{~s}, 1 \mathrm{H}), 9.06$ (s br, 1H), 7.65 (s, 1H), 6.98 (s br, $1 \mathrm{H}), 6.92(\mathrm{~d}, J=1.5 \mathrm{~Hz}, 1 \mathrm{H}), 3.93(\mathrm{~s}, 3 \mathrm{H}), 3.81(\mathrm{~s}, 3 \mathrm{H}), 3.81(\mathrm{~s}, 3 \mathrm{H}), 1.45$ (s, 9H) ppm.

${ }^{13}$ C-NMR $\left(75 \mathrm{MHz}\right.$, DMSO- $\left.d_{6}\right) \delta=158.9,158.7,152.9,137.9,130.7,122.4,121.8,118.2$, $115.4,105.1,78.3,51.71,36.2,35.4,28.2$ ppm.

MS (ESI): $\quad \quad m / z$ ber. für $\left.\mathrm{C}_{17} \mathrm{H}_{22} \mathrm{~N}_{5} \mathrm{O}_{5}([\mathrm{M}-\mathrm{H}]]^{-}\right)$: 376.2; gef.: 376.2. 
10.5.24 Synthese von 1-Methyl-4-nitropyrrol-2-carbonsäure $\left(\mathrm{O}_{2} \mathrm{~N}-\mathrm{Py}-\mathrm{OH}\right) 26$

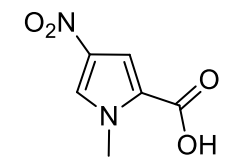

26

$\mathrm{C}_{6} \mathrm{H}_{6} \mathrm{~N}_{2} \mathrm{O}_{4}$

FW: $170.12 \mathrm{~g} / \mathrm{mol}$

Verbindung 2 (2.52 g, 9.3 mmol, 1.0 eq) wurde in wässriger $\mathrm{KOH}$ (23 mL, $46 \mathrm{mmol}, 5.0$ eq) gelöst und $2 \mathrm{~h}$ bei RT gerührt. Im Anschluss wurde mit $1 \mathrm{M} \mathrm{HCl}$ angesäuert. Den entstandenen Feststoff filtrierte man ab, wusch ihn mit EE und trocknete inn im Vakuum. Das Produkt wurde als farbloser Feststoff erhalten.

Ausbeute: $740 \mathrm{mg}, 2.41 \mathrm{mmol}, 77 \%$.

${ }^{1} \mathrm{H}-\mathrm{NMR}\left(500 \mathrm{MHz}, \mathrm{DMSO}-\mathrm{d}_{6}\right) \delta=8.05(\mathrm{~d}, J=2.0 \mathrm{~Hz}, 1 \mathrm{H}), 7.07(\mathrm{~d}, J=2.1 \mathrm{~Hz}, 1 \mathrm{H}), 3.92$ $(\mathrm{s}, 3 \mathrm{H}) \mathrm{ppm} .^{\mathrm{e}}$

${ }^{13}$ C-NMR $\left(126 \mathrm{MHz}\right.$, DMSO- $\left.d_{6}\right) \delta=161.9,133.7,127.5,109.4,39.5,37.3$ ppm.

MS (ESI): $\quad \quad m / z$ ber. für $\mathrm{C}_{6} \mathrm{H}_{5} \mathrm{~N}_{2} \mathrm{O}_{4}([\mathrm{M}-\mathrm{H}])$ ): 169.0; gef.: 168.9.

\subsubsection{Synthese von Py-Im-OMe 27}

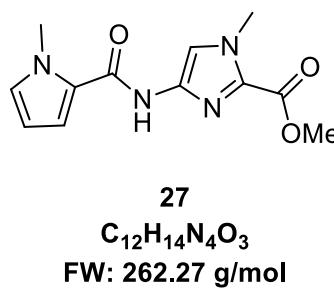

Verbindung 8 (1.00 g, $5.40 \mathrm{mmol}, 1.0 \mathrm{eq})$ wurde in abs. EE $(20 \mathrm{~mL})$ suspendiert, mit Pd/C (100 mg, $10 \%$ auf Aktivkohle) versetzt und $2 \mathrm{~h}$ in einer $\mathrm{H}_{2}$-Atmosphäre bei RT gerührt. Im Anschluss wurde über Celite filtriert, das Lösemittel unter vermindertem Druck entfernt und der Rückstand im Vakuum getrocknet.

Verbindung 13 (810 mg, $6.48 \mathrm{~mol}, 1.2 \mathrm{eq})$ wurde in abs. DMF (10 mL) gelöst, mit HOBt (1.00 mg, $6.48 \mathrm{mmol}, 1.2 \mathrm{eq}, 12 \% \mathrm{H}_{2} \mathrm{O}$ ) sowie DIC (1.36 mL, $10.8 \mathrm{mmol}, 2.0$ eq) versetzt und $3 \mathrm{~h}$ bei RT gerührt. Die Lösung wurde filtriert und das Filtrat zu dem Amin gegeben. Man gab DIPEA (1.84 mL, $10.8 \mathrm{mmol}, 2.0 \mathrm{eq})$ hinzu und erwärmte $3 \mathrm{~h}$ auf $60^{\circ} \mathrm{C}$. Im Anschluss wurde $16 \mathrm{~h}$ bei RT und weitere $5 \mathrm{~h}$ bei $60^{\circ} \mathrm{C}$ gerührt. Nachdem die Lösung auf RT abgekühlt war, wurde sie mit $20 \%$ iger $\mathrm{Na}_{2} \mathrm{HCO}_{3}$-Lösung versetzt und mit DCM

e Das Signal des Säureprotons konnte aufgrund eines Austauschs mit dem im Lösemittel enthaltenen Wasser nicht detektiert werden. 
extrahiert. Die vereinigten organischen Phasen wurden über $\mathrm{MgSO}_{4}$ getrocknet und das Lösemittel unter vermindertem Druck entfernt. Der Rückstand wurde säulenchromatographisch (CH/EE 1:4) aufgearbeitet und 27 als farbloser Feststoff erhalten.

Ausbeute: $1.12 \mathrm{~g}, 4.27 \mathrm{mmol}, 79 \%$.

${ }^{1} \mathrm{H}-N M R\left(500 \mathrm{MHz}, \mathrm{DMSO}-d_{6}\right) \delta=10.58(\mathrm{~s}, 1 \mathrm{H}), 7.67(\mathrm{~s}, 1 \mathrm{H}), 7.17(\mathrm{dd}, J=4.0,1.7 \mathrm{~Hz}, 1 \mathrm{H})$, $6.97(\mathrm{t}, J=2.0 \mathrm{~Hz}, 1 \mathrm{H}), 6.04(\mathrm{dd}, J=4.0,2.5 \mathrm{~Hz}, 1 \mathrm{H}), 3.93(\mathrm{~s}, 3 \mathrm{H}), 3.88(\mathrm{~s}, 3 \mathrm{H}), 3.81$ (s, 3H) ppm.

${ }^{13}$ C-NMR $\left(126 \mathrm{MHz}\right.$, DMSO- $\left.d_{6}\right) \delta=159.0,158.7,137.9,130.7,128.9,124.4,115.3,114.0$, 107.0, 51.7, 36.5, 35.4 ppm.

DC: $R_{f}: 0.55(C H / E E ~ 1: 4)$

MS (ESI): $\quad \quad m / z$ ber. für $\mathrm{C}_{12} \mathrm{H}_{15} \mathrm{~N}_{4} \mathrm{O}_{3}\left([\mathrm{M}+\mathrm{H}]^{+}\right): 263.1$; gef.: 263.1

HRMS (MALDI): $\quad m / z$ ber. für $\mathrm{C}_{12} \mathrm{H}_{15} \mathrm{~N}_{4} \mathrm{O}_{3}\left([\mathrm{M}+\mathrm{H}]^{+}\right): 263.11387$; gef.: 263.11403 .

\subsubsection{Synthese von Py-Py-OMe 28}

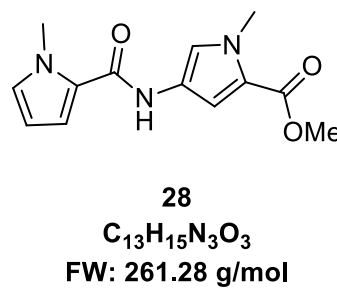

Verbindung 3 (500 mg, $2.70 \mathrm{mmol}, 1.0 \mathrm{eq})$ wurde in abs. EE (10 mL) suspendiert und nach Zugabe von Pd/C (50 mg, 10 \% auf Aktivkohle) über Nacht bei RT in einer $\mathrm{H}_{2}$-Athmosphäre gerührt. Die Suspension wurde über Celite filtriert, das Lösemittel unter vermindertem Druck entfernt und der Rückstand im Vakuum getrocknet.

Verbindung 13 (400 mg, $3.00 \mathrm{mmol}, 1.1 \mathrm{eq}$ ) wurde mit HOBt (460 mg, $3.00 \mathrm{mmol}, 1.1 \mathrm{eq}$, $88 \%)$ in abs. DMF (5 mL) gelöst und mit DIC (930 $\mu \mathrm{L}, 6.00 \mathrm{mmol}, 2.2 \mathrm{eq})$ versetzt. Im Anschluss wurde die Lösung über Nacht bei RT gerührt und dann zu dem frisch hergestellten Amin gegeben. Nach der Zugabe von DIPEA (460 $\mu \mathrm{L}, 5.4 \mathrm{mmol}, 2$ eq) erhitzte man die Lösung für $5 \mathrm{~h}$ auf $60^{\circ} \mathrm{C}$ und rührte im Anschluss über Nacht bei RT. Das Reaktionsgemisch wurde mit $\mathrm{H}_{2} \mathrm{O}(20 \mathrm{~mL})$ versetzt und mit EE extrahiert. Die vereinigten organischen Phasen wurden mit konz. $\mathrm{NaHCO}_{3}-\mathrm{Lösung}, \mathrm{H}_{2} \mathrm{O}$ und Brine gewaschen und über $\mathrm{MgSO}_{4}$ getrocknet. Das Lösemittel wurde unter vermindertem Druck entfernt und der Rückstand säulenchromatisch (CH/EE 3:1 zu 1:1) gereinigt. 
Ausbeute: $630 \mathrm{mg}, 2.40 \mathrm{mmol}, 89 \%$.

${ }^{1} \mathrm{H}-\mathrm{NMR}\left(250 \mathrm{MHz}, \mathrm{DMSO}-d_{6}\right) \delta=9.81(\mathrm{~s}, 1 \mathrm{H}), 7.45(\mathrm{~d}, J=1.9 \mathrm{~Hz}, 1 \mathrm{H}), 6.97-6.93(\mathrm{~m}$, $1 \mathrm{H}), 6.90-6.86(\mathrm{~m}, 2 \mathrm{H}), 6.06(\mathrm{dd}, J=3.9,2.5 \mathrm{~Hz}, 1 \mathrm{H}), 3.87(\mathrm{~s}, 3 \mathrm{H}), 3.84(\mathrm{~s}, 3 \mathrm{H}), 3.73$ $(\mathrm{s}, 3 \mathrm{H}) \mathrm{ppm}$.

DC: $R_{f}: 0.58(C H / E E ~ 3: 1)$

\subsubsection{Synthese von Boc- $\gamma$-Py-Im-OMe 29}

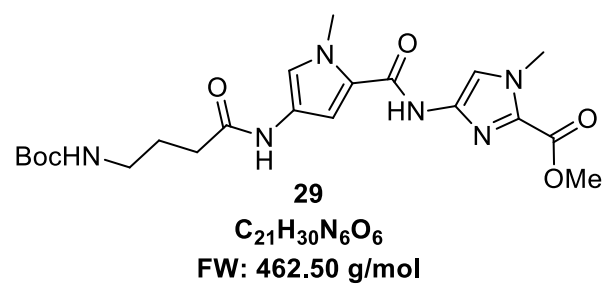

Zunächst wurde Boc-GABA (538 mg, $2.65 \mathrm{mmol}, 1.1 \mathrm{eq}$ ) in abs. (DMF) $10 \mathrm{~mL}$ gelöst, mit HOBt (407 mg, $2.65 \mathrm{mmol}, 1.1 \mathrm{eq}, 12 \% \mathrm{H}_{2} \mathrm{O}$ ) sowie DIC (820 $\left.\mu \mathrm{L}, 5.30 \mathrm{mmol}, 2.2 \mathrm{eq}\right)$ versetzt und bei RT 26 h gerührt.

Verbindung 22 (740 mg, $2.40 \mathrm{mmol}, 1.0 \mathrm{eq})$ wurde in abs. EE (10 mL) suspendiert, mit Pd/C (70 mg, $10 \%$ auf Aktivkohle) versetzt und $17 \mathrm{~h}$ bei $40{ }^{\circ} \mathrm{C}$ und 40 bar $\mathrm{H}_{2}$-Druck gerührt. Im Anschluss wurde über Celite filtriert und das Lösemittel entfernt. Nach kurzem Trocknen wurde die oben beschriebene Lösung sowie DIPEA (820 mL, $4.80 \mathrm{mmol}, 2.0 \mathrm{eq}$ ) zugegeben und $48 \mathrm{~h}$ bei RT gerührt. Die entstandene Suspension wurde filtriert und mit $\mathrm{EE}$ nachgewaschen. Dann versetzte man das Filtrat mit einer 4:1 Mischung aus $\mathrm{H}_{2} \mathrm{O}$ und konz. $\mathrm{NaHCO}_{3}(100 \mathrm{~mL})$, trennte die Phasen und extrahierte die wässrige Phase dreimal mit EE $(40 \mathrm{~mL})$ sowie dreimal mit DCM (40 mL). Die vereinigten organischen Phasen wurden über $\mathrm{Na}_{2} \mathrm{SO}_{4}$ getrocknet und das Lösemittel unter vermindertem Druck entfernt. Das Rohprodukt wurde säulenchromatographisch (DCM/MeOH 99:1 auf 9:1) gereinigt und Verbindung 29 als farbloser Feststoff erhalten.

Ausbeute: $586 \mathrm{mg}, 1.26 \mathrm{mmol}, 53 \%$.

${ }^{1} \mathrm{H}-\mathrm{NMR}\left(500 \mathrm{MHz}, \mathrm{DMSO}-\mathrm{d}_{6}\right) \delta=10.65(\mathrm{~s}, 1 \mathrm{H}), 9.80(\mathrm{~s}, 1 \mathrm{H}), 7.66(\mathrm{~s}, 1 \mathrm{H}), 7.28(\mathrm{~d}$, $J=1.8 \mathrm{~Hz}, 1 \mathrm{H}), 6.93(\mathrm{~d}, J=1.8 \mathrm{~Hz}, 1 \mathrm{H}), 6.82(\mathrm{t}, J=5.5 \mathrm{~Hz}, 1 \mathrm{H}), 3.93(\mathrm{~s}, 3 \mathrm{H}), 3.82(\mathrm{~s}, 3 \mathrm{H})$, $3.81(\mathrm{~s}, 3 \mathrm{H}), 2.93(\mathrm{q}, J=6.7 \mathrm{~Hz}, 2 \mathrm{H}), 2.21$ (t, $J=7.5 \mathrm{~Hz}, 2 \mathrm{H}), 1.70-1.60(\mathrm{~m}, 2 \mathrm{H}), 1.37$ (s, 9H) ppm. 
${ }^{13} \mathrm{C}-N M R\left(126 \mathrm{MHz}\right.$, DMSO- $\left.d_{6}\right) \delta=169.3,159.0,158.7,155.7,137.9,130.7,122.1,121.6$, $119.4,115.5,104.8,77.5,51.8,36.4,35.5,33.1,28.3,25.9$ ppm. $^{\dagger}$

DC: $R_{f}: 0.79$ (DCM:MeOH 9:1)

MS (ESI): $\quad \quad m / z$ ber. für $\mathrm{C}_{21} \mathrm{H}_{31} \mathrm{~N}_{6} \mathrm{O}_{6}\left([\mathrm{M}+\mathrm{H}]^{+}\right): 463.2$; gef.: 463.1.

HRMS (MALDI): $\quad m / z$ ber. für $\mathrm{C}_{21} \mathrm{H}_{30} \mathrm{~N}_{6} \mathrm{NaO}_{6}\left([\mathrm{M}+\mathrm{Na}]^{+}\right): 485.21190 ;$ gef.: 485.21173 .

\subsubsection{Synthese von Boc- $\gamma$ Py-Im-OH 30}

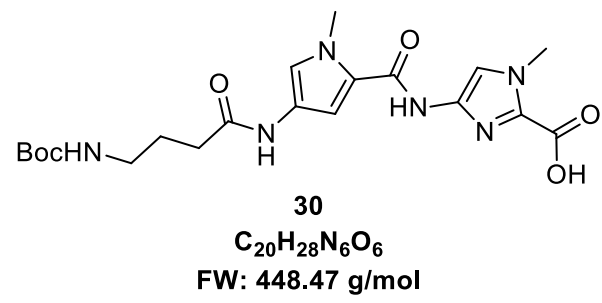

Verbindung 29 (200 mg, $432 \mu \mathrm{mol}, 1$ eq) wurde in einer Mischung aus $\mathrm{MeOH} / \mathrm{H}_{2} \mathrm{O}(1: 1$, $8 \mathrm{~mL}$ ) suspendiert und mit einer $10 \mathrm{M} \mathrm{KOH}$-Lösung $(0.2 \mathrm{~mL}, 2.0 \mathrm{mmol}, 4.6 \mathrm{eq})$ versetzt. Dann wurde $21.5 \mathrm{~h}$ bei RT gerührt und das $\mathrm{MeOH}$ unter vermindertem Druck entfernt. Die wässrige Lösung wurde mit $1 \mathrm{M} \mathrm{HCl}$ angesäuert, der entstandene Niederschlag abfiltriert und im Vakuum getrocknet. Verbindung $\mathbf{3 0}$ konnte als farbloser Feststoff erhalten werden.

Ausbeute: $147 \mathrm{mg}, 327 \mu \mathrm{mol}, 76 \%$.

${ }^{1} \mathrm{H}-\mathrm{NMR}\left(500 \mathrm{MHz}, \mathrm{DMSO}-\mathrm{d}_{6}\right) \delta=10.60(\mathrm{~s}, 1 \mathrm{H}), 9.81(\mathrm{~s}, 1 \mathrm{H}), 7.60$ (s, 1H), 7.27 (d, $J=1.7 \mathrm{~Hz}, 1 \mathrm{H}), 6.93(\mathrm{~d}, J=1.8 \mathrm{~Hz}, 1 \mathrm{H}), 6.83(\mathrm{t}, J=5.4 \mathrm{~Hz}, 1 \mathrm{H}), 3.92(\mathrm{~s}, 3 \mathrm{H}), 3.82(\mathrm{~s}, 3 \mathrm{H})$, $2.93(\mathrm{q}, J=6.7 \mathrm{~Hz}, 2 \mathrm{H}), 2.21(\mathrm{t}, J=7.4 \mathrm{~Hz}, 2 \mathrm{H}), 1.69-1.61(\mathrm{~m}, 2 \mathrm{H}), 1.37(\mathrm{~s}, 9 \mathrm{H}) \mathrm{ppm} .^{\mathrm{g}}$

${ }^{13}$ C-NMR $\left(126 \mathrm{MHz}\right.$, DMSO- $\left.d_{6}\right) \delta=169.3,160.1,158.7,155.7,137.4,131.7,122.1,121.7$, $119.3,115.2,104.7,77.5,36.4,35.6,33.1,28.3,25.9$ ppm. $^{\mathrm{h}}$

MS (ESI): $\quad m / z$ ber. für $\mathrm{C}_{20} \mathrm{H}_{29} \mathrm{~N}_{6} \mathrm{O}_{6}\left([\mathrm{M}+\mathrm{H}]^{+}\right)$: 449.2; gef.: 449.3 .

HRMS (MALDI): $\quad m / z$ ber. für $\mathrm{C}_{20} \mathrm{H}_{28} \mathrm{~N}_{6} \mathrm{NaO}_{6}\left([\mathrm{M}+\mathrm{Na}]^{+}\right): 471.19625$; gef.: 471.19662 .

\footnotetext{
${ }^{f}$ Für die Verbindung 29 wurde im ${ }^{13} \mathrm{C}$-Spektrum ein Signal im Bereich von 39 ppm erwartet. Dieses wurde durch das Lösemittelsignal überlagert.

g Das Säureproton konnte aufgrund eines zu schnellen Austauschs nicht detektiert werden.

${ }^{\mathrm{h}}$ Für die Verbindung 30 wurde im ${ }^{13} \mathrm{C}$-Spektrum ein Signal im Bereich von 39 ppm erwartet. Dieses wurde durch das Lösemittelsignal überlagert.
} 


\subsection{Festphasensynthese der Polyamide}

Der Boc- $\beta$-Ala-Pam-Träger $(0.5 \mathrm{mmol} / \mathrm{g})$ wurde in eine $5 \mathrm{~mL}$ Spritze mit Filter gegeben und $30 \mathrm{~min}$ in abs. DMF equilibriert. Im Anschluss entschützte man mit einer TFA-Lösung (TFA/ $\mathrm{H}_{2} \mathrm{O} /$ Phenol 92.5/2.5/5; zweimal, $1 \mathrm{~mL}, 5 \mathrm{~min}$ ). Daraufhin wurde mit DMF gewaschen (viermal $2 \mathrm{~mL}$ ) und der Träger 2 min in THF (1 mL) inkubiert. In der Zwischenzeit wurde die Boc-geschützte Aminosäure (4 eq) mit BTC (1.3 eq) in THF (1 mL) gelöst und mit 2,4,6-Collidin (12 eq) versetzt. Nach einer Minute gab man DIPEA (8 eq) zu, um den entstandenen Niederschlag zu lösen. Die erhaltene Lösung wurde zum Träger gegeben und 45 min geschüttelt. Im Anschluss wusch man viermal mit DMF (2 $\mathrm{mL})$ und gab eine Capping-Lösung $\left(\mathrm{Ac}_{2} \mathrm{O}(100 \mu \mathrm{l})\right.$ und DIPEA $(175 \mu \mathrm{l})$ in $\left.1 \mathrm{~mL} \mathrm{DMF}\right) \mathrm{zu}$. Dann wurde viermal mit DMF (2 mL) gewaschen und ein neuer Zyklus begonnen. Im Fall der PIPs PA2 und PA3 erfolgte die abschließende Kupplung durch die Zugabe von Verbindung 6 (4 eq) und DIPEA (8 eq). Die Kupplungszeit betrug $60 \mathrm{~min}$.

Zur Abspaltung wurde das Amin $12(1 \mathrm{~mL})$ zugegeben und mit dem Träger $23 \mathrm{~h}$ bei $55^{\circ} \mathrm{C}$ inkubiert. Im Anschluss wurde die Mischung filtriert, mit $\mathrm{MeOH}$ nachgewaschen und das Lösemittel unter vermindertem Druck entfernt. Zur Entfernung des überschüssigen Amins wurde der Rückstand in $\mathrm{MeOH}$ aufgenommen, mit dem zehnfachen Volumen an $\mathrm{Et}_{2} \mathrm{O}$ versetzt und auf $-20^{\circ} \mathrm{C}$ gekühlt. Die entstandenen Suspension wurde zentrifugiert und der Überstand entfernt. Das erhaltene Rohprodukt wurde getrocknet und mittels rp-HPLC gereinigt.

\subsubsection{Im-Py-Py- $\gamma$-Py-Py-Py- $\beta$-Linker- $\mathrm{NH}_{2}$ (PA2)}

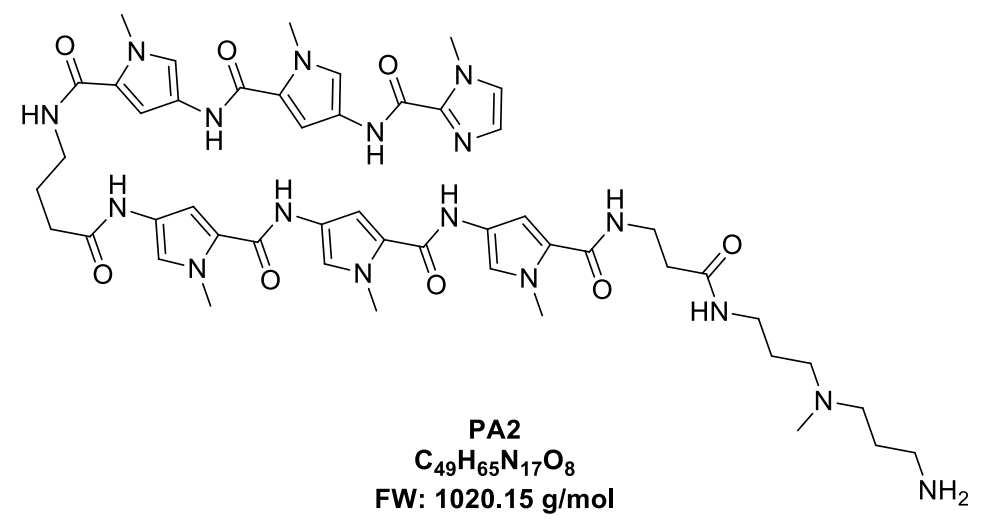

Die Synthese erfolgte mit den Verbindungen 5, 6 und 11.

Träger: $105.29 \mathrm{mg}, 52.6 \mathrm{mmol}$ Theoretische Ausbeute: $53.7 \mathrm{mg}$.

Ausbeute nach HPLC-Reinigung: $5.76 \mathrm{mg}$. Die Verbindung wurde als TFA-Salz erhalten.

Da der TFA-Anteil nicht bekannt war, entspricht dies einer Ausbeute von $9-11 \%$. 
MS (ESI): $\quad \quad m / z$ ber. für $\mathrm{C}_{49} \mathrm{H}_{66} \mathrm{~N}_{17} \mathrm{O}_{8}\left([\mathrm{M}+\mathrm{H}]^{+}\right):$1020.5; gef.: 1020.7.

$m / z$ ber. für $\mathrm{C}_{49} \mathrm{H}_{67} \mathrm{~N}_{17} \mathrm{O}_{8}\left([\mathrm{M}+2 \mathrm{H}]^{+}\right)$: 510.8; gef.: 510.9 .

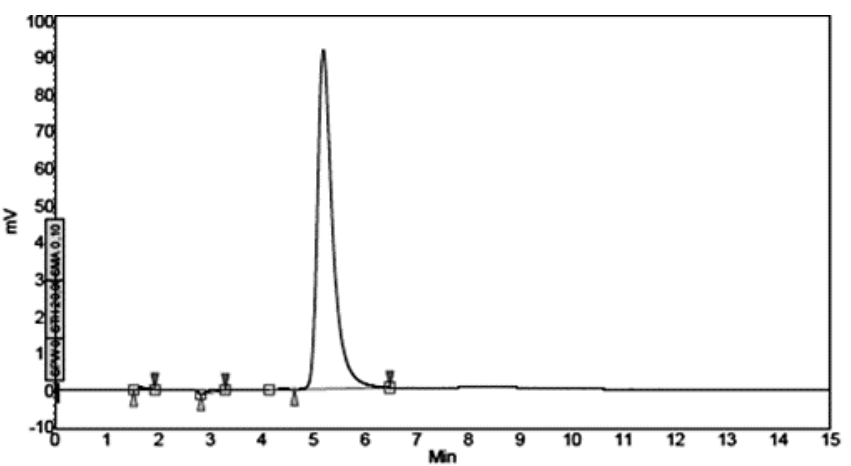

Abbildung 95: rp-HPLC-Chromatogramm des gereinigten Polyamids PA2. Laufmittel: $77 \% 0.1 \%$ TFA, $23 \%$ ACN.

\subsubsection{Im-Py-Py-Py- $\gamma$-Py-Py-Py-Py- $\beta$-Linker-NH2 (PA3)}

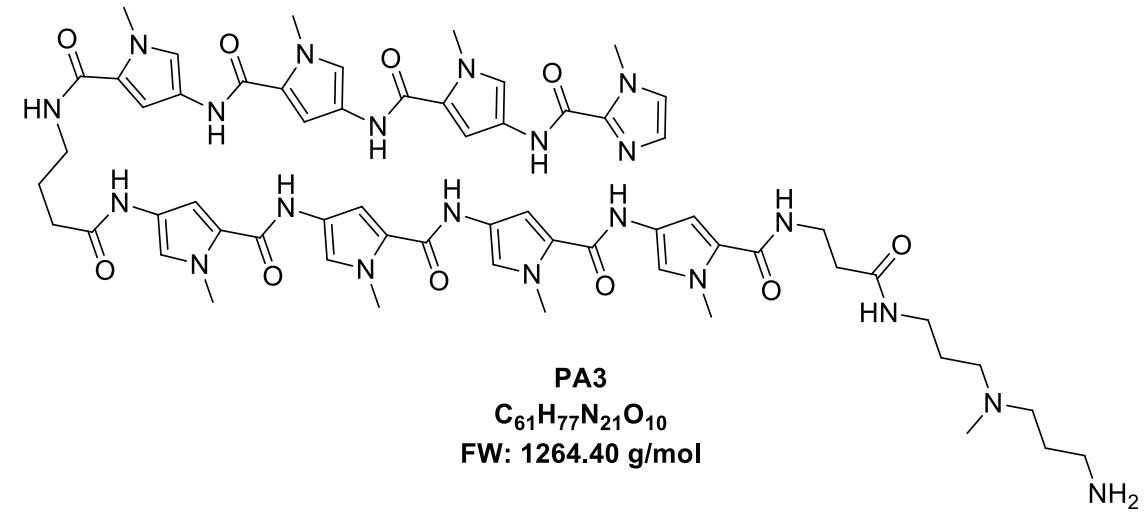

Die Synthese erfolgte mit den Verbindungen 5, 6 und 11.

Träger: $105.72 \mathrm{mg}, 52.9 \mathrm{mmol}$. Theoretische Ausbeute: $66.8 \mathrm{mg}$.

Ausbeute nach HPLC-Reinigung: $2.07 \mathrm{mg}$. Die Verbindung wurde als TFA-Salz erhalten.

Da der TFA-Anteil nicht bekannt war, entspricht dies einer Ausbeute von ca. 3 \%.

\section{Alternative:}

PA3-Boc (10 mg, $7.9 \mu \mathrm{mol})$ wurde in DCM/TFA (1:1, $1 \mathrm{~mL})$ für 40 min bei RT gerührt. Das Lösemittel wurde im Vakuum entfernt und der Rückstand getrocknet. Dieser konnte ohne weitere Aufarbeitung weiter umgesetzt werden.

MS (ESI): $\quad \quad m / z$ ber. für $\mathrm{C}_{61} \mathrm{H}_{79} \mathrm{~N}_{21} \mathrm{O}_{10}\left([\mathrm{M}+2 \mathrm{H}]^{+}\right)$: 632.8; gef.: 633.1 .

MS (MALDI): $\quad m / z$ ber. für $\mathrm{C}_{61} \mathrm{H}_{79} \mathrm{~N}_{21} \mathrm{O}_{10}\left([\mathrm{M}+\mathrm{H}]^{+}\right)$: $1263.6162 ;$ gef.: 1263.8716 . 


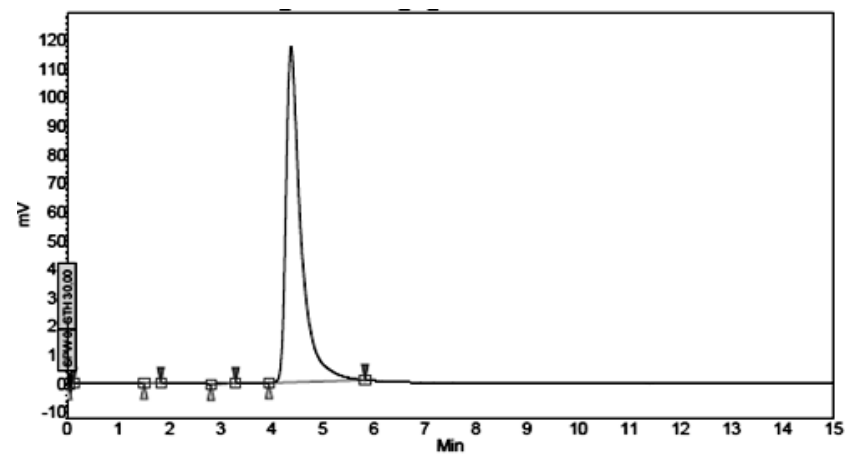

Abbildung 96: $r p$-HPLC-Chromatogramm des gereinigten Polyamids PA3. Laufmittel: $74 \% 0.1 \%$ TFA, $26 \%$ ACN.

\subsubsection{Py-Py-Py-Py- $\gamma$-Py-Im-Py-Py- $\beta$-Linker-NH2 (PA5)}

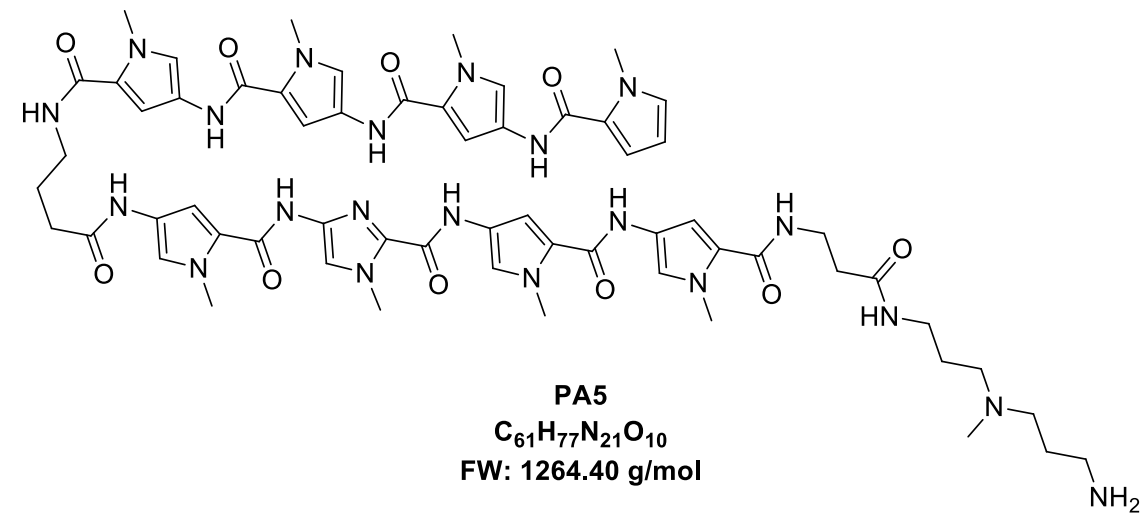

Die Synthese erfolgte mit den Verbindungen 14, 18 und 30.

Träger: $101.23 \mathrm{mg}, 50.6 \mathrm{mmol}$ Theoretische Ausbeute: $64.0 \mathrm{mg}$.

Ausbeute nach HPLC-Reinigung: $6.0 \mathrm{mg}$. Die Verbindung wurde als TFA-Salz erhalten.

Da der TFA-Anteil nicht bekannt war, entspricht dies einer Ausbeute von ca. $9 \%$.

MS (ESI): $\quad \quad m / z$ ber. für $\mathrm{C}_{61} \mathrm{H}_{78} \mathrm{~N}_{21} \mathrm{O}_{10}\left([\mathrm{M}+\mathrm{H}]^{+}\right)$: 1264.6; gef.: 1265.7 .

$m / z$ ber. für $\mathrm{C}_{61} \mathrm{H}_{79} \mathrm{~N}_{21} \mathrm{O}_{10}\left([\mathrm{M}+2 \mathrm{H}]^{+}\right)$: 632.8; gef.: 633.1 .

MS (MALDI): $\quad m / z$ ber. für $\mathrm{C}_{61} \mathrm{H}_{77} \mathrm{~N}_{21} \mathrm{O}_{10}\left([\mathrm{M}]^{+}\right): 1263.6157$; gef.: 1263.2139 .

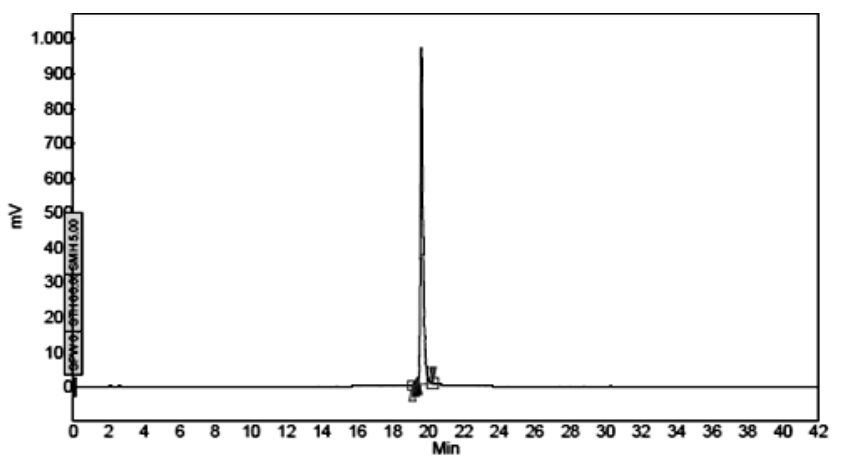

Abbildung 97: rp-HPLC-Chromatogramm nach der Reinigung von PA5. Linearer Gradient von $10 \%$ B zu $70 \%$ B in 30 min. A: $0.1 \%$ TFA in $\mathrm{H}_{2} \mathrm{O}$; $\mathrm{B}$ : ACN. 


\subsection{Synthese der PIPs in Lösung}

\subsubsection{Synthese von $\mathrm{H}_{2} \mathrm{~N}$-Linker-Boc 31}

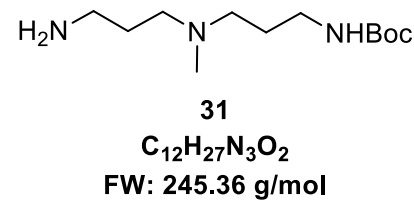

3,3'-Diamino- $N$-methyldipropylamin $(15.0 \mathrm{~mL}, 92.8 \mathrm{mmol}, 4.1 \mathrm{eq})$ wurde in Dioxan $(25 \mathrm{~mL})$ gelöst und dazu eine Lösung von $\mathrm{Boc}_{2} \mathrm{O}(5.01 \mathrm{~g}, 22.9 \mathrm{mmol}, 1.0 \mathrm{eq})$ in Dioxan $(25 \mathrm{~mL})$ getropft. Die entstandene Suspension rührte man für $20 \mathrm{~h}$ bei RT. Im Anschluss wurde das Lösemittel unter vermindertem Druck entfernt, der Rückstand in $\mathrm{H}_{2} \mathrm{O}$ (40 mL) aufgenommen und mit DCM extrahiert. Die vereinigten organischen Phasen trocknete man über $\mathrm{Na}_{2} \mathrm{SO}_{4}$ und entfernte das Lösemittel unter vermindertem Druck. Das Rohprodukt wurde zweimal säulenchromatographisch (1. DCM/MeOH 5:1 mit $5 \% \mathrm{NEt}_{3}, \mathrm{DCM} / \mathrm{MeOH}$ $2: 1+5 \% \mathrm{NH}_{3}$ ) gereinigt. 31 wurde als farbloses Öl erhalten.

Ausbeute: $2.88 \mathrm{~g}, 11.7 \mathrm{mmol}, 51 \%$.

${ }^{1} \mathrm{H}-\mathrm{NMR}\left(300 \mathrm{MHz}, \mathrm{CDCl}_{3}\right) \delta=5.37(\mathrm{~s}, 1 \mathrm{H}), 3.16(\mathrm{q}, J=6.0 \mathrm{~Hz}, 2 \mathrm{H}), 2.76(\mathrm{t}, J=6.8 \mathrm{~Hz}$, 2H), $2.38(\mathrm{t}, J=6.9 \mathrm{~Hz}, 4 \mathrm{H}), 2.18(\mathrm{~s}, 3 \mathrm{H}), 1.94(\mathrm{~s} b r, 2 \mathrm{H}), 1.69-1.56(\mathrm{~m}, 4 \mathrm{H}), 1.43$ (s, 9H) ppm.

${ }^{13} \mathrm{C}-\mathrm{NMR}\left(75 \mathrm{MHz}, \mathrm{CDCl}_{3}\right) \delta=156.3,79.0,56.4,55.8,42.2,40.6,40.0,30.8,28.6$, $27.1 \mathrm{ppm}$.

DC: $R_{\mathrm{f}}: 0.31\left(\mathrm{DCM} / \mathrm{MeOH} 2: 1+5 \% \mathrm{NH}_{3}\right)$

MS (ESI): $\quad \quad m / z$ ber. für $\mathrm{C}_{12} \mathrm{H}_{28} \mathrm{~N}_{3} \mathrm{O}_{2}\left([\mathrm{M}+\mathrm{H}]^{+}\right):$246.2; gef.: 246.2.

HRMS (MALDI): $\quad m / z$ ber. für $\mathrm{C}_{12} \mathrm{H}_{28} \mathrm{~N}_{3} \mathrm{O}_{2}\left([\mathrm{M}+\mathrm{H}]^{+}\right)$: 246.21760; gef.: 246.21791.

\subsubsection{Synthese von z- $\beta$-Linker-Boc 32}

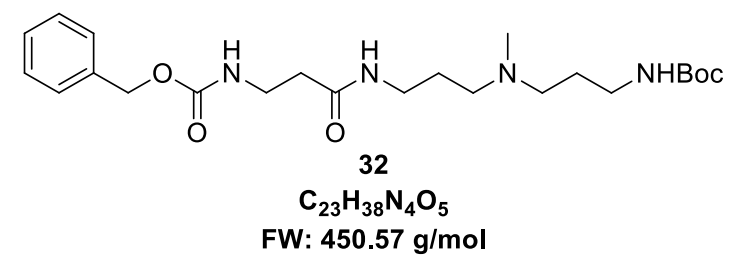

Cbz- $\beta$-Alanin $(1.84 \mathrm{~g}, 8.25 \mathrm{mmol}, 1.1 \mathrm{eq})$ wurde in abs. DMF $(15 \mathrm{~mL})$ gelöst, mit HOBt $(1.27 \mathrm{~g}, 8.25 \mathrm{mmol}, 1.1 \mathrm{eq})$ sowie DIC (2.3 mL, $15 \mathrm{mmol}, 2.0 \mathrm{eq})$ versetzt und $22 \mathrm{~h}$ bei RT gerührt. Dann wurde die Suspension zu Verbindung 31 (1.84 g, $7.50 \mathrm{mmol}, 1.0 \mathrm{eq})$ gegeben, der Kolben mit DMF ( $3 \mathrm{~mL}$ ) nachgespült und $24 \mathrm{~h}$ bei RT gerührt. Im Anschluss 
filtrierte man die entstandene Suspension und überführte das Filtrat in $20 \%$ ige $\mathrm{NaHCO}_{3}$-Lösung (100 mL). Die wässrige Phase wurde dreimal mit DCM (40 mL) extrahiert und die organische Phase über $\mathrm{MgSO}_{4}$ getrocknet. Das Lösemittel wurde unter vermindertem Druck entfernt und das Rohprodukt säulenchromatographisch (EE/MeOH $6: 1+1 \% \mathrm{NEt}_{3}$ ) gereinigt. Man erhielt 32 als farbloses Öl.

Ausbeute: $2.70 \mathrm{~g}, 5.99 \mathrm{mmol}, 73 \%$.

${ }^{1} \mathrm{H}-\mathrm{NMR}\left(500 \mathrm{MHz}, \mathrm{CDCl}_{3}\right) \delta=7.40-7.27(\mathrm{~m}, 5 \mathrm{H}), 7.10(\mathrm{~s} \mathrm{br}, 1 \mathrm{H}), 5.59(\mathrm{~s} \mathrm{br}, 1 \mathrm{H})$, $5.17-4.96(\mathrm{~m}, 3 \mathrm{H}), 3.47$ (q, $J=6.0 \mathrm{~Hz}, 2 \mathrm{H}), 3.37-3.27(\mathrm{~m}, 2 \mathrm{H}), 3.17$ (q, $J=6.2 \mathrm{~Hz}, 2 \mathrm{H}$ ), $2.56-2.34(\mathrm{~m}, 6 \mathrm{H}), 2.20(\mathrm{~s}, 3 \mathrm{H}), 1.75-1.59(\mathrm{~m}, 4 \mathrm{H}), 1.43(\mathrm{~s}, 9 \mathrm{H}) \mathrm{ppm}$.

${ }^{13} \mathrm{C}-\mathrm{NMR}\left(126 \mathrm{MHz}, \mathrm{CDCl}_{3}\right) \delta=171.5,156.6,156.3,136.8,128.6,128.2,79.4,66.7,56.0$, 55.6, 41.7, 39.0, 38.5, 37.5, 36.1, 28.6, 27.6, 25.9 ppm.

DC: $R_{f}=0.5\left(E E / M e O H ~ 2: 1+1 \% \mathrm{NEt}_{3}\right)$

\subsubsection{Synthese von $\mathrm{H}_{2} \mathrm{~N}$ - $\beta$-Linker-Boc 33}

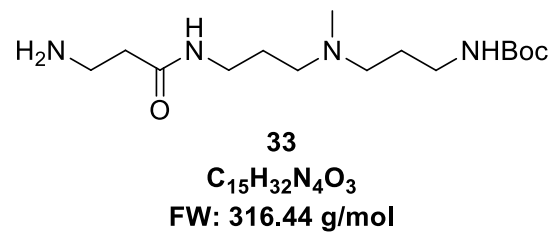

Verbindung 32 (625 mg, 1.39 mmol, 1.0 eq) wurde in abs. MeOH (10 mL) gelöst. Dazu gab man $\mathrm{Pd} / \mathrm{C}$ (70 mg, $10 \%$ auf Aktivkohle) und rührte in einer $\mathrm{H}_{2}$-Atmospäre $18 \mathrm{~h}$ bei RT. Die Suspension wurde über Celite filtriert und das Lösemittel unter vermindertem Druck entfernt. Verbindung $\mathbf{3 3}$ konnte als farbloses Öl erhalten werden.

Ausbeute: $420 \mathrm{mg}, 1.33 \mathrm{mmol}, 96 \%$.

${ }^{1} \mathrm{H}-\mathrm{NMR}\left(500 \mathrm{MHz}, \mathrm{CDCl}_{3}\right) \delta=7.86(\mathrm{t}, J=5.2 \mathrm{~Hz}, 1 \mathrm{H}), 6.77(\mathrm{t}, J=5.2 \mathrm{~Hz}, 1 \mathrm{H}), 3.04$ (q, $J=6.8 \mathrm{~Hz}, 2 \mathrm{H}$ ), $2.91(\mathrm{q}, J=6.7 \mathrm{~Hz}, 2 \mathrm{H}), 2.72(\mathrm{t}, J=6.6 \mathrm{~Hz}, 2 \mathrm{H}), 2.26-2.20(\mathrm{~m}, 4 \mathrm{H}), 2.14$ (t, $J=6.6 \mathrm{~Hz}, 2 \mathrm{H}), 2.08(\mathrm{~s}, 3 \mathrm{H}), 1.53-1.45(\mathrm{~m}, 4 \mathrm{H}), 1.36(\mathrm{~s}, 9 \mathrm{H}) \mathrm{ppm}$.

${ }^{13} \mathrm{C}-\mathrm{NMR}\left(126 \mathrm{MHz}, \mathrm{CDCl}_{3}\right) \delta=171.2,155.6,77.3,54.8,54.8,41.7,39.0,38.3,36.7,28.3$, 27.2, 26.9 ppm.

MS (ESI): $\quad \quad m / z$ ber. für $\mathrm{C}_{15} \mathrm{H}_{33} \mathrm{~N}_{4} \mathrm{O}_{3}([\mathrm{M}+\mathrm{H}])^{+}=317.3$; gef.: 317.3

\footnotetext{
i Die Signale der $\mathrm{NH}_{2}$-Gruppe können durch einen schnellen Austausch mit dem im Lösemittel enthaltenen Wasser nicht detektiert werden.

j Ein Alkyl-C kann durch Überlagerung mit dem Lösemittel oder einem weiteren Peak nicht detektiert werden.
} 


\subsubsection{Synthese von $\mathrm{O}_{2} \mathrm{~N}-\mathrm{Py}-\mathrm{Py}-\mathrm{Py}-\mathrm{Py}-\mathrm{OH} 34$}

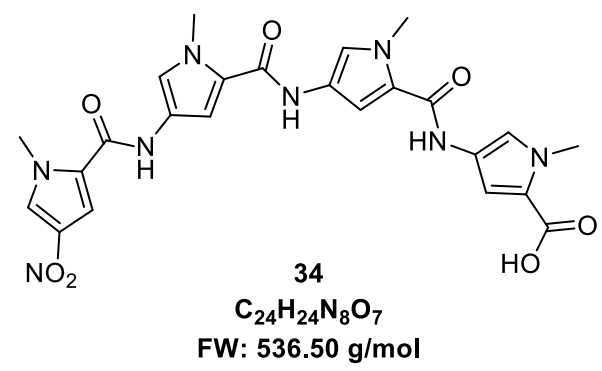

Verbindung 36 (104 mg, $189 \mu \mathrm{mol}, 1 \mathrm{eq})$ und $\mathrm{NaOH}$ (22.6 mg, $567 \mu \mathrm{mol}, 3 \mathrm{eq}$ ) wurden in EtOH (1.32 mL) und $\mathrm{H}_{2} \mathrm{O}(0.95 \mathrm{~mL})$ suspendiert und $1 \mathrm{~h}$ zum Sieden erhitzt. Im Anschluss wurde die Lösung mit konz. $\mathrm{HCl}$ angesäuert und der entstandene Niederschlag abfiltriert. Dieser wurde im Vakuum getrocknet und Verbindung 34 als beiger Feststoff erhalten.

Ausbeute: $90 \mathrm{mg}, 168 \mu \mathrm{mol}, 89 \%$.

${ }^{1} \mathrm{H}-\mathrm{NMR}\left(500 \mathrm{MHz}, \mathrm{DMSO}-d_{6}\right) \delta=12.15(\mathrm{~s} \mathrm{br}, 1 \mathrm{H}), 10.30(\mathrm{~s}, 1 \mathrm{H}), 10.00(\mathrm{~s}, 1 \mathrm{H}), 9.91$ (s, 1H), $8.19(\mathrm{~d}, J=1.7 \mathrm{~Hz}, 1 \mathrm{H}), 7.60(\mathrm{~d}, J=1.9 \mathrm{~Hz}, 1 \mathrm{H}), 7.43(\mathrm{~d}, J=1.8 \mathrm{~Hz}, 1 \mathrm{H}), 7.28(\mathrm{~d}$, $J=1.6 \mathrm{~Hz}, 1 \mathrm{H}), 7.25(\mathrm{~d}, J=1.6 \mathrm{~Hz}, 1 \mathrm{H}), 7.07(\mathrm{~d}, J=1.7 \mathrm{~Hz}, 1 \mathrm{H}), 7.05(\mathrm{~d}, J=1.7 \mathrm{~Hz}, 1 \mathrm{H})$, $6.85(\mathrm{~d}, J=1.9 \mathrm{~Hz}, 1 \mathrm{H}), 3.97(\mathrm{~s}, 3 \mathrm{H}), 3.87(\mathrm{~s}, 3 \mathrm{H}), 3.85(\mathrm{~s}, 3 \mathrm{H}), 3.82(\mathrm{~s}, 3 \mathrm{H}) \mathrm{ppm}$.

${ }^{13}$ C-NMR $\left(126 \mathrm{MHz}\right.$, DMSO- $\left.d_{6}\right) \delta=162.0,158.5,158.4,156.9,133.8,128.3,126.3,123.0$, 122.7, 122.6, 122.2, 121.4, 120.3, 119.5, 118.7, 118.6, 108.4, 107.6, 104.8, 104.5, 37.5, $36.2,36.2,36.1 \mathrm{ppm}$.

MS (ESI): $\quad \quad m / z$ ber. für $\mathrm{C}_{24} \mathrm{H}_{23} \mathrm{~N}_{8} \mathrm{O}_{7}\left([\mathrm{M}-\mathrm{H}]^{-}\right)$: 535.2 ; gef.: 535.1 .

HRMS (MALDI): $\quad m / z$ ber. für $\mathrm{C}_{24} \mathrm{H}_{24} \mathrm{~N}_{8} \mathrm{NaO}_{7}\left([\mathrm{M}+\mathrm{Na}]^{+}\right)$: 559.16602; gef.: 559.16564 .

\subsubsection{Synthese von $\mathrm{O}_{2} \mathrm{~N}-\mathrm{Py}-\mathrm{Py}-\mathrm{Py}-\mathrm{OMe} 35$}

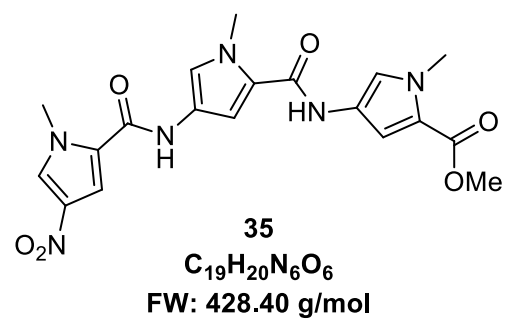

Das Dimer 20 (2.00 g, $6.53 \mathrm{mmol}, 1 \mathrm{eq})$ wurde in abs. EE ( $40 \mathrm{~mL}$ ) suspendiert und $\mathrm{mit} \mathrm{Pd} / \mathrm{C}$ (300 mg, $10 \%$ auf Aktivkohle) versetzt. Die Suspension rührte man für $3 \mathrm{~h}$ bei $45^{\circ} \mathrm{C}$ und 40 bar $\mathrm{H}_{2}$-Druck. Nachdem die Reaktionslösung auf RT abgekühlt war, wurde sie über Celite gefiltert und das Lösemittel unter vermindertem Druck entfernt. Der Rückstand wurde kurz im Vakuum getrocknet, anschließend in abs. DCM (10 mL) aufgenommen und zu einer Lösung von 2 (1.95 g, 7.18 mmol, $1.1 \mathrm{eq})$ in abs. DCM (30 mL) gegeben. Das Gemisch 
wurde mit DIPEA $(1.7 \mathrm{ml}, 10 \mathrm{mmol}, 1.5 \mathrm{eq})$ versetzt und $22 \mathrm{~h}$ bei RT gerührt. Danach filtrierte man den entstandenen gelben Feststoff ab und trocknete inn im Vakuum. Verbindung 35 wurde als gelber Feststoff erhalten.

Ausbeute: $2.21 \mathrm{~g}, 5.16 \mathrm{mmol}, 79 \%$.

${ }^{1} \mathrm{H}-\mathrm{NMR}\left(500 \mathrm{MHz}, \mathrm{DMSO}-d_{6}\right) \delta=10.29(\mathrm{~s}, 1 \mathrm{H}), 9.98(\mathrm{~s}, 1 \mathrm{H}), 8.18(\mathrm{~d}, J=1.7 \mathrm{~Hz}, 1 \mathrm{H}), 7.59$ $(\mathrm{d}, J=2.0 \mathrm{~Hz}, 1 \mathrm{H}), 7.47(\mathrm{~d}, J=1.8 \mathrm{~Hz}, 1 \mathrm{H}), 7.26(\mathrm{~d}, J=1.7 \mathrm{~Hz}, 1 \mathrm{H}), 7.06(\mathrm{~d}, J=1.8 \mathrm{~Hz}$, $1 \mathrm{H}), 6.91(\mathrm{~d}, J=1.9 \mathrm{~Hz}, 1 \mathrm{H}), 3.96(\mathrm{~s}, 3 \mathrm{H}), 3.86(\mathrm{~s}, 3 \mathrm{H}), 3.84(\mathrm{~s}, 3 \mathrm{H}), 3.74(\mathrm{~s}, 3 \mathrm{H}) \mathrm{ppm}$.

${ }^{13} \mathrm{C}-\mathrm{NMR}\left(126 \mathrm{MHz}\right.$, DMSO- $\left.d_{6}\right) \delta=160.8,158.4,157.0,133.8,128.3,126.3,122.9,122.8$, $121.5,120.8,118.8,118.6,108.4,107.6,104.6,51.0,37.5,36.2,36.2$ ppm.

MS (ESI): $\quad m / z$ ber. für $\mathrm{C}_{19} \mathrm{H}_{21} \mathrm{~N}_{6} \mathrm{O}_{6}\left([\mathrm{M}+\mathrm{H}]^{+}\right): 429.2$; gef.: 429.0 .

HRMS (MALDI): $\quad m / z$ ber. für $\mathrm{C}_{19} \mathrm{H}_{21} \mathrm{~N}_{6} \mathrm{O}_{6}\left([\mathrm{M}+\mathrm{H}]^{+}\right): 429.15171$; gef.: 429.15153 .

\subsubsection{Synthese von $\mathrm{O}_{2} \mathrm{~N}-\mathrm{Py}-\mathrm{Py}-\mathrm{Py}-\mathrm{Py}-\mathrm{OMe} 36$}

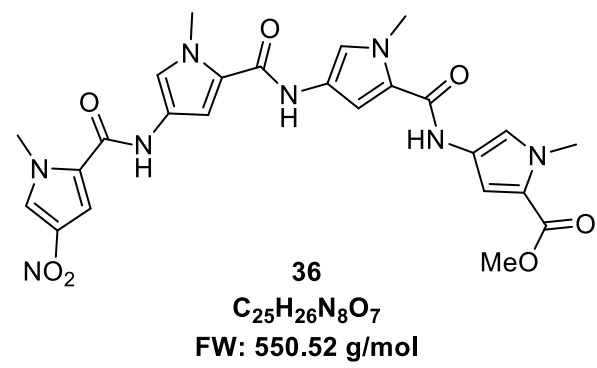

Verbindung 35 (200 mg, 467 umol, 1.0 eq), Boc $2 \mathrm{O}$ (204 mg, $934 \mu \mathrm{mol}, 2.0$ eq) sowie Pd/C (20 mg, $10 \%$ auf Aktivkohle) wurden in abs. $\mathrm{MeOH}(5 \mathrm{~mL})$ suspendiert und für $18 \mathrm{~h}$ bei $50{ }^{\circ} \mathrm{C}$ und 40 bar $\mathrm{H}_{2}$-Druck gerührt. Im Anschluss filtrierte man die Suspension über Celite und entfernte das Lösemittel unter vermindertem Druck. Das Rohprodukt wurde mit TFA/DCM (2:3, $5 \mathrm{~mL})$ versetzt und für $30 \mathrm{~min}$ bei RT gerührt. Nach der Reaktion wurde das Lösemittel im Vakuum entfernt und der Rückstand getrocknet. Das erhaltene TFA-Salz suspendierte man in abs. DCM (5 mL), versetze es mit Verbindung 2 (254 mg, $934 \mu \mathrm{mol}$, 2.0 eq) sowie DIPEA (238 $\mu \mathrm{L}, 1.40 \mathrm{mmol}, 3.0 \mathrm{eq}$ ) und rührte $49 \mathrm{~h}$ bei RT. Die entstandene Suspension wurde filtriert, der Feststoff mit DCM gewaschen und getrocknet. Man erhielt Verbindung $\mathbf{3 6}$ als leicht gelben Feststoff.

Ausbeute: $182 \mathrm{mg}, 331 \mu \mathrm{mol}, 71 \%$.

${ }^{1} \mathrm{H}-\mathrm{NMR}\left(500 \mathrm{MHz}, \mathrm{DMSO}-\mathrm{d}_{6}\right) \delta=10.30(\mathrm{~s}, 1 \mathrm{H}), 10.00(\mathrm{~s}, 1 \mathrm{H}), 9.94(\mathrm{~s}, 1 \mathrm{H}), 8.16(\mathrm{~d}$, $J=1.8 \mathrm{~Hz}, 1 \mathrm{H}), 7.59(\mathrm{~d}, J=2.0 \mathrm{~Hz}, 1 \mathrm{H}), 7.46(\mathrm{~d}, J=1.9 \mathrm{~Hz}, 1 \mathrm{H}), 7.27(\mathrm{~d}, J=1.7 \mathrm{~Hz}, 1 \mathrm{H})$, 
$7.24(\mathrm{~d}, J=1.7 \mathrm{~Hz}, 1 \mathrm{H}), 7.06(\mathrm{~d}, J=1.8 \mathrm{~Hz}, 1 \mathrm{H}), 7.05(\mathrm{~d}, J=1.8 \mathrm{~Hz}, 1 \mathrm{H}), 6.91(\mathrm{~d}, J=1.9 \mathrm{~Hz}$, $1 \mathrm{H}), 3.96(\mathrm{~s}, 3 \mathrm{H}), 3.86(\mathrm{~s}, 3 \mathrm{H}), 3.84(\mathrm{~s}, 3 \mathrm{H}), 3.83(\mathrm{~s}, 3 \mathrm{H}), 3.73(\mathrm{~s}, 3 \mathrm{H}) \mathrm{ppm}$.

${ }^{13} \mathrm{C}-\mathrm{NMR}\left(126 \mathrm{MHz}\right.$, DMSO- $\left.d_{6}\right) \delta=161.0,158.6,158.5,157.1,133.9,128.4,126.4,123.1$, 123.1, 122.7, 122.3, 121.5, 120.9, 118.8, 118.8, 118.7, 108.5, 107.6, 105.0, 104.7, 51.1, $37.6,36.3,36.3,36.2 \mathrm{ppm}$.

MS (ESI): $\quad \quad m / z$ ber. für $\mathrm{C}_{25} \mathrm{H}_{25} \mathrm{~N}_{8} \mathrm{O}_{7}\left([\mathrm{M}-\mathrm{H}]^{-}\right)$: 549.2 ; gef.: 549.2 .

HRMS (MALDI): $\quad m / z$ ber. für $\mathrm{C}_{25} \mathrm{H}_{26} \mathrm{~N}_{8} \mathrm{O}_{7}\left(\left[\mathrm{M}^{\circ}\right]^{+}\right)$: 550.19190; gef.: 550.19124.

\subsubsection{Synthese von $\mathrm{O}_{2} \mathrm{~N}-\mathrm{Py}-\mathrm{Py}-\mathrm{OH} 37$}

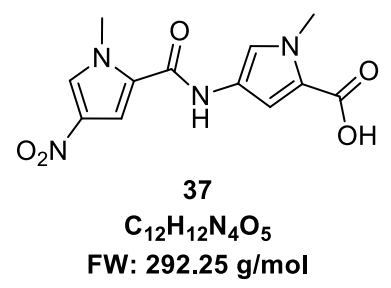

Verbindung 20 (610 mg, $2.00 \mathrm{mmol}, 1.0$ eq) wurde mit $0.3 \mathrm{M} \mathrm{NaOH}(20 \mathrm{~mL}, 6.00 \mathrm{mmol}$, 3.0 eq) sowie $\mathrm{EtOH}(20 \mathrm{~mL}$ ) versetzt und für $1 \mathrm{~h}$ unter Rückfluss zum Sieden erhitzt. Nach Ende der Reaktion wurde mit $1 \mathrm{M} \mathrm{HCl}(10 \mathrm{~mL})$ angesäuert und der gelbe Niederschlag abfiltriert. Man erhielt Verbindung $\mathbf{3 7}$ als gelben Feststoff.

Ausbeute: $532 \mathrm{mg}, 1.82 \mathrm{mmol}, 91 \%$.

${ }^{1} \mathrm{H}-N M R\left(500 \mathrm{MHz}, \mathrm{DMSO}-d_{6}\right) \delta=12.25(\mathrm{~s}, 1 \mathrm{H}), 10.23(\mathrm{~s}, 1 \mathrm{H}), 8.18(\mathrm{~d}, J=1.6 \mathrm{~Hz}, 1 \mathrm{H})$, 7.55 (d, $J=1.9 \mathrm{~Hz}, 1 \mathrm{H}), 7.42(\mathrm{~d}, J=1.8 \mathrm{~Hz}, 1 \mathrm{H}), 6.83$ (d, $J=1.9 \mathrm{~Hz}, 1 \mathrm{H}), 3.95(\mathrm{~s}, 3 \mathrm{H}), 3.83$ (s, 3H) ppm.

${ }^{13}$ C-NMR $\left(126 \mathrm{MHz}\right.$, DMSO- $\left.d_{6}\right) \delta=161.9,156.9,133.8,128.3,126.2,121.9,120.4,119.9$, 108.3, 107.6, 37.5, $36.2 \mathrm{ppm}$.

HRMS (MALDI): $\quad m / z$ ber. für $\mathrm{C}_{12} \mathrm{H}_{12} \mathrm{~N}_{4} \mathrm{O}_{5}\left(\left[\mathrm{M}^{*}\right]^{+}\right)$: $292.08022 ;$ gef.: 292.08042 . 


\subsubsection{Synthese von Py-Im-Py-Py- $\gamma$-OMe 38}

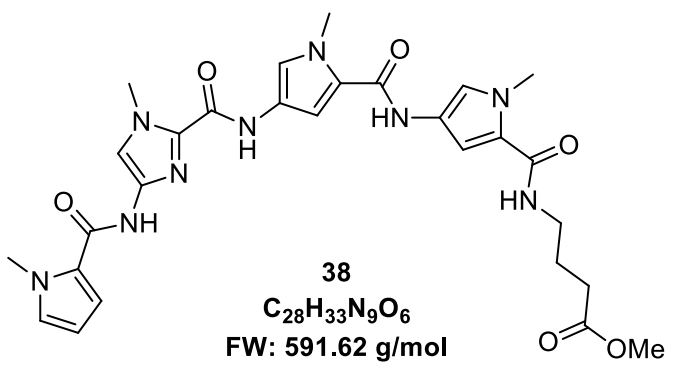

Abs. $\mathrm{MeOH}(3 \mathrm{~mL})$ wurde auf $0{ }^{\circ} \mathrm{C}$ gekühlt und mit $\mathrm{AcCl}(1 \mathrm{~mL})$ versetzt. Die Lösung wurde $20 \mathrm{~min}$ bei $0^{\circ} \mathrm{C}$ gerührt und Verbindung $24(100 \mathrm{mg}, 217 \mu \mathrm{mol}, 1.0 \mathrm{eq})$ in abs. $\mathrm{MeOH}$ (2 mL) zugegeben. Nachdem die Lösung für $20 \mathrm{~min}$ bei $0^{\circ} \mathrm{C}$ und $60 \mathrm{~min}$ bei $\mathrm{RT}$ rührte, entfernte man das Lösemittel unter vermindertem Druck und trocknete das Rohprodukt im Vakuum. Das entstandene Hydrochlorid, Verbindung 17 (65 mg, $260 \mu \mathrm{mol}, 1.2 \mathrm{eq}$ ) sowie HBTU (107 mg, $282 \mu \mathrm{mol}, 1.3 \mathrm{eq})$ wurden in abs. DMF $(5 \mathrm{~mL})$ gelöst und mit DIPEA ( $111 \mu \mathrm{L}, 650 \mu \mathrm{mol}, 3.0 \mathrm{eq}$ ) versetzt. Die Mischung rührte man für $19 \mathrm{~h}$ bei RT und gab sie im Anschluss zu einer 20\%igen $\mathrm{NaHCO}_{3}$-Lösung. Die wässrige Phase wurde mit DCM extrahiert und die organische Phase über $\mathrm{Mg}_{2} \mathrm{SO}_{4}$ getrocknet. Das Lösemittel wurde unter vermindertem Druck entfernt und das Rohprodukt säulenchromatographisch $(\mathrm{CH} / \mathrm{EE} / \mathrm{MeOH}$ 2:9:1) gereinigt. 38 konnte als leicht brauner Feststoff erhalten werden.

Ausbeute: $109 \mathrm{mg}, 184 \mu \mathrm{mol}, 85 \%$.

${ }^{1} \mathrm{H}-\mathrm{NMR}\left(500 \mathrm{MHz}, \mathrm{DMSO}-d_{6}\right) \delta=10.24(\mathrm{~s}, 1 \mathrm{H}), 9.98(\mathrm{~s}, 1 \mathrm{H}), 9.90(\mathrm{~s}, 1 \mathrm{H}), 8.04$ (t, $J=5.6 \mathrm{~Hz}, 1 \mathrm{H}), 7.55(\mathrm{~s}, 1 \mathrm{H}), 7.28(\mathrm{~d}, J=1.5 \mathrm{~Hz}, 1 \mathrm{H}), 7.19(\mathrm{~d}, J=1.5 \mathrm{~Hz}, 1 \mathrm{H}), 7.13-7.09$ $(\mathrm{m}, 2 \mathrm{H}), 7.00-6.97(\mathrm{~m}, 1 \mathrm{H}), 6.88(\mathrm{~d}, J=1.6 \mathrm{~Hz}, 1 \mathrm{H}), 6.06(\mathrm{dd}, J=3.8,2.6 \mathrm{~Hz}, 1 \mathrm{H}), 3.99$ (s, 3H), $3.89(\mathrm{~s}, 3 \mathrm{H}), 3.86(\mathrm{~s}, 3 \mathrm{H}), 3.80(\mathrm{~s}, 3 \mathrm{H}), 3.59(\mathrm{~s}, 3 \mathrm{H}), 3.18(\mathrm{q}, J=6.5 \mathrm{~Hz}, 2 \mathrm{H}), 2.34$ (t, $J=7.4 \mathrm{~Hz}, 2 \mathrm{H}), 1.78-1.70(\mathrm{~m}, 2 \mathrm{H}) \mathrm{ppm}$.

${ }^{13} \mathrm{C}-\mathrm{NMR}\left(126 \mathrm{MHz}\right.$, DMSO- $\left.d_{6}\right) \delta=173.2,161.3,158.8$ 158.4, 155.8, 136.2, 134.1, 128.9, 124.6, 123.1, 122.9, 122.0, 121.2, 118.5, 117.9, 114.5, 113.8, 107.0, 105.1, 104.3, 51.3, $37.7,36.5,36.2,36.0,34.9,30.8,24.7 \mathrm{ppm}$.

DC: $\mathrm{R}_{\mathrm{f}}: 0.39(\mathrm{CH} / \mathrm{EE} / \mathrm{MeOH} 2: 9: 1)$

MS (ESI): $\quad \quad m / z$ ber. für $\mathrm{C}_{28} \mathrm{H}_{34} \mathrm{~N}_{9} \mathrm{O}_{6}\left([\mathrm{M}+\mathrm{H}]^{+}\right): 592.3$; gef.: 592.3

HRMS (MALDI): $\quad m / z$ ber. für $\mathrm{C}_{28} \mathrm{H}_{33} \mathrm{~N}_{9} \mathrm{NaO}_{6}\left([\mathrm{M}+\mathrm{Na}]^{+}\right): 614.24460 ;$ gef.: 614.24463. 


\subsubsection{Synthese von Py-Im-Py-Py- $\gamma-\mathrm{OH} 39$}

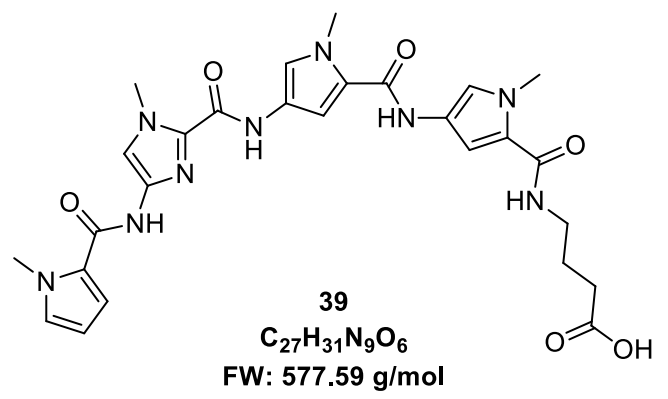

Verbindung 38 (153 mg, $259 \mu \mathrm{mol}, 1 \mathrm{eq})$ wurde in $\mathrm{MeOH} / \mathrm{H}_{2} \mathrm{O}(3: 1,5 \mathrm{ml})$ suspendiert und auf $0{ }^{\circ} \mathrm{C}$ gekühlt. Dazu gab man $\mathrm{LiOH} \bullet \mathrm{H}_{2} \mathrm{O}(54 \mathrm{mg}, 1.29 \mathrm{mmol}, 5 \mathrm{eq})$ und rührte über Nacht, wobei die Lösung langsam auf RT erwärmt wurde. Die Reaktionslösung wurde auf Kieselgel absorbiert und säulenchromatographisch ( $\mathrm{DCM} / \mathrm{MeOH} 5: 1)$ gereinigt. Verbindung 39 wurde als farbloser Feststoff erhalten.

Ausbeute: $127 \mathrm{mg}, 221 \mu \mathrm{mol}, 85 \%$.

${ }^{1} \mathrm{H}-\mathrm{NMR}\left(500 \mathrm{MHz}, \mathrm{DMSO}-d_{6}\right) \delta=12.04(\mathrm{~s} \mathrm{br}, 1 \mathrm{H}), 10.24(\mathrm{~s}, 1 \mathrm{H}), 9.97(\mathrm{~s}, 1 \mathrm{H}), 9.90(\mathrm{~s}, 1 \mathrm{H})$, $8.03(\mathrm{t}, J=5.7 \mathrm{~Hz}, 1 \mathrm{H}), 7.55(\mathrm{~s}, 1 \mathrm{H}), 7.28(\mathrm{~d}, J=1.7 \mathrm{~Hz}, 1 \mathrm{H}), 7.19(\mathrm{~d}, J=1.7 \mathrm{~Hz}, 1 \mathrm{H})$, $7.13-7.09(\mathrm{~m}, 2 \mathrm{H}), 7.00-6.97(\mathrm{~m}, 1 \mathrm{H}), 6.88(\mathrm{~d}, J=1.8 \mathrm{~Hz}, 1 \mathrm{H}), 6.06$ (dd, $J=3.9,2.5 \mathrm{~Hz}$, 1H), 3.99 (s, 3H), $3.89(\mathrm{~s}, 3 \mathrm{H}), 3.86(\mathrm{~s}, 3 \mathrm{H}), 3.80(\mathrm{~s}, 3 \mathrm{H}), 3.18(\mathrm{q}, J=6.5 \mathrm{~Hz}, 2 \mathrm{H}), 2.22$ (t, $J=7.3 \mathrm{~Hz}, 2 \mathrm{H}), 1.71(\mathrm{p}, J=7.2 \mathrm{~Hz}, 2 \mathrm{H}) \mathrm{ppm}$.

${ }^{13} \mathrm{C}-N M R\left(126 \mathrm{MHz}\right.$, DMSO- $\left.d_{6}\right) \delta=174.3,161.3,158.8,158.4,155.8,136.2,134.1,128.9$, 124.6, 123.2, 123.0, 122.0, 121.2, 118.5, 117.9, 114.5, 113.8, 107.0, 104.7, 104.3, 37.9, $36.4,36.2,36.0,34.9,31.1,24.8$ ppm.

DC: $R_{\mathrm{f}}: 0.72(\mathrm{DCM} / \mathrm{MeOH}$ 5:1)

MS (ESI): $\quad \quad m / z$ ber. für $\mathrm{C}_{27} \mathrm{H}_{30} \mathrm{~N}_{9} \mathrm{O}_{6}\left([\mathrm{M}-\mathrm{H}]^{-}\right)$: 576.2 ; gef.: 576.2 .

HRMS (MALDI): $\quad m / z$ ber. für $\mathrm{C}_{27} \mathrm{H}_{32} \mathrm{~N}_{9} \mathrm{O}_{6}\left([\mathrm{M}+\mathrm{H}]^{+}\right): 578.24701$; gef.: 578.24758 . 


\subsubsection{Synthese von Im-Py-Py-Py- $\gamma$-OMe 40}

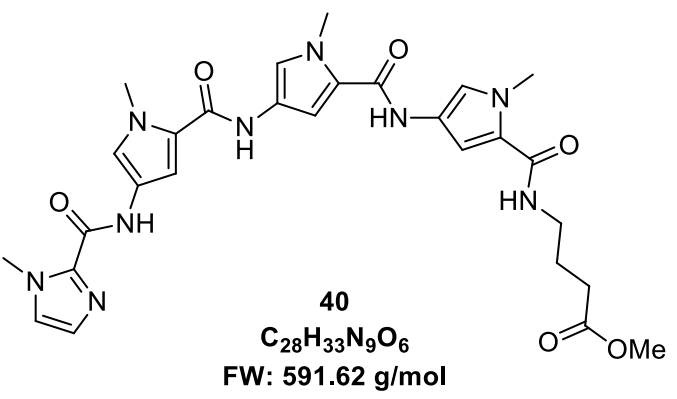

Verbindung 24 (100 mg, $221 \mu \mathrm{mol}, 1.0$ eq) wurde in abs. $\mathrm{MeOH}(1 \mathrm{~mL})$ gelöst und auf $0{ }^{\circ} \mathrm{C}$ gekühlt. Dazu wurde eine Lösung von $\mathrm{AcCl}(1 \mathrm{~mL})$ in abs. $\mathrm{MeOH}(3 \mathrm{~mL})$ gegeben und für $1.5 \mathrm{~h}$ bei $0^{\circ} \mathrm{C}$ gerührt. Das Lösemittel wurde unter vermindertem Druck entfernt und der Rückstand im Vakuum getrocknet. Im Anschluss wurde der Rückstand in abs. DMF ( $5 \mathrm{~mL})$ aufgenommen und mit 43 (66 mg, $187 \mu \mathrm{mol}, 1.2 \mathrm{eq}$ ) sowie HBTU (109 mg, $287 \mu \mathrm{mol}$, $1.3 \mathrm{eq})$ versetzt. Nach der Zugabe von DIPEA (113 $\mu \mathrm{L}, 663 \mu \mathrm{mol}, 3.0$ eq) wurde $20.5 \mathrm{~h}$ bei RT gerührt. Im Anschluss wurde die Lösung mit einer $1 \mathrm{M} \mathrm{NaHCO}_{3}$-Lösung, $\mathrm{H}_{2} \mathrm{O}$ sowie DCM versetzt und die Phasen getrennt. Die wässrige Phase wurde mit DCM extrahiert, die organische Phase mit Brine gewaschen und über $\mathrm{Na}_{2} \mathrm{SO}_{4}$ getrocknet. Das Lösemittel wurde unter vermindertem Druck entfernt und der Rückstand säulenchromatographisch ( $\mathrm{CH} / \mathrm{EE}$ 2:9 auf $\mathrm{CH} / \mathrm{EE} / \mathrm{MeOH} 2: 9: 1)$ gereinigt. Verbindung $\mathbf{4 0}$ wurde als farbloser Feststoff erhalten.

Ausbeute: $90 \mathrm{mg}, 152 \mu \mathrm{mol}, 68 \%$.

${ }^{1} \mathrm{H}-\mathrm{NMR}\left(500 \mathrm{MHz}, \mathrm{DMSO}-\mathrm{d}_{6}\right) \delta=10.46(\mathrm{~s}, 1 \mathrm{H}), 9.97(\mathrm{~s}, 1 \mathrm{H}), 9.90(\mathrm{~s}, 1 \mathrm{H}), 8.04$ (t, $J=5.7 \mathrm{~Hz}, 1 \mathrm{H}), 7.40(\mathrm{~s}, 1 \mathrm{H}), 7.30(\mathrm{~d}, J=1.7 \mathrm{~Hz}, 1 \mathrm{H}), 7.25(\mathrm{~d}, J=1.7 \mathrm{~Hz}, 1 \mathrm{H}), 7.18(\mathrm{~d}$, $J=1.7 \mathrm{~Hz}, 1 \mathrm{H}) 7.17(\mathrm{~d}, J=1.8 \mathrm{~Hz}, 1 \mathrm{H}), 7.07-7.03(\mathrm{~m}, 2 \mathrm{H}), 6.87(\mathrm{~d}, J=1.8 \mathrm{~Hz}, 1 \mathrm{H}), 4.00$ (s, 3H), $3.85(\mathrm{~s}, 3 \mathrm{H}), 3.85(\mathrm{~s}, 3 \mathrm{H}), 3.80(\mathrm{~s}, 3 \mathrm{H}), 3.59(\mathrm{~s}, 3 \mathrm{H}), 3.19$ (q, J=6.6 Hz, 2H), 2.34 (t, $J=7.4 \mathrm{~Hz}, 2 \mathrm{H}), 1.74(\mathrm{p}, J=7.1 \mathrm{~Hz}, 2 \mathrm{H}) \mathrm{ppm}$.

${ }^{13} \mathrm{C}-N M R\left(126 \mathrm{MHz}\right.$, DMSO- $\left.d_{6}\right) \delta=173.2,161.4,158.5,158.5,156.1,138.8,127.0,126.4$, 123.0, 122.9, 122.8, 122.2, 122.2, 121.5, 118.7, 118.5, 117.8, 105.0, 104.7, 104.2, 51.3, $37.7,36.1,36.1,36.0,35.1,30.8,24.7$ ppm.

DC: $R_{\mathrm{f}}: 0.21(\mathrm{CH} / \mathrm{EE} / \mathrm{MeOH} 2: 9: 1)$

MS (ESI): $\quad \quad m / z$ ber. für $\mathrm{C}_{28} \mathrm{H}_{34} \mathrm{~N}_{9} \mathrm{O}_{6}\left([\mathrm{M}+\mathrm{H}]^{+}\right)$: 592.3 ; gef.: 592.4 .

MS (MALDI): $\quad m / z$ ber. für $\mathrm{C}_{28} \mathrm{H}_{34} \mathrm{~N}_{9} \mathrm{O}_{6}\left([\mathrm{M}+\mathrm{H}]^{+}\right)$: 592.2627; gef.: 592.3173 . 


\subsubsection{Synthese von Im-Py-Py-Py- $\gamma-\mathrm{OH} 41$}

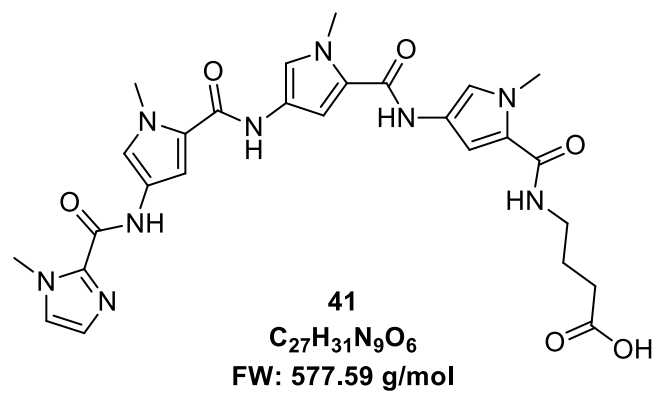

Verbindung 40 (200 mg, $338 \mu \mathrm{mol}, 1.0$ eq) wurde in $\mathrm{MeOH}(5.1 \mathrm{~mL})$ gelöst, auf $0{ }^{\circ} \mathrm{C}$ gekühlt und mit einer $1 \mathrm{M}$ Lösung von $\mathrm{LiOH}$ in Wasser $(1.7 \mathrm{~mL}, 1.7 \mathrm{mmol}, 5.0$ eq) versetzt. Das Gemisch wurde $19 \mathrm{~h}$ gerührt und dabei langsam auf RT erwärmt. Die Lösung wurde auf Kieselgel absorbiert und säulenchromatographisch (DCM/MeOH 9:1) gereinigt. Das Produkt konnte als blass-gelber Feststoff erhalten werden.

Ausbeute: $149 \mathrm{mg}, 258 \mu \mathrm{mol}, 77 \%$.

${ }^{1} \mathrm{H}-\mathrm{NMR}\left(500 \mathrm{MHz}\right.$, DMSO-d $\left.d_{6}\right) \delta=12.01(\mathrm{~s} b r, 1 \mathrm{H}), 10.46(\mathrm{~s}, 1 \mathrm{H}), 9.98(\mathrm{~s}, 1 \mathrm{H}), 9.91(\mathrm{~s}, 1 \mathrm{H})$, $8.06(\mathrm{t}, J=5.6 \mathrm{~Hz}, 1 \mathrm{H}), 7.40(\mathrm{~s}, 1 \mathrm{H}), 7.30(\mathrm{~d}, J=1.7 \mathrm{~Hz}, 1 \mathrm{H}), 7.25(\mathrm{~d}, J=1.6 \mathrm{~Hz}, 1 \mathrm{H}), 7.19$ $(\mathrm{d}, J=1.7 \mathrm{~Hz}, 1 \mathrm{H}) 7.17(\mathrm{~d}, J=1.8 \mathrm{~Hz}, 1 \mathrm{H}), 7.06(\mathrm{~d}, J=1.7 \mathrm{~Hz}, 1 \mathrm{H}), 7.04(\mathrm{~d}, J=0.7 \mathrm{~Hz}$, $1 \mathrm{H}), 6.88(\mathrm{~d}, J=1.7 \mathrm{~Hz}, 1 \mathrm{H}), 4.00(\mathrm{~s}, 3 \mathrm{H}), 3.85(\mathrm{~s}, 3 \mathrm{H}), 3.85(\mathrm{~s}, 3 \mathrm{H}), 3.80(\mathrm{~s}, 3 \mathrm{H}), 3.18(\mathrm{q}$, $J=6.6 \mathrm{~Hz}, 2 \mathrm{H}), 2.24$ (t, $J=7.4 \mathrm{~Hz}, 2 \mathrm{H}), 1.71(\mathrm{p}, J=7.1 \mathrm{~Hz}, 2 \mathrm{H})$ ppm.

${ }^{13}$ C-NMR $\left(126 \mathrm{MHz}\right.$, DMSO- $\left.d_{6}\right) \delta=174.6,161.3,158.5,158.5,156.1,138.8,127.0,126.4$, 123.0, 123.0, 122.8, 122.2, 122.2, 121.5, 118.7, 118.5, 117.8, 105.0, 104.7, 104.2, 37.9, $36.1,36.1,36.0,35.1,31.4,24.9 \mathrm{ppm}$.

DC: Rf: 0.44 (DCM/MeOH 9:1)

MS (ESI): $\quad \quad m / z$ ber. für $\mathrm{C}_{27} \mathrm{H}_{32} \mathrm{~N}_{9} \mathrm{O}_{6}\left([\mathrm{M}+\mathrm{H}]^{+}\right)$: 578.3 ; gef.: 578.4 .

HRMS (MALDI): $\quad m / z$ ber. für $\mathrm{C}_{27} \mathrm{H}_{32} \mathrm{~N}_{9} \mathrm{O}_{6}\left([\mathrm{M}+\mathrm{H}]^{+}\right): 578.24701$; gef.: 578.24629 .

\subsubsection{Synthese von Im-Py-OMe 42}

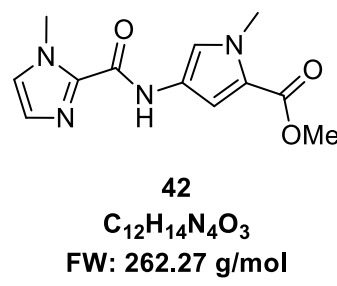

Verbindung $3(1.00 \mathrm{~g}, 5.43 \mathrm{mmol}, 1.0 \mathrm{eq})$ wurde in abs. EE $(20 \mathrm{~mL})$ gelöst, mit $\mathrm{Pd} / \mathrm{C}$ (100 mg, $10 \%$ auf Aktivkohle) versetzt und $2.5 \mathrm{~h}$ bei $\mathrm{RT}$ in einer $\mathrm{H}_{2}$-Atmosphäre gerührt. 
Im Anschluss wurde die Suspension über Celite filtriert und das Lösemittel unter vermindertem Druck entfernt. Nach kurzem Trocknen gab man 6 (1.48 g, $6.50 \mathrm{mmol}$, $1.2 \mathrm{eq})$, abs. DCM (10 mL) sowie DIPEA (1.85 mL, $10.9 \mathrm{mmol}, 2 \mathrm{eq}) \mathrm{zu}$ und rührte $17 \mathrm{~h}$ bei RT. Im Anschluss wurde die Lösung auf Kieselgel absorbiert und säulenchromatographisch $(\mathrm{CH} / \mathrm{EE} 1: 1)$ gereinigt. Das Produkt konnte als farbloser Feststoff erhalten werden.

Ausbeute: $1.34 \mathrm{~g}, 5.10 \mathrm{mmol}, 94 \%$.

${ }^{1} \mathrm{H}-\mathrm{NMR}\left(500 \mathrm{MHz}, \mathrm{DMSO}-d_{6}\right) \delta=10.52(\mathrm{~s}, 1 \mathrm{H}), 7.53(\mathrm{~d}, J=1.9 \mathrm{~Hz}, 1 \mathrm{H}), 7.39(\mathrm{~s}, 1 \mathrm{H})$, $7.05-7.02(\mathrm{~m}, 2 \mathrm{H}), 3.98(\mathrm{~s}, 3 \mathrm{H}), 3.84(\mathrm{~s}, 3 \mathrm{H}), 3.73(\mathrm{~s}, 3 \mathrm{H}) \mathrm{ppm}$.

${ }^{13}$ C-NMR $\left(126 \mathrm{MHz}\right.$, DMSO- $\left.d_{6}\right) \delta=160.8,156.2,138.6,127.0,126.5,122.2,121.0,118.7$, 108.8, 50.9, 36.3, $35.1 \mathrm{ppm}$.

DC: $R_{f}: 0.22(\mathrm{CH} / \mathrm{EE} \mathrm{1:1)}$

MS (ESI): $\quad \quad m / z$ ber. für $\mathrm{C}_{12} \mathrm{H}_{15} \mathrm{~N}_{4} \mathrm{O}_{3}\left([\mathrm{M}+\mathrm{H}]^{+}\right): 263.1$; gef.: 263.1 .

HRMS (MALDI): $\quad m / z$ ber. für $\mathrm{C}_{12} \mathrm{H}_{15} \mathrm{~N}_{4} \mathrm{O}_{3}\left([\mathrm{M}+\mathrm{H}]^{+}\right): 263.11387$; gef.: 263.11402 .

\subsubsection{Synthese von Im-Py-OH 43}

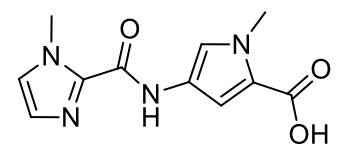

43

$\mathrm{C}_{11} \mathrm{H}_{12} \mathrm{~N}_{4} \mathrm{O}_{3}$

FW: $248.24 \mathrm{~g} / \mathrm{mol}$

Verbindung 42 (1.32 g, $5.03 \mathrm{mmol}, 1.0 \mathrm{eq})$ wurde in $\mathrm{EtOH} / \mathrm{H}_{2} \mathrm{O}(1: 1,60 \mathrm{~mL})$ suspendiert. Dazu gab man $\mathrm{NaOH}(1.00 \mathrm{~g}, 25.2 \mathrm{mmol}, 5.0 \mathrm{eq})$ und erhitzte die Mischung für 40 min zum Sieden. Nachdem die Lösung auf RT abgekühlt war, säuerte man sie mit $1 \mathrm{M} \mathrm{HCl}$ an und filtrierte den entstandenen Niederschlag ab. Dieser wurde im Vakuum getrocknet und man erhielt Verbindung $\mathbf{4 3}$ als farbloser Feststoff.

Ausbeute: $1.15 \mathrm{~g}, 4.63 \mathrm{mmol}, 92 \%$.

${ }^{1} \mathrm{H}-N M R\left(500 \mathrm{MHz}, \mathrm{DMSO}-d_{6}\right) \delta=12.20(\mathrm{~s}, 1 \mathrm{H}), 10.48(\mathrm{~s}, 1 \mathrm{H}), 7.47(\mathrm{~d}, J=1.9 \mathrm{~Hz}, 1 \mathrm{H})$, $7.38(\mathrm{~s}, 1 \mathrm{H}), 7.03(\mathrm{~d}, J=0.9 \mathrm{~Hz}, 1 \mathrm{H}), 6.98(\mathrm{~d}, J=2.0 \mathrm{~Hz}, 1 \mathrm{H}), 3.98(\mathrm{~s}, 3 \mathrm{H}), 3.82(\mathrm{~s}, 3 \mathrm{H}) \mathrm{ppm}$.

${ }^{13} \mathrm{C}-\mathrm{NMR}\left(126 \mathrm{MHz}, \mathrm{DMSO}-d_{6}\right) \delta=162.0,156.1,138.7,127.0,126.4,122.0,120.5,119.7$, 108.9, 36.2, $35.1 \mathrm{ppm}$.

MS (ESI): $\quad \quad m / z$ ber. für $\mathrm{C}_{11} \mathrm{H}_{11} \mathrm{~N}_{4} \mathrm{O}_{3}\left([\mathrm{M}-\mathrm{H}]^{-}\right): 247.1$; gef.: 247.2 .

HRMS (MALDI): $\quad m / z$ ber. für $\mathrm{C}_{11} \mathrm{H}_{13} \mathrm{~N}_{4} \mathrm{O}_{3}\left([\mathrm{M}+\mathrm{H}]^{+}\right)$: 249.09822; gef.: 249.09836 . 


\subsubsection{Synthese von $\mathrm{O}_{2} \mathrm{~N}-\mathrm{Py}-\mathrm{Py}-\mathrm{Py}-\mathrm{Py}$ - $\beta$-Linker-Boc 44}

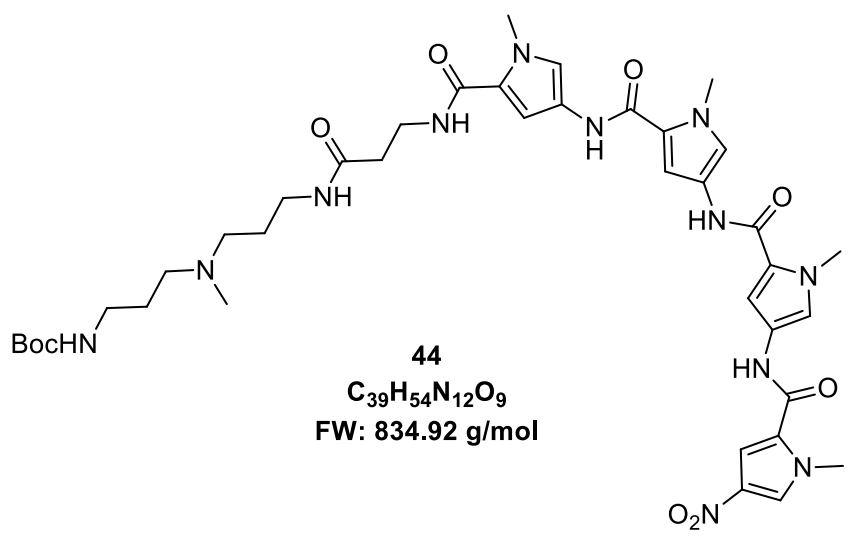

Verbindung 34 (100 mg, $186 \mu \mathrm{mol}, 1.0 \mathrm{eq})$ wurde in abs. DMF (5 mL) gelöst und mit HOBt (28.5 mg, $186 \mu \mathrm{mol}, 1 \mathrm{eq}), 33$ (70.8 mg, $223 \mu \mathrm{mol}, 1.2 \mathrm{eq})$ sowie DIPEA (63.0 $\mu \mathrm{l}, 223 \mu \mathrm{mol}$, 2.0 eq) versetzt. Man erwärmte auf $60^{\circ} \mathrm{C}$, gab DIC (57.0 $\left.\mu \mathrm{l}, 371 \mu \mathrm{mol}, 2.0 \mathrm{eq}\right)$ zu und rührte $3 \mathrm{~h}$ bei $60^{\circ} \mathrm{C}$ sowie weitere $18.5 \mathrm{~h}$ bei RT. Das Lösemittel wurde im Vakuum entfernt und das Rohprodukt zweimal säulenchromatographisch (1. DCM/MeOH 9:1 + $1 \% \mathrm{NEt}_{3}$, 2. $\mathrm{DCM} / \mathrm{MeOH}$ 9:1 $\left.+1 \% \mathrm{NH}_{3}\right)$ gereinigt. Das Produkt wurde als gelber Schaum erhalten.

Ausbeute: $124 \mathrm{mg}, 148 \mu \mathrm{mol}, 80 \%$.

${ }^{1} \mathrm{H}-\mathrm{NMR}\left(500 \mathrm{MHz}, \mathrm{DMSO}-\mathrm{d}_{6}\right) \delta=10.30(\mathrm{~s}, 1 \mathrm{H}), 10.00(\mathrm{~s}, 1 \mathrm{H}), 9.91(\mathrm{~s}, 1 \mathrm{H}), 8.20(\mathrm{~d}$, $J=1.8 \mathrm{~Hz}, 1 \mathrm{H}), 8.01(\mathrm{t}, J=5.6 \mathrm{~Hz}, 1 \mathrm{H}), 7.89(\mathrm{t}, J=5.3 \mathrm{~Hz}, 1 \mathrm{H}), 7.60(\mathrm{~d}, J=1.9 \mathrm{~Hz}, 1 \mathrm{H})$, $7.28(\mathrm{~d}, J=1.6 \mathrm{~Hz}, 1 \mathrm{H}), 7.25$ (d, $J=1.5 \mathrm{~Hz}, 1 \mathrm{H}), 7.20$ (d, $J=1.5 \mathrm{~Hz}, 1 \mathrm{H}), 7.09-7-02$ (m, 2H), $6.84(\mathrm{~d}, J=1.5 \mathrm{~Hz}, 1 \mathrm{H}), 6.79(\mathrm{t}, J=4.9 \mathrm{~Hz}, 1 \mathrm{H}), 3.97(\mathrm{~s}, 3 \mathrm{H}), 3.87(\mathrm{~s}, 3 \mathrm{H}), 3.85$ (s, $3 \mathrm{H}$ ), $3.80(\mathrm{~s}, 3 \mathrm{H}), 3.06(\mathrm{q}, J=6.6 \mathrm{~Hz}, 2 \mathrm{H}), 2.92(\mathrm{q}, J=6.5 \mathrm{~Hz}, 2 \mathrm{H}), 2.39-2.24(\mathrm{~m}, 6 \mathrm{H})$, $2.14(\mathrm{~s} b r, 3 \mathrm{H}), 1.59-1.47(\mathrm{~m}, 4 \mathrm{H}), 1.36(\mathrm{~s}, 9 \mathrm{H}) \mathrm{ppm}^{\mathrm{k}}$

${ }^{13} \mathrm{C}-\mathrm{NMR}\left(126 \mathrm{MHz}\right.$, DMSO- $\left.d_{6}\right) \delta=170.4,161.3,158.5,158.4,156.9,155.6,133.8,128.3$, 126.3, 123.0, 122.8, 122.8, 122.2, 122.1, 121.4, 118.7, 118.5, 117.9, 107.6, 104.7, 104.5, $104.2,77.4,54.6,54.6,41.5,38.2,37.5,36.7,36.2,36.1,36.0,35.6,35.5,28.3,26.9$, $26.6 \mathrm{ppm}$.

DC: $\mathrm{R}_{\mathrm{f}}: 0.34\left(\mathrm{DCM} / \mathrm{MeOH} 9: 1+1 \% \mathrm{NEt}_{3}\right)$

MS (ESI): $\quad \quad m / z$ ber. für $\mathrm{C}_{39} \mathrm{H}_{55} \mathrm{~N}_{12} \mathrm{O}_{9}\left([\mathrm{M}+\mathrm{H}]^{+}\right)$: 835.9; gef.: 835.7.

HRMS (MALDI): $\quad m / z$ ber. für $\mathrm{C}_{39} \mathrm{H}_{55} \mathrm{~N}_{12} \mathrm{O}_{9}\left([\mathrm{M}+\mathrm{H}]^{+}\right)$: 835.42095; gef.: 835.42168.

${ }^{k}$ Ein Signal von 2 Protonen im Bereich von 3.4 ppm wird durch im Lösemittel vorhandenen Wasser überlagert. 


\subsubsection{Synthese von PA4-Boc}

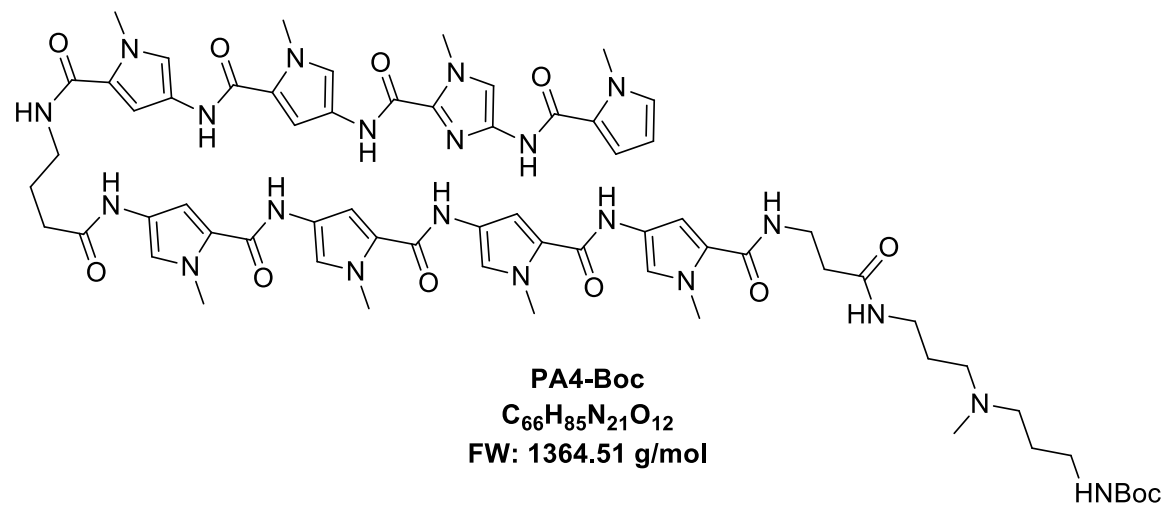

Verbindung 44 (50.0 mg, $59.5 \mu \mathrm{mol}, 1.0 \mathrm{eq})$ wurde $\mathrm{mit} \mathrm{Pd} / \mathrm{C}$ (5 mg, $10 \%$ auf Aktivkohle) in abs. DMF (2 mL) suspendiert und in einer $\mathrm{H}_{2}$-Atmosphäre $16 \mathrm{~h}$ bei RT gerührt.

Verbindung 39 (41.3 mg, $71.9 \mu \mathrm{mol}, 1.2 \mathrm{eq})$ wurde mit HBTU (29.0 mg, $77.4 \mu \mathrm{mol}, 1.3 \mathrm{eq})$ in abs. DMF $(1.5 \mathrm{~mL})$ aufgenommen, mit DIPEA $(20.0 \mu \mathrm{L}, 119 \mu \mathrm{mol}, 2.0 \mathrm{eq})$ versetzt und 5 min bei $0^{\circ} \mathrm{C}$ gerührt. Die resultierende Mischung wurde zu der Reduktions-Lösung gegeben und $5 \mathrm{~h}$ bei RT gerührt. Im Anschluss wurde die Suspension über Celite filtriert, das Filtrat mit konz. $\mathrm{NaHCO}_{3}$-Lösung $(20 \mathrm{~mL})$ sowie $\mathrm{H}_{2} \mathrm{O}(20 \mathrm{~mL})$ versetzt und mit $\mathrm{DCM}$ extrahiert. Die vereinigten organischen Phasen wurden über $\mathrm{MgSO}_{4}$ getrocknet und das Lösemittel unter vermindertem Druck entfernt. Das Rohprodukt wurde zweimal säulenchromatographisch (1. DCM/MeOH 5:1+1\% NEt 3 ; 2. DCM/MeOH 5:1 + $1 \% \mathrm{NH}_{3}$ ) gereinigt. Das Produkt konnte als beiger Feststoff erhalten werden

Ausbeute: $50.0 \mathrm{mg}, 36.6 \mu \mathrm{mol}, 62 \%$

${ }^{1} \mathrm{H}-\mathrm{NMR}\left(500 \mathrm{MHz}, \mathrm{DMSO}-d_{6}\right) \delta=10.22(\mathrm{~s}, 1 \mathrm{H}), 9.97(\mathrm{~s}, 1 \mathrm{H}), 9.94(\mathrm{~s}, 1 \mathrm{H}), 9.92-9-86(\mathrm{~m}$, $3 \mathrm{H}$ ), $9.84(\mathrm{~s}, 1 \mathrm{H}), 8.06(\mathrm{t}, J=5.7 \mathrm{~Hz}, 1 \mathrm{H}), 7.99(\mathrm{t}, J=5.6 \mathrm{~Hz}, 1 \mathrm{H}), 7.86(\mathrm{t}, J=5.5 \mathrm{~Hz}, 1 \mathrm{H}$ ), $7.55(\mathrm{~s}, 1 \mathrm{H}), 7.27(\mathrm{~d}, J=1.7 \mathrm{~Hz}, 1 \mathrm{H}), 7.26-7-22(\mathrm{~m}, 2 \mathrm{H}), 7.21-7.16(\mathrm{~m}, 3 \mathrm{H}), 7.13(\mathrm{~d}$, $J=1.7 \mathrm{~Hz}, 1 \mathrm{H}), 7.11(\mathrm{dd}, J=4.0,1.7 \mathrm{~Hz}, 1 \mathrm{H}), 7.08-7.03(\mathrm{~m}, 2 \mathrm{H}), 7.00-6.97(\mathrm{~m}, 1 \mathrm{H})$, $6.91(\mathrm{~d}, J=1.7 \mathrm{~Hz}, 1 \mathrm{H}), 6.89(\mathrm{~d}, J=1.6 \mathrm{~Hz}, 1 \mathrm{H}), 6.84(\mathrm{~d}, J=1.7 \mathrm{~Hz}, 1 \mathrm{H}), 6.76(\mathrm{t}, J=5.4 \mathrm{~Hz}$, 1H), 6.06 (dd, J=3.9, $2.5 \mathrm{~Hz}, 1 \mathrm{H}$ ), $3.99(\mathrm{~s}, 3 \mathrm{H}), 3.89(\mathrm{~s}, 3 \mathrm{H}), 3.86(\mathrm{~s}, 3 \mathrm{H}), 3.86(\mathrm{~s}, 3 \mathrm{H}), 3.85$ (s, 3H), $3.84(\mathrm{~s}, 3 \mathrm{H}), 3.81(\mathrm{~s}, 3 \mathrm{H}), 3.80(\mathrm{~s}, 3 \mathrm{H}), 3.22(\mathrm{q}, J=6.5 \mathrm{~Hz}, 2 \mathrm{H}), 3.06$ (q, J = $6.7 \mathrm{~Hz}$, $2 \mathrm{H}), 2.92(\mathrm{q}, J=6.6 \mathrm{~Hz}, 2 \mathrm{H}), 2.35-2.20(\mathrm{~m}, 8 \mathrm{H}), 2.09(\mathrm{~s}, 3 \mathrm{H}), 1.84-1.76(\mathrm{~m}, 2 \mathrm{H})$, $1.55-1.45(\mathrm{~m}, 4 \mathrm{H}), 1.36(\mathrm{~s}, 9 \mathrm{H}) \mathrm{ppm}$.

${ }^{13} \mathrm{C}-N M R\left(126 \mathrm{MHz}\right.$, DMSO- $\left.d_{6}\right) \delta=170.4,169.3,161.3,161.2,158.8,158.5,158.5,158.5$, $158.4,155.8,155.6,136.2,134.1,128.9,124.6,123.1,123.0,122.8,122.8,122.7,122.2$, 122.2, 122.2, 122.1, 122.0, 121.2, 118.5, 118.4, 118.2, 117.9, 114.6, 113.8, 107.0, 104.7,

\footnotetext{
' Ein Signal von 2 Protonen im Bereich von 3.4 ppm wird durch im Lösemittel vorhandenen Wasser überlagert.
} 
104.7, 104.3, 104.2, 104.0, 77.4, 54.8, 54.7, 41.7 38.3, 38.2, 36.8, 36.4, 36.2, 36.1, 36.0, $36.0,35.6,35.5,34.9,33.3,28.3,27.1,26.8,25.7$ ppm.

DC: $\mathrm{R}_{\mathrm{f}}: 0.28\left(\mathrm{DCM} / \mathrm{MeOH} 5: 1+1 \% \mathrm{NH}_{3}\right)$

MS (ESI): $\quad m / z$ ber. für $\mathrm{C}_{66} \mathrm{H}_{86} \mathrm{~N}_{21} \mathrm{O}_{12}\left([\mathrm{M}+\mathrm{H}]^{+}\right): 1364.7$; gef.: 1364.7

MS (MALDI): $\quad m / z$ ber. für $\mathrm{C}_{66} \mathrm{H}_{86} \mathrm{~N}_{21} \mathrm{O}_{12}\left([\mathrm{M}+\mathrm{H}]^{+}\right): 1364.6759 ;$ gef.: 1364.2140 .

\subsubsection{Synthese von PA4}

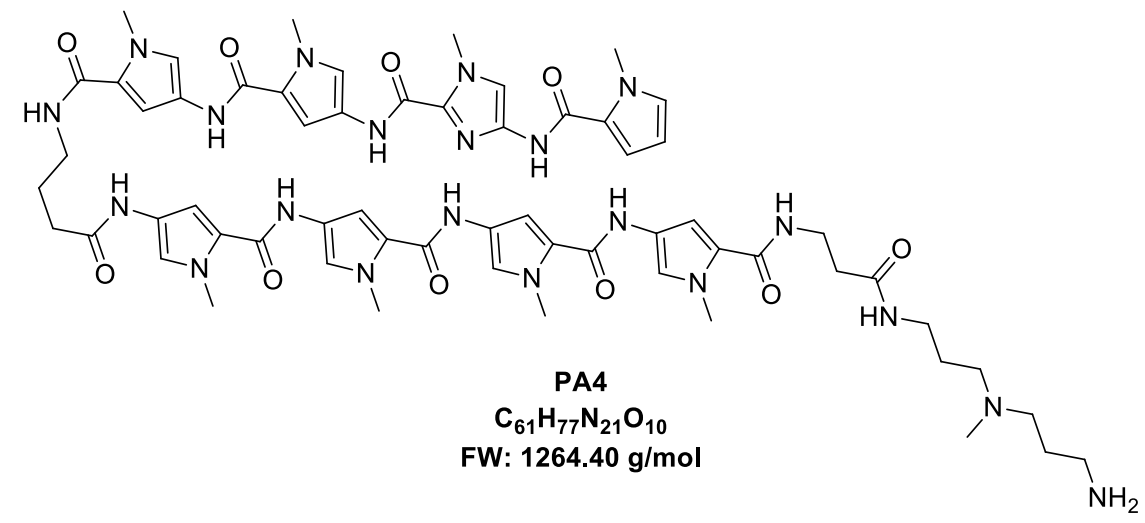

PA4-Boc (20 mg, $16 \mu \mathrm{mol})$ wurde in DCM/TFA (1:1, $1 \mathrm{~mL})$ für $1.5 \mathrm{~h}$ bei $0{ }^{\circ} \mathrm{C}$ gerührt. Das Lösemittel wurde im Vakuum entfernt und der braune Rückstand getrocknet. Dieser konnte ohne weitere Aufarbeitung weiter umgesetzt werden.

Ausbeute: Quantitativ.

MS (ESI): $\quad \quad m / z$ ber. für $\mathrm{C}_{61} \mathrm{H}_{78} \mathrm{~N}_{21} \mathrm{O}_{10}\left([\mathrm{M}+\mathrm{H}]^{+}\right)$: 1264.6; gef.: 1264.6.

$m / z$ ber. für $\mathrm{C}_{61} \mathrm{H}_{79} \mathrm{~N}_{21} \mathrm{O}_{10}\left([\mathrm{M}+2 \mathrm{H}]^{+}\right)$: 632.8; gef.: 633.0 .

MS (MALDI): $\quad m / z$ ber. für $\mathrm{C}_{61} \mathrm{H}_{78} \mathrm{~N}_{21} \mathrm{O}_{10}\left([\mathrm{M}+\mathrm{H}]^{+}\right):$1264.6235; gef.: 1264.4244 .

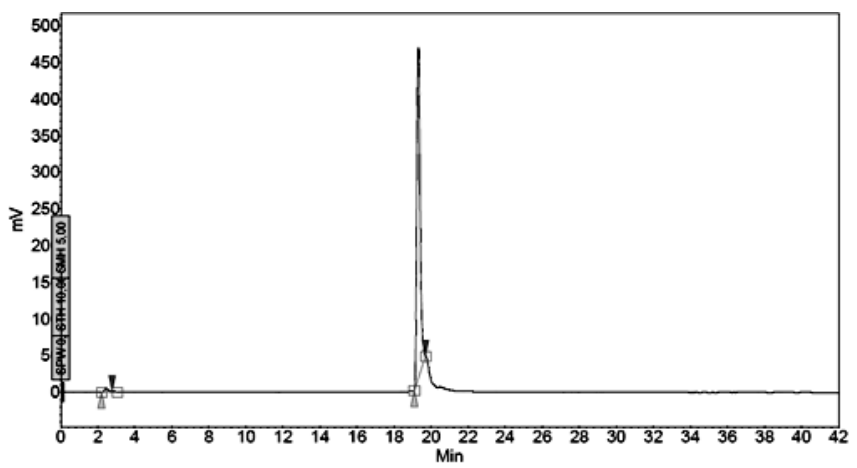

Abbildung 98: rp-HPLC-Chromatogramm nach der Reinigung von PA4. Linearer Gradient von $10 \%$ B zu $70 \%$ B in 30 min. A: $0.1 \%$ TFA in $\mathrm{H}_{2} \mathrm{O}$; $\mathrm{B}$ : $\mathrm{ACN}$. 


\subsubsection{Synthese von PA3-Boc}

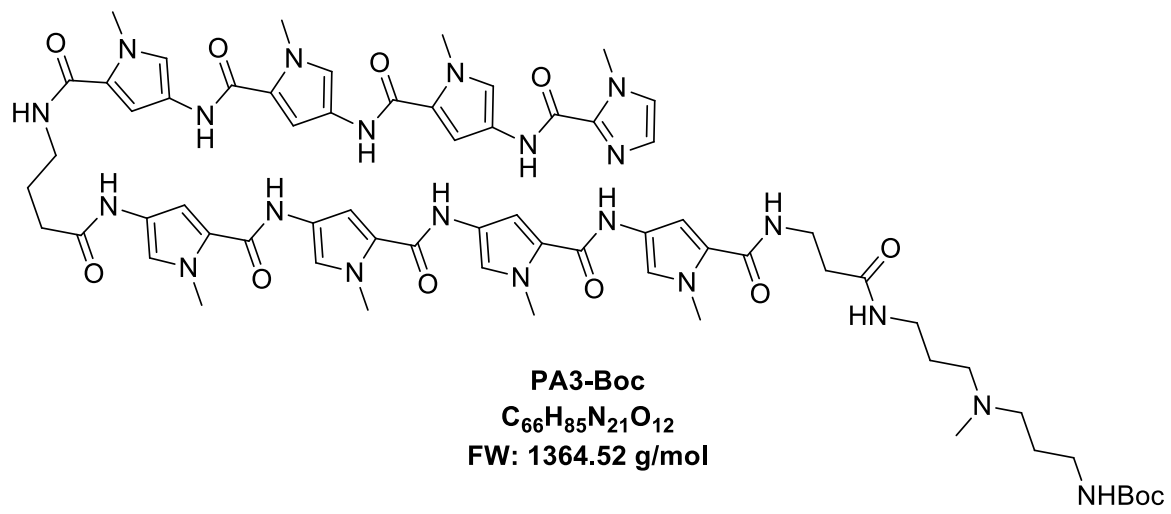

Verbindung 44 (50.0 mg, 59.9 umol, 1.0 eq) wurde mit Pd/C (5 mg, $10 \%$ auf Aktivkohle) in abs. DMF (5 mL) suspendiert und in einer $\mathrm{H}_{2}$-Atmosphäre bei $\mathrm{RT} 24 \mathrm{~h}$ gerührt.

Verbindung 41 (41.5 mg, $71.9 \mu \mathrm{mol}, 1.2 \mathrm{eq})$ und HBTU (29.5 mg, $77.4 \mu \mathrm{mol}, 1.3 \mathrm{eq})$ wurde in abs. DMF ( $1 \mathrm{~mL})$ gelöst, mit DIPEA ( $20 \mu \mathrm{l}, 110 \mu \mathrm{mol}, 2 \mathrm{eq})$ versetzt und $5 \mathrm{~min}$ bei RT gerührt. Die resultierende Lösung wurde zu der Reduktionsmischung gegeben und $5 \mathrm{~h}$ bei $60^{\circ} \mathrm{C}$ sowie im Anschluss für weitere $19 \mathrm{~h}$ bei RT gerührt. Die Lösung wurde über Celite filtriert, mit einer $20 \%$ igen $\mathrm{NaHCO}_{3}$-Lösung $(40 \mathrm{~mL}$ ) versetzt und mit DCM extrahiert. Die vereinigten organischen Phasen wurden über $\mathrm{MgSO}_{4}$ getrocknet und das Lösemittel unter vermindertem Druck entfernt. Das Rohprodukt wurde zweimal säulenchromatographisch (DCM/MeOH 9:1 auf 5:1 + 1\% $\mathrm{NH}_{3}$ ) gereinigt. Das Produkt konnte als beiger Feststoff erhalten werden.

Ausbeute: $20 \mathrm{mg}, 15 \mu \mathrm{mol}, 26 \%$.

${ }^{1} \mathrm{H}-\mathrm{NMR}\left(500 \mathrm{MHz}, \mathrm{DMSO}-d_{6}\right) \delta=10.43(\mathrm{~s}, 1 \mathrm{H}), 9.97(\mathrm{~s}, 1 \mathrm{H}), 9.94(\mathrm{~s}, 1 \mathrm{H}), 9.92(\mathrm{~s}, 1 \mathrm{H})$, $9.92-9.88(\mathrm{~m}, 3 \mathrm{H}) 8.11-8.05(\mathrm{~m}, 2 \mathrm{H}), 8.03(\mathrm{t}, J=5.6 \mathrm{~Hz}, 1 \mathrm{H}), 7.39(\mathrm{~d}, J=0.6 \mathrm{~Hz}, 1 \mathrm{H})$, $7.30(\mathrm{~d}, J=1.8 \mathrm{~Hz}, 1 \mathrm{H}), 7.25-7.23(\mathrm{~m}, 3 \mathrm{H}), 7.20-7.16(\mathrm{~m}, 4 \mathrm{H}), 7.09-7.05(\mathrm{~m}, 3 \mathrm{H}), 7.04$ (d, $J=1.0 \mathrm{~Hz}, 1 \mathrm{H}), 6.94-6.89(\mathrm{~m}, 3 \mathrm{H}), 6.87(\mathrm{~d}, J=1.7 \mathrm{~Hz}, 1 \mathrm{H}), 4.00(\mathrm{~s}, 3 \mathrm{H}), 3.88-3.85$ $(\mathrm{m}, 9 \mathrm{H}), 3.84(\mathrm{~s}, 3 \mathrm{H}), 3.84(\mathrm{~s}, 3 \mathrm{H}), 3.81(\mathrm{~s}, 3 \mathrm{H}), 3.81(\mathrm{~s}, 3 \mathrm{H}), 3.41-3.36(\mathrm{~m}, 2 \mathrm{H}), 3.22(\mathrm{q}$, $J=6.3 \mathrm{~Hz}, 2 \mathrm{H}), 3.12(\mathrm{q}, J=6.0 \mathrm{~Hz}, 2 \mathrm{H}), 3.00-2.89(\mathrm{~m}, 6 \mathrm{H}), 2.63(\mathrm{~s}, 3 \mathrm{H}), 2.34$ (t, $J=7.1 \mathrm{~Hz}, 2 \mathrm{H}), 2.30$ (t, $J=7.5 \mathrm{~Hz}, 2 \mathrm{H}), 1.83-1.71(\mathrm{~m}, 6 \mathrm{H}), 1.37(\mathrm{~s}, 9 \mathrm{H}) \mathrm{ppm}$.

${ }^{13}$ C-NMR $\left(126 \mathrm{MHz}\right.$, DMSO- $\left.d_{6}\right) \delta=170.9,169.3,161.3,161.3,158.5,158.5$ 158.5, 156.1, 155.7, 138.8, 127.0, 126.4, 123.1, 123.0, 122.8, 122.8, 122.8, 122.7 122.2, 122.2, 122.2, 122.1, 121.5, 118.7, 118.5, 118.5 118.2, 118.0, 117.8, 105.0, 104.8, 104.3, 104.0, 77.8, $53.153 .0,38.2,37.2,36.1,36.1,36.0,35.8,35.6,35.5,35.1,33.3$, 28.2, 25.8, 24.3, $24.1 \mathrm{ppm}$.

DC: $\mathrm{R}_{\mathrm{f}}: 0.35$ (DCM:MeOH 5:1+1\% $\left.\mathrm{NH}_{3}\right)$ 
MS (ESI): $\quad m / z$ ber. für $\mathrm{C}_{66} \mathrm{H}_{86} \mathrm{~N}_{21} \mathrm{O}_{12}\left([\mathrm{M}+\mathrm{H}]^{+}\right): 1364.7$; gef.: 1365.4.

MS (MALDI): $\quad m / z$ ber. für $\mathrm{C}_{66} \mathrm{H}_{85} \mathrm{~N}_{21} \mathrm{O}_{12}\left([\mathrm{M}]^{+}\right):$1363.6687; gef.: 1363.9575 .

\subsubsection{Synthese von $\mathrm{O}_{2} \mathrm{~N}-\mathrm{Py}$-Py-Py-Py-Linker-Boc 45}

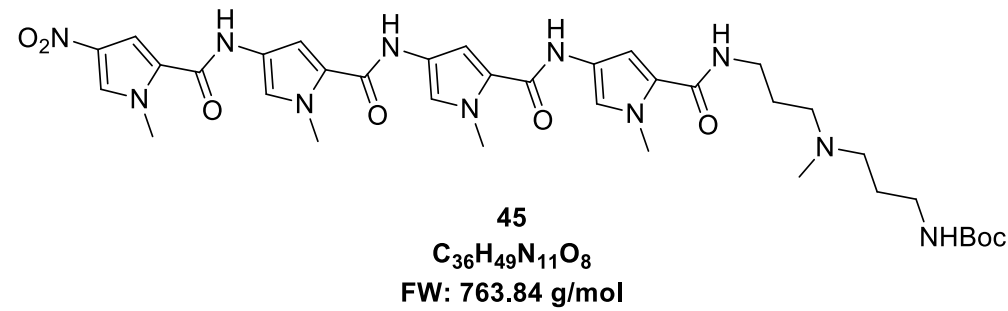

Verbindung 34 (100 mg, $186 \mu \mathrm{mol}, 1$ eq) wurde in abs. DMF (2 mL) gelöst und mit HOBt (28.5 mg, $186 \mu \mathrm{mol}, 1 \mathrm{eq}$ ), Verbindung 31 (54.7 mg, $223 \mu \mathrm{mol}, 1.2 \mathrm{eq}$ ) sowie DIPEA (63 $\mu \mathrm{l}$, $370 \mu \mathrm{mol}, 2 \mathrm{eq})$ versetzt. Man erwärmte auf $60^{\circ} \mathrm{C}$ und gab DIC (57 $\left.\mu \mathrm{l}, 370 \mu \mathrm{mol}, 2 \mathrm{eq}\right) \mathrm{zu}$. Es wurde $3 \mathrm{~h}$ bei $60^{\circ} \mathrm{C}$ und $18.5 \mathrm{~h}$ bei RT gerührt. Das Lösemittel wurde im Vakuum entfernt. Das Rohprodukt wurde zweimal säulenchromatographisch (1. DCM/MeOH $9: 1+1 \% \mathrm{NEt}_{3}$, 2. DCM/MeOH 9:1+1\% $\mathrm{NH}_{3}$ ) gereinigt. Das Produkt wurde als gelber Feststoff erhalten.

Ausbeute: $118 \mathrm{mg}, 154 \mu \mathrm{mol}, 83 \%$

${ }^{1} \mathrm{H}-\mathrm{NMR}\left(500 \mathrm{MHz}, \mathrm{DMSO}-\mathrm{d}_{6}\right) \delta=10.30(\mathrm{~s}, 1 \mathrm{H}), 10.00(\mathrm{~s}, 1 \mathrm{H}), 9.90(\mathrm{~s}, 1 \mathrm{H}), 8.20(\mathrm{~d}$, $J=1.7 \mathrm{~Hz}, 1 \mathrm{H}), 8.03(\mathrm{t}, J=5.6 \mathrm{~Hz}, 1 \mathrm{H}), 7.60(\mathrm{~d}, J=1.9 \mathrm{~Hz}, 1 \mathrm{H}), 7.28(\mathrm{~d}, J=1.6 \mathrm{~Hz}, 1 \mathrm{H})$, $7.25(\mathrm{~d}, J=1.6 \mathrm{~Hz}, 1 \mathrm{H}), 7.18(\mathrm{~d}, J=1.6 \mathrm{~Hz}, 1 \mathrm{H}), 7.08-7.03(\mathrm{~m}, 2 \mathrm{H}), 6.84(\mathrm{~d}, J=1.7 \mathrm{~Hz}$, $1 \mathrm{H}), 6.79(\mathrm{t}, J=5.4 \mathrm{~Hz}, 1 \mathrm{H}), 3.97(\mathrm{~s}, 3 \mathrm{H}), 3.87(\mathrm{~s}, 3 \mathrm{H}), 3.85$ (s, 3H), 3.80 (s, 3H), 3.19 (q, $J=6.6 \mathrm{~Hz}, 2 \mathrm{H}), 2.94(\mathrm{q}, J=6.6 \mathrm{~Hz}, 2 \mathrm{H}), 2.34-2.23(\mathrm{~m}, 4 \mathrm{H}), 2.12(\mathrm{~s}, 3 \mathrm{H}), 1.65-1.57(\mathrm{~m}$, $2 \mathrm{H}), 1.55-1.48(\mathrm{~m}, 2 \mathrm{H}), 1.36(\mathrm{~s}, 9 \mathrm{H}) \mathrm{ppm}$.

${ }^{13} \mathrm{C}-N M R\left(126 \mathrm{MHz}\right.$, DMSO- $\left.d_{6}\right) \delta=161.2,158.5,158.4,156.9,155.6,133.8,128.3,126.3$, 123.0, 122.8, 122.1, 121.4, 118.6, 118.5, 117.7, 107.6, 104.7, 104.5, 104.0, 77.3, 55.2, $54.8,41.8,38.3,37.5,37.0,36.2,36.1,35.9,28.3,27.2,27.0$ ppm.

DC: $R_{\mathrm{f}}: 0.62\left(\mathrm{DCM} / \mathrm{MeOH} 9: 1+1 \% \mathrm{NH}_{3}\right)$

MS (ESI): $\quad \quad m / z$ ber. für $\mathrm{C}_{36} \mathrm{H}_{50} \mathrm{~N}_{11} \mathrm{O}_{8}\left([\mathrm{M}+\mathrm{H}]^{+}\right):$764.4; gef.: 764.6.

HRMS (MALDI): $\quad m / z$ ber. für $\mathrm{C}_{36} \mathrm{H}_{50} \mathrm{~N}_{11} \mathrm{O}_{8}\left([\mathrm{M}+\mathrm{H}]^{+}\right):$764.38383; gef.: 764.38435 . 


\subsubsection{Synthese von PA6-Boc}

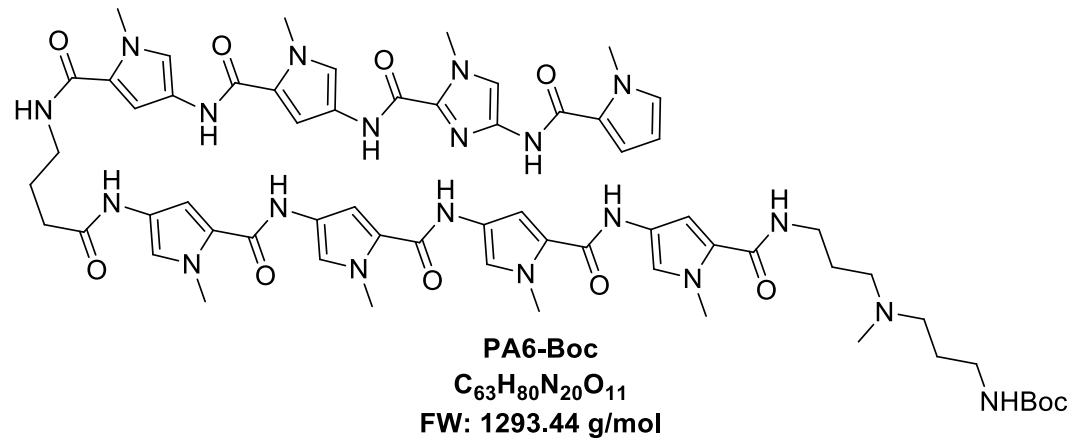

Verbindung 45 (50.0 mg, $65.4 \mu \mathrm{mol}, 1.1 \mathrm{eq})$ wurde in abs. DMF (5 mL) gelöst und $\mathrm{mit} \mathrm{Pd/C}$ (18 mg, $10 \%$ auf Aktivkohle) versetzt. Die Lösung rührte man für $17.5 \mathrm{~h}$ in einer $\mathrm{H}_{2}$-Atmosphäre.

Verbindung 39 (35.4 mg, $61.3 \mu \mathrm{mol}, 1.0 \mathrm{eq})$ und HBTU (25.6 mg, $67 \mu \mathrm{mol}, 1.1 \mathrm{eq})$ wurden in abs. DMF $(0.5 \mathrm{~mL})$ gelöst und mit DIPEA $(22.3 \mu \mathrm{L}, 131 \mu \mathrm{mol}, 2.1 \mathrm{eq}) \mathrm{zu}$ der Reduktionslösung gegeben. Diese rührte man in einer Argon-Atmosphäre $4 \mathrm{~h}$ bei $60^{\circ} \mathrm{C} . \mathrm{Im}$ Anschluss wurde die Suspension über Celite filtriert und das Lösemittel unter vermindertem Druck entfernt. Nach einer säulenchromatographischen Reinigung (DCM/MeOH 9:1 auf $5: 1+1 \% \mathrm{NH}_{3}$ ) wurde PA6-Boc als beiger Feststoff erhalten.

Ausbeute: $58 \mathrm{mg}, 45.1 \mu \mathrm{mol}, 73 \%$.

${ }^{1} \mathrm{H}-\mathrm{NMR}\left(500 \mathrm{MHz}, \mathrm{DMSO}-d_{6}\right) \delta=10.22(\mathrm{~s}, 1 \mathrm{H}), 9.95(\mathrm{~s}, 1 \mathrm{H}), 9.93(\mathrm{~s}, 1 \mathrm{H}), 9.91(\mathrm{~s}, 2 \mathrm{H})$, $9.89(\mathrm{~s}, 1 \mathrm{H}), 9.85(\mathrm{~s}, 1 \mathrm{H}), 8.05(\mathrm{t}, J=5.6 \mathrm{~Hz}, 2 \mathrm{H}), 7.55(\mathrm{~s}, 1 \mathrm{H}), 7.28(\mathrm{~d}, J=1.8 \mathrm{~Hz}, 1 \mathrm{H})$, $7.26-7.22(\mathrm{~m}, 2 \mathrm{H}), 7.20-7.16(\mathrm{~m}, 3 \mathrm{H}), 7.14(\mathrm{~d}, J=1.8 \mathrm{~Hz}, 1 \mathrm{H}), 7.11(\mathrm{dd}, J=4.0,1.7 \mathrm{~Hz}$, $1 \mathrm{H}), 7.08-7.05(\mathrm{~m}, 2 \mathrm{H}), 7.00-6.97(\mathrm{~m}, 1 \mathrm{H}), 6.92(\mathrm{~d}, J=1.8 \mathrm{~Hz}, 1 \mathrm{H}), 6.89(\mathrm{~d}, J=1.7 \mathrm{~Hz}$, $1 \mathrm{H}), 6.87(\mathrm{~d}, J=1.4 \mathrm{~Hz}, 1 \mathrm{H}), 6.85-6.78(\mathrm{~m}, 1 \mathrm{H}), 6.06(\mathrm{dd}, J=3.9,2.5 \mathrm{~Hz}, 1 \mathrm{H}), 3.99$ $(\mathrm{s}, 3 \mathrm{H}), 3.89(\mathrm{~s}, 3 \mathrm{H}), 3.86(\mathrm{~s}, 3 \mathrm{H}), 3.86(\mathrm{~s}, 3 \mathrm{H}), 3.85(\mathrm{~s}, 3 \mathrm{H}), 3.84(\mathrm{~s}, 3 \mathrm{H}), 3.82(\mathrm{~s}, 3 \mathrm{H}), 3.80$ (s, 3H), $3.25-3.18(\mathrm{~m}, 4 \mathrm{H}), 2.95(\mathrm{q}, J=6.5 \mathrm{~Hz}, 2 \mathrm{H}), 2.46(\mathrm{~s} b r, 3 \mathrm{H}), 2.35-2.15(\mathrm{~m}, 6 \mathrm{H})$, $1.84-1.77(\mathrm{~m}, 2 \mathrm{H}), 1.71-1.64(\mathrm{~m}, 2 \mathrm{H}), 1.61-1.54(\mathrm{~m}, 2 \mathrm{H}), 1.36(\mathrm{~s}, 9 \mathrm{H}) \mathrm{ppm}$.

${ }^{13}$ C-NMR $\left(126 \mathrm{MHz}\right.$, DMSO- $\left.d_{6}\right) \delta=169.3,161.3,158.8,158.5,158.5,158.5,158.4,155.8$, 155.6, 136.2, 134.1, 128.9, 124.6, 123.2, 123.0, 122.9, 122.8, 122.8, 122.7, 122.2, 122.2, 122.2, 122.1, 122.0, 121.2, 118.5, 118.4, 118.2, 117.9, 117.8, 114.6, 113.8, 107.0, 104.8 104.7, 104.7, 104.3, 104.2, 104.0, 77.5, 54.7, 54.4, 41.2, 38.2, 38.0, 36.7, 36.4, 36.2, 36.1, $36.0,35.9,34.9,33.3,28.3,26.4,25.7 \mathrm{ppm}$.

DC: $\mathrm{R}_{\mathrm{f}}: 0.40$ (DCM:MeOH 5:1+1\% $\mathrm{NH}_{3}$ )

MS (ESI): $\quad \quad m / z$ ber. für $\mathrm{C}_{63} \mathrm{H}_{81} \mathrm{~N}_{20} \mathrm{O}_{11}\left([\mathrm{M}+\mathrm{H}]^{+}\right)$: 1293.6; gef.: 1294.1.

MS (MALDI): $\quad m / z$ ber. für $\mathrm{C}_{63} \mathrm{H}_{81} \mathrm{~N}_{20} \mathrm{O}_{11}\left([\mathrm{M}+\mathrm{H}]^{+}\right):$1293.6388; gef.: 1293.5610 . 


\subsubsection{Synthese von PA6}

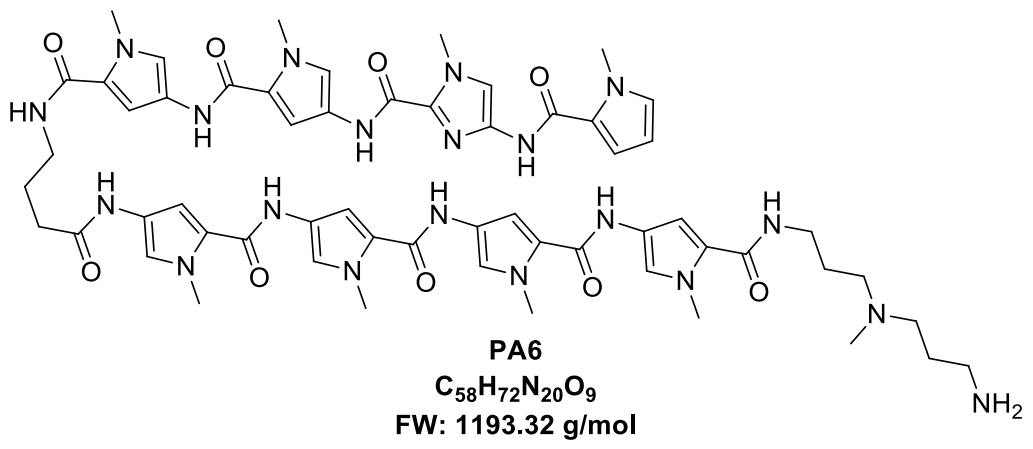

PA6-Boc (30 mg, $25 \mu \mathrm{mol}$ ) wurde in DCM/TFA (1:1, $1 \mathrm{~mL})$ für $1.5 \mathrm{~h}$ bei $0{ }^{\circ} \mathrm{C}$ gerührt. Das Lösemittel wurde im Vakuum entfernt und der braune Rückstand getrocknet. Dieser konnte ohne weitere Aufarbeitung weiter umgesetzt werden.

Ausbeute: Quantitativ.

MS (ESI): $\quad \quad m / z$ ber. für $\mathrm{C}_{58} \mathrm{H}_{73} \mathrm{~N}_{20} \mathrm{O}_{9}\left([\mathrm{M}+\mathrm{H}]^{+}\right):$1193.6; gef.: 1194.0.

$m / z$ ber. für $\mathrm{C}_{58} \mathrm{H}_{72} \mathrm{~N}_{20} \mathrm{O}_{9}\left([\mathrm{M}+2 \mathrm{H}]^{+}\right)$: 597.3; gef.: 597.6 .

MS (MALDI): $\quad$ m/ $z$ ber. für $\mathrm{C}_{58} \mathrm{H}_{73} \mathrm{~N}_{20} \mathrm{O}_{9}\left([\mathrm{M}+\mathrm{H}]^{+}\right):$1193.5864; gef.: 1192.3091.

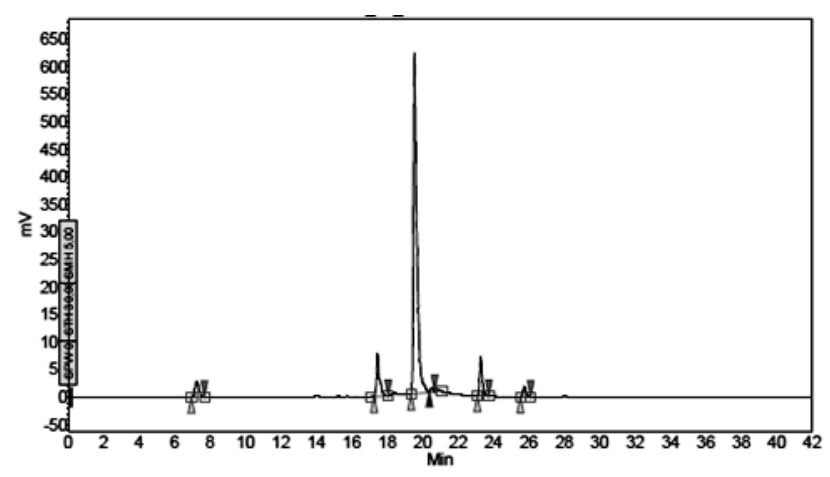

Abbildung 99: $r p$-HPLC-Chromatogramm vor der Reinigung von PA6. Linearer Gradient von $10 \%$ B zu $70 \%$ B in 30 min. A: $0.1 \%$ TFA in $\mathrm{H}_{2} \mathrm{O}$; $\mathrm{B}$ : ACN. 


\subsection{Synthese der Konjugate}

Es wurden $10 \mathrm{mg}$ des Trägers (ca. $250 \mathrm{nmol}$ ) mit darauf gebundenem voll geschützten $\mathrm{ON}$ (fast deprotection) in abs. DCM (1 mL) für 30 min aufgeschlämmt. Anschließend inkubierte man für 5 min mit 3\%iger TCA in abs. DCM (0.5 mL), um die MMT-Gruppe abzuspalten. Die orangefarbene Lösung wurde entfernt, der Träger kurz mit abs. DCM $(0.5 \mathrm{~mL})$ gewaschen und danach für weitere 5 min mit einer $3 \%$ igen TCA-Lösung $(0.5 \mathrm{~mL})$ behandelt. Anschließend wusch man fünfmal mit abs. ACN (je $0.5 \mathrm{~mL}$ ) und gab eine Lösung von DIPEA (1.7 $\mu \mathrm{L}, 10 \mu \mathrm{mol})$ und 1,6-Diisocyanatohexan $(8.42 \mu \mathrm{L}, 48 \mu \mathrm{mol})$ in abs. ACN $(1 \mathrm{~mL}) \mathrm{zu}$. Es wurde $18 \mathrm{~h}$ bei RT geschüttelt und anschließend fünfmal mit abs. ACN $(0.5 \mathrm{~mL})$ gewaschen.

Dann gab man eine Lösung des jeweiligen PIPs $(2.5 \mu \mathrm{mol}$, ca. 10 eq $)$ in abs. $\mathrm{MeOH}$ $(150 \mu \mathrm{L})$ sowie DIPEA $(25-75 \mu \mathrm{L})$ in abs. ACN $(750 \mu \mathrm{L}) \mathrm{zu}$. Im Anschluss wurde $24 \mathrm{~h}$ bei RT geschüttelt und dann fünfmal mit abs. ACN $(0.5 \mathrm{~mL})$ gewaschen.

Zur Abspaltung von der festen Phase wurde viermal 32\%ige $\mathrm{NH}_{3}$-Lösung $(0.5 \mathrm{~mL})$ zugegeben und jeweils 30 min bei RT geschüttelt. Im Anschluss erwärmte man die Lösung für $5 \mathrm{~h}$ auf $55^{\circ} \mathrm{C}$. Das Lösemittel wurde in einer Speedvac getrocknet und der Rückstand in Wasser aufgenommen. Zu der Lösung gab man Harnstoff, bis eine gesättigte Lösung entstand. Diese Mischung wurde mittels dPAGE (16 \%, 230 - $250 \mathrm{~V})$ getrennt, wobei im Fall des Konjugats $\mathrm{K} 9$ eine Temperatur von $50^{\circ} \mathrm{C}$ angelegt wurde. Die entsprechenden Banden wurden ausgeschnitten, das Konjugat aus der Gelmatrix gelöst und durch die Zugabe von Ethanol bei $-20^{\circ} \mathrm{C}$ gefällt. Die resultierenden Pellets wurden in Wasser aufgenommen und ihre Konzentration bestimmt.

K1:

Im-Py-Py- $\gamma$-Py-Py-Py- $\beta$-DMDPA- $\gamma-\mathrm{C}_{6}-\mathrm{C}_{6}{ }^{-5}{ }^{\prime}$ TTTTTATTCGATCGGGGCGGGGCGAGC

MS (ESI - TOF): $\quad m / z$ ber. für $\mathrm{C}_{332} \mathrm{H}_{431} \mathrm{~N}_{122} \mathrm{O}_{179} \mathrm{P}_{27}$ ([M]'): 9826.1 ; gef.: 9829.4

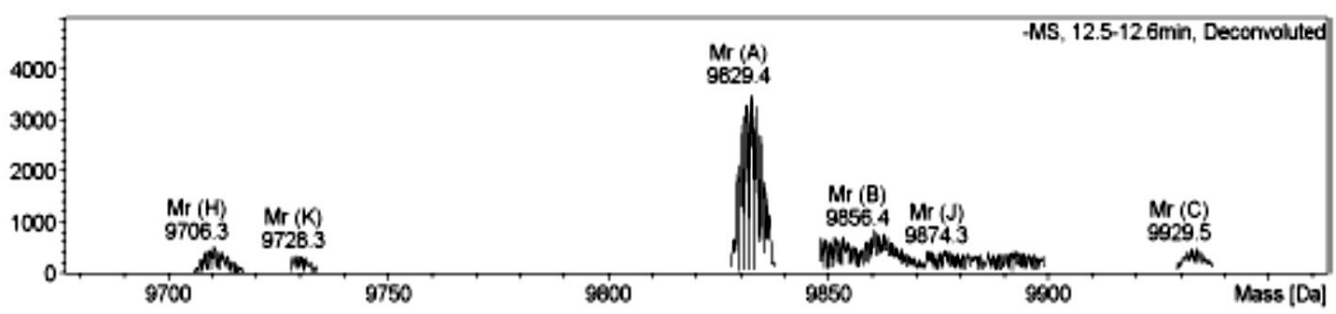


K2:

Im-Py-Py- $\gamma$-Py-Py-Py- $\beta$-DMDPA-C ${ }_{6}-\mathrm{C}_{6}{ }^{-}{ }^{\prime}$ TTTTTATTCGATCGGGGCGGGGCGAGC

MS (ESI - TOF): $\quad m / z$ ber. für $\mathrm{C}_{328} \mathrm{H}_{424} \mathrm{~N}_{121} \mathrm{O}_{178} \mathrm{P}_{27}$ ([M]') 9741.1; gef.: 9742.6

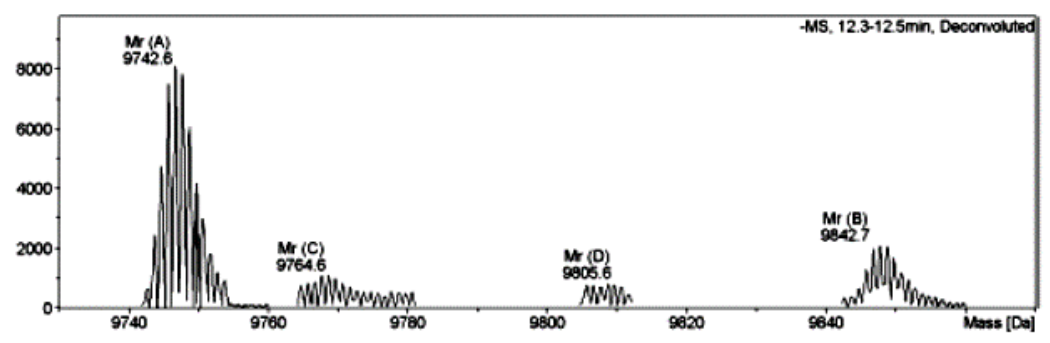

K3:

Im-Py-Py-Py- $\gamma$-Py-Py-Py-Py- $\beta$-DMDPA- ${ }_{6}-\mathrm{C}_{6}-$

5’TTTTTATTCGATCGGGGCGGGGCGAGC

MS (ESI - TOF): $\quad m / z$ ber. für $\mathrm{C}_{340} \mathrm{H}_{436} \mathrm{~N}_{125} \mathrm{O}_{180} \mathrm{P}_{27}$ ([M] ): 9985.2; gef.: 9986.8

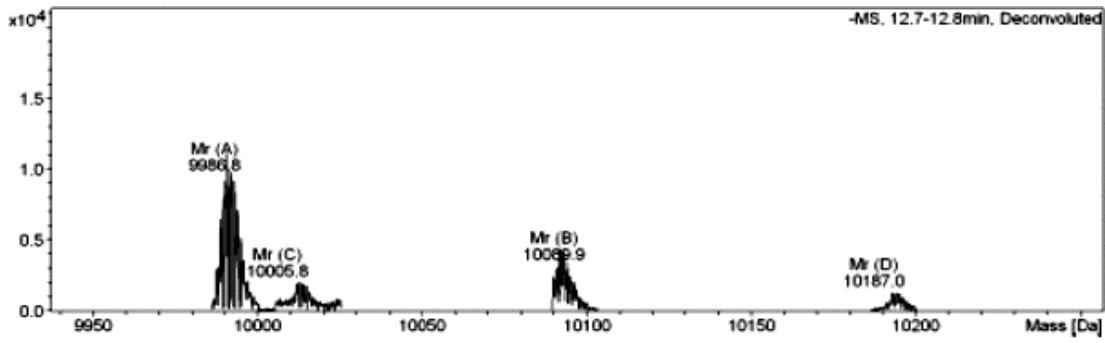

K4:

Im-Py-Py- $\gamma$-Py-Py-Py- $\beta$-DMDPA-C $6-\mathrm{C}_{6}{ }^{-5}{ }^{\prime}$ TTTTTGGCGAGGAGGGGCGTGGCCGGC MS (ESI - TOF): $\quad m / z$ ber. für $\mathrm{C}_{328} \mathrm{H}_{422} \mathrm{~N}_{127} \mathrm{O}_{177} \mathrm{P}_{27}\left([\mathrm{M}]^{-}\right): 9807.1$; gef.: 9809.0

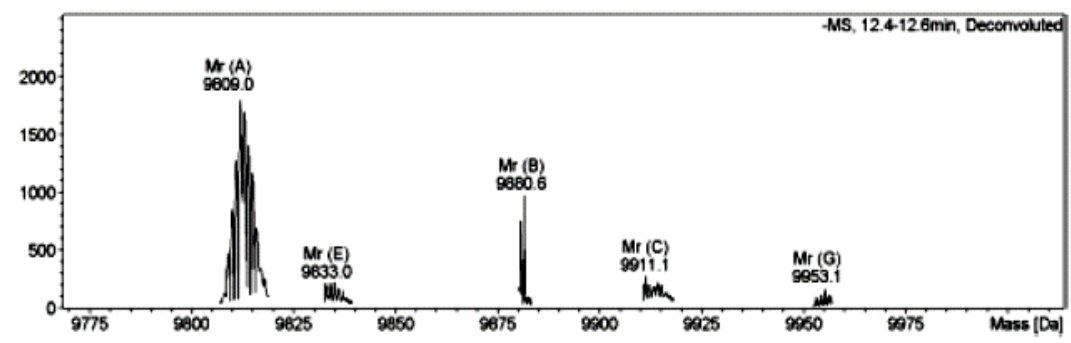


K5:

Py-Im-Py-Py- $\gamma-\mathrm{Py}-\mathrm{Py}$-Py-Py- $\beta$-DMDPA-C $6^{-} \mathrm{C}_{6}{ }^{-}$

5’TTTTTGGCGAGGAGGGGCGTGGCCGGC

MS (ESI - TOF): $\quad m / z$ ber. für $\mathrm{C}_{340} \mathrm{H}_{434} \mathrm{~N}_{131} \mathrm{O}_{179} \mathrm{P}_{27}$ ([M] ):10051.2; gef.: 10051.8

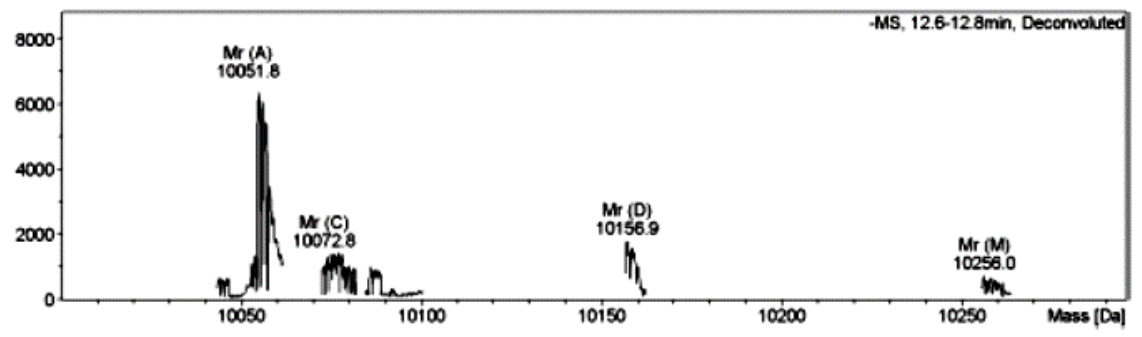

K6:

Py-Py-Py-Py- $\gamma$-Py-Im-Py-Py- $\beta$-DMDPA-C ${ }_{6}-\mathrm{C}_{6}{ }^{-}$

5’TTTTTGGCGAGGAGGGGCGTGGCCGGC

MS (ESI - TOF): $\quad m / z$ ber. für $\mathrm{C}_{340} \mathrm{H}_{434} \mathrm{~N}_{131} \mathrm{O}_{179} \mathrm{P}_{27}$ ([M]-): 10051.2; gef.: 10053.8

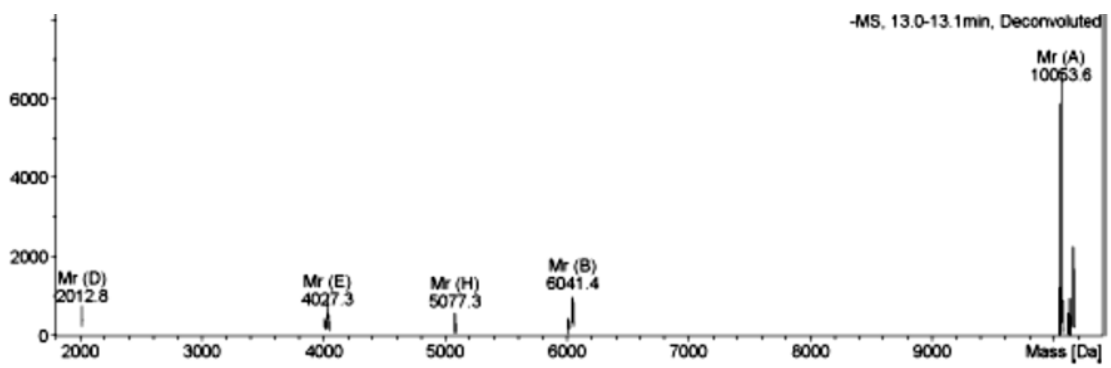

K7:

Py-Im-Py-Py- $\gamma$-Py-Py-Py-Py-DMDPA-C $6-\mathrm{C}_{6}{ }^{5}{ }^{5}$ TTTTTGGCGAGGAGGGGCGTGGCCGGC

MS (ESI - TOF): $\quad m / z$ ber. für $\mathrm{C}_{337} \mathrm{H}_{429} \mathrm{~N}_{130} \mathrm{O}_{178} \mathrm{P}_{27}$ ([M]'): 9980.1 ; gef.: 9987.0

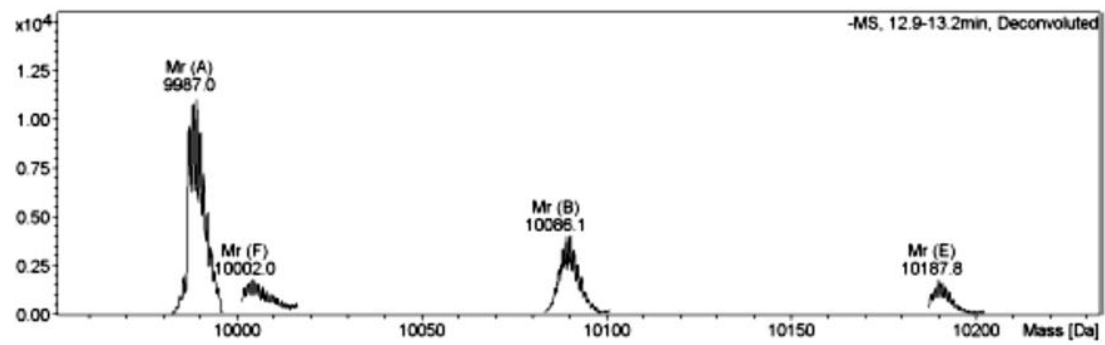


K8:

Im-Py-Py-Py- $\gamma-\mathrm{Py}-\mathrm{Py}$-Py-Py- $\beta$-DMDPA- $\mathrm{C}_{6}-\mathrm{C}_{6}{ }^{-}$

5`TTTTTGGCGAGGAGGGGCGTGGCCGGC

MS (ESI - TOF): $\quad m / z$ ber. für $\mathrm{C}_{340} \mathrm{H}_{434} \mathrm{~N}_{131} \mathrm{O}_{179} \mathrm{P}_{27}$ ([M]):10051.2; gef.: 10052.3

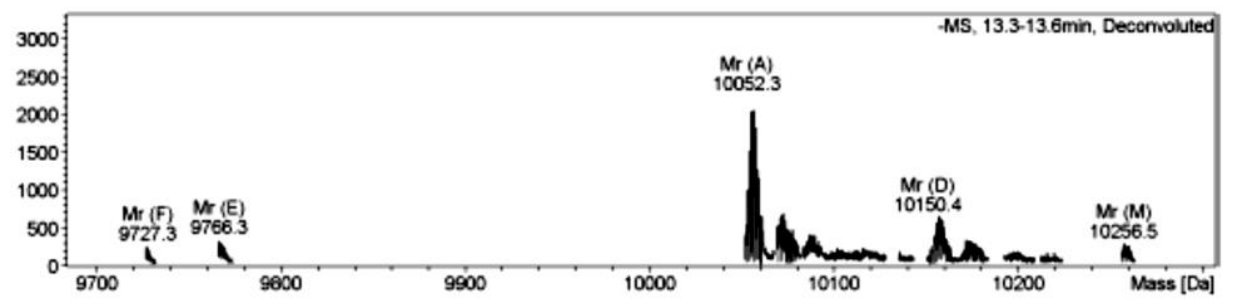

K9:

Py-Im-Py-Py- $\gamma-\mathrm{Py}-\mathrm{Py}-\mathrm{Py}-\mathrm{Py}-\beta$-DMDPA- $\mathrm{C}_{6}-\mathrm{C}_{6}{ }^{-}$

5`TTTTTGGCGAGGAGGGGCGTGGCCGGC-TTTTTGCCGGCCACGCCCCTCCTCGCC

Aufgrund der Läge des Konjugats musste es nach der Gelelektrophorese zusätzlich mittels rp-HPLC gereinigt werden.

Verwendete Geräte: Jasco DG-980-50, Jasco LG-980-02, Jasco Pu-980, Jasco UV-970, Jasco MD 2010 Plus; Säule: Macherey-Nagel 250/8/4 Nucleosil 120-5-C18.

Laufbedingungen A: Wasser, B: ACN, C: 1 M TEAA-Puffer; Fluss 4 mL/min

\begin{tabular}{|r|r|r|r|}
\hline \multicolumn{1}{|l|}{ Zeit } & A & B & \multicolumn{1}{l|}{ C } \\
\hline $0 \min$ & $85 \%$ & $5 \%$ & $10 \%$ \\
\hline $3 \min$ & $85 \%$ & $5 \%$ & $10 \%$ \\
\hline $25 \min$ & $50 \%$ & $40 \%$ & $10 \%$ \\
\hline $26.5 \min$ & $45 \%$ & $45 \%$ & $10 \%$ \\
\hline
\end{tabular}

In diesem Fall konnte keine Masse gemessen werden. Die Identität des Konjugats wurde über die UV-Absorption, das Laufverhalten und seine Bindungseigenschaften an die Ziel-DNA identifiziert. 


\subsection{Synthese der PNA-Bausteine}

10.9.1 Synthese von Ethyl-2-(2-(2-methyl-4-methoxybenzyl)thiouracil-1yl)acetat 48

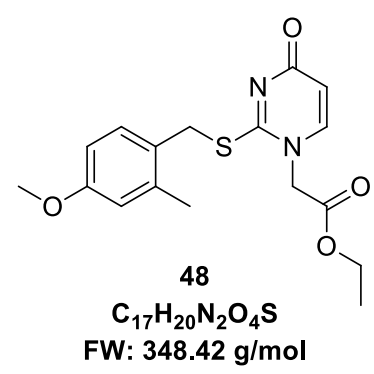

Verbindung 53 (200 mg, $762 \mu \mathrm{mol}, 1.0 \mathrm{eq})$ wurde in abs. DCM (5 mL) suspendiert. Dazu gab man HMDS (195 $\mu \mathrm{L}, 941 \mu \mathrm{mol}, 1.2 \mathrm{eq}$ ) sowie Saccharin (1.39 mg, $7.62 \mu \mathrm{mol}, 0.01 \mathrm{eq}$ ) und erhitzte die Lösung für $1 \mathrm{~h}$ zum Sieden. Im Anschluss wurde Verbindung 55 (243 mg, $1.03 \mu \mathrm{mol}, 1.4 \mathrm{eq})$ in abs. DCM (1 mL) zugegeben und für eine weitere Stunde refluxiert. Nachdem die Lösung auf RT abgekühlt war, gab man konz. $\mathrm{Na}_{2} \mathrm{CO}_{3}$-Lösung (12 mL) und $\mathrm{H}_{2} \mathrm{O}(5 \mathrm{~mL})$ zu. Die Mischung wurde mit DCM extrahiert und die vereinigten organischen Phasen über $\mathrm{Na}_{2} \mathrm{SO}_{4}$ getrocknet. Nach Entfernen des Lösemittels wurde das Rohprodukt säulenchromatographisch (EE/MeOH 19:1) gereinigt. 48 wurde als farbloser Feststoff erhalten.

Ausbeute: $214 \mathrm{mg}, 614 \mu \mathrm{mol}, 80 \%$.

${ }^{1} \mathrm{H}-N M R\left(500 \mathrm{MHz}, \mathrm{DMSO}-\mathrm{d}_{6}\right) \delta=7.67\left(\mathrm{~d}, J=7.5 \mathrm{~Hz}, 1 \mathrm{H}, \mathrm{C}^{6}-\mathrm{H}-\mathrm{U}_{\mathrm{s}}\right), 7.31(\mathrm{~d}, J=8.4 \mathrm{~Hz}$, $1 \mathrm{H}, \mathrm{C}^{6}-\mathrm{H}-\mathrm{Ar}$ ), 6.78 (d, J=2.4 Hz, 1H, C $\mathrm{C}^{3}-\mathrm{H}-\mathrm{Ar}$ ), 6.71 (dd, J=8.4, 2.6 Hz, 1H, C $\mathrm{C}^{5} \mathrm{H}-\mathrm{Ar}$ ), 5.94 (d, J=7.5 Hz, 1H, C $\mathrm{C}^{5} \mathrm{H}-\mathrm{U}_{\mathrm{s}}$ ), 4.78 (s, 2H, $\mathrm{CH}_{2}-\mathrm{N}$ ), 4.35 (s, 2H, $\mathrm{CH}_{2}-\mathrm{S}$ ), 4.16 (q, J = 7.1 Hz, $2 \mathrm{H}, \mathrm{CH}_{2}-\mathrm{O}$ ), $3.72(\mathrm{~s}, 3 \mathrm{H}, \mathrm{OMe}), 2.30\left(\mathrm{~s}, 3 \mathrm{H}, \mathrm{CH}_{3}-\mathrm{Ar}\right), 1.17$ (d, J=7.1 Hz, 3H, $\left.\mathrm{CH}_{3}\right)$ ppm.

${ }^{13} \mathrm{C}-N M R\left(126 \mathrm{MHz}\right.$, DMSO- $\left.d_{6}\right) \delta=167.0,166.4,162.4,158.9,145.5,138.5,131.5,125.1$, $115.9,111.3,108.6,61.7,55.0,52.5,33.3,19.0,13.9$ ppm.

DC: $R_{f}: 0.30$ (EE/MeOH 19:1).

MS (ESI): $\quad m / z$ ber. für $\mathrm{C}_{17} \mathrm{H}_{20} \mathrm{~N}_{2} \mathrm{NaO}_{4} \mathrm{~S}\left([\mathrm{M}+\mathrm{Na}]^{+}\right): 371.1$; gef.: 371.0 .

HRMS (MALDI): $\quad m / z$ ber. für $\mathrm{C}_{17} \mathrm{H}_{20} \mathrm{~N}_{2} \mathrm{NaO}_{4} \mathrm{~S}$ ([M+Na] $\left.]^{+}\right): 371.10360$; gef.: 371.10374 .

Schmelzpunkt: $121-122.5^{\circ} \mathrm{C}$. 
10.9.2 Synthese von 4-Methoxy-2-methylbenzylalkohol 50

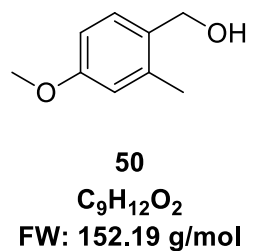

4-Methoxy-2-methylbenzylaldehyd (2.00 g, $13.3 \mathrm{mmol}, 1.0 \mathrm{eq})$ wurden in $\mathrm{EtOH}(32 \mathrm{~mL})$ gelöst und mit $\mathrm{NaBH}_{4}(0.55 \mathrm{~g}, 14.6 \mathrm{mmol} 1.1 \mathrm{eq})$ versetzt. Nach $15 \mathrm{~min}$ wurde $\mathrm{H}_{2} \mathrm{O}$ $(240 \mathrm{~mL})$ zugegeben. Die Lösung wurde mit $4 \mathrm{M} \mathrm{HCl}$ angesäuert und mit $\mathrm{Et}_{2} \mathrm{O}$ extrahiert. Die vereinigten organischen Phasen wurden mit $\mathrm{H}_{2} \mathrm{O}$ und Brine gewaschen und über $\mathrm{Na}_{2} \mathrm{SO}_{4}$ getrocknet. Das Lösemittel wurde entfernt und $\mathbf{5 0}$ als gelbes Öl erhalten.

Ausbeute: $1.91 \mathrm{~g}, 12.6 \mathrm{mmol}, 94 \%$.

${ }^{1} \mathrm{H}-\mathrm{NMR}\left(500 \mathrm{MHz}, \mathrm{CDCl}_{3}\right) \delta=7.23\left(\mathrm{~d}, J=8.3 \mathrm{~Hz}, 1 \mathrm{H}, \mathrm{C}^{6}-\mathrm{H}\right), 6.75(\mathrm{~d}, J=2.5 \mathrm{~Hz}, 1 \mathrm{H}, \mathrm{H}-\mathrm{C} 3)$, $6.72\left(\mathrm{dd}, J=8.3,2.6 \mathrm{~Hz}, 1 \mathrm{H}, \mathrm{C}^{5}-\mathrm{H}\right), 4.63\left(\mathrm{~s}, 2 \mathrm{H}, \mathrm{CH}_{2}\right), 3.80(\mathrm{~s}, 3 \mathrm{H}, \mathrm{OMe}) 2.37\left(\mathrm{~s}, 3 \mathrm{H}, \mathrm{CH}_{3}\right)$, $1.60(\mathrm{~s}, 1 \mathrm{H}, \mathrm{OH}) \mathrm{ppm}$.

${ }^{13}$ C-NMR $\left(126 \mathrm{MHz}, \mathrm{CDCl}_{3}\right) \delta=159.4,138.3,131.3,129.7,116.4,110.9,63.5,55.4$, $19.1 \mathrm{ppm}$.

DC: $R_{f}: 0.39(\mathrm{CH} / \mathrm{EE} \mathrm{2:1).}$

\subsubsection{Synthese von 2-(2-Methyl-4-methoxybenzyl)thiouracil 53}

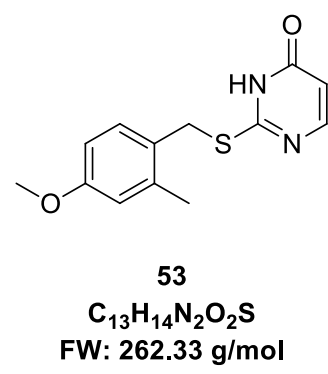

\section{Variante A:}

Verbindung 50 (4.00 g, $26.3 \mathrm{mmol}, 2.2$ eq.) wurde in DCM (160 mL) gelöst und auf $0{ }^{\circ} \mathrm{C}$ gekühlt. Zu dieser Lösung tropfte man langsam $\mathrm{PBr}_{3}(2.7 \mathrm{~mL}, 28.9 \mathrm{mmol}, 2.4 \mathrm{eq})$. Im Anschluss wurde 20 min bei $0^{\circ} \mathrm{C}$ gerührt und die Reaktionsmischung in eine eisgekühlte $\mathrm{NaHCO}_{3}$-Lösung gegeben. Die Reaktionsmischung wurde mit $\mathrm{Et}_{2} \mathrm{O}$ extrahiert, die vereinigten organischen Phasen mit $\mathrm{H}_{2} \mathrm{O}$ und Brine gewaschen und über $\mathrm{Na}_{2} \mathrm{SO}_{4}$ getrocknet. Das Lösemittel wurde unter vermindertem Druck entfernt. Das erhaltende Bromid wurde ohne weitere Aufreinigung weiter umgesetzt. 
2-Thiouracil (1.53 g, $11.9 \mathrm{mmol}, 1.0$ eq.) wurde in $\mathrm{EtOH}(15 \mathrm{~mL})$ suspendiert und mit einer wässrigen $\mathrm{KOH}$-Lösung ( $878 \mathrm{mg}, 15.7 \mathrm{mmol}, 1.3$ eq., in $15 \mathrm{~mL} \mathrm{H} \mathrm{H}_{2} \mathrm{O}$ ) versetzt. Die Suspension erhitzte man auf $45^{\circ} \mathrm{C}$, bis eine klare Lösung vorlag. Nachdem die Lösung auf RT abgekühlt war, wurde das Bromid in $\mathrm{EtOH}(9 \mathrm{~mL})$ gelöst und zur Reaktionsmischung hinzugegeben. Die entstandene Suspension wurde für $19 \mathrm{~h}$ bei RT gerührt. Nach Entfernen des Lösemittels unter vermindertem Druck, nahm man den Rückstand in einer konz. $\mathrm{NaHCO}_{3}$-Lösung (30 mL) auf. Die Mischung wurde filtriert und der erhaltende Feststoff mit $\mathrm{H}_{2} \mathrm{O}, \mathrm{EtOH}, \mathrm{EE}$ und $\mathrm{Et}_{2} \mathrm{O}$ gewaschen. Verbindung $\mathbf{5 3}$ wurde als farbloser Feststoff erhalten.

Ausbeute: $655 \mathrm{mg}, 2.50 \mathrm{mmol}, 21 \%$.

\section{Variante B:}

Verbindung 50 (500 mg, 3.29 mmol, 1.7 eq) wurde mit TMSCl (500 $\mu \mathrm{L}, 3.94 \mathrm{mmol}, 2.0$ eq) versetzt und $1 \mathrm{~h}$ bei RT gerührt.

2-Thiouracil (253 mg, 1,97 mmol, 1.0 eq) wurde zu einer Lösung von $\mathrm{KOH}$ (144 mg, $2.56 \mathrm{mg}, 1.3 \mathrm{eq})$ in $\mathrm{EtOH} / \mathrm{H}_{2} \mathrm{O}(1: 1,4 \mathrm{~mL})$ gegeben und auf $45^{\circ} \mathrm{C}$ erhitzt, bis das Reaktionsgemisch aufklarte. Nach dem dieses auf RT abgekühlt war, gab man die oben beschriebene Lösung zu. Im Anschluss wurde mit $\mathrm{KOH}$ ein basischer $\mathrm{pH}$-Wert eingestellt und die Mischung wurde 3 Tage bei RT gerührt. Das Solvens wurde entfernt und der Rückstand in einer konz. $\mathrm{NaHCO}_{3}$-Lösung $(10 \mathrm{~mL})$ aufgenommen. Die Mischung wurde filtriert und der erhaltende Feststoff mit $\mathrm{H}_{2} \mathrm{O}, \mathrm{EtOH}, \mathrm{EE}$ und $\mathrm{Et}_{2} \mathrm{O}$ gewaschen. Verbindung 53 wurde als farbloser Feststoff erhalten.

Ausbeute: $288 \mathrm{mg}, 1.08 \mathrm{mmol}, 56 \%$.

${ }^{1} \mathrm{H}-\mathrm{NMR}\left(500 \mathrm{MHz}, \mathrm{DMSO}-\mathrm{d}_{6}\right) \delta=12.64(\mathrm{~s} b r, 1 \mathrm{H}, \mathrm{NH}), 7.91$ (s $\left.b r, 1 \mathrm{H}, \mathrm{C}^{6}-\mathrm{H}-\mathrm{U}_{\mathrm{s}}\right), 7.28$ (d, $J=8.4 \mathrm{~Hz}, 1 \mathrm{H}, \mathrm{C}^{6}-\mathrm{H}-\mathrm{Ar}$ ), 6.78 (d, $J=2.4 \mathrm{~Hz}, 1 \mathrm{H}, \mathrm{C}^{3}-\mathrm{H}-\mathrm{Ar}$ ), 6.71 (dd, $J=8.4,2.6 \mathrm{~Hz}, 1 \mathrm{H}$, $\mathrm{C}^{5}-\mathrm{H}-\mathrm{Ar}$ ), 6.12 (d, J = 4.8 Hz, 1H, $\mathrm{C}^{5}-\mathrm{H}-\mathrm{U}_{\mathrm{s}}$ ), 4.35 (s, 2H, $\mathrm{CH}_{2}$ ), 3.71 (s, 3H, OMe), 2.31 (s, $\left.3 \mathrm{H}, \mathrm{CH}_{3}\right) \mathrm{ppm}$.

${ }^{13}$ C-NMR $\left(126 \mathrm{MHz}\right.$, DMSO- $\left.d_{6}\right) \delta=176.1,161.0,158.8,142.1,138.2,131.2,125.9,115.8$, 111.3, 105.3, 55.0, 31.9, 19.0 ppm.

DC: $R_{f}: 0.31(C H / E E ~ 1: 1)$.

MS (ESI): $\quad \quad m / z$ ber. für $\mathrm{C}_{13} \mathrm{H}_{14} \mathrm{~N}_{2} \mathrm{NaO}_{2} \mathrm{~S}\left([\mathrm{M}+\mathrm{Na}]^{+}\right)$: 285.1; gef.: 285.1.

HRMS (ESI): $\quad m / z$ ber. für $\mathrm{C}_{13} \mathrm{H}_{14} \mathrm{~N}_{2} \mathrm{NaO}_{2} \mathrm{~S}\left([\mathrm{M}+\mathrm{Na}]^{+}\right)$: 285.06682; gef.: 285.06700 .

Schmelzpunkt: $200-201^{\circ} \mathrm{C}$. 
10.9.4 Synthese von Ethoxycarbonyl-methyltrifluoromethansulfonat 55

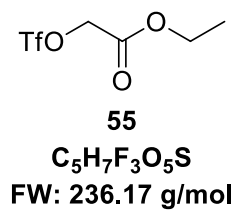

Ethyl-2-hydroxyacetat $(950 \mu \mathrm{L}, 10.0 \mathrm{mmol}, 1.0 \mathrm{eq})$, und abs. Pyridin (1.00 mL, $13.0 \mathrm{mmol}$, $1.3 \mathrm{eq})$ wurden in $\mathrm{DCM}(16 \mathrm{~mL})$ gelöst und auf $-70^{\circ} \mathrm{C}$ gekühlt. Dann wurde $\mathrm{Tf}_{2} \mathrm{O}(1.90 \mathrm{~mL}$, $11.5 \mathrm{mmol}, 1.2 \mathrm{eq})$ zugegeben, wobei die Temperatur unter $-60^{\circ} \mathrm{C}$ gehalten wurde. $\mathrm{Im}$ Anschluss wurde 30 min bei $-60^{\circ} \mathrm{C}$ und $1.5 \mathrm{~h}$ bei RT gerührt. Dann gab man $\mathrm{H}_{2} \mathrm{O}(20 \mathrm{~mL})$ und DCM zu, trennte die Phasen und extrahierte die wässrige Phase mit DCM. Die vereinigten organischen Phasen wurden über $\mathrm{Na}_{2} \mathrm{SO}_{4}$ getrocknet und das Lösemittel unter vermindertem Druck entfernt. Verbindung 55 wurde als braunes Öl erhalten und ohne weitere Reinigung verwendet.

Ausbeute: $1.98 \mathrm{~g}, 8.4 \mathrm{mmol}, 84 \%$.

${ }^{1} \mathrm{H}-\mathrm{NMR}\left(500 \mathrm{MHz}, \mathrm{CDCl}_{3}\right) \delta=4.90(\mathrm{~s}, 2 \mathrm{H}), 4.33(\mathrm{q}, J=7.2 \mathrm{~Hz}, 2 \mathrm{H}), 1.33(\mathrm{t}, J=7.2 \mathrm{~Hz}$, 3H) ppm.

${ }^{13} \mathrm{C}-\mathrm{NMR}\left(126 \mathrm{MHz}, \mathrm{CDCl}_{3}\right) \delta=164.6,118.6\left(\mathrm{q}, J_{\mathrm{CF}}=319.5 \mathrm{~Hz}\right), 69.1,63.0,14.1 \mathrm{ppm}$.

\subsubsection{Synthese von 2-(2-(2-Methyl-4-methoxybenzyl)thiouracil-1-yl)acetat 56}

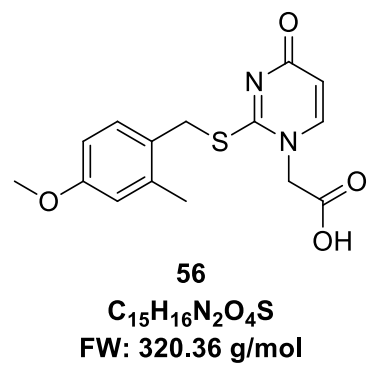

Zu einer Suspension von 48 (50 mg, $144 \mu \mathrm{mol}, 1.0 \mathrm{eq})$ in THF/MeOH $(7: 3,1.2 \mathrm{~mL})$ wurde eine $2 \mathrm{M}$ Lösung von $\mathrm{LiOH}$ in $\mathrm{H}_{2} \mathrm{O}(0.12 \mathrm{~mL}, 240 \mathrm{mmol} 1.7$ eq) gegeben und 20 min bei RT gerührt. Das Lösemittel wurde unter vermindertem Druck entfernt und der Rückstand in $\mathrm{H}_{2} \mathrm{O}(0.5 \mathrm{~mL})$ aufgenommen. Die Suspension wurde filtriert und der Feststoff mit EE und $\mathrm{Et}_{2} \mathrm{O}$ gewaschen und getrocknet. 56 wurde als farbloser Feststoff erhalten.

Ausbeute: $14 \mathrm{mg}, 44 \mu \mathrm{mol}, 30 \%$. 
${ }^{1} \mathrm{H}-\mathrm{NMR}\left(500 \mathrm{MHz}, \mathrm{DMSO}-d_{6}\right) \delta=13.62(\mathrm{~s} b r, 1 \mathrm{H}, \mathrm{COOH}), 7.67\left(\mathrm{~d}, J=7.5 \mathrm{~Hz}, 1 \mathrm{H}, \mathrm{C}^{6}-\mathrm{U}_{\mathrm{s}}\right.$ ), $7.31\left(\mathrm{~d}, J=8.4 \mathrm{~Hz}, 1 \mathrm{H}, \mathrm{C}^{6}-\mathrm{H}-\mathrm{Ar}\right), 6.78$. (d, $J=2.4 \mathrm{~Hz}, 1 \mathrm{H}, \mathrm{C}^{3}-\mathrm{H}-\mathrm{Ar}$ ), 6.71 (dd, $\left.J=8.3,2.6 \mathrm{~Hz}, 1 \mathrm{H}, \mathrm{C}^{5}-\mathrm{H}-\mathrm{Ar}\right), 5.92\left(\mathrm{~d}, J=7.5 \mathrm{~Hz}, 1 \mathrm{H}, \mathrm{C}^{5}-\mathrm{H}-\mathrm{U}_{\mathrm{s}}\right), 4.66\left(\mathrm{~s}, 2 \mathrm{H}, \mathrm{CH}_{2}-\mathrm{N}\right), 4.34$ (s, $2 \mathrm{H}, \mathrm{CH}_{2}-\mathrm{S}$ ), 3.72 (s, 3H, OMe), 2.30 (s, 3H, $\mathrm{CH}_{3}$ ) ppm.

${ }^{13} \mathrm{C}-N M R\left(126 \mathrm{MHz}\right.$, DMSO- $\left.d_{6}\right) \delta=168.4,166.6,162.4,158.9,145.7,138.5,131.5,125.2$, $115.9,111.3,108.5,55.0,52.6,33.2,19.1$ ppm.

\subsubsection{Synthese von 2-(4-Methoxybenzyl)thiouracil 61}

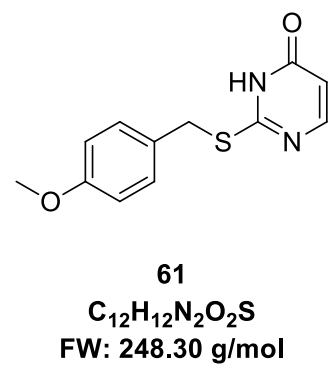

2-Thiouracil (640 mg, $4.99 \mathrm{mmol}, 1.0 \mathrm{eq})$ wurde in $\mathrm{EtOH} / \mathrm{H}_{2} \mathrm{O}(1: 1,6 \mathrm{~mL})$ suspendiert und mit KOH (395 mg, 7.04 mmol, 1.4 eq) versetzt. Nachdem eine klare Lösung entstand, gab man PMBCl ( $800 \mu \mathrm{L}, 7.92 \mathrm{mmol}, 1.6 \mathrm{eq})$ zu und rührte $1 \mathrm{~h}$ bei RT. Das EtOH wurde unter vermindertem Druck entfernt und der Rückstand in 50\%iger $\mathrm{NaHCO}_{3}$-Lösung aufgenommen. Der Niederschlag wurde abfiltriert und mit $50 \%$ iger $\mathrm{NaHCO}_{3}$, EE und $\mathrm{Et}_{2} \mathrm{O}$ gewaschen. 61 wurde als farbloser Feststoff erhalten.

Ausbeute: $767 \mathrm{mg}, 3.09 \mathrm{mmol}, 61 \%$.

${ }^{1} \mathrm{H}-\mathrm{NMR}\left(500 \mathrm{MHz}, \mathrm{DMSO}-d_{6}\right) \delta=12.44(\mathrm{~s} 1 \mathrm{H}, b r, \mathrm{NH}), 7.89\left(\mathrm{~d}, J=6.5 \mathrm{~Hz}, 1 \mathrm{H}, \mathrm{C}^{6}-\mathrm{H}-\mathrm{U}_{\mathrm{s}}\right)$, $7.34-7.30$ (m, 2H, $\left.\mathrm{C}^{2}-\mathrm{H}-\mathrm{Ar}\right), 6.90-6.84\left(\mathrm{~m}, 2 \mathrm{H}, \mathrm{C}^{3}-\mathrm{H}-\mathrm{Ar}\right), 6.10$ (d, J=6.5 Hz, $1 \mathrm{H}, \mathrm{C}^{5}-\mathrm{H}-\mathrm{U}_{\mathrm{s}}$ ), $4.33\left(\mathrm{~s}, 2 \mathrm{H}, \mathrm{CH}_{2}\right), 3.72(\mathrm{~s}, 3 \mathrm{H}, \mathrm{OMe}) \mathrm{ppm}$.

${ }^{13}$ C-NMR $\left(126 \mathrm{MHz}\right.$, DMSO- $\left.d_{6}\right) \delta=163.4,163.0,158.5,153.8,130.3,128.8,113.9,109.7$, $55.1,33.3$ ppm.

MS (ESI): $\quad m / z$ ber. für $\mathrm{C}_{12} \mathrm{H}_{11} \mathrm{~N}_{2} \mathrm{O}_{2} \mathrm{~S}\left([\mathrm{M}-\mathrm{H}]^{-}\right): 247.1$; gef.: 247.1 .

HRMS (MALDI): $\quad m / z$ ber. für $\mathrm{C}_{12} \mathrm{H}_{12} \mathrm{~N}_{2} \mathrm{NaO}_{2} \mathrm{~S}\left([\mathrm{M}+\mathrm{Na}]^{+}\right): 271.05117$; gef.: 271.05164 .

Schmelzpunkt: $201^{\circ} \mathrm{C}$. 
10.9.7 Synthese von Ethyl-2-(2-(4-methoxybenzyl)thiouracil-1-yl)acetat 62

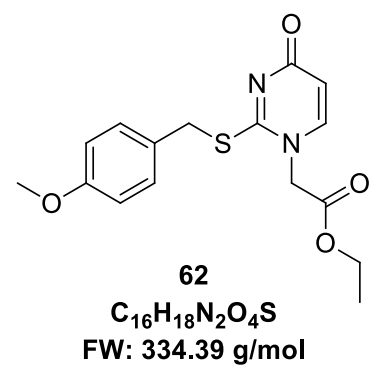

Zu einer Suspension von Verbindung 61 (500 mg, $2.01 \mathrm{mmol}, 1.0 \mathrm{eq})$ in DCM $(10 \mathrm{~mL})$ wurde HMDS ( $375 \mu \mathrm{L}, 1.81 \mu \mathrm{mol}, 0.9 \mathrm{eq})$ und Saccharin $(3.7 \mathrm{mg}, 20 \mu \mathrm{mol}, 0.01 \mathrm{eq})$ gegeben. Im Anschluss erhitzte man die Lösung für $1 \mathrm{~h}$ zum Sieden und gab dann Verbindung 55 (642 mg, $2.72 \mathrm{mmol}, 1.4 \mathrm{eq}$ ) in abs. DCM (1 mL) zu. Die Lösung wurde für eine weitere Stunde refluxiert und nach dem Abkühlen auf RT mit konz. $\mathrm{NaHCO}_{3}$-Lösung (5 mL), $\mathrm{H}_{2} \mathrm{O}(2 \mathrm{~mL}), \mathrm{MeOH}(5 \mathrm{~mL})$ und DCM $(10 \mathrm{~mL})$ versetzt. Die Mischung wurde mit $\mathrm{DCM}$ extrahiert und die vereinigten organischen Phasen über $\mathrm{Na}_{2} \mathrm{SO}_{4}$ getrocknet. Nach Entfernen des Lösemittels wurde das Rohprodukt säulenchromatographisch (EE/MeOH 9:1) gereinigt. 62 wurde als farbloser Feststoff erhalten.

Ausbeute: $387 \mathrm{mg}, 1.16 \mathrm{mmol}, 58 \%$.

${ }^{1} \mathrm{H}-\mathrm{NMR}\left(500 \mathrm{MHz}, \mathrm{DMSO}-d_{6}\right) \delta=7.67\left(\mathrm{~d}, J=7.6 \mathrm{~Hz}, 1 \mathrm{H}, \mathrm{C}^{6}-\mathrm{H}-\mathrm{U}_{\mathrm{s}}\right), 7.36-7.31(\mathrm{~m}, 2 \mathrm{H}$, $\mathrm{C}^{2}-\mathrm{H}-\mathrm{Ar}$ ), $6.90-6.85\left(\mathrm{~m}, 2 \mathrm{H}, \mathrm{C}^{3}-\mathrm{H}-\mathrm{Ar}\right), 5.94\left(\mathrm{~d}, J=7.5 \mathrm{~Hz}, 1 \mathrm{H}, \mathrm{C}^{5}-\mathrm{H}-\mathrm{U}_{\mathrm{s}}\right), 4.79(\mathrm{~s}, 2 \mathrm{H}$, $\mathrm{CH}_{2}-\mathrm{N}$ ), $4.36\left(\mathrm{~s}, 2 \mathrm{H}, \mathrm{CH}_{2}-\mathrm{S}\right.$ ), 4.16 (q, J = 7.1 Hz, 2H, $\mathrm{CH}_{2}-\mathrm{O}$ ), $3.72(\mathrm{~s}, 3 \mathrm{H}, \mathrm{OMe}), 1.17$ (t, $\left.J=7.1 \mathrm{~Hz}, 3 \mathrm{H}, \mathrm{CH}_{3}\right) \mathrm{ppm}$.

${ }^{13}$ C-NMR $\left(126 \mathrm{MHz}\right.$, DMSO-d $\left.d_{6}\right) \delta=167.1,166.5,162.4158 .7,145.6,130.5,128.0,113.9$, $108.7,61.8,55.1,52.5,34.4,14.0 \mathrm{ppm}$.

DC: $R_{f}: 0.42(E E: M e O H ~ 9: 1)$

MS (ESI): $\quad m / z$ ber. für $\mathrm{C}_{16} \mathrm{H}_{18} \mathrm{~N}_{2} \mathrm{NaO}_{4} \mathrm{~S}\left([\mathrm{M}+\mathrm{Naa}]^{+}\right): 357.1$; gef.: 357.2 .

HRMS (MALDI): $\quad m / z$ ber. für $\mathrm{C}_{16} \mathrm{H}_{19} \mathrm{~N}_{2} \mathrm{O}_{4} \mathrm{~S}\left([\mathrm{M}+\mathrm{H}]^{+}\right): 335.10600$; gef.: 335.10645 .

Schmelzpunkt: $137^{\circ} \mathrm{C}$. 
10.9.7.1Synthese von Ethyl-2-(thiouracil-1-yl)acetat 60

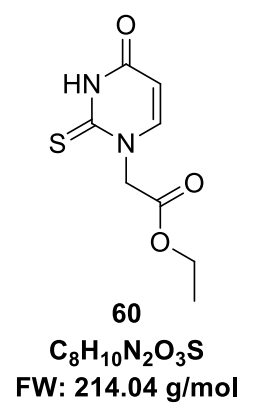

Verbindung 62 (20 mg) wurde in TFA/TIPS/ $\mathrm{H}_{2} \mathrm{O}(95: 2.5: 2.5,1 \mathrm{~mL})$ aufgenommen und $1 \mathrm{~h}$ bei RT gerührt. Das Lösemittel wurde unter vermindertem Druck entfernt und Verbindung 60 als farbloser Feststoff erhalten.

Ausbeute: Quantitativ.

${ }^{1} \mathrm{H}-N M R\left(500 \mathrm{MHz}, \mathrm{DMSO}-d_{6}\right) \delta=12.76(\mathrm{~s}, 1 \mathrm{H}, \mathrm{N}-\mathrm{H}) 7.83\left(\mathrm{~d}, J=7.8 \mathrm{~Hz}, 1 \mathrm{H}, \mathrm{C}^{6}-\mathrm{H}_{-} \mathrm{U}_{\mathrm{s}}\right)$, $6.01\left(\mathrm{dd}, J=7.9,2.2 \mathrm{~Hz}, 1 \mathrm{H}, \mathrm{C}^{5}-\mathrm{H}-\mathrm{U}_{\mathrm{s}}\right.$ ), $4.95\left(\mathrm{~s}, 2 \mathrm{H}, \mathrm{CH}_{2}-\mathrm{N}\right), 4.16$ (q, J=7.1 Hz, 2H, $\mathrm{CH}_{2}-\mathrm{O}$ ), $1.21\left(\mathrm{t}, J=7.1 \mathrm{~Hz}, 3 \mathrm{H}, \mathrm{CH}_{3}\right) \mathrm{ppm}$.

${ }^{13} \mathrm{C}-\mathrm{NMR}\left(126 \mathrm{MHz}, \mathrm{DMSO}-d_{6}\right) \delta=176.9,167.1,160.2,146.4,106.1,61.2,54.3,14.0 \mathrm{ppm}$. MS (ESI): $\quad \quad m / z$ ber. für $\mathrm{C}_{8} \mathrm{H}_{11} \mathrm{~N}_{2} \mathrm{NaO}_{3} \mathrm{~S}\left([\mathrm{M}+\mathrm{H}]^{+}\right): 215.1$; gef.: 215.1 .

HRMS (MALDI): $\quad m / z$ ber. für $\mathrm{C}_{8} \mathrm{H}_{11} \mathrm{~N}_{2} \mathrm{O}_{3} \mathrm{~S}\left([\mathrm{M}+\mathrm{H}]^{+}\right): 215.04849$; gef.: 215.04859 .

\subsubsection{Synthese von 2-(2-(4-Methoxybenzyl)thiouracil-1-yl)acetat 63}

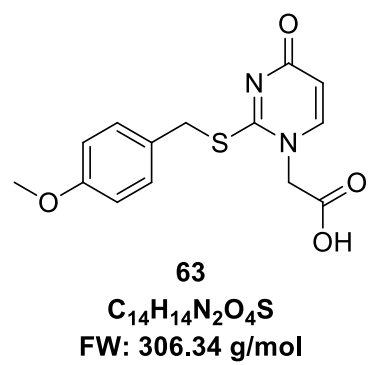

Zu einer Suspension von Verbindung 62 (350 mg, $1.05 \mathrm{mmol}, 1.0 \mathrm{eq})$ in THF/MeOH (2:1, $8.8 \mathrm{~mL}$ ) wurde eine $2 \mathrm{M}$ Lösung von $\mathrm{LiOH}$ in $\mathrm{H}_{2} \mathrm{O}(875 \mu \mathrm{L}, 1.75 \mathrm{mmol} 1.7 \mathrm{eq})$ gegeben und 10 min bei RT gerührt. Im Anschluss wurde die Mischung mit $2 \mathrm{M} \mathrm{HCl}$ angesäuert, die organischen Lösemittel unter vermindertem Druck entfernt und die erhaltene Lösung auf $4^{\circ} \mathrm{C}$ abgekühlt. Der Niederschlag wurde abfiltriert und der Feststoff mit Wasser und $\mathrm{Et}_{2} \mathrm{O}$ gewaschen und getrocknet. 63 wurde als farbloser Feststoff erhalten.

Ausbeute: $170 \mathrm{mg}, 555 \mu \mathrm{mol}, 53 \%$. 
${ }^{1} \mathrm{H}-\mathrm{NMR}\left(500 \mathrm{MHz}, \mathrm{DMSO}-d_{6}\right) \delta=13.54(\mathrm{~s}, 1 \mathrm{H}, \mathrm{COOH}), 7.67\left(\mathrm{~d}, J=7.6 \mathrm{~Hz}, 1 \mathrm{H}, \mathrm{C}^{6}-\mathrm{H}_{-} \mathrm{U}_{\mathrm{s}}\right)$, $7.36-7.32$ (m, 2H, $\left.\mathrm{C}^{2}-\mathrm{H}-\mathrm{Ar}\right), 6.90-6.85$ (m, 2H, C $\left.\mathrm{C}^{3}-\mathrm{H}-\mathrm{Ar}\right), 5.92$ (d, J=7.5 Hz, 1H, C $\mathrm{C}^{5}-\mathrm{H}-\mathrm{U}_{\mathrm{s}}$ ), $4.67\left(\mathrm{~s}, 2 \mathrm{H}, \mathrm{CH}_{2}-\mathrm{N}\right), 4.36\left(\mathrm{~s}, 2 \mathrm{H}, \mathrm{CH}_{2}-\mathrm{S}\right), 3.73$ (s, 3H, OMe) ppm.

${ }^{13}$ C-NMR $\left(126 \mathrm{MHz}\right.$, DMSO- $\left.d_{6}\right) \delta=168.3,166.5,162.3$ 158.7, 145.6, 130.4, 127.9, 113.9, 108.5, 55.1, 52.5, $34.3 \mathrm{ppm}$.

MS (ESI): $\quad \quad m / z$ ber. für $\mathrm{C}_{14} \mathrm{H}_{15} \mathrm{~N}_{2} \mathrm{O}_{4} \mathrm{~S}\left([\mathrm{M}+\mathrm{H}]^{+}\right): 307.1$; gef.: 307.2 .

Schmelzpunkt: $149^{\circ} \mathrm{C}$.

\subsubsection{Synthese von 2-(4-Methoxybenzyl)thiouracil-Fmoc/Bn-PNA-Monomer} 64

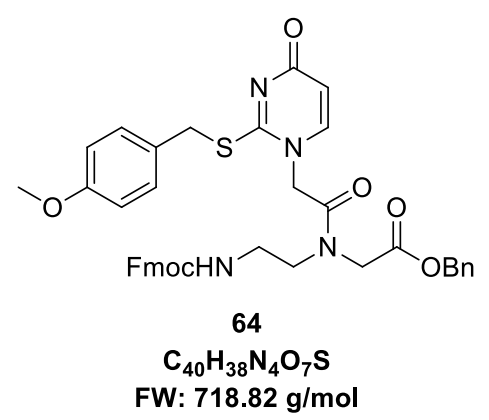

Verbindung 63 (100 mg, $326 \mu \mathrm{mol}, 1.0$ eq.) wurde in abs. DMF (5 mL) gelöst und mit HBTU (136 mg, 359 mmol, 1.1 eq.) sowie DIPEA (100 $\mathrm{L}, 588 \mu \mathrm{mol}, 1.8$ eq.) versetzt. Anschließend gab man das Amidrückgrat (168 mg, $359 \mu$ mol, 1.1 eq.) hinzu und rührte $2 \mathrm{~h}$ bei RT. Nach Ende der Reaktion überführte man die Lösung in EE und wusch mit 10\%iger $\mathrm{KHSO}_{4}{ }^{-}$und $10 \%$ iger $\mathrm{NaHCO}_{3}$-Lösung. Die organische Phase wurde über $\mathrm{Na}_{2} \mathrm{SO}_{4}$ getrocknet und das Lösemittel unter vermindertem Druck entfernt. Der Rückstand wurde säulenchromatographisch $(\mathrm{DCM} / \mathrm{MeOH} 19: 1)$ gereinigt und Verbindung 64 als farbloser Feststoff erhalten.

Ausbeute: $100 \mathrm{mg}, 139 \mu \mathrm{mol}, 43 \%$.

Dieses Produkt besteht aus zwei Rotameren, welche im Verhältnis von 1:0.4 vorliegen.

${ }^{1} \mathrm{H}-\mathrm{NMR}\left(500 \mathrm{MHz}, \mathrm{DMSO}-d_{6}\right) \delta=7.88(\mathrm{~d}, J=7.4 \mathrm{~Hz}, 2 \mathrm{H}), 7.64(\mathrm{~d}, J=6.9 \mathrm{~Hz}, 2 \mathrm{H}), 7.46$ und $7.41(\mathrm{~d}, J=7.5 \mathrm{~Hz}$, [maj/min], $1 \mathrm{H}), 7.44-7.38(\mathrm{~m}, 3 \mathrm{H}), 7.37-7.28(\mathrm{~m}, 7 \mathrm{H}), 7.25$ und 7.30 (d, $J=8.6 \mathrm{~Hz}$, [maj/min], 2H), 6.76 und 6.83 (d, $J=8.6 \mathrm{~Hz}$, [maj/min], 2H), 5.89 und $5.87(\mathrm{~d}, J=7.5 \mathrm{~Hz}$, [maj/min], $1 \mathrm{H}), 5.16$ und 5.11 (s, [min/maj], 2H), 4.98 und 4.78 (s, [maj/min], 2H), 4.35 und 4.14 (s, [min/maj], 2H), $4.31-4.28(\mathrm{~m}, 2 \mathrm{H}), 4.27(\mathrm{~s}, 2 \mathrm{H})$, $4.21-4.15(\mathrm{~m}, 1 \mathrm{H}), 3.70$ und 3.65 (s, [min/maj], $3 \mathrm{H}), 3.43$ und 3.35 (t, J=6.4 Hz, [maj/min], $2 \mathrm{H}$ ), 3.24 und 3.11 (q, $J=6.2 \mathrm{~Hz}$, [maj/min], $2 \mathrm{H}$ ) 
DC: $\mathrm{Rf}=0.32(\mathrm{DCM} / \mathrm{MeOH}: 19: 1)$.

MS (ESI): $\quad \quad m / z$ ber. für $\mathrm{C}_{40} \mathrm{H}_{39} \mathrm{~N}_{4} \mathrm{O}_{7} \mathrm{~S}\left([\mathrm{M}+\mathrm{H}]^{+}\right)$: 719.3 ; gef.: 719.5 .

HRMS (MALDI): $\quad m / z$ ber. für $\mathrm{C}_{40} \mathrm{H}_{39} \mathrm{~N}_{4} \mathrm{O}_{7} \mathrm{~S}\left([\mathrm{M}+\mathrm{H}]^{+}\right): 719.25340$; gef.: 719.25309 . 


\section{Literatur}

[1] C. I. E. Smith, R. Zain, Annu. Rev. Pharmacol. Toxicol. 2019, 59, 605-630.

[2] T. C. Roberts, R. Langer, M. J. A. Wood, Nat. Rev. Drug Discov. 2020, 19, 673-694.

[3] F. Wang, T. Zuroske, J. K. Watts, Nat. Rev. Drug Discov. 2020, 19, 441-442.

[4] S. Fields, O. Song, Nature 1989, 340, 245-246.

[5] V. Ratushny, E. A. Golemis, BioTechniques 2008, 44, 655-662.

[6] M. F. La Russa, L. S. Qi, Mol. Cell. Biol. 2015, 35, 3800-3809.

[7] M. K. Ghosh, A. Katyal, R. Chandra, V. Brahmachari, Mol. Cell. Biochem. 2005, 278, 147-155.

[8] S. Patel, D. Jung, P. T. Yin, P. Carlton, M. Yamamoto, T. Bando, H. Sugiyama, K.-B. Lee, ACS Nano 2014, 8, 8959-8967.

[9] R. Rupaimoole, F. J. Slack, Nat. Rev. Drug Discov. 2017, 16, 203-222.

[10] J. Hanna, G. S. Hossain, J. Kocerha, Front. Genet. 2019, 10, 478.

[11] D. Wirth Hamdoune, Konjugate Minor-Groove-Bindender Imidazol-Pyrrol-Polyamide Als DNA-Spalter Und Potentielle Transkriptionsaktivatoren, Dissertation, Goethe Universität, 2016.

[12] M. Bolz, Synthese von Adaptermolekülen Zur Rekrutierung von Transkriptionsfaktoren an Nichtnative Bindungsstellen, Masterarbeit, Goethe Universität, 2015.

[13] M. Bolz, L. Thomas, U. Scheffer, E. Kalden, R. K. Hartmann, M. W. Göbel, Chem. Biodivers. 2020, 17, e2000272.

[14] J. W. Trauger, E. E. Baird, P. B. Dervan, Nature 1996, 382, 559-561.

[15] J. M. Gottesfeld, L. Neely, J. W. Trauger, E. E. Baird, P. B. Dervan, Nature 1997, 387, 202-205.

[16] H. E. Moser, P. B. Dervan, Science 1987, 238, 645-650.

[17] F. Svinarchuk, I. Nagibneva, D. Chern, S. Ait-Si-Ali, L. L. Pritchard, P. Robin, C. Malvy, A. Harel-Bellan, Nucleic Acids Res. 1997, 25, 3459-3464.

[18] D. Ackermann, M. Famulok, Nucleic Acids Res. 2013, 41, 4729-4739.

[19] W. Kameshima, T. Ishizuka, M. Minoshima, M. Yamamoto, H. Sugiyama, Y. Xu, M. Komiyama, Angew. Chem. Int. Ed. 2013, 52, 13681-13684.

[20] D. P. Bartel, Cell 2004, 116, 281-297.

[21] D. P. Bartel, Cell 2009, 136, 215-233.

[22] A. Fire, S. Xu, M. K. Montgomery, S. A. Kostas, S. E. Driver, C. C. Mello, 1998, 391, 6.

[23] Y. Fang, M. J. Fullwood, Genomics Proteomics Bioinformatics 2016, 14, 42-54.

[24] K. V. Morris, J. S. Mattick, Nat. Rev. Genet. 2014, 15, 423-437. 
[25] J. M. Berg, J. L. Tymoczko, G. J. Gatto, L. Stryer, in Stryer Biochem., Springer Berlin Heidelberg, Berlin, Heidelberg, 2018, pp. 127-162.

[26] K. S. Gates, Chem. Res. Toxicol. 2009, 22, 1747-1760.

[27] U. Kaukinen, Nucleic Acids Res. 2002, 30, 468-474.

[28] J. M. Berg, J. L. Tymoczko, G. J. Gatto, L. Stryer, in Stryer Biochem., Springer Berlin Heidelberg, Berlin, Heidelberg, 2018, pp. 1059-1095.

[29] D. Shames, J. Minna, A. Gazdar, Curr. Mol. Med. 2007, 7, 85-102.

[30] A. M. Krieg, Oncogene 2008, 27, 161-167.

[31] J. D. Watson, F. H. C. Crick, Nature 1953, 171, 737-738.

[32] "Nucleic acid secondary structure," can be found under https://en.wikipedia.org/w/index.php?title=Nucleic_acid_secondary_structure\&oldid=9523 68594, 2020.

[33] J. D. Watson, F. H. C. Crick, Nature 1953, 171, 964-967.

[34] R. E. Franklin, R. G. Gosling, Acta Crystallogr. 1953, 6, 673-677.

[35] D. M. Chenoweth, J. L. Meier, P. B. Dervan, Angew. Chem. Int. Ed. 2013, 52, 415418.

[36] A. H.-J. Wang, G. J. Quigley, F. J. Kolpak, J. L. Crawford, J. H. van Boom, G. van der Marel, A. Rich, Nature 1979, 282, 680-686.

[37] J. Zhao, A. Bacolla, G. Wang, K. M. Vasquez, Cell. Mol. Life Sci. 2010, 67, 43-62.

[38] E. I. Zagryadskaya, Nucleic Acids Res. 2003, 31, 3946-3953.

[39] B. P. Belotserkovskii, S. M. Mirkin, P. C. Hanawalt, Chem. Rev. 2013, 113, 86208637.

[40] N. T. Thuong, C. Hélène, Angew. Chem. Int. Ed. Engl. 1993, 32, 666-690.

[41] M. Cooney, G. Czernuszewicz, E. Postel, S. Flint, M. Hogan, Science 1988, 241, 456459.

[42] C. Giovannangeli, M. Rougee, T. Garestier, N. T. Thuong, C. Helene, Proc. Natl. Acad. Sci. 1992, 89, 8631-8635.

[43] J.-S. Sun, C. Hélène, Curr. Opin. Struct. Biol. 1993, 3, 345-356.

[44] F. Raguseo, S. Chowdhury, A. Minard, M. Di Antonio, Chem. Commun. 2020, 56, 1317-1324.

[45] J. Spiegel, S. Adhikari, S. Balasubramanian, Trends Chem. 2020, 2, 123-136.

[46] D. Varshney, J. Spiegel, K. Zyner, D. Tannahill, S. Balasubramanian, Nat. Rev. Mol. Cell Biol. 2020, 21, 459-474.

[47] D. A. Glazier, J. Liao, B. L. Roberts, X. Li, K. Yang, C. M. Stevens, W. Tang, Bioconjug. Chem. 2020, 31, 1213-1233.

[48] M. L. Stephenson, P. C. Zamecnik, Proc. Natl. Acad. Sci. 1978, 75, 285-288.

[49] S. Wang, E. T. Kool, Biochemistry 1995, 34, 4125-4132. 
[50] M. Majlessi, Nucleic Acids Res. 1998, 26, 2224-2229.

[51] F. Eckstein, Nucleic Acid Ther. 2014, 24, 374-387.

[52] C. A. Stein, C. Subasinghe, K. Shinozuka, J. S. Cohen, Nucleic Acids Res. 1988, 16, 3209-3221.

[53] S. T. Crooke, J. L. Witztum, C. F. Bennett, B. F. Baker, Cell Metab. 2018, 27, 714739.

[54] J. Wengel, M. Petersen, M. Frieden, T. Koch, Lett. Pept. Sci. 2003, 10, 237-253.

[55] S. Freier, Nucleic Acids Res. 1997, 25, 4429-4443.

[56] C. Förster, A. Eichert, D. Oberthür, C. Betzel, R. Geßner, A. Nitsche, J. P. Fürste, J. Nucleic Acids 2012, 2012, 1-8.

[57] P. H. Hagedorn, R. Persson, E. D. Funder, N. Albæk, S. L. Diemer, D. J. Hansen, M. R. Møller, N. Papargyri, H. Christiansen, B. R. Hansen, H. F. Hansen, M. A. Jensen, T. Koch, Drug Discov. Today 2018, 23, 101-114.

[58] A. Khvorova, J. K. Watts, Nat. Biotechnol. 2017, 35, 238-248.

[59] I. Yildirim, E. Kierzek, R. Kierzek, G. C. Schatz, J. Phys. Chem. B 2014, 118, 1417714187.

[60] J. Kurreck, E. Wyszko, C. Gillen, V. A. Erdmann, Nucleic Acids Res. 2002, 30, 19111918.

[61] R. Crinelli, Nucleic Acids Res. 2002, 30, 2435-2443.

[62] S. Obad, C. O. dos Santos, A. Petri, M. Heidenblad, O. Broom, C. Ruse, C. Fu, M. Lindow, J. Stenvang, E. M. Straarup, H. F. Hansen, T. Koch, D. Pappin, G. J. Hannon, S. Kauppinen, Nat. Genet. 2011, 43, 371-378.

[63] P. H. Hagedorn, V. Yakimov, S. Ottosen, S. Kammler, N. F. Nielsen, A. M. Høg, M. Hedtjärn, M. Meldgaard, M. R. Møller, H. Ørum, T. Koch, M. Lindow, Nucleic Acid Ther. 2013, 23, 302-310.

[64] R. Ge, J. E. Heinonen, M. G. Svahn, A. J. Mohamed, K. E. Lundin, C. I. E. Smith, FASEB J. 2007, 21, 1902-1914.

[65] E. M. Zaghloul, A. S. Madsen, P. M. D. Moreno, I. I. Oprea, S. El-Andaloussi, B. Bestas, P. Gupta, E. B. Pedersen, K. E. Lundin, J. Wengel, C. I. E. Smith, Nucleic Acids Res. 2011, 39, 1142-1154.

[66] P. M. D. Moreno, S. Geny, Y. V. Pabon, H. Bergquist, E. M. Zaghloul, C. S. J. Rocha, I. I. Oprea, B. Bestas, S. E. Andaloussi, P. T. Jorgensen, E. B. Pedersen, K. E. Lundin, R. Zain, J. Wengel, C. I. E. Smith, Nucleic Acids Res. 2013, 41, 3257-3273.

[67] V. V. Demidov, V. N. Potaman, M. D. Frank-Kamenetskil, M. Egholm, O. Buchard, S. H. Sönnichsen, P. E. Nlelsen, Biochem. Pharmacol. 1994, 48, 1310-1313.

[68] P. E. Nielsen, Curr. Pharm. Des. 2010, 16, 3118-3123. 
[69] A. Kiliszek, K. Banaszak, Z. Dauter, W. Rypniewski, Nucleic Acids Res. 2016, 44, 1937-1943.

[70] P. Nielsen, M. Egholm, R. Berg, O. Buchardt, Science 1991, 254, 1497-1500.

[71] P. E. Nielsen, M. Egholm, Curr. Issues Mol. Biol. 1999, 1, 89-104.

[72] P. Muangkaew, T. Vilaivan, Bioorg. Med. Chem. Lett. 2020, 30, 127064.

[73] J. Lohse, O. Dahl, P. E. Nielsen, Proc. Natl. Acad. Sci. 1999, 96, 11804-11808.

[74] G. Haaima, Nucleic Acids Res. 1997, 25, 4639-4643.

[75] T. Sugiyama, G. Hasegawa, C. Niikura, K. Kuwata, Y. Imamura, Y. Demizu, M. Kurihara, A. Kittaka, Bioorg. Med. Chem. Lett. 2017, 27, 3337-3341.

[76] Y. Aiba, Y. Honda, M. Komiyama, Chem. - Eur. J. 2015, 21, 4021-4026.

[77] P. E. Nielsen, Chem. Biodivers. 2010, 7, 786-804.

[78] A. Ghidini, H. Bergquist, M. Murtola, T. Punga, R. Zain, R. Strömberg, Org Biomol Chem 2016, 14, 5210-5213.

[79] X. Wang, X. Xiao, B. Zhang, J. Li, Y. Zhang, Chem. Commun. 2019, 55, 2106-2109.

[80] R. Marchelli, R. Corradini, A. Manicardi, S. Sforza, T. Tedeschi, E. Fabbri, M. Borgatti, N. Bianchi, R. Gambari, in Targets Gene Ther. (Ed.: Y. You), InTech, 2011.

[81] J. M. Berg, J. L. Tymoczko, G. J. Gatto, L. Stryer, in Stryer Biochem., Springer Berlin Heidelberg, Berlin, Heidelberg, 2018, pp. 1017-1058.

[82] G. Suske, E. Bruford, S. Philipsen, Genomics 2005, 85, 551-556.

[83] C. Vizcaíno, S. Mansilla, J. Portugal, Pharmacol. Ther. 2015, 152, 111-124.

[84] W. S. Dynan, R. Tjian, Cell 1983, 32, 669-680.

[85] M. Marin, A. Karis, P. Visser, F. Grosveld, S. Philipsen, Cell 1997, 89, 619-628.

[86] G. Suske, Gene 1999, 238, 291-300.

[87] J. T. Kadonaga, K. R. Carner, R. Tjian, Cell 1987, 51, 1079-1090.

[88] S. S. Solomon, G. Majumdar, A. Martinez-Hernandez, R. Raghow, Life Sci. 2008, 83, 305-312.

[89] L. Li, J. R. Davie, Ann. Anat. - Anat. Anz. 2010, 192, 275-283.

[90] W.-C. Chang, J.-J. Hung, J Biomed Sci 2012, 19, 94.

[91] L. O'Connor, J. Gilmour, C. Bonifer, Yale J. Biol. Med. 2016, 89, 513-525.

[92] I. A. Mastrangelo, A. J. COUREYt, J. S. Wall, S. P. Jackson, P. V. C. Hough, Proc Natl Acad Sci USA 1991, 88, 5670-5674.

[93] V. H. Y. Lee, B. K. C. Chow, K. W. Lo, L. S. N. Chow, C. Man, S. W. Tsao, L. T. O. Lee, Gene 2009, 443, 55-63.

[94] S. He, J.-M. Sun, L. Li, J. R. Davie, Mol. Biol. Cell 2005, 16, 4073-4083.

[95] E. Hedrick, Y. Cheng, U.-H. Jin, K. Kim, S. Safe, Oncotarget 2016, 7, 22245-22256.

[96] S. Safe, J. Abbruzzese, M. Abdelrahim, E. Hedrick, Cancer Prev. Res. (Phila. Pa.) 2018, 11, 371-382. 
[97] I. Krüger, M. Vollmer, D. Simmons, H.-P. Elsässer, S. Philipsen, G. Suske, Dev. Dyn. 2007, 236, 2235-2244.

[98] J.-E. Oh, J.-A. Han, E. S. Hwang, Biochem. Biophys. Res. Commun. 2007, 353, 8691.

[99] K. Beishline, J. Azizkhan-Clifford, FEBS J. 2015, 282, 224-258.

[100] S. Safe, I. Jutooru, G. Chadalapaka, Gastrointest. Cancer Targets Ther. 2014, 65.

[101] C. W. Garvie, C. Wolberger, Mol. Cell 2001, 8, 937-946.

[102] J. Rodríguez, J. Mosquera, R. García-Fandiño, M. E. Vázquez, J. L. Mascareñas, Chem. Sci. 2016, 7, 3298-3303.

[103] K. Roy, A. Mazumder, P. Ghosh, G. Naiya, B. Ghosh, S. Roy, Chem. Commun. 2018, 54, 1611-1614.

[104] P. Marchand, K. Resch, H. H. Radeke, J. Immunol. 2000, 164, 2070-2076.

[105] M. K. Ghosh, A. Katyal, V. Brahmachari, R. Chandra, J. Biomol. Sruckture Dyn. 2002, 20, 265-273.

[106] S. Kuznetsova, S. Ait-Si-Ali, I. Nagibneva, F. Troalen, J.-P. Le Villain, A. Harel-Bellan, F. Svinarchuck, Nucleic Acids Res. 1999, 27, 3995-4000.

[107] D. Stanojevic, R. A. Young, Biochemistry 2002, 41, 7209-7216.

[108] Y. Ruiz García, Y. V. Pabon-Martinez, C. I. E. Smith, A. Madder, Chem. Commun. 2017, 53, 6653-6656.

[109] C. Rathnam, S.-T. D. Chueng, L. Yang, K.-B. Lee, Theranostics 2017, 7, 2775-2793. [110] R. R. Beerli, B. Dreier, C. F. Barbas, Proc. Natl. Acad. Sci. 2000, 97, 1495-1500.

[111] R. R. Beerli, C. F. Barbas, Nat. Biotechnol. 2002, 20, 135-141.

[112] K.-H. Bae, Y. Do Kwon, H.-C. Shin, M.-S. Hwang, E.-H. Ryu, K.-S. Park, H.-Y. Yang, D. Lee, Y. Lee, J. Park, H. Sun Kwon, H.-W. Kim, B.-I. Yeh, H.-W. Lee, S. Hyung Sohn, J. Yoon, W. Seol, J.-S. Kim, Nat. Biotechnol. 2003, 21, 275-280.

[113] A. M. Chiarella, D. Lu, N. A. Hathaway, Int. J. Mol. Sci. 2020, 21, 943.

[114] E. A. Heiderscheit, A. Eguchi, M. C. Spurgat, A. Z. Ansari, FEBS Lett. 2018, 592, 888-900.

[115] J. Boch, U. Bonas, Annu. Rev. Phytopathol. 2010, 48, 419-436.

[116] R. Morbitzer, P. Romer, J. Boch, T. Lahaye, Proc. Natl. Acad. Sci. 2010, 107, 2161721622.

[117] M. Jinek, K. Chylinski, I. Fonfara, M. Hauer, J. A. Doudna, E. Charpentier, Science 2012, 337, 816-821.

[118] L. Cong, F. A. Ran, D. Cox, S. Lin, R. Barretto, N. Habib, P. D. Hsu, X. Wu, W. Jiang, L. A. Marraffini, F. Zhang, Science 2013, 339, 819-823.

[119] L. A. Syding, P. Nickl, P. Kasparek, R. Sedlacek, Cells 2020, 9, 993. 
[120] L. A. Gilbert, M. H. Larson, L. Morsut, Z. Liu, G. A. Brar, S. E. Torres, N. SternGinossar, O. Brandman, E. H. Whitehead, J. A. Doudna, W. A. Lim, J. S. Weissman, L. S. Qi, Cell 2013, 154, 442-451.

[121] M. E. Tanenbaum, L. A. Gilbert, L. S. Qi, J. S. Weissman, R. D. Vale, Cell 2014, 159, 635-646.

[122] S. Konermann, M. D. Brigham, A. E. Trevino, J. Joung, O. O. Abudayyeh, C. Barcena, P. D. Hsu, N. Habib, J. S. Gootenberg, H. Nishimasu, O. Nureki, F. Zhang, Nature 2015, $517,583-588$.

[123] W. S. Wade, M. Mrksich, P. B. Dervan, J. Am. Chem. Soc. 1992, 114, 8778-8783.

[124] W. S. Wade, M. Mrksich, P. B. Dervan, Biochemistry 1993, 32, 11385-11389.

[125] M. L. Kopka, C. Yoon, D. Goodsell, P. Pjura, R. E. Dickerson, Proc. Natl. Acad. Sci. 1985, 82, 1376-1380.

[126] J. G. Pelton, D. E. Wemmer, J. Am. Chem. Soc. 1990, 112, 1393-1399.

[127] M. Mrksich, P. B. Dervan, J. Am. Chem. Soc. 1993, 115, 2572-2576.

[128] M. Mrksich, M. E. Parks, P. B. Dervan, J. Am. Chem. Soc. 1994, 116, 7983-7988.

[129] S. White, E. E. Baird, P. B. Dervan, Chem. Biol. 1997, 4, 569-578.

[130] M. E. Parks, E. E. Baird, P. B. Dervan, J. Am. Chem. Soc. 1996, 118, 6147-6152.

[131] S. E. Swalley, E. E. Baird, P. B. Dervan, J. Am. Chem. Soc. 1999, 121, 1113-1120.

[132] D. M. Herman, E. E. Baird, P. B. Dervan, J. Am. Chem. Soc. 1998, 120, 1382-1391.

[133] P. B. Dervan, B. S. Edelson, Curr. Opin. Struct. Biol. 2003, 13, 284-299.

[134] M. A. Marques, R. M. Doss, A. R. Urbach, P. B. Dervan, Helv. Chim. Acta 2002, 85, 4485-4517.

[135] Y.-W. Han, T. Matsumoto, H. Yokota, G. Kashiwazaki, H. Morinaga, K. Hashiya, T. Bando, Y. Harada, H. Sugiyama, Nucleic Acids Res. 2012, 40, 11510-11517.

[136] J. M. Turner, S. E. Swalley, E. E. Baird, P. B. Dervan, J. Am. Chem. Soc. 1998, 120, 6219-6226.

[137] S. Patel, P. T. Yin, H. Sugiyama, K.-B. Lee, ACS Nano 2015, 9, 6909-6917.

[138] S. Patel, S.-T. D. Chueng, P. T. Yin, K. Dardir, Z. Song, N. Pasquale, K. Kwan, H. Sugiyama, K.-B. Lee, Angew. Chem. Int. Ed. 2015, 54, 11983-11988.

[139] P. Dervan, Science 1986, 232, 464-471.

[140] I. Kers, Bioorg. Med. Chem. 2002, 10, 3339-3349.

[141] Y. Kawamoto, A. Sasaki, K. Hashiya, S. Ide, T. Bando, K. Maeshima, H. Sugiyama, Chem Sci 2015, 6, 2307-2312.

[142] D. Renneberg, P. B. Dervan, J. Am. Chem. Soc. 2003, 125, 5707-5716.

[143] P. B. Dervan, R. W. Bürli, Curr. Opin. Chem. Biol. 1999, 3, 688-693.

[144] J. A. Raskatov, A. E. Hargrove, A. Y. So, P. B. Dervan, J. Am. Chem. Soc. 2012, 134, 7995-7999. 
[145] E. E. Baird, P. B. Dervan, J. Am. Chem. Soc. 1996, 118, 6141-6146.

[146] N. R. Wurtz, J. M. Turner, E. E. Baird, P. B. Dervan, Org. Lett. 2001, 3, 1201-1203.

[147] W. Su, S. J. Gray, R. Dondi, G. A. Burley, Org. Lett. 2009, 11, 3910-3913.

[148] Y. Kawamoto, T. Bando, F. Kamada, Y. Li, K. Hashiya, K. Maeshima, H. Sugiyama, J. Am. Chem. Soc. 2013, 135, 16468-16477.

[149] P. O. Krutzik, A. R. Chamberlin, Bioorg. Med. Chem. Lett. 2002, 12, 2129-2132.

[150] J. W. Puckett, J. T. Green, P. B. Dervan, Org. Lett. 2012, 14, 2774-2777.

[151] L. Fang, G. Yao, Z. Pan, C. Wu, H.-S. Wang, G. A. Burley, W. Su, Org. Lett. 2015, $17,158-161$.

[152] J. Xiao, G. Yuan, W. Huang, A. S. C. Chan, K.-L. D. Lee, J. Org. Chem. 2000, 65, $5506-5513$.

[153] D. Wirth-Hamdoune, S. Ullrich, U. Scheffer, T. Radanović, G. Dürner, M. W. Göbel, ChemBioChem 2016, 17, 506-514.

[154] D. M. Chenoweth, D. A. Harki, P. B. Dervan, J. Am. Chem. Soc. 2009, 131, 71757181.

[155] T. F. Martinez, J. W. Phillips, K. K. Karanja, P. Polaczek, C.-M. Wang, B. C. Li, J. L. Campbell, P. B. Dervan, Nucleic Acids Res. 2014, 42, 11546-11559.

[156] A. K. Mapp, A. Z. Ansari, M. Ptashne, P. B. Dervan, Proc. Natl. Acad. Sci. 2000, 97, 3930-3935.

[157] A. Z. Ansari, A. K. Mapp, D. H. Nguyen, P. B. Dervan, M. Ptashne, Chem. Biol. 2001, 8, 583-592.

[158] P. S. Arora, A. Z. Ansari, T. P. Best, M. Ptashne, P. B. Dervan, J. Am. Chem. Soc. 2002, 124, 13067-13071.

[159] Y. Kwon, H.-D. Arndt, Q. Mao, Y. Choi, Y. Kawazoe, P. B. Dervan, M. Uesugi, J. Am. Chem. Soc. 2004, 126, 15940-15941.

[160] X. Xiao, P. Yu, H.-S. Lim, D. Sikder, T. Kodadek, Angew. Chem. Int. Ed. 2007, 46, 2865-2868.

[161] X. Xiao, P. Yu, H.-S. Lim, D. Sikder, T. Kodadek, J. Comb. Chem. 2007, 9, 592-600. [162] A. Ohtsuki, M. T. Kimura, M. Minoshima, T. Suzuki, M. Ikeda, T. Bando, H. Nagase, K. Shinohara, H. Sugiyama, Tetrahedron Lett. 2009, 50, 7288-7292.

[163] G. N. Pandian, Y. Nakano, S. Sato, H. Morinaga, T. Bando, H. Nagase, H. Sugiyama, Sci. Rep. 2012, 2, DOI 10.1038/srep00544.

[164] G. N. Pandian, J. Taniguchi, S. Junetha, S. Sato, L. Han, A. Saha, C. AnandhaKumar, T. Bando, H. Nagase, T. Vaijayanthi, R. D. Taylor, H. Sugiyama, Sci. Rep. 2015, 4, 3843. [165] S. Patel, T. Pongkulapa, P. T. Yin, G. N. Pandian, C. Rathnam, T. Bando, T. Vaijayanthi, H. Sugiyama, K.-B. Lee, J. Am. Chem. Soc. 2015, 137, 4598-4601.

[166] J. W. Trauger, E. E. Baird, P. B. Dervan, J. Am. Chem. Soc. 1998, 120, 3534-3535. 
[167] J. K. W. Lam, M. Y. T. Chow, Y. Zhang, S. W. S. Leung, Mol. Ther. - Nucleic Acids 2015, 4, e252.

[168] V. Kotikam, J. A. Viel, E. Rozners, Chem. - Eur. J. 2020, 26, 685-690.

[169] R. W. Carthew, E. J. Sontheimer, Cell 2009, 136, 642-655.

[170] R. Garzon, G. Marcucci, C. M. Croce, Nat. Rev. Drug Discov. 2010, 9, 775-789.

[171] R. C. Friedman, K. K.-H. Farh, C. B. Burge, D. P. Bartel, Genome Res. 2008, 19, 92105.

[172] L. M. Wee, C. F. Flores-Jasso, W. E. Salomon, P. D. Zamore, Cell 2012, 151, 10551067.

[173] M. R. Fabian, N. Sonenberg, W. Filipowicz, Annu. Rev. Biochem. 2010, 79, 351-379.

[174] S. Jonas, E. Izaurralde, Nat. Rev. Genet. 2015, 16, 421-433.

[175] D.-H. Kim, M. A. Behlke, S. D. Rose, M.-S. Chang, S. Choi, J. J. Rossi, Nat. Biotechnol. 2005, 23, 222-226.

[176] M. P. Gantier, B. R. G. Williams, Cytokine Growth Factor Rev. 2007, 18, 363-371.

[177] D. A. Braasch, S. Jensen, Y. Liu, K. Kaur, K. Arar, M. A. White, D. R. Corey, Biochemistry 2003, 42, 7967-7975.

[178] C. R. Allerson, N. Sioufi, R. Jarres, T. P. Prakash, N. Naik, A. Berdeja, L. Wanders, R. H. Griffey, E. E. Swayze, B. Bhat, J. Med. Chem. 2005, 48, 901-904.

[179] M. Matsui, T. P. Prakash, D. R. Corey, Mol. Ther. 2016, 24, 946-955.

[180] N. Hosseinahli, M. Aghapour, P. H. G. Duijf, B. Baradaran, J. Cell. Physiol. 2018, 233, 5574-5588.

[181] M. Fabbri, A. Paone, F. Calore, R. Galli, C. M. Croce, RNA Biol. 2013, 10, 169-174. [182] J. Krützfeldt, N. Rajewsky, R. Braich, K. G. Rajeev, T. Tuschl, M. Manoharan, M. Stoffel, Nature 2005, 438, 685-689.

[183] M. Thomas, K. Lange-Grünweller, E. Dayyoub, U. Bakowsky, U. Weirauch, A. Aigner, R. K. Hartmann, A. Grünweller, RNA Biol. 2012, 9, 1088-1098.

[184] J. Ariyoshi, Y. Matsuyama, A. Kobori, A. Murakami, H. Sugiyama, A. Yamayoshi, Nucleic Acid Ther. 2017, 27, 303-308.

[185] J. Ariyoshi, N. Eimori, A. Kobori, A. Murakami, H. Sugiyama, A. Yamayoshi, Chem. Lett. 2017, 46, 143-145.

[186] S. Niaz, Biol. Chem. 2018, 399, 525-547.

[187] E. Elkayam, C.-D. Kuhn, A. Tocilj, A. D. Haase, E. M. Greene, G. J. Hannon, L. Joshua-Tor, Cell 2012, 150, 100-110.

[188] N. T. Schirle, J. Sheu-Gruttadauria, I. J. MacRae, Science 2014, 346, 608-613.

[189] E. Mogilyansky, I. Rigoutsos, Cell Death Differ. 2013, 20, 1603-1614.

[190] A. Ota, H. Tagawa, S. Karnan, S. Tsuzuki, A. Karpas, S. Kira, Y. Yoshida, M. Seto, Cancer Res. 2004, 64, 3087-3095. 
[191] L. He, J. M. Thomson, M. T. Hemann, E. Hernando-Monge, D. Mu, S. Goodson, S. Powers, C. Cordon-Cardo, S. W. Lowe, G. J. Hannon, S. M. Hammond, Nature 2005, 435, 828-833.

[192] A. Ventura, A. G. Young, M. M. Winslow, L. Lintault, A. Meissner, S. J. Erkeland, J. Newman, R. T. Bronson, D. Crowley, J. R. Stone, R. Jaenisch, P. A. Sharp, T. Jacks, Cell 2008, 132, 875-886.

[193] L. de Pontual, E. Yao, P. Callier, L. Faivre, V. Drouin, S. Cariou, A. Van Haeringen, D. Geneviève, A. Goldenberg, M. Oufadem, S. Manouvrier, A. Munnich, J. A. Vidigal, M. Vekemans, S. Lyonnet, A. Henrion-Caude, A. Ventura, J. Amiel, Nat. Genet. 2011, 43, 1026-1030.

[194] I. Ivanovska, A. S. Ball, R. L. Diaz, J. F. Magnus, M. Kibukawa, J. M. Schelter, S. V. Kobayashi, L. Lim, J. Burchard, A. L. Jackson, P. S. Linsley, M. A. Cleary, Mol. Cell. Biol. 2008, 28, 2167-2174.

[195] J. T. Mendell, Cell 2008, 133, 217-222.

[196] A. Aartsma-Rus, D. R. Corey, Nucleic Acid Ther. 2020, 30, 67-70.

[197] S. M. Hoy, Drugs 2018, 78, 1625-1631.

[198] M. Hecker, S. Wagner, S. W. Henning, A. H. Wagner, in RSC Biomol. Sci. (Ed.: J. Kurreck), Royal Society Of Chemistry, Cambridge, 2008, pp. 163-188.

[199] M. Hecker, A. H. Wagner, Biochem. Pharmacol. 2017, 144, $29-34$.

[200] R. Morishita, G. H. Gibbons, M. Horiuchi, K. E. Ellison, M. Nakama, L. Zhang, Y. Kaneda, T. Ogihara, V. J. Dzau, Proc. Natl. Acad. Sci. 1995, 92, 5855-5859.

[201] M. Borgatti, I. Lampronti, A. Romanelli, C. Pedone, M. Saviano, N. Bianchi, C. Mischiati, R. Gambari, J. Biol. Chem. 2003, 278, 7500-7509.

[202] H. Wagner, S. Bauer, J. Exp. Med. 2006, 203, 265-268.

[203] A. M. Krieg, Nat. Rev. Drug Discov. 2006, 5, 471-484.

[204] H. Mollaei, R. Safaralizadeh, Z. Rostami, J. Cell. Physiol. 2019, 234, 12369-12384.

[205] R. H. E. Hudson, A. Heidari, T. Martin-Chan, G. Park, J. A. Wisner, J. Org. Chem. 2019, 84, 13252-13261.

[206] S. Ullrich, Synthese von Aminopyrrol- Und Aminoimidazolcarbonsäuren Als Bausteine DNA-Bindender Peptide, Diplomarbeit, J. W. Goethe-Universität (Frankfurt am Main), 2004.

[207] S. Ullrich, Sequenzselektive, Metallfreie DNA-Spalter Auf Der Basis von Bisguanidiniumalkoholen, Dissertation, J. W. Goethe-Universität (Frankfurt am Main), 2009. [208] M. Ikeda, H. Nakagawa, S. Ban, H. Tsumoto, T. Suzuki, N. Miyata, Free Radic. Biol. Med. 2010, 49, 1792-1797.

[209] T. Nagamatsu, The Improved Stationary Phase for Capillary Electrophoresis DNA Polymorphism Analysis, 2009, JP 2009011183. 
[210] D. Jaramillo, Q. Liu, J. Aldrich-Wright, Y. Tor, J. Org. Chem. 2004, 69, 8151-8153.

[211] L. Buyachuihan, Bachelorarbeit Lynn Buyachuihan 2015.pdf, Bachelorarbeit, Goethe Universität, 2015.

[212] I. Singh, C. Wendeln, A. W. Clark, J. M. Cooper, B. J. Ravoo, G. A. Burley, J. Am. Chem. Soc. 2013, 135, 3449-3457.

[213] A. J. Fallows, I. Singh, R. Dondi, P. M. Cullis, G. A. Burley, Org. Lett. 2014, 16, 46544657.

[214] P. K. Mandal, J. S. McMurray, J. Org. Chem. 2007, 72, 6599-6601.

[215] I. Beria, P. G. Baraldi, P. Cozzi, M. Caldarelli, C. Geroni, S. Marchini, N. Mongelli, R. Romagnoli, J. Med. Chem. 2004, 47, 2611-2623.

[216] C. Badía, F. Souard, C. Vicent, J. Org. Chem. 2012, 77, 10870-10881.

[217] T. Kubo, M. Morikawa, H. Ohba, M. Fujii, Org. Lett. 2003, 5, 2623-2626.

[218] E.-A. Raiber, R. Kranaster, E. Lam, M. Nikan, S. Balasubramanian, Nucleic Acids Res. 2012, 40, 1499-1508.

[219] A. M. P. Romani, Arch. Biochem. Biophys. 2011, 512, 1-23.

[220] Z. Yu, G. N. Pandian, T. Hidaka, H. Sugiyama, Adv. Drug Deliv. Rev. 2019, 147, 6685.

[221] P. Vekhoff, A. Ceccaldi, D. Polverari, J. Pylouster, C. Pisano, P. B. Arimondo, Biochemistry 2008, 47, 12277-12289.

[222] E. Kowarz, D. Löscher, R. Marschalek, Biotechnol. J. 2015, 10, 647-653.

[223] V. V. Demidov, E. Protozanova, K. I. Izvolsky, C. Price, P. E. Nielsen, M. D. FrankKamenetskii, Proc. Natl. Acad. Sci. 2002, 99, 5953-5958.

[224] K. Yilmaz, Herstellung von Bausteinen für die Synthese pseudokomplementärer PNA Bachelorarbeit, Bachelorarbeit, Goethe Universität, 2018.

[225] N. Ajvazi, S. Stavber, Tetrahedron Lett. 2016, 57, 2430-2433.

[226] K. R. Mulholland, A. R. Ross, G. R. Slater, G. E. Smith, Process to Prepare (1Carboxymethyl)-Pyrimidinone Compounds, 2007.

[227] F. Guibbal, S. Bénard, J. Patché, V. Meneyrol, J. Couprie, J. Yong-Sang, O. Meilhac, E. Jestin, Bioorg. Med. Chem. Lett. 2018, 28, 787-792.

[228] M. Komiyama, Y. Aiba, T. Ishizuka, J. Sumaoka, Nat. Protoc. 2008, 3, 646-654.

[229] M. Góngora-Benítez, L. Mendive-Tapia, I. Ramos-Tomillero, A. C. Breman, J. TullaPuche, F. Albericio, Org. Lett. 2012, 14, 5472-5475.

[230] C. Kost, Synthese Pseudokomplementärer PNA Zur Sequenzspezifischen Erkennung Doppelsträngiger DNA, Masterarbeit, Goethe Universität, 2019.

[231] R. C. Lee, R. L. Feinbaum, V. Ambros, Cell 1993, 75, 843-854.

[232] S. M. Hammond, Curr. Opin. Genet. Dev. 2006, 16, 4-9. 
[233] M. Thomas, K. Lange-Grünweller, U. Weirauch, D. Gutsch, A. Aigner, A. Grünweller, R. K. Hartmann, Oncogene 2012, 31, 918-928.

[234] Y. Tursynbay, J. Zhang, Z. Li, T. Tokay, Z. Zhumadilov, D. Wu, Y. Xie, Biomed. Rep. 2016, 4, 140-146.

[235] "Explore Tools async - GeneGlobe," can be found under https://geneglobe.qiagen.com/us/explore/tools/Ina-oligo-optimizer/form, 2020.

[236] J. N. Zadeh, C. D. Steenberg, J. S. Bois, B. R. Wolfe, M. B. Pierce, A. R. Khan, R. M. Dirks, N. A. Pierce, J. Comput. Chem. 2011, 32, 170-173.

[237] A. G. Torres, M. M. Fabani, E. Vigorito, M. J. Gait, RNA 2011, 17, 933-943.

[238] L. Thomas, Inaktivierung von MRNAs Und MiRN As Durch DNA/LNA-Basierte Und Mit Zusätzlichen Funktionalitäten Konjugierte Antisense-Oligonukleotide, Dissertation, Philipps-Universität Marburg, 2020.

[239] C. A. Hunter, H. L. Anderson, Angew. Chem. 2009, 121, 7624-7636.

[240] F. Zellmann, L. Thomas, U. Scheffer, R. K. Hartmann, M. W. Göbel, Molecules 2019, $24,807$.

[241] U. Zabel, R. Schreck, P. A. Baeuerle, J. Biol. Chem. 1991, 266, 252-260.

[242] Z. Yu, C. Guo, Y. Wei, K. Hashiya, T. Bando, H. Sugiyama, J. Am. Chem. Soc. 2018, 140, 2426-2429.

[243] Z. Yu, W.-C. Hsieh, S. Asamitsu, K. Hashiya, T. Bando, D. H. Ly, H. Sugiyama, Chem. - Eur. J. 2018, 24, 14183-14188.

[244] D. M. Gray, S.-H. Hung, K. H. Johnson, Methods Enzymol. 1995, 246, 19-34.

[245] M. Bialer, B. Yagen, R. Mechoulam, Tetrahedron 1978, 34, 2389-2391.

[246] C. Bailly, J.-P. Henichart, N. Pommery, R. Houssin, J. Pharm. Sci. 1989, 78, 910917.

[247] L. Grehn, U. Ragnarsson, J. Org. Chem. 1981, 46, 3492-3497. 
12. Anhang

12.1 Puffer und Gele

12.1.1 Puffer und Stammlösungen:

10x Blotting buffer

$250 \mathrm{mM}$ Tris

1.9 M Glycin

Blocking buffer:

$0.5 \%$ Casein, Hammarsten Grade

$1 \mathrm{mM}$ Tris-HCl pH 8

Gelelutionspuffer:

$500 \mathrm{mM} \mathrm{NaOAc} \mathrm{pH} 7.0$

2 mM EDTA

$0.1 \%$ SDS

Puffer 1:

25 mM HEPES-NaOH pH 7.5

$100 \mathrm{mM} \mathrm{KCl}$

$2.5 \mathrm{mM} \mathrm{MgCl} 2$

$0.01 \mathrm{mM} \mathrm{ZnCl} 2$

$5 \%$ Glycerol

Puffer 2: 
50 mM Tris-HCl pH 8

$100 \mathrm{mM} \mathrm{KCl}$,

$2 \mathrm{mM} \mathrm{MgCl}_{2}$

Puffer 3 (P3)

100 mM Tris-HCl pH 9.5

$100 \mathrm{mM} \mathrm{NaCl}$

$5 \mathrm{mM} \mathrm{MgCl}_{2}$

Puffer Z:

25 mM HEPES-NaOH pH 7.5

$100 \mathrm{mM} \mathrm{KCl}$

$12.5 \mathrm{mM} \mathrm{MgCl}$

$0.01 \mathrm{mM} \mathrm{ZnCl} 2$

$20 \%$ Glycerol

10x SDS-Laufpuffer:

$250 \mathrm{mM}$ Tris

1.92 M Glycin

$1 \%(w / v)$ SDS

SSPE 20x:

$0.2 \mathrm{M} \mathrm{Na}_{2} \mathrm{H}_{2} \mathrm{PO}_{4}$

0.02 M EDTA

$3 \mathrm{M} \mathrm{NaCl}$

TBE Puffer 10x:

$1 \mathrm{M}$ Tris 
830 mM Borsäure

$10 \mathrm{mM} \mathrm{Na}_{2} \mathrm{EDTA}^{*} 2 \mathrm{H}_{2} \mathrm{O}$

TBS:

$150 \mathrm{mM} \mathrm{NaCl}$

10 mM Tris-HCl pH 8.0

TBST:

$150 \mathrm{mM} \mathrm{NaCl}$

10 mM Tris-HCl pH 8.0

$0.1 \%$ Tween 20

TEMg:

40 mM Tris- $\mathrm{HCl} \mathrm{pH} 7.4$

$2.5 \mathrm{mM}$ EDTA

$12.5 \mathrm{mM} \mathrm{MgCl}_{2}$

Triplexpuffer:

50 mM HEPES-NaOH pH 7.0

$50 \mathrm{mM} \mathrm{NaCl}$

$2 \mathrm{mM} \mathrm{MgCl} 2$

Gelladepuffer:

Denaturierender Ladepuffer 2x:

8 M Harnstoff 
20 mM EDTA

$0.2 \%$ Orange G

Ladepuffer 6x:

$0.25 \%$ Orange G

$40 \%$ Saccharose

Laemmli-Puffer 2x:

100 mM Tris-HCl pH 6.8

$20 \%$ Glycerol

$4 \%$ SDS

$0.1 \%$ Bromphenolblau, oder $0.2 \%$ Orange G

\subsubsection{PAGE}

Denaturierende PAGE

Acrylamid Stock Lösung 19:1

7M Harnstoff

$16 \%$ Acrylamid (19:1)

1x TBE

Nativ PAGE

$8 \% \quad 16 \%$

$34.5 \%$ Acrylamid-Lösung $\quad 2.3 \mathrm{~mL} \quad 4.6 \mathrm{~mL}$

TBE 10x

$1.0 \mathrm{~mL}$ 
$50 \%$ Glycerol

$1.0 \mathrm{~mL}$

Wasser

$6.8 \mathrm{~mL}$

$4.5 \mathrm{~mL}$

APS

$100 \mu \mathrm{L}$

TEMED

$10 \mu \mathrm{L}$

SDS-PAGE

Stacking Gel:

$6 \%$

$8 \%$

$34.5 \%$ Acrylamid-Lösung

$0.9 \mathrm{~mL}$

$1.2 \mathrm{~mL}$

0.5 M Tris- $\mathrm{HCl}, \mathrm{pH} 6.8$

$1.25 \mathrm{~mL}$

$20 \%$ SDS

$25 \mu \mathrm{L}$

Wasser

$2.6 \mu \mathrm{L} \quad 2.8 \mathrm{~mL}$

APS

$50 \mu \mathrm{L}$

TEMED

$5 \mu \mathrm{L}$

Resolving Gel:

$8 \%$

$10 \%$

$34.5 \%$ Acrylamid-Lösung

$1.7 \mathrm{~mL} \quad 2.2 \mathrm{~mL}$

1.5 M Tris- $\mathrm{HCl}, \mathrm{pH} 8.8$

$1.9 \mathrm{~mL}$

$20 \%$ SDS

$37.5 \mu \mathrm{L}$

Wasser

$3.8 \mu \mathrm{L} \quad 3.3 \mathrm{~mL}$

APS

$75 \mu \mathrm{L}$

TEMED

$7.5 \mu \mathrm{L}$

\subsubsection{Färbelösungen}

BCIP/NBT-Lösung

P3:

$6 \mathrm{~mL}$ 
BCIP: $\quad 21 \mu \mathrm{L}$

NBT: $\quad 27 \mu \mathrm{L}$

SYBR Gold-Lösung

10 mM Tris- $\mathrm{HCl} \mathrm{pH} 7.5$

$1 \mathrm{mM}$ EDTA

$0.01 \%$ SYBR Gold in DMSO 


\subsection{Abkürzungsverzeichnis}

2'-F-RNA

2'-Fluor-RNA

2'-MOE-RNA

2'-O-Methoxyethyl-RNA

2'-OMe-RNA

2'-Methoxy-RNA

A

Adenin

abs.

absolut

$\mathrm{AcCl}$

Acetylchlorid

$\mathrm{Ac}_{2} \mathrm{O}$

Essigsäureanhydrid

ACN

Acetonitril

$A D$

Aktivierungsdomäne

Ago

Argonaut-Protein

AMP

Adenosinmonophosphat

ASGPR

Asialoglycoproteinrezeptor 1

ASO

antisense oligonucleotide

ATF

artificial transkription factor (artifizieller Transkriptionsfaktor)

$\beta$-Ala-OH $/ \beta$

$\beta$-Alanin

BCIP

5-Brom-4-chlor-3-indoxylphosphat

Boc

tert-Butyloxycarbonyl

bp

Basenpaar

BTC

Bis(trichlormethyl)carbonat/Triphosgen

C

Cytosin

ca.

zirka

Cas9

CRISPR associated protein 9

$\mathrm{Cbz}$

Benzyloxycarbonyl

CDK

cyclin dependent kinase (cyclin-abhängige Kinase)

$\mathrm{CH}$

Cyclohexan 
CPP

CRISPR

Cy5

D

d

dAMP

DBD

dCas9

DCM

DIC

DIPEA

DMAP

DMDPA

DMF

DMSO

DNA

dPAGE

ds

DSI

EDTA

EE/EtOAc

EMA

$\mathrm{EtOH}$

FDA

Fmoc

GalNac

h cell penetrating peptide

clustered regularly interspaced short palindromic repeats

Cyanin 5

Diaminopurin

$\operatorname{dies}(\mathrm{Tag})$

Desoxyadenosinmonophosphat

DNA-bindende Domäne

deactivated CRISPR associated protein 9

Dichlormethan

Diisopropylcarbodiimid

Diisopropylethylamin

4-N,N-Dimethylaminopyridin

3,3'-Diamino- $N$-methyl-diaminopropylamin

Dimethylformaid

Dimethylsulfoxid

desoxyribonucleic acid (Desoxyribonukleinsäure)

denaturierende Polyacrylamid-Gelektrophorese

double stranded (doppelsträngig)

Doppelstranginvasion

Ethylendiamintetraacetat

Essigsäureethylester

European Medicines Agency

Ethanol

Food and Drug Administration

Fluorenylmethoxycarbonyl

$N$-Acetylgalatosamin

hora (Stunde) 
HATU

HBTU

HDAC

HEG

HEPES

HMDS

HOAt

$\mathrm{HOBt}$

HPLC

G

$\mathrm{GABA} / \gamma$

gRNA

Im

IR-Spektroskopie

KLF

LD

LNA

IncRNA

LNP

$\mathrm{m}^{5} \mathrm{C}$

$\mathrm{MeOH}$

$\min$

$\mathrm{mL}$

$\mu \mathrm{L}$
O-(7-Azabenzotriazol-1-yl)- $N, N, N^{\prime}, N^{\prime}$-tetramethyluroniumhexafluorphosphat

$O$-(Benzotriazol-1-yl)- $N, N, N^{\prime}, N^{\prime}$-tetramethyluroniumhexafluorphosphat

Histon-Deacetylase

Hexaethylenglycol

2-(4-(2-Hydroxyethyl)-1-piperazinyl)-ethansulfonsäure

Hexamethyldisilazan

1-Hydroxy-7-azabenzotriazol

1-Hydroxybenzotriazol

high performance liquid chromatography

(Hochleistungsflüssigkeitschromatographie)

Guanin

$\gamma$-Aminobuttersäure

guide RNA

$N$-Methylimidazol

Infrarot-Spektroskopie

Krüppel-like factor

Linkerdomäne

locked nucleic acid

long non-coding RNA

Lipidnanopartikels

5-Methylcytidin

Methanol

Minute

Milliliter

Microliter 
MMPM

MMT

mRNA

miRNA

NBT

NLS

NMR

ON

PAGE

PAM

PAZ

PEG

PIP

PMB

PMO

PNA

PS

Py

RISC

RNA

RNAi

rp

RT

SAHA

SAM

SDS

Sp1
2-Methyl-4-methoxybenzyl

Monomethoxytrityl

Messenger-RNA

microRNA

Nitroblautetrazoliumchlorid

nuclear localization signal (Kernlokalisierungssignal)

nuclear magnetic resonance (Kernresonanz)

Oligonukleotid

Polyacrylamid-Gelektrophorese

protospacer-adjacent motif

PIWI-ARGONAUTE-ZWILLE

Polyethylenglycol

Pyrrol-Imidazol-Polyamid

p-Methoxybenzyl

Phosphoramidat-Morpholino-Oligonukleotid

peptide nucleic acid

Phosphorthioat

N-Methylpyrrol

RNA-induced silencing complexes

ribonucleic acid (Ribonukleinsäure)

RNA-Interferenz

reversed phase (Umkehrphase)

Raumtemperatur

suberanilohydroxamic acid

synergistic activation mediator

sodium dodecyl sulfate (Natriumdodecylsulfat)

specificity protein 1 
SiRNA

SS

SSO

SSPE

$\mathrm{T}$

TALE

TBE

TBS

TBST

TBP

TCA

TCACI

TEAA

TEMED

TF

Tf

TFA

TFD

TFO

THF

TIPS

TLR

TMS

TNRC

tRNA

Tris small interfering RNA

single stranded (einzelsträngig)

splice-switching oligonucleotide

saline-sodium phosphate-EDTA

Thymin

Transcription Activator-Like Effectors

Tris-Borat-EDTA

tris buffered saline

TBS + Tween 20

TATA-Box-bindendes Protein

Trichloroacetic acid (Trichloressigsäure)

Trichloracetylchlorid

Triethylammoniumacetat

$N, N, N^{\prime}, N^{\prime}$-Tetramethylethylendiamin

Transkriptionsfaktor

Trifluomethansulfonat/Triflat

Trifluoroacetic acid (Trifluoressigsäure)

transcription factor decoy

triplex forming oligonucleotide (Triplex bildendes

Oligonukleotid)

Tetrahydrofuran

Triisopropylsilan

Toll-like-Rezeptor

Trimethylsilyl

tri-nucleotide repeat-containing protein

Transfer-RNA

Tris(hydroxymethyl)aminomethan 
U

$U_{s}$

UV

$\mathrm{vgl.}$

vis

ZFP
Uracil

Thiouracil

ultraviolett

vergleiche

visible (sichtbar)

Zinkfingerproteine 


\subsection{Nomenklatur der synthetisierten Verbindungen}

In dieser Arbeit werden die synthetisierten Verbindungen mit 1, 2, usw. abgekürzt. Die Polyamide, Konjugate und ON werden gesondert mit PAx, Kx und ON $\mathbf{x}$ bezeichnet, wobei $\mathbf{x}$ für eine ganze Zahl steht.

Der Nomenklatur der synthetisierten Verbindungen liegt die IUPAC-Nomenklatur zugrunde.

Für die Polyamide wurde eine verkürzte Nomenklatur verwendet. Dabei werden die Pyrroleinheiten als Py, die Imidazoleinheiten als Im und die $\omega$-Aminosäuren als $\omega$ abgekürzt. Des Weiteren werden Alkylketten mit $\mathrm{C}_{\mathrm{n}}$ oder Linker abgekürzt, wobei $\mathrm{n}$ für die Anzahl der $\mathrm{CH}_{2}$-Gruppen steht. Daraus ergibt sich beispielsweise:
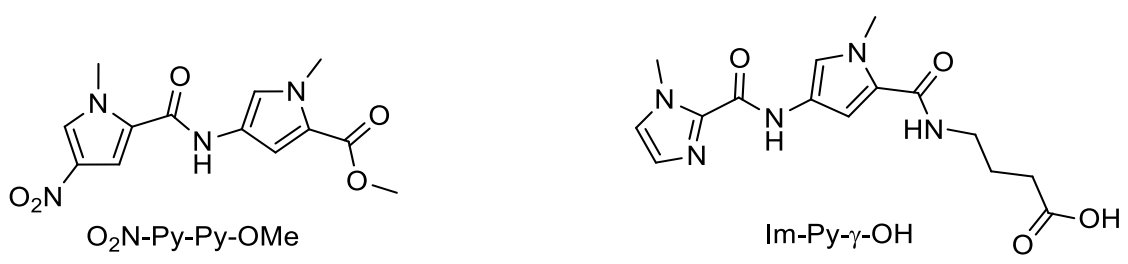

Abbildung 100: Nomenklatur der Polyamide.

Für die Nummerierung der Nukleoside wurden die Nukleobasen mit 1, 2, usw. und die Desoxyribose mit 1', 2', usw. verwendet (Abbildung 101).
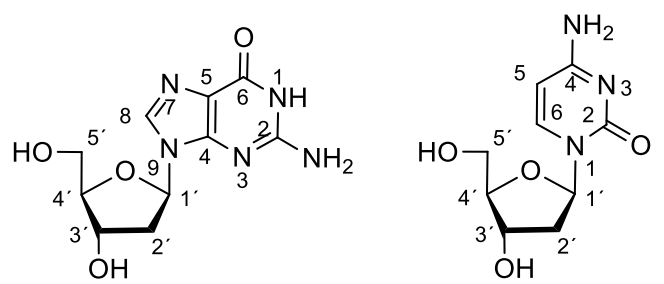

Abbildung 101: Nummerierung der Nukleoside am Beispiel von G und C.

Bei den Verwendeten ONs werden die unterschiedlichen Modifikationen farblich unterschieden. Dabei steht:

Schwarz für DNA, Blau für RNA, Violett für 2'-OMe-RNA und Rot für LNA. 


\subsection{Sequenz von Sp1 und Sp1-H8}

\section{Alignment: Sp1 (UniProtKB/Swiss-Prot: P08047.3); SP1-H8}

\begin{tabular}{|c|c|c|}
\hline \multirow{2}{*}{$\begin{array}{l}\text { Sp1 } \\
\text { Sp1-H8 }\end{array}$} & Msdqdhsmdemtavvkiekgvggnnggngngggafsqarssstgsssstggggqesqpsp & 60 \\
\hline & 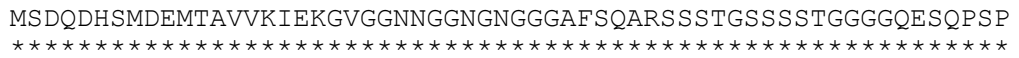 & 60 \\
\hline Sp1 & lallaatcsriespnensnnsqgpsqsggtgeldltatqlsqgangwqiissssgatpts & 20 \\
\hline $\mathrm{Sp} 1-\mathrm{H} 8$ & 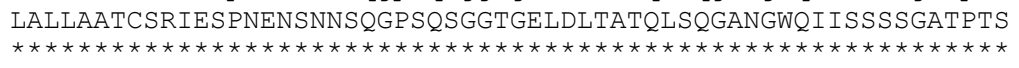 & 120 \\
\hline Sp1 1 & keqsgsstngsngsessknrtvsggqyvvaaapnlqnqqvltglpgvmpniqyqvipqfq & \\
\hline $\mathrm{Sp} 1-\mathrm{H} 8$ & 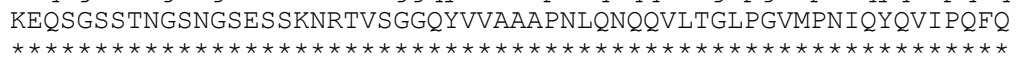 & \\
\hline Sp1 & tvdgqqlqfaatgaqvqqdgsgqiqiipganqqiitnrgsggniiaampnllqqavplqg & 240 \\
\hline Sp1-H8 & 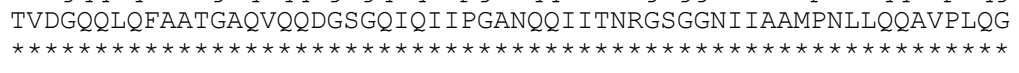 & 10 \\
\hline Sp1 & lannvlsgqtqyvtnvpvalngnitllpvnsvsaatltpssqavtisssgsqesgsqpvt & 300 \\
\hline $\mathrm{Sp} 1-\mathrm{H} 8$ & 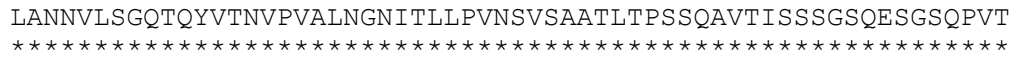 & 0 \\
\hline Sp1 & sgttissaslvssqassssfftnansysttttsnmgimnfttsgssgtnsqgqtpqrvs & 360 \\
\hline Sp $1-H 8$ & 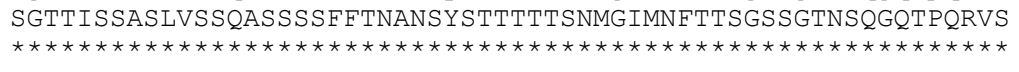 & \\
\hline SP1 & glqgsdalniqqnqtsggslqagqqkegeqnqqtqqqqiliqpql vqggqalqalqaapl & 420 \\
\hline $\mathrm{SP} 1-\mathrm{H} 8$ & 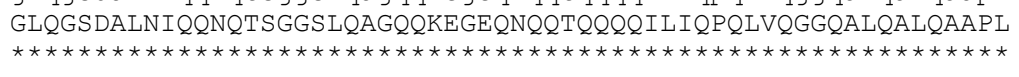 & \\
\hline Sp1 & sgqtfttqaisqetlqnlqlqavpnsgpiiirtptvgpngqvswqtlqlqnlqvqnpqaq & \\
\hline $\mathrm{Sp} 1-\mathrm{H} 8$ & 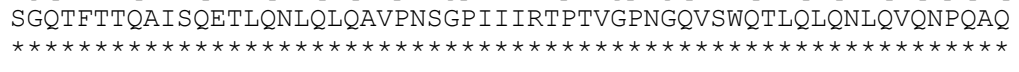 & \\
\hline Sp1 & titlapmqgvslgqtsssnttltpiasaasipagtvtvnaaqlssmpglqtinlsalgts & 540 \\
\hline Sp $1-\mathrm{H} 8$ & 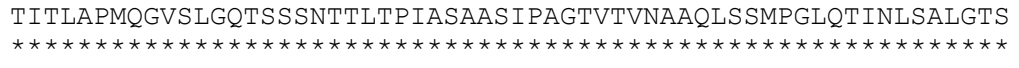 & 10 \\
\hline Sp1 & giqvhpiqglplaianapgdhgaqlglhgaggdgihddtaggeegenspdaqpqagrrtr & 600 \\
\hline Sp $1-\mathrm{H} 8$ & 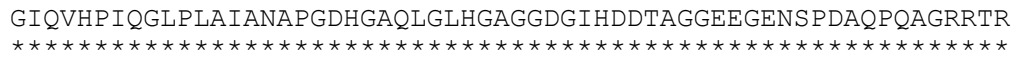 & \\
\hline Sp1 & reactcpyckdsegrgsgdpgkkkqhichiqgcgkvygktshlrahlrwhtgerpfmctw & \\
\hline $\mathrm{Sp} 1-\mathrm{H} 8$ & 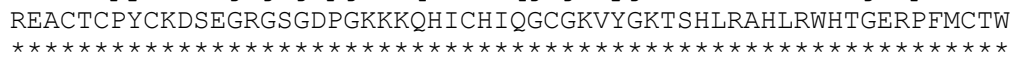 & 660 \\
\hline Sp1 & sycgkrftrsdelqrhkrthtgekkfacpecpkrfmrsdhlskhikthqnkkggpgvals & \\
\hline $\mathrm{Sp} 1-\mathrm{H} 8$ & 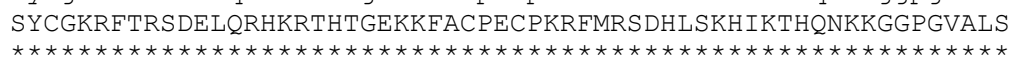 & \\
\hline Sp1 & vgtlpldsgagsegsgtatpsalittnmvameaicpegiarlansginvmqvadlqsini & \\
\hline Spl-H 8 & 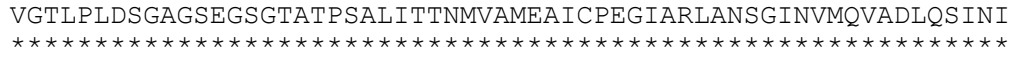 & \\
\hline Sp1 & sgngf--------------- & \\
\hline Sp1-H8 & SGNGFGGGGSLEHHHHHHHH & \\
\hline
\end{tabular}




\subsection{Erklärungen zu Kooperationen und Copy Right}

Wenn nicht anders beschrieben wurden die abgebildeten Ergebnisse in während meiner Doktorarbeit durch mich unter Aufsicht von Prof. Dr. M. W. Göbel erhalten. Die Mitwirkung meiner Kollegen ist explizit in der Arbeit ausgewiesen. Das aufgelistete Material wurde in Kooperationen erhalten:

Abbildung 85: Laura Thomas, Philipps-Universität Marburg, Die Experimente wurden durch Frau Thomas durchgeführt. Die Adaptoren wurden von mir entworfen.

Abbildung 92: Laura Thomas, Philipps-Universität Marburg, Die Experimente wurden durch Frau Thomas durchgeführt. Die Adaptoren wurden von mir entworfen.

Immer wenn Abbildungen, Tabellen oder Texte identisch mit vorherigen Publikationen sind, werden sie explizit ausgewiesen und wenn notwendig wurde eine Erlaubnis eingeholt.

Die Folgenden Teile der Arbeit sind bereits publiziert.

Abbildungen: 4, 10, 15, 16, 20, 21, 22, 64, 74, 81, 82. 


\subsection{Wissenschaftliche Beiträge}

\subsubsection{Publikationen}

M. Bolz, L. Thomas, U. Scheffer, E. Kalden, R. K. Hartmann, M. W. Göbel, Chem. Biodivers. 2020, 17, e2000272.

"Redirection of miRNA-Argonaute Complexes to Specific Target Sites by Synthetic Adaptor Molecules"

\subsubsection{Vorträge}

IV. Doktorandenseminar Nucleinsäurechemie, 20. - 21. September 2018, Bad Herrenalb

"Adaptor molecules for the redirection of RISC-complexes and transcription factors to nonnatural binding sites"

\subsubsection{Poster}

Summer School - Nucleic acid chemistry and synthetic biology, 28. Juli - 02. August 2019, Würzburg

Mathias Bolz, Ute Scheffer, Michael Göbel: "Adaptor molecules for the redirection of transcription factors to non-natural binding sites" 


\subsection{Eidesstattliche Erklärung}

Hiermit versichere ich, dass ich die vorliegende Arbeit „Adaptormoleküle zur Rekrutierung von Transkriptionsfaktoren oder miRNAs an nicht native Bindestellen" selbstständig und ohne anderer als der angegebenen Quellen und Hilfsmittel verfasst habe. Alle Stellen der Arbeit, die wörtlich oder sinngemäß aus Veröffentlichungen oder aus anderen fremden Mitteilungen entnommen wurden, sind als solche kenntlich gemacht. Dies gilt auch für verwendete Abbildungen. Die Arbeit wurde in dieser oder ähnlicher Form noch keiner Prüfungskommission vorgelegt.

Flörsheim, den

Datum, (Mathias Bolz) 